\title{
2nd Interface Between Ecology and Land Development in California
}

Edited by Jon E. Keeley, Melanie Baer-Keeley, and C.J. Fotheringham

U.S. GEOLOGICAL SURVEY

Open-File Report 00-62

Sacramento, California

2000 


\title{
U.S. DEPARTMENT OF THE INTERIOR \\ BRUCE BABBITT, Secretary
}

\author{
U.S. GEOLOGICAL SURVEY \\ Charles G. Groat, Director
}

The use of firm, trade, and brand names in this report is for identification purposes only and does not constitute endorsement by the U.S. Geological Survey

For additional information write to:

Center Director

Western Ecological Research Center

U.S. Geological Survey

Placer Hall, Suite 2012

$6000 \mathrm{~J}$ Street

Sacramento, CA 95819-6129
Copies of this report can be purchased from:

U.S. Geological Survey

Information Services

Box 25286

Federal Center

Denver, CO 80225 
Dedicated to Kathryn, Daniel, Ursula and the rest of California's future generation 


\section{ACKNOWLEDGMENTS}

This conference and proceedings was generously supported by:

USDA Forest Service, Angeles National Forest

Tree of Life Nursery, San Juan Capistrano

Sapphos Environmental, Pasadena

Occidental College, Los Angeles

Ogden Environmental and Energy Services, San Diego

S\&S Seeds, Carpinteria 


\section{PREFACE}

The $2^{\text {nd }}$ Interface Between Ecology and Land Development Conference was held in association with Earth Day 1997, five years after the first Interface Conference. Rapid population growth in California has intensified the inevitable conflict between land development and preservation of natural ecosystems. Sustainable development requires wise use of diminishing natural resources and, where possible, restoration of damaged landscapes. These Earth Week Celebrations brought together resource managers, scientists, politicians, environmental consultants, and concerned citizens in an effort to improve the communication necessary to maintain our natural biodiversity, ecosystem processes and general quality of life.

As discussed by our keynote speaker, Michael Soulé, the best predictor of habitat loss is population growth and nowhere is this better illustrated than in California. As urban perimeters expand, the interface between wildlands and urban areas increases. Few problems are more vexing than how to manage the fire prone ecosystems indigenous to California at this urban interface. Today resource managers face increasing challenges of dealing with this problem and the lead-off section of the proceedings considers both the theoretical basis for making decisions related to prescribed burning and the practical application.

Habitat fragmentation is an inevitable consequence of development patterns with significant impacts on animal and plant populations. Managers must be increasingly resourceful in dealing with problems of fragmentation and the often inevitable consequences, including susceptibility to invasive organisms. One approach to dealing with fragmentation problems is through careful landplanning. California is the national leader in the integration of conservation and economics. On Earth Day 1991, Governor Pete Wilson presented an environmental agenda that promised to create partnerships between land owners and environmentalists, agreements that would guarantee the protection of endangered species and out of this grew the pioneering initiative, known as the Natural Communities Conservation Planning (NCCP) program.

California's vast expanse of seemingly endless resources has traditionally been viewed as justification for abusive land use practices. The modern day recognition that resources are finite has led to greater concern, not only for conserving what is left, but for restoring abused landscapes. Ecological restoration is a new science devoted to returning disturbed environments to a semblance of their "pristine" state. Based on principles of "revegetation," restoration goes far beyond simple replanting, rather the ambition of ecological restoration is to return landscapes to functioning ecosystems and is the focus of the last section.

Jon E. Keeley

U.S. Geological Survey

Biological Resources Division

Western Ecological Research Center

Sequoia-Kings Canyon Field Station

Three Rivers, CA 93271

jon_keeley@ugsg.gov 


\section{CONTENTS}

\section{Keynote Address}

The Wildlands Project: An Affirmative Response to a Creeping Crisis

Michael E. Soulé

\section{Fire Management Along the Wildland/Urban Interface}

Age Mosaics and Fire Size in Chaparral: A Simulation Study

Paul H. Zedler and Leslie A. Seiger

Role of Prescribed Burning in the Management of Chaparral Ecosystems in Southern California

Jon C. Regelbrugge

Barriers to the Use of Prescribed Fire in the National Forests of Southern California

Gregory S. Greenhoe

Vegetation Management and Prescribed Fire

Scott E. Franklin

Fire Management Strategies and Stand Structure Development in Torrey Pine

Michael L. Wells

Season of Burn Effects in Southern California Chaparral

Jan L. Beyers and Carla D. Wakeman

Unburned and Grazed Chaparral: A Case Study

Frank C. Landis

Prescribed Burning Impacts on Late Successional Species

Peter A. Bowler and Richard E. Riefner, Jr.

Effective Fire Planning for California Native Grasslands

Robin Wills

Post-Fire Recruitment of Yucca brevifolia and Yucca schidigera in Joshua Tree

National Park, California

Michael E. Loik, Christine D. St. Onge and Jane Rogers 
Estimation of Pre-Suppression Fire Intervals in Californian Mixed Conifer Forest

Richard A. Minnich and Richard G. Everett

Fire Suppression and Drought Induced Mortality in Southern California

Mixed-Conifer Forests

Melissa Savage

\section{Habitat Fragmentation}

Mammalian Carnivores as Target Species for Conservation in Southern California

Kevin Crooks 105

Distribution and Status of Carnivores in the Santa Monica Mountains, California:

Prelimary Results from Radio Telemetry and Remote Camera Surveys

Raymond M. Sauvajot, Eric C. York, Todd K. Fuller, H. Sharon Kim, Denise A.

Kamradt and Robert K. Wayne

Landscape-Level Urbanization Effects on Chaparral Birds: A Santa Monica

Mountains Case Study

Diana Stralberg

Distribution of the Herpetofauna of Coastal Southern California With

Reference to Elevation Effects

Robert N. Fisher and Ted J. Case

Alien Species in the Flora and Vegetation of the Santa Monica Mountains, California:

Patterns, Processes, and Management Implications

Philip W. Rundel

Mammal Burrowing, Erratic Rainfall and the Annual Lifestyle in the California Prairie:

Is it Time for a Paradigm Shift?

Paula M. Schiffman

\section{NCCP and Land Planning}

Natural Community Conservation Planning: A 1997 Interim Report

Dan Silver

Research Guidance to Address the Needs of Land Mangers: Coastal Sage Scrub Natural Community Conservation Planning (NCCP)

Peter A. Stine . 
Gnatcatchers and the NCCP: Will We Know When the Species Should be Delisted?

Jonathan L. Atwood

Transferable Credit Programs as land Preservation Tools in the Santa Monica

Mountains National Recreation Area

Bryan D. Stumpf

\section{Restoration Ecology}

Climate, Vegetation, and Considerations for Restoration

Nathan L. Stephenson

Population Genetic Theory and Data in Restoration of Rare Plants: Examples from

Serpentine and Vernal Pool Taxa

Diane R. Elam

Evolutionary Factors Affecting the Probability of Local Adaptation or Should We Expect to See Ecotypes Behind Every Rock?

Kevin J. Rice and Eric E. Knapp

Fitness Consequences of Non-Local Transplantation: Preliminary Tests of the Home Team Advantage and Outbreeding Depression Hypotheses

Arlee M. Montalvo and Norman C. Ellstrand

Assessing Success of Restoration Attempts: What Can Terrestrial Arthropods Tell Us?

Kathy S. Williams

Improving the Design of Fish Habitat Mitigation Projects in Southern California

Julie S. Desmond, Gregory D. Williams and Joy B. Zedler

What Are the Limits to Restoration of Coastal Sage Scrub in Southern California

Edith B. Allen, Scott A. Eliason, Viviane J. Maraquez,

Gillian P. Schultz, Nancy K. Storms, Cathyln Davis Stylinski,

Thomas A Zink, and Michael F. Allen

Recovery of Coastal Sage Shrub Species After Mechanical Disturbance

Marcia G. Narog, Jan L. Beyers,

Timothy E. Paysen and Bonni M. Corcoran

Translocation and Grafting of Coastal Cholla (Opuntia prolifera) and Coastal Prickly

Pear (Opuntia littoralis) as Mitigation for Cactus Wren Habitat Loss in Burned Areas

Peter A. Bowler, Kenneth B. Pierce, Jr.,

Vanessa Beauchamp, and Tarek Tabshouri 
Survival of Transplanted Coast Live Oaks (Quercus agrifolia) in Southern California Rosi Dagit

On the Perils of Ecological Restoration: Lessons From the El Segundo Blue Butterfly

Travis Longcore, Rudi Mattoni, Gordon Pratt, and Catherine Rich

Preserving the Higher Aims of Restoration: Toward Transpersonal Restorations

Peter A. Bowler

Container Plants For Revegetation: What About the Container?

Mike Evans

Developing Temporary On-Site Nurseries for Land Restoration

Melanie Baer-Keeley

Index

297 


\title{
The Wildlands Project: An Affirmative Response to a Creeping Crisis
}

\author{
Michael E. Soulé \\ Wildlands Project, Hotchkiss, CO 81419 \\ Email: soule@massive.gj.net
}

\begin{abstract}
Worldwide, the best predictor of habitat loss is population growth rate density. California is no exception. In this state, massive sprawl and the ranchette phenomenon have driven many ecosystems to or beyond the 90 percent destruction/fragmentation threshold for loss of ecological integrity and species. Virtually all of the habitats in the state will follow this course unless a new way of planning is adopted. MSHCP's and NCCP's present one alternative to business as usual. Another approach (The Wildlands Project) is to create a more ambitious and scientifically rigorous vision of what California could become (or retain), if boldness and imagination replaced sprawl and growth as the forcing variables.
\end{abstract}

Keywords: Biodiversity; conservation; endangered species; extinction; habitat conservation plans; resources.

Thank you very much, Jon, for that very kind introduction and for inviting me. Before I begin, maybe I should make a few comments about public speaking. I was flying down here yesterday from San Francisco and reading the United Airlines magazine. There was an insert for some company advertising something and they have in this insert a list from the People's Alamanac, of "The Ten Worst Human Fears in the United States." I will start with the least of the fears and work up towards the most fearful thing. Least is dogs, that is number ten, number nine is loneliness, number eight is flying, number seven is death. Even more fearful than death is sickness and deep water, even worse than deep water is financial problems, and then, number three is insects and bugs. Number two is heights and number one is speaking before a group. I am sure many of you can identify with that. And it had a quote from Roscoe Drummand, "A mind is a wonderful thing. It starts working the minute we are born and never stops until we get up to speak in public." So, if I suddenly stop somewhere in the middle, you'll understand.

\section{Introduction}

I am very honored to be here and it is a pleasure to be here because, this is my home territory, I was born and raised in San Diego. And, of course, I have a very special place, like we all do, in our hearts for the places where we grew up. I have left, I've abandoned you, I've moved to Colorado. But, all the more I feel that those of you who still remain and are fighting the good fight are setting an example in southern California for crisis planning and crisis management that will be noted and is being noted, certainly nationally by Secretary Babbitt and others. So, I am honored to be in your presence.

I am going to begin talking about some global matters having to do with what is causing the global biodiversity crisis - partly because it is interesting in itself and partly because southern California is just a microcosm of the global problem that is occurring. I will discuss some different ideas and hypotheses about why the world is in such bad shape in terms of nature, and then go on to briefly mention and try to place in context some of the policy issues that we are facing today, particularly with regards to the Endangered Species Act (ESA), Habitat Conservation Plans (HCP's), and Natural Communities Conservation Plans (NCCP's). Although I am not going to spend a lot of time on that, but I will use it as a bridge to then launch into discussion of one of my current passions, The Wildlands Project.

I don't know if you can read this slide, it is a Calvin and Hobbes cartoon that starts on the left panel with the gentleman yawning and then getting up and asking Ted if he'd like sume coffee. Ted says "No thanks, Frank," as he is going to get some coffee, some deer come out of the elevator and shoot him. One says, "You got him!" And the next one says, "He's a big one too!" The third one says, "Nice shot, Bam!" And the fourth one said, "Somebody get the camera!" Then in the next to the last panel, (Is that Calvin or Hobbes, I don't know which one!) It is saying, "Needless to say, Frank's family was upset when he didn't come home that night. But everybody understood that the human population has doubled in just two generations to almost six billion, so some thinning of the herd was necessary to prevent starvation."

This introduces the polarity and conflict and perhaps somewhat artificial dicotomy between anthropocentrism and ecocentrism. This particular cartoon represents, of course, an extremely ecocentric view, a rather misan- 
thropic ecocentric view, to be sure, of the current situation regarding human numbers and the impact of those numbers on nature and the environment. I've been studying, in a way, informally, a related dicotomy for many years. I was at the University of Michigan in the school of Natural Resources before I went to UC Santa Cruz. For about eleven years, I've been involved in environments where there is an attempt to marry social science and biological science in the study of the environment and to create better conditions, better policy for resolution of environmental problems and conflicts. And it is, as many of you probably know, difficult to communicate across that disciplinary divide between the social sciences and the biological sciences. The issue that usually acts as a kind of a fuse for the fire and heat that result from the attempts to communicate is the population issue.

Many social scientists believe that in fact, it is wrong and misleading and inappropriate to talk about the population problem. Whereas, of course, to most biologists, and particularly conservation biologists, the population problem is the problem, it's the source of all other problems. The view from many social scientists, certainly not all, but many anthropologists and sociologists and gcographers, is that if there is a population problem, it's not the ultimate problem. It is the result of social injustice and the result of poverty. So, to address the population problem as a problem is not to understand the funnel of causation or the nexus of causality that causes people to have large families.

There is a deeper problem too. It is not just a matter of interpretation of causality and this complex web of causality, but, the deeper issue is a fundamental difference in the target of concern and in the mission of one's academic and personal life. Most people, I dare say, are concerned primarily with people, with human welfare. A minority of people are concerned primarily with the welfare of nature. I happen to be in the latter group. But, if one identifies very deeply with nature, more than with our own species, there is almost no way to talk to people, I believe. You can talk, but there is no way to reach a solid understanding of values and of priorities with people who primarily are anthropocentric. Most people love people, not only their family, but everyone. And in fact, probably most of us ecocentrists, if you scratched deeply, also have similar affections about human diversity and our own species. But the depth of the love of our own species in our species, is probably almost greater than any other species. I don't think that rattlesnakes love rattlesnakes so much. I don'think cats love other cats very much. There are only a few species that love people as much as people love people. Dogs are one, cockroaches and certain lice, but $I$ think humans are almost unique in their adoration of our own species and their concern for the welfare of our own species. Perhaps I am exaggerating, but I wanted to bring this out because of what comes next.

\section{Consumers}

To begin a discussion of the global crisis in biodiversity or for creation or nature, or whatever term you like, I've divided the world into two groups of consumers-because we are all consumers. I really don't like to think of our species as just consumers, I like to think of them as citizens, as lovers, as a whole lot of different things. But these days we're all called consumers. So, there's two types of consumers, there are the rich consumers and the poor consumers, another artificial dicotomy, but unfortunately, there are many, many poor people in the world. And the majority of people are very poor indeed. But the rich people like to consume or feel they need or desirc, at least, many things that affect biodiversity. They feel they need meat. Now we all know that the consumption of meat results in seven times the amount of grain being grown, as compared to the situation if everyone were vegetarians. That is a huge impact on the world.

Also, rich people like us and most northerners-I am talking about Europeans, Canadians, people in the U.S. and Japan and more and more people around the world want fresh seafood and that is becoming a serious problem for the oceans and the rivers of the world. This is because the consumption of fresh seafood means the serial destruction of one fishery after another. We know the cod fishery, one of the great North Atlantic fisheries, has recently been shut down in Canada and the United States, and will soon be shut down in Europe as well. It means the consumption of sharks. It means the destruction of millions of hectares of habitat in the coastal zone of the tropics. We love shrimp. Where, does shrimp come from? Well, some of them come from the Caribbean, the Gulf of Mexico and the Gulf of California. More and more they are grown in aquacultural ponds that used to be mangroves and that used to be lagoons and bays \& estuaries that have been blocked off and converted into huge aquacultural systems for the production of shrimp so that we can eat shrimp. This is causing the destruction of many tropical habitats that are important for their ecological services and for the existence of many species.

We rich people like to consume fresh produce, not only when it is appropriate which is in the summer when it is grown, but all year long. Where does that fresh produce come from? Where do our Roma tomatoes come from? Where do our strawberries in March come from? Where do our grapes in January come from? Where do our cut flowers in December come from? They come from the conversion of tropical habitats, of forests, savannas, and coastal plains. And the diversion of water from aquafers and from tropical rivers into new agricultural lands that are set up so that we can eat, we meaning the northern rich, and some of the southern rich, can eat fresh fruit and vegetables, not to mention the shrimp, as I've said before, all year long. 
We create other kinds of demands on the tropics. We like tropical fish. And this desire for tropical fish is causing the destruction of tropical reefs around the world. We like parrots and other tropical birds and there is a tremendous amount of smuggling of birds. And the destruction of avifaunas throughout the tropics because of our desire for these pets. Though our needs in the north-or our desires, they are not needs, they are desires-are problematic for biodiversity, the southerners-the poor people-I don't mean the people in Alabama or Georgia, I mean the people in the tropics who are mostly poor also have needs. There are many more of them and their numbers are growing much, much faster than our numbers. And they are causing problems too-different kinds of problems. Their needs are for survival, and survival means subsistence food. They need land so that they can grow food and eat. They need forest products for thatch for wood to build their homes and for some medicinal purposes. They need hard currency so that they can pay school fees so that they can have a few luxuries like books, occasionally a television set, some clothes and so on, money to pay doctors. I am talking about people who earn $\$ 500, \$ 600, \$ 700$ a year. Their needs have impacts too. And as I've said, their mushrooming numbers is creating problems in the tropics. So, the bottom line is that the northern rich are creating environmental problems in their own continents as we see in southern California, but also, many problems in the tropics and whereas most of the poor are just creating problems where they live, more locally, mostly in the tropics.

As I mentioned before, the issue of population rears its ugly head, because when people like me say there is a population problem and we ought to provide people with the ability to plan their family size if they want, others feel that it's not politically correct, that we should not be talking population. We should be talking about social justice. Because it is injustice, it's the lack of liberty, it's the lack of civil rights, it's corruption, it's poverty that are causing people to have large families.

If you ask the question, 'How much of the national wealth, or how much of the national income do the richest $20 \%$ of the people sequester?" Or, "How much of the national income do the poorest $40 \%$ of a nation's people sequester?" You get some very interesting answers. In general, on average around the world, the richest $20 \%$ of the populations receive $40 \%$ of the income. And the poorest $40 \%$ generally receive around $15 \%$ of the income. So there is a great disparity, a very large asymmetry in the distribution of wealth. But countries differ very greatly in this asymmetry of distribution of wealth. Most developed, northern countries have a ratio of the top $20 \%$ to low $40 \%$ incomes of about $2: 1$. But, some countries in the world have ratios of $9: 1$, that is, one country has a ratio of 9:1. Several have a ratio of about 7:1 and then it is a very skewed curve. Can you guess which country has the worst asymmetry? The 9:1? Iraq? No. The United
States is typical of developed countries, 2:1. Mexico, no, its about 5:1. Its pretty bad, but its not the worst. Bangledesh is very good, 2:1. Africa is variable, but it is generally about 2 or 3 to 1 , not so bad. There are some exceptions in Africa that are quite asymmetrical. It is Brazil. Brazil is off the map in terms of this measure of social injustice. Next comes Panama. Chile is not so good either.

This is just one of the variables that l've been using to look at as a measure of social injustice. There are also measures of corruption, measures of political rights, measures of civil libertics that are available at a price from corporations that specialize in providing this kind of information to other corporations that are thinking of investing in third world countries. This is very valuable information. So, the result of this regression analysis that I've been doing shows that about half of the variation among countries in their rates of habitat destruction, according to statistics from the World Resources Institute, is due to population density. And none of it is due to the social justice indicators, which are, in fact, correlated in the opposite way as would have been predicted. So, for this measure, it is clear that population per se, is a driving force in the destruction of habitat in the third world.

For another variable, however, the loss of forests, one region of the world does have a significant $\mathrm{r}^{2}$ value for this income disparity statistic, and that is South America. It does appear that social justice factors are important in the loss of habitat for forests per se, but not for habitat in general. And here are some scatter diagrams showing the relationship between habitat loss on the ordinate and log of population density on the abscissa, for different measures of habitat loss. So, population is important. That is not to say that there are social and cultural factors involved or causing people to have large families.

Let me go back and show you the nexus. Here is a web of causation that I've been talking about. The two hypotheses are at the top. The elimination of tropical nature could be caused either by high population growth rates (that is 'high r' on the left), or by injustice. My results suggest that high population growth rates are the main factor, though injustice could be causing high growth rates to occur through that complex web of causation that needs further study by some sort of path analysis probably, which I may get around to. One of the things I'd like to point out, although it is not politically correct, is that culture causes people to have large families sometimes. One aspect of culture is male domination, patriarchy. And male domination of women is certainly a factor of why, in some places in the world, particularly in the Middle East and in Africa, people have large families.

One of the problems I've come across recently is the goals established by international conservation organizations. The World Wildlife Fund just came out, with a lot of publicity, with a map of the forests of the world. And the narrative that accompanies the map of the remaining 
forests of the world argues that the objective of many nations should be to protect $10 \%$ of their forests. Ten per cent! Now, coincidentally, that is how much coastal sage scrub is left. The major conservation organizations are telling the nations of the world that they should have the same goal as southern California. Ten per cent. Isn't that amazing. The Bruntlen Report had statistics in it that one of my graduate students and I are now looking into, that has led to governments of the world claiming that the goals shouldn't be $10 \%$, that is way too low, it should be $12 \%$. I call that a tithe plus a tip. So, the most ambitious estimates of what we should be saving is what island biogeographers say will lead to a loss of fifty per cent of species diversity in the world, because you all know that if you reduce habitats down to $10 \%$, that in general, only half of the species can persist, at best. Depending on how fragmented that $10 \%$ is-if it is highly fragmented, even less than half can exist. So, that is what we are up against. That's what the conservation establishment's goals are, $50 \%$ die-off of species.

So, just to reinforce just how misanthropic I am [slide], Gary Larsen said, "I know you miss the Wainright's, Bobbie, but they were weak and stupid people, and that is why we have wolves and other large predators." So, that's how a lot of people view me.

\section{Endangered Species Act}

I want to talk about the Endangered Species Act (ESA) for just a minute. In order to try to put it into some perspective - and try to put Natural Communities Conservation Plans (NCCP's) and Habitat Conservation Plans (HCP's) and 'no-surprises' and 'safe harbors' and prelisting agreements in some perspective. The negative slope on this curve [slide] shows a sort of slope of endangerment or vulnerability of species. Species travel down this slope and of course, when they get near the end the curve drops sharpley and species rapidly go extinct. Just before the end, we have the Endangered Species Act. The Endangered Species Act, and this is acknowledged by everybody in the policy arena, is an emergency-room act. Its a safety net act. We don't involve listing until a species is almost extinct, until its down to the last three salmon in a run, or the last hundred or two hundred individuals in a species. Although the Endangered Species Act was the most visionary, and perhaps most ethical law ever passed dealing with wildlife and nature by any country, we have to bear in mind that its function is not to protect biodiversity writ large, its function is to act as the safety net, the last phase and if all else has failed.

The Endangered Species Act used to have a lot of teeth in it. Recently, it has been concluded even by the most staunch supporters of the Act, that those teeth have to be filed down-because the Act is not working well. Most of the endangered species and threatened species in North
America and the United States are on private land. Seventy per cent of them are on private land and over half of them are only on private land. And the Act has not been effective on private land. The Fish and Wildlife Service has not enforced the Act well on private land because of the fear of a backlash. And we see that backlash now. Its called the 'brownlash' sometimes. Or it is called the 'property rights' movement or the 'wise use' movement. This is a very powerful force, politically.

So, as a result of this backlash, we see this large list of proposals starting in 1982 with the habitat conservation plans. Recently in the so-called Babbitt Administration, with no surprises, we see these attempts to make the Endangered Species Act more user-friendly, more landowner friendly. This is necessary. What many scientists are concerned about is that the rush to achieve the goal of user-friendliness of the Act is so great, that many necessary components of these principles or new propositions are being ignored. Including these agreements, such as HCP's which are being entered into with virtually no scientific oversight and no objective expert review. There is almost no funding in the Act to protect species against the inevitable surprises that will occur in HCP's under the 'no-surprises' provisions. The HCP's are being developed and signed off by the Secretary without taking into account the regional biographic context of many of these HCP's. Some HCP's have been good. But, many have not been. There are a few that are so awful that they are held up to ridicule at every meeting we go to about HCP's. For example, the one in the Southeast in either Georgia or Alabama for red cockaded woodpeckers that not only allowed the cutting of all of the pine trees that were the nest trees for the red cockaded woodpeckers, but it required the land owners to move the surviving woodpeckers to adjacent Forest Service land...just pick them up and move them, as if they would survive. Then there were the Plum Creek HCP's in the Northwest and in the northern Rockies and in the state of Washington. In the most recent one, 281 species were added to the agreement, so that if they were ever listed, that Plum Creek Timber Company would be protected from having to mitigate for those 281 species. This was done without any study of the life history or ecological requirements of these 281 species. So this type of abuse of the ESA in the rush to make it appear more user-friendly by this Administration is causing a great deal of concern and bad press for the ESA.

Another point I want to make is that proposals to create a condition or situation in the US for more thoughtful protection of nature, such as ecoregional planning and new laws for protecting ecosystems as well as species are still not bold enough. They are still being conceived of as protecting the last 10 or $20 \%$ of the habitat left. So, the ESA has teeth in it and they are being filed down to make the Act more user-friendly. This is probably necessary. But the teeth of the ESA come at the very end of the pro- 
cess, when it is far too late to rescue many species and to prevent endangerment in the first place. In a sense, it is like having teeth imbedded in your anal sphincter. It is too late to do much chewing then. Excuse me.

\section{Wildlands Project}

Switching topics, I'd like to talk a few minutes about the Wildlands Project. The frontier disappeared, according to the US Bureau of Census in about 1890. The frontier was thought to be the crucible of the American character. What was left though, were large areas of wilderness, huge areas where there were no roads, large un-trammeled expanses of habitat. But by 1990 , we realized that even these refugia of the wild, and refugia of wilderness were rapidly disappearing in North America. And with it were going the grizzlies and the wolves and the jaguars and the wolverines, the fishers, the caribou and the lynx and many raptors. Bill Newmar pointed out 10 years ago that even our national parks and wilderness areas were too small, as others had said before. But he proved it. And that they were getting smaller and that they were losing species at a visible rate, losing carnivores and other mammals, at a rate that could be determined empirically it was so fast. That was because our little refugia of wildness in North America were becoming isolated by development, by agricultural development, by ranchette parks, and other types of development.

Around 1990, many people concluded that the fabric of land and waters that once was America the beautiful was being torn apart. And it needed to be woven together again. So, we envisaged a therapy. A therapy, involving a marriage of science and advocacy, a kind of Manhattan Project for the land. We founded the Wildland Project based on the principles of wildlife biology, conservation biology and restoration ecology. This was to be an organization informed by science, not necessarily based on science, but, informed by science. We envisioned producing a compelling vision. A map-based vision of what North America ought to be in one hundred years. Our idea was not to become a huge conservation organization like The Nature Conservancy or Audubon, or World Wildlife Fund. But to remain very small and to function as a coordinating center for other groups. Other grassroots conservation groups around the country and around the continent that would actually do the work in their own ecoregions. Our job was to provide good science, networking, help in fund-raising, and coordination, and peer review. The grizzly is a good example of a species that has been threatened by human activity. Its been reduced to less than $5 \%$ of its native range south of Canada. Wildlands Project seeks to restore grizzlies, and wolves, and fishers, and condors to most of the regions that they once inhabited. It won't happen immediately, but it will never happen unless we begin now. So, the conservation move- ment in 1990 and its still true today, is mostly on the defensive. It is reactive, not proactive. It responds to brush fires and $90 \%$ of the energy expended by most conservationists is trying to keep development from occurring too fast. Its not trying to stop development. We are often stuck in the role of responding to a proposal by a developer for logging or for a housing development. We are told to be reasonable, we are told to compromise. We are told to be willing to give up half of what's left in order to save the other half. And then in five years another developer comes along and we are told to be reasonable and to compromise and to give up half of what's left so we can have the rest - and so on and so on until nothing is left. And there is not enough room in the world for space intensive creatures like the wolverine.

Now there is no reason that people who love nature have to accept this kind of defensive role. We have been deluded into believing that this is the only way to operate to protect nature in North America. But it isn't true. The goal of the Wildlands. Project is much more ambitious, and much more positive, affirmative and proactive. We wish to restore, on a large scale, the processes that maintain biotic diversity in a mosaic across the landscape, these natural disturbance regimes such as we've seen recently in Yellowstone with the fires. Fire is just one of these kinds of natural disturbances. We wish to maintain a diverse landscape and we wish to protect animals against global change as well. Otherwise animals and plants too will find themselves in the wrong place. Perhaps the thing that Wildlands Project is known best for is its emphasis on corridors, on networks. Our model is based on three components: core reserves, much bigger than the current ones including much of the Forest Service land and even some private land, multiple-use buffer zones where sustained harvesting and sustained resource exploitation can occur, and connectivity, which in a way is most controversial. One of the reasons we emphasize large, roadless areas is because it is the only way of protecting species that need interior habitat like lynx, martin, many songbirds, owls, woodpeckers and goshawks. And it is the only way to protect species from edge affects and edge predators such as cowbirds and magpies and skunks and raccoons.

So, this is the general idea, which you've seen a hundred times, I hope. Core reserves connected by corridors linked with inter-regional corridors for the dispersal of just a few target species that need inter-regional corridors to maintain viable populations, including many so-called 'keystone' species like grizzly, wolves, lynx, and wolverine. These wide-ranging species that have to move between reserves. Corridors are a complex issue. Many people think a corridor is something that you just stick on a map between two patches of core habitat or two roadless areas, but corridors should not be drawn unless you know exactly what species are going to use them and if that's the appropriate habitat for dispersal for those species or 
migration of those species. In Australia, an adequate corridor might be $10 \mathrm{~m}$ wide, for the dispersal of certain birds that won't budge out of their natural habitat unless they can see another patch of that natural habitat. For example, in the wheatlands of Western Australia where many of the birds won't fly to another patch of habitat unless they can see it. So, a corridor doesn't even have to go all the way to the next patch of habitat, just far enough so that they can see and then they'll fly there-and provide demographic or demographic rescue for the species that still persists in that patch.

We rely on grassroots conservation organizations. We rely on local naturalists and local biologist to tell us where the 'hotspots' are, where the nesting areas are, where the key foraging areas are, where the hibernacular are, where the bat caves are. And we use GIS and other good science to produce regional maps for the entire continent eventually. One of the origins of the process was Reed Noss's original concept map of the state of Florida, which was laughed at when he first produced it, when he said Florida needs to be connected up to protect the black bear and to protect the Florida panther, otherwise, they will go extinct in their little isolated nature reserves. And everybody said, well that's impossible. Well, ten years later, the state of Florida passed a three billion dollar bond issue to start buying land to protect the natural biodiversity of Florida. Today there are many landscape linkages, particularly along riparian corridors. People ask, how can this happen in Florida, a state that's growing as fast as California. The fact is that the Floridians voted for it. They want it. They want wildlife. They want to be able to hunt and fish in their state. The county commissioners throughout the state were on the right side of this issue because they are concerned about recreation in these areas. They don't all have to be pure reserves. Many of these areas can be multiple use zones as long as they are managed correctly. And this is what the Wildlands Project wants in a hundred years.

Similar proposals are now being developed for the Sky Island region of southern Arizona and New Mexico and northern Sonora and Sinaloa in Mexico. I will be attending a meeting next weekend in the Black Range in New Mexico to continue to add details and science to this proposal to protect this region, so that the Mexican wolf will have a large enough, connected enough area, for its viability, and to protect the jaguar (there are now two jaguars in the United States, we think). The concept for the northern Rockies began with a very primitive Wildlands Reserve-type map produced by the Alliance for the Wild Rockies about 10 years ago. They've gone a long ways since then and the current conceptual map is much better founded in good science directed towards restoring the northern Rockies to viable habitat for grizzlies and wolves and many other species.

A recent map produced by Dr. Michael Kaufman, who is a spokesperson for the Wise Use Movement, purport- edly shows what the Wildlands Project is going to do to the Midwest. Needless to say, this [slide] is not a Wildlands Project map, though, it implies that it is. Kaufman states "The plan is to protect biodiversity as defined by the convention on biological diversity, the UN Global Biodiversity Assessment, the U.N., U.S. Man in the Biosphere Program and the Wildlands Project." We are seeing maps like this appear as a scare tactic in many publications now of the Wise Use Movement and the Property Rights Movement, to scare the shit out of people all over the country. At the bottom of his map, in very, very tiny type, it says, "This map was produced using the principles of the Wildlands Project." Well, these aren't the principles of the Wildlands Project, we are not this ambitious. There are many parts of the country that have already been so overdeveloped that we probably would almost ignore them. But this is one of the things that we are up against. However, we are getting some attention.

\section{Conclusions}

So, we belicve in being bold. We belicve that boldness is compelling. We believe that it is necessary to create a plan for North America that is good and that is correct and that is scientifically rigorous and that will do the job. We think that if people are inspired by this boldness and this vision, that a movement will start that will lead to the realization of this vision. We Americans have taken much in our frantic scramble for the good life and for private property. We think that in giving back some of what we Americans have taken, we will win back much of what the American spirit has lost. The question is, do we really have the generosity of spirit to let America once again be beautiful? I think the answer is, yes! 


\section{Fire Management Along the Wildland/Urban Interface}

"I don't care to put any of my men in the danger they would have to face while fighting a brush fire... I do not believe it is within the power of man to stop one of these fires..."

William Mulholland 1908 


\title{
Age Mosaics and Fire Size in Chaparral: A Simulation Study
}

\author{
Paul H. Zedler ${ }^{1,2}$ and Leslie A. Seiger ${ }^{1}$ \\ ${ }^{1}$ Biology Department, San Diego State University, San Diego, CA 92182 \\ Tel. (619) 594-6328; Fax (619) 594-5676
}

\begin{abstract}
Large fires are a serious problem along the urban-wildland interface of Mediterranean-type shrublands in California. Managers are being urged by some in the research community to base their management on a theory which emphasizes the controlling importance of fuels on the fire regime and the close correspondence between age and propensity to burn (the "fuel/age paradigm"). Arguing from these premises, the deduction is made that fire suppression, by allowing vegetation to form large blocks of burnable vegetation, is the principal cause of the large fires that are presently characteristic of California shrubland landscapes. It has been suggested that management should de-emphasize suppression and reestablish an age mosaic that would return the landscape to a more natural condition in which fire size is constrained by discontinuities in fuels. In this paper we question if the age mosaic postulated in the fuel/age paradigm would be sustained by a pattern of random uncontrolled fires. We use spatially explicit models that incorporate the essential elements of the fuel/age paradigm. We conclude that age-based mosaics following the strict rules of the fuel/age paradigm are a transient phenomenon, and therefore we question if fine-grained age mosaics are characteristic of natural systems and whether they should be the objective of long-term landscape planning.
\end{abstract}

Keywords: California; cellular automata; chaparral; coastal sage scrub; fire; fire management; fire spread; fire suppression; landscape mosaic.

\section{Introduction}

Fire is the most important non-site factor influencing the chaparral of southern California. Though it has been

\footnotetext{
${ }^{2}$ Present address: Arboretum and Institute for Environmental Studies, University of Wisconsin, 1207 Seminole Hwy., Madison, WI 53711. Tel: (608) 265-8018; Fax (608) 2652993, e-mail: pzedler@facstaffwisc.edu
}

much studied, there remains considerable disagreement about both historical fire regime and the use of fire as a management tool. One of the most important questions centers on the relation between fire size and fire frequency. This has both historic and current management importance. From a historical point of view, we wish to know if the regional conflagrations that occur today were always a feature of the vegetation dynamics of the chaparral, or if large fires were rare or non-existent before modern fire suppression technology was imposed. Practically and currently, we wish to know if management burning and fire suppression can be used to minimize the probability of large uncontrolled fires while maintaining other desirable attributes of the system such as biodiversity and watershed protection.

We identify two extremes on the continuum of ideas about what controls fire size. One view stresses the importance of weather factors, arguing that although there can be many small fires, most of the acreage of chaparral landscapes burns in large fires that occur under extreme meteorological conditions (e.g., protracted drought followed by high winds and low humidity) when differences in the amount and type of fuel exert minimum control on fire size. Though the age of the vegetation is a factor affecting ignition, the age-fuel loading correlation is weak (Paysen and Cohen 1990). It follows that management actions that burn small portions of the landscape to create a mosaic of age patches are unlikely to provide significant protection against catastrophic fire unless the fire rotation is shortened significantly so that a substantial portion of the landscape is maintained in an early fire recovery stage.

At the other extreme are the fuel based theories which stress the accumulation of biomass over time as the fundamental control on fire occurrence and fire size. For chaparral, the clearest statement of this view is contained in a series of articles by Minnich (e.g., Minnich 1983, $1989,1995)$. Similar views, however, are widely held by those concerned with fire management in the western U.S. We believe that this view can be fairly represented by the 
following propositions and deductions from them: (1) The amount of fuel is the primary variable determining whether or not a fire occurs. (2) The accumulation of fuel is strongly age-related (e.g., Green 1981), so that increasing age inevitably means increasing fuel. (3) A minimum amount of fuel must accumulate before an area will burn, therefore there is a minimum age below which fire is highly improbable. (4) As a consequence of \#3, where a diverse age mosaic is present, fires will cease to spread when they encounter arcas less than this minimum age. (5) Under primeval (i.e., without humans), pre-European conditions, and today in areas where fire protection is not practiced or is ineffective, ignitions are not limiting, and therefore areas will burn soon after reaching the minimum age of flammability. (6) Because of conditions \#4 and \#5, if a diverse age mosaic is present, the mosaic will be perpetuated. (7) In contrast, in situations where fire suppression is practiced without compensatory management burning, areas will age beyond the minimum age. More and more of the landscape will move into a burnable condition until eventually fires larger than those possible without suppression will occur. This obliterates the age mosaic and sets up the region for a cycle of recurrent large burns. Thus, comparison of landscapes with and without fire suppression show that in a non-suppression landscape fires are more numerous but on average much smaller than those that occur in a suppression landscape (Minnich, 1983, 1989, 1995).

As a consequence of this reasoning, proponents of the fuel/age paradigm urge land managers to reestablish the age mosaic either by abandoning suppression or supplementing it with a burning program that substitutes management burning for natural or unregulated human burning.

Is it possible for an age mosaic operating under the rules of the fuels model to be stable?

This is an important question for managers, because the appeal of the fuels model is that it offers the hope of building a landscape that is immune from very large fires. Because management would be presumed to be working with, rather than against nature. it would seem possible to maintain this immunity with relative ease and low costs. But if the age mosaic is not stable, then something beyond age-based management will be necessary to prevent large fires, such as the establishment of firebreaks, or burning with a frequency significantly higher than that of the recent past, or control on the number of ignitions at times of the highest fire danger.

The implication of the fuel/age paradigm is that a finegrained age mosaic is the natural condition of a shrubland landscape. There are some empirical reasons to doubt that this necessarily is the case, but this study was motivated by a suspicion that fine-grained mosaics are inherently unstable even under the rules of the fuel/age paradigm, and therefore not likely to be more than a transient condition of shrubland landscapes. This has implications for management because, if a fine-grained mosaic is not a natural tendency, more time and effort will be needed for management to maintain this condition. There is the additional concern that the management necessary to maintain what might be an artificially complex mosaic might bring about changes in the system that would have other unintended negative consequences, such as increasing soil erosion, or a reduction in the abundance of rare species.

\section{The Model}

We explored the question of stability and persistence of age mosaics with the simplest possible spatially explicit model, a landscape of cellular automata (Green 1997). The model simulated a shrub-dominated landscape composed of a mosaic of shrub patches of different ages and was designed to conform qualitatively to the elements of the fuel-based theory noted above. For heuristic purposes, we examine age boundaries in a two-cell landscape. Questions about age mosaics were explored with a simulated landscape composed of 400 grid cells ( $20 \times 20$ cells), the attributes of which were location and age. The model ran in annual time steps with vegetation repeatedly exposed to the possibility of fire within each annual time step. We assumed that there is a minimum age that vegetation must reach before it is capable of burning (MINAGE) and that prior to this age vegetation will not burn, even if exposed to an ignition. Input variables were the number of years to be simulated, the number of ignition events per annual time step (IGNITS), and the minimum age at which a patch has sufficient fuel to carry fire (MINAGE).

At the start of each run, each cell was randomly assigned an age between 0 and 60 years so that every simulation began with an even age distribution. In each year, an ignition event was randomly assigned to an individual ccll. If the age of the cell were less than the minimum age at which burning was possible (MINAGE), the ignition event failed. If the age of the cell were greater than MINAGE, it was considered burned and the age reset to zero. There is much anecdotal but relatively few rigorous quantitative data on what actual values of MINAGE might be. Managers seem to think of MINAGE as being in the range of 15 to 30 years, but it is known that chaparral less than 20 years old will commonly burn (Barro and Conard 1991).

Fire spread contagiously from burned cells to all contiguous cells and ceased to spread when all contiguous cells had ages less than MINAGE. This was repeated until the preassigned number of ignition events had occurred, after which the ages of all cells were incremented by one year and the next annual time step began. 
We ran the model using different values of MINAGE $(10,20,30,40$ and 50 years of age) and IGNITS $(1,4,10$, 42 , or 100 strikes/year). These latter represented ignition event probabilities of $.0025, .01, .025, .1$ and .22 , respectively. Each simulation was carried out for 500 annual time steps. The simulation was repeated 10 times for each set of conditions using a unique random seed and the results were averaged. A subset of these simulations was carried out for 1000 annual time steps, with five replicate runs.

It is widely recognized that weather affects fire, and we therefore wished to explore the effect of extreme weather on the age mosaic by a set of simulations in which the probability of occurrence of a Santa Ana-type extreme fire danger day $(S A)$ was set at the beginning of the run. Within each one year run each ignition event was assigned either to a "Santa Ana" day with a probability $S A$ or to a "normal" day with probability 1-SA. The effect of extreme weather was simulated by lowering the MINAGE by 5 years, which meant that a greater proportion of the cells could be burned. The probability of these extreme events $(S A)$ was set to 0.02 for all runs.

\section{Results}

\section{Persistence of age boundaries - the two-cell landscape.}

For purposes of clarifying the behavior of age boundaries, we begin with the simplest possible landscape mosaic, one consisting of two cells $\mathrm{A}$ and $\mathrm{B}$ of equal size and of age $a_{A}$ and $a_{B}$, in general for the initial condition $a_{A}$ $\neq a_{B}$. Thus the boundary between the two cells is an age boundary. MINAGE, following the definition above, is the minimum age at which a fire can be carried. We also assume that each cell has a probability $p$ of being burned in each year. If a fire occurs, and the age is equal to or greater than MINAGE, the cell burns. If the age of the other cell is less than MINAGE, it cannot burn. If it is greater than MINAGE fire will spread into it and both cells will burn.

The state of the age boundary can be followed over time in a graph in which the two axes are the age of the two cells (Fig 1A). With increasing time, and no fires, the system moves along the bold lines in the direction of the arrows (upward and to the right), necessarily parallel to the line of no difference because the cells age at the same rate. MINAGE can be plotted on each axis of this graph to define four sectors. When the system is in the lower left sector, both cells are younger than MINAGE, and neither can burn. When it enters the upper left or the lower right, one but not the other can burn, and if it enters the upper right, both cells would burn because both have ages that equal or exceed MINAGE. When a cell does burn, its age instantly drops to zero, and the system is moved to one of the two axes, or to the origin with the age of the burned cell (or cells) set to zero. This is indicated by the dashed lines, which represent the instantaneous change in age. When both cells burn, both are moved to origin. We use the term coalescence to describe the situation that occurs when two cells of different age burn at the same time, that is, the system moves from $0<a_{A} \neq a_{B}$ to $a_{A}=a_{B}$ $=0$ and the age boundary disappears.

In Figure $1 \mathrm{~A}, p=1$, meaning that as soon as a cell reaches MINAGE, it is burned and its age set to zero. If the system is launched with either age difference $d_{1}$ or $d_{2}$, the landscape will follow the graphed pattern, cycling between the two age differences. It cannot enter the upper right sector. It is possible for the age difference to be unchanged by fire, a situation represented in Figure 1B. It is apparent from the geometry of the graph that this will be the case when $\mathrm{d}_{1}=\mathrm{d}_{2}=$ MINAGE $/ 2$.

If $p<1$, it is possible for the landscape to enter the other three sectors because when years pass without fire, the cells can age beyond MINAGE. In Figure 1C, the landscape is burned four times, starting with fire \#1. In the first three fires, one of the cells has aged beyond MINAGE, with the result that through time the landscape does not follow a fixed path. Finally, prior to fire \#4, the two cells both age beyond MINAGE, so that when the fire occurs, both burn and the landscape is returned to the origin $(0,0)$. In the next period, and forever after, the landscape will move up the diagonal line of no difference and return to origin, that is, $a_{A}=a_{B}$ is an absorbing condition (Feller 1950). Thus, unless $p=1$, the system must eventually coalesce.

When $p<1$ and for a given MINAGE the time it takes, on average, for the age boundary to disappear will be a function of the initial age difference along the boundary, and $p$. From the graphs, it is evident that, on average, starting with an age difference of MINAGE/2 (corresponding to Fig. 1B) will lead to the longest persistence. This is because the greatest period of time is necessary to traverse the upper left and lower right sectors. When the initial situation places the system on the lower line of Figure $1 \mathrm{C}$, the persistence time should be shorter.

Varying MINAGE also changes the time before loss of the age boundary because the average period of time from crossing the MINAGE line to entering the upper right sector will be less when MINAGE is smaller. This can be illustrated for a special case where the age difference is set to MINAGE/2 and the probability of reaching the upper right before the first fire occurs is calculated. This will simply be (1-p)n where 1- $p$ is the probability in any one year of a fire not occurring, and $n=$ MINAGE/2. Plotting this probability as a function of $p$ for different values of MINAGE (Fig. 2) shows that as the probability of fire approaches 1 , the probability of coalescence approaches 0 (as pointed out above); and also that for any given intermediate probability of fire, the probability of coalescence increases with decreasing values of MINAGE. 


\section{A. FIRE CERTAIN, AGE DIFFERENCE ALTERNATES}
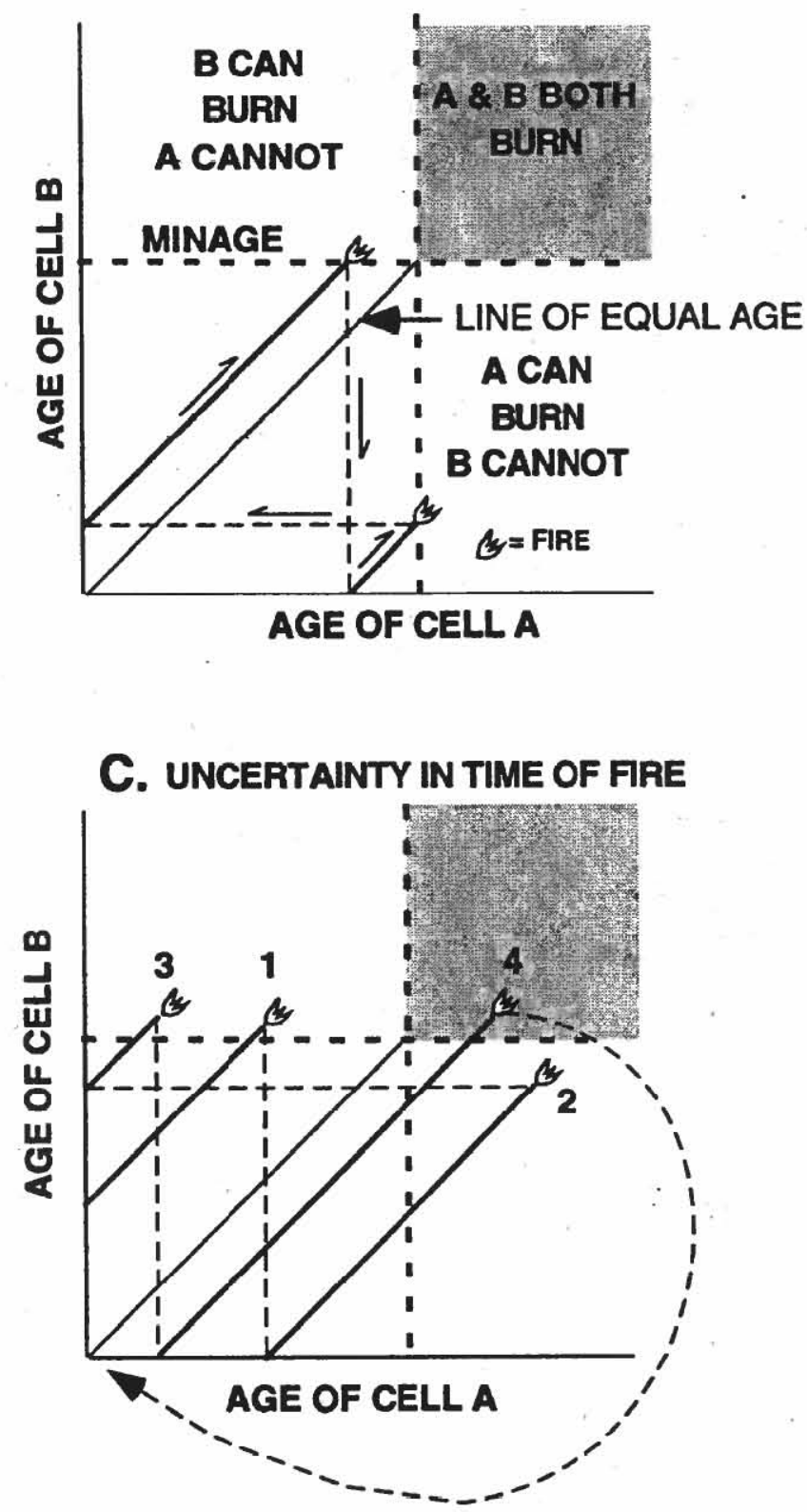

\section{B. FIRE CERTAIN, AGE DIFFERENCE CONSTANT}

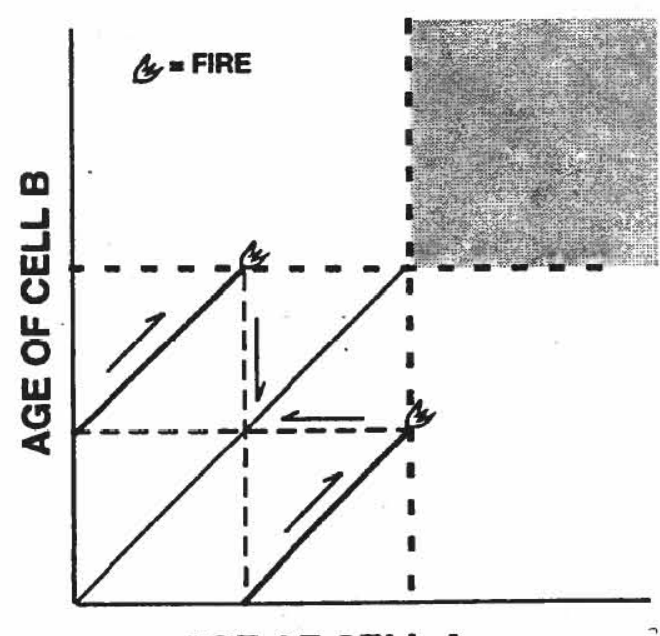

AGE OF CELL A

Figure 1. Behavior of an age boundary in a two-cell landscape. Between fires, the two cells age, moving parallel to the line of no difference or on the line of no difference. When a fire occurs, the age of the burned cell falls to zero - indicated by the lighter dashed lines. MINAGE, the minimum age at which fire can occur, defines four sectors in the graph space. In the lower left quadrant, when both cells are less than MINAGE, neither can burn. The other three sectors are labeled in (A) and described in the text. (A) Case where the age difference is asymmetrical and fire is certain. (B) Fire certain, but the age difference constant. (C) Example of behavior when fire is not certain so that one or both cells can age beyond MINAGE. (D.) Example of behavior when MINAGE differs for the two cells. Further explanation in the text.

If MINAGE is different for the two cells the behavior of the system will be different, most interestingly when $p$ $<1$ (Fig. 1D). This could occur if, for example, dead wood accumulated at different rates on the two sites. Because of the asymmetry, when by chance the system enters the upper right sector and is returned to the origin by a fire, the system is not trapped on the line of no difference, as for the case where MINAGE is equal for both cells. In the example (Fig. 1D) there is a sequence of four fires. The first two occur in the upper left sector, which returns the system to the $\mathrm{x}$ axis. The third fire places the system at the origin, that is, the ages of A and B are the same as the cells age along the line of no difference. But the fourth fire takes the system off of the line of no difference, recreating an age boundary. 


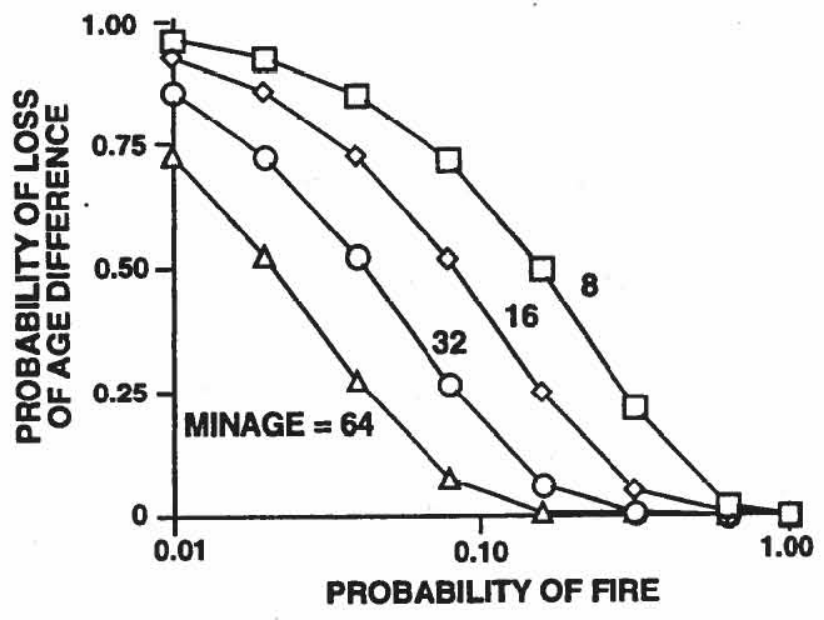

Figure 2. Probability of the loss of the age difference (coalescence) in the two-cell landscape for the special case of one fire only in a situation like that of Figure 1.B. Essentially this is the probability, for different values of probability of fire $(p)$ and MINAGE, of the system crossing into the upper right quadrant before being burned. If this occurs, both will burn and their ages simultaneously be reset to zero. This probability decreases with increasing $p$ and MINAGE.

What this simple example shows is that an age boundary governed by rules that correspond to those of the age paradigm cannot be stable unless it is certain that fires will occur in the year that MINAGE is attained, or equivalently, that ignition events occur in each cell in every year. This suggests that age mosaics in a more realistic probabilistic system are likely to be transient phenomena. They are likely to persist longest when MINAGE is high, and when the age difference in the initial condition is half of MINAGE.

The example also shows that age boundaries can regenerate if MINAGE differs between the cells. This is equivalent to allowing fuel characteristics to be a function of site as well as age. Thus, if MINAGE is different on two adjacent sites, age boundaries can reestablish after coalescence.

\section{Age mosaics can persist in a deterministic system}

From the results of the 2-cell case and simple logic, it is apparent without resorting to simulation that persistence of an agc mosaic of any degrec of complexity is possible within the rules set out above. This will be the case if (a) the maximum age of the vegetation at the onset of the first fire season is equal to MINAGE, and (b) each patch, or at least each patch that is at MINAGE receives an ignition event. When these conditions hold, by definition, each year all blocks at MINAGE will burn and only blocks at this age will burn. The vegetation then ages a year, a new cohort of patches reaches MINAGE, these and only these burn, and the original age mosaic can persist forever. The details of the spatial configuration are irrelevant.
The case where the initial mosaic includes patches greater than MINAGE is only slightly more complicated in that there will be a one-year transient condition in which all patches greater than or equal to MINAGE burn in the first year, after which all these patches form a new cohort that will burn in MINAGE years, and the resulting mosaic will then persist forever. If there is a sufficient number of cells greater than MINAGE, then there can be a large fire in the first year and, consequently, at regular intervals every time this large group of cells reaches MINAGE. Thus, the persistence of an age mosaic in itself does not preclude large fires.

\section{Persistence of the age mosaic with randomness}

Simulation using the 400 element landscape allows us to follow the changes in the age mosaic for stochastic situations. The single variable of greatest interest is the maximum fire size per year, expressed as the percentage of the total landscape. The variation in this statistic over simulated time bears out conclusions reached for the 2-cell case (Fig. 3). Three examples of the transient behavior of the landscape for different values of MINAGE and IGNITS show that in all there is a tendency toward coalescence as evidenced by the fact that the maximum fire size increases over time, starting with the highly diverse mosaic. Further, as expected, increasing MINAGE tends to slow the process (Fig. 3A vs. Fig. 3C). The effect of the probability of fire is shown by comparison of a high rate of ignition versus a low rate of ignition (Fig. 3B versus Fig 3 C). With a higher rate, there is a lower probability that adjacent blocks of different age will both exceed MINAGE with the subsequent loss of the age boundary when either receives an ignition event.

The time sequences also show a marked periodic behavior, most apparent in Figure 3A. This would be expected according to the rules of the fuel-based model, because as coalescence proceeds, it becomes almost certain that the largest blocks will burn at or soon after MINAGE because the probability of a hit somewhere increases in proportion to the area occupied by burnable cells. To the best of our knowledge, it has never been suggested that this kind of fuel-driven periodic behavior exists in chaparral landscapes, yet it would be expected in a strictly fuel-based system. The exception would be the special case in which the age-size distribution was uniform, and coalescence precluded by a certainty of ignition, as explained above.

The outcome of the 500 year simulations can be summarized to show the effects of MINAGE and IGNITS by displaying the maximum fire size as function of both (Fig. 4). At very low MINAGE, the complex mosaic is substantially lost for all ignition rates, and maximum fire size becomes very large. With increasing MINAGE, the maximum fire size declines, slowly for low rates of ignition, and more rapidly for high. Thus, increasing ignition fre- 

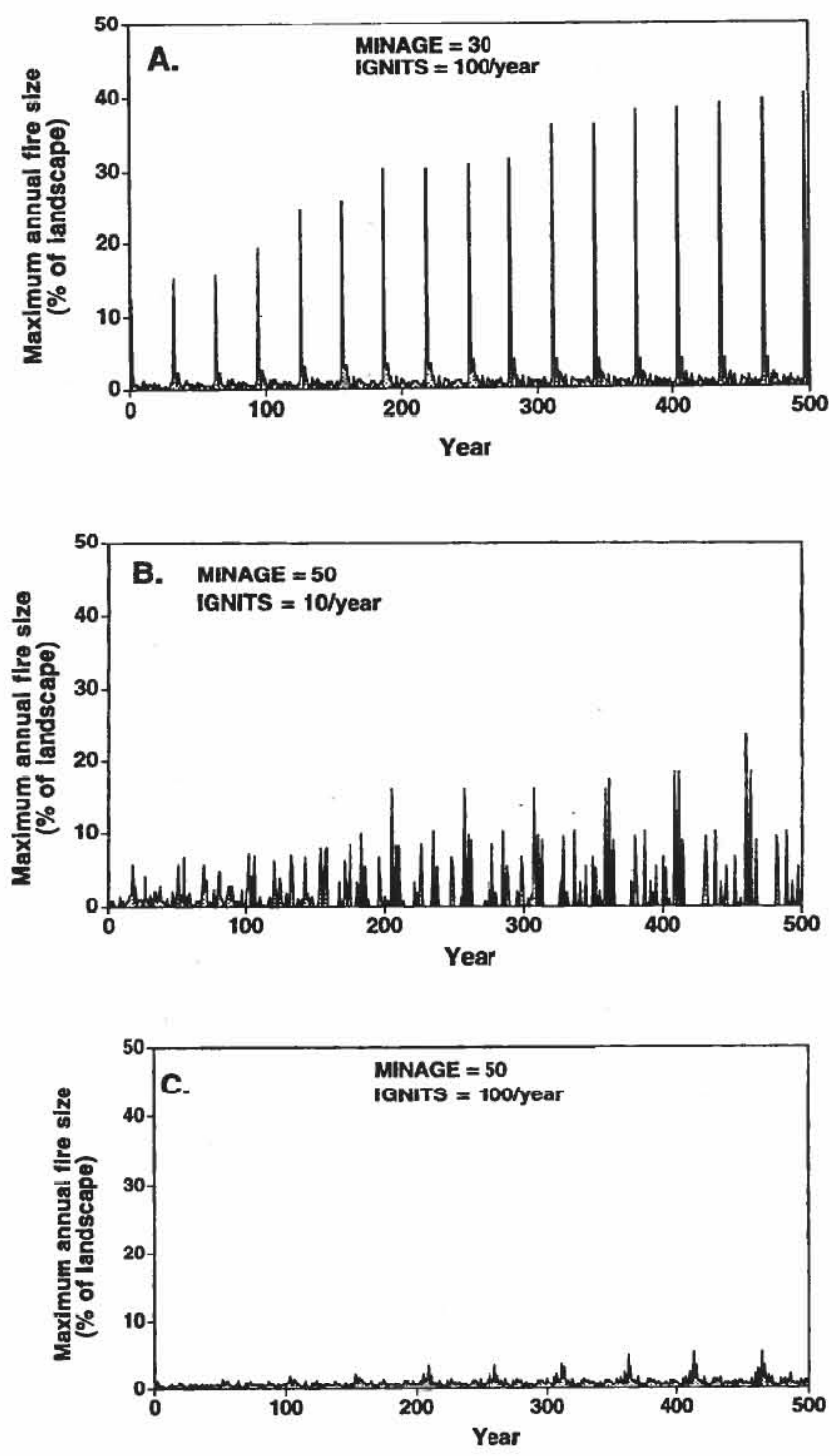

Figure 3. Transient behavior of the 400 cell model with respect to the maximum size fire occurring in each year. Simulations were run for 500 years. (A) MINAGE at 30 with high ignition of 100 / year. (B) MINAGE at 50 with ignitions at 10/year. (C) MINAGE at 50 with 100 ignitions/year. All three graphs show an increase in the maximum fire size with time as coalescence occurs, but the rate of increase is very slow with a very high MINAGE and a very high rates of ignition.

quency can sharply decrease the maximum fire size, but only where MINAGE is above 30 years. Recalling that our initial condition is to set maximum vegetation age at 60 years, this result is expected from percolation theory, which predicts that contagion (in our case fire) sharply increases when more than about $60 \%$ of the elements of a landscape are susceptible (Stauffer, 1985).

It is apparent from Figure 3 that there is a tendency toward coalescence for all values of IGNITS and MINAGE, suggesting that the main difference between
EFFECT OF MINIMUM AGE TO BURN AND IGNITION EVENT FREQUENCY

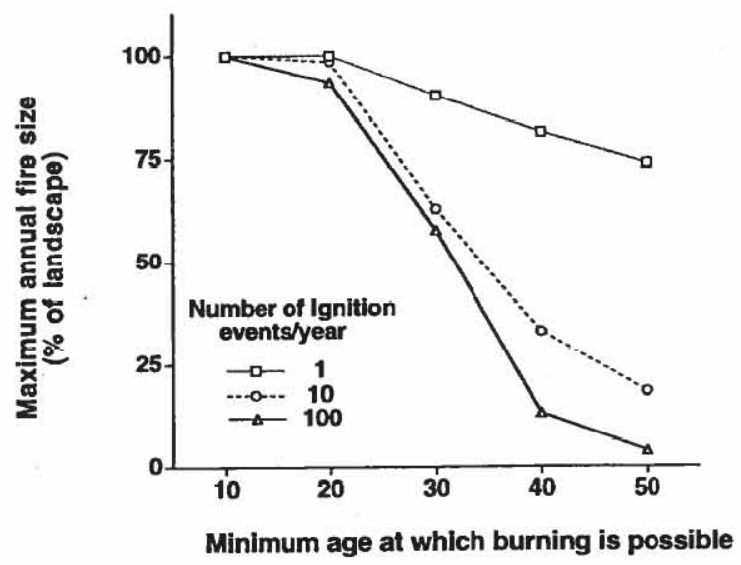

Figure 4. Maximum fire size in the 400 cell landscape as a function of the minimum age at which burning is possible (MINAGE) and the number of ignitions per year. High rates of ignition and high MINAGE slow the loss of the mosaic.

landscapes with different sets of values is the length of time before coalescence occurs. To confirm this, we ran a subset of the simulations for 1000 years, replicating the runs five times, varying IGNITS and MINAGE. We observed that for all combinations of the parameters, for MINAGE 20 years or less, complete coalescence was observed within the 1000 year simulations (Fig. 5). Where this was the case, maximum fire size is that of the entire landscape. High rates of ignition significantly slowed the minimum time required for coalescence, and more than the 1000 years of the simulation was required for coalescence when MINAGE was greater than 20 for 100 ignitions/yr and greater than 30 for 10 ignitions/yr. This shows that mosaics may disappear slowly, but they do disappear.

\section{EFFECT OF MINIMUM AGE TO BURN AND IGNITION EVENT FREQUENCY}

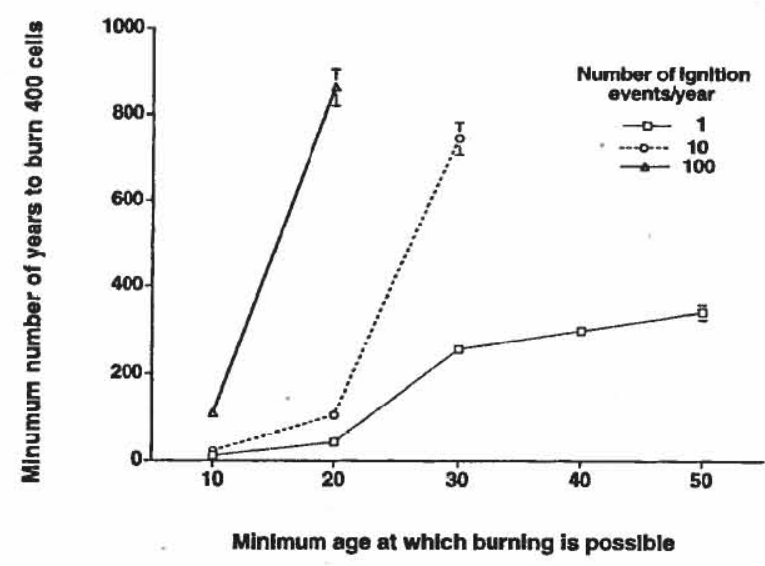

Figure 5. Minimum time out of 5 runs of the 1000 year simulation for the entire landscape to burn, that is, for complete coalescence to occur. The missing points indicated that complete coalescence was not achieved in any of the 5 replicate 1000 year runs. 
Because we believe in the overriding importance of weather, we considered how the occasional imposition of simulated extreme conditions might affect the coalescence process. We imposed "Santa Ana" years in which MINAGE was dropped to simulate extreme weather in which vegetation is burnable at a younger age than usual because of the extremely dry conditions. As expected, moving more cells into the burnable classes increased the maximum annual fire size in the 500 year simulations (Fig. 6).

For completeness, we might have also run a simulation in which weather unusually unfavorable for fire reduced the number of susceptible cells by raising MINAGE. This would, of course have the opposite effect, but could not regenerate elements of the mosaic lost to coalescence.

\section{Discussion}

\section{The simulation results at face value}

We must first acknowledge that our simulation clearly supports one of the major tenets of the fuel/age paradigm, namely that effective suppression of fires (in our model: reducing ignition events) has the effect of hastening coalescence and therefore leads to an increase in maximum fire size. But our simulation also shows that within the strict confines of a fuel/age paradigm coalescence is inevitable regardless of degree of suppression so long as there is some fire and the probability of a block burning in the year it achieves MINAGE is less than 1. As explained in the 2-cell landscape, this is because failure to burn results in aging which inexorably leads to coalescence, though at variable rates depending on the parameters chosen. Thus, within a strict fuel/age model, a finegrained age mosaic is only a transient phenomenon. We

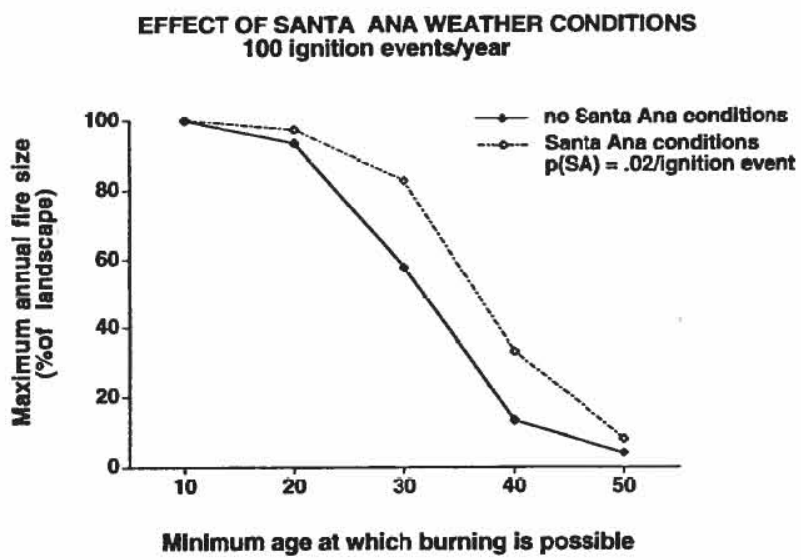

Figure 6. Effect of introducing severe weather into the simulation model. The method used increases the population of susceptible elements in the mosaic, thereby increasing maximum fire size attained in each 500 year simulation. except where values converge at the entire landscape at MINAGE of 10. also show that during this transient phase, the landscape will probably have a periodic behavior in acres burned.

We believe that the fuel/age paradigm does not describe the inevitable tendency of a natural system. An age mosaic inevitably fades away and cannot be regenerated without invoking other processes or controlling factors.

\section{Models and reality}

Of course our simulated landscape of cellular automata is at best a sketch of the behavior of real fires in real landscapes. Our purpose was to test the validity of the basic elements of the fuel/age paradigm. Our model is simple, but relative to the complexity of nature, we believe that it is commensurate with the fuel/age paradigm. A theory is fairly tested by the simplest system to which it applies.

We also recognize that the conclusions of our simulation can be dismissed on the basis of many ad hoc arguments. One avenue of attack was suggested in our 2-cell results which show that age boundaries can persist if the age boundaries are also fuel discontinuities that cause MINAGE to differ significantly across the boundary. The asymmetry of MIN $\Lambda \mathrm{GE}$ offers the possibility of the rebirth of age boundaries to offset their loss through coalescence. But to invoke this goes against the basic assumptions of the fuel based theory. Heterogeneity in fuels is required so that age boundaries will correspond to discontinuities in the rate at which fuels accumulate, or the rate at which flammability develops. This amounts to saying that site as well as age determines the propensity to burn. If the distribution of these site-determined fuel characteristic boundaries is appropriate, it might be possible for a fine-grained mosaic to be stable. If site is important, then differences in fire behavior in different regions cannot be wholly ascribed to differences in management practices.

Specifying such a paradigm-saving modification is easy, but presenting hard data to show that it corresponds to reality would be more difficult. Someone must demonstrate the reality of such boundaries and show that their effect on fire size is as postulated in general, and not just in a few specific instances. If this proves to be the case, it would then be the job of managers to locate the discontinuities and to use them as the boundaries of management burns.

Another simple modification of the fuel model would be to allow fires to stop before reaching the limits of a particular burnable patch rather than inexorably propagating to limits of the contiguous burnable age classes, as in our model. As in the previous case, this would allow a mechanism by which new age boundaries could be created to offset the loss of boundaries by coalescence. But what mechanistic explanation can be given for fires behaving in this way? There could be site-determined variation in fuel characteristics, which makes this essentially the same point as that of the previous paragraph. Or a 
purely random limit to propagation could be postulated: "Fires will spread in burnable vegetation until they cease to spread." If weather is invoked to explain such random behavior, the purity of the fuel-based model is lost (appropriately, we believe) and then attention must focus on introducing weather explicitly into the fuel/age model. At a minimum it would be necessary to state: "At any given time, the spread of fire is determined by the meteorological conditions." Then it is the task of the fire managers to demonstrate that although weather is an important control, its capacity in a non-suppression landscape to create new age boundaries within existing mosaic elements offsets the tendency of weather to lead to coalescence in extreme weather conditions.

\section{Comparisons with a more detailed model}

Davis and Burrows (1994) published a far more complex simulation based on the Rothermel fire spread model (Rothermel 1972) that described spatial patterns of fire in chaparral. They parameterized their model with data from a 1865 ha area in Santa Barbara County dominated by Adenostoma fasciculatum. Their conclusions that "[the results] conform to the behavior of fire mosaics predicted by ...... Minnich (1983)" and that "... over long time periods (e.g., 500 years) ..... chaparral fire mosaics may behave as quasi-equilibrium systems" appear to contradict our conclusions. We believe, however, that Davis and Burrows were speaking only generally. Their model results do not agree with the expectations of the fuel/age paradigm. Further, it seems to suggest that factors other than age are very important in determining fire behavior.

For example, they note that the average age of vegetation is sensitive to numbers of ignitions, as is the average fire size. With many ignitions, the mean age of the landscape is lower than it is with fewer ignitions. This observation, which seems reasonable to us, violates the tenet of the fuel/age paradigm that regions with and without suppression have about the same recurrence interval (Minnich 1983, 1989).

In Davis and Burrows model, unlike our "pure age" model, factors other than age can stop fires. These include a change in vegetation type, topography, a change in weather conditions, or the presence of an inflammable cover type. As noted above, introducing these complexities would be expected to promote greater age diversity, but owe nothing to a belief in the fuel/age theory. Another contradiction appears in the comparison of fire interval in a modern landscape in which the chaparral is fragmented to that in the more continuous vegetation of the prehistoric landscape. This revealed that the average recurrence intervals were dramatically longer in the modern landscape because isolated patches are protected from fire and can reach great ages. Again, this shows that in a stochastic system average vegetation age is a variable and can be very sensitive to factors other than age.
The quasi-stability they observed is difficult to evaluate. Because we believe that the age-dependent component cannot be stabilizing, we presume that the quasi-stability they report arises from the interactions of the other factors with each other or with age, and not from the age factor itself.

Finally, the model results of Davis and Burrows can be compared to the empirical study of Moritz (1997) of fire size and recurrence in a region not far from the modeled landscape of Davis and Burrow. Moritz could find no evidence that fire suppression in his two study areas had an effect on the size of the largest fires, though it did appear to reduce the frequency of smaller fires. He attributed this to the fact that the largest fires are controlled by extreme climatic events. If such a system can be said to have quasi-stability, it seems very unlikely that the kind of age mosaic expected under the fuel/age paradigm could be an important means by which the variability of the landscape mosaic is constrained. Further, it shows that whether the scattering of small fires expected under a non-suppression situation are present or not, large fires will still occur. This raises questions about how effective artificially produced age mosaics can be in limiting fire size unless they shift average age of the vegetation to unprecedented low levels.

\section{Empirical tests}

We believe that our simple model does point the way toward appropriate empirical tests of the fuel based theory. The age-dependent fuel model promises to deliver a landscape that is immune to very large fires. In thinking what this means, a useful simplification is to visualize the landscape at each moment being divided into burnable and not burnable. The age-dependent theory holds that this division corresponds closely to age, with young vegetation being not burnable and old vegetation burnable. It also seems to presume that "old" and "young" is in this context similar for all landscapes, whether subject to stringent societal pressures against ignitions and vigorous suppression, or to a regime of frequent and widely distributed ignitions and less certainty of effective suppression. Moreover, it also holds that the proportion of old-burnable will almost always be a relatively small proportion of the whole. In our terms, the assumption is that MINAGE is great enough to insure that only a small portion (certainly less than about 60 percent, according to percolation theory) will be in the burnable category. This assertion could be tested by a combination of measurements to assess flammability and observations of actual fires to determine the age of the vegetation in which they propagated, the number of age boundaries that they burned over, whether or not they stopped along an age boundary, and the ages on either side of the boundary.

Note that simply observing that fires often extinguish along age boundaries is not a sufficient proof of the va- 
lidity of the age/fuel paradigm. In our model, in which fire size grows with time and coalescence is inevitable, fires always stop along age houndaries. In the transient condition, however, this typically occurs only after one or more age boundaries have been obliterated. Thus, for the fuel/age paradigm to hold, what must be shown is that the pattern of burning acts against the coalescence pattern, with each fire on average creating the same perimeter of age boundary as it destroys.

There are also questions about age and fuel discontinuities. Paysen and Cohen (1990) showed that fuel/age correlations are weak. A similar question could be asked about the magnitude of fuel differences along age boundaries as a function of age difference and the youngest age. Obviously there will usually be very large differences where 75 year old chaparral abuts 2 year old chaparral But can one statistically separate $30 / 50$ year boundaries from $40 / 70$ boundaries? - very possibly not.

Another question concerns the change in fuel type. If it were true that the features of our simulation model applied to the real world, then there would be a MINAGE below which fires could not be sustained. Whether or not this were attainable in a natural setting, it would be possible to insure by artificial means that a substantial fraction of the landscape were maintained below MINAGE. This could be done, for example, by a management-imposed rotation in which all stands that exceeded MINAGE were burned each year.

This system would not preclude vegetation from burning, but merely delay burning until young vegetation matures, at which time it would again be capable of burning. In order to maintain a majority of vegetation below MINAGE, MINAGE has to be high so that there is a significant range of ages possible in the unburnable condition, and the probability of ignition would have to be 1 so as to prevent coalescence. That is, control burning would have to be carried out annually wherever vegetation exceeding MINAGE did not burn from natural causes.

Further, the success of such vigorous management is based on the assumption that MINAGE in more natural landscapes and in human influenced landscapes is the same and is not subject to changes that might be brought about by the use of fire. In terms of our model, the assumption is that MINAGE remains constant over the full range of IGNITS. But in the real world there is a significant complication because changing fire regime can also cause changes in fuel type. Specifically, frequent burning can increase the herbaceous component in vegetation which can have the effect of lowering MINAGE to 1 in cases where herbaceous production is sufficient in a single year to carry fire. Thus, an attempt to alter the landscape by insuring that a large proportion is below MINAGE for the existing shrub vegetation may shift the system to one in which fire at short intervals is possible (Haidinger and Keeley 1993). How likely this is to occur is probably impossible to predict in theory, but relatively straightforward to observe empirically. For shrublands the question is: how short can a fire rotation be before there is a significant increase in the herbacenus and suffrutescent component? To prevent an increase in herbaceous fuels, at the least, it would seem necessary to allow the vegetation to age until the shrub canopies had eliminated most of the gaps receiving direct sunlight and rainfall.

We doubt that such empirical observations will support the age/fuel theory. Rather, we predict that detailed study will show that even quite young vegetation will burn under the right conditions, and that fire boundaries will be related much more to topography and to changes in weather conditions during the burn than to age boundaries. That is, we expect that study will show that the age mosaic is continually shifting over time with new fires being overlaid on old without much respect to the age of patches.

\section{Forests and shrublands}

The age/fuel paradigm is seen by many as relevant beyond Pacific Coast shrublands. There is a clear consensus that fire is sorely lacking in many of the woody plant communities of the western U.S. The arguments in favor of more controlled burns in western forests parallel those made for shrublands. Fires were frequent in the past, they are rare now. Fuels have built up, and therefore there are uncontrollable regional conflagrations (e.g., Dickmann and Rollinger 1998). It seems possible to us that in forests, as in shrublands, there may be the application of a too-simple model to a complex situation, but we set this concern aside and accept that the case for the fuel/age paradigm is more compelling for forests. But does granting this strengthen the case for the applicability of the paradigm in shrublands?

In forests the issues of the vertical distribution of fuels and fuel types looms large. In the past in ponderosa pine forests, it is said, ground fires that were carried in herbaceous and light woody fuels were the rule and standreplacing crown fires only local. In the present, it is said to be almost the reverse. Shrubs and saplings form dense sub-canopy populations that both suppress herbaceous fuels and provide a bridge by which fires can be carried upward into the canopy (Agee 1993). But in shrublands, no one can claim such a dramatic change in fuel structure and type. In northern Baja California, Mexico, fires in scrub and chaparral typically remove almost all of the living above ground biomass, just as they do in California. Indeed, since vegetation is said to hurn at ahout the same age in the two systems (Minnich 1983), even the intensity factor cannot be markedly different since roughly the same amount of fuel must be consumed. Thus, according to the fuel/age paradigm the choices in shrublands are alleged to be between intense crown fires that burn small areas or intense (or if one prefers, very intense) crown fires that burn large areas. 
Of course, as noted above, significant change in fuel type is observed in shrublands, but this is not because of fire exclusion, but a consequence of the introduction of exotic species, or high fire frequency, or both (Zedler et al. 1983; D'Antonio and Vitousek, 1992). Because this kind of conversion is known to occur, it could be a management objective. There would be certain advantages to a grass-dominated landscape. Although fires could still be large, they would not be nearly as intense because there would be less fuel. Despite these advantages, few would advocate such conversion as a regional policy. We emphatically do not.

\section{Living with the land}

The conference at which is this paper was presented was concerned with the interaction of development and ecology. Discussion of fire in such a forum is very fitting, because fire is one of the most serious problems along the urban-wildland boundary. Like many others, we propose that the solution to the wildfire problem is to learn to live with it instead of clinging to the idea that we can always manage the forces of nature to suit ourselves. This means keeping our human habitations our of harm's way. In principle, there is no reason that this could not be done. In practice, our society seems very reluctant to accept natural limits and the inconvenience of natural processes.

\section{Literature Cited}

Agee, J. K. 1993. Fire ecology of Pacific Northwest Forests. Island Press. Washington, D. C.

Barro, S.C. and S.G. Conard. 1991. Fire effects on California chaparral systems: an overview. Environemental International 17:135-149.

D'Antonio, C.M. and P.M. Vitousek. 1992. Biological invasions by exotic grasses, the grass/fire cycle, and global change. Annual Review of Ecology and Systematics 23:63-87.

Dickmann, D.I. and J.L. Rollinger. 1998. Fire for restoration of communities and ecosystems. Bulletin of the Ecological Society of America 79:157-160.

Feller, W. 1968. An introduction to probability theory and its applications. Volume I. Third Edition. John Wiley and Sons, New York.

Green, D.G. 1997. Modelling plants in landscapes. Pp. 85-96 in M.T. Michalewicz, ed. Plants to ecosystems. CSIRO Publishing, Collingwood, VIC, Australia.

Green, L.R. 1981. Burning by prescription in chaparral. USDA Forest Service, Pacific Southwest Forest and Range Experimental Station. General Technical Report PSW-51.

Haidinger, T.L. and J.E. Keeley. 1993. Role of high fire frequency in destruction of mixed chaparral. Madroño 40:141-147.

Minnich, R.A. 1983. Fire mosaics in southern California and northern Baja California. Science 219:1287-1294.
Minnich, R.A. 1989. Chaparral fire history in San Diego County and adjacent northern Baja California: an evaluation of natural fire regimes and the effects of suppression management. Pp. 37-47 in S.C. Keeley, ed. The California chaparral: paradigms reexamined. Science Series No. 34, Natural History Museum of Los Angeles County, Los Angeles, CA.

Minnich, R.A. 1995. Fuel-driven fire regimes of the California chaparral. Pp. 21-27 in J.E. Keeley and T. Scott, eds. Brushfires in California wildlands: ecology and resource management. International Association of Wildland Fire, Fairfield, WA.

Moritz, M.A. 1997. Analyzing extreme disturbance events: fire in Los Padres National Forests. Ecol. Appl..7: 1252-1262.

Paysen, T.E., and J.D. Cohen. 1990. Chamise chaparral dead fuel fraction is not reliably predicted by age. Western Journal of Applied Forestry 5:127-131.

Rothermel, R.C. 1972. A mathematical model for predicting fire spread in wildland fuels. USDA Forest Service, Research Paper INT-115.

Stauffer, D. 1985. Introduction to percolation theory. Taylor \& Francis Ltd., London.

Zedler, P. H., C. R. Gautier, and G. S. McMaster. 1983. Vegetation change in response to extreme events: The effect of short interval between fires in California chaparral and coastal scrub. Ecology 64: 809-818. 


\title{
Role of Prescribed Burning in the Management of Chaparral Ecosystems in Southern California
}

\author{
Jon C. Regelbrugge \\ USDA Forest Service, Pacific Southwest Research Station, 4955 Canyon Crest Dr., Riverside, CA 92549. \\ Tel. (909) 680-1542; Fax (909) 680-1501; e-mail: jregelbr/psw_rfl@fs.fed.us
}

\begin{abstract}
Recurrent, high-intensity fires are common in chaparral ecosystems, but considerable controversy exists regarding the historic fire regime of chaparral ecosystems, and whether this fire regime has been altered by management practices such as fire suppression. Wildfires result in considerable damage to human property in the wildland-urban interface through postfire flooding and debris flows as well as burning of structures. Prescribed burning of chaparral has been used to mitigate the impacts of wildfires on human lives and property. Potential benefits and limitations of prescribed fire are discussed in relation to the wildland-urban interface, and in relation to chaparral ecosystem management.
\end{abstract}

Keywords: Biomass; fire size; fire suppression; fuels; standage.

\section{Introduction}

Recurrent, high-intensity fires are common in the shrub-dominated plant communities that comprise chaparral ecosystems in California. These fires kill aboveground parts of most existing vegetation, consume varying amounts of stand biomass depending on the fire behavior, release large quantities of gaseous and particulate emissions into the atmosphere, and cause increased runoff and erosion of surface soil. This increased soil erosion occurs through dry ravel movement during and immediately following fire, as well as runoff-induced erosion during the subsequent rainy season. Although chaparral plant communities have sufficient resilience to regenerate following many fires (Hanes 1971), under certain situations such as two or more fires occurring in subsequent years, chaparral plant community composition can be dramatically altered (Zedler et al. 1983). Chaparral fires also cause considerable damage to human property, both through burning of structures, and damage caused by postfire flooding and debris flows. Fire imposes other costs on society as well. Large wildfires, especially those occurring in the wildland-urban interface, often cost several million dollars to suppress, and maintenance of de- bris basins where mountain watersheds empty onto the urbanized floodplain entails significant costs as well (Riggan et al. 1994). Fires can also cause other damages to ecosystems. Large wildfires potentially could alter habitat to a sufficient extent and for enough time to cause local extinction of endangered species, a problem that is exacerbated by increasing habitat fragmentation resulting from urban and rural development. Postfire erosion and sedimentation can also cause significant damage to riparian areas.

However, there is evidence that chaparral ecosystems have evolved with fire, and chaparral plants are not only tolerant of fire, but well adapted to reproduce following fire (Hanes 1971; Keeley and Zedler 1978). Given the flammable nature of chaparral, the widespread occurrence of ignitions, and the role of fire as an ecosystem process, elimination of fire is neither possible nor desirable. Use of prescribed fire has been suggested as a way to mitigate the unwanted impacts of destructive wildfires, while allowing fire to remain as an influence on ecosystem structure and function. The specifics of how, when, and where to use prescribed fire are the focus of considerable controversy and debate. These are complex issues with biological and societal components, and it is likely that neither full understanding of the role of fire in chaparral, nor consensus regarding use of prescribed fire as a management tool will be achieved in the near future. The purpose of this paper is to discuss the potential benefits and limitations of prescribed fire in relation to the wildlandurban interface, and in relation to chaparral ecosystem management. To do this, I will discuss the chaparral fire regime and how it is affected by fuels and weather, and how prescribed burning relates to the chaparral fire regime.

\section{Chaparral Fire Regime}

Chaparral plant communities burn in high-intensity, stand replacement fires. Unlike many forested ecosystems, where surface fires can burn without killing a sig- 
nificant number of mature trees, chaparral fires burn through the shrub canopy and typically kill the aboveground parts of all plants. Survival of aboveground plant parts is relegated to unburned islands missed by fire. The high intensity of these fires can cause the development of a hydrophobic layer in the soil profile, which causes dramatically increased erosion, and is believed to be related to the generation of debris flows (DeBano 1981; Wells 1981).

The various plant species that comprise chaparral communities are well-adapted to regenerate after fire (Hanes 1971; Keeley and Zedler 1978). Grasses and forbs are typically abundant in the first growing season following a fire, and within a few years shrubs usually regain dominance. Many shrubs and herbaceous plants regenerate from a soil seed bank, the germination of which is stimulated by fire in several ways (Keeley and Keeley 1981). Several important shrub species also sprout from basal burls, and the surviving root system from the parent shrub can contain significant carbohydrate reserves that help the resprouts to grow rapidly. Under certain conditions of burning (Riggan et al. 1988), or depending on the interval between fires (Zedler et al. 1983; Zedler 1995 ), community composition can be dramatically altered by fire, but many authors have documented the resilience of chaparral communities to high-intensity fires (e.g. Hanes 1971; Keeley and Zedler 1978; Riggan et al. 1988).

Two aspects of the historic chaparral fire regime that are poorly understood are the size distribution of fires and the fire return interval. Lack of dendrochronological information makes determination of historical fire return intervals difficult. Byrne et al. (1977) used analysis of varved charcoal cores from the Santa Barbara Channel to assess patterns of fire occurrence and fire size in the Santa Ynez Mountains. However, this technique lacks sufficient resolution, accuracy, and precision to estimate an average fire return interval, Patterns of fire occurrence from 1919 to 1980 in the Santa Monica Mountains were studied by Radtke et al. (1982), based on records obtained from the Los Angeles County Fire Department. On average, most of the Santa Monica Mountains burned 3 to 5 times, with an average fire return interval ranging from 12.4 to 20.7 years, depending on geographic location and species composition (Radtke et al. 1982).

The historical distribution of fire size is also poorly understood, primarily because it was not well documented. Some authors have suggested that the fire size distribution has been altered by fire suppression, such that suppression of fires burning under relatively moderate weather conditions results in wildfires burning under severe weather conditions that grow larger than during the presuppression period (Minnich 1983; Minnich and Dezzani 1991). While it is clear that fires burning under severe weather conditions, such as Santa Ana winds or heat waves, often burn very large areas, it is not clear that this is a recent development, or that it results from suppression of fires burning under less extreme conditions.

The proposed mechanism by which suppression shifts the fire size distribution toward larger fires is as follows. Following a fire, a chaparral stand must grow for some period of time to develop sufficient fuel loading and continuity to be flammable. Frequent small fires would prevent the development of large areas with high fuel loading by fragmenting continuous stands of mature chaparral into a mosaic of various ages and fuel conditions (Minnich 1983). This idea was supported by the assumption that dead wood was the primary component of the chaparral that influenced its flammability, and that dead fuel accumulated in proportion to age (Rothermel and Philpot 1973; Green 1981). The phenomenon of fire suppression resulting in the occurrence of large, catastrophic fires was proposed by Minnich (1983) following a comparison of fire patterns in southern California and northern Baja California.

Several reasons exist why this time-dependent, nonrandom occurrence of fires may be an over-simplified explanation of chaparral fire size distribution and return interval. Weather patterns may account for some of the differences in fire size reported between southern California and northern Baja California. Santa Ana winds are common in southern California but appear to be absent south of the border (Schroeder et al. 1964; Minnich 1983). Uncontrolled burns exhibiting the "smolder and run" pattern described in Minnich (1987) might be expected to burn very large areas during the one to several day duration typical of Santa Ana wind events. Also, wind driven fires can burn extremely young stands, for example the Old Topanga Fire of 1993 burned through a 5-year old prescribed burn in Pena Canyon (Regelbrugge, personal observation), and the 1993 Kinneloa Fire burned though a two year old burn (Dave Kerr, Angeles National Forest, personal communication). Dunn (1989), and Dunn and Piirto (1987) also document cases of fires burning through chaparral stands 10 to 20 years of age. Furthermore, several authors have found that dead fuel in chaparral does not accumulate in direct proportion to stand age (Paysen and Cohen 1990; Riggan et al. 1988).

If fire suppression has affected the chaparral fire regime, one might expect that altering of fuel properties of chaparral stands across the landscape would be the main mechanism by which fire suppression would exert its influence. Because the fuel structure of chaparral stands changes somewhat slowly, that is, several years must pass before significant changes are detectable, one might expect that fire suppression would have to be effective for some time before fuel changes would be pronounced enough to influence the fire regime. Therefore, one might reasonably expect to see some trend in fire size distribution or return interval during the twentieth century.

So far I have been able to obtain only a limited dataset for examining this hypothesis, but my initial investiga- 
tions show no obvious trend in fire size over the course of this century on either the San Bernardino National Forest or the Los Padres National Forest (Fig. 1). Although fire size distribution does vary somewhat by decade, median and mean fire size fluctuate higher and lower through the 80 to 90 years during which records have been kept (Fig. 1). Also, note that the largest fires on these two national forests have not necessarily occurred most recently, but some of the largest fires ever recorded occurred prior to 1940 (Fig. 1). Finally, Figure 1 shows the strongly skewed distribution of fire size and a logarithmic transformation does not normalize the distribution. All fires less than 40 ha have been omitted from Figure 1 and from the analysis below. Including the many fires less than 40 ha would change the median somewhat, but the mean would be little affected, as it is strongly influenced by the relatively few very large fires which are outliers in the fire size distribution, but account for disproportionately large amounts of the total area burned. Between 1911 and 1990, there were 714 fires greater than 40 ha on the San Bernardino National Forest, with median fire size of 145 ha and mean fire size of 742 ha. Median fire size by decade on the San Bernardino National Forest ranged from 99 ha to 245 ha, and mean fire size by decade ranged from 320 ha to 1394 ha during that period (San Bernardino National Forest records on file with the author). Median fire size between 1901 and 1990 on the Los Padres National Forest was 224 ha, mean fire size was 1857 ha, and 628 fires larger than 40 ha occurred. Median fire size by decade on the Los Padres National Forest during this period ranged from

\section{San Bernardino NF}

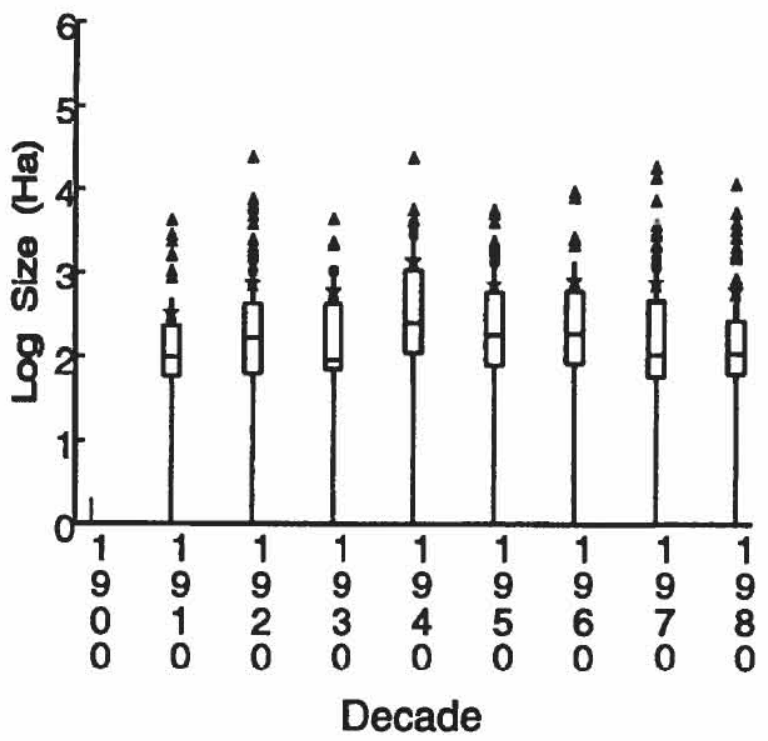

121 ha to 404 ha, and mean fire size by decade ranged from 960 to 2936 ha (Los Padres National Forest records on file with the author). Although there is considerable variation in fire size distributions by decade and annually, no clear trends appear to exist during this century on either forest, both of which contain much chaparral.

The above data show considerable differences in fire size distribution between these two forests, with larger fires occurring on the Los Padres National Forest. This demonstrates additional complications regarding whether fire suppression has led to increased fire size. Clearly, geographic variability has some influence on chaparral fire regimes. These two forests are in different mountain ranges, but are much closer together than much of the chaparral in southern California is to the chaparral in Baja California studied by Minnich (1983). Many authors have documented the compositional and structural variability among chaparral stands over geographic areas both large and small in extent (e.g. Hanes 1971; Riggan et al. 1988; Keeley and Keeley 1988). Combined with climatic variability over the large area occupied by chaparral, one might expect that these community differences would result in significant variability in fire size and fire return interval. For example, contrast the estimated fire return interval in the Santa Monica Mountains of 12 to 20 years (Radtke et al. 1982) with that of 70 years estimated for San Diego County (Minnich 1989). We need to recognize that regional and temporal variations in fire size and fire return interval are related to complex ecological processes. Therefore, even if we can describe their central tendency,

\section{Los Padres NF}

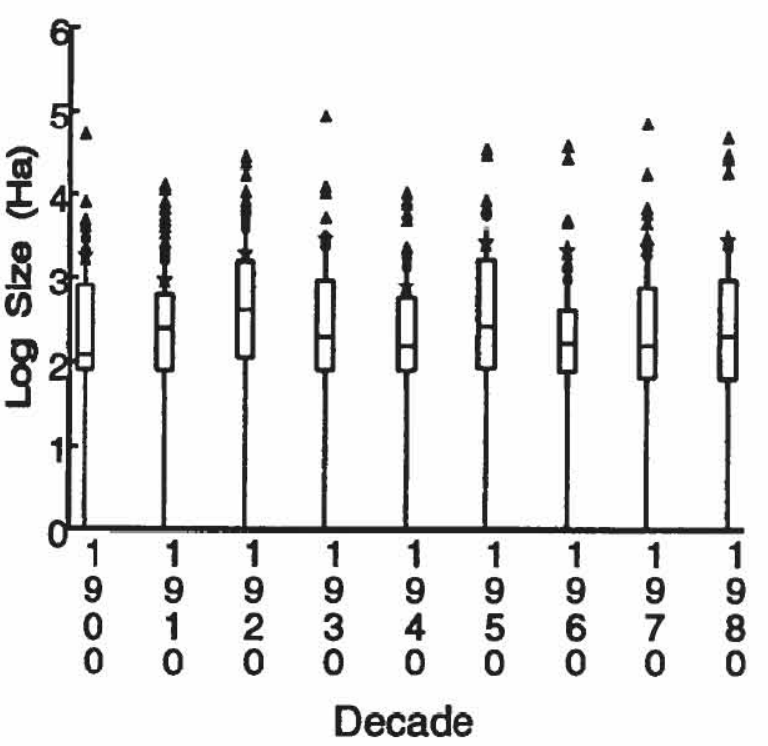

Figure 1. Box plots of fire size distribution for the San Bernardino National Forest and the Los Padres National Forest, California. Fires on both of these forests are dominated by chaparral. Only fires larger than $\mathbf{4 0}$ ha are included. Records were obtained from forest supervisor's offices in San Bernardino, CA, and Goleta, CA, respectively, and are on file with the author. The bottom, center, and top horizontal lines of the boxes indicate the 25 th, 50 th, and 75 th percentiles of the data, respectively. The star represents the mean. The vertical lines extend 1.5 times the interquartile range above and below the 75 th and 25 th percentiles, and the triangles indicate more extreme values. Note base ten logarithmic scale. 
we must expect considerable variation about this central tendency both spatially and temporally.

\section{Potential Adverse Effects of High Intensity Fires}

From a societal perspective, the most obvious adverse effect of high-intensity chaparral fires is the burning of homes and other structures. Fires can also disrupt peoples' lives and livelihood through evacuation and closures of communities and thoroughfares threatened by fire. Postfire flooding, sedimentation, and debris flows can also cause considerable damage to homes, roads, and other structures. Ecologically, exceptionally large and intense fires can cause considerable damage to chaparral watersheds. Postfire erosion can result in loss of surface soil, retarding vegetation recovery, and sedimentation and debris flows can alter riparian areas such that they are temporarily unsuitable habitat for plant and animal species that may depend on them. Because of fragmentation of wildland areas by human impacts such as urban encroachment, and by the complex geography of southern California, large fires could possibly result in local extinctions. If fire were to burn a large portion of Palomar Mountain, in San Diego County, for example, isolated populations could be at risk. It is important to recognize that urban and agricultural development have reduced the amount of wildland, which exacerbates the negative ecological impact of large, high-intensity fires.

\section{Potential Benefits of Prescribed Fire}

Prescribed fire can be used to mitigate some of the adverse effects of uncontrolled fires. Fuel hazards can be reduced in sensitive areas, including areas with ecological values at risk from fire as well as in the wildland urban interface. Watershed impacts can be mitigated by controlling the amount of watershed area burned in any given year, as well as the specific location burned within a watershed. Because prescribed burns are conducted under weather conditions and fuel moisture conditions that are less conducive to extreme fire behavior, fire intensity of prescribed burns is typically lower than that of wildfires. Prescribed burns are therefore less likely to cause formation of soil hydrophobic layers. Reduced fire intensity has also been related to reduced postfire nitrate concentrations in runoff, and to reduced sedimentation (Riggan et al. 1994).

Prescribed burning allows control of timing and location of fires, which are the keys to mitigating adverse impacts of high-intensity fires. In this way, fuel and weather conditions can be selected to allow successful burning, but also to allow control of the fire, and to keep fire effects within the range of the prescribed burn objectives (Green 1981). Ignition patterns also provide a means for influencing prescribed fire behavior and effects (Green 1981).

\section{Chaparral Fuels and Fire Behavior}

To understand how prescribed fire might be used, and how it might achieve desired effects such as fire hazard reduction, one must understand how chaparral fuels develop, and how fuel properties of chaparral stands influence fire behavior. Chaparral stands may contain any of three categories of plant species that have dramatically different fuel properties; herbaceous plants (grasses and forbs), suffrutescents or subshrubs, and woody shrubs. The information that follows regarding fire behavior in chaparral fuels are derived from my observations of chaparral fires, and discussions with numerous fire management personnel from the USDA Forest Service, Los Angeles County Fire Department, and the California Department of Forestry and Fire Protection.

\section{Fuel properties of vegetation}

Grasses and forbs have high surface to volume ratios and are therefore relatively easy to ignite. They burn with relatively low intensity and rapid spread rates, and fires will spread through herbaceous fuels by heading, backing, and flanking. Spotting, the aerial transport of burning embers, does not spread fires in grass fuels long distances ahead of the flame front, because the light weight of fuel particles means that embers have a rapid burnout time. Herbaceous fuels burn most readily after the onset of summer drought, when these plants cure.

Subshrubs such as Salvia mellifera (black sage) burn with greater intensity than herbaceous fuels, but are still easily ignitable. Fires in subshrub fuels such as coastal sage scrub stands spread rapidly via heading, but significant backing and flanking can occur. Fires in subshrub fuels burn surface litter, and dead and live woody material and foliage in the shrub canopy. Decreasing live fuel moisture content following the onset of the summer drought increases the flammability of these fuels. Spotting may be more likely over longer distances in these fuels than in herbaceous fuels, because the heavier fuels provide a source of larger firebrands that have a longer burnout time.

Compared to grass or subshrub fuels, woody shrubs such as Adenostoma fasciculatum (chamise) and Ceanothus spp. (ceanothus) are more difficult to ignite, due to the fine branches and foliage being less spatially continuous, but once ignited, burn with high intensity and long flame lengths. Spread rates in shrub fuels are slower than either of the two fuel types previously discussed, and fires typically spread primarily in the heading direction, with relatively little backing or flanking spread. These heavier fuels can produce prolific long distance spotting, which leads to a much faster effective spread rate than 
the rate at which a flame front moves through the fuels. Fires in woody shrub fuels propagate by burning foliage, live and dead fine stems, and surface litter, if any is present. Decreases in live fuel moisture as the summer drought progresses increase the propensity of these fuels to ignite, and to propagate fire.

The type of fuel burning, and the weather and topographic conditions, affect the effectiveness of suppression, and what suppression techniques may be used, by the intensity, spread mode and rate, and whether significant spotting is occurring. Direct attack can only be used on relatively low intensity fires. As fire intensity increases, equipment such as dozers and aircraft may be used, but eventually intensity becomes high enough that fires can be contained only be removing the fuels ahead of the fire. Construction of firelines well ahead of the fire front, and burning out of the fuels adjacent to the fireline creates a large enough zone with no fuel to prevent further spread of the fire. Topographic breaks such as ridgelines and riparian corridors are typically used as strategic locations for firelines. Fires in the Santa Monica Mountains often spread all the way to the Pacific Ocean under Santa Ana winds. High-intensity chaparral fires are often controlled when severe fire weather changes to less extreme conditions. Examples of this include subsidence of Santa Ana winds, decreases in temperatures, increases in relative humidity such as occur during the onshore flow of a substantial marine layer, or, as is quite rare in southern California, arrival of rain storms.

\section{Development of chaparral fuels}

After a fire, grasses and forbs dominate a chaparral site for 3 to 5 years. Shrubs will be present as both seedlings and resprouts, but initially shrubs typically account for a small proportion of total cover (Horton and Kraebel 1955; Hanes 1971). If the herbaceous cover is of sufficient amount and continuity, sites of this age can propagate fire, as documented by Zedler et al. (1983) and the aforementioned examples. By age 10, herbaceous importance typically decreases dramatically and shrubs and perhaps suffrutescents dominate the site. During this time, continuity of shrub cover and amount of shrub biomass increase. Beyond age 10, shrub biomass continues to increase, and self-thinning can occur in sufficiently wellstocked stands. These are general trends, but much remains unknown regarding the rate and duration of biomass increase, the rate of increase of fuel components such as fine twigs and foliage, and the accumulation of dead wood, in relation to age, species composition, and site factors such as geographic location and topography.

Much variability in total aboveground biomass (Figs. 2 and 3a) has been documented by various authors (Specht 1969; Rundel and Parsons 1979; Schlesinger and Gill 1980; Gray 1982; Stohlgren et al. 1984; Riggan et al. 1988; Regelbrugge and Conard in press). Generally, stands com-

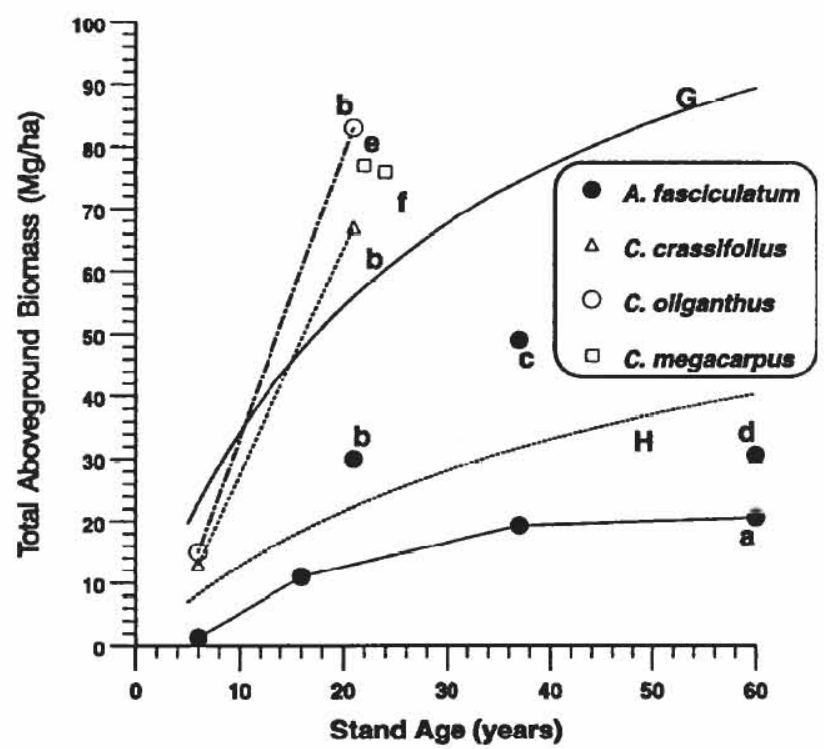

Figure 2. Biomass of chaparral plant communities of varying species composition in relation to stand age. Letters indicate the source of the data. $\mathbf{a}=$ Rundel and Parsons (1979); $\mathbf{b}=$ Riggan et al. (1988), c = Specht (1979); d = Stohlgren et al. (1984); $\mathbf{e}=$ Schlesinger and Gill (1978); $\mathbf{f}=$ Gray (1982); G, H = Rothermel and Philpot (1973), fuel models for mixed chaparral and chamise chaparral, respectively.

posed of broadleaved species such as Ceanothus have greater biomass than do stands of $A$. fasciculatum (Fig. 2, Fig. 3a), but significant variability in biomass with respect to age exists among stands of a given species composition.

Total available fuel, that is, the foliage, fine live twigs, and dead wood (Riggan et al. 1994; Regelbrugge and Conard in press) displays trends similar to total aboveground biomass with respect to age, but is related to total biomass (Figs. 3b, 3c). Although Ceanothus-dominated stands tend to have more available fuel than $A$. fasciculatum stands (Fig. 3b), available fuel is a smaller fraction of the total biomass in Ceanothus stands (Fig. $3 c$ ), because much of the biomass is contained in large diameter live stems that are slow to ignite and do not influence fire spread. Foliage fraction shows no clear relationship to aboveground biomass (Fig. 3d), and is probably related to leaf morphology as much as to shrub size and growth form. Similar to Riggan et al. (1988), and Paysen and Cohen (1990), Regelbrugge and Conard (in press) found no clear relationship between dead fraction and stand age (Fig. 4). This holds true whether dead biomass is expressed as a fraction of total biomass, or as a fraction of available fuel (Fig. 4). The data presented in Figures 3 and 4 are described more thoroughly in Regelbrugge and Conard (in press). 


\section{Role of Prescribed Burning}

The variability in rates of fucl accumulation described above likely relates to the differences in fire return interval previously described. Radtke et al. (1982) documented short fire return intervals of 12 to 20 years in the Santa Monica Mountains between 1919 and 1980, which is where some of the sites with high biomass at a young age displayed in Figure 3 were sampled by Regelbrugge and Conard (in press). Variability in fuels, topography, climatic conditions, and ignitions result in complex fire regimes throughout the chaparral ecosystem, and it is unlikely that any simple solutions will mitigate completely the adverse impacts that chaparral fires can cause. Therefore, while prescribed burning can be a valuable tool in managing chaparral fire effects, it is unlikely that prescribed burning can solve all of the problems related to fire in chaparral.

An obvious application of prescribed burning is to the wildland-urban interface problem. Prescribed burning in carefully chosen, specifically targeted areas can help reduce loss of structures in wildfires. Although a wildfire may not be stopped at the boundary of a prescribed burn, the modified fuel in the previously burned area can give fircfighters better access, reduced fire intensity, and an easier fuel situation for burnout operations to create a buffer zone that will halt the spread of the wildfire. Prescribed burns for this objective should be located to take advantage of topographic features where possible, and may not necessarily be located adjacent to the community to be protected.

The Bee Fire in June and July of 1996 on the San Jacinto Ranger District of the San Bernardino National Forest gives a good example of a prescribed burn assisting with control of a subsequent wildfire. The rate and direction of progression of the Bee Fire was altered when the fire encountered a prescribed burn that was conducted in 1983 along the North Fork of the San Jacinto River (Joe Millar, San Bernardino National Forest, personal communication). This prescribed burn was located at least 2 miles from the communities of Idyllwild, Pine Cove, and Stone Creek, but was strategically located between the river and a ridgeline, and was between these communities and a large area of chaparral that was correctly per-

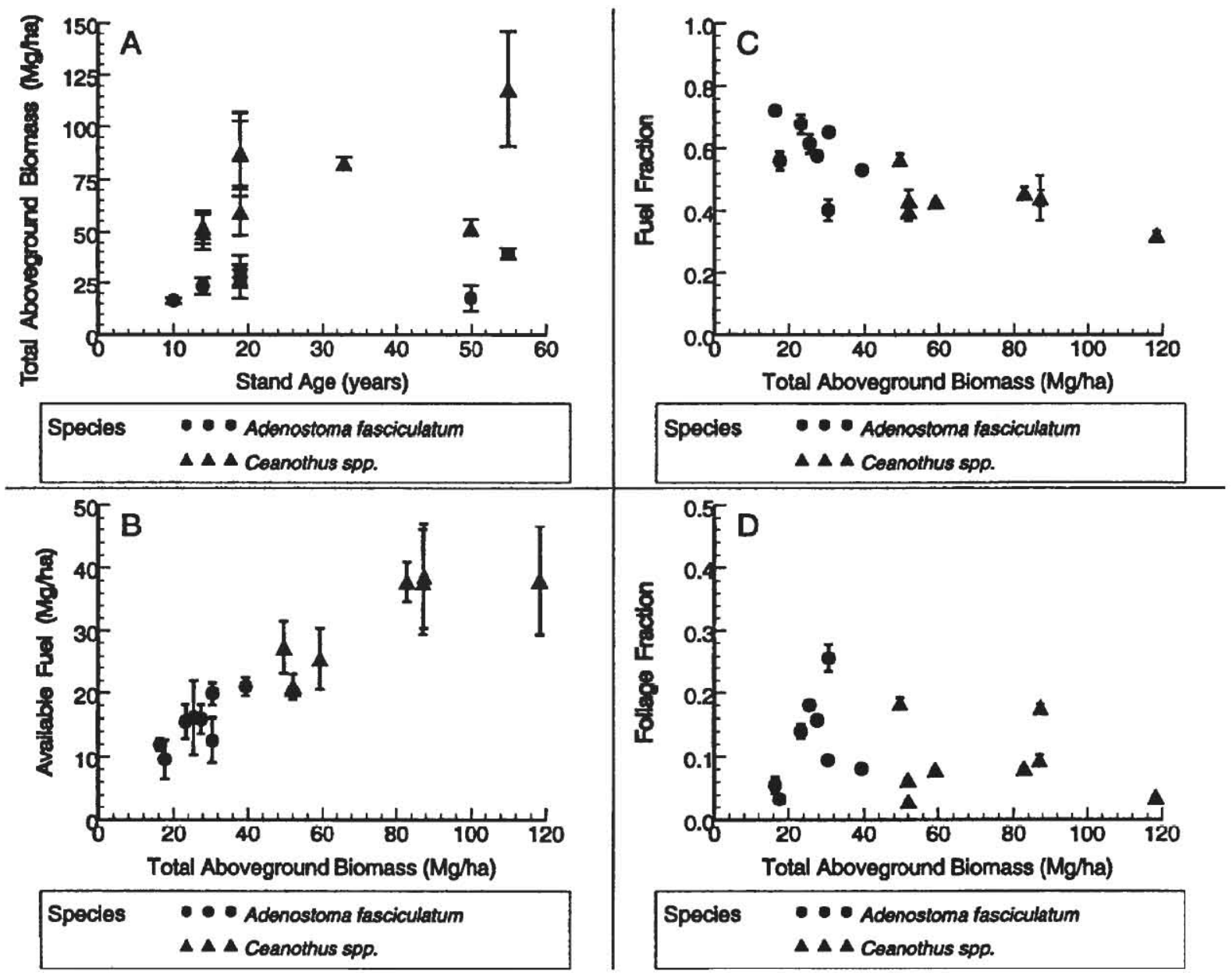

Figure 3. Total aboveground biomass versus stand age (A), and available fuel (B), fraction of stand biomass that constitutes available fuel (C), and foliage as a fraction of stand biomass (D) versus total aboveground biomass for 16 chaparral sites in southern California, USA. Values are means with S.E. Data are described in Regelbrugge and Conard (in press). 
- Role of Prescribed Burning in the Management of Chaparral Ecosystems in Southern California -
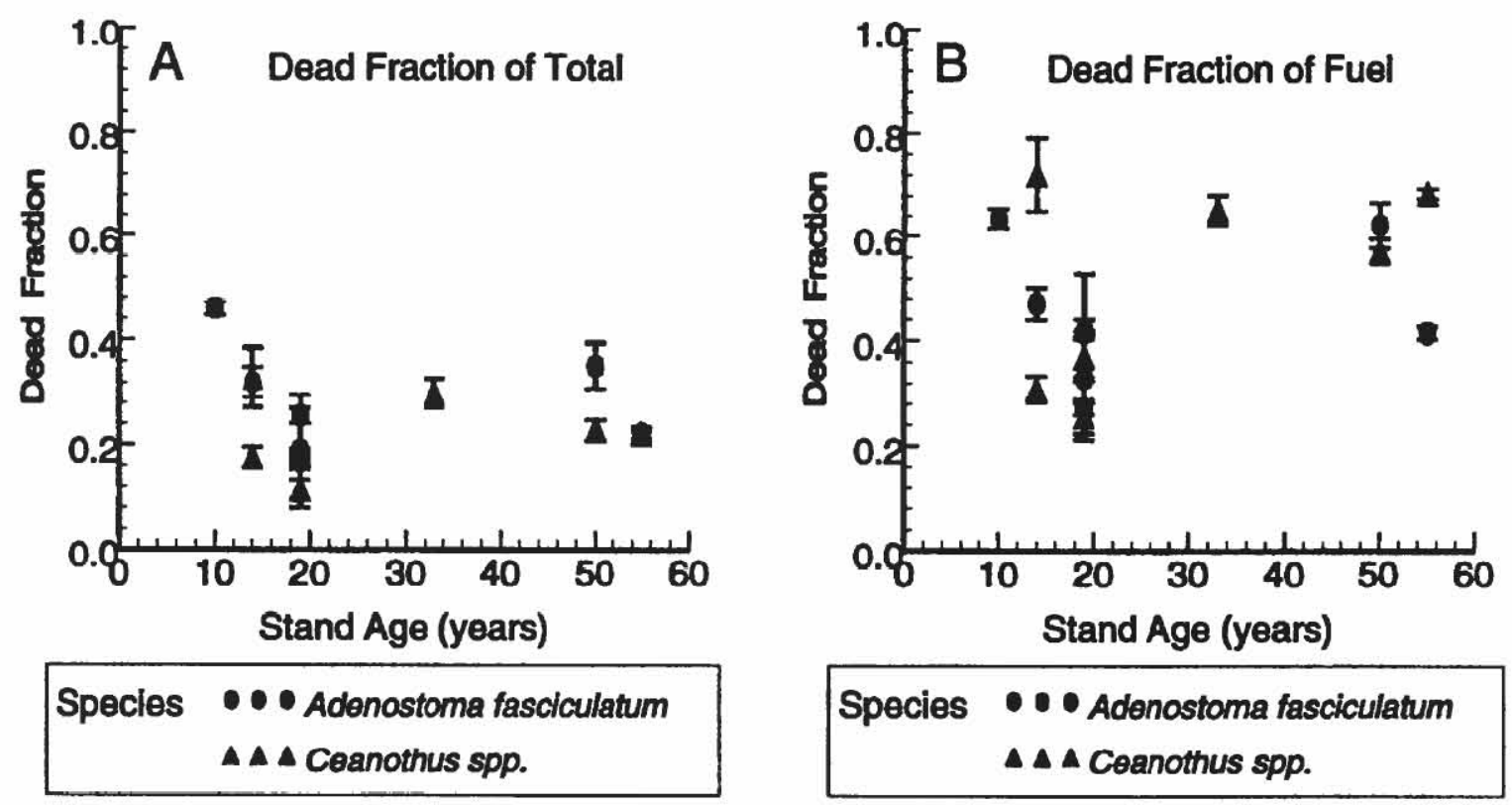

Figure 4. Dead biomass in relation to stand age, expressed as a fraction of total aboveground biomass, (A) and as a fraction of available fuel (B), of 16 chaparral sites in southern California. Values are means with S.E. Data are described in Regelbrugge and Conard (in press).

ceived to be a source of fire that might threaten the communities. The Bee Fire did not propagate through the 1983 burn, and therefore not only never spread towards Stone Creek, but also did not cross the North Fork of the San Jacinto River on 30 June when it reached the prescribed burn. Although the fire did eventually spot across the river in the afternoon on 1 July, the delay gave fire fighters an extra day to prepare to protect the communities upslope from the river. The prescribed burn also reduced the length of the fire front approaching the communities because it acted as a bottleneck of available fuel. On 2 July air temperature dropped and relative humidity rose, and the fire was prevented from reaching the communities. The fact that the Bee Fire did not propagate through a 12-year-old stand, but, as previously mentioned, other wildfires propagated through younger stands, illustrates the complex interactions between stand development, fuels, weather, topography and fire behavior. This fire also demonstrates the idea of carefully choosing sites for prescribed burning, and that burns conducted to protect values in the wildland-urban interface may be located a considerable distance from the interface. Finally, this fire illustrates that prescribed fire is but one tool useful in fire suppression, but does not obviate the need for deployment of suppression forces during wildfires. It should be pointed out that property owners in the wildland-urban interface can help to protect their property through using fire-safe construction materials and methods, and by management of fuels adjacent to their structures (e.g. Cohen 1995).

Prescribed burning can also be used to alter habitat for wildlife or plant species. Burning can be used to create a diversity of habitat types in a given area, and to reduce the risk of complete habitat loss by a single large fire.
If prescribed burning can be used to reduce the intensity of fires, and their areal extent in any given year, then the watershed impacts of large, high-intensity fires can be mitigated. Riggan et al. (1994), discussed reduced sedimentation in lower intensity fires, as well as the partitioning of watershed impacts over a number of fires in subsequent years, rather than a single large fire. This partitioning of watershed impacts can benefit society by reducing flood and debris control damage and costs, and probably also helps to maintain healthy ecosystem function.

We still have much to learn about chaparral fire regimes and how they can be influenced by prescribed burning. The development of chaparral fuels through time, and how this development is influenced by species composition and site factors is still poorly understood, as is the relationship between fuel properties and fire behavior. Better understanding of weather conditions required for fire to propagate through chaparral stands of differing fuel conditions will aid not only in planning and execution of prescribed burns, but also in understanding the limitations of prescribed burning for fuel hazard reduction. Some of this understanding may possibly be gleaned from historical data. For example, analysis of landscape patterns of fire occurrence such as conducted by Minnich (1983) could be expanded to include topographic and weather data, and perhaps fuels information and observations of suppression personnel. Salazar and GonzalezCaban (1987) found that the spatial relationships of roads, fuelbreaks, and recently burned areas were important in determining the perimeter of the 1985 Wheeler Fire. Much of this type of information is available in records of fire management agencies and other sources, and synthesis of such information may help to elucidate the processes that 
influence the fire regime of chaparral ecosystems in southern California.

\section{Literature Cited}

Byrne, R., J. Michaelson, and A. Soutar. 1977. Fossil charcoal as a measure of wildfire frequency in southern California: a preliminary analysis. Pp. 361-367 in H.A. Mooney and C.E. Conrad, eds. Proceedings of the symposium on environmental consequences of fire and fuel management in Mediterranean ecosystems. USDA Forest Service, General Technical Report WO-3.

Cohen, J.D. 1995 Structure ignition assessment model (SIAM). Pp. 85-92 in Weise, D.R. and Martin, eds. The Biswell symposium: fire issues and solutions in the urban interface and wildland ecosystems. USDA Forest Service, General Technical Report PSW-GTR-158.

DeBano, L.F. 1981. Water repellent soils: a state of the art.USDA Forest Service, Pacific Southwest Forest and Range Experiment Station, General Technical Report PSW-46.

Dunn, A.T. 1989. The effects of prescribed burning on fire hazard in the chaparral: toward a new conceptual synthesis. Pp. 2324 in N.H. Berg ED. Proceedings of the symposium on fire and watershed management. USDA Forest Service, General Technical Report PSW-109.

Dunn, A.T. and D. Piirto. 1987. The Wheeler Fire in retrospect: Factors affecting fire spread and perimeter formation. Report on file, USDA Forest Service, Forest Fire Laboratory, Riverside, $C A$.

Green, L.R. 1981. Burning by prescription in chaparral. USDA Forest Service, General Technical Report PSW - 51.

Gray, J.T. 1982. Community structure and productivity in Ceanothus chaparral and coastal sage scrub of southern California. Ecological Monographs. 52: 415-435.

Hanes, T.L. 1971. Succession after fire in the chaparral of southern California. Ecological Monographs 41: 27-52.

Horton, J.S. and C.J. Kraebel. 1955. Development of vegetation after fire in the chamise chaparral of southern California. Ecology 36:244-262.

Keeley, J.E. and S.C. Keeley. 1981. Postfire regeneration of California chaparral. American Journal of Botany 68:524530.

Keeley, J.E. and S.C. Keeley. 1988. Chaparral. P.165-208 in M.G. Barbour and W.D. Billings eds. North American terrestrial vegetation. Cambridge University Press, Cambridge, U.K.

Keeley, J.E. and P.H. Zedler. 1978. Reproduction of chaparral shrubs after fire: a comparison of sprouting and seeding strategies. American Midland Naturalist 99:142-161.

Minnich, R.A. 1983. Fire mosaics in southern California and northern Baja California. Science 219:1287-1294

Minnich, R.A. 1987. Fire behavior in southern California chaparral before fire control: the Mount Wilson burns at the turn of the century. Annals of the Association of American Geographers 77:559-618.

Minnich, R.A. 1989. Chaparral fire history in San Diego County and adjacent northern Baja California: an evaluation of natural fire regimes and the effects of suppression management. Pp. 37-47 in S.C. Keeley, ed. The California chaparral: paradigms reexamined. Science series 34 . Natural History Museum of Los Angeles County, Los Angeles, CA.
Minnich, R.A. and R.J. Dezzani. 1991. Suppression, fire behavior, and fire magnitudes in Californian chaparral at the urban/ wildland interface. Pp. 67-83 in J.J. DeVries and S.G. Conard, eds. California watersheds at the urbaninterface: proceedings of the third biennial watershed conference. Report No. 75 . California Water Resources Center, Riverside, CA.

Paysen, T.E. and J.D. Cohen. 1990. Chamise chaparral dead fuel fraction is not reliably predicted by age. Western Journal of Applied Forestry. 5:127-131.

Radtke, K.W-H., A.M. Amdt, and R.H. Wakimoto. 1982. Fire history of the Santa Monica Mountains. Pp. 438-443 in W.C Oechel and C.E. Conrad, eds. Proceedings of the symposium on the dynamics andmanagement of Mediterranean-typeecosystems. USDA Forest Service, General Technical Report PSW-58.

Regelbrugge, J.C. and S.G. Conard. in press. Biomass and fuel characteristics of chaparral in southern California. Presented at the 13th Conference on Fire and Forest Meteorology, October 27-31, 1996, Lorne, Australia.

Riggan, P.J., S. Goode, P.M. Jacks, and R.N. Lockwood. 1988. Interaction of fire and community development in chaparral of southern California. Ecological Monographs. 58:155-176.

Riggan, P.J., S.E. Franklin, J.A. Brass, and F. Brooks. 1994. Perspectives on fire management in mediterranean ecosystems of southern California. Pp. 140-162 in J.M. Moreno and W.C Oechel, eds. The role of fire in mediterranean-type ecosystems. Springer-Verlag, New York, NY.

Rothermel, R.C. and C.W. Philpot. 1973. Predicting changes in chaparral flammability. Journal of Forestry. 71:640-643.

Rundel, P.W. and D.J. Parsons. 1979. Structural changes in chamise (Adenostoma fasciculatum) along a fire-induced age gradient. Journal of Range Management. 32:462-466.

Salazar, L.A. and A. Gonzalez-Caban. 1987. Spatial relationships of a wildfire, fuelbreaks, and recently burned areas. Western Journal of Applied Forestry 2:55-58.

Schlesinger, W.H. and D.S. Gill. 1980. Biomass, production, and changes in the availability of light, water, and nutrients during the development of pure stands of the chaparral shrub, Ceanothus megacarpus, after fire. Ecology 61:781-789.

Schroeder, M.J., M. Glovinsky and V. Hendricks. 1964. Synoptic weather patterns associated with critical fire weather. Contract OCD-05-62-143. USDA Forest Service, Pacific Southwest Forest and Range Experiment Station. Berkeley, CA.

Specht, R.L. 1969. A comparison of sclerophyllous vegetation characteristic of Mediterranean-type climates in France, California, and southern Australia. II. Dry matter, energy and nutrient accumulation. Australian Journal of Botany. 48:293-308.

Stohlgren, T. J., D. J. Parsons, and P. W. Rundel. 1984. Population structure of Adenostoma fasciculatum in mature stands of chamise chaparral in the southern Sierra Nevada, California. Oecologia 64: 87-91.

Wells, W.G. II. 1981. Some effects of brushfires on erosion processes in coastal southern California, pp. 305-342 in Erosion and sediment transport in Pacific rim steeplands. International Association of Hydrological Sciences Publication No. 132.

Zedler, P.H., C.R. Gautier, and G.S. McMaster. 1983. Vegetation change in response to extreme events. The effect of a short interval between fires in California chaparral and coastal scrub. Ecology 64:809-818.

Zedler, P.H. 1995. Fire frequency in southern California shrublands: biological effects and management options. pp. 101-112 in J.E. Keeley and T. Scott, eds. Brushfires in California wildlands: ecology and resource management. International Association of Wildland Fire, Fairfield, WA. 


\title{
Barriers to the Use of Prescribed Fire in the National Forests of Southern California
}

\author{
Gregory S. Greenhoe \\ USDA Forest Service, Angeles National Forest, 701 N. Santa Anita Ave., Arcadia, CA 91006 \\ Tel. (626) 574-5359; Fax (626) 574-5233
}

\begin{abstract}
While the need to return fire as an agent of change in the ecosystems of southern California is clear, many challenges confront land managers and fire service professionals in accomplishing this work. Both internal and external hurdles must be addressed to reach land management goals in fire-adapted ecosystems.
\end{abstract}

Keywords: Air quality; ignitions; litigation; smoke management.

\section{Introduction}

There are a multitude of reasons to conduct prescribed burns in the chaparral fuel beds of southern California. We all know the positive benefits of younger chaparral stands and reduced danger that brings to homeowners who live in this volatile vegetation. But for every good reason there is to burn, there are a dozen reasons that stop us, or at the very least, slow us down.

In addition, the new Federal Wildland Fire Policy calls for the return of fire into the ecosystem to a more natural role.

The purpose of this paper is to discuss and expose these barriers to the reintroduction of fire, not to offer excuses or state why we can't get the job done. By understanding these issues we can better plan for the desired outcome and return fire to a more natural role.

There are several categories for these barriers. They include:

- Cost

- Selr Imposed Internal Rules and Regulations

- External Laws and Regulations

- Fear of Litigation

- Physiological

- Societies Perceptions

- Cultural Bias

\section{Cost}

The difference between a "controlled" prescribed fire and a wildfire is very small. Most desired is for fire to burn in the crowns of the chaparral, but it must also stay within planned control lines. To keep control can be labor intensive, requiring large numbers of holding resources. While burning in certain short interval vegetation types (eastern pines) is inexpensive and can be done for $\$ 60$ to $\$ 80$ per ha, burning in chaparral adjacent to communities can exceed $\$ 500$ per ha. This figure still may improve upon a $\$ 1225$ to $\$ 3675$ per ha pricetag for the cost of suppression of a wildfire, but when funds are allocated to the National Forests, southern California must compete for dollars with forests who have the economic edge.

\section{Self Imposed Internal Regulations}

Several internal barriers exist to completing prescribed burning. One of the primary problems lies with the documentation of environmental concerns. Fire on the landscape of southern California is as natural as the winter rains falling from the sky. Why then would detailed environmental documents and decision records be necessary to justivy the need to burn in the first place? Planning costs for prescribed fire projects can easily exceed the cost of implementing the project on the ground.

Other internal barriers include restrictions on the availability of resources such as man power, which depends upon suppression needs within as well as outside the area. When burning is planned within fire season, resources are often limited. Firefighting resources are the same resources that do the prescribed burning.

\section{External Regulations}

Air quality and smoke management concerns are probably the number one external problem that threatens the practice of prescribed burning. Regulators must be made aware that chaparral will burn one way or another, either under prescribed conditions or by wildfire, the results will be smoke in the air.

Natural fire ignitions were more likely to start high on a ridgetop and burn downhill as a backing fire. In most 
cases human caused fires start low on the slope and race uphill with much greater intensity. These fires consume more fuel and organic material above the soil. More smoke is generated from wildfires than from prescribed fires.

But there seems to be a big difference among regulators over whether we ignite the fire or its done by accident or an 'act of God'. Wildfire is not considered to be a controllable event so the smoke these fires produce is not regulated. On the other hand prescribed fire is considered to be a management tool that can be eliminated or reduced to have a positive impact on air quality. In cither case, smoke goes in the air and vegetation is consumed. It would be far better to pick those days where smoke is vented and transported away from the Los Angeles Basin rather than wait for an arsonist to make that decision.

One of the proposals that now rests before Congress as a proposed amendment to the Clean Air Act is to exempt certain areas, such as the Angeles National Forest, from the Federal conformity guidelines so that the reduction of smoke from increased use or prescribed burning can be demonstrated. Long term prescribed burning will reduce overall emissions from chaparral fuels, not to mention all of the not-so-natural combustion by-products that enter the atmosphere every year from the hundreds of homes, vehicles and out-buildings that are destroyed on an annual basis.

Other external barriers include the Endangered Species Act. When we manage for a single species we tend to manage for the "status quo" and drastic change like the return of fire, can be unacceptable. In 1987 a prescribed fire project was proposed in coastal-sage scrub west of Escondido, California. This was gnatcatcher habitat, and although the land owner agreed with the project, objections were raised over burning in this area. The proposal was to burn $1 / 3$ of the project at a time over a 9 year period thereby assuring that some habitat was always there. This was unacceptable. Any burning of this coastal sage scrub, it was argued, meant destruction of a threatened and endangered species habitat. Later that summer I was the Incident Commander on a wildfire that burned all of this habitat at an intensity far greater than a prescribed fire resulting in zero habitat.

While we deal with not enough fire, we also have to deal with areas where there has been and continues to be too much fire. Too frequent fires result in the decline of the ecosystem in the same way that some species will suffer by lacking periodic fire.

\section{Fear of Litigation}

Liability in the case of accidental "escapes" or loss of "control" of a burn costs money and takes time. And when "playing with fire," escapes are bound to occur. Escapes in the past have led to investigations and new policies and procedures that will prevent the re-ocurrence. In many cases the cost of preventing the next escape may eventually exceed the value of the project. Planning costs go up and the type and amount of holding equipment at the burn project must also increase.

To a public agency the fear of litigation can be divided into two separate categories; first the fear of an expensive, high cost investigation and the following litigation. Second is the loss of public trust for the organization and the goals we are trying to reach. But like airline safety, no amount of moncy will prevent all aircraft from falling from the sky. Some will fall and some fires will find their way outside of the project area.

The state of Florida's legislation, which protects public agencies from litigation where all reasonable steps are taken, should be adopted nation-wide. As long as this litigation cloud is hanging over land manager's heads the more likely the manager is not to use fire in the wildland urban-interface.

\section{Psychological}

Having conducted prescribed burns over many years and over thousands of hectares I can speak to the psychological effect on prescribed fire practitioners. Completing these burns in and around the wildland urban interface can be very stressful. And losing a fire and having that fire destroy private property can be devastating to a program as well as to the mental well-being of the prescribed fire manager.

In the summer of 1986 I had completed a burn in San Diego County. The burn was completed and patrol status in effect, when the next day, a series of wildland fires occurred throughout the county. While I was responding to a new fire, I overheard on the radio, that my prescribed burn, completed the day before, had escaped the project boundaries. My heart sank as I worked as Operations Section Chief on the new fire, while I listened to firefighters across the county try and bring my prescribed fire back under control. Had someone gotten hurt or had private property been damaged, I would have taken it very personally.

\section{Society's Perceptions}

We all know the Bambi syndrome. We have managed to convince the public over the past 90 years that fire is bad and green is good. However, the public is not a major stumbling block. With a little explanation there is generally good support for prescribed burning. But what society is not willing to accept is an escaped prescribed fire damaging private property. But this is inevitable! Over the past 20 years in southern California, approxi- 
mately 1600 to 2400 ha have burned annually and escape occurs every 4 or 5 years that causes some damage to private property. We need to be burning, at a minimum, $16,000-24,000$ ha per year. If we take no additional steps to reduce escapes we can expect escapes that damage private property 1 or 2 times per year. This will certainly be unacceptable to the public.

The Catch 22 here is that we need to burn additional area but unacceptable are escapes that will naturally occur with this burning. To eliminate escapes, we will add additional constraints and procedures that will make it more difficult to burn.

\section{Land Ownership Patterns}

Control lines for prescribed burning and land ownership patterns very rarely match. Property lines and fire behavior do not go together. Land ownership can inhibit prescribed burning by the very fact that one landowner can block a larger project and if we try and work around them we are inviting disaster. The more complicatd a burn is, the more likely an escape will occur.

\section{Cultural Bias}

Our mostly European heritage wants to bring order to nature and we don't see fire as a tool to accomplish our need to have a well organized "garden." In our bias it is a very crude tool that is too hard to control. Yet, fire offers the most powerful tool. A firefighter with a drip torch, can, in one day, have a bigger and more positive effect on the ecosystem than a firefighter swinging a pulaski for an entire lifetime. We need to see fire as a tool in our garden, just another way to trim and prune to meet the land management goals.

\section{Summary}

We will return and use fire in the wildlands of southern California but we have a lot of work ahead to find solutions to the barriers we face. As each are eliminated we can move forward with a more healthy and productive chaparral ecosystem. 


\title{
Vegetation Management and Prescribed Fire
}

\author{
Scott E. Franklin \\ Urban-Wildland Fire Management, 25059 Highspring Ave, Santa Clarita, CA 91321 \\ Tel. (805) 254-2376; Fax (805) 254-2376; e-mail: rxlsef@fisnet.net
}

\begin{abstract}
Branch dieback coupled with the lingering effects of the 1985-1991 drought has produced a significant dead to live ratio in chaparral in Southern California. Nowhere is this more evident than in the "I-Zone" areas of the Santa Monica Mountains - Brentwood, Mandeville Canyon, Pacific Palisades - and the front range of the San Gabriel and Verdugo Mountains. It is proposed that the application of prescribed fire coupled with an aggressive vegetation management program would allow these highly populated urban communities to survive not only catastrophic wildfire, but to endure the effects of mud and debris mobilization following winter rains.
\end{abstract}

Keywords: Branch dieback; crush and burn; I-Zone; prescribed fire; State Responsibility Area.

\section{Introduction}

I have been tracking chaparral cover in the middle Santa Monica Mountains from Las Flores Canyon in Malibu to Stone Canyon above Bel-Air and in the San Gabriel, San Rafael, Verdugo mountain front adjacent to La Cañada Flintridge since 1982-83. Some chaparral has not burned in portions of these areas since the early 1930 s and 1940s. Adjacent areas burned in the 1993 fires - with devastating effects.

A new term has been introduced by the California Department of Forestry and Fire protection that encompasses all previous descriptive terminology regarding development encroachment to wildlands. The new term is "I-Zone" (Franklin 1996). Both Malibu and La Cañada Flintridge, including portions of Glendale and Burbank reflect equal I-Zone management problems. Both communities were developed during the 1950 s; both display an equal amount of decadent exotic ornamental vegetation; both reside within and/or south of thousands of acres of mountainous wildland and are susceptible to extreme Santa Ana wind conditions.

Following the 1982-83 El Niño episode, a chlorotic condition appeared on leaves in broad-leaved chaparral species. This condition was observed in late 1984 in the vicinity of Stunt Road and Mulholland Highway, Calabasas. By the spring of 1985 the dieback was found throughout the Santa Monica Mountains, but only at lower elevations (below $800 \mathrm{~m}$ ) in the San Gabriel Range. The effect was referred to as "Ceanothus dieback." Research scientists from USDA Forest Service PSW Fire Lab and U.C. Riverside identified the pathogen Botryosphaeria dothidea as the culprit and termed this condition, more appropriately a "branch dieback" (Brooks 1994). By 1987 branch dieback was observed from Gaviota Pass in Santa Barbara County into Baja California and at elevations above $800 \mathrm{~m}$. A contributing cause of branch dieback was the severe drought that affected all of California from 1985 through 1991, after which a significant dead to live ratio was observed.

Very subtly, drought-induced water rationing created havoc within the I-Zone. Residents in many communities had to literally make a decision on whether to bathe or water their yards. Bathing won out. Shallow rooted exotic ornamental shrubs and trees displayed major stress. The ornamental shrubs took on the same characteristics as the adjacent wildland fuels. In June of 1990, catastrophic fires occurred in Santa Barbara, Goleta, Glendale and Corona. Ornamental shrubs and trees contributed to the structure loss on each incident. In 1991 the Oakland-Berkeley fire exhibited the same characteristics - ornamental vegetation carried the fire.

The 1993 fires of southern California exhibited the full effects of branch dieback coupled with stressed exotic landscaping. These fires displayed flame lengths exceeding 32 meters (100 feet) and phenomenal energy releases exceeding 488,000 Kilowatts per meter (134,000 BTU's/ FT/S). Riparian areas were decimated from this rapid energy release. The winter rains of 1993 and 1994 created as much devastation as the fires with mud and debris flowing from denuded canyons. Concerned fire agencies with I-Zone responsibility in southern California have or are in the process of modifying their wildland fire code requirements due in large measure to apparent higher wildland fire intensity. 


\section{Rx Fire and the I-Zone}

Several prescription burn projects offer an opportunity to evaluate riparian zone protection as well as vegetation management within the I-Zone. The most studied project (Beyers et al. 1994), Bel-mar, located in the Santa Monica Mountains, in the upper portion of Peña Canyon, above the community of Big Rock involved Los Angeles County Fire, USDA Forest Service, PSW Riverside and California Department of Forestry and Fire Protection (CDF\&FP). The objective of the project was to study the impact of rye grass seeding on postfire ecosystems. Prior to 1993 , this area last burned in 1958. CDF\&FP provided the money. PSW Riverside provided the scientists. Los Angeles County Fire provided the site, personnel, equipment and conducted the burn. Researchers from PSW instrumented the site in 1987 and the site was burned in June 1988.

Care was taken during the burn to keep fire from the riparian zone of Peña drainage. This was accomplished under the burning prescription and the use of water drops from a helicopter. The entire untreated Peña drainage was burned out by the catastrophic wildfire that occurred during the "Old Topanga" Firestorm of 1993 [Temperature was $29^{\circ} \mathrm{C}\left(85^{\circ} \mathrm{F}\right)$, RH $5 \%$, and windspeed $70 \mathrm{~km} / \mathrm{hr}(40$ $\mathrm{mph}$ ), with a $1 \mathrm{hr}$ fuel moisture of $2 \%$ and live fuel moisture 55\%). The riparian zone of the project area was left practically intact after the wildfire, as was the oak woodland at the top of the project. The remainder of the vegetation in the drainage was totally consumed. PSW has continued to monitor this site since 1988.

Wildfire as well as hydrolugy experts have observed intact riparian areas display minimized mud and debris flows and that younger age fuels, even under extreme fire conditions contain the flanks of a fire. Following the 1993 Firestorm fires, the governing body of Los Angeles County selected a panel of citizens composed of fire and building experts to analyze the effects of the fires and make recommendations to the Board of Supervisors. The "Wildfire Safety Panel," unlike previous appointed bodies, strongly recommended changes in the fire code, with stringent guidelines for new development. The panel also encouraged an increase in prescribed fire by L.A. County.

Los Angeles County and Los Angeles City Fire ordinances have been modified to provide for more adequate clearance around structures, including ornamental vegetation, with consideration given to fuel loading and topography. However, the situation that presently exists adjacent to La Cañada - Flintridge and Brentwood - Palisades, or Encino - Woodland Hills requires wildland vegetation management if the twin scourges of fire and flood are to be addressed. Prescribed fire techniques have evolved to replicate high intensity fire, so necessary for shrub succession, riparian zones and areas of instability. Crushing and burning has proven most successful in assuring shrub succession, soil stability and most importantly, a manage- able energy release factor. Where the use of high intensity fire will decimate riparian or sensitive areas up stream or adjacent to development, crushing has proven to the safest option. Research by M. Stassforth (1991), while focused on Ceanothus seedling regeneration, discusses the crush \& burn approach. Los Angeles County Fire in conjunction with a FEMA grant is designing a gravity roller/ crusher along the lines of the unit developed by L. Norton of New Zealand. The prototype is expected out by spring of 1998 .

\section{Prescribed Fire and Vegetation Management}

It is imperative that the watersheds above La Cañada Flintridge and above Brentwood, Pacific Palisades, Encino and Woodland Hills be treated with prescribed fire to protect the riparian zones within the canyons. The significant dead to live ratio present will lead to catastrophic wildfire, with only moderate Santa Ana Winds surface. Complete destruction of all vegetation within sensitive drainages will produce massive mud and debris flows. These canyons plummet over $600 \mathrm{~m}$ in less than $11 / 2$ $\mathrm{km}$. Appropriate burning prescriptions, crush and burn techniques and water drops can be employed to assure riparian integrity. Higher intensity prescribed fire in the form of broadcast burning can be utilized on upper slopes to insure regeneration of all present chaparral species. Following the management practices advocated by the new fire codes adopted by L.A. City and County for all structures located within and adjacent to high hazard areas, including the code requirements regarding ornamental biomass, will provide I-Zone residents a measure of protection that presently does not exist.

\section{Areas of Concern}

Prescribed burns conducted on state lands or areas of responsibility are covered statutorily with third party liability for escaped fires or other fire related impacts. Unfortunately, federal agencies involved in prescribed burning have no such coverage. In Yellowstone National Park this makes little difference, but in California operating without a liability program in place is courting disaster and definitely not in the public interest. The United States Attorney's office must have legislative guidelines regarding escaped fires. The present adversarial approach creates animosity between the state and federal government (Anderson vs. USA 1991).

Los Angeles County Fire Department needs to aggressively pursue a prescribed burn program to mitigate impacts to critical watersheds in the Santa Monica Mountains and the front side of the San Gabriel Mountains. Burning less than 1500 ha per year is not adequate. All federal, state and local fire agencies need to incorporate the I-Zone fire management philosophy (Franklin 1996). 


\section{Literature Cited}

Beyers, J.L., S.G. Conard, and C.D. Wakeman. 1994. Impacts of an introduced grass, seeded for erosion control, on postfire community composition and species diversity in southern California chaparral. Pp. 594-601 in Proceedings of the 12th conference on fire and forest meteorology. Society of American Foresters, Bethesda, MD.

Brooks, F. 1994. Branch dieback of southern California vegetation. American Phytopathological Society 84:78-83.
Franklin, S.E. 1996. California's I Zone. Fuel Management 15:185-193.

Franklin, S.E. 1995. Fuel management, fire behavior ad prescribed burning. Pp. 29-33 in J.E. Keeley and T. Scott, eds. Brushfires in California: ecology and resource management. International Association of Wildland Fire, Fairfield, WA.

Stassforth, M.L. 1991. Chaparral shrub regeneration after prescribed burns in the Santa Monica Mountains. M.S. thesis, University of California, Los Angeles. 


\title{
Fire Management Strategies and Stand Structure Development in Torrey Pine
}

\author{
Michael L. Wells \\ California Department of Parks and Recreation, San Diego Coast District \\ 9609 Waples, Suite 200, San Diego, CA 92121 \\ Tel. (619) 755-2063; Fax (619) 642-4222; e-mail:wells@goeg.ucsd.edu
}

\begin{abstract}
Plant species are able to survive in fire prone environments due to adaptive life history attributes. In conifers combinations of such attributes, collectively referred to as life history strategies, allow trees to either survive fire and/or reproduce successfully following fire. Life history strategies tend to be related to elements of fire regimes such as intensity and frequency. Human fire management alters natural fire regimes and so affects the demography and spatial distribution of conifer populations.
\end{abstract}

This study applies techniques of point pattern analysis to three stands of Pinus torreyana which have been managed under different fire control policies. Two stands are located at Torrey Pines State Reserve. Of these, one stand has burned twice since 1972. Fire has been successfully excluded from the other stand since the early part of this century. A third stand, on Santa Rosa Island, Channel Islands National Park, has been grazed heavily since the mid-19th century and has not experienced fire since that time. The histories of the stands are analogous to fire management strategies of prescribed burning, firc exclusion and physical fuel reduction, respectively. One hectare study plots were established in the interior of each stand. All trees within each study plot were sized by diameter breast height (DBH) and mapped. Point pattern analysis is applied to the resulting unweighted point pattern distributions and the distributions weighted by the square root of DBH as a surrogate for age. Allowing for variation in physical site characteristics between the two sites, the results suggest that different fire management regimes give rise to different patterns of temporal and spatial aggregation in $P$. torreyana stands. The stand which had been burned twice shows statistically significant clustering at distance increments less than ten $\mathrm{m}$. In that stand young trees, representing post-fire recruitment, were the most highly clustered. The undisturbed stand showed little clustering and no recent recruitment. The constantly grazed stand showed significant clustering at all distance increments out to $45 \mathrm{~m}$, constant recruitment, and greater aggregation among older rather than younger trees.
Keywords: Channel Islands; fire regimes; Pinus torreyana.

\section{Introduction}

Pinus torreyana Parry ex Carr, the rarest species of pine in North America, is known from only two native populations. Torrey Pines State Reserve in La Jolla contains most of a local population of 5,000 - 6,000 trees. The other native population is located on Santa Rosa Island in Channel Islands National Park, approximately 280 $\mathrm{km}$ to the northwest, and consists of approximately 3,000 $-5,000$ trees. Pinus torreyana is a diploxyloid pine in the Section Macrocarpae (Perry 1991). Its closest relatives are $P$. coulteri and $P$. sabiniana, both of which are found in more inland, continental habitats. Its closest ecological affinities appear to be with the coastal closed cone pines (Vogl et al. 1988). At present the fire ecology of the Macrocarpae is somewhat obscure. Borchert (1985) found that the expression of cone serotiny in $P$. coulteri was variable between populations growing within different plant community types. McMaster (1980), McMaster and Zedler (1981), and Scheidlinger and Zedler (1986) have studied the fire response of Torrey pine and attribute to it partial cone serotiny. This habit consists of the retention of at least some seed in most cones for a period of several years and an observed increase in seed drop following exposure to fire. In this view, partial cone serotiny is adaptive to a fire regime characterized by a modal fire return interval longer than the typical life span of the species

\section{Existing conditions}

Three one-hectare study plots were included in the study. Two of the plots were located at Torrey Pines State Reserve in La Jolla and an additional stand was on Santa Rosa Island in Channel Islands National Park. There are important climatic differences between these two sites. Mean annual precipitation is higher at Santa Rosa Island $(330 \mathrm{~mm})$ than at Torrey Pines $(254 \mathrm{~mm})$. The amount of 
precipitation due to fog drip between these sites also may be significantly different (Estberg personal comunication). The East Grove and Guy Fleming Grove sites at Torrey Pines were similar in elevation (29- $56 \mathrm{~m}$ and $48-85 \mathrm{~m}$, respectively), and slope (20-25\% and $25-35 \%$, respectively), but vary in exposure (WNW and NE, respectively). The soils on both sites were sandy loams and the slope topography is uniform, i.e., there was little topographic variation other than the major trend of the slope.

The Santa Rosa Island plot was located in the central portion of the island's $\boldsymbol{P}$. torreyana population. It was impossible to find a site that was as topographicaly uniform as the two sites at Torrey Pines. The island site was dissected by a steep gully paralleling its western boundary and was on a north facing aspect with a maritime exposure between 20 and $80 \mathrm{~m}$ elevation.

An important difference between the sites was in the disturbance regimes to which they have been exposed in the recent past. The East Grove study site at Torrey Pines was in a portion of the reserve that experienced a high intensity wildfire in 1972 (McMaster 1980) and low-intensity prescribed fires in 1984 and 1985 (Scheidlinger and Zedler 1986). These fires were contiguous, and may have overlaped somewhat within the study site. The other plot was in Guy Fleming Grove, an area that had not experienced fire since at least 1927.

The disturbance regime of the Santa Rosa Island plot has been very different from that of the mainland study sites and was largely the product of grazing by sheep, cattle, elk and deer (Viers and Halvorson 1994). Grazing has been established on the island for at least 140 years. Prior to the advent of grazing there was evidence that the Santa Rosa Island Torrey pine population frequently experienced fire. Samples of wood taken from the callus boles around old wounds on two trees located just west of the study site by Viers and Halvorson (1994), revealed a series of fire scars going back approximately 260 years. Prior to 1850 new scars were formed at an interval of approximately 20-30 years. Since 1850 no new fire scars have been formed.

The fire histories of the different stands were analogous to common fire management strategies employed by land management and fire suppression organizations. The repeated fires in East Grove at Torrey Pines simulated a "let burn", or prescribed fire management regime. Guy Fleming Grove, which had not experienced fire since 1916, represented an area where successful fire exclusion had been achieved. The heavily grazed stand on Santa Rosa Island was similar in management regime to areas where physical fuel reduction, by grazing, had been practiced.

\section{Methods}

\section{Field data collection}

Within each plot the location of each tree was assigned X-Y UTM coordinates. Two surrogates for tree age, diameter breast height (DBH) and number of branch whorls, were recorded for each tree where possible. The corners of each plot were marked and recorded with a Trimble GPS unit. At each corner, the GPS recorded 200 points which were later differentially corrected and averaged to establish UTM coordinates. The corners were then used as reference points to establish the locations of the trees within the plot. This was done by taking the azimuth and distance from the reference point with a Brunton compass and tape, or a Leica Geovid laser range finder. $\mathrm{DBH}$ was measured with a diameter tape and live or dead status of each tree recorded. Seedlings were considered to be trees less than $1.45 \mathrm{~m}$ high that had not branched. Saplings were trees less than $1.45 \mathrm{~m}$ tall which had produced at least one branch whorl. Adults were trees greater than $1.45 \mathrm{~m}$ tall. Fire scars on trees were also noted. Seedlings were not found within either of the two Torrey Pines study plots. Seedlings were found in such great numbers and density within portions of the Santa Rosa Island study plot that to accurately record their positions would have exhausted the time available for the field study and were excluded from the data collection in the island plot.

\section{Surrogates for tree age}

$\mathrm{DBH}$ and the number of branch whorls were recorded as surrogates for the relative age of individual trees. $P$. torreyana, in a manner similar to that observed in $P$. coulteri (Borchert 1985), produce a whorl of branches each year at the location of the previous year's apical bud. In the absence of outside influences, the number of branch whorls should be a reasonably good indication of tree age. However, number of branch whorls could not be recorded reliably for all trees because of self-pruning, loss of limbs due to fire damage, and loss of apical buds due to herbivory. $\mathrm{DBH}$ was regressed against the number of branch whorls for all trees in East Grove at Torrey Pines, for which both measurements could reliably be obtained. The relationship between the two estimators was reasonably strong (Pearson's $r=0.736$ ) but $\log$ linear in nature. A square root conversion of DBH produced a relationship that was more linear and stronger (Pearson's $r=0.826$ ) and was considered a surrogate for relative tree age.

\section{Point pattern analysis}

The trees produce a pattern of points within the mapped study areas. Analysis of the point patterns were conducted using boundary-corrected $\mathrm{K}$-function analysis as developed by Ripley (1981) and Getis (1984). To conduct this 
type of analysis the area within a specified distance (d) of all trees is considered. This can be conceptualized as a circle of radius $d$ placed around each tree in the entire study area. The total number of other trees (other than the center tree), occurring within the circles around each tree, are counted for the entire study area. This total is scaled to produce a statistic $\mathrm{L}(\mathrm{d})$. When applied to a completely spatially random point pattern the value of $L(d)$ will be equal to $\mathrm{d}$ for all distance increments. Confidence intervals around the value of $\mathrm{d}$ can be calculated as per Ripley (1979). Values of L(d) exceeding d, plus the confidence interval, indicate that there are more trees within that distance increment (d) than would be the case in a spatially random pattern. This suggests that the pattern is significantly aggregated or clustered within that distance increment. Values of $\mathrm{L}(\mathrm{d})$ less than $\mathrm{d}$, minus the confidence interval, indicate that there are fewer points within the distance interval (d) than would be the case in a random point pattern. This suggests that the pattern is significantly regular or dispersed within that distance interval. By calculating $L(d)$ for progressively increasing values of $\mathrm{d}$ a correlogram can be produced which illustrates distance dependent variation in spatial patterning.

Point locations can also be weighted by a variable (Getis 1984), in this case the square root of $\mathrm{DBH}$ as a surrogate for age. If the mean of values of $\sqrt{D B H}$ included within a given distance is less than the mean of all values within the study plot, then the value of $L(d)$ will be less than the $L(d)$ value calculated for the unweighted point pattern. The opposite is true when the mean of $\sqrt{\mathrm{DBH}}$ included within a given distance increment exceeds the mean of $\mathrm{VDBH}$ within the entire study plot. This analysis identified the tendency for clustering of old trees [high L(d)] or young trees [low L(d)].

\section{Results}

\section{Aspatial characteristics}

An examination of descriptive statistics of $\sqrt{\mathrm{DBH}}$ of the trees in each population was performed to determine gross characteristics of the size and age distributions of each population. The mean $\sqrt{D B H}$ for the East Grove plot (Table 1) was the lowest of the three study areas. This population represented three reproductive cohorts whose origins were related to the fire history of the area. The East Grove study plot (Fig. 1) can be divided into por- tions that were burned in 1972 (the western 60\%), and the remainder burned in the $1984 / 85$ prescribed fires (eastern $40 \%$ ). In addition there were a number of larger and presumably older fire-scarred trees throughout the plot, which survived either the prescribed fires or the wildfire. The largest cohort in number was the group which became established following the 1972 wildfire with 105 individuals. The total number of individuals in the post 1984/5 cohort was much less (32). The third cohort was the trees that survived the $1984 / 5$ prescribed fires, and, as inferred from their large size, predated the 1972 wildfire. All 18 of these trees had fire scars on their lower trunks. Three other trees could not with certainty be assigned to a fire history cohort and were excluded from the preceding discussion.

The Guy Fleming Grove poplation (Fig. 2) was very different from the East Grove population. The $\mathrm{N}$ of the plot is smaller and there are no seedlings or saplings in the population, the standard deviation of $\sqrt{D B H}$ is less than that of East Grove, and the mean $\sqrt{D B H}$ is nearly three times as large (Table 1). This indicates that the Guy Fleming population is made up of relatively larger, older trees than is the East Grove population. The smaller standard deviation indicates that there is less variation in size and age. An inference that is supported by the leptokurtic (relative kurtosis $=2.012$ ) nature of the size/age distribution.

The age structure of the Santa Rosa Island stand (Fig. 3 ) is different from the two mainland study plots. Proportionally there are more trees in both the smallest and largest size classes. The mean of the distribution of $\sqrt{D B H}$ is medial to the other two plots, the $\mathrm{N}$ is larger, and the range of $\sqrt{D B H}$ is greater. Due to differences in site conditions between Santa Rosa Island and Torrey Pines comparisons of the study plots may be misleading.

\section{Spatial analysis}

A plot of the $L(d)$ values against the distance increments (Fig. 4) for the East Grove study plot reveals a high degree of clustering within a distance of ten $\mathrm{m}$, indicating that this is the typical radius of clusters within this study area. The level of clustering declines over distance implying that the trees are generally found in short distance clusters and that the plot as a whole is made up of a series of clusters.

A similar analysis of the data collected at the Guy Fleming plot describes a different pattern of aggregation.

Table 1. Density and relative size of Torrey Pines from the three study plots.

\begin{tabular}{lcccc}
\hline Study Plot & Number of Trees & Mean sqrtDBH & Standard Dev \\
\hline East Grove & 158 & 2.17 & 1.09 \\
Guy Fleming & 44 & 6.34 & 0.87 & $4.5-8.5$ \\
Santa Rosa Is. & 198 & 4.61 & 2.63 & 0.10 .5 \\
\hline
\end{tabular}




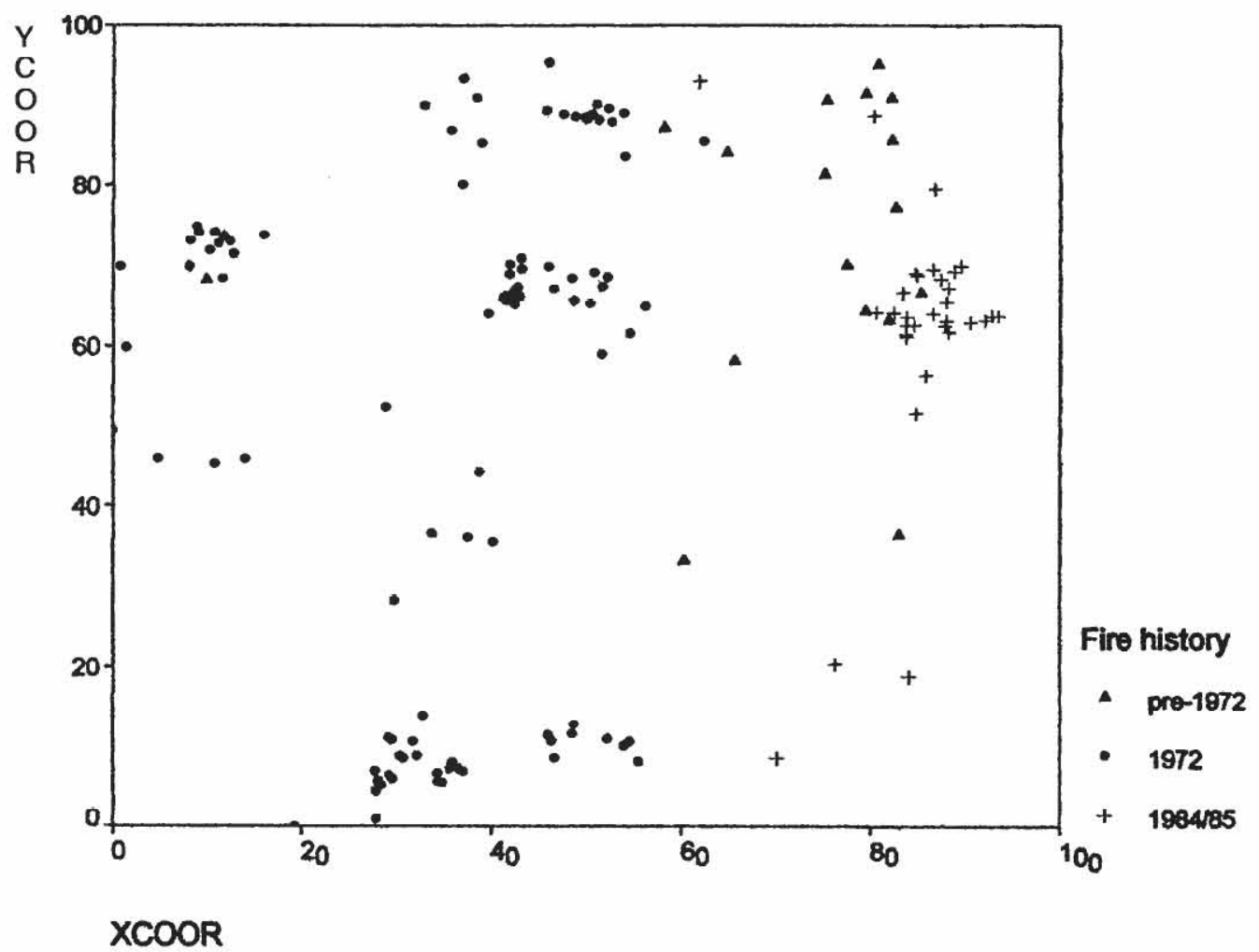

Figure 1. The location of trees classified by reproductive cohort in East Grove, Torrey Pines State Reserve. Triangles represent pre-existing trees which survived the 1972 wildfire or the 1984/85 prescribed fires. Circles are trees whose recruitment followed the 1972 wildfire. Crosses represent trees that became established following the 1984/85 prescribed fires. Map units are meters.

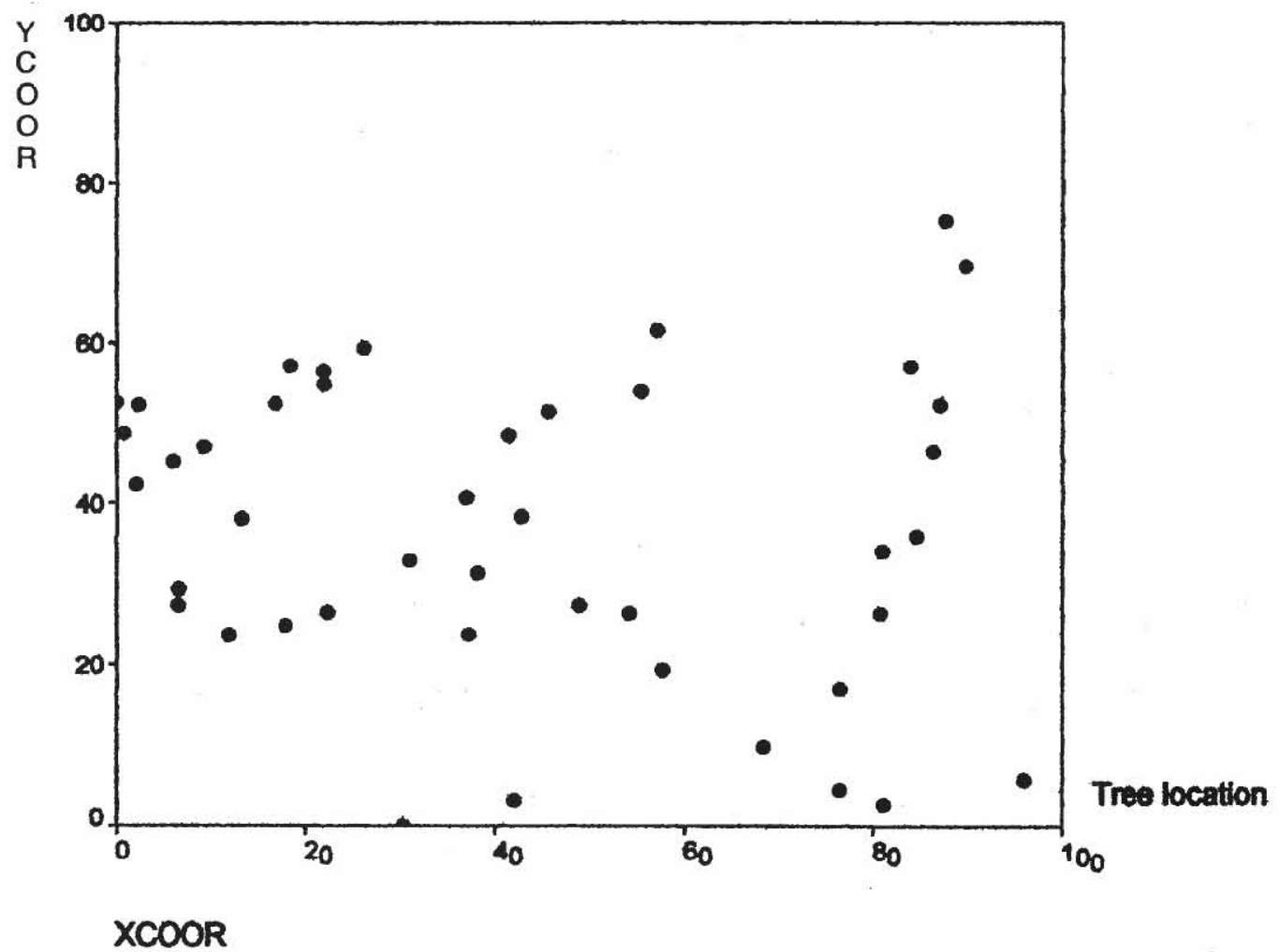

Figure 2. Location of trees in Guy Fleming Grove, Torrey Pines State Reserve, details same as in Figure 1 legend. 


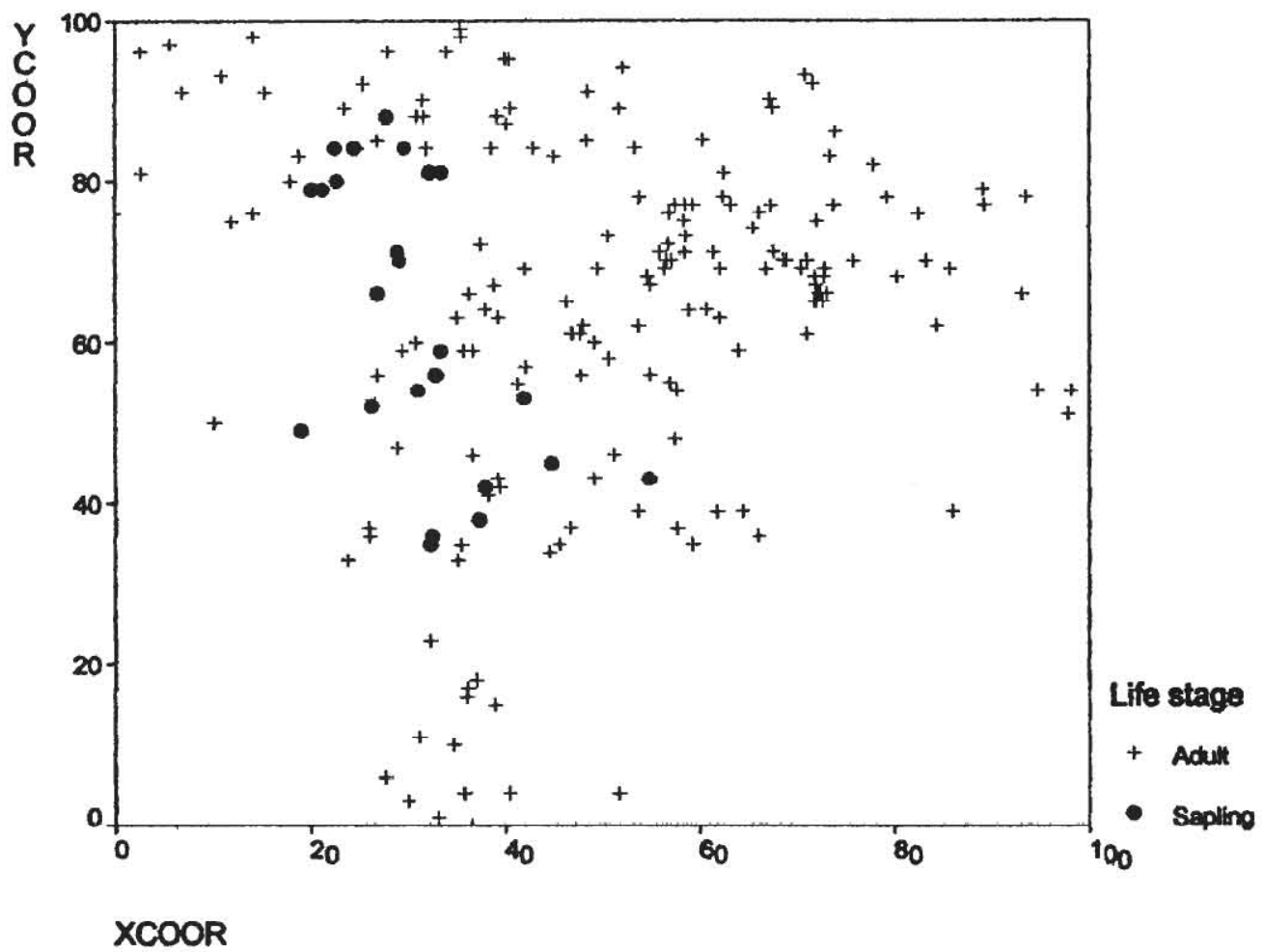

Figure 3. Location of trees in the study plot on Santa Rosa Island, Channel Islands National Park classified by life stage. Crosses are trees taller than $1.45 \mathrm{~m}$. Circles are trees less than $1.45 \mathrm{~m}$.

The $L(d)$ values reveal that for distances under ten $m$ the null hypothesis of CSR cannot be rejected (Figure 5). Clustering increases to significant levels, but just barely so, for distances beyond ten $\mathrm{m}$. This implies that near neighbor trees are not clustered but found within loose, longer distance clusters.

The results of $\mathrm{K}$ function analysis for the Santa Rosa Island study plot show a pattern of aggregation that is distinctly different from the two mainland study plots. A plot of the $L(d)$ values against the distance increments (Figure 6) shows that there is a significantly greater number of points within all distance increments from five to $50 \mathrm{~m}$ than the amount that would be expected under a condition of CSR. This implies that trees are highly clustered in one or more clumps that range to about $40 \mathrm{~m}$.

The $\mathbf{L}(\mathrm{d})$ values produced using $\sqrt{\mathrm{DBH}}$ as a weight for the trees in the East Grove study plot are somewhat different than $\mathrm{L}$ (d) values produced with size weights held at a value of one. When $\sqrt{\mathrm{DBH}}$ is included as a weight $L(d)$ values are significantly high at small distance increments and increase as the distance increment between pairs of trees increases (Figure 7). The difference between this pattern, and the pattern of $L$ (d) values for the unweighted tree locations, suggests that there are relatively more weights of high value (i.e. bigger, older trees) in the distant, as opposed to the nearer, pairs of trees. This would be consistent with a pattern of relatively small clusters of younger, smaller trees; and larger trees that are more regularly dispersed.

The addition of $\sqrt{D B H}$ as a weight also changes the L(d) values for the Guy Fleming Grove study plot. A plot of the weighted $L(d)$ values (Figure 8) reveals that at distance increments less than $35 \mathrm{~m}$ the weighted values do not accumulate at a rate significantly greater than that of a random distribution. At larger distance increments $(40-50 \mathrm{~m})$ the values accumulate at a rate significantly lower than random. This suggests that within the Guy Fleming study plot, relatively smaller trees are more regularly dispersed than are larger trees.

A similar reversal in the trends of the $L$ (d) statistic is seen when $\mathrm{K}$ function analysis is weighted by $\sqrt{\mathrm{DBH}}$ for the Santa Rosa Island study plot. A plot of the L(d) values for the weighted values (Figure 9) show that the rate of accumulation of weighted values is significantly less than random at small distance increments and becomes increasingly less so as the distance increment increases. This pattern suggests that smaller trees tend to be more regularly distributed than are larger trees and make up a greater portion of the pairs at larger distance increments.

\section{Discussion}

Life history attributes. The spatial structure of a tree stand is the product of the interaction of the life history 


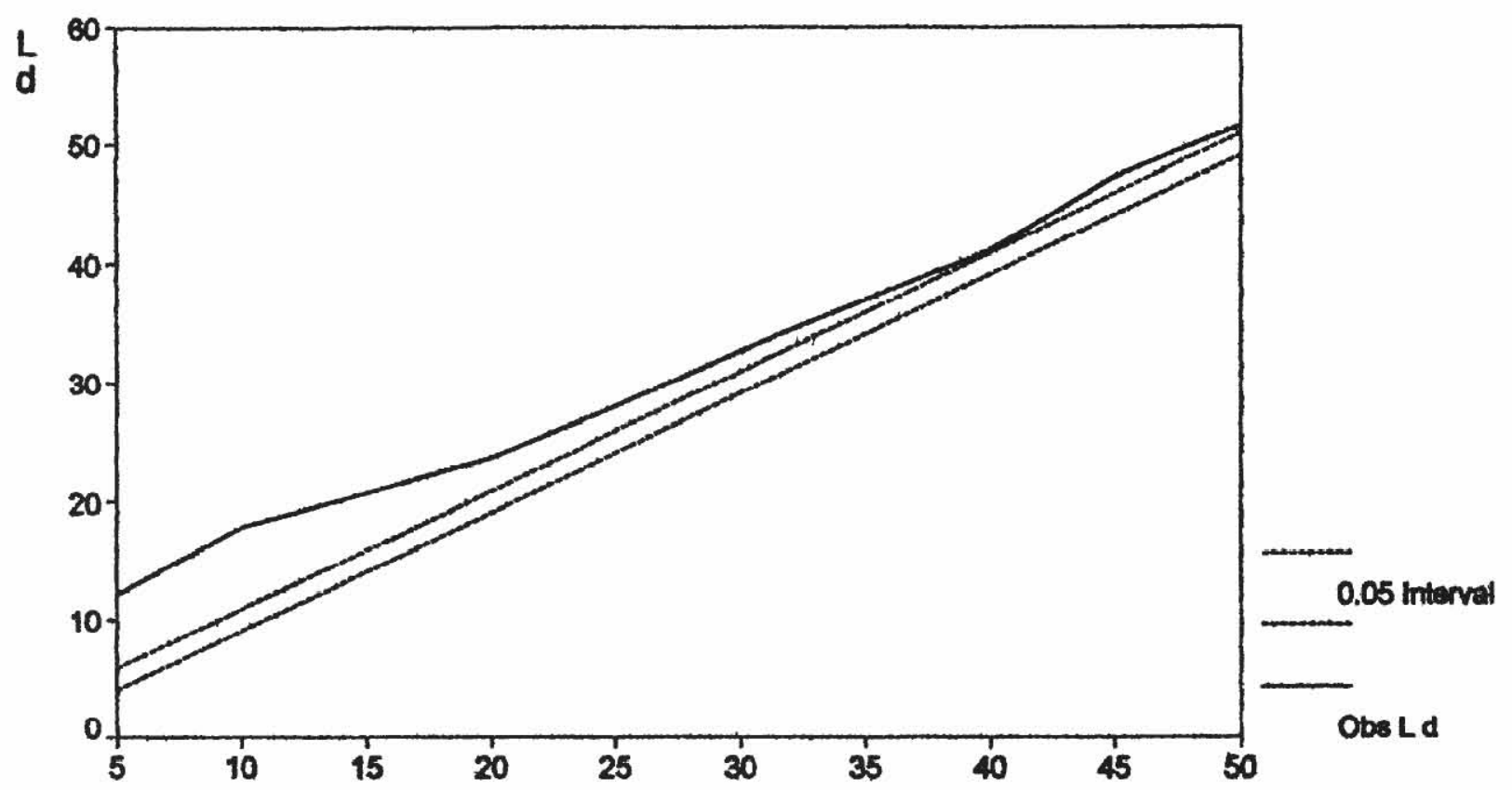

\section{Distance Increment}

\section{$N=158$}

Figure 4. Correlogram of observed L(d) value (heavy line) plotted against distance increment for trees in East Grove, Torrey Pines State Reserve. Under conditions of complete spatial randomness $L(d)=$ distance increment. Dotted lines are the $95 \%$ confidence interval around the expectation of randomness.

attributes of a species with the environment at a particular site. Environmental conditions are not static but constantly change over time. Change in southern California vegetation may be perceptible on a decadal scale, for successional processes, or may be nearly instantaneous, as in the case of wildfire.

McMaster (1980), McMaster and Zedler (1981) and Scheidlinger and Zedler (1986) have investigated the life history attributes of Torrey pine in relation to fire. The important aspects of those findings regarding the current study are related to recruitment and mortality. Recruitment of Torrey pine seedlings is maximized following fire due to increased seed release from cones, suppression of interspecific competition with other plants, and some suppression of granivory from rodents. Recruitment is maximized on substrates where competing vegetation is absent and tends to be highly clustered because of the limited vagility of Torrey pine seeds (they are large in size and have a very small wing). Dispersal of Torrey pine seed by birds has been observed, but only rarely. Torrey pine bark provides only limited protection to the trees' cambium. The population in East Grove experienced considerable mortality following even relatively cool prescribed fires (1984/85), but some trees survived each of these fires, as well as a high intensity wildfire (1972).

Recurrent fire. The ultimate result of recurrent fire, as seen in the East Grove study area, is temporal and spatial aggregation of the Torrey pine population. The age struc- ture of this population, with three well defined post-fire cohorts, reflects the life history attributes noted above. The spatial patterning within the stand is highly clustered with young trees displaying the greatest degree of aggregation. This is due to limited dispersal of seed. It is likely that a non-random thinning process over time would eventually produce a less aggregated distribution (Harvey 1989).

Fire exclusion. The spatial characteristics of the Guy Fleming population display less aggregation in both space and time than does the East Grove population. Because of limited variance in size, and the difficulty of identifying distinct branch whorls in older trees, we were not able to determine if the Guy Fleming population is composed of one or more age cohort. It is obvious though, from the complete absence of seedlings, saplings and small trees, that little if any recruitment has occurred in the last few decades. In this stand the exclusion of fire has also resulted in the absence of post-fire recruitment.

Spatially the trees in Guy Fleming Grove are more dispersed in pattern than the East Grove population and display no discernible tendency to be grouped by size, and inferentially age. This may be attributed either to decades of non-random thinning on what was originally a more aggregated stand structure, or on occasional recruitment as the result of long-range seed dispersal by fauna. A population-wide dendrochronological survey, which 
- Fire Management Strategies and Stand Structure Development in Torrey Pine -

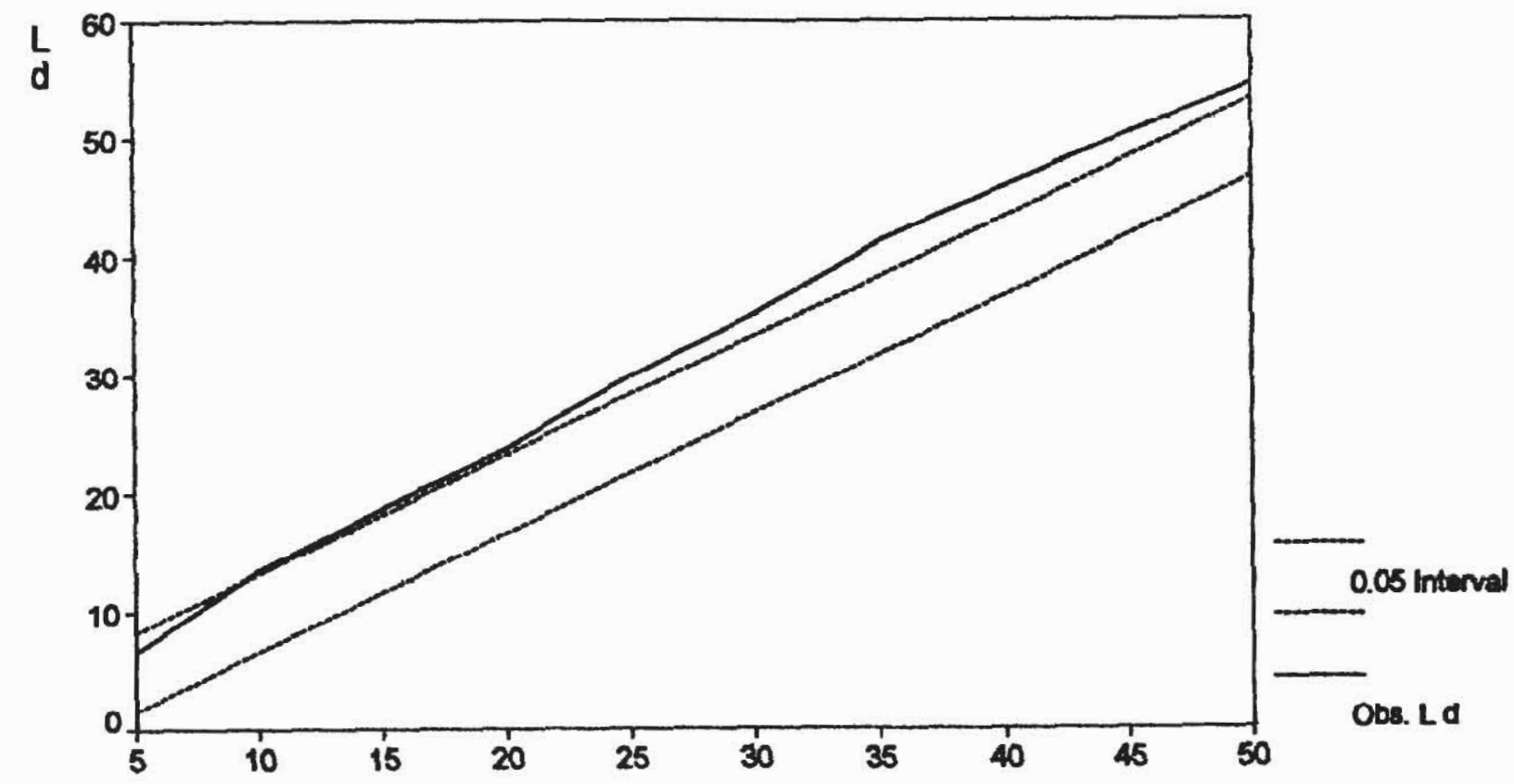

\section{Distance Increment}

$$
N=44
$$

Figure 5. Correlogram of observed L(d) value (heavy line) and $95 \%$ confidence interval (dotted lines) plotted against distance increment for trees in Guy Fleming Grove, Torrey Pines State Reserve.

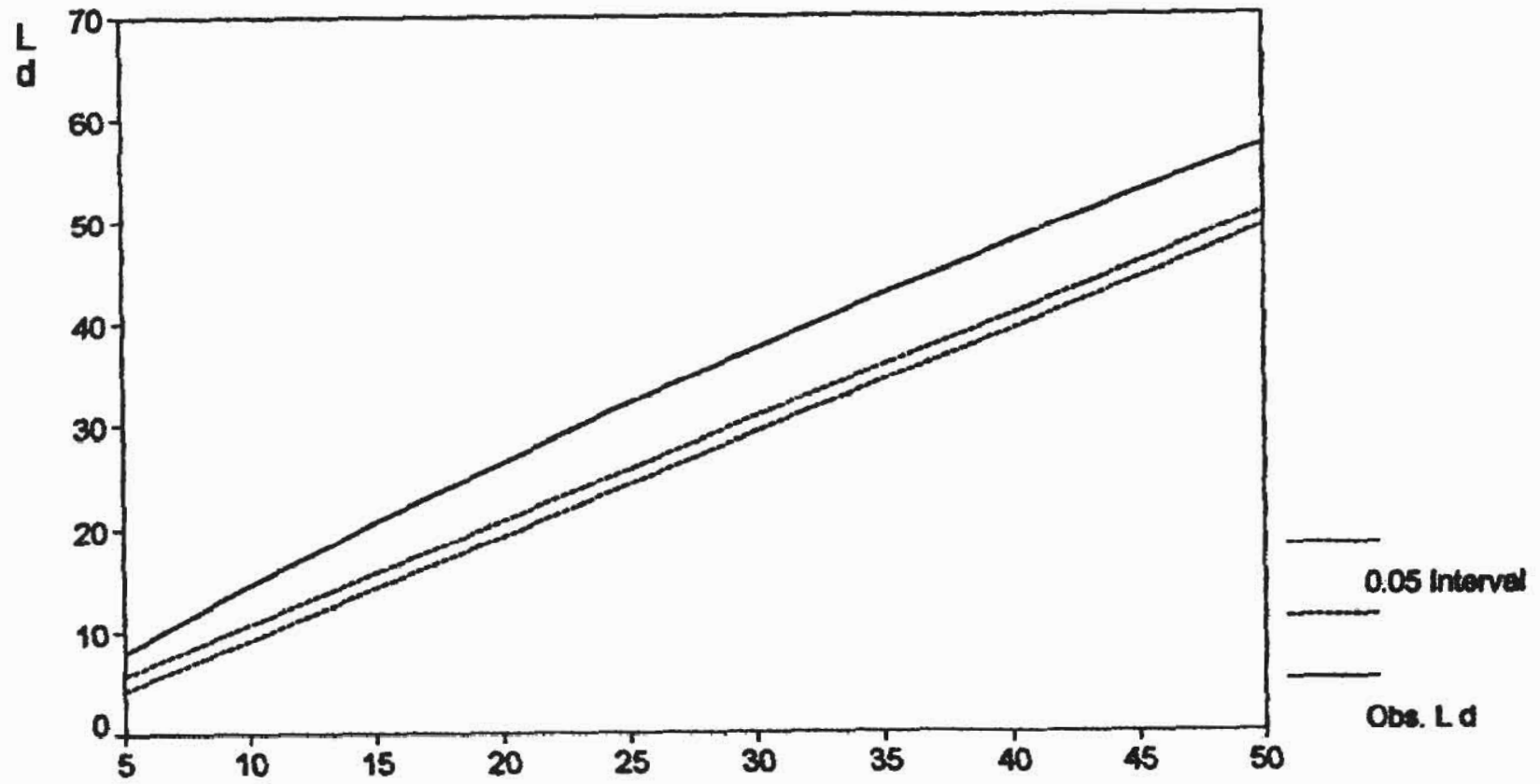

\section{Distance increment}

$$
N=196
$$

Figure 6. Correlogram of observed L(d) value (heavy line) and $95 \%$ confidence interval (light lines) plotted against distance increment for trees on Santa Rosa Island, Channel Islands National Park. 


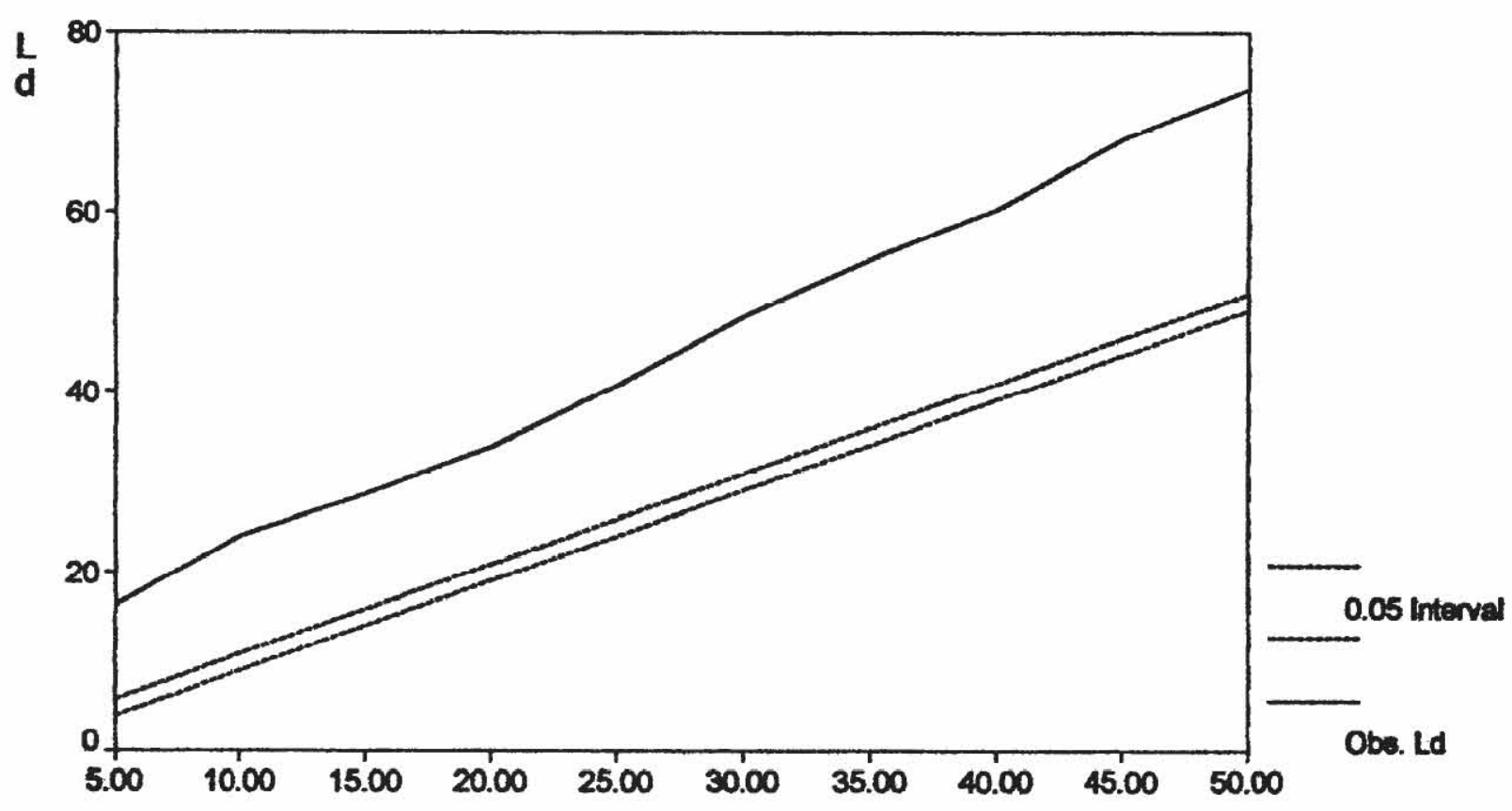

\section{Distance Increment}

$$
N=158
$$

Figure 7. Correlogram of observed L(d) value weighted by square root of DBH (heavy line) and $95 \%$ confidence interval (light lines) plotted against distance increment for trees in East Grove, Torrey Pines State Reserve.

was beyond the scope of the current study, would be required to investigate the alternative hypotheses.

Grazing. The spatial characteristics of the Santa Rosa Island study area are not consistent with either of the two stands examined at Torrey Pines State Reserve, and suggest that inferences drawn from one population are not necessarily applicable to the other. The wide variance in tree size suggests that recruitment has been continuous if not constant over time. Distinct age cohorts are not readily apparent. This is likely related to the continuous rather than episodic nature of grazing as a disturbance, and the lack of a fire-stimulated pulse in seed release (Scheidlinger and Zedler 1986). Higher mean annual precipitation and reduced evapotranspiration (Biondi et al. 1996) may also mean that there are more "good" years for Torrey pine recruitment on Santa Rosa Island as compared to Torrey Pines State Reserve.

Spatially, aggregation is positively correlated with age on Santa Rosa Island. Older trees are more aggregated and younger trees are more dispersed. This in part is related to high stand density. Older trees may already occupy the most favorable microhabitats within the stand. Thus sites available for occupation by younger trees are limited and peripheral to the sites of older larger trees. An examination of the Santa Rosa Island stand (Fig. 3) reveals that there are no saplings located within the areas of greatest stand density, and that saplings tend to occur in the open, or around the perimeter of clusters of larger trees.

\section{Implications for fire management}

The current study is based on observation of three stands of $\boldsymbol{P}$. torreyana whose structure has developed, at least in part, in response to different fire histories. However, Torrey pine is a highly restricted endemic. Inferences draw from observations of such species should be carefully considered when applied to other species or locales. In reference to $\boldsymbol{P}$. torreyana the findings of this study indicate that different fire management policies can influence demographic trends and produce contrasting patterns of spatial association in local populations. It is emphasized though that the mechanisms by which these contrasting patterns are produced are not completely understood and require further investigation.

A more general inference may be drawn because of its consistency with previous work (Rowe 1983, Zedler et al. 1983, Keeley and Keeley 1988, Whelan 1996, Keeley and Zedler 1998). Fire management policies influence the type, frequency, spatial extent and intensity of disturbance that will be applied to, or excluded from a particular area. The effect(s) of a particular fire management 
- Fire Management Strategies and Stand Structure Development in Torrey Pine -

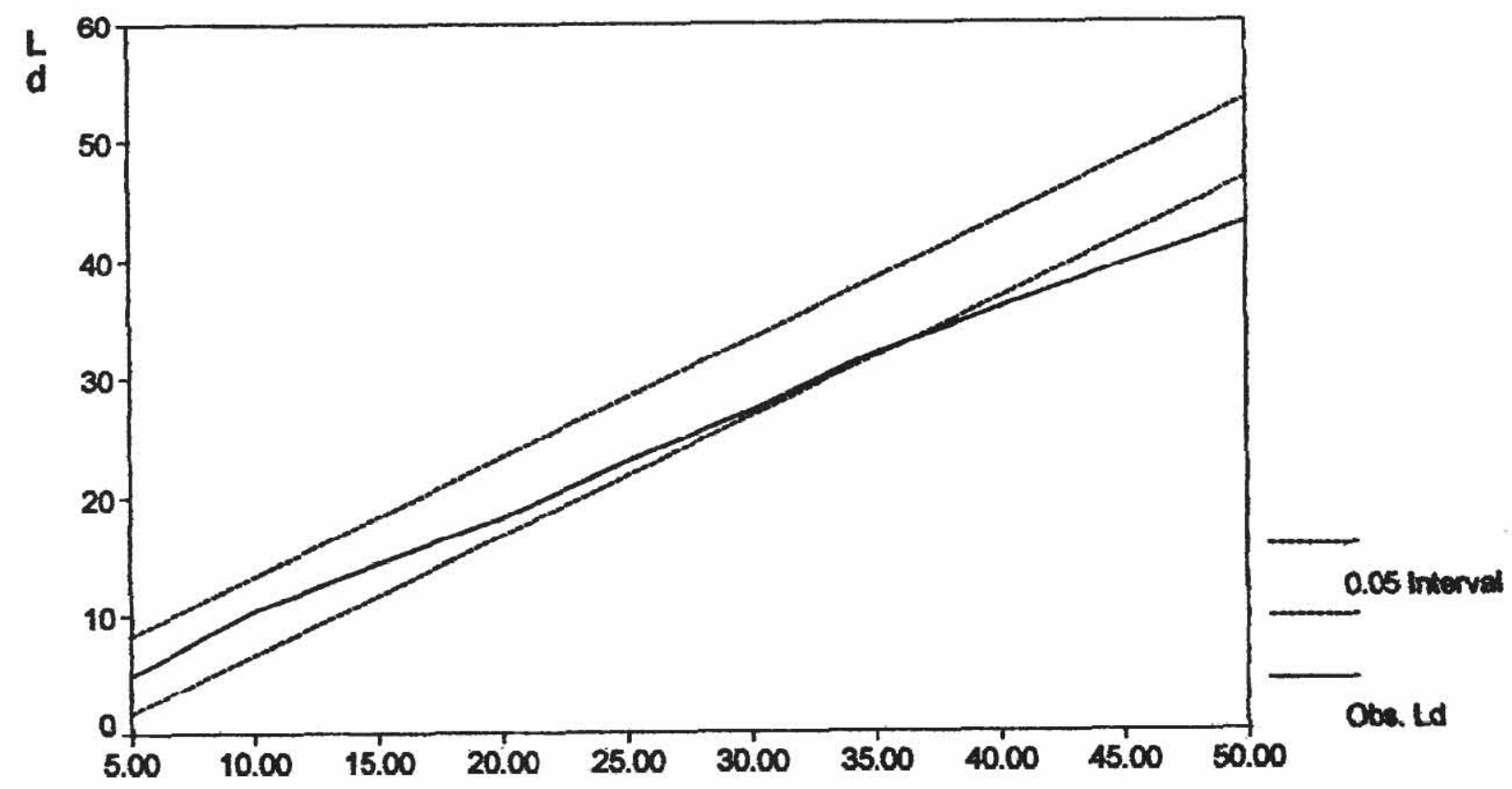

\section{Distance Increment}

$$
N=44
$$

Figure 8. Correlogram of observed L(d) value weighted by square root DBH (heavy line) and $95 \%$ confidence interval (light lines) plotted against distance increment for trees in Guy Fleming Grove, Torrey Pines State Reserve.

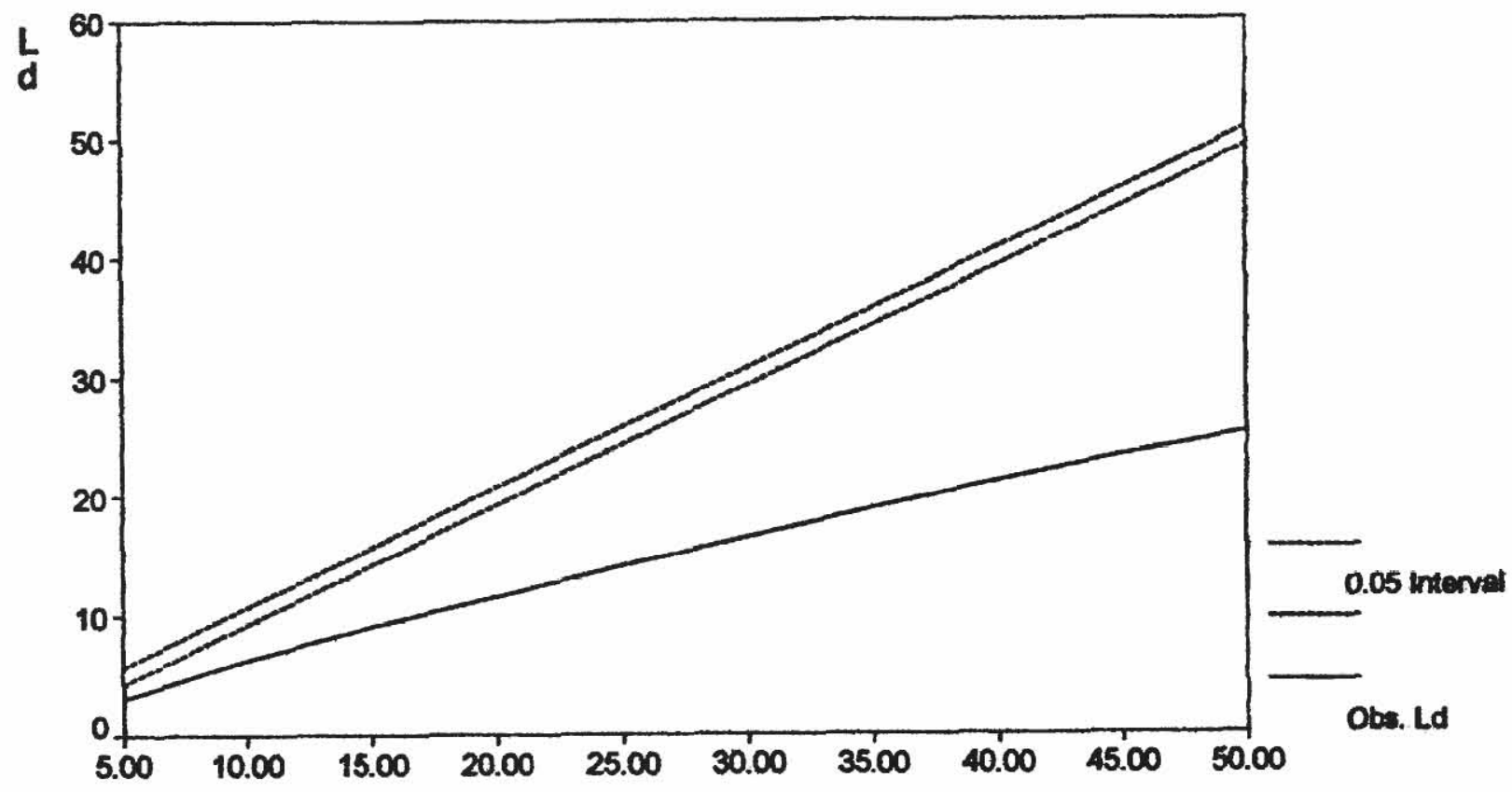

\section{Distance Increment}

$$
N=196
$$

Figure 9. Correlogram of observed L(d) value weighted by square root DBH (heavy line) and 95\% confidence interval (light lines) plotted against distance increment for trees on Santa Rosa Island, Channel Islands National Park. 
strategy on a species will depend on the species life history attributes and the nature of disturbance. Following from this is the corollary that not all species will be similarly affected by the same fire management policy. This is especially apparent in the Santa Rosa Island study plot. In that stand, because of selective browsing, Torrey pine has benefited by the suppression of competition from shrubby perennials (McMaster 1980). Viers and Halvorsen (1994) report increases in population size and geographic range of Torrey pine associated with grazing on Santa Rosa Island. However, Hobbs (1980) attributed a decrease in range and population size, for Pinus muricata on Santa Cruz Island, to a similar grazing history. It is well-documented that such grazing pressure is associated with degradation of native floral communities and with extreme soil erosion on the Channel Islands (Brumbaugh 1980, Minnich 1980). The lesson is that a fire management policy beneficial to a particular species is not necessarily beneficial to all other species and the ecosystem as a whole.

Acknowledgments. I acknowledge the assistance of the following persons. John O'Leary sponsored the independent study for which this data was originally collected. Arthur Getis advised and assisted in the application of spatial statistics. Paul Zedler, Greg McMaster, Gerald Estberg, Stephen Viers and William Halvorson generously allowed access to previously unpublished data which is cited in this paper. The portion of the study conducted on Santa Rosa Island were done with the cooperation of Channel Islands National Park staff especially Kate Faulkner and Cece Selgrin. The assistance of volunteer interns Tom Mahoney, Rick Thompson and Charlie Kerns was essential in conducting the field work. The loan of a Leica Geovid range finder by Douglas Stow greatly facilitated the field work. The original manuscript was improved by suggestions from Joel Michaelsen.

\section{Literature Cited}

Biondi, F., D.R. Cayan, and W.H. Berger. 1997. Long-term response of Torrey pine to coastal climate: Precipitation, temperature and fog. PACLIM Proceedings, in press.

Borchert, M. 1985. Serotiny and cone-habit variation in populations of Pinus coulteri(Pinaceae) in the southern Coast Ranges of California. Madrono 32:29-48.

Brumbaugh, R.W. 1980. Recent geomorphic and vegetal dynamics on Santa Cruz Island, California. Pp.139-158 in D.M. Power ed. The California Islands: Proceedings of a multidisciplinary symposium. Santa Barbara Museum of Natural History, Santa Barbara, CA.

Getis, A. 1984. Interaction modeling using second-order analysis. Environment and Planning. 16:173-183.
Harvey, L.E. 1989. Spatial and temporal dynamics of a blue oak woodland. Ph.D. dissertation, University of California Santa Barbara, Santa Barbara, CA.

Hobbs, E. 1980. Effects of grazing on the northern population of Pinus muricata on Santa Cruz Island, California. Pp.159-165 in D.M. Power, ed. The California islands: Proceedings of a multidisciplinary symposium. Santa Barbara Museum of Natural History, Santa Barbara, CA.

Keeley, J.E. and S.C. Keeley. 1988. Chaparral. Pp.165-206 in M.G. Barbour and W.D. Billings, eds. North American terrestrial vegetation. Cambridge University Press, Cambridge, U.K.

Keeley, J.E. and P.A. Zedler. 1978. Reproduction of chaparral shrubs after fire: A comparison of sprouting and seeding strategies. American Midland Naturalist. 99:142-161.

Keeley, J.E. and P.A. Zedler. 1998. Evolution of life histories in Pinus. Pp. 219-251 in D.M. Richardson, ed. Ecology and biogeography of Pinus. Cambridge University Press, Cambridge, U.K.

McMaster, G.S. 1980. Patterns of reproduction in Torrey pine. M.S. thesis, San Diego State University, San Diego, CA.

McMaster, G.S. and P.H. Zedler. 1981. Delayed seed dispersal in Pinus torreyana (Torrey pine). Oecologia. 51:62-66.

Minnich, R.A. 1980. Vegetation of Sant Cruz and Santa Catalina islands. Pp.123-137 in D.M. Power, ed. The California islands: Proceedings of a multidisciplinary symposium. Santa Barbara Museum of Natural History, Santa Barbara, CA.

Perry, J.P. Jr. 1991. The pines of Mexico and Central America. Timber Press, Portland, OR.

Ripley, B.D. 1979. The analysis of geographical maps. Pp. 5372 in C.P.A. Bartels and R.H. Katellapper, eds. Exploratory and explanatory statistical analysis of spatial data. Nijoff, The Hague, the Netherlands.

Ripley, B.D. 1981. Spatial statistics. John Wiley and Sons, New York, NY.

Rowe, J.S. 1983. Concepts of fire effects on plant individuals and species. Pp.135-154 in R.W. Wein and D.A. MacLean, eds. The role of fire in northern circumpolar ecosystems. John Wiley and Sons, New York, NY.

Scheidlinger, C.R. and P.H. Zedler. 1986. Response of Torrey pine to spring and winter controlled burns. Final Report Contract No.4-400-5076. California Department of Parks and Recreation. San Diego State University, San Diego, CA.

Viers, S.D., and W.L. Halvorson. 1994. The recent population history of Torrey pines (Pinus torreyana) on Santa Rosa Island, Channel Islands National Park: Management implications for a rare species. unpublished abstract.

Vogl, R.J., W.P.Armstrong, K.L. White, and K.L. Cole. 1988. The closed-cone pines and cypress. Pp. 295-358. in M.G. Barbour and J. Major, cds. Terrestrial vegetation of California. John Wiley and Sons, New York, NY.

Whelan, R.J. 1995. The ecology of fire. Cambridge University Press, New York, NY.

Zedler,P.H., C.R. Gautier, and G.S, McMaster. 1983. Vegetation change in response to extreme events: The effects of a short interval between fires in California chaparral and coastal scrub. Ecology 64:809-18. 


\title{
Season of Burn Effects in Southern California Chaparral
}

\author{
Jan L. Beyers and Carla D. Wakeman \\ USDA Forest Service, Pacific Southwest Research Station, 4955 Canyon Crest Dr., Riverside, CA 92507 \\ Tel.(909) 680-1527; Fax (909) 680-1501; e-mail: jbeyers/psw_rfl@fs.fed.us
}

\begin{abstract}
Prescribed burning for fuel reduction is most safely implemented during the wet season or early summer in southern California chaparral. Previous studies suggest that wet-season burns result in poor germination of fire-dependent species and that growing season burns may reduce sprouting vigor of shrubs. We examined vegetation recovery after March, June, and November prescribed fires at different sites, and after spring and fall wildfires in a single area. At all sites, good germination of obligate-seeding Ceanothus was observed, and herbaceous species with both heat- and charate-stimulated germination were found. Shrub sprouting percentage tended to be lower after the late spring burn than the fall burns. Fire intensity and postfire weather patterns may also affect chaparral regeneration response.
\end{abstract}

Keywords: Adenostomafasciculatum; Ceanothus; chamise; fire effects; fire-followers; fire intensity; prescribed fire.

\section{Introduction}

Chaparral is the fire-prone, shrub-dominated vegetation type abundant in the foothills surrounding many southern California urban centers. Shrubs are typically 1 to $4 \mathrm{~m}$ tall with evergreen, sclerophyllous leaves (Cooper 1922; Keeley 1999). California's Mediterranean-type climate is characterized by mild, wet winters and hot, dry summers (Barbour and Major 1988). By late summer and early fall, chaparral shrubs have developed low tissue water content and conditions are ideal for stand-replacement fires (Green 1981). The natural fire return interval in chaparral is estimated to be 20 to 70 years (Keeley et al. 1989; Minnich 1995). Under extreme conditions of hot, dry "Santa Ana" winds, chaparral fires may rapidly burn thousands of hectares.

As a result of the extensive wildland-urban interface that has developed as more people have moved into chaparral areas seeking a semi-rural lifestyle, homes may be consumed by flames as well. To protect human communities intermixed in chaparral and reduce the likelihood of very large fires, agencies such as the USDA Forest Service and the California Department of Forestry and Fire Protection use prescribed fire to convert old stands of chap- arral to less-flammable new growth and break up fuel continuity (Riggan et al. 1986). Prescribed burning is usually conducted in the cooler seasons, between November and June, when soil moisture and live fuel moisture are relatively high and fires are easier to control (Green 1981).

The conditions under which prescribed fires burn, and the resultant fire intensity and fire effects, may be very different from those experienced by chaparral plant and animal communities with a natural summer or fall fire regime (Parker 1990). There is concern that cool season burning may adversely affect postfire plant community recovery (Parker 1987). The literature on chaparral growth and fire response is extensive, but few studies have examined the impacts of season of burn directly. This paper will review what is known or can be hypothesized about burn season effects in California chaparral, then examine data on vegetation recovery after burns from two case studies in southern California.

\section{Literature Review}

In a recent review on chaparral fire effects, Borchert and Odion (1995) defined "fire intensity" as the relative strength of the fire, which is usually based on observations of fire behavior. This is related to but distinct from "fireline intensity," which is the measured rate of heat release per unit ground surface area (proportional to flame height and rate of spread) (Wells et al. 1979). The term "fire severity" has been used to describe the effects of fire on the biophysical environment, particularly soil charring and fuel consumption, and DeBano (1990) has described the general relationship between fire intensity and fire severity in chaparral. The terms "intensity" and "severity" are often used inter-changeably in the chaparral literature.

Chaparral wildfires typically occur during the dry seasons: summer (June - August) and fall (September - November). Summer fires may be started by lightning or by human activity. In southern California, virtually all fall fires are anthropogenic (both accidental and intentional), although historically they may have originated from smoldering of summer fires (Minnich 1987, 1989). During these seasons, soils are dry and fuel moisture is typically 
low (more so in fall). The combination of high daytime air temperatures and low relative humidity usually produce high fire intensity (Green 1981). Combustion of plant material is fairly complete, and upper soil layers can reach high temperatures (DeBano et al. 1979). The most intense fires tend to be fall fires started under conditions of hot, dry "Santa Ana" winds, and these fires produce the most severe fire effects in terms of soil heating and fuel and litter consumption. By late summer, most chaparral shrubs have completed annual growth and have low tissue water potentials (Oechel et al. 1981; Poole et al. 1981).

Winter and spring burning conditions are quite different. Soil moisture may be high at the time of the fire. Particularly during spring, fuel moisture is fairly high and air temperature moderate, so fires generally burn with lower intensity. The effects of fire are less severe: soil heating will be minimized, and fuel consumption may not be complete. Chaparral shrubs typically begin growth after initial winter rains and are physiologically active at the time of the fire, which may affect regeneration potential (Radosevich and Conard 1980). Many species bloom in winter and spring as well (Mooney and Miller 1985).

Chaparral species are well adapted to regenerate after fire. Keeley (1977) identified three major modes of postfire reproduction among chaparral shrubs: obligate seeders, in which mature plants are killed by fire and populations regenerate from seedlings that germinate the following winter or spring; sprouters, in which shrubs are top-killed by fire but resprout vigorously from underground storage organs, and seedlings are seldom found; and sprouter/seeders, in which both resprouts and seedlings are produced after fire. Reproductive modes among herbaceous plants include fire followers, which are annual and perennial herbaceous species that are abundant during the first year or two after fire and decline as shrub cover increases (Horton and Kraebel 1955; Sweeney 1956; Keeley and Keeley 1988), and opportunistic annuals, which appear most abundantly the second year after fire and are also found within canopy gaps between fires (Keeley et al. 1985; Keeley 1991). Plants in these functional groups may respond differently to changes in fire seasonality.
Obligate seeders and fire followers - species that regenerate after fire only from seed - frequently have refractory seeds, which require either heat or leachate from charred wood (and smoke) to stimulate germination (Sampson 1944; Sweeney 1956; Keeley 1984; Keeley 1987; Keeley 1999). Sceds remain dormant during the long period between fires. Although most species with refractory seeds produce some that are capable of germination without exposure to heat or charate, the most successful regeneration of these species occurs after fire (Keeley 1991). Environmental conditions during wet season and dry season burns will affect the two predominant groups of plants with refractory seeds in different ways.

Species in which heat enhances germination typically have hard seeds. Most require temperatures of at least $100^{\circ} \mathrm{C}$ for several minutes (Sampson 1944; Keeley 1987; Keeley and Keeley 1987), which breaks the seed coat, allowing oxygen and water to reach the embryo and growth to begin. Plants with heat-stimulated germination include virtually all species of Ceanothus (Rhamnaceae), a few other shrub species, and some herbs, especially in the genera Lotus and Lupinus (Fabaceae) (Keeley 1991; Table 1). Summer and fall fires produce soil temperatures high enough to meet this requirement. During a high intensity chaparral fire, surface soil temperature can exceed $500^{\circ} \mathrm{C}$, and temperatures at the $2.5 \mathrm{~cm}$ depth can exceed $100^{\circ} \mathrm{C}$ for 20 minutes or more. In a moderately intense fire, the surface temperature can exceed $300^{\circ} \mathrm{C}$, and soil at $2.5 \mathrm{~cm}$ can reach $100^{\circ} \mathrm{C}$ for at least 10 minutes (DeBano et al. 1979). Very high temperatures will kill any seeds present, but where soil temperatures remain around $100^{\circ} \mathrm{C}$, buried seeds will be stimulated to germinate.

During winter or spring prescribed burns, low fire intensity or the presence of moist soil may prevent soil temperature from becoming high enough to crack hard seed coats. DeBano ct al (1979) found that while surface temperature during a low intensity burn may exceed $200^{\circ} \mathrm{C}$, soil temperature at the $2.5 \mathrm{~cm}$ depth may not even reach $100^{\circ} \mathrm{C}$. Although moist soil conducts heat more rapidly than dry soil, it does not reach temperatures higher than about $95^{\circ} \mathrm{C}$ until most of the water has evaporated (Campbell et al. 1995). Germination of heat-requiring

Table 1. Chaparral species with seeds that are stimulated to germinate by heat (Keeley 1991).

\begin{tabular}{ll}
\hline Shrubs and Sub-shrubs & Herbaceous Annuals and Perennials \\
\hline Ceanothus (many species) (California lilac) & Apiastrum angustifolium (wild celery) \\
Fremontodendron californicum (flannel bush) & Calyptridium monandrum (pussypaws) \\
Helianthemum scoparium (rockrose) & Calystegiamacrostegia (wild morning glory) \\
Lotus scoparius (deerweed) & Camissonia hirtella (suncup) \\
Malacothamnus fasciculatus (bush mallow) & Lotus salsuginosus (coastal lotus) \\
Malosma laurina (laurel sumac) & Lotus strigosus (strigose lotus) \\
Rhus integrifolia (lemonadeberry) & Lupinus excubitus (grape soda Lupine) \\
Rhus ovata (sugarbush) & \\
Salvia apiana (white sage) &
\end{tabular}


Table 2. Chaparral species with seeds that are stimulated to germinate by charate (leachate from charred wood) (Keeley 1991).

\begin{tabular}{ll}
\hline Shrubs and Sub-shrubs & Herbaceous Annuals and Perennials \\
\hline Adenostoma fasciculatum (chamise) & Antirrhinum coulterianum (white snapdragon) \\
Arctostaphylos spp. (manzanita) & A. kelloggii (twining snapdragon) \\
Artemisia californica (coastal sagebrush) & Camissonia californica (false mustard) \\
Fremontodendron californicum (flannel bush) & Chaenactis artemisiifolia (white pincushion) \\
Garrya flavescens (silk tassel) & Clarkia (several species) \\
Rhus trilobata (squawbush) & Cryptantha intermedia (popcorn flower) \\
Romneya coulteri (matilija poppy) & Emmenanthe penduliflora (whispering bells) \\
Salvia mellifera (black sage) & Gilia australis (southern gilia) \\
Toxicodendron diversilobum (poison oak) & Gnaphalium californicum \\
& Papaver californicum (fire poppy) \\
& Phacelia (several species) \\
& Rafinesquia californica (chicory) \\
& Stephanomeria virgata (wand chicory) \\
\hline
\end{tabular}

seeds could be very low under such conditions. Kelly and Parker (1984) found only 0.02 Ceanothus ramulosus seedlings per square meter after an April prescribed fire in an area where $C$. ramulosus density had been $0.5 \mathrm{~m}^{-2}$ before the fire. Ceanothus greggii seedlings were rare after a January prescribed burn in southern California, resulting in the absence of that species from a stand in which it was formerly a co-dominant (Parker 1990).

Seeds of chaparral species that germinate in response to leachate from charred wood (Table 2) imbibe water when soil is moist, but they do not germinate in significant numbers unless charate is present (Parker 1987; Keeley 1991). These seeds may be more sensitive to soil heating when soil is moist than when it is dry. For example, Sweeney (1956) found that seeds of several species exhibited complete mortality after only 5 minutes at $80^{\circ} \mathrm{C}$ when the seeds were soaked for 24 hours first, but they germinated after exposure to temperatures over $150^{\circ} \mathrm{C}$ when dry. Lotus strigosus seeds retained full viability after 45 minutes at $80^{\circ} \mathrm{C}$ when dry, but suffered $100 \%$ mortality after exposure to that temperature when presoaked (Westermeier 1978). Parker (1987) reported complete mortality of moist Emmenanthe penduliflora seeds after short exposure to $80^{\circ} \mathrm{C}$, while dry seeds had $60 \%$ germination after exposure to $100^{\circ} \mathrm{C}$. E. penduliflora is well-known to be charate-stimulated (Wicklow 1977, Jones and Schlesinger 1980). Winter prescribed fires, burning over moist soil, could lethally heat seeds at or near the soil surface. On the other hand, deeply-buried seeds might survive a wet-season prescribed fire and be induced to germinate, as charate has been shown to overcome darkness-induced dormancy in some species (Keeley 1984, 1986).

Sprouter shrubs include scrub oaks (Quercus berberidifolia, $Q$. dumosa), toyon (Heteromeles arbutifolia), hollyleaf cherry (Prunus ilicifolia), and Rhamnus spp. Seedlings of these species are seldom found after fire; establishment of new plants occurs instead during the intervals between fires by germination of their animal-dispersed seeds (Keeley 1991, 1992). Sprouter/ seeders include laurel sumac (Malosma laurina), manzanita (Arctostaphylos spp.), and that most common chaparral plant, chamise (Adenostoma fasciculatum); these plants often have heat- or charate-enhanced seed germination (Table 2; Keeley 1991).

Several factors interact to influence the sprouting potential of chaparral shrubs. Typically 70 to $100 \%$ of plants of sprouter species do resprout after a fire (Plumb 1961, Biswell 1974; Parker 1986). In chamise, a seeder/sprouter, mortality has been shown to increase with increasing fire intensity, and those plants that do survive a high intensity fire tend to have fewer resprouts than those burned under more moderate conditions (Rundel 1982; Moreno and Oechel 1991a). Chamise may also suffer greater mortality after spring or early summer (growing season) fires. Parker (1986) reported that only $30 \%$ of chamise sprouted after an April prescribed fire, whereas more than $80 \%$ sprouted after an October fire in the same vicinity. White et al. (1995) noted that some patches of chamise burned in a prescribed fire in May had $100 \%$ mortality. Low sprouting percentage after late spring or early summer fires may be due to low starch reserves in stems and roots, which are depleted after winter and spring growth (Jones and Laude 1960; Shaver 1981). On the other hand, Radosevich and Conard (1980) observed little effect of season of burn on the amount of shoot growth in individual sprouting chamise plants in northern California, suggesting that fire seasonality primarily affected survival.

These studies of burn season effects in chaparral suggests that wet season (winter or early spring) burns could result in low germination of heat-requiring seeds, reduced germination of charate-stimulated seeds, and reasonably abundant resprouting of shrubs. Sprouters such as chamise and scrub oak would increase in the plant community compared to obligate seeders such as Ceanothus species. Postfire spring wildflower displays would be reduced. On the other hand, late spring or early summer fires, burning over dry surface soil, could result in reduced survival of chamise and other sprouting shrubs, but plentiful seed germination. This might produce a shift in plant commu- 
nity dominance from chamise to obligate-seeding shrubs. Compared to high intensity summer or fall fires, moderate intensity late spring fires could produce more herbaceous seed germination because less soil would be heated to very high temperatures, possibly resulting in abundant postfire spring wildflowers. Very high intensity fall fires could result in lower shrub sprouting percentage than cooler winter fires.

Most of the reported data on season of burn effects in chaparral come from northern and central California (Florence 1986; Parker 1986, 1987, 1990). To further evaluate predictions about chaparral response to scason of burn, we examined two case studies from southern California.

\section{Study Sites}

In the first case study, chaparral stands $4.8 \mathrm{~km}$ apart burned in late spring and late fall wildfires in 1993 at Boden Canyon in San Diego County (Fig. 1). The spring fire started as an escaped prescribed burn during a period of sudden high wind and hot temperatures on 10 May 1993. The fall fire burned during a period of "Santa Ana" winds on 28-29 October 1993. Postfire vegetation was sampled at both sites the following spring.

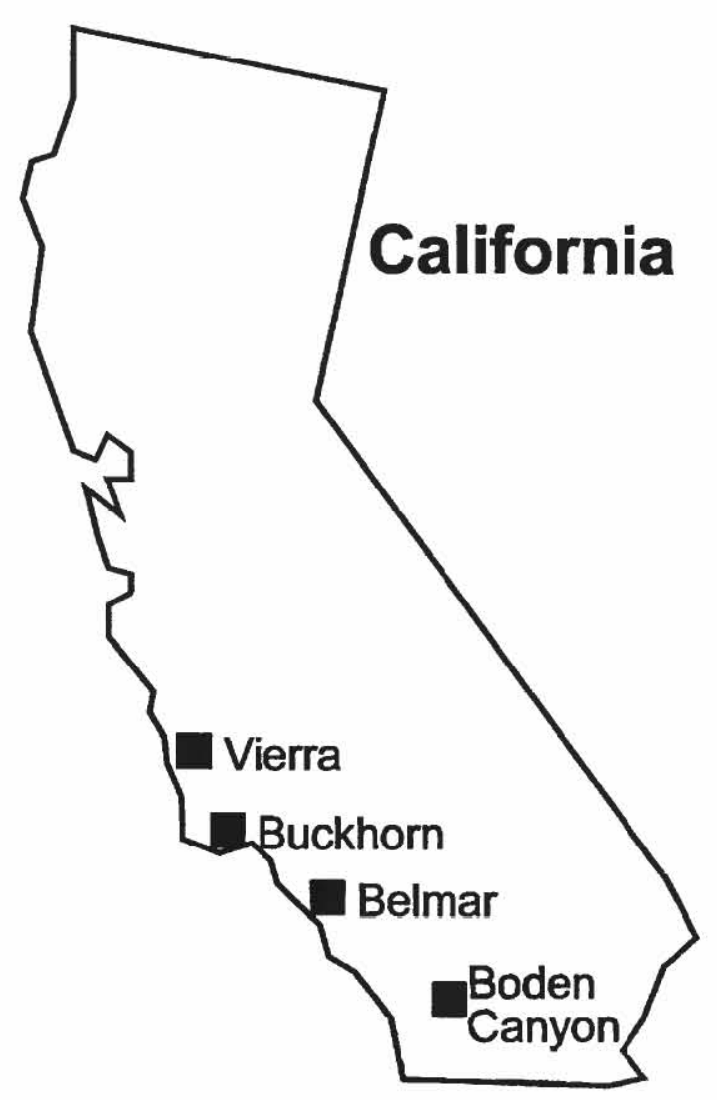

Figure 1. Chaparral sites in southern California used in this study.
The second case study compares vegetation data from three prescribed fire sites. The "Belmar" site, located in the Santa Monica Mountains (near Los Angeles, CA), burned 10 June 1988 (early summer burn) (Fig. 1). The "Vierra" site, in the Santa Lucia Mountains (near San Luis Obispo), burned 21 November 1990 (fall burn). The "Buckhorn" site, in the Santa Ynez Mountains (near Santa Barbara), burned 4 March 1994 (wet season burn). Vegetation was sampled in late spring for several years after fire at all three sites.

\section{Methods}

At the two Boden Canyon wildfire sites, 10 vegetation sample plots were established in each burn area during early June 1994. Random numbers were used as coordinates on a topographic map of each study area to locate plots. Slope angle and aspect were recorded at each plot, and elevation was determined from the topographic map. Plots were $2 \mathrm{~m}$ by $10 \mathrm{~m}$ and were oriented uphill. Each plot was divided into five $2 \mathrm{~m}$ by $2 \mathrm{~m}$ subplots for sampling. The percentage, ground cover of every species present in a subplot, along with bare ground, rock, and litter, was estimated visually and recorded. The burned stumps of shrubs that had not sprouted were counted and identified to species if possible. Height and two canopy diameters of all sprouting-shrubs were measured. In addition, five $1 \mathrm{~m}$ by $1 \mathrm{~m}$ quadrats were randomly selected (one per subplot) and all shrub seedlings within them were counted by species. Differences between sites were tested using a t-test (physical attributes) or a non-parametric bootstrap procedure (vegetation data) that compared actual values to 1,000 randomly generated data sets (Manly 1991).

The prescribed burn sites in the second case study were established as part of a project testing whether postfire grass seeding affects hillslope erosion after fire (Wohlgemuth et al. in press). At each site, 40 vegetation sample plots, each $2 \mathrm{~m}$ by $10 \mathrm{~m}$, were installed in mature mixed chaparral before burning. Plots were uphill from trails that more or less followed slope contours. Within each plot, all shrubs were identified, measured (height and two canopy diameters), and mapped, and aerial cover was estimated from below. Cover of herbaceous species was recorded as well. Weather data were recorded at each site and cross-referenced to a nearby weather station to fill in gaps.

After the prescribed fire on each site, fire severity was evaluated on each plot by visually estimating the degree of litter consumption and amount of white ash present, and measuring the depth of soil char and the minimum diameter of remaining plant stems. Intensity was not measured directly during the fire. Half of all completely burned plots (no foliage or litter remaining) were randomly selected for seeding with annual ryegrass (Lolium 
Table 3. Characteristics of Boden Canyon spring and fall burn sites. Values are means \pm standard error. Differences between sites with a $\mathrm{P}$ value less than 0.05 were considered significant (boldface type).

\begin{tabular}{|c|c|c|c|c|c|}
\hline \multirow[b]{2}{*}{ Elevation (m) } & \multicolumn{2}{|c|}{ Spring Burn } & \multicolumn{2}{|c|}{ Fall Burn } & \multirow{2}{*}{$\begin{array}{l}P \text { value } \\
<0.001\end{array}$} \\
\hline & 520 & \pm 20.8 & 434 & \pm 16.2 & \\
\hline Slope (\%) & 30.9 & $\pm \quad 4.6$ & 30.2 & $\pm \quad 3.5$ & 0.71 \\
\hline Fire severity & \multicolumn{2}{|r|}{ High } & \multicolumn{2}{|c|}{ High } & \\
\hline All' prefire ${ }^{2}$ shrubs $\left(\# m^{-2}\right)$ & 1.1 & 0.43 & 0.5 & 0.23 & 0.002 \\
\hline Postfire sprouting shrubs (\# $\mathrm{m}^{-2}$ ) & 0.48 & \pm 0.21 & 0.35 & 0.14 & 0.06 \\
\hline$\%$ all shrubs resprouted & 45 & \pm 15.0 & 74 & \pm 11.5 & $<0.001$ \\
\hline Prefire ${ }^{2}$ chamise $\left(\# \mathrm{~m}^{-2}\right.$ ) & 0.7 & 0.32 & 0.2 & 0.14 & $<0.001$ \\
\hline Postfire sprouting chamise $\left(\# \mathrm{~m}^{-2}\right.$ ) & 0.34 & 0.15 & 0.15 & 0.10 & 0.001 \\
\hline$\%$ chamise resprouted & 46 & \pm 14.3 & 61 & \pm 28.6 & 0.07 \\
\hline Average shrub volume $\left(\mathrm{m}^{3}\right)$ & 0.57 & 0.06 & 0.36 & 0.05 & 0.01 \\
\hline Ceanothus seedlings $\left(\# \mathrm{~m}^{-2}\right)$ & 3.0 & 1.1 & 3.9 & 1.1 & 0.30 \\
\hline All' shrub seedlings $\left(\# \mathrm{~m}^{-2}\right)$ & 5.4 & 3.5 & 6.6 & 5.2 & 0.29 \\
\hline Species plot $t^{-1}$ (species richness) & 15.2 & 1.6 & 23.8 & 1.8 & 0.003 \\
\hline$\%$ herbaceous cover & 5.0 & 4.6 & 8.5 & 8.4 & 0.13 \\
\hline
\end{tabular}

'All = all shrub species present, including chamise and Ceanothus.

${ }^{2}$ Prefire shrubs $=$ posttire sprouting shrubs + non-sprouting burned stumps.

multiflorum), and the other half were left unseeded (controls). Only the unseeded plots were used for this burn season comparison. Further details on study design can be found in Beyers et al. (1994) and Conard et al. (1995).

Postfire vegetation data were collected as described for the Boden Canyon sites. Because not all plots burned completely in the fires, the number of plots from which data were collected varied among sites. At Belmar, late afternoon fog put the fire out prematurely, and only five unseeded plots had both pre- and postfire shrub data available (additional postfire plots were added to the site for the grass seeding study; they were used in this comparison to quantify shrub seedling density and herbaceous plant cover). Statistical comparisons were not made among sites because of the great variation in number of replicates and because many factors varied among sites in addition to season of burn (year of burn, postfire rainfall, etc.).

\section{Results}

\section{Boden Canyon spring-fall comparison}

The two Boden Canyon sites were close together and the intervening unburned vegetation appeared homogeneous. Average percentage slope was similar at both sites (Table 3), and fire severity appeared similarly high, based on the large size of remaining shrub stems (ash and soil char were no longer present to use as measures of severity). The fall burn site was on average lower in clevation by about $90 \mathrm{~m}$ (Table 3 ), and plots there tended to be northwest in aspect while the spring burn plots were more westfacing. Prefire shrub density was calculated as the sum of sprouting shrubs and remaining stumps; the spring burn site apparently had a higher average density of shrubs before the fires than did the fall burn site (Table 3 ). These site differences complicate interpretation.

Dominant sprouting shrub species at both sites were chamise (Adenostoma fasciculatum), mission manzanita (Xylococcus bicolor), and bushrue (Cneoridium dumosum). If the assumption is correct that all shrubs alive before the fire left visible remains, the average percentage survival of all shrubs was significantly lower on the spring burn site than the fall burn (Table 3 ). It was not possible to determine how many of the burned, nonsprouting stumps were of the two Ceanothus species present, which are killed by fire, and the difference between sites may reflect a difference in prefire Ceanothus density. Chamise stumps were positively identified, however, and the difference in average chamise sprouting percentage was not statistically significant between burns at the 0.05 level (Table 3 ), though sprouting tended to be higher at the fall site. Average volume per sprouted shrub (product of three canopy dimensions, representing each shrub as a rectangular block) was significantly greater on the spring burn plots.

Seedlings of hairy ceanothus (Ceanothus oliganthus) and hoaryleaf ceanothus $(C$. crassifolius) were found at both sites. There was no difference between sites in the average density of ceanothus seedlings or of all shrub seedlings combined (Table 3 ).

There were more herbaceous species per plot (herbaceous species richness per plot) at the fall burn site, but average total herbaceous cover did not differ between sites (Table 3). Many of the species in the fall burn site were uncommon, appearing in only one plot. The most frequent herbaceous species at the two sites included those with both heat- and charate-stimulated germination (Table 4). 
Table 4. Percent cover (+ S.E.) of the ten most frequent herbaceous species at the Boden Canyon spring and fall burn sites. Only species that appear after fire by seed germination are included. Both sites also contained perennial herbaceous plants that had sprouted from underground storage organs.

\begin{tabular}{|c|c|c|c|c|c|c|c|}
\hline $\begin{array}{l}\text { SPRING BURN } \\
\text { Species }\end{array}$ & Germ.' & Freq. $^{2}$ & \% Cover & $\begin{array}{l}\text { FALL BURN } \\
\text { Species }\end{array}$ & Germ. & Freq. & $\%$ Cover \\
\hline Helianthemum scoparium & $\mathrm{H}$ & 1.0 & $0.51+0.20$ & Cryptantha intermedia & $\mathrm{Ch}$ & 1.0 & $0.24+0.11$ \\
\hline Sonchus asper* & $\mathrm{N}$ & 0.7 & $0.04+0.02$ & Pterostegia drymarioides & $\mathrm{N}$ & 0.8 & $0.82+0.28$ \\
\hline Camissonia sp. & $\mathbf{U}$ & 0.6 & $0.08+0.05$ & Antirrhinum nutallianum & $\mathrm{N}$ & 0.7 & $1.99+0.87$ \\
\hline Conyza canadensis* & $\mathrm{N}$ & 0.6 & $0.03+0.02$ & Gnaphalium californicum & $\mathrm{Ch}$ & 0.7 & $0.04+0.02$ \\
\hline Cryptantha intermedia & $\mathrm{Ch}$ & 0.5 & $2.33+1.43$ & Calandrinia ciliata & $\mathrm{N}$ & 0.5 & $0.08+0.04$ \\
\hline Pterostegia drymarioides & $\mathrm{N}$ & 0.4 & $0.03+0.03$ & Calystegia macrostegia & $\mathrm{H}$ & 0.5 & $0.04+0.02$ \\
\hline Chaenactis artemisiifolia & $\mathrm{Ch}$ & 0.3 & $0.26+0.22$ & Eucrypta chrysanthemifolia & $\mathrm{U}$ & 0.5 & $0.59+0.36$ \\
\hline Gnaphalium californicum & $\mathrm{Ch}$ & 0.3 & $0.01+0.01$ & Helianthemum scoparium & $\mathrm{H}$ & 0.5 & $0.06+0.04$ \\
\hline Lactuca seriola* & $\mathrm{N}$ & 0.3 & $0.03+0.02$ & Vulpia octoflora & $\mathrm{N}$ & 0.5 & $0.08+0.06$ \\
\hline Antirrhinum nutallianum & $\mathrm{N}$ & 0.2 & $0.01+0.01$ & Bromus madritensis* & $\mathrm{N}$ & 0.4 & $0.05+0.04$ \\
\hline
\end{tabular}

'Germination stimulus: $\mathrm{H}=$ heat; $\mathrm{Ch}=$ charate; $\mathrm{U}=$ unknown, but seeds are refractory; $\mathrm{N}=$ none required (Keeley 1991; personal observation).

${ }^{2}$ Frequency: proportion of plots (out of 10 ) in which species was found.

*Non-native.

\section{Three season prescribed fire comparison}

All three prescribed fire sites had a general southerly aspect, although individual plots varied. The fall burn (Vierra) and the wet-season burn (Buckhorn) were judged to be high severity, while the early summer burn (Belmar) was moderate (Table 5). Over 50\% of all prefire shrubs, excluding obligate-seeding Ceanothus, were counted as alive in the first spring after fire at all three sites. At Vierra (fall burn), $90 \%$ of the chamise plants (Adenostoma fasciculatum), the dominant species on the site, sprouted the first spring (Table 5) (the only other potentially-sprouting shrub species with significant prefire cover, black sage [Salvia mellifera], produced very few sprouts). There was little chamise at the Belmar site, so that the response of chamise to the growing season burn there could not be evaluated.

An obligate-seeding species of Ceanothus was an important component of the prefire vegetation at all three sites, and Ceanothus seedlings were reasonably abundant during the first spring after fire. Seedlings were counted in late April or May, after some mortality had undoubt-

Table 5. Characteristics of three prescribed fire sites in southern California. Values are means \pm standard errors.

\begin{tabular}{|c|c|c|c|c|c|c|c|c|c|}
\hline & \multicolumn{3}{|c|}{ Buckhorn } & \multicolumn{3}{|c|}{ Belmar } & \multicolumn{3}{|c|}{ Vierra } \\
\hline Burn season & \multicolumn{3}{|c|}{ Wet Season } & \multicolumn{3}{|c|}{ Early Summer } & \multicolumn{3}{|c|}{ Fall } \\
\hline Burn date & \multicolumn{3}{|c|}{4 March 1994} & \multicolumn{3}{|c|}{10 June 1988} & \multicolumn{3}{|c|}{21 November 1990} \\
\hline Burn severity ${ }^{1}$ & \multicolumn{3}{|c|}{ High } & \multicolumn{3}{|c|}{ Moderate } & \multicolumn{3}{|c|}{ High } \\
\hline Prefire shrub density $\left(\# \mathrm{~m}^{-2}\right.$ ) & 0.62 & \pm & 0.07 & 0.76 & \pm & 0.21 & 1.75 & \pm & 0.15 \\
\hline Prefire sprouter density ${ }^{2}\left(\# \mathrm{~m}^{-2}\right)$ & 0.31 & \pm & 0.07 & 0.61 & \pm & 0.23 & 1.37 & \pm & 0.12 \\
\hline Postfire sprouter density ${ }^{3}\left(\# m^{-2}\right)$ & 0.20 & \pm & 0.07 & 0.28 & \pm & 0.08 & 0.87 & \pm & 0.19 \\
\hline Percentage survival & 63.3 & \pm & 22.3 & 61.3 & \pm & 11.2 & 57.4 & \pm & 7.7 \\
\hline Prefire chamise density $\left(\# \mathrm{~m}^{-2}\right)$ & & & & & & & 0.97 & \pm & 0.15 \\
\hline Postfire chamise density $\left(\# \mathrm{~m}^{-2}\right)$ & & & & & & & 0.87 & \pm & 0.19 \\
\hline Percentage survival & & & & & & & 90.4 & \pm & 8.2 \\
\hline Prefire Ceanothus density ${ }^{4}\left(\# \mathrm{~m}^{-2}\right)$ & 0.31 & \pm & 0.04 & 0.15 & \pm & 0.09 & 0.38 & \pm & 0.06 \\
\hline Ceanothus density year 1 after fire 5 & 6.9 & \pm & 2.0 & 4.6 & \pm & 1.4 & 5.4 & \pm & 0.9 \\
\hline Ceanothus density year 2 after fire & 6.9 & \pm & 1.7 & 0.45 & \pm & 0.22 & 3.9 & \pm & 0.7 \\
\hline Ceanothus density year 3 after fire & 6.9 & \pm & 2.0 & 0.45 & \pm & 0.22 & 2.0 & \pm & 0.4 \\
\hline Year 1 herbaceous cover $(\%)$ & 10.7 & \pm & 2.1 & 26.1 & \pm & 4.6 & 0.46 & \pm & 0.13 \\
\hline Year 1 herbaceous species richness ${ }^{6}$ & & 8 & & & 19 & & & 8 & \\
\hline Year 2 herbaceous species richness & & 24 & & & 29 & & & 27 & \\
\hline Number of plots used $(\mathrm{N})$ & & 11 & & $5(10 \mathrm{f}$ & r se & llings) & & 19 & \\
\hline
\end{tabular}

'Based on litter and foliage consumption, depth of soil char, and diameter of remaining plant stems.

${ }^{2}$ All shrubs excluding obligate-seeder species of Ceanothus.

${ }^{3}$ Number of sprouted shrubs during first growing season after the prescribed fire.

${ }^{4}$ Obligate-seeding Ceanothus only: C. cuneatus at Buckhorn, C. megacarpus at Belmar, and C. cuneatus at Vierra.

${ }^{5}$ Seedlings counted during April or May of the first spring after fire, which was the same year as the fire at Buckhorn.

${ }^{6}$ Species richness $=$ total number of herbaceous species encountered at a site. 

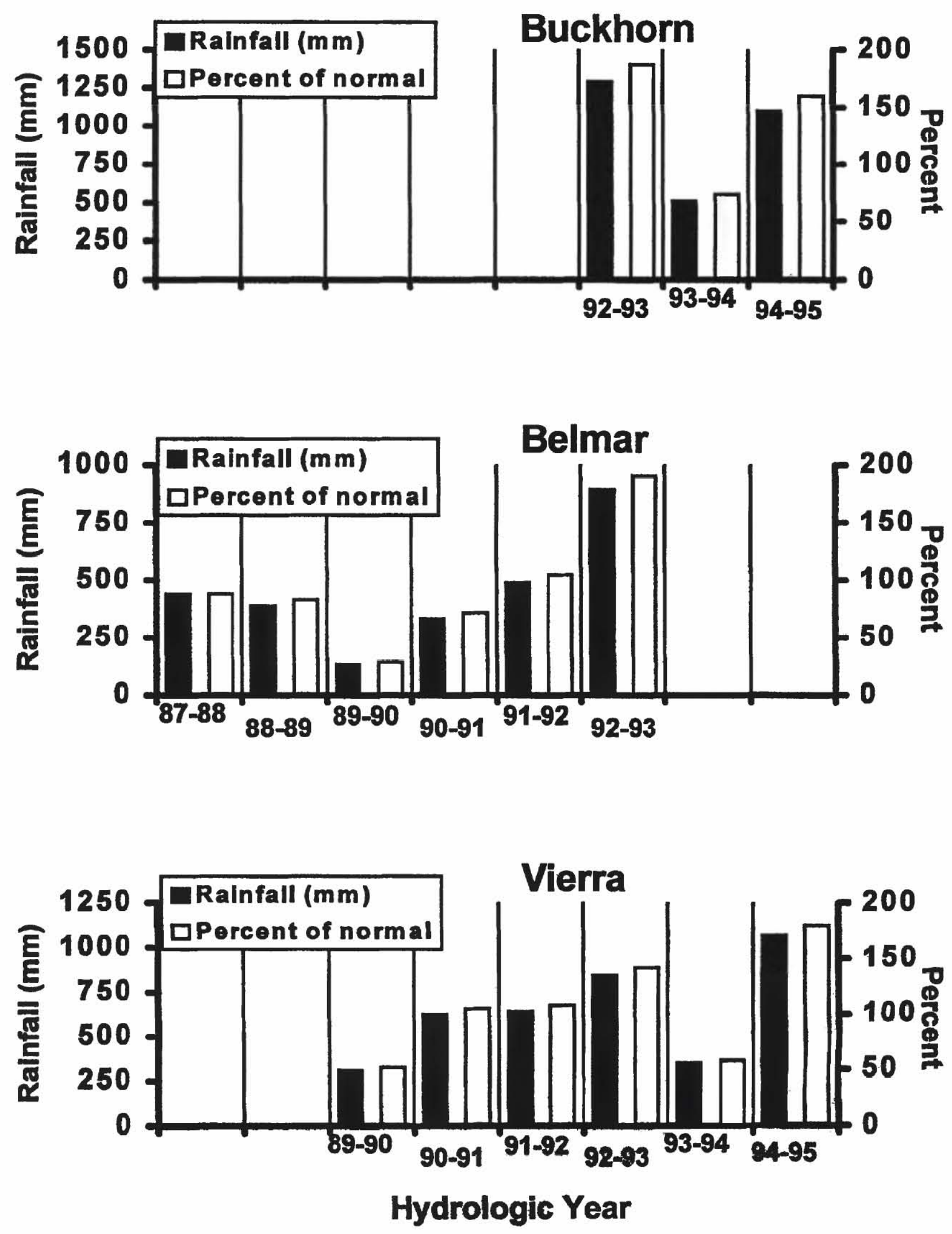

Figure 2. Annual precipitation and percentage of long-term average at three chaparral study sites for the year before and several years after burning. Solid bars: total precipitation for the hydrologic year (October 1- September 30); open bars: percentage of long-term average precipitation for that site. Note difference in Y-axis scales. 
edly occurred. At Belmar, seedling numbers decreased $90 \%$ between the first and second springs (Table 5), most likely because of low rainfall (approximately $30 \%$ of the long-term average for the 1989-90 hydrologic year; Fig. 2). However, after 3 years the density of Ceanothus megacarpus seedlings remained slightly higher than the prefire Ceanothus shrub density. At Buckhorn, some Ceanothus cuneatus seedlings germinated during the first short growing season after the fire (year 1 in Table 5), and a second flush appeared the next year, making up for mortality that occurred during the first summer. As at Belmar, Ceanothus seedling density after three growing seasons at both Buckhorn and Vierra was greater than the prefire Ceanothus shrub density.

Average herbaceous species cover and total herbaceous species richness (Table 5) were greatest at Belmar (early summer burn) during the first spring after fire. All three burn sites produced herbaceous species with both heatand charate-stimulated germination (Table 6). Plants such as wild morning-glory (Calystegia spp., heat-stimulated) and members of the waterleaf family (Hydrophyllaceae, Phacelia spp. and Emmenanthe penduliflora, typically charate-stimulated) occurred at all three sites. Herbaceous cover was extremely low, less than $1 \%$, during the first spring after fire at Vierra (fall burn), possibly because most of the winter's rain did not fall until March, toward the end of the growing season (unpublished project records). The first winter after fire at Belmar was also relatively dry (about $80 \%$ of average precipitation in hydrologic year 1988-89; Fig. 2), but the rain was evenly spaced. The first postfire growing season at Buckhorn (wet season burn) was short because of the timing of the prescribed fire. All three sites had higher species richness (Table 5) and herbaceous plant cover the second year. Cover was greatest at Buckhorn, and species richness was similar among sites. The herbaceous flora included a number of opportunistic, disturbance-adapted species during the second and subsequent growing seasons after fire at all three sites. Some of these species are non-natives or species with no special stimulus required for germination (Table 6).

\section{Discussion and Management Implications}

Kelly and Parker (1984) and Parker (1986) predicted negative consequences for long-term chaparral community composition and diversity after wet season burns in northern California. Management plans for burns were changed as a result of their and others' research (Ross and Ross 1993). In contrast, the southern California sites compared in this study did not appear to suffer adverse impacts from out-of-season burning.

Germination of heat-requiring Ceanothus seeds and early seedling survival seemed adequate to replace killed plants at all three prescribed fire sites. Shrub seedling survival appeared to respond strongly to winter precipitation and the resulting length of the summer dry season (contrast Belmar to Buckhorn: Table 5, Fig. 2), a factor possibly more important to stand composition than initial density (Jacks 1984). While additional Ceanothus mortality will undoubtedly occur (Riggan et al. 1988), major changes in plant composition in these stands, compared to prefire composition, seem unlikely. At Boden Canyon, the proportion of Ceanothus in the shrub community may increase relative to that of sprouters at the spring burn site because of the low apparent sprouting percentage. However, many sprouters recruit new individuals to their populations between fires (Keeley 1992), so any advantage to seeders may be temporary.

Table 6. Most abundant herbaceous species during the first spring(s) after fire at three prescribed fire sites in southern California. Species are listed in order of abundance (percentage cover). All herbaceous species that were present the first spring are listed for Buckhorn and Vierra, and species that appeared the second spring are added. Only the 14 most abundant species from the first year after fire are listed for Belmar, which had higher first-year species richness. Herbaceous species that were present the first spring after fire also appeared during the second.

\begin{tabular}{|c|c|c|}
\hline Buckhorn - Wet Season Burn & Belmar — Early Summer Burn & Vierra - Fall urn \\
\hline Phacelia longipes $(\mathrm{Nt})^{1}$ & Calystegia macrostegia $(\mathrm{H})$ & Marah fabacea (probably N; respouts) \\
\hline Marah fabacea (probably N; resprouts) & Marah macrocarpus (N; resprouts) & Emmenanthe penduliflora (Ch) \\
\hline Phacelia brachyloba (U) & Phacelia cicutaria $(\mathrm{Ch})$ & Chlorogalum pomeridianum (N; resprouts) \\
\hline Mentzelia micrantha $(\mathrm{Nt})$ & Phacelia grandiflora (Ch) & Calystegia macrostegia $(\mathrm{H})$ \\
\hline Cryptantha spp. (possibly Ch) & Mentzelia micrantha (Nt) & Antirrhinum kelloggii (Ch) \\
\hline Solanum xantï (Nt) & Lotus salsuginosus $(\mathrm{H})$ & Helianthemum scoparium $(\mathrm{H})$ \\
\hline Calystegia purpurea (probably $\mathrm{H}$ ) & Leymus condensatus (N; resprouts) & Acourtia microcephala (N; resprouts) \\
\hline Lotus sp. (probably H) & Eucrypta chrysanthemefolia (U) & Added in 2nd spring: \\
\hline Added in 2nd spring: & Chaenactis artemisiifolia (Ch) & Cryptantha sp. (probably Ch) \\
\hline Phacelia cicutaria (Ch) & Malacothrix saxatilis (Nt; resprouts) & Solanum xantii $(\mathrm{Nt})$ \\
\hline Rafinesquia californica (Ch) & Bromus madritensis* $(\mathrm{N})$ & Rafinesquia californica (Ch) \\
\hline Emmenanthe penduliflora $(\mathrm{Ch})$ & Phacelia viscida (Ch) & Lactuca serriola* $(\mathrm{N})$ \\
\hline Eschscholtzia californica $(\mathrm{N})$ & Cryptantha sp. (probably Ch) & Silybum marianum* $(\mathrm{N})$ \\
\hline Bromus madritensis* $(\mathrm{N})$ & Emmenanthe penduliflora (Ch) & Calandrinia breweri $(\mathrm{N})$ \\
\hline
\end{tabular}

'Germination stimulus: $\mathrm{H}=$ heat; $\mathrm{Ch}=$ charate; $\mathrm{U}=$ unknown, but seeds are refractory; $\mathrm{Nt}=$ not tested; $\mathrm{N}=$ none (Keeley 1991 ; personal observation). *Non-native. 
The surface soil was dry on all our burns, although only to a few centimeters deep at the Buckhorn site, increasing the probability of overcoming dormancy in heatrequiring seeds and reducing the possibility of "steam cooking" others. This situation is more likely in southern California, where weather between rainstorms in winter can be quite warm. All study sites had good representation of heat and charate stimulated fire followers in the first year herbaceous flora. The very low herbaceous cover at Vierra (fall prescribed burn) may have been a result of high fire severity, a naturally small soil seed bank, or the delayed winter rains. Moreno and Oechel (199lb) found lower density of most herbaceous plants in their high intensity burn treatment. However, higher herbaceous cover followed the high severity Boden Canyon wildfires. The moderate severity early summer burn at Belmar produced the greatest cover of herbaceous species during the first spring after fire, suggesting that fewer seeds were killed by soil heating during the fire. Florence (1986) noted a similar response after winter and spring burns in central California chaparral, where the greatest herbaceous cover followed the lowest intensity burns. Thus, moderate intensity prescribed burning for fuel reduction could produce an added benefit of high herbaceous plant cover and a reduced risk of postfire erosion.

Prescribed fire managers in southern California recognize the need to balance fire behavior and fire effects when igniting fires. Burn prescriptions are written to balance between burning hot enough to stimulate germination yet not so hot as to result in severe postfire erosion from completely denuded slopes (Greenhoe, this volume). In an examination of vegetation development after several early summer prescribed fires in the Santa Monica Mountains of southern California, Stassforth (1997) concluded that most of the fires did not change plant community composition substantially or reduce populations of obligate seeder shrubs. Most burns produced substantial populations of postfire herbaceous plants as well. Some of the fires had been preceded by crushing and drying of the brush to increase fire intensity and ease of burning (Green 1981; Riggan et al. 1986). The dry fuel provides a hotter burn that stimulates germination of Ceanothus and other heat-requiring species (Stassforth 1997). However, crushing may be detrimental if it uproots and kills the burls of sprouter shrubs. In a few cases, crushing was not followed by burning for up to a year, which then resulted in high mortality of sprouters that had put out new growth (Stassforth 1991).

Chamise is generally considered to be highly flammable at a younger age than other chaparral species, while the various species of Ceanothus resist fire well when young (Biswell 1974). Low or moderate intensity fires burning over wet soil, as sampled by Kelly and Parker (1984), could result in an increase in chamise in chaparral stands and a consequent increase in fire hazard to adjacent suburban development. On the other hand, crush- ing followed by late spring burning might result in a reduction in chamise density and enhanced Ceanothus populations in a chaparral stand, postponing future wildfire risk. Some species of Ceanothus provide superior wildlife forage as well (Biswell 1989). Knowledge of reduced shrub survival after late spring and early summer fires has been used intentionally to reduce competing shrub populations in tree plantations (Weatherspoon et al. 1991). Repeated growing season burning should be particularly effective.

\section{Conclusions}

Wet season and spring burns did not produce the anticipated decrease in obligate seeder shrub populations or postfire herbaceous flora at several sites in southern California. These results can not be generalized to all possible wet season or spring burns in southern California, however, because all five fires burned with fairly high intensity. The prescribed fires were deliberately lit to produce complete burns (though less successfully at Belmar) that met research objectives of simulating wildfire, and only plots that had completely burned were used for further study. Shrub seedling and herbaceous plant responses could be different after low or moderate intensity fires.

Postfire vegetation response was obviously affected by winter precipitation as well as season of burn, making it difficult to draw conclusions from just two case studies. However, it appears that if wet season burning is carefully conducted in southern California, significant negative impacts on the chaparral plant community may be avoided. High intensity late spring burning could reduce sprouting shrub populations, especially chamise, but examination of more burns will be necessary to fully test this hypothesis. Well-planned studies using prescribed burns during contrasting seasons within a single year, repeated in successive years to include variations in postfire growing season conditions, are clearly needed before the impacts of out-of-season prescribed burning can be thoroughly anticipated and understood.

Acknowledgments. Financial support was provided by the California Department of Forestry and Fire Protection, the David and Lucile Packard Foundation, and the USDA's National Research Initiative Competitive Grants Program, and Forest Service Pacific Southwest Region. Prescribed fires were conducted by the Los Padres National Forest, California Department of Forestry and Fire Protection, and the Los Angeles County Fire Department. Many technical and professional employees of the USDA Forest Service's Pacific Southwest Research Station performed the field and laboratory work on the prescribed burns. Ginger Peña and Benjamin Matibag assisted with the field data collection at Boden Canyon. Susan G. Conard, Marcia 
Narog, Timothy E. Paysen, Haiganoush Preisler, and Ruth C. Wilson reviewed an earlier version of this manuscript and provided many helpful suggestions. The data reported here were also presented at the 13th International Conference on Fire and Forest Meteorology (October 1996, Lorne, Australia).

\section{Literature Cited}

Barbour, M.G. and J. Major (eds). 1988. Terrestrial vegetation of California. New expanded edition. California Native Plant Society, Special Publication Number 9. 1030 p.

Beyers, J.L., S.C. Conard, and C.D. Wakeman. 1994. Impacts of an introduced grass, seeded for erosion control, on postfire community composition and species diversity in southern California chaparral. Pp. 594-601 in Proceedings of the 12th international conference on fire and forest meteorology. Society of American Foresters, Bethesda, MD.

Biswell, H.H. 1974. Effects of fire on chaparral. Pp. 321-364 in T.T. Kozlowski. and C.E. Ahlgren, eds. Fire and ecosystems. Academic Press, New York, NY.

Biswell, H.H. 1989. Prescribed burning in California wildlands vegetation management. University of California Press, Berkeley, CA. 255 p.

Borchert, M.I. and D.C. Odion. 1995. Fire intensity and vegetation recovery in chaparral: a review. Pp. 91-100 in J.E. Keeley and T. Scott, eds. Brushfires in California wildlands: ecology and resource management. International Association of Wildland Fire, Fairfield, WA.

Campbell, G.S., J.D. Jungbauer, Jr., K.L. Bristow, and R.D. Hungerford. 1995. Soil temperature and water content beneath a surface fire. Soil Science 159:363-374.

Conard, S.G., J.L. Beyers, and P.M. Wohlgemuth. 1995. Impacts of postfire grass seeding on chaparral systems - what do we know and where do we go from here? Pp. 149-161 in J.E. Keeley and T. Scott, eds. Brushfires in California wildlands: ecology and resource management. International Association of Wildland Fire, Fairfield, WA.

Cooper, W.S. 1922. The broad-sclerophyll vegetation of California: an ecological study of the chaparral and its related communities. Carnegie Institutuion of Washington Publication $319.145 \mathrm{p}$.

DeBano, L.F. 1990. Effects of fire on the soil resource in Arizona chaparral. Pp. 65-77 in J.S. Krammes, tech. coord. Effects of fire management of southwestern natural resources. General Technical Report RM-191. USDA Forest Service, Rocky Mountain Forest and Range Experiment Station, Fort Collins, $\mathrm{CO}$.

DeBano, L.F., R.M. Rice, and C.E. Conrad. 1979. Soil heating in chaparral fires: effects on soil properties, plant nutrients, erosion, and runoff. USDA Forest Service, Research Paper PSW-145. $21 \mathrm{p}$.

Florence, M. 1986. Plant succession on prescribed burn sites at Pinnacles National Monument. Fremontia 14(3):31-33.

Green, L.R. 1981. Burning by prescription in chaparral. General Technical Report PSW-51. USDA Forest Service. $36 \mathrm{p}$.

Horton, J.S. and C.J. Kraebel. 1955. Development of vegetation after fire in the chamise chaparral of southern California. Ecology 36:244-262.
Jacks, P.M. 1984. The drought tolerance of Adenostoma fasciculatum and Ceanothus crassifolius seedlings and vegetation change in the San Gabriel chaparral. M.A. thesis, Department of Biology, San Diego State University. 89 p.

Jones, C.S. and W.H.Schlesinger. 1980. Emmenanthe penduliflora (Hydrophyllaceae): further consideration of germination response. Madroño 27:122-125.

Jones, M.B. and H.M. Laude. 1960. Relationships between sprouting in chamise and the physiological condition of the plant. Journal of Range Management 13:210-214.

Keeley, J.E. 1977. Seed production, seed populations in soil, and seedling production after fire for two congeneric pairs of sprouting and nonsprouting chaparral shrubs. Ecology 58:820829.

Keeley, J.E. 1984. Factors affecting germination of chaparral seeds. Bulletin of the Southern California Academy of Sciences 83:113-120.

Keeley, J.E. 1986. Seed germination patterns of Salvia mellifera in fire-prone environments. Oecologia 71:1-5.

Keeley, J.E. 1987. Role of fire in seed germination of woody taxa in California chaparral. Ecology 68:434-443.

Keeley, J.E. 1991. Seed germination and life history syndromes in the California chaparral. Botanical Revicw 57:81-116.

Keeley, J.E. 1992. Demographic structure of California chaparral in the long-term absence of fire. Journal of Vegetation Science 3:79-90.

Keeley, J.E. and S.C. Keeley. 1987. The role of fire in the germination of chaparral herbs and suffrutescents. Madroño 34:240-249.

Keeley, J.E. 1999. Chaparral. Pp. 201-251 in M.G. Barbour, ed. North American terrestrial vegetation. Second Edition. Cambridge University Press, Cambridge, UK.

Keeley, J.E., P.H.Zedler, C.A.Zammit, and T.J. Stohlgren. 1989. Fire and demography. Pp. 151-153 in S.C. Keeley, ed. The California chaparral: paradigms reexamined. Natural History Museum of Los Angeles County, Science Series No. 34, Los Angeles, CA.

Keeley, S.C., J.E. Keeley, S.M. Hutchinson, and A.W. Johnson. 1985. Postfire succession of the herbaceous flora in southern California chaparral. Ecology 62:1608-1621.

Kelly, V.R. and V.T. Parker. 1984. The effects of wet season fires on chaparral vegetation in Marin County, California. Unpublished report submitted to the Marin Municipal Water District, San Rafael, CA. 19 p.

Manly, B.F.J. 1991. Randomization and Monte Carlo methods in biology. Chapman and Hall, London. 281 p.

Minnich, R.A. 1987. Fire behavior in southern California chaparral before fire control: the Mount Wilson burns at the turn of the century. Annals of the Association of American Geographers 28:1-120.

Minnich, R.A. 1989. Chaparral fire history in San Diego County and adjacent northern Baja California: an evaluation of natural fire regimes and the effects of suppression management. Pp. 37-47 in S.C. Keeley, ed. The California chaparral: paradigms reexamined. Natural History Museum of Los Angeles County, Science Series No. 34, Los Angeles, CA.

Minnich, R.A. 1995. Fuel-driven fire regimes of the California chaparral. Pp. 21-27 in J.E. Keeley and T. Scott, eds. Brushfires in California wildlands: ecology and resource management. International Association of Wildland Fire, Fairfield, WA. 
Mooney, H.A. and P.C. Miller. 1985. Chaparral. Pp. 213-231 in B.F. Chabot. and W.D. Billings, eds. Physiological ecology of North American plant communities. Chapman and Hall, New York, NY.

Moreno, J.M. and W.C. Oechel. 1991a. Fire intensity and herbivory effects on postfire resprouting of Adenostoma fasciculatum in southern California chaparral. Oecologia 85:429-433.

Moreno, J.M. and W.C. Oechel. 1991b. Fire intensity effects on germination of shrubs and herbs in southern California chaparral. Ecology 72:1993-2004.

Oechel, W.C., W. Lawrence, J. Mustafa, and J. Martinez. 1981. Energy and carbon acquisition. Pp. 151-183 in P.C. Miller, ed. Resource use by chaparral and matorral: a comparison of vegetation function in two Mediterranean type ecosystems. Springer-Verlag, New York, NY.

Parker, V.T. 1986. Evaluation of the effect of off-season prescribed burning on chaparral in the Marin Municipal Water District watershed. Unpublished report submitted to the Marin Municipal Water District. $14 \mathrm{p}$.

Parker, V.T. 1987. Effects of wet-season management burns on chaparral vegetation: implications for rare species. Pp. 231237 in T.S. Elias, ed. Conservation and management of rare and endangered plants. California Native Plant Society, Sacramento, CA.

Parker, V.T. 1990. Problems encountered while mimicking nature in vegetation management: an example from a fireprone vegetation. Pp. 231-234 in R.S. Mitchell, , C.J.Sheviak, and D.J. Leopold, eds. Ecosystem management: rare species and significant habitats. New York State Museum Bulletin No. 471. The State Education Department, Albany, NY.

Plumb, T.R. 1961. Sprouting of chaparral by December after a wildfire in July. Technical Paper PSW-57. USDA Forest Service. $12 \mathrm{p}$.

Poole, D.K., S.W. Roberts, and P.C. Miller. 1981. Water utilization. Pp. 123-149 in P.C. Miller, ed. Resource use by chaparral and matorral: a comparison of vegetation function in two mediterranean type ecosystems. Springer-Verlag, New York, NY.

Radosevich, S.R. and S.G. Conard. 1980. Physiological control of chamise shoot growth after fire. American Journal of Botany 67:1442-1447.

Riggan, P.J., S. Franklin, and J.A. Brass. 1986. Fire and chaparral management at the chaparral/urban interface. Fremontia 14(3):28-30.

Riggan, P.J., S. Goode, P.M. Jacks, and R.N. Lockwood. 1988. Interaction of fire and community development in chaparral of southern California. Ecological Monographs 58:155-176.

Ross, S. and E.S. Ross. 1993. Preservation of natural urban interface habitats on Marin County's Mt. Tamalpais: the threat from wet season prescribed burning. Pp. 143-146 in J.E. Keeley, ed. Interface between ecology and land development in California. Southern California Academy of Sciences, Los Angeles, CA.

Rundel, P.W. 1982. Successional dynamics of chamise chaparral: the interface of basic research and management. Pp. 8690 in C.E. Conrad and W.C. Oechel, eds. Dynamics and management of Mediterranean-type ecosystems. USDA Forest Service, General Technical Report PSW-58.

Sampson, A.W. 1944. Plant succession on burned chaparral lands in northern California. University of California Agricultural Experiment Station, Bulletin 685, Berkeley, CA. 144 p.
Shaver, G.R. 1981. Mineral nutrient and nonstructural carbohydrate utilization. Pp. 237-257 in P.C. Miller, ed. Resource use by chaparral and matorral: a comparison of vegetation function in two mediterranean-type ecosystems. Springer-Verlag, New York, NY.

Stassforth, M.L. 1991. Chaparral shrub regeneration after prescribed burns in the Santa Monica Mountains. M.S. thesis, Department of Geography, University of California, Los Angeles, CA. $161 \mathrm{p}$.

Stassforth, M.L. 1997. Chaparral response to prescribed burns in the Santa Monica Mountains. Fremontia 25(1):9-14.

Sweeney, J.R. 1956. Responses of vegetation to fire: a study of the herbaceous vegetation following fires. University of California Publications in Botany 28:143-250.

Weatherspoon, C.P., C.N. Skinner, and C.S. Simpson. 1991. Reducing bearclover by repeated growing-season prescribed burns: preliminary test results. Pp. 1-9 in Proceedings: twelfth annual forest vegetation management conference, May 1416, 1991, Red Lion Inn, Redding, California. Shasta County Opportunity Center, Redding, CA.

Wells, C.G., R.E. CampbelI, L.F. DeBano, C.E. Lewis, R.L. Fredriksen, E.C. Franklin, R.C. Froelich, and P.H. Dunn. 1979. Effects of fire on soil: a state-of-knowledge review. USDA Forest Service, General Technical Report WO-7. 34 p.

Westermeier, L.J. 1978. Effects of dry and moist heat shocks on seed viability and germination of Lotus strigosus and Lupinus excubitus var. hallii. M.S. thesis, California State University at Fullerton, Fullerton, CA. 42 p.

White, T.C., J. Stephenson, and F. Sproul. 1995. Postburn monitoring of the Eagle fire: first year recovery on sites seeded with buckwheat and coastal sage. Pp. 185-187 in J.E. Kecley and T. Scott, eds. Brushfires in California wildlands: ecology and resource management. International Association of Wildland Fire, Fairfield, WA.

Wicklow, D.T. 1977. Germination response in Emmenanthe penduliflora (Hydrophyllaceae). Ecology 58:201-205.

Wohlgemuth, P.M., S.G. Conard, C.D. Wakeman, and J.L. Beyers. In press. Postfire hillslope erosion and recovery in chaparral: variability in responses and effects of postfire rehabilitation treatments. In J. Greenlee, ed. Proceedings of the 13th conference on fire and forest meteorology. International Association of Wildland Fire, Fairfield, WA. 


\title{
Unburned and Grazed Chaparral: A Case Study
}

\author{
Frank C. Landis \\ Department of Botany, University of Wisconsin-Madison, WI 53706 \\ Tel. (608) 262-1057; email: fclandis@sprintmail.com
}

\begin{abstract}
Santa Catalina Island's chaparral has a history of being overgrazed with few fires, yet both the vegetation and its history are poorly documented. Because this disturbance regime is unusual, I sampled 77 plots in the island's chaparral, making plant counts, height measurements and cover estimates for all woody species. Fifty-two plots were dominated by Quercus pacifica, eight hy Adenostoma fasciculatum, three each by both Heteromeles arbutifolia and Ceanothus megacarpus and one by Arctostaphylos catalinae, Ceanothus arboreus and Xylococcus bicolor. Seven plots had no dominant species. The counts of individual species were skewed: one group (Quercus, Rhus, Rhamnus, Heteromeles and Prunus), had abundant seedlings, proportionally few dead plants, and were widespread across the island. The other group (Adenostoma, Ceanothus, Arctostaphylos and Xylococcus) had few seedlings, proportionally more dead plants, and were generally localized on the island. These results are consistent with the idea that there have been no widespread fires for about 100 years. Plot observations also showed that grazing affected species differently. Rhamnus pirifolia and Ceanothus megacarpus showed persistent grazing damage, whereas Quercus showed little permanent damage.
\end{abstract}

Keywords: Adenostomafasciculatum; browsing;California; chaparral; fire ecology; grazing; Quercus pacifica; Rhamnus pirifolia; Rhus integrifolia; Santa Catalina Island.

\section{Introduction}

While California has a number of distinctive chaparral types (Sawyer and Keeler-Wolf 1995), there is a stereotypic view of chaparral. Chaparral is dense. Growth is shrubby, usually less than $4 \mathrm{~m}$ tall, and humans either have to follow trails or crawl, since there is usually less than $50 \mathrm{~cm}$ clearance under the shrub canopy.

Chaparral on Santa Catalina Island is different. At first sight, many stands of island chaparral look like woodlands. The plants are large, even arborescent, and the vegetation is open both underneath the canopy and between plants. For someone accustomed to mainland chaparral, the effect is startling, especially since the Catalina species are either the same or close relatives of mainland plants.

What also makes Catalina chaparral interesting is that it has an unusual disturbance regime of intensive grazing, coupled with an apparent lack of fire (Minnich 1980). While fire is a central feature in chaparral ecology, the question of what happens to chaparral in the absence of fire has not been fully explored.

For several decades, the dominant paradigm in chaparral ecology has been that chaparral plants in general need fire to reproduce, and that, in the absence of fire, the chaparral senesces and is replaced by other types of vegetation (Hanes 1988). More recent research has shown that the situation is more complicated (Keeley 1992a; Keeley 1998).

Within the chaparral dominants there are apparently two groups of species. The first group has seeds that germinate after fire; without fire, these species seldom reproduce. The second group of plants survive fires by resprouting, often from lignotubers. However, due to their seedling's requirements, these plants can only reproduce in the long term absence of fire (Keeley 1992b).

These findings have two implications. First, when chaparral is dominated by this second group, it may persist indefinitely without fire, perhaps forming "old growth chaparral." More practically, these findings mean that an area's fire history can be partially reconstructed from the vegetation itself, from species composition, the size of the plants, numbers of dead plants, and the presence or absence of seedlings.

On the mainland, patches of unburned chaparral tend to be small. If a large portion of Catalina's chaparral is unburned, then the island would be an excellent locale to study what happens to chaparral in the absence of fire. Unfortunately, the island's fire history is largely undocumented.

Similarly, the island's grazing history could be useful. Mainland chaparral fires often threaten wealthy suburbs. Land managers have looked for ways to reduce the chaparral fuel load (Hanes 1988). Since grazing is a form of fuel removal, Catalina is essentially an experiment in 
long term fuel reduction, and it can show how different sclerophylls respond to this treatment. While the island's grazing history is hetter documented than its fire history, no source contains a complete account (Coblentz 1977; 1980; Bushing 1990; O’Malley 1994).

Finally, the island's chaparral is sparsely documented. While there are two vegetation maps and a flora for Catalina as a whole (Propst et al. 1974; Minnich 1980; Thorne 1967), only one study contains actual data on chaparral composition and structure (Hollis 1987). This latter study's small sample size is inadequate to characterize the island's chaparral.

To fill these gaps, the present study documents the chaparral in terms of dominance patterns, species composition and species ecology. It also summarizes the land use history available in the literature. The goal of this work is to provide a baseline by documenting the island's chaparral, by determining whether the current vegetation is consistent with the island's known fire history, and by documenting the effect of grazing on different chaparral species.

\section{Background}

\section{Environment}

Santa Catalina Island (Catalina) is one of the southern Channel Islands, lying $32 \mathrm{~km}$ off Pt. Vicente. The island has the rough shape of a horse's head and mane $35 \mathrm{~km}$ long and $12 \mathrm{~km}$ wide, stretching southeast to northwest. Catalina is nearly two islands, the east and west sections joined by a low, $0.85 \mathrm{~km}$ wide neck of land known as the Isthmus. Overall, the island has an area of $194 \mathrm{~km}^{2}$ (Power 1980).

Catalina has been described as a mountain range rising out of the ocean. The island's second highest peak, $610 \mathrm{~m}$ tall Black Jack Mt., is only two km from the ocean. The island is rugged, with little flat ground. The island's ridge crest runs closer to its northern side, resulting in short steep canyons on the northern, channel side of the island and larger canyon systems on the southern side, facing the Pacific. Small permanent streams run in a few of the longer Pacific slope canyons (Landis 1997).

Lithologically, Catalina is very similar to the California Coast Ranges (Rowland 1984). Miocene plutonic rocks underlie much of the southern half of the island. The rest of the island has outcrops of serpentine, various sedimentary rocks from the Mincene and Quaternary, and Catalina schist, which is very similar to the mainland Franciscan formation.

The island has a typically Mediterranean climate with dry, warm summers and wet, cool winters. Mean annual rainfall is around $31.4 \mathrm{~cm}$ for Avalon, but rainfall is variable both between years and among locations (Dunkle 1950). Mean annual rainfall can vary by almost $20 \mathrm{~cm} / \mathrm{yr}$ across the island (Laughrin et al. 1994).

\section{Land use history}

Catalina has a long history of settlement; it has been inhabited the last 4,000-8,000 years (Bushing 1990). This time span can be divided into three different land use regimes. Until the early 1800 s, the island was inhabited by Native Americans. White squatters first settled in 1824, and until the 1950 s the island's economy depended mainly on ranching. Finally, from the 1960 s to the present, tourism has been the mainstay of the island's economy, and conservation has been a priority.

At the time of contact with Europeans, Catalina was known as Pimu, and the natives were Pimugnans. The Pimugnans were predominantly fishermen and stone carvers, who dug for bulbs using weighted digging sticks and processed other plant materials, such as Prunus ilicifolia ssp. lyonii pits, for food. Unlike many mainland tribes, they apparently did not eat acorns, . The native population is estimated to have been 1,000-1,500 at the time of European contact (Bushing 1990). Based on their diet, we can speculate that the Pimugnans burned patches on the island regularly to maintain the grasslands where their bulbs grew, although there is no evidence.

This first period ended around 1832, when the Pimugnans, victims probably of measles or possibly of undocumented attacks by Russian sea otter hunters, left the island (Bushing 1990). The first white man to live on the island settled above Emerald Bay in 1824. He shipped firewood on the mainland, but subsequent squatters raised cattle, sheep and goats (Bushing 1990). By 1850, ranching was the major industry on the island. Goats may have been introduced in 1827 (Dunkle 1950), while sheep and cattle were present by 1850 (See Fig. 1 for a grazing history of the island).

By 1863 , the island's human population was 100 , half of whom were miners. A small gold rush hit Catalina in 1863 , lasting until 1865 , and most claims were apparently staked west of the Isthmus in Cherry Valley and the surrounding area (Probert 1982).

In the 1920's, the sheep were removed and Bison and wild pigs were introduced. Mule deer were introduced to the island in 1930 (Mallan 1992). Some time after this, black buck (Antilope cervicapra) were imported. While the bison, mule deer and pigs have thrived, there are only a few black buck left on the island; they have apparently never been plentiful.

By the 1950 s, overstocking was a serious problem. There were 5,200 cattle on an island that could support roughly 440 cattle at that time. In the late 1950 s the cattle were removed, ending ranching on Catalina (O'Malley 1994). Tourism, first started in the early 1900 s, became the island's main industry.

Conservation began to play an increasing role in island management in the $1950 \mathrm{~s}$, partly due to the damage caused by grazers, and partly due to Thorne's work in educating the island's managers about the value of the native 


\section{Santa Catalina Island Chaparral}

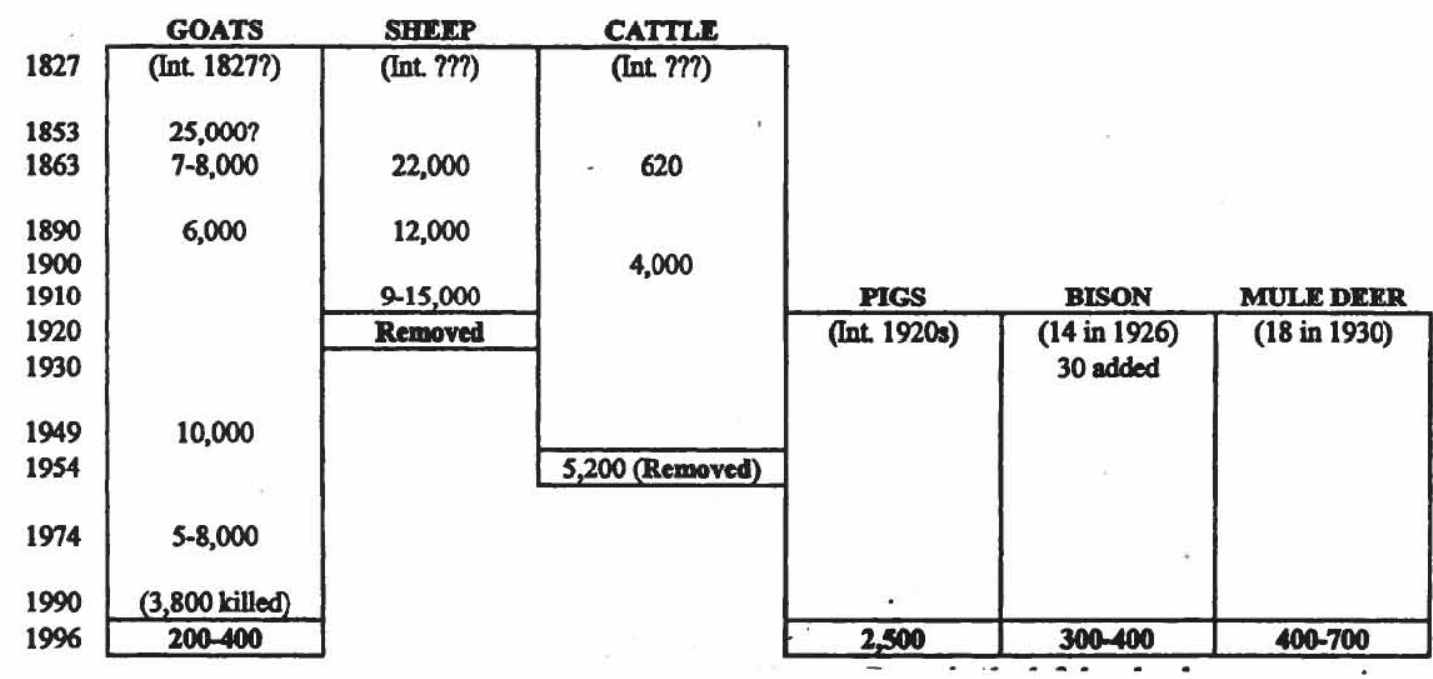

Figure 1. Diagrammatic illustration of Catalina's grazing history. Dates in the left hand column represent reports cited in the literature (Dunkle 1950; Coblentz 1977; Bushing 1990; Mallan 1992; O'Malley 1994; A. Fone, personal communicalion). Bars under each species represent a timeline for each grazer on the island. "Int." show the date the species was introduced, if known, wheras numbers represent the number of animals reported at each date. "Removed" indicates the date the species was removed from the island (1996 numbers are the most recent figures available).

flora (O’Malley 1994). In 1972 the Santa Catalina Island Conservancy was created, and it was deeded 86 percent of the island in 1975. The Conservancy has a strong mandate to protect the natural resources of the island, and it began efforts to restorc the island to a more "natural" state.

In 1990, feral goat and pig removal programs were initiated by the Conservancy. Overall, 6,500 goats and over 600 pigs were killed between 1990 and 1992 (Garcelon 1992). Currently, 200-400 goats, perhaps 2,500 pigs, 400-700 mule deer, 300-400 bison and 20-25 black buck are believed to live on the island (A. Fone personal communication) and control efforts continue.

\section{Fire history}

While there is no information whether the Pimugnans set fires on Catalina, the presence of fire-dependent species such as Adenostoma fasciculatum and Ceanothus megacarpus on the island suggest that fires occurred in the island's past.

Similarly, early ranchers may have set fires to clear pastures for their flocks, but there are no records for this either. Much of Avalon burned in 1915, but there is no mention of whether this fire spread into the surrounding canyon (Mallan 1992).

The Los Angeles County Fire Department station on Catalina maintains incomplete records dating from 19591960 and 1981-present. Unfortunately, these records do not include maps and often describe fires as occurring in "brush," a term that may or may not include chaparral. During the period covered by these records, the largest brush fire covered 7 ha. There have been a number of small brush fires (usually $<1 \mathrm{ha}$ ) reported, all caused by humans. While rare lightning-caused fires have been recorded from the northern Channel Islands, there is no record of any such fire on Catalina. The details are sketchy, but it appears that fire on Catalina is overwhelmingly an anthropogenic phenomenon.

\section{Methods}

Most plant names follow The Jepson Manual (Hickman 1993), except for Quercus pacifica (Roberts 1995). Also, several exotics not found in the Manual follow Hortus Third (Bailey and Bailey 1976).

Woody plants were divided into two classes: "sclerophylls" and "non-sclerophylls". Sclerophylls are the typical chaparral dominants, large shrubs or small trees with sclerophyllous leaves (Hanes 1988). Nonsclerophyllous shrubs do not have the full sclerophyllous suite of characters and are either non-native, characteristic of coastal sage scrub, or woody understory plants.

Plot size and shape were determined in a preliminary study using semivariograms and fractal analysis (Landis 1997). Based on four preliminary sites measured, the consensus plot was a $20 \times 24 \mathrm{~m}$ rectangle.

Two vegetation maps (Propst et al. 1975; Minnich 1980) show the location of the major chaparral areas on the island. Reconnaissance showed that cach arca contained many variably-sized patches of chaparral. Since the purpose of this study was to characterize the chapar- 
Table 1. Scale of cover values.

\begin{tabular}{cl}
\hline Cover & \multicolumn{1}{c}{ Value } \\
\hline 0 & Species not present on plot \\
1 & Few small plants, insignificant cover \\
2 & Many small plants, insignificant cover \\
3 & Larger plants, $<5 \%$ of plot covered by species \\
4 & 5 to $25 \%$ of plot covered by species \\
5 & 25 to $50 \%$ of plot covered by species \\
6 & 50 to $75 \%$ of plot covered by species \\
7 & $>75 \%$ of plot covered by species \\
\hline
\end{tabular}

ral across the island, I decided to sample all of the chaparral areas and as many different patches within the areas as possible. Chaparral patches were defined as relatively homogenous patches of vegetation where sclerophylls were dominant ( $>25$ percent total cover).

Only patches larger than the plot size were sampled. Where small patch size or accessibility were major problems, plot edges were located near the edge of the patch. Otherwise, the plot was located randomly within the patch away from the edge.

Where the chaparral consisted of patches of similar structure and species composition, patches were randomly sampled. Where chaparral patches showed marked differences (different dominant species or structure), attempts were made to sample the different types present in the area. This procedure characterized chaparral variation on a landscape level across the island, at the expense of characterizing within-patch variation.

Seventy-seven plots were measured between June 12 and July 26, 1995. Within each plot, I measured species composition and plant structure data, as well as noting evidence of animal use and past fires.

Only woody shrubs were measured. Since the herbaceous species composition changed throughout the six week study period as annuals set seed and died, data on herbaceous plants would not have been comparable among plots taken at different times.

Species composition was determined by counting the number of live and dead woody plants by species within each plot. Live plant cover was estimated per species using a modified Braun-Blanquet scale (Table 1). The height of each individual plant was mcasurcd to the nearest 0.1 $m$. In addition, I noted plant condition, including evidence of browsing, and whether the plant was growing under the canopy line of another plant (a condition denoted as "under cover").

Within the sclerophylls, single-stemmed plants $0.1 \mathrm{~m}$ tall were labeled "seedlings." This restrictive category was designed to increase the liklihood that the "seedlings" were less than one year old.

Plots were categorized by dominant species into four major and three minor types. The dominant species in a plot was the sclerophyllous species with the highest cover value over 4. However, 7 of the 77 plots had no single sclerophyllous species with a cover $>4$ and were considered "mixed" chaparral (Fig. 2).

For each dominance type, a list of species was created. and the number of plots that contained each species was counted. Mean number of plants per species per plot and the median cover per species per plot were calculated for each type.

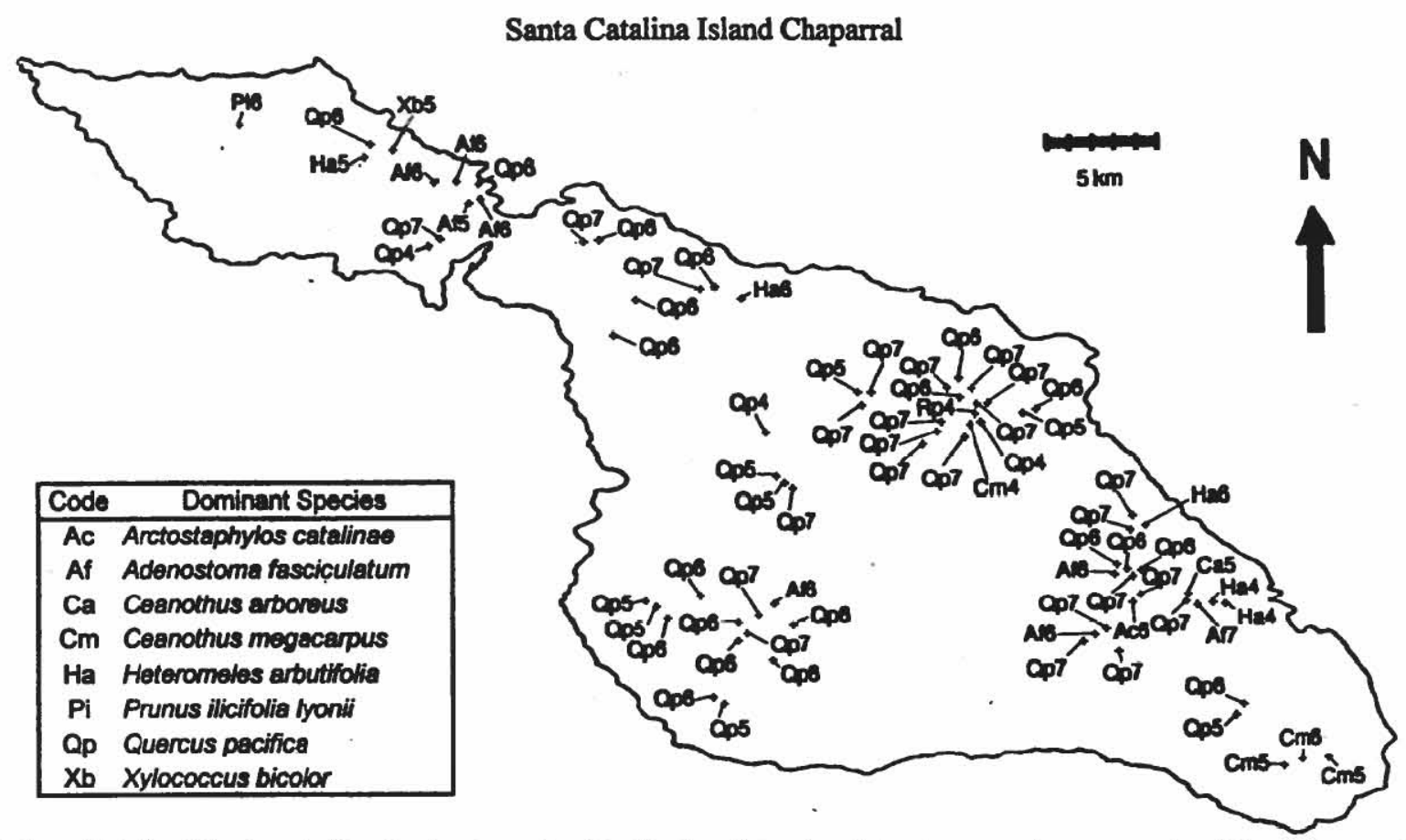

Figure 2. Plots on Catalina Island, coded by dominant species (the first two letters) and dominant species cover value. Mixed chaparral plots are designated by cover value $=4$. 
Species ecology and demographics were evaluated by pooling the data from all plots, then counting numbers of live plants, dead plants and seedlings (for sclerophylls) per species. For each species height distribution graphs were created, showing the number of plants measured at each $0.1 \mathrm{~m}$ height increment, plus the number of plants under cover at each height.

Qualitative descriptions of disturbance were made in each plot. Plants showed evidence of both current and past browsing damage, and four plots contained evidence of past fires.

\section{Results}

\section{Composition and structure}

Quercus pacifica dominated chaparral. Quercus pacifica dominated 52 plots (Table 2). Generally, these plots had an understory of Rhus and small Rhamnus along with Quercus. Opuntia, Artemisia and Mimulus were also common. Scattered Heteromeles and Adenostoma were in about half the plots.

Mean Quercus height was $3.4 \mathrm{~m}$, with a range of 1.0 $4.9 \mathrm{~m}$. The plots with the shortest oaks were typically dense, much like mainland chaparral. As the oaks became taller, plots (with few exceptions) were more open underneath, and when the oaks averaged over $4 \mathrm{~m}$, the stands were open enough to walk through and appeared to be woodlands. Despite this structural diversity, the only compositional difference was the presence of shade-tolerant genera in some of the plots with taller oaks. However, in one plot near the city of Avalon, the oaks were both tall and exceptionally dense.

Adenostoma fasciculatum dominated chaparral. Adenostoma dominated eight plots, scattered across the island, near roads, ranches, old mine sites reservoirs (Table 3). Rhus was usually present in these patches, as was Opuntia. Quercus, Rhamnus and Heteromeles; common as scattered individuals, and other species were present in low numbers.

Four of the plots were taken in the Cherry Valley and Fourth of July Cove area west of the Isthmus, in the largest patches of Adenostoma dominated chaparral on the island. These plots were typically open, with average crown heights ranging from $1.7-2.5 \mathrm{~m}$. They contained large numbers of dead plants and dead stems, and the living plants were arborescent.

Four other plots were taken in small patches scattered across the island near roads, reservoirs and Middle Ranch. The Adenostoma here were lower, with crown heights averaging $0.7-1.3 \mathrm{~m}$. These plants were typically bushy, and the plots less open, though not continuous, thickets. Dead plants were uncommon.
Table 2. Quercus pacifica dominated chaparral $(n=52)$. \#Plots is the number of plots where a species was found, \#Plants is the mean number of plants/plot/species, and cover is the median cover/ species/plot. Asterisks mark non-native species.

\begin{tabular}{|c|c|c|c|}
\hline Species & \#Plots & \#Plants & Cover \\
\hline \multicolumn{4}{|l|}{ Sclerophylls } \\
\hline Adenostoma fasciculatum & 24 & 5.4 & 3 \\
\hline Arctostaphylos catalinae & 4 & 3 & 3 \\
\hline Ceanothus arboreus & 1 & 10 & 5 \\
\hline Cercocarpus betuloides & 5 & 9.4 & 3.5 \\
\hline Heteromeles arbutifolia & 39 & 10.1 & 3 \\
\hline Prunus ilicifolia ssp. lyonii & 1 & 19 & 4 \\
\hline Quercus pacifica & 52 & 41.4 & 6 \\
\hline Rhamnus pirifolia & 51 & 12.5 & 2 \\
\hline Rhus integrifolia & 42 & 15.6 & 4 \\
\hline Rhus ovata & 1 & 1 & 1 \\
\hline Xylococcus bicolor & 1 & 2 & 3 \\
\hline \multicolumn{4}{|l|}{ Non-sclerophylls } \\
\hline Artemisia californica & 18 & 34.1 & 3 \\
\hline Baccharis pilularis & 21 & 15.4 & 2 \\
\hline Crossosoma californica & 8 & 3.1 & 2 \\
\hline Eriogonum giganteum & 2 & 9 & 2 \\
\hline Keckiella cordifolia & 8 & 3.9 & 3 \\
\hline Lonicera hispidula & 14 & 8.4 & 3 \\
\hline Lotus dendroideus & 11 & 9.6 & 2.5 \\
\hline Mimulus aurantiacus & 14 & 32.4 & 2 \\
\hline Opuntia littoralis & 35 & 34.6 & 3 \\
\hline Ribes viburnifolium & 3 & 5.3 & 1 \\
\hline Salvia apiana & 2 & 13 & 2.5 \\
\hline Salvia mellifera & 3 & 25 & 4 \\
\hline Symphoricarpus mollis & 1 & 32 & 3 \\
\hline Toxicodendron diversilobum & 15 & 22 & 3 \\
\hline \multicolumn{4}{|l|}{ Non-natives } \\
\hline Aeonium sp.* & 1 & 13 & 3 \\
\hline Agave sp.* & 1 & 1 & 3 \\
\hline Aloe arborescens* & 1 & 16 & 2 \\
\hline Aloe sp.* & 1 & 8 & 3 \\
\hline Crassula erecta* & 1 & 13 & 3 \\
\hline Crassula tetragona* & 1 & 486 & 4 \\
\hline Genista linifolia* & 2 & 69 & 3.5 \\
\hline Opuntia robusta* & 1 & 1 & 1 \\
\hline
\end{tabular}

Heteromeles arbutifolia dominated chaparral. Heteromeles dominated chaparral was found relatively near the ocean, especially on the eastern portions of the island (Table 4). Three plots were taken in Toyon Canyon, the Empire Landing area and above Emerald Bay. This type was characterized by large Heteromeles and sprawling Rhus. Toxicodendron was common, sometimes binding the vegetation into a solid mass. Within this thicket was a diverse array of scattered sclerophylls, such as Quercus, Rhamnus, or Prunus. Heteromeles dominated chaparral occurred in relatively small, discrete patches, and did not cover large areas. Unsampled patches of this type were seen below the Stage Road and in the steep canyons on the southeastern side of the island. 
Table 3. Adenostoma fasciculatum dominated chaparral $(n=8)$. Table format follows Table 2 .

\begin{tabular}{lccc}
\hline Species & \#Plots & \#Plants & Cover \\
\hline Sclerophylls & & & \\
& & & \\
Adenostoma fasciculatum & 8 & 102.5 & 6 \\
Arctostaphylos catalinae & 1 & 1 & 3 \\
Ceanothus megacarpus & 2 & 2 & 2.5 \\
Heteromeles arbutifolia & 5 & 2 & 3 \\
Quercus pacifica & 6 & 7.2 & 3 \\
Rhamnus pirifolia & 6 & 4.3 & 2 \\
Rhus integrifolia & 7 & 10 & 4 \\
Xylococcus bicolor & 1 & 6 & 3 \\
& & & \\
Non-sclerophylls & & & \\
& & & \\
Artemisia californica & 3 & 26.3 & 2.5 \\
Baccharis pilularis & 1 & 1 & 3 \\
Crossosoma californica & 4 & 2.3 & 1 \\
Eriogonum giganteum & 1 & 1 & 1 \\
Lotus dendroideus & 1 & 1 & 1 \\
Mimulus aurantiacus & 3 & 35.3 & 3 \\
Opuntia littoralis & 6 & 19.8 & 1.5 \\
Ribes viburnifolium & 1 & 1 & 3 \\
Salvia mellifera & 3 & 51.7 & 4 \\
\hline
\end{tabular}

Ceanothus megacarpus dominated chaparral. This Ceanothus chaparral was much more localized on the island, dominant on ocean-facing ridges on the east end and in scattered patches in the White's Landing area. The plots analyzed here were all measured on the east end (Table 5).

Plots were dominated by Ceanothus megacarpus and Salvia mellifera; the latter often covered the majority of the plot. Secondary species included Malosma, Rhamnus, Heteromeles and Adenostoma. Structurally the plots were patches of black sage interspersed with patches of sclerophylls. While the arborescent Ceanothus plants reached $4 \mathrm{~m}$ in height, the mean height of $2.2 \mathrm{~m}$ was caused by the number of Ceanothus that had fallen over and continued to grow. The absence of Quercus and the scarcity

Table 4. Heteromeles arbutifolia dominated chaparral $(n=3)$. Format follows Table 2.

\begin{tabular}{lccc}
\hline Species & \#Plots & \#Plants & Cover \\
\hline Sclerophylls & & & \\
Heteromeles arbutifolia & 3 & 20 & 6 \\
Prunus ilicifolia ssp. lyonii & 1 & 1 & 3 \\
Quercus pacifica & 2 & 5.5 & 5 \\
Rhamnus pirifolia & 2 & 17 & 3 \\
Rhus integrifolia & 3 & 8 & 4 \\
Sambucus mexicana & 1 & 1 & 1 \\
& & & \\
Non-sclerophylls & & & \\
Artemisia californica & 2 & 7 & 2.5 \\
Crossosoma californica & 1 & 1 & 1 \\
Opuntia littoralis & 2 & 39.5 & 2.5 \\
Toxicodendron diversilobum & 1 & 6 & 3 \\
\hline
\end{tabular}

of Heteromeles, Adenostoma and other such species set this type apart from the chaparral on the rest of the island.

Minor dominance types. Three plots, dominated by either Arctostaphylos catalinae, Ceanothus arboreus or Xylococcus bicolor, were distinctive enough to deserve recognition. Also, a plot dominated by Prunus ilicifolia ssp. lyonii deserves mention. It was taken above Parson's Landing near an ephemeral stream and contained five $5 \mathrm{~m}$ tall Prunus, one $6 \mathrm{~m}$ Sambucus mexicana, and over 1,200 Prunus seedlings and young plants. This plot showed the pattern of Prunus ilicifolia ssp. lyonii regeneration, which was previously undocumented. Otherwise, this plot is an oddity that will not be included in the composition and structure results.

Arctostaphylos catalinae occured in six plots but dominated only one plot east of Haypress Reservoir (Table 6). This plot also contains many Adenostoma, with scattered Rhamnus, Quercus, Heteromeles, Malosma, Rhus, Opuntia. The sclerophylls usually had low canopies, with openings between the shrubs.

Table 5. Ceanothus megacarpus dominated chaparral $(n=3)$. Format follows Table 2.

\begin{tabular}{lccc}
\hline Species & \#Plots & \#Plants & Cover \\
\hline Sclerophylls & & & \\
& & & \\
Adenostoma fasciculatum & 1 & 4 & 3 \\
Ceanothus megacarpus & 3 & 55.7 & 5 \\
Heteromeles arbutifolia & 2 & 1.5 & 2 \\
Malosma laurina & 3 & 15.7 & 4 \\
Rhamnus pirifolia & 2 & 5.5 & 2 \\
Rhus integrifolia & 1 & 2 & 3 \\
& & & \\
Non-sclerophylls & & & \\
& & 6 & 2 \\
Artemisia californica & 1 & 21. & 5 \\
Baccharis pilularis & 2 & 2 & 2 \\
Eriogonum giganteum & 2 & 4 & 2 \\
Mimulus aurantiacus & 1 & 30 & 2.5 \\
Opuntia littoralis & 3 & 210.7 & 6 \\
Salvia mellifera & 3 & & \\
\hline
\end{tabular}

Ceanothus arboreus dominated only in one plot in the Stage Road area (Table 7). This plot had more dead Ceanothus plants than live ones, and many of the living Ceanothus did not appear healthy. Cercocarpus, Heteromeles, Rhamnus, and four non-sclerophyllous species rounded out a rather sparse list. The number of dead, downed Ceanothus has created large grass-filled gaps in the stand. Living sclerophylls were relatively large, averaging $4.8 \mathrm{~m}$ tall for the Ceanothus and $4.2 \mathrm{~m}$ for the Heteromeles. 
Table 6. Arctostaphylos catalinae dominated chaparral $(n=1)$. \#Plants and Cover format follow Table 2.

\begin{tabular}{lcc}
\hline Species & \#Plants & Cover \\
\hline Sclerophylls & & \\
Adenostoma fasciculatum & 19 & 4 \\
Arctostaphylos catalinae & 41 & 6 \\
Heteromeles arbutifolia & 2 & 3 \\
Malosma laurina & 1 & 3 \\
Quercus pacifica & 4 & 4 \\
Rhamnus pirifolia & 5 & 2 \\
Rhus integrifolia & 1 & 1 \\
Non-sclerophylls & & \\
Opuntia littoralis & & 3 \\
\hline
\end{tabular}

Xylococcus bicolor was limited to the channel side of the island's west end, where it was common and occasionally dominant. This plot was a mix of Xylococcus and Adenostoma, with Rhamnus, Heteromeles, Rhus also present (Table 8). Clumps of Mimulus were scattered in the understory.

In seven plots, no sclerophyllous species achieved a cover value greater than $25 \%$ (Table 9). These plots were not identical, although two can be described as black sage dominant.

Two plots in upper White's Landing consisted of scattered chaparral shrubs in a matrix of black sage. One was similar to the Ceanothus megacarpus type, whereas the "Rhamnus type" might be considered more a lack of other sclerophylls than a potential dominance type. Three other plots were similar to Quercus dominant and two plots to Heteromeles dominant.

Table 7. Ceanothus arboreus dominated chaparral $(n=1)$. \#Plants and Cover format follow Table 2.

\begin{tabular}{lcc}
\hline Species & \#Plants & Cover \\
\hline Sclerophylls & & \\
Adenostornu fusciculutum & 1 & 3 \\
Ceanothus arboreus & 15 & 5 \\
Cercocarpus betuloides & 1 & 1 \\
Heteromeles arbutifolia & 2 & 3 \\
Rhamnus pirifolia & 5 & 3 \\
Non-sclerophylls & & \\
Artemisia californica & & \\
Crossosoma californica & 1 & 1 \\
Eriogonum giganteum & 7 & 3 \\
Toxicodendron diversilobum & 6 & 3 \\
& 2 & 3 \\
\hline
\end{tabular}

Species abundance

There were more than 500 individuals for each of six sclerophylls: Quercus, Prunus, Adenostoma, Rhamnus, Rhus integrifolia and Heteromeles (Table 10). Other sclerophylls were much less common. Of the six most common species, all except Adenostoma showed abundant seedlings, and proportionally few dead plants. If the number of dead plants were compared to the total number of live and dead plants, less than $3 \%$ of these top five species' populations were dead. Ignoring Sambucus and Rhus ovata, between $9-44 \%$ of the other species' total counts were dead. Moreover, these other sclerophylls had few seedlings.

Table 8. Xylococcus bicolor dominated chaparral. \#Plants and Cover format follow Table 2.

\begin{tabular}{lcc}
\hline Species & \#Plants & Cover \\
\hline Sclerophylls & & \\
Adenostoma fasciculatum & 83 & 4 \\
Heteromeles arbutifolia & 8 & 3 \\
Rhamnus pirifolia & 23 & 4 \\
Rhus integrifolia & 16 & 4 \\
Xylococcus bicolor & 79 & 5 \\
Non-sclerophylls & & \\
Keckiella cordifolia & & \\
Mimulus aurantiacus & 2 & 2 \\
& 45 & 3 \\
\hline
\end{tabular}

Non-sclerophylls were similar in that six species (Opuntia littoralis, Artemisia, Mimulus, Baccharis and Toxicodendron) had over 400 individuals. However, few dead non-sclerophylls were seen. This may be due to two factors: either non-sclerophylls decayed faster, or (more likely) most of the non-sclerophylls counted were relatively young plants. The one exception was Eriogonum giganteum, which had almost $15 \%$ dead plants (from the total count). This species had woody, chamise-like stems that may not have decayed as quickly.

The height distribution for sclerophylls and nonsclerophylls showed that seedlings of Rhamnus and Quercus were so abundant they were off scale (Fig. 3).

These graphs may be interpreted structurally or demographically. Structurally, they show the range of heights for each species and the number of plants at each height increment. Since size is related to age, these graphs suggest species demographics. Important demographic details include the number of plants at each height increment, the number under cover at each height, the overall shape and smoothness of the curve, and the presence of gaps or low numbers at various height increments. 
Table 9. "Mixed" chaparral. Format follows Table 2.

\begin{tabular}{llll}
\hline Species & \#Plots & \#Plants & Cover \\
\hline C. megacarpus type $(n=1)$ &
\end{tabular}

Sclerophylls

$\begin{array}{lccc}\text { Ceanothus megacarpus } & 1 & 6 & 4 \\ \text { Heteromeles arbutifolia } & 1 & 1 & 3 \\ \text { Quercus pacifica } & 1 & 3 & 4 \\ \text { Rhamnus pirifolia } & 1 & 74 & 4 \\ \text { Rhus integrifolia } & 1 & 9 & 4 \\ & & & \\ \text { Non-sclerophylls } & & & \\ & 1 & 2 & 3 \\ \text { Baccharis pilularis } & 1 & 1 & 2 \\ \text { Opuntia littoralis } & 1 & 395 & 6 \\ \text { Salvia mellifera } & \end{array}$

Heteromeles type ( $n=2)$

Sclerophylls

Cercocarpus betuloides Heteromeles arbutifolia Malosma laurina

Prunus ilicifolia ssp. lyonii

Rhamnus pirifolia

Rhus integrifolia

Non-Sclerophylls

Artemisia californica
Eriogonum giganteum
Keckiella cordifolia
Lonicera hispidula
Lotus dendroideus
Lupinus albifrons
Mimulus aurantiacus
Salvia apiana
Toxicodendron diversilobum
Genista linifolia*

Quercus type ( $n=3)$

Sclerophylls

Ceanothus arboreus

Heteromeles arbutifolia

Malosma laurina

Quercus pacifica

Rhamnus pirifolia

Rhus integrifolia

Non-Sclerophylls

Artemisia californica

Baccharis pilularis

Crossosoma californica

Eriodictyon traskiae

Malacothamnus fasciculatus

Opuntia littoralis

Salvia mellifera

Rhamnus pirifolia type $(n=1)$

Sclerophylls

Adenostoma fasciculatum

Rhamnus pirifolia

Rhus integrifolia

Non-Sclerophylls

Baccharis pilularis

Eriodictyon traskiae

Mimulus aurantiacus

Opuntia littoralis

Salvia mellifera
There are a number of patterns visible in these graphs. First, the number of plants under cover generally decreased as height increment increased. Second, there were no major gaps in the height distribution curves for both Heteromeles and Quercus, but the curves were notably jagged (the spikes at meter and half meter marks are measurement artifacts). Conversely, Ceanothus arboreus and Arctostaphylos showed notably jagged curves, but with large gaps. Rhamnus showed relatively smooth curves at low heights, but major gaps at the scale's high end.

Table 10. Number of live plants/species (\#Live), number of dead plants/species (\#Dead) and number of seedlings/species (\#Seedl.) from all plots $(n=77)$. Seedling numbers were only determined for sclerophylls.

\begin{tabular}{lccc}
\hline Species & \#Live & \#Dead & \#Seedl. \\
\hline Scerophylls & & & \\
& & & \\
Quercus pacifica & 2243 & 91 & 871 \\
Prunus ilicifolia ssp. lyonii & 1251 & 0 & 422 \\
Adenostoma fasciculatum & 1058 & 180 & 0 \\
Rhamnus pirifolia & 932 & 1 & 195 \\
Rhus integrifolia & 856 & 2 & 63 \\
Heteromeles arbutifolia & 525 & 20 & 23 \\
Ceanothus megacarpus & 177 & 37 & 1 \\
Xylococcus bicolor & 87 & 15 & 3 \\
Cercocarpus betuloides & 58 & 9 & 1 \\
Malosma laurina & 55 & 6 & 0 \\
Arctostaphylos catalinae & 54 & 13 & 3 \\
Ceanothus arboreus & 26 & 20 & 0 \\
Sambucus mexicana & 2 & 0 & 0 \\
Rhus ovata & 1 & 0 & 1
\end{tabular}

Non-sclerophylls

$\begin{array}{lcc}\text { Opuntia littoralis } & 1754 & 1 \\ \text { Salvia mellifera } & 1340 & 5 \\ \text { Artemisia californica } & 955 & 5 \\ \text { Mimulus aurantiacus } & 802 & 1 \\ \text { Baccharis pilularis } & 446 & 0 \\ \text { Toxicodendron diversilobum } & 401 & 0 \\ \text { Lonicera hispidula } & 127 & 0 \\ \text { Lotus dendroideus } & 116 & 1 \\ \text { Eriogonum giganteum } & 76 & 13 \\ \text { Lupinus albifrons } & 67 & 0 \\ \text { Eriodictyon traskiae } & 56 & 0 \\ \text { Keckiella cordifolia } & 47 & 0 \\ \text { Crossosoma californica } & 43 & 0 \\ \text { Symphoricarpus mollis } & 32 & 0 \\ \text { Salvia apiana } & 27 & 0 \\ \text { Ribes viburnifolium } & 17 & 0 \\ \text { Malacothamnus fasciculatus } & 3 & 0\end{array}$

Non-natives

$\begin{array}{lcl}\text { Crassula tetragona* } & 486 & 0 \\ \text { Genista linifolia* } & 150 & 0 \\ \text { Aloe arborescens* } & 16 & 0 \\ \text { Aeonium sp.* } & 13 & 0 \\ \text { Aloe } \text { sp.* } & 8 & 0 \\ \text { Agave sp.* } & 1 & 0 \\ \text { Opuntia robusta* } & 1 & 0\end{array}$


- Santa Catalina Island Chaparral -

65

Landis, F. C.
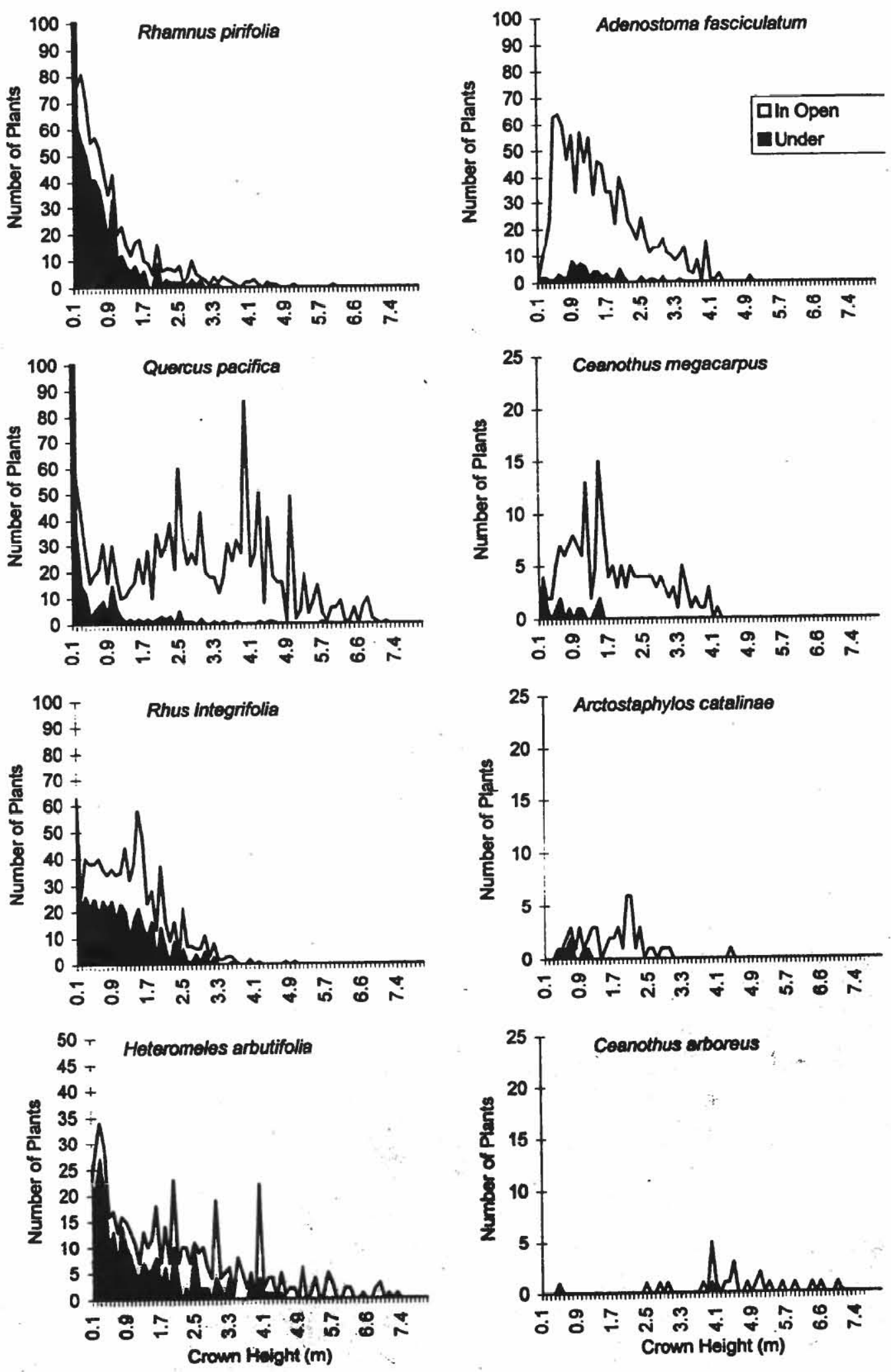

Figure 3. Crown height profiles of chaparral species. The upper curve plots all plants by height, while the shaded area shows the number of plants under other plants. Not all $0.1 \mathrm{~m}$ plants are shown for Rhamnus $\left(\mathrm{n}_{0.1}=204\right)$ and Quercus $\left(\mathrm{n}_{0.1}=871\right)$. 
Fire evidence

Determining the locations of previous fires is difficult. The Los Angeles County Fire Department's records do not record precise locations. Nonetheless, some plots contained evidence of past fires.

One plot was west of the West End Dump, where trash is incinerated in an open trench. The area had been subject to repeated fires over the last 30 years, the latest in 1993 (M. Gaye personal communication). In this fire, seven large Quercus and a Heteromeles were killed, and several living plants bore fire scars up to $2.4 \mathrm{~m}$ on standing stems. In some cases, it appeared that the fire had girdled the dead plants, rather than burning their canopies. This fire was a low intensity burn on a fairly open, grassy location.

Three plots showed more scanty evidence. One was taken at the top of Toyon Canyon next to the road, another in a side canyon by Haypress Reservoir, and the third on a slope facing Patrick's Reservoir. All three plots showed remnant burned stumps or charcoal on exposed roots. Shrubby Adenostoma dominated the first two, while the third was dominated by Arctostaphylos. These plots were probably taken on the sites of spot fires that occurred over a decade in the past, though there were no records of these events.

\section{Grazing impact}

Persistent browse lines were observed on large living and dead Rhamnus and Ceanothus megacarpus. These browse lines were probably relics from earlier overgrazing for two reasons: (1) other plants in the area showed no signs of current browsing, (2) these browse lines were still apparent even on plants that had fallen over, and a browse line canted at 45 degrees and resting on the ground is unlikely to be caused by current browsing.

Current browsing damage was seen on six Quercus, three Rhus and seven Ceanothus arboreus. In all cases, the damage was confined to basal suckers.

Other evidence of animal (and human) activity was not hard to find (Table 11). Evidence ranged from carcasses and bones to tracks, hair and especially droppings, as well as animals seen in the immediate area of the plot or heard nearby.

Many sites contained evidence of multiple species, although no site had evidence in more than three categories. Conversely, only four plots showed no evidence. Pig trails and droppings were especially pervasive, occurring on almost two thirds of the plots taken.

Finally, the herbivores may cause impacts unrelated to browsing. For instance, bison were repeatedly seen using Quercus patches for shade, and one bison bull was observed using an oak as a back scratcher. Large animal movement may thus help to account for the openness observed in many of the Quercus-dominated plots.

\section{Discussion}

One question is how well the numbers for the different dominance types reflect the actual makeup of the island's chaparral. Since my sampling method emphasized variation, I suspect the numbers here under-represent Quercus pacifica chaparral. The Heteromeles-type was also under sampled, simply because I was unable to sample small Heteromeles-dominated patches that occurred in inaccessible areas. With these caveats, I believe this study shows the composition and structure of the chaparral on Catalina.

The pattern of dominant species on Catalina is different than that seen in similar mainland areas such as the Santa Monica Mountains. From personal observation, chaparral in the Santa Monicas is largely dominated by Ceanothus megacarpus and Adenostoma fasciculatum, with Quercus berberidifolia only occasionally dominant. On Catalina, Quercus pacifica dominated 52 plots, Adenostoma dominated eight plots and Ceanothus megacarpus dominated three. In other mainland areas, Arctostaphylos spp. are common chaparral dominants (Hanes 1988), but Arctostaphylos catalinae dominated only one plot. In these ways, Catalina's chaparral dominant species pattern is the inverse of mainland patterns.

While there are compositional and structural differences among the dominance types, the same species show up repeatedly. Because of this, the different dominance types are best regarded as tools for understanding variation within the chaparral, rather than as separate entities in themselves. Dominance types simply record the dominance of a particular species in a particular area.

Height distribution may be used to infer the dynamics of a population. A Gaussian distribution (many small plants, few large ones) suggests that only a few seedlings survive to maturity, or it may show the early stage of a wave of recruitment. Conversely, a jagged pattern suggests that the species recruits new members occasionally and in small numbers, leading to individuals of all sizes and ages in one population, a condition known as "old growth" when seen in forest species such as redwoods. Missing plants may be due to low sample size, or they

Table 11. Summary of animal disturbance evidence $(n=77)$.

\begin{tabular}{lc}
\hline Species or Disturbance Type & $\begin{array}{c}\text { Number of } \\
\text { plots present }\end{array}$ \\
\hline Pig & $49(64 \%)$ \\
Animal trails & $34(44 \%)$ \\
Bison & $27(35 \%)$ \\
Mule deer & $13(17 \%)$ \\
Human (litter) & $11(14 \%)$ \\
Goat & $9(11 \%)$ \\
Unidentified herbivore & $5(6 \%)$ \\
Island Fox & $3(4 \%)$ \\
\hline
\end{tabular}


may indicate past high mortality. All of these patterns show up in the data.

However, these graphs may not accurately reflect the age of the plants, as they represent data pooled from 77 plots spread across the island. For some species this is not a problem, either because most members were measured in a few plots, or because the curves from each plot have the same shape as the total population curve. For Quercus pacifica, the composite nature of the curve is a major problem. Its jagged height distribution graph apparently indicates that continuous recruitment has taken place over the years. Since the island is environmentally heterogeneous, plant growth rates undoubtedly vary across the island. These differences confound the relationship between height and age, so a continuous height distribution graph may well hide periods when no plants were established.

Evidence of disturbance from the sites corroborates the island's documented disturbance history. There is no evidence of recent widespread chaparral fires, so the gap in Los Angeles County Fire Department records does not apparently cover any major blazes. However, there is widespread evidence for herbivores and human disturbance.

Grazing has different effects on different plant species. Among the sclerophylls, there was little evidence of permanent grazing damage on Quercus, Heteromeles, Rhus, Arctostaphylos, Cercocarpus and Xylococcus. These species show no browse lines. Indeed, if the oaks shown in old photographs are still present, they have lost their browse lines, since the current plants do not show them.

Not all chaparral species were so fortunate. Remnant browse lines were evident on Ceanothus megacarpus and Rhamnus pirifolia, suggesting that these species are vulnerable to permanent damage. The lack of large Rhamnus and Prunus, despite the number of young plants, suggests that these species were greatly reduced by grazing pressure. In these cases, goats are probably the main culprits, since they can eat more bitter forage than can other browsers (Coblentz 1980).

Finally, Ceanothus arboreus is arguably the species most affected by grazing. While it shows no browse lines, most of the basal sprouts had been browsed and there is no cvidence of regencration. Both decr and goats are likely culprits, since this Ceanothus is known to be eaten by deer in mainland plantings (Wilson 1993).

\section{Interpretation}

The Catalina sclerophylls mostly fall into two groups. The first group, which includes species of Quercus, Rhamnus, Rhus, Prunus and Heteromeles, has animal dispersed fruits with no germination cue (Emery 1988; Keeley
1991). Members of this group have many seedlings and are the most common sclerophylls on the island.

The second group, of which Adenostoma, Arctostaphylos, both Ceanothus spp. and Xylococcus are members, has seeds requiring fire for germination (Emery 1988; Keeley 1991). These species, except for Adenostoma, are localized, often uncommon, and are reproducing at low levels if at all.

These two groups follow the pattern found in mainland "unburned" chaparral (Keeley 1992 a,b; Keeley, 1998). Species that only reproduce in the long term absence of fire are common and reproducing. However, species that require fire for reproduction are reproducing at low levels (at best) and small plants of these species are found in areas with evidence of recent small fires.

However, the presence of Adenostoma, Ceanothus megacarpus, C. arboreus and an endemic Arctostaphylos suggest that fire was more common in the past. It is possible that any plot that is dominated by these species is the site of an old fire.

When were the last big fires? The scattered Adenostoma found across the island provide an answer. These $\Lambda$ denostoma are both mature and often overtopped by Quercus, implying that the fires that germinated these plants occurred long ago. Since Adenostoma life span is roughly 100 to 120 years (Keeley, personal communication), the areas where scattered Adenostoma occur, probably burned in the late 1800s. Minnich (1980) reports an island wide Adenostoma die-off in the 1970s, supporting this hypothesis.

Similarly, Fourth of July Cove and Cherry Valley were the sites of the 1860s mining boom (Probert 1982). Old and dead Adenostoma are common in this area, and Xylococcus is only found in this region of the island. Although there is no proof, the correlation of vegetation to history is tantalizing.

While active fire suppression is a major reason why there have been no major fires on Catalina, another cause is grazing. Introduced herbivores greatly reduced the island's fuel load through overgrazing (O'Malley 1991), and any fires that started were thus easier to control. Ironically, controlling Catalina's herbivore population will increase the intensity of future fires on the island, which may in turn benefit fire-dependent species.

Although the chaparral on Catalina is dominated by island endemics, the oddities of its composition and structure are not due to peculiarities in the island's flora. Rather, the structure and composition of this chaparral can best be explained by the island's unusual land use history, just as Minnich (1980) contended. If Catalina had been subjected to the land use patterns prevalent on the mainland, little would be noteworthy about its chaparral. Fortunately it was not, and it gives us an idea of how chaparral develops under unusual conditions. 


\section{Conclusions}

In 77 plots taken in Catalina chaparral, Quercus pacifica dominated 52, Adenostoma fasciculatum dominated 8 plots, Heteromeles arbutifolia and Ceanothus megacarpus dominated three each, and Arctostaphylos catalinae, Ceanothus arboreus and Xylococcus bicolor dominated one plot each. From pooled species data, a group of sclerophylls (Quercus, Heteromeles, Rhus integrifolia, Rhamnus pirifolia and Prunus ilicifolia ssp. lyonii) are widespread and abundant with numerous seedlings, whereas another group of sclerophylls (Adenostoma, Arctostaphylos, Ceanothus and Xylococcus) are generally localized, few in number, and reproducing in low numbers. These results are consistent with a long-term absence of large fires on Catalina. Available evidence suggests that the last major fires took place about 100 years ago.

Catalina has a history of overgrazing by introduced herbivores. Different sclerophylls show different responses to browsing, ranging from tolerance (Quercus), to signs of persistent damage (Rhamnus and $C$. megacarpus) to major impairment of regeneration ( $C$. arboreus).

The lesson for land managers is two-fold. First, chaparral plants can reproduce and regenerate in the absence of fire. Second, different sclerophyll species show different tolerances to physical damage (grazing). Hence, the ecology of the component species needs to be considered in the management of any patch of chaparral.

Acknowledgments. This work was funded by the California Native Plant Society and Humboldt State University. Housing, transportation and other assistance was provided by the Catalina Conservancy. The author also wishes to thank John Sawyer, Amy Anderson, Alan Fone, Janet Takara, Elisabeth Landis and Charles Burgwin.

\section{Literature Cited}

Bailey, L.H. and E. Z. Bailey. 1976. Hortus third: a concise dictionary of plants cultivatedin the United States and Canada. MacMillan Publishing Company, New York. NY.

Bushing, W.W. 1990. Reference series for Santa Catalina Island Company tours. Unpublished reference notebook. Santa Catalina Island Company, Avalon, CA.

Coblentz, B.E. 1977. Some range relationships of feral goats on Santa Catalina Island, California. Journal of Range Management 30:415-419.

Coblentz, B.E. 1980. Effects of feral goats on the Santa Catalina Island ecosystem. Pp. 167-170 in D. M. Power, ed. The California islands: proceedings of a multidisciplinary symposium. Santa Barbara Museum of Natural History. Santa Barbara, CA.
Dunkle, M.B. 1950. Plant ecology of the Channel Islands of California. Allan Hancock Pacific Expeditions 13(3). The University of Southern California Press, Los Angeles, CA.

Emery, D.E. 1988. Seed propagation of California native plants. Santa Barbara Botanic Garden, Santa Barbara, CA.

Garcelon, D. 1992. Unpublished letter to Douglas Propst.

Hanes, T.L. 1988. California chaparral. Pp. 418-469 in M. G. Barbour and J. Major, eds. Terrestrial vegetation of California (new expanded edition). California Native Plant Society Special Publication Number 9. Sacramento, CA.

Hickman, J.C. 1993. The Jepson manual: higher plants of California. University of California Press, Berkeley, CA.

Hollis, H.E. 1987. A pre-management study of some Santa Catalina Island chaparral communities. M.S. thesis. California State University, Long Beach, CA.

Keeley, J.E. 1991. Seed germination and life history syndromes in California Chaparral. Botanical Review 57: 81-116.

Keeley, J.E. 1992a. Demographic structure of California chapar$\mathrm{ral}$ in the long-term absence of fire. Journal of Vegetation Science 3:79-90.

Keeley, J.E. 1992b. Recruitment of seedlings and vegetative sprouts in unburned chaparral. Ecology 73:1194-1208.

Keeley, J.E. 1998. Coupling demography, physiology and evolution in chaparral shrubs. Pp. 257-264 in P. W. Rundel, G. Montenegro and F. Jaksic, eds. Landscape degradation and biodiversity in mediterranean-type ecosystems. SpringerVerlag, New York.

Landis, F.C. 1997. Composition, structure and dynamics of chaparral on Santa Catalina Island, California. M. A. thesis. Humboldt State University, Arcata, CA.

Laughrin, L., M. Carroll, A. Bromfield, and J. Carroll. 1994. Trends in vegetation changes with removal of feral animals on Santa Catalina Island. Pp. 157-164 in W. L. Halvorson and G. J. Maender, eds. The fourth California islands symposium: update on the status of resources. Santa Barbara Museum of Natural History, Santa Barbara, CA.

Mallan, C. 1992. CatalinaIslandhandbook: aguide to California's Channel Islands. Fourth edition. Moon Publications, Chico, CA.

Minnich, R.A. 1980. Vegetation of Santa Cruz and Santa Catalina Islands. Pp. 123-137 in D. M. Power, ed. The California islands: proceedings of a multidisciplinary symposium. Santa Barbara Museum of Natural History. Santa Barbara, CA.

O’Malley, P.G. 1991. Large-scale restoration on Santa Catalina Island, California. Restoration and Management Notes 9(1):715.

O'Malley, P.G. 1994. Animal husbandry on the three southernmost Channel Islands: a preliminary overview, 1820-1950. Pp. 157-164 in W. L. Halvorson and G. J. Maender, eds. The fourth California Islands symposium: update on the status of resources. Santa Barbara Museum of Natural History, Santa Barbara, CA..

Power, D.M. 1980. Introduction. Pp. 1-4 in D. M. Power, ed. The California islands: proceedings of a multidisciplinary symposium. Santa Barbara Museum of Natural History. Santa Barbara, CA.

Probert, A. 1982. Mining history, Santa Catalina Island, Los Angeles County, California. Pp. 485-493 in D. L. Fife and J. A. Minch, eds. Geology and mineral wealth of the California Transverse Ranges. South Coast Geological Society Annual and Guide Book Number 10. Los Angeles, CA. 
Propst, B., A.D. Propst, and E. Walker. 1975. Santa Catalina Island generalized vegetation map. Unpublished map. Santa Catalina Island Company, Avalon, CA

Roberts, F.M. 1995. Illustrated guide to the oaks of the southern Californian floristic province: the oaks of coastal southern California and northwestern Baja California, Mexico. F. M. Roberts Productions, Encinitas, CA.

Rowland, S.M. 1984. Geology of Santa Catalina Island. California Geology 37:239-251.
Sawyer, J.O. and T. Keeler-Wolf. 1995. A manual of California vegetation. California Native Plant Society, Sacramento, CA.

Thorne, R.F. 1967. A flora of Santa Catalina Island, California. Aliso 6:1-77.

Wilson, B. 1993. A manual of California native plants: the catalog of Las Pilitas Nursery, version 3.1. Las Pilitas Nursery, Santa Margarita, CA. 


\title{
Prescribed Burning Impacts on Late Successional Species
}

\author{
Peter A. Bowler and Richard E. Riefner, Jr. ${ }^{1}$ \\ Department of Ecology and Evolutionary Biology, Irvine, CA 92697-2525 \\ Tel. (714) 824-6006; Fax (714) 824-2181; email: pabowler@uci.edu
}

\begin{abstract}
Prescribed burning of coastal sage scrub is often proposed primarily to relieve fire hazard to human property from large fuel loads in old stands. Many academic researchers have made the point that prescribed burning may serve human ends but has little to no "benefit" to the habitat; most say just leave it alone. Westman suggested that the more open canopy of sage scrub could serve as a refuge for understory taxa excluded by closed canopy chaparral, and similarly old stands of coastal sage scrub act as refugia for late successional species such as lichens. In several papers we have recommended preserving old fire cycle stands to act as refuges and sites of inocula to perpetuate late successional lichens, many of which qualify for federal and state protection.
\end{abstract}

Keywords: Prescribed burning; coastal sage scrub; late successional species; lichens.

\section{Introduction}

The lichen flora of southern California is in decline due to many reasons including air pollution, habitat loss, as well as the effects of increasing isolation and reduction of lichen-rich stands in coastal sage scrub (Bowler and Riefner 1990; Bowler and Riefner 1995). These stands are old in terms of the fire cycle, allowing colonization by late successional flora such as lichens. Bratt (1987) documented species losses in fruticose lichens at Point Loma comparing historic with current species richness, and Herre (1936) called for the conservation of lichen habitat, which even then was being imperiled along the coast in a poignant paper entitled "Our Vanishing Lichen Flora." Herre described the loss to development of site after site in a diversity of coastal habitats with which he had direct botanical experience since 1912. While long distance dispersal in lichens occurs, it happens slowly over

${ }^{1}$ Present address: 17554 Vanderberg \#14, Tustin, CA 92680 a far longer time period than inter-fire cycle colonization. The dependency of lichen colonization and species richness upon mosaics of differing age class stands can be seen at age class burn interfaces, where lichens from old stands leak into the edges of adjacent younger (more recently burned) stands. This effect is particularly evident in exceptionally species-rich sites such as those along coastal northwestern Baja California, but occur throughout the sage scrub community. Lichens are notoriously patchy, so that not all old stands have good representations of them - thus underscoring the significance of those which do.

Sites like San Clemente Island where historic grazing effectively eliminated most corticolous substrates exhibit a depauperate corticolous flora (Bowler et al. 1996), and it is clear that a similar fate awaits late successional lichen species in southern California coastal sage scrub. Areas that have experienced large burns, such as the Laguna Beach fires of 1993 that created a 40,000 acre "lichen free" hole in distributions, will likely not recover historic lichen species richness. Prescribed burning of remnant lichen-rich old growth would eliminate near neighbor sources of inoculum, and realistically it is not likely that they will persist.

Local southern California floras are not well known, and it should be understood that saxicolous (rock inhabiting) and terricolous (soil dwelling) taxa also require local sources from which to draw for colonization. If these are lost, so is the species richness, though it may take many years for a species to actually perish, even in the face of a lack of recolonization. In a sense, death is incremental, and an isolated rock outcrop is like a fragment of a former constellation of subpopulations.

An example of a primarily saxicolous local flora in a maritime chaparral stand (Cneoridium dumosum, Salvia mellifera dominants) in Laguna Beach is presented below (Table 1). Maritime chaparral is itself a candidate threatened habitat. At this site 36 species of lichens were recorded, including a first record for southern California (Thelomma californicum; Riefner et al. 1995). 
Table 1. The lichen flora of an old stand of maritime chaparral in Laguna Beach. The site, known as Diamond Crestview, is a relict stand of Cneoridium dumosum, Salvia mellifera, Rhamnus crocea and other characteristic taxa. Voucher collections of nearly all of these taxa are in IRVC.

Acarospora obpallens (Nyl.) Zahlbr.

Acarospora schleicheri (Ach.) A. Massal.

Aspicilia sp.

Buellia halonia (Ach.) Tuck.

Buellia oidalea (Nyl.) Tuck.

Buellia retrovertens Tuck.

Caloplaca bolacina (Tuck.) Herre

Caloplaca luteominia (Tuc,) Zahlbr. var. luteominia

Caloplaca saxicola $(\mathrm{Hoffm}$.) Nordin

Chrysothrix candelaris (L.) J.R. Laundon

Cladonia fimbriata (L.) Fr.

Cladonia furcata (Hudson) Schrader

Cladonia macilenta Hoffm.

Cladonia sp.

Dimelaena radiata (Tuck.) Hale \& Culb.

Diploicia canescens (Dickson) A. Massal.

Diploschistes muscorum (Scop.) R. Sant. subsp. muscorum

Diploschistes scruposus (Schreber) Norman

Flavoparmelia caperata (L.) Hale

Flavopunctelia flaventior (Stirton) Hale

Lecania sp. Lecanora sp.

Lecanora caesiorubella Ach. ssp. merrillii Imshaug \& Brodo

Lecanora campestris (Schaerer) Hue

Lecanora muralis (Schreber) Rabenh

Lecanora varia (Hoffm.) Ach.

Lecidella stigmatea (Ach.) Hertel \& Leuckert

Leprocaulon microscopicum (Vill.) Gams ex D. Hawksw.

Leproloma membranaceum (Dickson) Vainio

Pertusaria sp.

Physconia sp.

Rinodina bolanderi H. Magn.

Thelomma californicum (Tuck.) Tibell

Thelomma mammosum (Hepp) A. Massal.

Trapeliopsis wallrothii (Florke) Hertel \& Gotth.

Xanthoparmelia mexicana (Gyelnik) Hale

Examples of late successional epiphytic taxa (Table 2) are such fruticose genera/species as Alectoria, Bryoria, Usnea, Ramalina, Ramalina lacera, Teloschistes exilis, Niebla ceruchis, - as well as many foliose species. $N$. ceruchoides and $N$. polymorpha (both saxicolous) are other species with limited occurrences in these coastal habitats. As Bowler and Reifner (1995) reported, conspicuous species present in historic lichen collections from sage scrub such as Ramalina lacera are now rare or extinct in southern California.

As Belsky (1996) and we have recommended (Bowler and Reifner, 1990; 1995), careful consideration needs to be made before prescribed burning is used, so that the natural mosaic of adjacent age classes is not lost. Different management strategies for forests have been documented to sustain different groups of species and have contributed to the decline of some species of epiphytic lichens. In Scandanavia the effects of modern forestry have been "disastrous" upon the lichen flora (Esseen et al. 1981). Esseen et al. (1981) demonstrated that the decline
Table 2. Late successional indicator species, most becoming increasingly rare, for soil, rock outcrop, and shrub habitats in coastal sage scrub habitats. This list is not comprehensive, they are merely indicator species. There are many other species also associated with and characteristic of such habitats.

\author{
Terricolous (soil dwelling) \\ Acarospora thelococcoides (Nyl.) Zahlbr. \\ Cladonia thiersii S. Hammer \\ Endocarpon subnitescens Nyl. \\ Mobergia calculiformis (W.A. Weber) H. Mayrh. \& Sheard
}

\author{
Saxicolous (rock outcrops) \\ Cypheliuim brunneum W.A. Weber \\ Punctelia punctilla (Hale) Krog \\ Niebla ceruchoides Rundel \& Bowler \\ Niebla polymorpha Bowler, Marsh, T. Nash, \& Riefner \\ Xanthoparmelia angustiphylla (Gyelnik) Hale
}

\author{
Corticolous (shrub inhabiting) \\ Heterodermia erinacea (Ach.) W.A. Weber \\ Heterodermia cf. galactophylla (Tuck.) Culb. \\ Niebla cephalota (Tuck.) Rundel \& Bowler \\ Niebla cerurhis (Ach.) Rundel \& Bowler \\ Ramalina lacera (With.) J.R. Laundon \\ Schizopelte californica Th. Fr. \\ Teloschistes culifornicus Sipman \\ Teloschistes exilis (Michaux) Vainio \\ Trichoramalina crinita (Tuck.) Rundel \& Bowler \\ Xanthoria ramulosa (Tuck.) Herre
}

of Usnea longissima, confined to spruce forests and "regarded as a symbol of virgin forests" (an indicator species) in central Sweden, was caused primarily by forest management practices. This altered specific habitat demands and reduced reproductive success in a species which has low dispersal ability and is very sensitive to environmental disturbances. Esseen et al. (1981) note that forestry has caused one macrolichen, Erioderma pedicellatum, to vanish from Scandinavia.

There is a direct parallel with human manipulation of mediterranean shrubland communities. Many academic researchers question the need and rational for prescribed burning sage scrub, and dispute the concept of "senescent stands" (Zedler, 1995) "needing burning" for ecological or other reasons. Fuel modification by removal of canopy plants in lichen rich sites such as Buck Gully in Irvine, California, and postfire hydroseeding on soil and rock are additional fire-related anthropogenic practices that damage lichen communities (Bowler 1995). If old stands that have rich lichen and other epiphyte floras (not all do) are burned to reduce fuel loads, there will be no near neighbor source from which recolonization could originate. If colonization is dependent upon long distance dispersal alone, species richness will be dramatically reduced in a short time period. While air pollution does have a significant contribution in reducing species richness of lichens in many areas of California, as has been noted since Herre's (1936) times, direct loss of habitat has had an enormous impact and is the primary contributor to the dimin- 
ishment of the lichen flora. Relict pockets of old growth sage scrub, which are "dripping" with lichens, still occur but with increasingly rarity. The presence of these remnant micro-sites suggests that habitat loss, including old growth stands, plays a strong role in local species losses - whatever the background of air pollution may or may not be. The magnitude of habitat loss, including disruption of fire cycles and historic survival of old growth sage scrub stands, far outweighs air pollution impacts in many areas along coastal southern California. There may be a synergism between these two contributors to lichen decline in terms of slowing the extent of recolonization after fires.

\section{Conclusion}

As habitat becomes more and more reduced in southern California, prescribed burning concepts should not disregard historic age class mosaics and the absolute dependency of late successional species like lichens upon them. Lichen rich stands should be identified, valued for their ecological significance, and protected. Mapping projects identifying the overall distribution and older stands rich in both epiphytic and terricolous lichens should be undertaken for conservation purposes, similar to those, in Switzerland (Clerc and Scheidegger 1990) and in other European countries. If these stands are sacrificed for anthropogenic purposes, there is little likelihood of even eventual recovery of species richness. Burning such sites contributes to the endangerment of now rare taxa and guarantees local extinctions and continued loss of species in southern California.

Acknowledgments. The University of California Natural Reserve System provided computer support for the project, which was sponsored in part by a grant from the Transportation Corridor Agencies.

\section{Literature Cited}

Belsky, J. 1996. Wild and prescribed fire in forests of the intermountain west. Wild Earth 6(3):44-45.

Bowler, P.A. 1991. The challenge of living with growth in a healthy environment. Crossosoma 17(3):1-10.

Bowler, P.A. 1995. Impact of postfire hydroseeding on sensitive plant communities in Laguna Canyon, California. Pp. 193194 in Keeley, J.E. and T. Scott, eds. Brushfires in California wildlands: ecology and resource management. International Association of Wildland Fire, Fairfield, WA.
Bowler, P.A. and R. E. Riefner, Jr.. 1990. A preliminary lichen checklist for the University of California, Irvine, campus and the San Joaquin wetlands. Crossosoma 16(6):1-10.

Bowler,P.A. and R.E. Riefner,Jr. 1995. Notes on the Ramalinaceae and current related research in California, U.S.A. Bulletin of the California Lichen Society 2(1):1-5.

Bowler, P.A., W.A. Weber, and R.E. Riefner, Jr. 1996. A checklist of the lichens of San Clemente Island, California. Bulletin of the California Lichen Society 3(2):1-8.

Bratt, C. 1987. Point Loma lichens - now and then. Pp. 289-293 in T.S. Elias, ed. Conservation and management of rare and endangered plants. California Native Plant Society, Sacramento, $\mathrm{CA}$.

Clerc, P. and C. Scheidegger. 1990. Lichen mapping in Switzerland: The lichens of the plateau and the prealps. Stuttgarter Beitr. Naturk. Ser. A, Nr. 456:73-77.

Esseen,P.-A.,L. Ericson, H. Lindstrom, and O.Zackrisson. 1981. Occurrence and ecology of Usnea longissima in central Sweden. Lichenologist 13: 177-190.

Herre, A.W.C.T. 1936. Our vanishing lichen flora. Madroño 3:198-200.

Riefner, R.E., Jr., P.A. Bowler, and B. D. Ryan. 1995. New and interesting records of lichens from California. Bulletin of the California Lichen Society 2(2):1-11.

Zedler, P.H. 1995. Firc frequency in southern California shrublands: biological effects and management options. Pp. 101-112 in J.E. Keeley and T. Scott, eds. Brushfires in California wildlands: ecology and resource management. International Association of Wildland Fire, Fairfield, WA. 


\title{
Effective Fire Planning for California Native Grasslands
}

\author{
Robin Wills \\ The Nature Conservancy, 13700 Monte Visata, Lake Elsinore, CA 92530 \\ Tel. (909) 609-0367; Fax (909) 609-0397; e-mail: fdog@gnn.com
}

\begin{abstract}
Effects of up to three successive spring and fall burns on composition and biomass of grasslands of the Santa Rosa Plateau Ecological Reserve were evaluated. Spring burns were found to reduce the number and biomass of alien grasses and some native forbs, while increasing the biomass of native grasses. Fall burns resulted in an increase of biomass of alien grasses. Effects of burn events were not maintained in the absence of fire. Results from burn treatment observations are incorporated into a planning model for longterm fire management of the Reserve.
\end{abstract}

Keywords: Alien grasses; biomass; fire; native forbs; native grasses; planning model; Santa Rosa Plateau Ecological Reserve.

\section{Introduction}

The Santa Rosa Plateau Ecological Reserve, located in southwestern Riverside County, encompasses nearly 3200 hectares. A rich mosaic of vegetation types exist within the reserve boundary. Rare species are abundant, as are excellent examples of upland bunchgrass prairies, oak savannas, riparian woodlands, coastal sage scrub and mixed chaparral vegetation types. With a significant component of native species, bunchgrass prairie communities have become a focus for conservation and management. Broad goals for this community include, maintaining a high diversity of native plant species, minimizing the cover of non-native grasses and protecting structural variables important for associated target species.

Little is known of the pre-European grasslands of California. Many of these grasslands are now dominated by species native to the Mediterranean Basin (Wester 1981). Prior adaptation to grazing by livestock has favored alien species in the replacement of native grasses and forbs (Barry 1972; Jackson 1985; MacDonald et al. 1988). Many authors consider Nassella pulchra to have been the dominant species in valley grasslands, prior to European settlement (Clements 1920; Heady 1977). Bartolome and Gemmill (1981) suggested that $N$. pulchra is the most common California native grass, not because the species dominated the original California grassland, but because it is favored by disturbance common now. In either case, Cali- fornia grasslands have apparently changed dramatically in terms of their composition and structure. Large numbers of exotic plant species appear to have arrived in California even before the period of Spanish influence (Heady 1977).

Similarly, little is known of the historic role of fire in the evolution of California native grasslands (Wright and Bailey 1982). Heady (1972) suggested that fire was important in the evolutionary history of the community, a conclusion supported by the observed fire tolerance of $\mathrm{N}$. pulchra (Wright and Bailey 1982), Muhlenbergia rigens (Lathrop and Martin 1982), and other native perennial species. There is abundant evidence that protection of grasslands from burning, for even a few years, results in accumulation of much litter and reduced productivity (Hadley and Kiekhefer 1963; Rice and Parents 1978; Wilson and Shay 1990).

Several authors have examined the impacts of fire frequency and seasonality upon species richness in California grasslands. It has been reported that fire increases the number of species over preburn conditions (Hansen 1986; Parsons and Stohlgren 1989). Repeated burns both decreased the relative dominance of introduced grasses and increased the diversity and dominance of native and alien forbs (Vogl 1974; Parsons and Stohlgren 1989). Parsons and Stohlgren (1989) also indicated that neither single nor repeated fall or spring burns resulted in the establishment of additional species of native grasses.

The stewardship challenge of protecting these communities and species into the future has led us to investigate a variety of management techniques. The use of fire as a management tool for species and communities is decades old (Biswell 1989). More recently, the use of fire to restore ecological communities has been increasing (e.g., Hastings and DiTomaso 1996). Historic records of periodic fire, together with contemporary evidence that the frequency and season of fire can influence species composition and production in grasslands (Parsons 1981; Bancroft et al 1985) led us to test the effects of varying fire regimes on species composition and structure.

Experiments on the Santa Rosa Plateau Ecological Reserve, investigated the effects of frequency and season of burning on the relative composition and dominance of 
native and alien species. Results indicate a complex and varying response to both season and frequency of burns. Though spring burning elicited a positive response from native perennial grass along with a reduction in the biomass of non-native annuals, biomass and cover of some native forbs were also reduced (Wills, unpublished data). Frequency of burns also complicates management decisions. Short return intervals are successful in reducing nonnative cover and thatch build up, but may also negatively affect the response of native forbs. The clear management challenge lies in developing a long term approach to applying prescribed fire to the landscapc. This method must avoid a focus on possible central tendencies and strive to capture the variability defining the regime. Our efforts to avoid a deterministic approach to fire management has resulted in an experimental planning model. The model, presented here, attempts to inject some stochasticity in landscape fire planning. Implemented in 1997, our program is currently under evaluation on the reserve.

\section{Methods}

Previous data collection efforts on the reserve have provided the basis for a fire planning model. In replicated $10 \mathrm{~m} \times 10 \mathrm{~m}$ plots, the effect of seven fire treatments were investigated. The influence of varying season and frequency of fire on biomass and species richness were quantified. Treatments included a single fall burn (1993), two successive fall burns (1993 and 1994), three successive fall burns (1993,1994 and 1995), a single spring burn (1993) two successive spring burns (1993 and 1994), three successive spring burns $(1993,1994$ and 1995), and unburned controls. Fall burns were conducted in late October or early November. Spring burns were carried out in late May or early June. These plots are continuing to be monitored with additional treatments of 5,8 and 10 year return intervals.

Results from the seasonal and frequency treatments were then used to weigh possible management burn prescriptions. Season of burn and return intervals were ranked, based on their likelihood of meeting management goals. Weighted treatments were organized in a table that is used to select when individual units are to be treated with prescribed fire.

\section{Results}

A pair of 1000 value tables were developed to select when a given prescribed burn unit would be treated with fire (Table 1). Each cell represents a season of burn and the number of years since the unit was previously treated. Two tables were developed for grasslands. One for units with a heavy infestation of non-native grasses and one for units with a dominance of native species.
The cell values were determined through a weighted random process. Season of burn appears in the table based on the percentage of native species responding positively to a given season. For grasslands with extensive cover of non-native, cool season, annual grasses ( $>50 \%), 84 \%$ of the cells call for spring burns, $12 \%$ for fall burns and $6 \%$ for winter burns. For units with less then $50 \%$ cover, $62 \%$ of the cells call for spring burns, $34 \%$ for fall burns and $2 \%$ for winter burns.

Frequency occurs in the tables based on a mean fire rotation of six years. During any six year period an approximate equivalent of all the grassland area on the reserve will burn. Any given area may burn repeatedly or not at all. For units with extensive cover of non-native grass, $70 \%$ of the cell values call for return intervals of one to six years. The remaining cells call for values between seven and twelve years. For grassland units with less than a $50 \%$ cover of non-native grasses, $40 \%$ of the cell values call for return intervals between 1 and 6 years with the remaining $60 \%$ between 7 and 12 years.

\section{Discussion}

Currently, two tables have been developed for grasslands of the Plateau. One table is used for grasslands with heavy infestations of non-native grasses and one for grasslands with a dominance of native grasses and forbs. Return intervals for the first table are weighted towards spring burning on shorter return intervals. As units are treated with prescribed fire they may quickly change in terms of which table is used for fire planning.

Once the appropriate table is selected, the season and return interval may be generated for individuals units. To determine the first return interval and season for a unit, the table is used like a standard random-numbers table. Subsequent burns are planned in the same way, keeping in mind that the table used may change.

The schedule generated is only a guide. Seasons are phenologically driven and appropriate timing must be determined given the current conditions. Also, other management issues and objectives may require a deviation from the generated schedule.

Following the generation of three burn schedules for each unit on the reserve, the next 16 years of burning have been scheduled. Six year periods are examined to be sure area approximating the equivalent of all grasslands on the reserve are being burned. In all cases, with the exception of the period 2001-2007, this assumption is met. During the period of 2001-2007 two burn units were eliminated from the schedule. Burn schedules will also be adjusted for area consumed in wildfires.

Implementation of the planning model began in 1991. A monitoring program has also been implemented to try to quantify the long term effects of this prescribed fire program. Table 2 outlines the multi-trophic levels being 
Table 1. Weighted random numbers table used to determine fire return intervals for non-nativedominated grasslands. W=winter, $\mathrm{S}=\mathrm{spring}$, $\mathrm{F}=$ fall, Numbers $=\mathrm{years}$ since last burned

\begin{tabular}{|c|c|c|c|c|c|c|c|c|c|c|c|c|c|c|c|c|c|c|c|}
\hline S5 & S6 & F7 & S7 & S9 & S2 & F2 & S3 & S4 & F3 & S1 & F10 & F2 & $\mathrm{S} 10$ & S1 & S1 & F9 & S4 & F3 & F2 \\
\hline F8 & F4 & S10 & S6 & F8 & S6 & S10 & S9 & F8 & S2 & S3 & S9 & S4 & S5 & S2 & S2 & S9 & S6 & S11 & S5 \\
\hline $\mathrm{F} 2$ & S9 & F8 & S7 & S8 & S5 & w9 & S9 & S9 & $\mathrm{S} 10$ & S8 & S2 & F4 & S3 & S1 & S3 & F9 & F3 & S3 & S8 \\
\hline S10 & S11 & S1 & S9 & S1 & S2 & $\mathrm{S} 12$ & S6 & S10 & F2 & S9 & S5 & S4 & S2 & S3 & S10 & S5 & F10 & F3 & S2 \\
\hline S6 & S5 & $\mathrm{S} 12$ & F8 & S4 & S4 & S4 & S7 & S4 & S5 & S1 & S4 & S5 & S1 & S7 & S1 & F2 & F5 & F4 & F2 \\
\hline S1 & F1 & $\mathrm{S} 12$ & s6 & S9 & S2 & S2 & F1 & S2 & S2 & S2 & S2 & F1 & S9 & S3 & $\mathrm{S} 10$ & S2 & F3 & S3 & S2 \\
\hline S1 & S1 & S2 & S11 & S1 & S2 & S8 & S3 & F4 & $\mathrm{S} 12$ & F2 & F7 & S10 & S7 & F5 & F8 & S2 & S3 & S3 & F2 \\
\hline S4 & F9 & F8 & S9 & S3 & F2 & S4 & F9 & S3 & S4 & F5 & S3 & S6 & $\mathrm{S} 12$ & S4 & S3 & F9 & F10 & S1 & S5 \\
\hline $\mathrm{F} 2$ & S2 & S1 & $\mathrm{S} 2$ & $\mathrm{~S} 12$ & F5 & W12 & S2 & S2 & S3 & F10 & S2 & S2 & F3 & F12 & S4 & S3 & S4 & S3 & F2 \\
\hline F12 & F5 & $\mathrm{F} 2$ & S2 & F4 & F6 & S1 & F3 & S1 & F2 & S1 & S3 & F1 & S2 & S1 & $\mathrm{S} 2$ & F2 & S11 & F3 & F2 \\
\hline F8 & F8 & S4 & S3 & S1 & S5 & S3 & S11 & $\mathrm{S} 10$ & F10 & S2 & S1 & S11 & W10 & S3 & S4 & S3 & S2 & S3 & S11 \\
\hline S8 & F11 & S1 & F5 & F7 & S2 & S1 & F3 & $\mathrm{S} 2$ & F1 & S6 & S5 & S7 & S7 & $\mathrm{S} 12$ & S7 & S7 & F4 & S1 & S8 \\
\hline S9 & F4 & S11 & S2 & S4 & S2 & S3 & S9 & S2 & S9 & S1 & F5 & F6 & S9 & S6 & S4 & S2 & F5 & S3 & F3 \\
\hline S10 & S4 & S1 & F2 & S9 & S1 & F8 & S3 & S1 & F3 & S3 & S1 & S5 & S2 & S2 & S3 & F2 & S1 & S5 & S6 \\
\hline S5 & S2 & S2 & $\mathrm{F} 2$ & S2 & F1 & F4 & S2 & S2 & S9 & F3 & F8 & F2 & S2 & S3 & F1 & F7 & F2 & F2 & S2 \\
\hline F2 & S2 & F7 & S7 & S2 & F6 & F3 & S8 & S2 & S9 & F2 & S7 & $\mathrm{S} 12$ & S2 & F2 & F3 & S3 & F6 & S1 & S5 \\
\hline s6 & F11 & S3 & S11 & S3 & S2 & S3 & F11 & S4 & S5 & S1 & S8 & F2 & S1 & S2 & S10 & S8 & F11 & F10 & S2 \\
\hline S9 & F9 & F8 & S9 & S2 & S1 & F3 & S4 & S2 & F1 & F2 & F3 & $\mathrm{S} 10$ & F1 & S1 & F3 & S1 & F3 & S9 & S1 \\
\hline S10 & S8 & S9 & S6 & S5 & S2 & S3 & S4 & S1 & S1 & S3 & $\mathrm{F} 2$ & F6 & S3 & S2 & S9 & S6 & S3 & S3 & S2 \\
\hline S1 & F12 & F10 & S11 & S6 & $\mathrm{S} 10$ & S3 & S2 & $\mathrm{S} 12$ & F1 & S2 & S9 & S3 & F1 & $\mathrm{S} 10$ & S6 & F2 & S11 & S1 & S5 \\
\hline S4 & S1 & S1 & S9 & S4 & $\mathrm{S} 2$ & S4 & F2 & $\mathrm{S} 10$ & S5 & F2 & F10 & S5 & S6 & S3 & F2 & S5 & S3 & F2 & S5 \\
\hline S4 & S6 & S9 & S5 & S6 & F2 & S5 & S5 & S2 & F7 & S6 & S7 & S6 & S2 & F2 & F12 & S4 & S6 & F9 & S2 \\
\hline S5 & $\mathrm{S} 12$ & S6 & S8 & S7 & S1 & F11 & S9 & S9 & F1 & S9 & $\mathrm{F} 2$ & S4 & F1 & S8 & F4 & F3 & F6 & F5 & F3 \\
\hline S.5 & F9 & F2 & F8 & S4 & F8 & $\mathrm{S} 4$ & S6 & S1 & F.3 & S9 & F.3 & S7 & F.3 & S6 & S8 & S9 & F8 & S8 & S7 \\
\hline S11 & W12 & S9 & F2 & S7 & S8 & S7 & S11 & S7 & S9 & F4 & S6 & S5 & S4 & F5 & S3 & S2 & F2 & S9 & S1 \\
\hline S5 & F11 & F4 & S4 & F5 & w3 & S4 & F3 & F5 & W10 & S3 & F2 & $\mathrm{S} 12$ & S4 & $\mathrm{S} 10$ & S5 & S2 & S3 & F9 & S7 \\
\hline $\mathrm{S} 12$ & F2 & S1 & $\mathrm{S} 2$ & S8 & $\mathrm{S} 10$ & S1 & F2 & F11 & S1 & S2 & W12 & S3 & F3 & S9 & S1 & F11 & S11 & F2 & S4 \\
\hline S8 & F9 & S3 & F9 & S9 & S2 & $\mathrm{S} 12$ & S9 & S1 & S6 & S8 & $\mathrm{S} 10$ & S6 & F1 & S6 & F3 & $\mathrm{S} 12$ & S4 & F3 & S2 \\
\hline S3 & F8 & S4 & F2 & S3 & S4 & F2 & F3 & S2 & F1 & F2 & S1 & S2 & F3 & S2 & S10 & W9 & F3 & F11 & S9 \\
\hline S4 & S3 & S9 & $\mathrm{S} 2$ & S2 & S6 & S2 & F9 & S6 & S3 & S2 & S3 & S3 & S9 & S3 & S8 & S2 & S3 & S6 & F7 \\
\hline S3 & $\mathrm{S} 12$ & S9 & S2 & S2 & S2 & W9 & F2 & F7 & F11 & S7 & S2 & S11 & S1 & S1 & S2 & S2 & S2 & F2 & S4 \\
\hline F4 & S7 & F10 & S2 & S2 & S1 & S2 & S3 & S1 & S6 & S6 & S10 & F3 & F1 & S4 & S5 & F2 & W12 & S5 & S3 \\
\hline S1 & $\mathrm{S} 10$ & S6 & S9 & F4 & S2 & S10 & S5 & S1 & F3 & S1 & F8 & S2 & $\mathrm{S} 10$ & S5 & S2 & $\mathrm{S} 10$ & F8 & F12 & S9 \\
\hline S9 & S5 & $\mathrm{S} 10$ & S9 & S7 & S8 & S10 & F3 & S6 & S2 & S3 & S9 & S10 & S6 & S9 & S6 & S3 & S10 & S2 & S2 \\
\hline Si0 & S8 & S1 & F9 & SI & S2 & F8 & S4 & $\mathrm{F} 2$ & S3 & S3 & F3 & S9 & S2 & S6 & s6 & S3 & F4 & S9 & S3 \\
\hline S11 & S3 & F2 & S3 & F2 & S2 & F11 & S2 & S2 & S9 & F5 & S1 & S1 & F3 & F5 & S1 & S2 & F3 & F11 & S3 \\
\hline S4 & $\mathrm{F} 2$ & S11 & S4 & F12 & F5 & S3 & F4 & $\mathrm{S} 12$ & S1 & S3 & S3 & S5 & F1 & F6 & S5 & F12 & S12 & F3 & $\mathrm{S} 12$ \\
\hline F8 & S4 & S4 & S9 & S4 & S5 & S2 & S5 & S6 & S11 & S3 & S12 & S8 & S3 & S6 & S9 & F1 & F4 & S6 & S3 \\
\hline S9 & F5 & S3 & S3 & F2 & $\mathrm{S} 10$ & F6 & S9 & S3 & S4 & S4 & F2 & S4 & S6 & S5 & S4 & F5 & S4 & S5 & S6 \\
\hline S9 & F11 & S1 & F2 & S8 & S5 & $\mathrm{S} 10$ & S3 & S10 & S3 & S2 & S1 & S5 & F7 & F11 & S10 & S2 & S10 & F7 & S2 \\
\hline S1 & S7 & S2 & F1 & S3 & S4 & S4 & S3 & S7 & W7 & S11 & S2 & S1 & F1 & S1 & S9 & S1 & F5 & S11 & S4 \\
\hline S10 & S1 & S7 & F9 & S7 & S8 & S10 & S4 & S4 & S11 & S1 & S5 & F2 & S2 & S1 & S11 & S3 & F2 & S7 & S8 \\
\hline S7 & S6 & F10 & S5 & F5 & S3 & W9 & F4 & S3 & S3 & F8 & S4 & S4 & S1 & S3 & S6 & W9 & F3 & F7 & W10 \\
\hline S5 & $\mathrm{S} 1$ & S6 & S9 & S7 & S2 & F3 & W11 & F3 & S9 & F2 & W4 & S1 & S3 & F11 & F3 & S3 & S4 & S9 & S6 \\
\hline S12 & S2 & S4 & S5 & F7 & S9 & S9 & F3 & S5 & S6 & S6 & S3 & S7 & F3 & \$3 & S2 & S6 & F3 & S5 & S4 \\
\hline S9 & S6 & S9 & S3 & S4 & S4 & S9 & S5 & S8 & S5 & S8 & S7 & S9 & S1 & S6 & $\mathrm{S} 10$ & S11 & $\mathrm{S} 12$ & S2 & S1 \\
\hline F2 & F5 & S4 & $\mathrm{S} 12$ & F11 & S5 & $\mathrm{S} 12$ & S2 & F2 & S2 & S2 & S8 & S1 & S12 & F11 & S3 & F12 & F3 & S3 & S1 \\
\hline S5 & S2 & S1 & S5 & s6 & S6 & F8 & S7 & S5 & S1 & S1 & S2 & S1 & S3 & S5 & S2 & F6 & S2 & S11 & S3 \\
\hline $\mathrm{F} 2$ & S7 & S1 & w9 & F2 & S5 & S10 & F3 & $\mathrm{S} 10$ & S2 & F3 & S11 & F3 & S5 & S3 & S3 & F5 & F8 & S3 & S7 \\
\hline S9 & F12 & F10 & S7 & F6 & S9 & S4 & S11 & S4 & F12 & S9 & S1 & F6 & S7 & S3 & F3 & F10 & F3 & S8 & S3 \\
\hline
\end{tabular}

proposed for monitoring. Nested plots including systematic sampling of all the taxa included in Table 2 are replicated and distributed throughout grasslands in the reserve. Unburned controls are also maintained.

Due to varying fire histories, this study utilizes a Optima Before/After: Control/Impact design (Green 1979). Long term permanent plots, with controlled treatments will still be maintained.

\section{Conclusion}

An opportunity to implement successful fire management on the Santa Rosa Plateau is driven, in part, by the high quality pre-treatment conditions of the reserve's plant communities. Highly degraded grasslands are not likely to respond positively to the program outlined here. Although grasslands are the current target, similar approaches to prescribed fire are planned for the coastal sage 
Table 2. Monitoring targets for measuring success.

\begin{tabular}{ll}
\hline Taxa & Sampling targets \\
\hline $\begin{array}{l}\text { vegetation } \\
\text { small mammals }\end{array}$ & $\begin{array}{l}\text { composition, structure } \\
\text { resilience, species } \\
\text { diversity, abundance } \\
\text { species diversity, } \\
\text { abundance, habitat use } \\
\text { population dynamics, } \\
\text { species diversity, abundance }\end{array}$ \\
herps & stream flow, sediment transport \\
\hline
\end{tabular}

scrub and chaparral communities. Still, the long term impacts of prescribed fire remain unknown. The program being implemented on the reserve remains highly experimental. What we do know about fire, in these communities, is that the protection of the process and the variability associated with fire regimes may be much more important then fire events themselves. It is hoped that this program will yield significant data and improved methods for the long term protection of native species.

\section{Literature Cited}

Bancroft, L., T. Nichols, D. Parsons, D. Graber, B. Evison, and J. van Wagtendonk. 1985. Evolution ofthe natural fire management program at Sequoia and Kings Canyon National Parks. Pp. 174-180, in Proceedings, wilderness fire symposium. USDA Forest Service, General Technical Report INT-182.

Barry, W.J. 1972. California prairie ecosystem (Vol. 1.); the Central Valley prairie. California Department of Parks and Recreation, Sacramento, CA. 81p.

Bartolome, J.W. and B. Gemmill. 1981. The ecological status of Stipa pulchra (Poaceae) in California. Madrono. Vol 23:172184.

Biswell, H. 1989. Prescribed burning in California wildland vegetation management. University of California Press, Berkeley. $225 \mathrm{p}$.

Clements, F.E. 1920. Plant indicators. Carnegie Institute of Washington. Publication 290, Washington, D.C.

Green, R.H. 1979. Sampling design and statistical methods for environmental biologists. John Wiley \& Sons, New York, NY. 257 p.

Hadley, E.B. and B.J. Kiekhefer. 1963. Productivity of two prairie grasses in relation to fire frequency. Ecology 44:389-395.

Heady, H.F. 1972. Burning and the grasslands in California. Proceedings of the Tall limbers Fire Ecology Conference 12:97-107.

Heady, H.F. 1977. Valley grasslands. Pp. 491-514 in M.G. Barbour and J. Major, eds. Terrestrial vegetation of California. Wiley Interscience. New York, NY.

Hansen, R.B. 1986. The effects of fire and frequency on the grasslands species composition in California's Tulare Basin. M.S. thesis, California State University, Fresno, CA.

Hastings, M.S. and J.M. DiTomaso. 1996. Fire controls yellow star thistle in California rangelands. Restoration and Management Notes 14:124-128.
Jackson, L.E. 1985. Ecological origins of California's mediterranean grasses. Journal of Biogeography 12:349-361.

Lathrop, E.W. and B. Martin. 1982. Fire ecology of deergrass (Muhlenbergia rigens) in Cuyamaca Rancho State Park, California. Crossosoma 8(6): 1-10.

MacDonald, L.A., D.M. Graber, S. Debenodetti, R.H. Groves, and E.R. Fuentes. 1988. Introduced species in nature reserves in mediterranean-type climate regions of the world. Biological Conservation 44:37-66.

Parsons D.J. 1981. The historical role of fire in the foothill communitics of Scquoia National Park. Madrono 28:112120.

Parsons D.J. and T.J. Stohlgren. 1989. Effects of varying fire regimes on annual grasslands in the southern Sierra Nevada of California. Madrono 36:154-168.

Rice, E.L. and R.L. Parents 1978. Causes of decreases in productivity in undisturbed tall grass prairie. American Journal of Botany 65:1091-1097.

Vogl, R.J. 1974. Effects of fire on grasslands. Pp. 139-194, in T.T. Kozlowski and E.E. Ahlgren, eds. Fire and ecosystems, Academic press, New York, NY.

Wester, L. 1981. Composition of native grasslands in the San Joaquin Vallcy, California. Madrono 28:231-241.

Wilson, S.D. and J.M. Shay. 1990. Competition, fire and nutrients in a mixedgrass prairie. Ecology 71:1959-1967.

Wright, H.A. and A.W. Bailey. 1982. Fire ecology- United States and Canada. John Wiley \& Sons, New York, NY. 


\title{
Post-Fire Recruitment of Yucca brevifolia and Yucca schidigera in Joshua Tree National Park, California
}

\author{
Michael E. Loik ${ }^{1}$, Christine D. St. Onge ${ }^{1}$, and Jane Rogers ${ }^{2}$

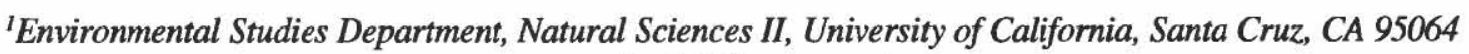 \\ email: mloik@cats.ucsc.edu \\ ${ }^{2}$ Joshua Tree National Park, Twentynine Palms, CA 92277 \\ Tel. (716) 367-4528; Fax (716) 367-4528
}

\begin{abstract}
Abiotic stresses of the environment, such as thermal extremes and drought, limit the successful recruitment of seedlings in desert ecosystems. In the Mojave Desert of California, fire can burn individual trees or shrubs, or can be carried over thousands of hectares, depending on fuel load. In regions experiencing an increase in human population size, fire frequency may also be increasing. Little is known about the post-fire recruitment of certain Mojave Desert plant species, which is important for management practices by local, state, and federal agencies. We examined root-crown sprouting and seedling establishment for plant species of the Joshua tree-piñonjuniper community 1.5 years following a lightning-strike fire at Lower Covington Flats, in Joshua Tree National Park, CA. Fire denuded vegetation on the valley floor but left some surviving plants on the adjacent slopes. Rootcrown sprouting was exhibited by several species, whereas no perennial seedling establishment since the time of the fire was apparent. Joshua trees (Yucca brevifolia) exhibited low rates of canopy survival yet $28 \%$ of burned trees had sprouts growing from the root-crown. All burned individuals of Yucca schidigera exhibited root-crown sprouting with a mean of 6.2 new rosettes per burned snag. Adjacent reference (non-burned) sites were dominated by Coleogyne ramosissima, a fire-prone shrub, which also appears to be the nurse-plant species for Yucca brevifolia (and other species). A fire chronosequence in the park suggests that root-crown sprouting for Joshua trees may be a viable alternative for post-fire recruitment, especially because it may take some time for the successional return of its nurse plant species.
\end{abstract}

Keywords: Fire; nurse plants; root-crown sprouting; seedling establishment; succession.

\section{Introduction}

Human population size has dramatically increased in the Mojave Desert of southern California, especially adjacent to the greater Los Angeles area. Expansion of commuter and retirement satellites (including Palmdale, Victorville, Joshua Tree, and Twentynine Palms, CA), has resulted in a $15 \%$ increase in human population size during the 1990s for certain regions (Anonymous). Coupled with other factors such as grazing practices (Gosz and Gosz 1996), fire management policy (Fule et al. 1997), and invasion by exotic species (Knapp 1992), increasing human populations may be influencing anthropogenic fire frequency in desert ecosystems. Changes in fire frequency and intensity due to increasing human populations will cause changes in ecosystem structure and function, altering the ecosystem services provided by the Mojave Desert (Smith et al. 1997; Tilman 1997).

The high desert of southern California is dominated at lower elevations $(<1500 \mathrm{~m})$ by Larrea tridentata - Ambrosia dumosa assemblages. At intermediate elevations $(1200$ to $1800 \mathrm{~m})$, Joshua tree woodland occurs, intergrading at higher elevations $(>1800 \mathrm{~m})$ into communities dominated by Coleogyne ramosissima, Juniperus californica, and Pinus monophylla (Vasek and Barbour 1988). The geographic distribution of Yucca brevifolia is coincident with the distribution of the Mojave Desert (Schoenherr 1992; Hickman 1993), yet in areas of high human populations Joshua trees appear to be experiencing decreasing population size due to human construction and development (Vasek and Barbour 1988; Cornett 1991). The distribution of plant species is determined by the balance of recruitment and mortality, which is related to responses to abiotic factors, including thermal extremes and drought (Nobel 1980). However, little is known about the effect of fire as an abiotic selective pressure during recruitment for plant species in Joshua tree-piñon-juniper woodlands of the Mojave Desert. 
Post-fire plant recruitment can occur by seedling establishment, or by root crown sprouting (or both) in a species-specific manner (Keeley 1992). For many desert species, successful seedling establishment occurs in years of suitable rainfall and temperature (Nobel 1992). Also, the presence of nurse plants may facilitate the microclimate adjacent to the soil surface (Franco and Nobel 1988, 1989), and may provide protection from seed predation and herbivory of young plants (Vander Wall 1997; Price and Joyner 1997) thereby enhancing the probability of successful seedling recruitment. In burned sites, seedling establishment may be limited by a lack of facilitation be cause nurse plants are absent, leaving an unfavorable microsite for seedling establishment (Lamont et al. 1993).

Knowledge of the manner in which plants recruit following fire is important for resource management by the National Park Service (Parsons 1996). The present study at Joshua Tree National Park, California was initiated to: (1) establish long-term monitoring sites to examine postfire recruitment and succession in Joshua tree-piñon-juniper woodlands, (2) assess the relative importance of seedling recruitment and root-crown sprouting for $Y u c c a$ brevifolia and $Y$. schidigera, two important species, and (3) determine the likely nurse-plant species for seedling recruitment of Yucca brevifolia and $Y$. schidigera. In particular, we examined species composition and species-specific differences in plant recruitment one year following a 2,025 ha fire that occurred in July 1995 at Lower Covington Flats. In addition, tree height and trunk thickness were measured as proxies for the age of Yucca brevifolia trees over a chronosequence to further examine post-fire recruitment for this Mojave Desert endemic species.

\section{Materials and Methods}

Long-term monitoring sites were established in 1996 in the valley at Lower Covington Flats, Joshua Tree National Park, California (34 01'39"N 116 $16^{\circ} 45^{\prime \prime} \mathrm{W}$ elev $=1426 \mathrm{~m}$ ). The valley is approximately $1 \mathrm{~km}$ wide in the east-west direction, and about $5 \mathrm{~km}$ long in a northwestsoutheast direction. The study included sites on the valley floor and on the adjacent slopes. In July 1995, a fire was started by a lightning strike at the southern end of the valley, burned on the valley floor in a northwesterly direction, and resulted in a total burned area of 2,025 ha.

Three $30 \mathrm{~m}$ long line transects were placed at six randomly selected sites located within the area burned. Six transects were also placed on an adjacent non-burned eastfacing slope, and on a section of unburned valley floor (to act as reference sites). The latitude, longitude, and elevation of each was recorded with a Magellan ProMark $X$ GPS unit (with $1 \mathrm{~m}$ accuracy following differential processing) to facilitate finding transects in the future.
Relative cover and frequency for each species was determined for each transect using a point intercept technique. An intercept was placed every $30 \mathrm{~cm}$ along each of the $30 \mathrm{~m}$ transects, the species were recorded, and the height of the canopy was measured at the point of interception. Relative cover and frequency were computed using software developed by the National Park Service for monitoring responses to fire in western ecosystems (Western Region Prescribed and Natural Fire Monitoring Task Force 1992). Data for all transects were pooled and compared by location (valley floor versus slope) and condition (burned versus non-burned sites).

To assess species-specific patterns of post-fire reproductive strategies, post-fire root-crown sprouting of burned adult plants of Yucca brevifolia and $Y$. schidigera was surveyed in burned sites. Root-crown sprouting was counted based on new green growth at the base of burned snags for five $1000 \mathrm{~m} 2$ belt transects. Seedling recruitment was assessed using detailed searches within the canopy of adult shrubs and grasses in five $1000 \mathrm{~m}^{2}$ belt transects in burned and non-burned sites.

In order to further describe post-fire survival and recruitment of Yucca brevifolia, we examined tree size for a chronosequence of fire sites at Joshua Tree National Park. Five sites of different ages (based on time since fire) were selected using a historical fire record map. Measurements were made at the following fire sites: Lost Horse (burned in 1968); Covington Flats (1978); Old Man Hidden Valley (1984); Lost Horse Mine (1987); and Lower Covington Flats (1995). Each site was selected such that there was no overlap with previous or subsequent fires. For each site, all individuals of Yucca brevifolia were identified and classified according to whether they were found growing from within the canopy of a nurse plant, growing independent of nurse plants, or if they had survived the fire (based upon fire scars on the trunk). The height and diameter at the base was measured for each tree in each class. Basal diameter was measured instead of diameter at breast height $(\mathrm{DBH})$ because plants growing from within the canopy of nurse plants were usually not tall enough for DBH measurements. Tree height was directly measured with a measuring tape, or calculated using a rangefinder.

\section{Results}

One year following the 2,025 ha fire at Lower Covington Flats, we observed that fire had essentially denuded the valley floor, and removed considerable amounts of vegetation from the adjacent slopes (Tables 1 and 2). The valley floor contained many burned snags of Juniperus californica and Yucca brevifolia, and all stems of Coleogyne ramosissima were completely consumed by the fire (most of the cover was made up by bare ground). Despite the apparent predominance of Yucca brevifolia 
Table 1. Frequency of bare ground, rock, and plant species for burned and reference (non-burned) sites, Lower Covington Flats, Joshua Tree National Park, California, measured for the valley floor and east-facing slope in November 1996, 16 months after fire.

\begin{tabular}{|c|c|c|c|c|}
\hline & \multicolumn{2}{|c|}{ Slope } & \multicolumn{2}{|c|}{ Valley Floor } \\
\hline & Reference & Burned & Reference & Burned \\
\hline Bare ground & 35 & 43 & 40 & 90 \\
\hline Rock & 28 & 16 & 0.0 & 0.0 \\
\hline Cercocarpus betuloides & 12 & 9.0 & 0.0 & 0.0 \\
\hline Coleogyne ramosissima & 1.0 & 0.0 & 8.3 & 0.0 \\
\hline Ephedra nevadensis & 0.0 & 0.0 & 27 & 0.0 \\
\hline Ericomeria cooperi & 4.0 & 0.0 & 0.0 & 0.0 \\
\hline Eriogonum fasciculatum & 1.0 & 0.0 & 0.0 & 0.0 \\
\hline Juniperus californica & 0.0 & 0.0 & 16.7 & 0.0 \\
\hline Nolina parryi & 1.0 & 0.0 & 0.0 & 0.0 \\
\hline Pinus monophylla & 4.0 & 3.0 & 0.0 & 0.0 \\
\hline Quercus spp. & 23 & 0.0 & 0.0 & 0.0 \\
\hline Achnatherum spp. & 0.0 & 0.0 & 1.0 & 0.0 \\
\hline Yucca brevifolia & 1.0 & 0.0 & 4.0 & 0.0 \\
\hline
\end{tabular}

on the adjacent reference sites, the unburned valley floor was dominated by Coleogyne ramosissima, Ephedra nevadensis and Juniperus californica. The burned slope had some partially-burned surviving individuals of Pinus monophylla and Cercocarpus betuloides, whereas the unburned reference slope sites were dominated by Quercus spp., $P$. monophylla, and $C$. betuloides. The canopy of all Yucca schidigera individuals on the burned slope was completely burned away, leaving standing snags. For both slope and valley floor, bare ground made up 35 to $40 \%$ of transect intercepts, and rock made up a large component for the slope.

Yucca brevifolia exhibited root-crown sprouting as well as canopy-sprouting (Table 3). For five $1000 \mathrm{~m}^{2}$ belt transects, $28 \%$ of Yucca brevifolia trees exhibited rootcrown sprouting, $2 \%$ exhibited canopy sprouting, none had both root-crown sprouting and canopy growth, and the balance had neither root-crown or canopy growth. For Yucca schidigera, $100 \%$ of the burned plants exhibited root-crown sprouting; such plants had $6.2 \pm 3.3$ post-fire sprouts per plant. Other species that exhibited root-crown sprouting included: Ephedra nevadensis, Lycium andersonii, Nolina parryi, Prunus fasiculata, and Quercus spp. The cacti Echinocereus triglochidiatus and Opuntia basilaris exhibited new growth emerging from burned stems. No individuals of Coleogyne ramosissima, Juniperus californica or Opuntia acanthocarpa showed any signs of post-fire regrowth.

Based on detailed searches within the canopy of perennials on the unburned, reference site, seedling and juvenile plants of five species were found growing from within the canopy of Coleogyne ramosissima (Table 4).

Table 2. Percentage bare ground, rock cover, and plant cover for burned and unburned sites, Lower Covington Flats, Joshua Tree National Park, California measured for the valley floor and east-facing slope in November 1996, 16 months after fire.

\begin{tabular}{|c|c|c|c|c|}
\hline & \multicolumn{2}{|c|}{ Slope } & \multicolumn{2}{|c|}{ Valley Floor } \\
\hline & Reference & Burned & Reference & Burned \\
\hline Bare ground & 36 & 58 & 51 & 100 \\
\hline Rock & 29 & 22 & 0.0 & 0.0 \\
\hline Cercocarpus betuloides & 4.6 & 12 & 0.0 & 0.0 \\
\hline Coleogyne ramosissima & 1.0 & 0.0 & 29 & 0.0 \\
\hline Ephedra nevadensis & 0.0 & 0.0 & 12 & 0.0 \\
\hline Ericameria cooperi & 4.1 & 0.0 & 0.0 & 0.0 \\
\hline Eriogonum fasciculatum & 2.0 & 1.4 & 0.0 & 0.0 \\
\hline Juniperus californica & 0.0 & 0.0 & 7.3 & 0.0 \\
\hline Nolina parryi & 2.0 & 1.4 & 0.0 & 0.0 \\
\hline Pinus monophylla & 5.4 & 3.1 & 0.0 & 0.0 \\
\hline Quercus spp. & 12 & 0.0 & 0.0 & 0.0 \\
\hline Nasella spp. & 0.0 & 0.0 & 0.7 & 0.0 \\
\hline Yucca brevifolia & 4.1 & 0.0 & 4.0 & 0.0 \\
\hline
\end{tabular}


Table 3. Number of plants exhibiting post-fire root crown sprouting or canopy sprouting for Yucca brevifolia and Yuccaschidigera, Lower Covington Flats, Joshua Tree National Park. Data are mean number of plants per transect $\left( \pm \mathrm{sd}\right.$ ) for five $1000 \mathrm{~m}^{2}$ belt transects. Measurements were made in November 1996, approximately 16 months after the fire.

\begin{tabular}{lcc}
\hline & \multicolumn{2}{c}{ Frequency (\%) } \\
\cline { 2 - 3 } & $Y$. brevifolia & Y. schidigera \\
\hline Root crown sprouting & $28(1.74)$ & 100 \\
Canopy sprouting & $4.0(0.2)$ & 0 \\
Root crown and canopy sprouting & 0 & 0 \\
Neither & $68(2.7)$ & 0 \\
\hline
\end{tabular}

The greatest number of young plants found under the canopy of blackbush stems were of the species Juniperus californica and Yucca brevifolia. No seedlings or juvenile plants were found under adults of other dominant perennial species.

In order to evaluate the survival of fires by Joshua trees over longer periods of time, we measured morphological characteristics for plants on sites of known burn dates. The height and basal diameter of Joshua trees increased over time for a fire chronosequence spanning the period from 1968 to 1995 (Fig. 1). Despite a decrease in height over time since fire $\left(r^{2}=0.87\right)$, the average height (Fig. 2) for Yucca brevifolia trees for the five sites was not significantly related to time $(P>0.05)$ based on a contingency table analysis. Similarly, basal diameter decreased with decreasing time since fire $\left(r^{2}=0.77\right)$ for the five sites and was not significant. The relative amount of independent trees, trees emergent from the canopy of nurse plants, and trees that resulted from post-fire root crown sprouting differed considerably for each fire site (Table 5). For the youngest site, all Joshua trees were the result of crown sprouting, yet for the two oldest sites 86 to $100 \%$ of the trees were independent of other vegetation or emergent from nurse plant canopies. For the 12 and 15 year old fires sites, there were trees that had resulted from successful seedling establishment as well as from post-fire crown sprouting.

Table 4. Number of seedling or juvenile perennial plants found under Coleogyne ramossisima on the unburned reference site in December 1996. Data are mean number of plants per transect $( \pm$ SE) for five $1000 \mathrm{~m}^{2}$ belt transects.

\begin{tabular}{ll}
\hline Species & Number \\
\hline Ephedra nevadensis & $5.4(4.47)$ \\
Juniperus californica & $12.6(3.25)$ \\
Opuntia ar.anthorarpa & $1.8(0.97)$ \\
Opuntia basilaris & $0.2(0.2)$ \\
Yucca brevifolia & $14.1(0.2)$ \\
\hline
\end{tabular}

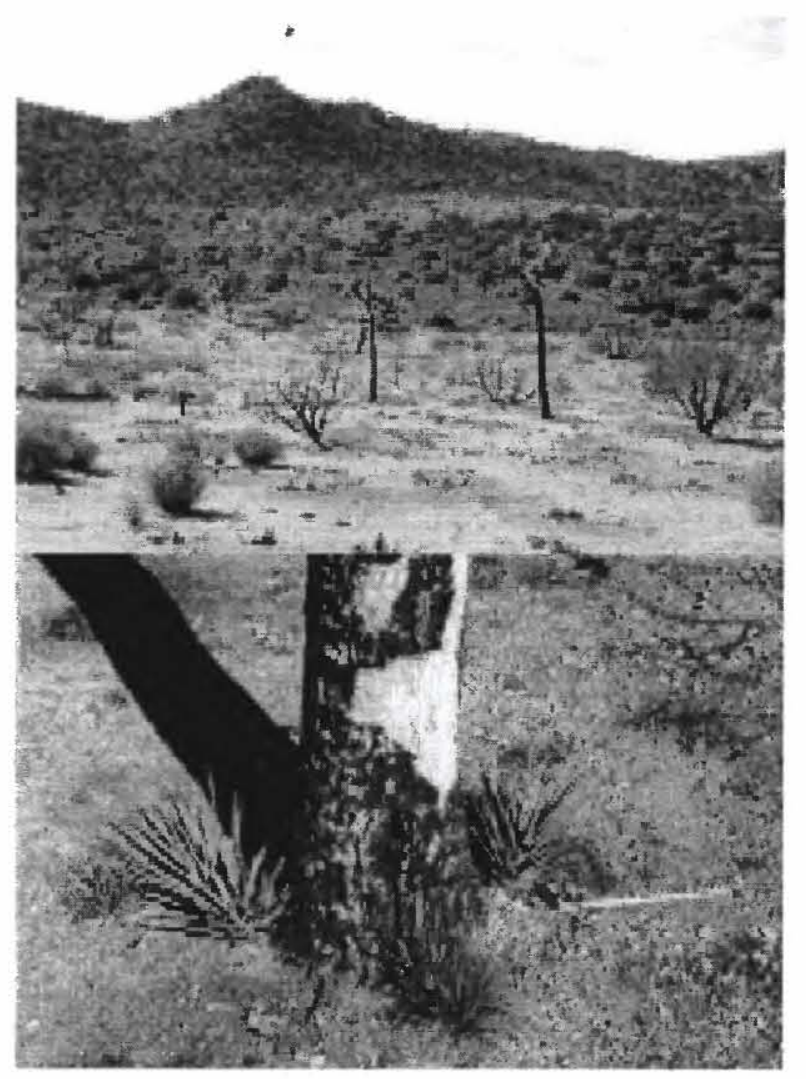

Fig. 1. Burned vegetation at Lower Covington Flats, Joshua Tree National Park, California. Top: Standing snags of Juniperus californica and Yucca brevifolia. The intact community of Joshua trees, blackbush, and juniper can be seen in the background. Bottom: Root-crown sprouts from rhizomes of Yucca brevifolia, 24 months following the 2,025 ha lightning-caused fire at Lower Covington Flats.

\section{Discussion}

Both Yucca brevifolia and Y. schidigera exhibited significant amounts of root-crown sprouting one year following the 1995 Lower Covington Flats fire. Previous observations of the amount of post-fire root-crown or rhizome sprouting have varied. For example, eight years following the 1981 Keys Fire, $40 \%$ of Joshua trees had stems that had originated from root-crown or rhizome sprouts, and some had grown an average of $15 \mathrm{~cm}$ per year (Cornett 1991). On the other hand, 25\% of Joshua trees had root-crown sprouts one year following the 1978 Covington Flats fire, but only $10 \%$ were alive in 1984 (Allison 1984). The amount of post-fire root-crown sprouting is likely related to the mortality of such tissues, which in turn is dependent on fire temperature. Basal sprouting appears to be a common response of Yucca schidigera to physical stem damage from fire, herbivory, or freezing, and may help lead to the formation of clonal rings for this species. In this regard, burned individuals of $Y$. schidigera often have more basal sprouts than nonburned individuals in adjacent areas (Allison 1984). Fire 


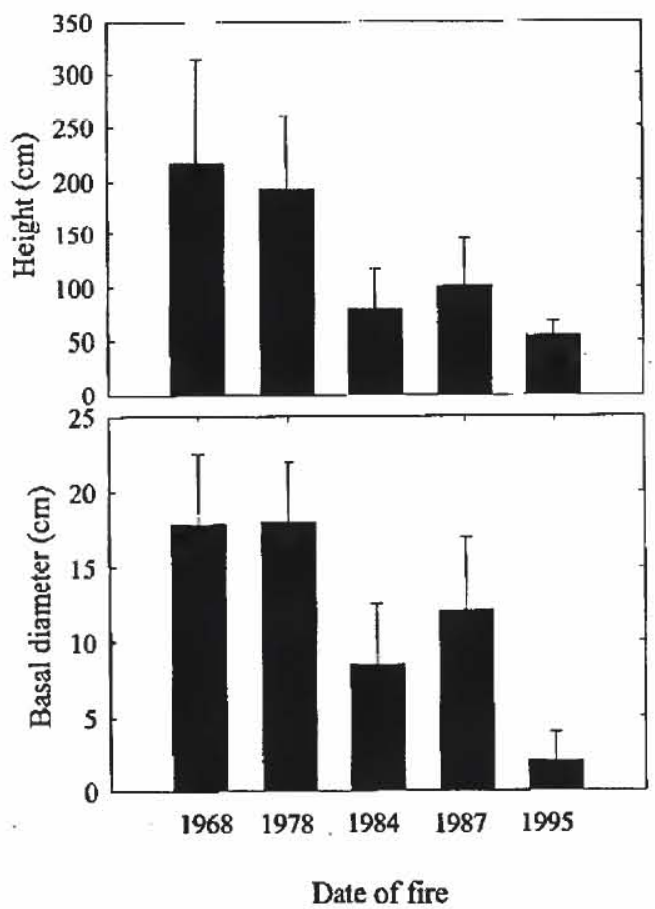

Fig. 2. Size of Yucca brevifolia trees for a chronosequence of fire sites at Joshua Tree National Park, California. Tree height (top) and basal diameter (bottom) is presented as means \pm SD for at least 12 plants at each site.

is also important for the biology of other southern California yucca species, as taller inflorescences of Yucca whipplei remain standing following fire whereas shorter ones fall, burn, and presumably recruit fewer seedlings (Huxman and Loik 1996).

In Larrea - Yucca assemblages and Joshua tree woodland communites of the Mojave Desert, it is common to see individually burned Joshua trees as a result of lightning-strikes. Presumably, the fuel load is low enough in the immediate area of the tree to preclude spreading of the fire. At higher elevations, such as Lower Covington Flats, Coleogyne ramosissima is the dominant species and forms mosaics of near-continuous canopy. This species also contains highly resinous stems and is therefore prone to burning (West 1988), thereby acting as a fuel that can carry a fire over many hectares depending on prevailing wind conditions. Invasive Mediterranean grass species establish under the canopy of Colengyne ramosissima and Juniperus californica and may enhance the spread of fire. Also, fires may not burn entire plants in piñon-juniper communities, thereby leaving biomass that can burn in subsequent fires. In this regard, the fire return interval for the piñon-juniper community of Quail Mountain at Joshua Tree National Monument (where vegetation does not always completely burn) is approximately 15 years.

Coleogyne ramosissima appears to be an important nurse plant for many species in the Covington Flats plant community, including Yucca brevifolia. Nurse plant associations are important for seedling recruitment in warm, arid ecosystems for several reasons. First, the canopy of nurse plants shade seedlings, thereby reducing high-temperature stress during the summer (Franco and Nobel 1988,1989 ). Second, freezing damage for seedlings may be prevented by the emission of infrared radiation by the nurse plant canopy during the winter (Steenbergh and Lowe 1977). Third, nurse plants can provide a refuge from seed and seedling predators (McAulliffe 1984). On the other hand, seedlings may compete with their nurse plant for resources such as water and soil nutrients (Franco and Nobel 1988, 1989) thereby reducing their growth rates, however, the survival advantages of the nurse plant appear to outweigh the cost of reduced growth. In the present study, Coleogyne ramosissima was eliminated from the valley floor by the 1995 fire and showed no signs of resprouting. Even though unburned individuals of $C$. ramosissima may clonaly reproduce by root splitting (Kundel and Gibson 1996), there is no such growth after a fire (Callison et al. 1985; West 1988). If C. ramosissima is indeed a nurse plant for Yucca brevifolia at this site, the time required for Joshua trees to begin recruitment via seeds will be delayed until $C$. ramosissima becomes re-established. Our observation of root-crown sprouting in the first years after a fire, followed by seedling recruitment in later years, is consistent with the time lag for the return of $C$. ramosissima as a nurse plant for $Y$. brevifolia. Whereas much is known about the germination and distribution of C. ramosissima (Lei 1997; Lei and Walker

Table 5. Frequency of independent trees, canopy-emergent trees, and crown-sprout trees for a fire chronosequence at Joshua Tree National Park, California. N indicates the total number of trees measured at each site.

\begin{tabular}{|c|c|c|c|c|c|}
\hline \multirow[t]{2}{*}{ Fire site } & \multirow[t]{2}{*}{ Year } & \multirow[t]{2}{*}{$\mathrm{N}$} & \multicolumn{3}{|c|}{ Frequency $(\%)$} \\
\hline & & & Independent & Canopy-emergent & Crown-sprout \\
\hline Lost Horse Valley & 1968 & 22 & 77.2 & 9.1 & 13.6 \\
\hline Covington Flats & 1978 & 15 & 66.0 & 33.0 & 0 \\
\hline Hidden Valley & 1984 & 14 & 7.1 & 28.6 & 64.3 \\
\hline Lost Horse Mine & 1987 & 12 & 16.6 & 41.6 & 41.6 \\
\hline Lower Covington Flats & 1995 & 37 & 0 & 0 & 100 \\
\hline
\end{tabular}


1997), it is unclear whether it requires a nurse plant for successful establishment.

Increases in park usage, as well as pressures outside the park boundaries (Harrison 1990), may cause an imbalance between Joshua tree mortality and recruitment. Changes in the local climate duc to anthropogenic greenhouse gases may cause warming of the microclimate near the soil surface thereby precluding the future establishment of Yucca brevifolia and other plants of the piñonjuniper community. Regional effects of climate change may include enhanced frequency and intensity of summer monsoon storms and lightning strikes, which may cause an increase in fire frequency (Torn and Fried 1992). Soils denuded by fire may experience enhanced soil erosion, especially if monsoonal precipitation increases in frequency or magnitude. Joshua Tree National Park is located approximately $180 \mathrm{~km}$ east of Los Angeles, which is the source of a large atmospheric nitrogen plume that affects local forests (Bytnerowicz and Fenn 1996), however it is not clear if the plume reaches Joshua Tree National Park or whether it is enhancing the growth of exotic species, which can enhance fire frequency. Natural and anthropogenic stresses represent a unique combination of pressures on ecosystems of the Mojave Desert and require further study to elucidate whether and how species composition and ecosystem services are being affected.

\section{Acknowledgments. We thank Paul Reeberg, Kathie Meyer, Stephanie Schmidt of the United States Department of Interior, National Park Service. Edmund Miranda, Sean Redar, and Michael St. Onge provided valuable field assistance.}

\section{Literature Cited}

Allison, A.E. 1984. Post-fire regeneration: Mohave Desert, pinyon-juniper belt. Research report, Joshua Tree National Park. Twentynine Palms, CA.

Anonymous. 1996. American population change annual. Second edition. Toucan Valley Publications, Inc. Milpitas, CA.

Bytnerowicz, A. and M.E. Fenn. 1996. Nitrogen deposition in California forests: A review. Environmental Pollution 92:127146.

Callison, J., J.D. Brotherson, and J.E. Bowns. 1985. The effects of fire on the blackbush (Coleogyne ramosissima) community of southwestern Utah. Journal of Range Management 38:535538.

Cornett, J.W. 1991. The Joshua tree. Palm Springs Desert Museum Natural Science Publication. 91 p.

Franco, A.C. and P.S. Nobel. 1988. Interactions between seedlings of Agave deserti and the nurse plant Hilaria rigida. Ecology 69:1731-1740.

Franco, A.C. and P.S. Nobel. 1989. Effect of nurse plants on the microhabitat and growth of cacti. Journal of Ecology 77:870886.
Fule, P.Z., W.W. Covington, and M.M. Moore. 1997. Determining reference conditions for ecosystem management of southwestern ponderosapine forests. Ecological Applications 7:895908.

Gosz, R.J. and J.R. Gosz. 1996. Species interactions on the biome transition zone in New Mexico: response of blue grama (Bouteloua gracilis) and black grama (Bouteloua eripoda) to fire and herbivory. Journal of Arid Environments 34:101-114.

Harrison, R. 1990. Protecting U.S. national parks: innovative measures for challenging times. Environment 32:18-19.

Hickman, J.C., 1993. The Jepson Manual. Higher plants of California. University of California Press, Berkeley, CA.

Huxman, T.E. and M.E. Loik. 1996. Abiotic and biotic inflorescence damage and reproductive strategy for Yucca whipplei. San Bernardino County Museum Quarterly 43: 45-48.

Keeley, J.E. 1992. Recruitment of seedlings and vegetative sprouts in unburned chaparral. Ecology 73:1194-1208.

Knapp, P.A. 1992. Secondary plant succession and vegetation recovery in 2 western Great Basin desert ghost towns. Biological Conservation 60:81-89.

Lamont, B.B., E.T.F. Witkowski, and N.J. Enright. 1993. Postfire litter microsites safe for seeds unsafe for seedlings. Ecology 74:501-512.

Lei, S.A. 1997. Variation in germination response to temperature and water availability in blackbush (Coleogyne ramosissima) and its ecological significance. Great Basin Naturalist 57:172177.

Lei, S.A. and L.R. Walker. 1997. Biotic and abiotic factors influencing the distribution of Coleogyne communities in southern Nevada. Great Basin Naturalist 57: 155-162.

McAuliffe, J.R. 1984. Prey refugia and the distributions of two Sonoran desert cacti. Oecologia 65:82-85.

Nobel, P.S. 1980. Influences of minimum stem temperatures on ranges of cacti in southwestern United States and central Chile. Oecologia 47:10-15.

Nobel, P.S. 1992. Annual variations in flowering percentage, seedling establishment, and ramet production for a desert perennial. International Journal of Plant Sciences 153:102107.

Ostertag, R. and E.S. Menges. 1994. Patterns of reproductive effort with time since last fire in Florida scrub plants. Journal of Vegetation Science 5:303-310.

Parsons, D.J. 1996. Fire research and management in the Sierra Nevada National Parks. Pp. 25-48 in W.L. Halvorson, and G.E. Davis, eds. Science and ccosystem management in the national parks. University of Arizona Press, Tucson, AZ.

Price, M.V. and J. W. Joyner. 1997. What resources are available to desert granivores: seed rain or soil seed bank? Ecology 78:764-773.

Rundel, P.W. and A.C. Gibson. 1996. Ecological communities and processes in a Mojave Desert ecosystem: Rock Valley, Nevada. Cambridge University Press, New York, NY.

Schoenherr, A. A. 1992. A natural history of California. University of California Press. Berkeley, CA.

Smith, S.D., R.K. Monson, and J.E. Anderson. 1997. Physiological ecology of North American desertplants. Springer-Verlag, New York, NY.

Steenbergh, W.F. and C.H. Lowe. 1977. Ecology of the saguaro: II. reproduction, germination, establishment, growth and survival of the young plant. National Park Service Scientific Monograph Series. Number 8, Washington, D.C. 
Tilman, D. 1997. Biodiversity and ecosystem functioning. Pp. 93112 in G.C. Daily, ed. Nature's services. Societal dependence on natural ecosystems. Island Press, Washington, D.C.

Torn, M.S. and J.S. Fried. 1992. Predicting the impacts of global warming on wildland fire. Climatic Change 21:257-274.

Vander Wall, S.B. 1997. Dispersal of singleleaf pinyon pine (Pinus monophylla) by seed-caching rodents. Journal of Mammalogy 78:181-191.

Vasek, F.C. and M.G. Barbour. 1988. Mojave Desert scrub vegetation. Pp. 835-867 in M.G. Barbour and J. Major, eds. Terrestrial vegetation of California. California Native Plant Society, Special Publication Number 9, Sacramento, CA.
West, N.E. 1988. Intermountain deserts, shrub steppes, and woodlands. Pp. 209-230 in M.G. Barbour and W.D. Billings, eds. North American terrestrial vegetation. Cambridge University Press, New York, NY.

Western Region Prescribed and Natural Fire Monitoring Task Force. 1992. National Park Service western region fire monitoring handbook. USDINational Park Service, San Francisco, CA. 


\title{
Estimation of Pre-Suppression Fire Intervals in Californian Mixed Conifer Forest
}

\author{
Richard A. Minnich and Richard G. Everett \\ Department of Earth Sciences, University of California, Riverside, CA 92521 \\ Tel. (909) 787-5515; e-mail: richard.minnich@ucr.edu
}

\begin{abstract}
The most important quantitative record of presuppression fire history of Californian mixed conifer forest has been provided by studies in fire-scar dendrochronology. These studies estimate that pre-suppression fire intervals ranged from 4-20 years. Because fire intervals were short (precluding large fuel accumulations), it was deduced that pre-suppression fire intensities were low, consuming mostly litter, shrubs, seedlings, immature trees, and senescent groups, leaving vigorous open stand structures. A fundamental problem with fire scar studies is that a spatial process is being extrapolated from point (sitespecific) data, and models of landscape dynamics developed from point studies may not capture the regional processes. To evaluate fire scar data, it is essential to assess how site-specific fire frequency estimates reflect the spatial extent of burns at the landscape-scale. Fire occurrence in all ecosystems is expressed in "long-tailed" size frequency distributions of numerous small events and relatively few large events, i.e., most fires fail and few reach large size. Two hypotheses concerning the landscape-scale importance of these fires are possible. (1) Small events cumulatively influence the periodicity of fire. Alternatively, (2) low intensity, local events recorded as fire scars collectively use up little fuel, cover little area, and have little demographic impact on forests. We hypothesize that fire interval estimates are too short because fire scar data reflect both landscape burns and numerous spot burns that have little spatial extent nor ecological impact.
\end{abstract}

Keywords: Aerial photo fire mapping; fire retum intervals; fire scar dendrochronology; lightning fires; spot burns.

\section{Introduction}

For nearly a century, fire suppression management has altered the fire regime of Californian mixed-conifer forests. The most profound evidence is seen in widespread directional vegetation changes, including stand-thickening, build-up of understory fuels, and an age-specific trend away from dominance by mature Pinus ponderosa or Pinus jeffreyi and toward dominance by juvenile, polesize classes of Abies concolor and Calocedrus decurrens (Kilgore 1973; Vankat 1977; Vankat and Major 1978; Parsons and DeBenedetti 1979; Weatherspoon et al. 1992; SNEP Science Team 1996; Barbour and Minnich 1998). In the San Bernardino Mountains of southern California, Minnich et al. (1995) found that forests at the time of the California Vegetation Type Map (VTM) survey in 1932 were open and park-like with stand densities (dbh >10 $\mathrm{cm}$ ) ranging from 90 to $174 \mathrm{stems} \mathrm{ha}^{-1}$, depending on forest type. VTM plot replicates show that densities have increased 100-200 stems ha-1 during the past 60 years of suppression. Forest densities $>4 \mathrm{~cm}$ dbh on the west slope of the Sierra Nevada average 500 stems ha $^{-1}$ (Vankat 1977; Vankat and Major 1978; McKelvey and Johnston 1992). Peterson and Arbaugh (1992) report stand densities of 175 to 2,770 stems ha $^{-1}$, including saplings $<4 \mathrm{~cm} \mathrm{dbh}$. Densities in the Sierra Nevada were about 200 stems ha $^{-1}$ during the early 20 th century.

The open structure of forests before fire control, seen in a large body of historical writings and old photographs, have been attributed to recurrent fire that selectively eliminated shrubs and young trees (summaries in Rundel et al. 1988; Minnich 1988; McKelvey and Johnston 1992; SNEP Science Team, 1996). VTM quadrats taken in the San Bernardino Mountains in 1930 (Minnich et al, 1995) and historical data from the Sierra Nevada (McKelvey and Johnston 1992; SNEP Science Team 1996) show that forests had a flat, multiple-age structure but some have an inverse $\mathrm{J}$-shaped distribution, with maximum stem densities in the 70 to $100 \mathrm{~cm} \mathrm{dbh}$.

The changes in fire regime (fire frequencies, intervals, size, intensities, stand fire damage and mortality) with suppression is not well documented. Furthermore, the preand post-suppression fire history data are not comparable owing to different methodologies that have been employed. Post-suppression data consists primarily of fire perimeter maps obtained mostly from field surveys and aerial photographs by land management agencies, includ- 
ing the National Park Service, Forest Service, and California Division of Forestry. These maps give the dates and limits of burns, as well as fire size, with return intervals by overlay of perimeter sequences. Still, perimeter maps provide no information on fire damage and forest dynamics.

Pre-suppression fire history consists of fragmentary accounts of smoke columns in newspapers, descriptions of understory fires, and rare photographs of fire scarred trees, and stand-replacement on steep mountain slopes (Minnich 1987, 1988). The most important quantitative record has been provided by fire-scar dendrochronology studies, and associated stand-age reconstructions. These studies estimate that pre-suppression fire intervals in Californian mixed conifer forest ranged from 4-20 years depending on vegetation type and slope aspect (Show and Kotok 1924; Wagener 1961; Weaver 1974; McBride and Laven 1976; Kilgore and Taylor 1979; Finney and Martin 1989; Swetnam 1993). Because fire intervals were short (precluding large fuel accumulations), it was deduced that pre-suppression fire intensities were low, consuming mostly litter, shrubs, seedlings, immature trees, and senescent groups, leaving vigorous stand structures (Kilgore and Taylor 1979; Kilgore 1981; McKelvey and Johnston 1992; SNEP Science Team 1996). Hence, open forests are caused by selective elimination of young trees. Gaps in the canopy layer created by local intense fires were colonized by seedling thickets protected from fire for lack of fuel. As the thicket matures, subsequent low intensity fires selectively thin it into an old-growth, low-density patch. Mature forests are believe to have L-shaped or multimodal diameter size frequency distribution curves (Bonnickson and Stone 1981, 1982; Kerscher and Axelrod 1984).

The fundamental problem with fire scar studies is that a spatial process is being extrapolated from point (sitespecific) data, and models of landscape dynamics developed from point studies may not capture the regional processes due to the large geographic variability in fire behavior (McIntosh, 1981; Johnson and Gutsell 1994). This paper examines whether site-based fire scar dendrochronology estimates reflect fire return intervals at the landscape scale.

\section{Limitations of the Fire Scar Dendrochronology Method}

In fire scar dendrochronology studies, the history of fire at a sampling site is recorded by trees over time scales of centuries. Usually a small percentage of trees in a forest form a hollow or "cat face" at the base of tree boles as the result of a fire burning through the bark layer into the sap and heartwood. With fire resistance being weakened, subsequent fires repeatedly re-injure cambial tissue, permitting an estimation of fire frequencies based on the num- ber of fire scars (burn injuries) compared against annual rings in the wood regrowing into the wound along catface margins.

Fire frequencies can be computed directly from fire scars, either from sets of fire intervals from single trees, or from composite fire intervals integrated from several trees, using a master chronology as a baseline (Arno and Sneck 1977; Dieterich 1980). Fire scar dendrochronology sampling has sources of error in determining fire chronologies, including false rings, missing rings which are prevalent at high altitudes, and other scar sources (Sheppard et al. 1988; Agee 1993; Johnson and Gutsell 1994). Ring anomalies due to marginal growth, snow burial, and drought may result in underestimation of tree age and fire intervals (Agee 1993).

To evaluate such data, it is essential to assess how sitespecific fire frequency estimates reflect the spatial extent of burns at the landscape-scale. Specifically, what does a scarring event represent: a large fire, a local spot burn, or perhaps a lightning strike? This issue is important because fire size is coupled with intensity and damage to vegetation. Moreover, a large fire by virtue of its size does not guarantee that it has a higher probability of being recorded by tree catfaces than small fires. As shown hypothetically in Fig. 1, fire occurrence in all ecosystems is expressed in "long-tailed" size frequency distributions of numerous small events and few large events. Moreover, the spatial extent of burning reaches maximum levels for large size classes with relatively few fires (Minnich 1983; Chou et al 1993; Minnich and Chou 1997). The distributions represent a natural continuum. For very large fires, the inverse relationship between fire size and frequency is an artifact of the finite vegetation area being examined (Minnich 1983). However, for small burns, the negative slope reflects two factors: (1) very high frequen-

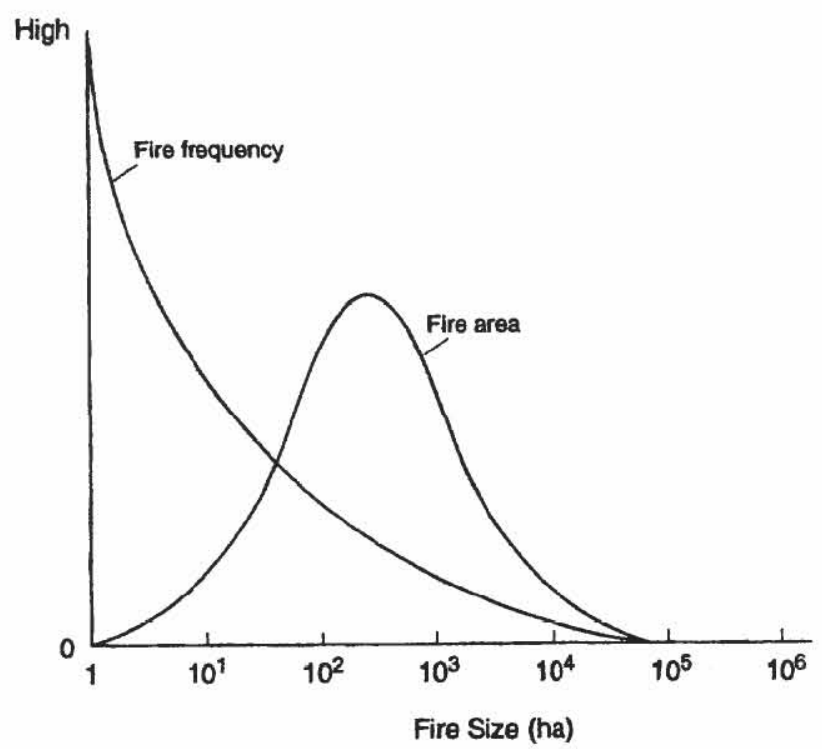

Figure 1. Hypothetical distributions of cumulative burn area along a fire size frequency distribution. 
cies of fire starts, and (2) a trend for ever fewer fires reaching larger size classes. The continuum reflects a probability domain of fire hazard related to fuels, weather, and other factors during which fires become established. There is no mode in the frequency distribution except for the very high frequency of small events. The assessment of very small burns is important because as fire frequency (events/area) becomes infinitely high with infinitely small fire size, the cumulative fire area approaches zero (Fig. 1), i.e., abundant small events could have limited spatial impact on the landscape, and leave abundant fire scars on catfaced tree boles.

The length of the size frequency distribution "tail" is significant with respect to assumptions on fire size versus point (site-specific) sampling (Fig. 1). An important question is whether the density of spot fires is sufficient such that any randomly selected sampling site has a greater probability of recording local events than large ones.

Two hypotheses concerning the landscape-scale importance of these fires are possible. (1) Small events cumulatively influence the periodicity of fire. Alternatively, (2) low intensity, local events recorded as firc scars collectively use up little fuel, cover little area, and have little demographic impact on forests.

From the standpoint of site-specific sampling in fire scar studies, the abundance of small fires raises the question whether fire scars represent a disturbance coming from outside the sampling site or establishing in situ. If it is assumed that disturbances all arrive from outside the site, then it follows that each disturbance is necessarily larger than the study site. Such is likely with low ignition frequencies (low densities/area). However, under very high ignition rates some portion of disturbances will cstablish in situ and may be smaller than the study site, leading to potential overestimation of the spatial extent of burns. The scarring record also represents a mixture of landscape burns and spot fires.

Assumptions used in fire scar dendrochronology, necessary for estimates of fire intervals, have been supported by very few studies on pre-suppression fire sizes. Most studies assume small events are important. Finney and Martin (1989) note that interpretations of fire scar data are influenced by assumptions regarding fire sizes. They contend, for example, that mean fire intervals are overestimated from point data because fire records on each sample are often incomplete, noting that mean fire intervals decrease as the study area/sample size increases (Arno and Peterson 1983). This assumption is supported by fire reports from land management agencies in California which give a low density of lightning fires (e.g, Keeley 1982) such that any site would have low probability of experiencing small burns within normal fire intervals. Hence, it is assumed that scars reflect exogenous fires arriving to the sampling site, i.e, landscape burns, rather than small burns established in situ.
Alternatively, a new database that compiles electromagnetic lightning detections (GEOMET 1994) suggests that lightning discharges and resulting small burns resulting from thunderstorms of the North American monsoon may influence the scarring record at a greater rate than previously envisioned. For example, the density of ignitions may be inversely related to broadscale fire intensities and removal of biomass because high fire frequencies are paralleled by a high failure rate of ignitions establishing fires. Because fire is a process of contagious diffusion, the maintenance of flame lines is dependent on intensities of burning fuels exceeding the latent energy of water in adjoining unburned fuels (Rothermel 1972). Very small burns imply deficient intensities, while larger burns have greater capacity to remove biomass.

Another important question in fire scar studies is whether landscape and spot burns can be differentiated because neither fire scars nor age class reconstructions directly evaluate fire processes leading to forest structure. Extant stands represent a composite of survivorship from multiple burns. The mechanisms by which recurrent understory fire removes forest biomass and shapes pre-suppression forest structure is not directly addressed.

\section{Fire Intervals Without Fire control in the Sierra San Pedro Mártir of Baja California}

In Minnich et al (in press), the relationship between fire size frequency distributions and return intervals in an unmanaged fire regime has been examined in mixed conifer forests in the Sierra San Pedro Mártir in northern Baja California Mexico, which is covered by 41,000 ha of Californian mixed-conifer forests (Pinus jeffreyi, $P$. lambertiana, P. contorta, Abies concolor, Calocedrus decurrens, and Cupressus montana, Fig. 2). This isolated range has not experienced fire control, widescale logging or land clearing (Minnich and Franco-Vizcaíno, in press).

The fire perimeter history was reconstructed synoptically using ten repeat aerial photographs obtained between 1942 and 1993 (Fig. 3). Fire perimeters and forest damage for burns $>5$ ha in the Sierra San Pedro Mártir were mapped from landscape burn scars using the rollfilm stereoscope. Repeat aerial photographs were then matched site-specifically on a Zoom Transfer Scope to follow fire distributions, patch turnover, and forest damage in a timeseries to distinguish disturbance from natural vegetation gradients (McIntosh 1981). Two scenes were superimposed to scale, as recognized from the unique nearestneighbor configurations of trees and shrubs within a stand, as well as from surrounding fixed features such as rock outcrops and watercourses.

Forests throughout in the Sierra San Pedro Mártir consist of open, park-like stands of mature trees forming umbrella-like canopies (78-156 trces ha ${ }^{-1}$, dbh mostly > $60 \mathrm{~cm})$, with few young trees $\left(<20 \mathrm{ha}^{-1}\right)$, and open stands 


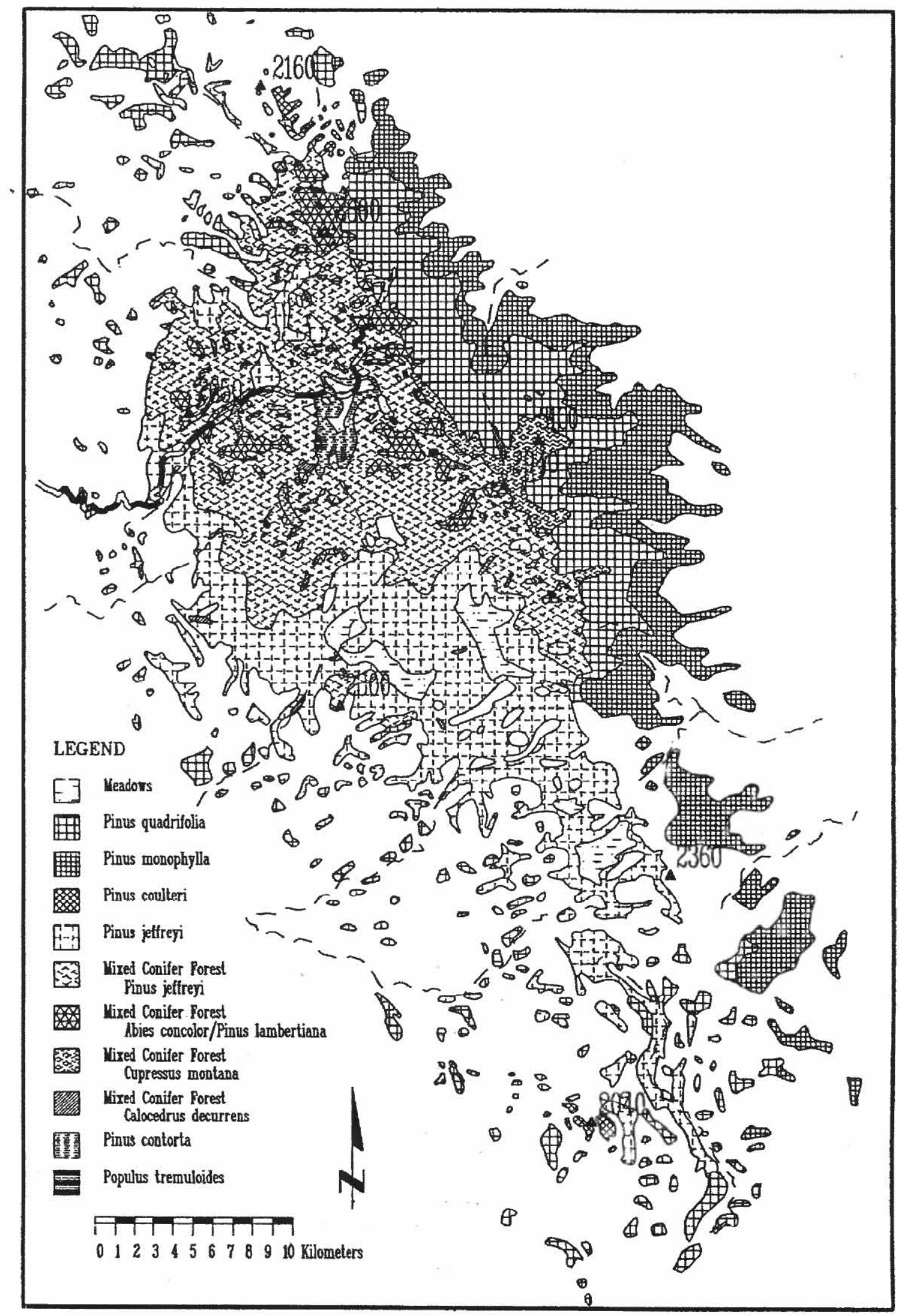

Figure 2. Conifer forests of Sierra San Pedro Mártir above $1400 \mathrm{~m}$ elevation, as interpreted from aerial photographs. 


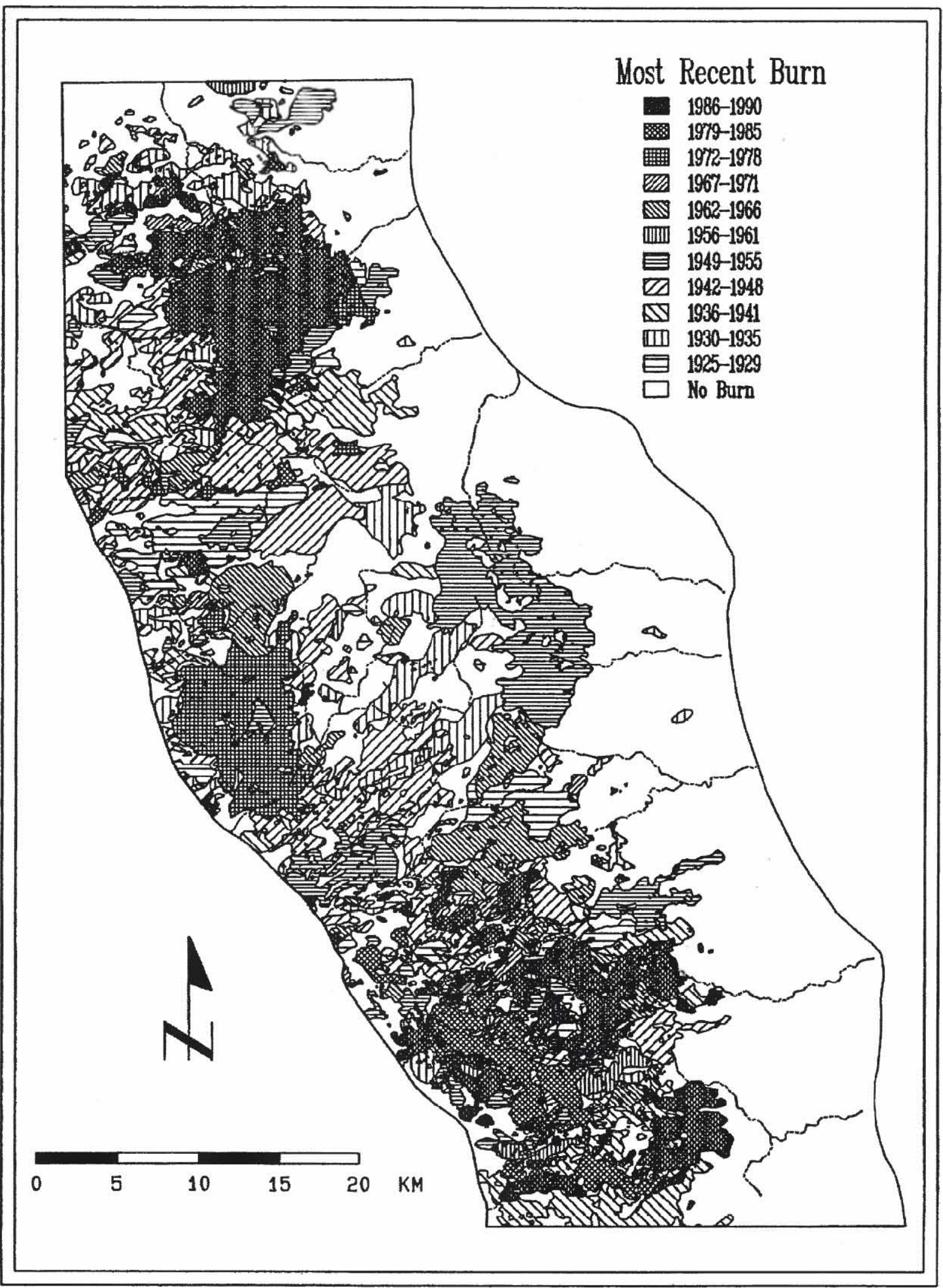

Figure 3. Sierra San Pedro Mártir patch mosaic (time-since-fire), excluding emplaced burn areas, as of 1991, based on a composite of fire perimeter maps in Minnich et al. (in press). 
of sclerophyllous shrubs in the understory, similar to presuppression forests of California (Minnich et al. 1995). Stand densities are similar to those recorded by the VTM survey of 1932 in the San Bernardino Mountains of southen California. Since little effort is given to extinguish fires, high fire frequencies have produced an intricate, finegrained patch mosaic (Fig. 3). During 1925-1991 there were 865 fires $>5$ ha which burned a total of 56,800 ha. Most fires (436) were smaller than 16 ha, while only 41 fires exceeded $800 \mathrm{ha}$, and only three exceeded 6,400 ha (Table 1). While small fires of $<16$ ha collectively accounted for only 2,511 ha, or $1.6 \%$ of the total burned area, size classes which burned the most area were 800$1,600 \mathrm{ha}(23,718 \mathrm{ha})$ and $3,200-6,400 \mathrm{ha}(35,241 \mathrm{ha})$. The 11 largest fires accounted for $35.6 \%$ of total burn area.

A verage fire rotation periods - the time required to burn an area equivalent to the total area of a vegetation type (Johnson and Gutsell 1994) - since 1925 is estimated to be 52 years, i.e, Sierra San Pedro Mártir forests have burned about 1.2 times for the 66 year period.

This suggests that fire occurrence is time-dependent, with minimum fire intervals being relatively long, regardless of management, due to the gradual, cumulative fuel buildup, as seen for chaparral (Minnich and Chou 1997). This is seen in nonrandom interlocking of patch sequences and small overlap between burns. The time-threshold for burning is a property set by the rate of fuel accumulation inherent to the vegetation, with stands younger than that threshold constraining the progress of burns. Thus, the evolution of patch mosaics created by fire is a non-random and self-organizing process, because the occurrence of one event is affected by past events, and in turn affects future events (Turner 1987; Urban et al. 1987; Minnich and Chou 1997).

The west-to-east long axis of fire perimeters (Fig. 3) indicates that most fires spread with prevailing slope winds (from the west) that dominate during summer, similar to that in the chaparral of northern Baja California (Minnich and Chou 1997). Our observations of past fires have shown that flames normally spread slowly uphill during the afternoon, when relative humidities reach minimum levels. Flames generally stop during air drainage circulations at night, with fires persisting in logs and snags. Larger burns invariably persisted for months, with fires alternatively static and smoldering or moving, depending on weather and fuel conditions.

Long fire intervals are attributed to the gradual build up of subcontinuous shrub cover, conifer recruitment, and litter accumulation (Minnich et al. in press). The potential for stand-thickening is seen in sapling densities which are 2-4 times that of overstory trees $\left(100-600 \mathrm{ha}^{-1}\right)$. Succession chronosequences reveal an increase of 15 polesize stems ha- ${ }^{-1}$ after 50 year. Local forests that have not burned for $>70$ years support tree densities as high as 400 stems $\mathrm{ha}^{-1}$, similar to forests that have experienced stand-thickening in southern California (Minnich et al. 1995) and in the Sierra Nevada (Vankat 1977; Vankat and Major 1978). Long-term cumulative fuel build-up encourages intense surface fires with heavy mortality to tree classes up to pole-size stems. In burns in 1989 and 1996, canopies were scorched as high as $10-20 \mathrm{~m}$ above ground.

There is little evidence that forests are undergoing stand-thickening at the landscape scale, even with 50 year fire intervals, because the growth of new stems is countered by high fire mortality rates.Present forest densities may in fact reflect a long-term stable forest population structure, despite widespread fire during the twentieth century, as modern forest densities, stem diameters, and species composition are remarkably similar to those taken during a forest survey of the Sierra San Pedro Mártir in 1888 (Minnich and Franco-Vizcaíno, 1998).

What is the role of small fires $(<5 \mathrm{ha})$ in the Sierra San Pedro Mártir mixed conifer forest? Anthropogenic ignitions appear to be infrequent, as the area is not inhabited except by a few vaqueros during summer. However, long-term lightning discharge densities from thunderstorms of the North American monsoon may be sufficiently high (3.0 x 10-3 $\mathrm{ha}^{-1} \mathrm{yr}^{-1}$, Minnich et al. 1993) that most stands experience a mixture of both local events and landscape fires. While records do not exist, the frequency

Table 1. Fire size frequency distributions for 1925-1991, total area burned, cumulative burn area, and cumulative fire frequency by fire size class, as calculated from GIS maps for the Sierra San Pedro Mártir. Cf = cumulative frequency, $\mathrm{BA}=$ burn area, $\mathrm{CBA}=$ cumulative burn area (ha).

\begin{tabular}{|c|c|c|c|c|c|c|c|c|c|c|c|}
\hline \multirow[b]{2}{*}{ Year } & \multicolumn{11}{|c|}{ Fire size class (ha) } \\
\hline & $\begin{array}{l}5- \\
16\end{array}$ & $\begin{array}{l}16- \\
50\end{array}$ & $\begin{array}{l}50- \\
100\end{array}$ & $\begin{array}{l}100- \\
200\end{array}$ & $\begin{array}{l}200- \\
400\end{array}$ & $\begin{array}{l}400- \\
800\end{array}$ & $\begin{array}{c}800- \\
1,600\end{array}$ & $\begin{array}{l}1,600 \\
3,200\end{array}$ & $\begin{array}{l}3,200- \\
6,400\end{array}$ & $>6,400$ & Total \\
\hline No. fires & 436 & 166 & 83 & 61 & 58 & 20 & 22 & 8 & 9 & 2 & 865 \\
\hline $\mathrm{Cf}$ & 436 & 602 & 685 & 746 & 804 & 824 & 846 & 854 & 863 & 865 & 865 \\
\hline $\mathrm{Cf}(\%)$ & 50.4 & 69.6 & 79.2 & 86.2 & 92.9 & 95.2 & 97.8 & 98.7 & 99.7 & 100.0 & 100.0 \\
\hline $\mathrm{BA}$ & 2,252 & 6,368 & 6,172 & 8,707 & 16,741 & 11,127 & 23,718 & 18,145 & 35,241 & 16,311 & 144,782 \\
\hline BA (\%) & 1.6 & 4.4 & 4.2 & 6.0 & 11.2 & 7.7 & 16.4 & 12.5 & 24.3 & 11.3 & - \\
\hline CBA & 2,252 & 8,620 & 14,792 & 23,499 & 40,240 & 51,567 & 75,085 & 93,230 & 128,471 & 144,782 & 144,782 \\
\hline $\mathrm{CBA}(\%)$ & 1.6 & 6.0 & 10.2 & 16.2 & 27.8 & 35.5 & 51.9 & 64.4 & 88.7 & 100.0 & 100.0 \\
\hline
\end{tabular}


of fires initiated by lightning is apparently quite high. In southern California, $2-4 \%$ of discharges initiate fires require suppression action (Minnich et al. 1993). Our best evidence comes from color aerial photographs in 1991 which recorded 204 ash beds of current year spot fires (ash is removed within one rainy season), with $190 \mathrm{oc}-$ curring in mixed conifer forest (Fig. 4). Only seven burns exceeded 8 ha (175 ha), with the remaining 197 burns accounting for only 218 ha. Most were far removed from roads and trails. Spot fires consumed litter beds but caused little disturbance to even prostrate shrubs and small trees. Apparently, spot burns consumed mostly conifer litter. The survival of prostrate shrubs (Arctostaphylos patula) and small conifer saplings suggests that flame lines were very low, with some fuels being consumed through glowing combustion. Spot burns died out of their own within a few days because the energy release was insufficient to sustain flame lines.

The high failure rates could be simply due to the overabundance of discharges. Given present lightning discharge rates, a median size patch (1,000 ha) sustains a discharge every three years, or ca. 20 times per fire interval. Clearly, most lightning will strike stands that have insufficient fuels to sustain large burns. Fire scars may also be a direct product of lightning paths of exposed cambian along the boles of canopy trees caused by light-

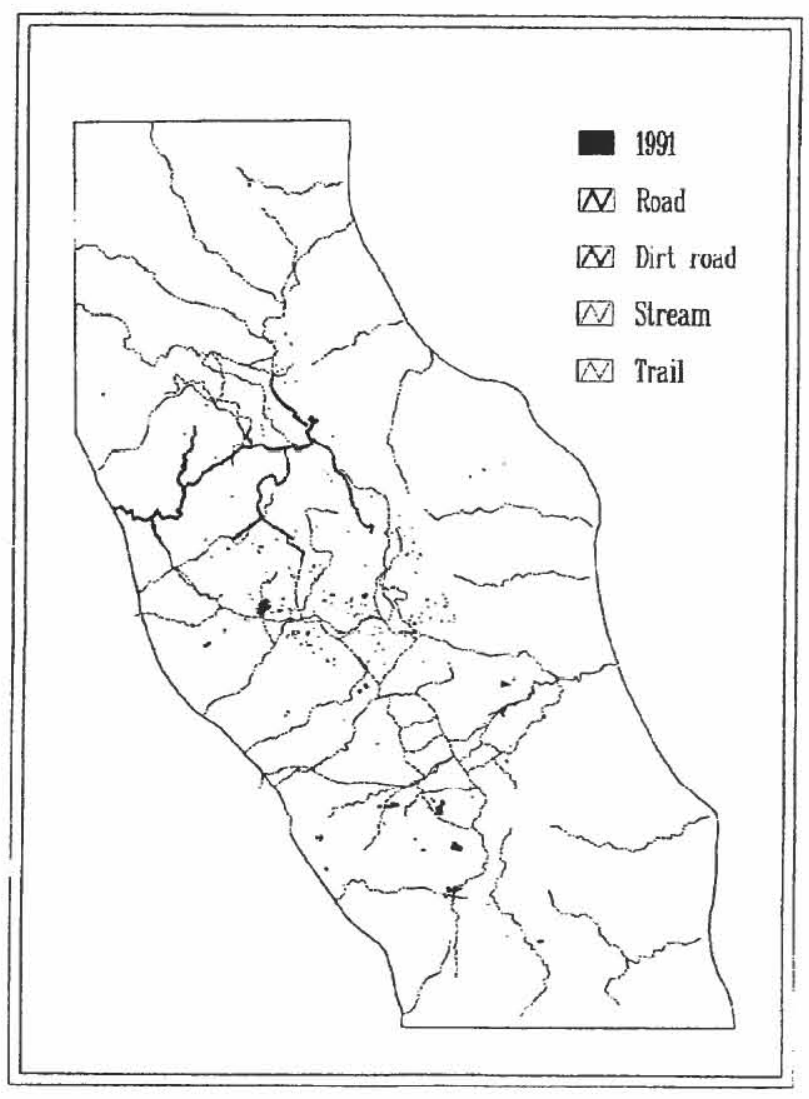

Figure 4. Distribution of spot burn ash beds (black polygons) resulting from two days of thunderstorms in June and July 1991 in the Sierra San Pedro Mártir. ning strikes, with some entering directly into bole catfaces. Lightning strokes on tree boles may be seen within "eye shot" throughout the forest.

The number of fires initiated by thunderstorms in 1991 suggest that small burns may occur at very high frequencies over ecological time scales of decades. Several evidences suggest that 1991 frequencies were not abnormally abundant: (1) lightning discharges occur in the thousands each summer (Minnich et al., 1993); (2) the 1991 burns established from a single thunderstorm episode in July; (3). Thunderstorms typically develop over the range on 30-50 days per summer; and (4) 1991 summer precipitation up to the July flight was subnormal, i.e, the incidence of convective storms was less than expected (Minnich et al, 1993). The effect of convective showers in dousing fires is mitigated by the ability of flames to store in logs and snags for days or weeks before establishing flames in ground fuels.

The fact that only two of 189 burns in 1991 were greater than the 5 ha minimum fire size for other mapped burns during 1925-1993 strongly indicates that long-term fire frequencies increase rapidly with decreasing fire size for very small events. Hence, it is possible that for every mapped burn in 1925-93, there is a "blind map" of spot events that are more frequent by one to two orders of magnitude. At this rate, the number of fire starts in the Sierra San Pedro Mártir for 1920-93 could number in the tens of thousands, i.e., at the order of magnitude of one spot ha-1 for cach fire cycle of 35-70 years.

\section{Resolving the disparity of fire interval estimates}

The 52 fire year fire rotation periods in the Sierra San Pedro Mártir are far longer than estimated 4-20 year fire intervals in mixed conifer forests of California. Summary temperature and precipitation data for locations in mixedconifer forests in the Sierra San Pedro Martir are well within the range of climate for stations in mixed conifer forest of California (Minnich et al. in press). Hence, climate alone cannot account for differences in fire return intervals.

We hypothesize that the disparity is an artifact related to spatial (fire mapping) versus site-specific data collection related to differences in the size class of fires being evaluated. Whereas the 52 year intervals are defined by a lower burn size limit of 5 ha in the Sierra San Pedro Mártir database, shorter interval estimates in fire scar studies reflect both landscape burns and numerous spot burns that have little spatial extent nor ecological impact. We postulate that burns $<5$ ha had low intensities, because at higher intensities and energy release the expansion of flame lines would have resulted in larger burns. The spot fires of 1991 would have been overlooked in other aerial photo coverages because the cover of ash that earmarks these burns disappears within a year. Damage to small 
shrubs and trees, that may be observed for several years was insufficient for systematic recognition. Hence, the omission of small fires is not an omission of biomass burning. As evidence, site specific matching of repeat aerial photographs reveals that vegetation outside our fire perimeters has a virtually fixed nearest-neighbor arrangement of stems. Since conifers and the dominant shrubs Arctostaphylos patula, A. pringlei, and A. pungens are nonsprouters, we conclude that fires intense enough to burn shrubs and saplings did not occur. Hence, it appears that low intensity, local events (recorded as fire scars) collectively use up little fuel, cover little area, have little demographic impact on forests, and lead to underestimates of true spatial fire intervals. The effect of small burns is unclear because the lower limit of fire sizes recorded by fire scars is unknown.

Fire scar dendrochronology methods address the issue of small burns by evaluating the synchronessness of fire scars over some sample area. Synchronous fire scar years at separate localities are conventionally interpreted to reflect single burns. However, this explanation is equivocal as several evidences indicate that spot fires could be vicariant and synchronous: (1) Individual thunderstorms produce multiple lightning strikes over small areas; (2) Fractal lightning discharges can each produce multiple ground strikes; (3) Lightning flux rates in a year are sufficiently high that relatively small areas receive multiple strikes each year; and (4) Over time scales of decades are massive thunderstorm outbreaks that produce thousands of strikes and fires in single day. A recent example is the Stanaslaus National Forest fire complex of 1987. While events of this magnitude are rare in the climate (ca. every 10 yr.), such events are ubiquitous in ecological time-scales associated with forest dynamics.

It has been hypothesized that fire intervals may be underestimated because trees scar easier in hotter fires in dry windy weather and not in creeping or smoldering fires (Romme 1982). To date, no studies have addressed this argument. In the Sierra San Pedro Mártir we have observed scarring from spot fires and propose that fire scar methods cannot systematically differentiate landscape burns from spot fires because the amount of burning of exposed heart and sapwood within bole cat faces takes place independently of flame line intensities.

There are few studies in California that estimate fire size distributions for comparison with the Sierra San Pedro Mártir. Fire scar studies have assumed that conifer litter can support frequent extensive fires (Kilgore and Taylor, 1979; Bonnickson and Stone 1981, 1982; Kerscher and Axelrod 1984; Stephenson et al. 1989; Swetnam 1991, 1993). Extensive "light fires" that burned needle litter exclusively were not observed. While large fires may have highly variable spread rates and intensities due to changes in weather, it can be argued on physical grounds that small fires are small because they have insufficient intensity (energy release) to form flame lines. Repeat aerial photo- graphs outside mapped fire perimeters consistently reveal fixed nearest-neighbor configurations of overstory and understory vegetation. This indicates that burns sufficiently intense to modify woody cover did not occur.

The most detailed analysis was undertaken by Kilgore and Taylor (1979), who correlated fire scar records with stand age data in the central Sierra Nevada. They concluded that fires were small (1-800 ha), patchy, and irregularly shaped. However, the small size of the study area (2,300 ha) may have resulted in an underestimation of fire size. Fire size estimates are also indirect because forests represent the residual (survivorship) of fire disturbances, the putative pattern of small burns deduced from age-class structure may instead be produced by local variability of fire intensity in larger burns. Synchronous fire scar years vicariously distributed across the landscape may be synchronous lightning strikes and spot fires, rather than a single burn.

Fire size estimates are also self-contradictory with the short-interval, low intensity fire model. If only a few years' litter accumulation were necessary to support fire recurrences (thereby obviating time-dependence), then fires should be large because the landscape is universally flammable regardless of previous fire history. The resulting fire process would also illustrate a pattern of spatial randomness.

\section{Implications and Conclusions}

In fire-prone ecosystems, knowledge of previous fire history and long-term generic fire regimes (fire intervals, intensities, size, weather) is essential in the evaluation of relationships between fire and vegetation dynamics, as well as in establishing ecologically sound fire management. Information on past fire can be used for such purposes as the inventory of fire damage, population dynamics, fuel build-up, and for the integration of planned burns with the regional stand mosaic.

Future studies on pre-suppression fire regimes of mixed conifer forest should address the natural frequency of very small events, whether they contribute significantly to the landscape, and how they influence site-specific fire scar dendrochronology methods. We hypothesize that fire return intervals determined by fire scars will give undo importance to local events and lead to erroneous estimates of the spatial extent of burns at the landscape scale.

Our long-interval, high intensity model for the Sierra San Pedro M-rtir has several implications for management. Forest managers, accepting fire scar estimates of fire intervals, commonly assume that forests have missed as many as 10-20 fire cycles as the result of suppression. The prospect that fire intervals were longer, however, means that fewer cycles were missed (perhaps only 1-3), and that stand-thickening was less severe relative to presuppression levels. As a corollary, the trend for high in- 
tensity understory fires in the Sierra San Pedro Mártir suggests that hotter prescribed burns may fall within the bounds of ecological stability in California forests.

\section{References}

Agee, J.K. 1993. Fire ecology of Pacific Northwest forests. Island Press, New York. $493 \mathrm{p}$

Arno, S.F. and K.M. Sneck. 1977. A method for determining fire history in coniferous forests of the mountain west. USDA Forest Service, General Technical Report INT -42 .

Arno, S.F. and T.D. Peterson. 1983. Variation in estimates of fire intervals: A closer look at fire history on the Bitterroot National Forest. USDA Forest Service, Research Paper INT301.

Barbour, M.G., and R.A. Minnich. 1999. Californian upland forests and woodlands. In M.G. Barbour and W.D. Billings, eds. North American terrestrial vegetation. Second edition. Cambridge University Press, New York (in press).

Bonnickson, T.M. andE.C. Stone. 1981. The giant sequoia-mixed conifer forest community characterized through pattern analysis as a mosaic of aggregations. Forest Ecology and Management 3:307-328.

Bonnickson, T.M. and E.C. Stone. 1982. Reconstruction of a presettlement giant sequoia-mixed conifer forest community using the aggregation approach. Ecology 63:11341148.

Chou, Y.H., R.A. Minnich, and R.J. Dezzani. 1993. Do fire sizes differ between southern California and northern Baja California? Forest Science 39: 835-844.

Dieterich, J.H. 1980. The composite fire interval: A tool for more accurate interpretation of fire history. Pp. 8-14 in J.A. Stokes and J.H. Dieterich, eds. Proceedings of the fire history workshop. USDA Forest Service, General Technical Report RM81.

Finncy, M.A. and R.E. Martin. 1989. Fire history in a Sequoia sempervirons forest at Salt Point State Park, California. Canadian Journal of Forestry Research 19:1451-1457.

GeoMet. 1994. 1989-1993 measured lightning flash density. Tuscon, Arizona. Map.

Johnson, E.A. and S.L. Gutsell. 1994. Fire frequency models, methods and interpretations. Advances in Ecological Research 15: 239-287.

Keeley, J.E. 1982. The distribution of lightning and man-caused wildfires in California. Pp. 431-437 in C.E. Conrad and W.E. Oechel, eds. Proceedings of the symposium on dynamics and management of mediterranean-type ecosystems, USDA Forest Service, General Technical Report PSW-58.

Kilgore, B.M. 1973. The ecological role of fire in Sierran conifer forests: Its application to National Park management. Quaternary Research 3:496-513.

Kilgore, B.M. 1981. Fire in ecosystem distribution and structure: Western forests and scrublands. Pp. 58-89 in H.A. Mooney, T. Bonnicksen, N.L. Christensen, J. Lotan, and W. Reiners, eds. Fire regimes and ecosystem properties, , USDA Forest Service, General Technical Report WO-26.

Kilgore, B.M. and D. Taylor. 1979. Fire history in a sequoiamixed conifer forest. Ecology 60:129-142.

Kercher, J.R. and M.C. Axelrod. 1984. A process model of fire ecology and succession in a mixed-conifer forest. Ecology 65:1735-1742.
McBride, J.R. and R.D. Laven. 1976. Fire scars as an indicator of fire frequency in the San Bernardino Mountains, California. Journal of Forestry $74: 439-442$.

McKelvey, K.S. and J.D. Johnston. 1992. Historical perspective on forests of the Sierra Nevada and the Transverse Ranges of southern California: Forest conditions at the turn of the century. Pp. 225-246in J.Verner, K.S. McKelvey, B.R. Noon, R.J. Gutiérrez, G.I. Gould, and T.W. Beck, eds. The California spotted owl: A technical assessment of its current status. USDA Forest Service General Technical Report PSW-GTR133.

McIntosh, R.P. 1981. Succession and ecological theory. Pp. 10-23 in D.C. West, H.H. Shugart, and D.B. Botkin, eds. Forest succession: concepts and application. Springer-Verlag. New York, NY.

Minnich, R.A. 1983. Fire mosaics in southern California and northern Baja California. Science 219:1287-1294.

Minnich, R.A. 1987. Fire behavior in southern California chaparral before fire control: The Mount Wilson burns at the turn of the century. Annals of the Association of American Geographers 77:599-618.

Minnich, R.A. 1988. The biogeography of fire in the San Bernardino Mountains of California: A historical study. University of California Publications in Geography 27:1-121.

Minnich, R.A., E. Franco-Vizcaíno, J. Sosa-Ramírez, and Y.H. Chou. 1993. Lightning detection rates and wildland fire occurrence in the mountains of northern Baja Califomia. Atmosfera 6: 235-253.

Minnich, R.A., M.G. Barbour, J.H. Burk, and R.F. Fernau. 1995. Sixty years of change in conifer forests of the San Bernardino Mountains: Reconstruction of Californian mixed conifer forests prior to fire suppression. Conservation Biology 9: 902 914.

Minnich, R.A. and Y.H. Chou. 1997. Wildland fire patch dynamics in the chaparral of southern California and northern Baja California. International Journal of Wildland Fire 7:221-248.

Minuich, R.A. and E. Franco Vizcaíno. 1998. Land of Chamisc and Pines: historical accounts and current status of northern Baja California's vegetation. University of California Publications in Botany, Volume 80. 166p.

Minnich, R.A., M.G. Barbour, J.H. Burk, and J. Sosa-Ramirez. Californian conifer forests under unnanaged fire regimes in the Sierra San Pedro Martír, Baja California, Mexico. Journal of Biogeography, (in press).

Parsons, D.J. and S.H. DeBenedetti. 1979. Impact of fire suppression on a mixed-conifer forest. Forest Ecology and Management 2:21-33.

Peterson, D.L. and M.J. Arbaugh. 1992. Mixed conifer forests of the Sierra Nevada. Pp.433-459 in R.K Olson, D. Binkley, and M. Bohm, eds. The response of westem forests to air pollution. Springer-Verlag, New York, NY.

Rothermel, R.C. 1972. A mathematical model for predicting fire spread in wildland fuels. USDA Forest Service, Research Paper INT-115.

Romme, W.H. 1982. Fire history and landscape diversity in Yellowstone National Park. Ecological Monographs 52:199221.

Rundel, P.W., D.T. Gordon, and D.J. Parsons. 1988. Montane and subalpine vegetationin the Sierra NevadaandCascade Ranges. Pp. 559-600 in M.G. Barbour and J. Major, eds. Terrestrial vegetation of California. Second Edition. California Botanical Society, Sacramento, CA. 
Sheppard, P.R., J.E. Means, and J.P. Lassoie. 1988. Cross-dating cores as a nondestructive method for dating living, scarred trees. Forest Science 34:781-789.

Show, S.B. and E.I. Kotok. 1924. The role of fire in the California pine forest. USDA Bulletin 1294, Washington, D.C.

SNEPScience Team, eds. 1996. Status of the Sierra Nevada, final report to Congress of the Sierra Nevada Ecosystem Project, 4 Volumes. Wildland Resources Center Report No. 36, University of California, Davis, CA.

Stephenson, N.L., Parsons, D.J. and T.W. Swetnam, T.W. 1989. Restoring natural fire to the sequoia-mixed conifer forest: Should intense fire play a role? Tall Timbers Fire Ecology Conference 20, 20-30.

Swetnam, T.W. 1991. Fire history and climate in the southwestern United States. Pp. 6-17 in J.S. Krammes, M.J. Swolinski, and W.W. Covington, eds. Effects of fire in management of southwestern natural resources. USDA Forest Service, General Technical Report INT-191.

Swetnam, T.W. 1993. Fire history and climatic change in giant sequoia groves. Science 262:885-890.
Turner, M.G. ed. 1987. Landscape heterogeneity and disturbance. Springer-Verlag, New York, NY.

Urban D.L., R.V. O' Neill, and H.H. Shugart, Jr. 1987. Landscape ecology. Bioscience 37:119-127.

Vankat, J.L. 1977. Fire and man in Sequoia National Park. Annals of the Association of American Geographers 67:17-27.

Vankat, J.L. and J. Major. 1978. Vegetation changes in Sequoia National Park, California. Journal of Biogeography 5:377402.

Wagener, W.W. 1961. Past fire incidence in Sierra Nevada forests. Journal of Forestry 59:739-748.

Weatherspoon, C.P., S.J. Husari, and J.W. van Wagtendonk. 1992. Fire and fuels management in relation to owl habitat in forests of the Sierra Nevada and southern California. Pp. 247 260 in J. Verner, K.S. McKelvey, B.R. Noon, R.J. Gutiérrez, G.I. Gould, and T.W. Beck, eds. The California spotted owl: A technical assessment of its current status. USDA Forest Service, General Technical Report PSW-GTR-133.

Weaver, H. 1974. Effects of fire on temperate forests: Western United States. Pp. 279-319 in T.T. Kozlowski and C.E. Ahlgren, eds. Fire and ecosystems. Academic Press, New York, NY. 


\title{
Fire Suppression and Drought Induced Mortality in Southern California Mixed-Conifer Forests
}

\author{
Melissa Savage \\ Department of Geography, University of California, Los Angeles, CA 90095 \\ Tel. (310) 825-1912; Fax (310) 206-5976; e-mail: savage@santafe.edu
}

\begin{abstract}
Levels of tree mortality were characterized in the Jeffrey pine/white fir phase of mixed-conifer forests under varying degrees of human influence. Two sites, in southern California, shared long-term fire suppression, while one had low levels of air pollution and the other had chronic, severe air pollution. A third site, in Baja, Mexico had little air pollution and no fire suppression. Approximately $14 \%$ of the standing trees in the southern California forests were dead, compared to about $4 \%$ in the Mexican forest. Anthropogenic effects, in particular fire suppression, may play an important role in enhancing the impact of natural stresses on the dynamics of mixed conifer forests.
\end{abstract}

Keywords: Abies concolor, air pollution; Baja California; fire suppression; forest decline; human disturbance; Pinus jeffreyi; San Bernardino Mountains; tree mortality.

\section{Introduction}

The complex interaction of human and natural stresses and disturbances in many forest communities has made the determination of the causal factors of forest dynamics difficult to assign. A wide variety of factors, for example, may be involved in forest mortality, including air pollution, pests, pathogens, and climate fluctuations such as drought (Innes 1992). One factor that may be overlooked is that the response of forests to disturbances and stresses may depend in part on their successional and demographic status. For example, the importance of cohort senescence in creating vulnerability to mortality has been documented in several forest communities (Mueller-Dombois 1986; Sprugel and Bormann 1981).

The demographic characteristics of mixed conifer forests in southern California have changed markedly in this century (Vankat and Major 1978, Kilgore and Taylor 1979). Most recently, starting in the mid-1980s, widespread mortality occurred in these forests (Barbour 1988). There are multiple stresses, including a recent severe drought, outbreaks of western pine bark beetle
(Dendroctonus spp.) (Savage 1994), and chronic exposure to air pollution (Miller et al. 1991). Higher forest density resulting from suppression of fire by humans in this century has also increased competitive stress (Kilgore and Taylor 1979). The effects of multiple disturbances and stresses can be damped or enhanced by their interaction.

The objective of this work is to compare stand structures and levels of tree death in the Jeffrey pine (Pinus jeffreyi Grev \& Balf.)/white fir (Abies concolor var. concolor (Gord. \& Glend.) Lindl.) phase of three mixed conifer forests that differ in pollution exposure and fire history. Two sampled sites are in the San Bernardino Mountains; the third is in the Sierra San Pedro Mártir in Baja California, Mexico. Both southern California sites have experienced fire suppression for about 90 years. One site experiences severe air pollution and the other, relatively little. The Mexican site is in a remote area with little air pollution and no history of fire suppression. As the last landscape-scale mixed conifer forest in North America with an unmanaged fire regime, the Mexican forest offers a unique opportunity to assess the influence of fire suppression (Minnich et al. 1995).

In a comparative study of stand structure traits such as density, basal area and age structure of forests with different disturbance histories, I investigated whether variation in stand structure is associated with varying levels of mortality (Savage 1997). The sampled forests occur in mountain ranges that stretch across the international border from southern California into Baja Mexico. Minnich et al. (1995) suggest that these forests are similar in composition and structure, and that the lack of fire suppression in the Mexican forests has allowed the forests there to retain the open structure that was historically typical of mixed conifer forest in general.

Drought, fire and beetle attack have been endemic disturbances in the Jeffrey pine-white fir phase of the forest. In this century, fire suppression and air pollution have been added to the disturbance regime in southern California forests. Multiple disturbances can interact in complex and poorly-understood ways. The effects of many natural dis- 
turbances are dependent on community status and environmental conditions (Schowalter 1985). For example, increased stand density can result in enhanced water stress, making trees more vulnerable to drought (Gerecke 1990). Drought has been implicated in increasing the intensity of Dendroctonus insect attack (Burns and Honkala 1990). Likewise, chronic exposure to oxidant pollution has been linked to Dendroctonus attack in southern California conifer forests (Stark et al. 1968). The intensity of insect outbreaks, however, was historically reduced by the patch, light fires that created an open park-like structure in mixed conifer forests (Kilgore 1973; Vankat and Major 1978). Structure in such forests, then, results from the interaction of disturbance with the structural legacy of past events (Schowalter 1985).

\section{Site Characteristics}

Three study sites were selected; Barton Flats and Holcolm Valley in the San Bernardino Mountain Range of southern California and La Corona Arriba in the Sierra San Pedro Mártir Range of Baja California.

The San Bernardino Mountains are an $80 \mathrm{~km}$ east-west trending range that bounds the Los Angeles basin on the north and east. The climate is mediterranean, with a mean annual precipitation in the western part of the range of around $80 \mathrm{~cm}$ a year (Minnich 1985). The mountains were grazed by domestic livestock in the latter half of the last century, but grazing ceased by 1900 (Minnich 1988). The rugged area of the western part of the range largely escaped logging (Minnich 1988). A more signiticant human influence was the elimination of the historic fire regime of frequent, light fires. Wildfire effectively disappeared in the San Bernardino Mountain Range from 1905, when fire suppression was instituted. Important ecological effects of this policy were the dramatic increase in stand density, and the increase in abundance of fire-sensitive tree species, such as white fir.

A second disturbance in these forests was identified in the 1950s, when ozone damage to pines was described (Miller et al. 1991). Concentrations of ozone are declining from high levels in the 1960 s, but remain locally severe in the region, depending on topography. Levels of ozone concentration are relatively high at Barton Flats but are fairly low at Holcolm Valley, which is cut off from the flow of urban air by ridge crests at around 2,500 m (Miller et al. 1986). Over a 5 year period the average daily maximum of ozone was 0.05 ppm at Holcolm Valley, about the rural mean for North America, but 0.07 ppm at Barton Flats, nearly $50 \%$ higher than the rural mean.

A severe drought occurred in the southern California region from around 1985 until the early 1990s, and 1989/ 90 were exceptionally dry years. Patches of dead trees, infested with Dendroctonus beetles, were clearly visible in most parts of the forest. Chronic exposure to ozone has been documented to increase susceptibility to disease and drought (Williams 1983; McLaughlin and Downing 1995), and it was widely thought that the death of trees resulted from the drought and subsequent insect infestation.

The Sierra San Pedro Mártir is located in Baja California about $350 \mathrm{~km}$ south of the San Bernardinos. The conifer forest covers a gently sloped plateau with steep escarpments on the east and west sides. A mediterranean climate prevails, with around $60 \mathrm{~cm}$ of precipitation a year (Minnich 1985). Substrates, as in the San Bernardino Mountains, are primarily granitic (Gastil et al. 1975). Light grazing by domestic livestock began in the 18th century in the montane meadows and continues today at moderate levels.

In this Mexican forest, wildfires are allowed to burn, and the forest displays the open structure associated with unmanaged fires. A fire history at La Corona Arriba reconstructed from tree-ring scars in Jeffrey pine trees by Jack Burk (unpublished data), gives a fire return interval of 13.5 years ( $\mathrm{SD}=10.6$ years), which has not changed over the past 200 years. The unmanaged regime of frequent fires in Baja seems to be parallel to the fire frequency in forests of southern California, prior to fire suppression (Minnich et al. 1995). Frequency of ignition results in low-intensity, patchy fires. There is little air pollution at the site, and air quality appears to be relatively pristine. The nearest urban area, Ensenada, is $150 \mathrm{~km}$ to the northwest.

Climate records in the range are short, but there is evidence that the San Pedro Mártir also experienced the recent regional drought over the same period as southern California. A water deficit, calculated from temperature (Miranda et al. 1991) and precipitation (Reyes Coca et al. 1990) data at the nearby Santa Cruz station [9 km away, 900 m elevation] from 1970 to 1990 indicates a steady decline in available water the latter half of the 1980s. Tree rings from 1989 and 1990 appear strikingly narrow as do those in southern Californian trees. However, there is no visible evidence of recent insect outbreak in the conifer forests of the San Pedro Mártir.

\section{Methods}

Jeffrey pine/white fir stands were sampled at three sites located between 2,200-2,500 $\mathrm{m}$ and similar in slope, aspect, and canopy dominance. Four pairs of $200 \mathrm{~m}$ transects were systematically placed on moderate NNE-facing slopes. Forest composition was estimated using the pointcentered quarter method. Species and condition (live or dead standing) of the nearest adult tree ( $\geq 1.4 \mathrm{~m}$ in height and $\geq 4 \mathrm{~cm}$ dbh [diameter at breast height]), seedling ( $<1.4$ $\mathrm{m}$ in height), or sapling ( $>1.4 \mathrm{~m}$ in height but $<4 \mathrm{~cm}$ $\mathrm{dbh}$ ) in each quarter within $15 \mathrm{~m}$ were recorded at points $20 \mathrm{~m}$ apart. $\mathrm{DBH}$ was recorded to the nearest centimeter. 
A small number of beetle-killed trees had been removed at Barton Flats to lower fire risk. For these stumps, basal circumference was measured and DBH estimated using linear regression equations relating circumference to diameter

Live adult trees were cored for age determination at $\sim 30 \mathrm{~cm}$ above the ground. Ages of dead trees and trees with rot or where the center was not reached were estimated, using linear regression equations relating age to DBH. Population structures, for both directly aged and reconstructed ages of trees of the two species, were represented in 20-ycar age classes to accommodate crror duc to variation in growth to $30 \mathrm{~cm}$ and regression estimation of age.

Density and cover were expressed as basal area. Additionally, age structure of the sampled forest was characterized. Age class histograms of the distribution of live and dead adult trees were constructed to compare differences in composition, abundance, and mortality by site. Density and basal area of all trees and relative density and basal area of each species were calculated. In order not to overestimate density, a correction factor was employed to compensate for the presence of empty quadrats, i.e., those with no tree within $15 \mathrm{~m}$ (Warde and Petranka 1981). Also, an undetermined number of pine trees in the lower transects at Barton Flats may have been ponderosa pine or hybrids of Jeffrey with ponderosa pine. These two morphologically and ecologically similar pines often overlap in a narrow band, where they display a low rate of hybridization (Haller 1962). Ponderosa pine and trees with intermediate traits at this site were grouped with Jeffrey pine for analysis.

\section{Results}

A total of 1,029 trees of six species were sampled at the three sites, predominantly Jeffrey pine and white fir with small numbers of sugar pine, mountain juniper, single-leaf pinyon pine, and incense cedar. Densities per ha of each species were as follows - at Holcolm Valley: Jeffrey pine: 184 live, 20 dead; white fir: 133 live, 33 dead; juniper: 7 live; pinyon pine: 17 live, 2 dead. At Barton Flats: Jeffrey pine: 298 live, 59 dead; white fir: 311 live, 47 dead; incense cedar: 6 live; pinyon pine: 3 dead. At La Corona Arriba: Jeffrey pine: 126 live, 9 dead; white fir 150 live, 3 dead; sugar pine: 24 live. Basal area in $\mathrm{m}$ per ha of each species were as follows. At Holcolm Valley: Jeffrey pine: 23.9 live, 5.7 dead; white fir: 7.2 live, 7.7 dead; juniper: 1 live. At Barton Flats: Jeffrey pine: 30.0 live, 3.8 dead; white fir: 7.8 live, 2.8 dead; incense cedar: 0.3 live. At La Corona Arriba: Jeffrey pine: 10.8 live, 1.2 dead; white fir: 10.4 live, 0.1 dead; sugar pine: 6.0 live. Jeffrey pine and white fir accounted for $94 \%$ of the adult trees, and the following analysis presents data only on these two species. The populations of living Jef- frey pine and white fir trees had roughly similar proportions.

\section{Mortality}

Stand structure analysis of the Jeffrey pine/white fir phase of these forests reveals that numbers of dead standing trees were dramatically higher at both of the San Bernardino sites than at the Sierra San Pedro Mártir site. The percentage of dead standing Jeffrey pine and white fir was $14.3 \%$ at Holcolm Valley and $14.7 \%$ at Barton Flats, in contrast to $4.3 \%$ at La Corona Arriba. A difference of proportions test indicates that the proportion of dead standing trees at Holcolm Valley was not significantly different from that at Barton Flats, but significantly greater at both sites from that at La Corona Arriba ( $\mathrm{p}<0.05)$. By species, the mortality levels were: at Holcolm Valley: $10 \%$ of Jeffrey pine and $10 \%$ of white fir; at Barton Flats: $15 \%$ of Jeffrey pine and $12 \%$ of white fir; at La Corona Arriba: $5 \%$ of Jeffrey pine and $2 \%$ of white fir.

There were no marked trends in numbers of dead standing trees by species. Dead trees were found across the range of age classes at all sites, suggesting that demographic structure of each species has not changed significantly because of the tree death represented by dead standing trees. At both sites in the San Bernardino Mountain Range, the dead trees appeared to have died within the past few years - small limbs, twigs, and needles remained on dead trees. By contrast, dead trees at the Sierra San Pedro Mártir site appeared to have been dead for a longer time-trunks were barkless, and needles had fallen.

\section{Age structure}

Seventy-four percent of the cored trees, 390 trees, were successfully aged. Ages of dead and unaged live adult trees were estimated using linear regression equations; the best relationship for each of the species from the San Bernardino Mountain Range was used to reconstruct tree ages, where there was a significantly positive relationship between age and size for each species.

The mean age of Jeffrey pine was 89 years at Holcolm Valley; 96 years at Barton Flats, and 108 years at La Corona Arriba. The mean age of white fir was 76 years at Holcolm Valley, 59 years at Barton Flats, and 86 years at La Corona Arriba. Mean age of Jeffrey pines exceeded that of white fir by $33 \%$ at Holcolm Valley, by $63 \%$ at Barton Flats, and by $26 \%$ at La Corona Arriba. A two tailed t-test for differences of means indicated mean ages of Jeffrey pine were not significantly different in any comparison of sites, whereas mean ages of white fir were significantly different in every comparison of sites $(p<0.05)$. Jeffrey pines were in general much older than white fir.

Maximum age of Jeffrey pine was 289 years at Holcolm Valley, 285 years at Barton Flats, and 448 years at La Corona Arriba. Maximum age of white fir was 155 
at Holcolm Valley, 96 at Barton Flats, and 285 at La Corona Arriba. Among aged trees, the oldest Jeffrey pines were about twice as old as the oldest white fir. The oldest Jeffrey pines at both San Bernardino sites were near 300 years, while the oldest white fir at Holcolm Valley was near 150 years, and at Barton Flats, near 100 years. The oldest aged Jeffrey pine at La Corona Arriba was 448 years compared to the oldest aged white fir at 285 years, but there were white fir at La Corona Arriba, not aged, that far exceeded the size, and probably the age, of the Jeffrey pines .

Jeffrey pine and white fir populations at all three sites were for the most part uneven-aged. The population age curve for white fir in the San Bernardino Mountains, however, suggests a recent expansion, with most trees establishing in the last 100 years. Jeffrey pine showed a shift toward younger age classes because of the white fir expansion. In the Sierra San Pedro Mártir, both species had trees in many age classes. Numbers of seedlings and saplings of both species; Holcolm Valley: 64; Barton Flats: 156; La Corona Arriba: 138. At the San Bernardino sites, white fir seedlings outnumbered those of Jeffrey pine at Holcolm Valley: (Jeffrey pine $=45 \%$; white fir $=55 \%$ ) and at Barton Flats: (Jeffrey pine $=26 \%$; white fir $=74 \%$ ). Jeffrey pine seedlings outnumbered white fir seedlings at $\mathrm{La}$ Corona Arriba: (Jeffrey pine $=72 \%$; white fir $=28 \%$ ). However, the interpretation of the composition and abundance of seedling populations must be very tentative, as the fate of seedlings is often uncertain and anomalous conditions may temporarily distort the structure of young age classes.

\section{Size and cover}

Jeffrey pines were in general much larger than white fir at all three sites. Mean DBH of live Jeffrey pines exceeded that of live white fir by $54 \%$ at Holcolm Valley, by $90 \%$ at Barton Flats, and by $27 \%$ at La Corona Arriba. At La Corona Arriba, however, trees of both species were significantly larger than in the San Bernardinos. Jeffrey pines were about half again as large, and white fir about twice as large as in the San Bernardinos. A two-tailed differences of mean $t$-test $(P<0.05)$ indicates that white fir diameter at La Corona Arriba was significantly different from values at the other two sites, but not significantly different between Holcolm Valley and Barton Flats. Jeffrey pine mean diameter values were not significantly different in any site comparisons $(\mathrm{P}<0.05)$

Basal area was greater at the San Bernardino sites for live and dead Jeffrey pine and white fir combined than at the Sierra San Pedro Mártir site. Basal area of live and dead trees combined was similar at the two San Bernardino sites at $46 \mathrm{~m}^{2} \mathrm{ha}^{-1}$ (Holcolm Valley) and (Barton Flats) $43 \mathrm{~m}^{2} \mathrm{ha}^{-1}$, compared with $29 \mathrm{~m}^{2} \mathrm{ha}^{-1}$ total basal area for these species at La Corona Arriba

There was a recent reduction in basal area in the San Bernardinos that can be attributed to the death of trees in many age classes, including many large old Jeffrey pines and young adult white fir. Jeffrey pine dominated basal area at these sites whether considering both live and dead standing trees or only surviving trees. White fir basal area was significantly more reduced by mortality relative to that of Jeffrey pine at the San Bernardino sites. Barton Flats, with more young trees than Holcolm Valley, had a lower proportion of loss of white fir basal area than Holcolm Valley.

At La Corona Arriba, on the other hand, basal area of dead standing trees was small compared to that of the San Bernardino sites. At La Corona $\Lambda$ rriba, dead standing trees accounted for $14 \%$ of Jeffrey pine and $8 \%$ of white fir basal area. Dead standing basal area of Jeffrey pine and white fir combined accounted for $31 \%$ at Holcolm Valley, $14 \%$ at Barton Flats, and $8 \%$ at La Corona Arriba of total basal area.

\section{Density}

Adult tree densities were lowest at La Corona Arriba (162 trees ha-1). Densities were nearly double at Holcolm Valley (306 trees ha-1), and even higher at Barton Flats (395 trees ha-1). In general, the higher density of the southern California sites can be accounted for by trees which established in this century. At La Corona Arriba, white fir also showed a small regeneration pulse in the 30 to 50 year age class. Also, there appeared to be no more mortality in those trees establishing in this century than in the population as a whole. Only at Barton Flats did more mortality occur in young adult Jeffrey pine than in the population as a whole. For young white fir adults, mortality was lower than the population as a whole at Holcolm Valley, similar at Barton Flats, and slightly higher at La Corona Arriba.

\section{Discussion}

Dead standing Jeffrey pine and white fir in the mixed conifer forest in southern California were over three times as numerous as in similar forests in Baja California. The lowest percentages of dead standing trees were found at the site with lowest density and basal area values. Even when surviving trees alone are considered, density and basal area values remain higher in southern California forests than in Mexican forests.

An increase in the density of forests, and the increase in the abundance of fire-sensitive species such as white fir, has been extensively documented as the result of a surface fire return interval considerably lengthened by fire suppression in the West (e.g., Vankat 1977; Barbour 1988; Minnich et al. 1995; Savage 1994). Successional trends initiated by fire protection have been accelerated by the recent death of large, old pines in the San Bernardino Mountains. In Baja California, where the historical fire 
regime still prevails, no such successional trends are evident. One feature of the La Corona Arriba site that remains unexplained is the large number of old white fir trees, more than expected under a regime of frequent fire. The presence of old white fir in the San Pedro Mártir, especially in light of the relative paucity of trees in many adult age classes, is a problem that deserves further attention.

At the two southern California sites, numbers of dead standing trees were similar, even though each has different air pollution intensities. This study revealed no more mortality in high pollution versus low pollution forests. This suggests that stresses associated with increased density created by fire suppression may be more important than those related to exposure to air pollution in predisposing trees to mortality.

The mixed conifer forest in Mexico represents a disjunct stand, and comparisons with stands in the San Bernardino Mountains must be tentative. Minnich et al. (1995), however, suggest that precipitation patterns and amounts are well within southern California values, and document mixed conifer forests as dense as those in southern California where local topography has prevented burning. These authors resampled southern California mixed conifer stands described quantitatively in 1929-1935, and found that pre-fire suppression forests displayed the open structure typical of modern Mexican forests. They conclude that increased density in the San Bernardino Mountains has been caused by the reduction of fire frequency. These authors also observed uniformly low numbers of dead standing trees in the Sierra San Pedro Mártir. Sixtyone percent of I-ha sites analyzed using aerial photography taken in 1991 had no dead standing trees; the rest had a mean of one dead standing tree per ha (unpublished data).

A striking difference in the southern California sites is the increase in density and basal area in this century. Both adult density and basal area values at the southern California sites are generally double those at the Mexican site. This suggests that the size of trees may be as important as density in indicating competitive conditions for soil moisture. Moreover, density and basal area values at Holcolm Valley and Barton Flats have changed considerably in this century, and competition for soil moisture may have changed comparably. Overall, the populations in Baja California are more stable in this century. A reconstruction of annual climate values generated from a treering chronology currently being developed will allow a better assessment of the relative strength of competitive conditions for moisture in the San Pedro Mártir during the recent drought.

Aging cohorts become increasingly vulnerable to stresses (Mueller-Dombois 1986). In the southern California mixed conifer stands, fire suppression may have created a forest with greater susceptibility to drought, beetle attack, and other natural stresses. Recent mortality in southern California forests has been thought to be pri- marily the result of the recent disturbances, specifically drought and subsequent beetle attack. If the severity of the recent drought were comparable at the three sites considered in this study, the more open structure of the forest in Baja Mexico, maintained by frequent surface fires, may have resulted in lower stress to trees during the recent drought.

The enhanced potential for stand destroying fires in increasingly dense forests of the western USA is already a concern for forest managers. This study suggests that increased density of these forest stands also enhances susceptibility to natural disturbances such as drought. If this is the case, then the potential for catastrophic fires is not the only reason for returning a natural fire cycle to mixed conifer forests. A natural fire regimes will also help to maintain forest health by keeping density at values that do not produce life-threatening levels of stress when drought occurs. The finding of the study suggest that in addition to fire management, there are other important ecological reasons to consider management choices such as prescribed fire or the re-creation of a natural wildfire regime for the maintenance of healthy mixed conifer forests.

Acknowledgments. I am grateful to the U. S. Forest Service and the Mexican government for permission to conduct research, and to R. Minnich, M. Arbaugh, J. Burk, N. Guelke, T. McBride, P. Miller, and B. Sawhill for data and advice. The research was supported in part by a UCLA Career Faculty Development Award. A version of this paper appeared in The Journal of Vegetation Science in 1997.

\section{Literature Cited}

Barbour, M.G. 1988. Californian upland forests and woodlands. Pp. 131-164 in M. G. Barbour and W.D. Billings, eds. North American terrestrial vegetation. Cambridge University Press, New York, NY.

Burns, R.M. and B.H. Honkala, technical coordinators. 1990. Silvics of North America. Volume one: conifers. U.S. Department of Agriculture, Washington, D.C.

Gastil, R.G., R.P. Phillips, and E.C. Allison. 1975. Reconnaissance geology of the State of Baja, California. Memoir 140. The Geological Society of America, Boulder, CO.

Gerecke, K.-L. 1990. 'Tannensterben' und 'neuartige waldschaden' - Ein beitrag aus der siche der waldwachstumskunde. Allgemeine Forst- und Jagdzeitung 161:81-96.

Haller, J.R. 1962. Variations and hybridization in ponderosa and Jeffrey pines. University of California Publications in Botany 34:123-166.

Innes, J.L. 1992. Forest decline. Progress in Physical Geography 16:1-64.

Kilgore, B.M. 1973. The ecological role of fire in Sierran conifer forests. Quaternary Research 3:496-513. 
Kilgore, B.M. and D. Taylor. 1979. Fire history of a sequoiamixed conifer forest. Ecology 60:129-142.

McLaughlin, S.B. and D.J. Downing. 1995. Interactive effects of ambient ozone and climate measured on growth of mature forest trees. Nature 374:252-254.

Miller, P.R., O.C. Taylor, and M.P. Peo. 1986. Spatial variation of summerozone concentrations in the San Bernardino Mountains. Proceedings of the 79th annual meeting of the air pollution control association, June 22-27, 1986. Minneapolis, $\mathrm{MN}$.

Miller, P.R., J.R. McBride, and S.L. Schilling. 1991. Chronic ozone injury and associated stresses affect relative conifer capacity of species comprising the California mixed coniferforest type. Primer SimposioNacional. Agricultura sostenible: Una opcion para el dessarrollo sin deterioro ambiental, Montecillo, Mexico.

Minnich, R.A. 1985. Fire mosaics in southern California and northern Baja California. Science 219:1287-1294.

Minnich, R.A. 1988. The biogeography of fire in the San Bernardino Mountains of California: A historical study. University of California Publications in Geography 27:1-121.

Minnich, R.A., M.G. Barbour, J.H. Burk, and R.F. Fernau. 1995. Sixty years of change in conifer forests of the San Bernardino Mountains. Conservation Biology 9:902-914.

Miranda, F., S. Reyes Coca, J.G. Espinoza, and J. Garcia Lopez. 1991. Climatologia de la region noroeste de Mexico (Baja California, Baja California Sur, Sonora y Sinaloa). Parte II. Temperatura: series de tiempo del valor mensual y estadisticas del ano climatologico. Reporte Tecnico CIOFT9108, Centro de Investigacion Cientifica y de Educacion Superior de Ensenada, Ensenada, Mexico.

Mueller-Dombois, D. 1986. Perspectives for an etiology of stand-level dieback. Annual Review of Ecology and Systematics 17:221-243.
Reyes Coca, S., F. Miranda, and J. Garcia Lopez. 1990 Climatologia de la region noroeste de Mexico (Baja California, Baja California Sur, Sonora y Sinaloa). Parte I. Precipitacion: series de tiempo del valor tottal mensual y estadisticas del ano climatologico. Reporte Tecnico CIOFT9001, Centro de Investigacion Cientifica y de Educacion Superior de Ensenada, Ensenada, Mexico.

Savage, M. 1991. Structural dynamics of a southwestern pine forest under chronic human disturbance. Annals of the Association of American Geographers 81:271-289.

Savage, M. 1994. Anthropogenic and natural disturbance and patterns of mortality in a mixed conifer forest in California. Canadian Journal of Forest Research 24:1149-1159.

Savage, M. 1997. The role of anthropogenic disturbance in a mortality episode in a mixed-conifer forest. Journal of Vegetation Science 8:95-194.

Schowalter, T.D. 1985. Adaptations of insects to disturbance. Pp. 235-252 in S.T.A. Pickett and P.S. White, eds. The Ecology of Natural Disturbance and Patch Dynamics. Academic Press, Orlando, FL.

Sprugel, D.G. and F.H. Bormann. 1981. Natural disturbance and the steady state in high-altitude balsam fir forests. Science 211:390-393

Stark, R.W., P.R. Miller, F.W. Cobb, D.L. Wood, and J.R. Parmenter. 1968. Incidence of bark infestation. Hilgardia 39:121-126.

Vankat, J.L. 1977. Fire and man in Sequoia National Park. Annual Association of American Geographers 67:17-27.

Vankat, J.L. and J. Major. 1978. Vegetation changes in Sequoia National Park, California. Journal of Biogeography 5:377402

Warde, W. and J. W. Petranka. 1981. A correction factor table for missing point-center quarter data. Ecology 62:491-494.

Williams, W.T. 1983. Tree growth and smog disease in the forests of California: Case history, ponderosa pine in the southern Sierra Nevada. Environmental Pollution 30A:59. 75. 


\section{Habitat Fragmentation}

Our economic system is a wholly-owned subsidiary of the environment 


\title{
Mammalian Carnivores as Target Species for Conservation in Southern California
}

\author{
Kevin Crooks \\ Biology Department, University of California, Santa Cruz, CA 95064 \\ Tel. (619) 646-0008; e-mail: crooks@biology.ucsc.edu
}

\begin{abstract}
Mammalian carnivores are particularly sensitive to environmental disturbances. Because of this, they may be valuable indicators of ecosystem health and as umbrella species on which to base conservation strategies. Herein, I review my ongoing research on the effects of urban habitat fragmentation on carnivore populations in southern California. My purpose is to use information to date on the distribution and abundance of mammalian predators across the urban landscape to assess their relative sensitivities to habitat fragmentation. I then use these differential vulnerabilities to evaluate the utility of mammalian predators as targets for conservation and management plans in southern California. In all, the protection of mammalian predators requires a marriage of scientific data, sound planning, and citizen involvement.
\end{abstract}

Keywords: Bobcat; coyote; domestic cat; habitat fragmentation; indicator species; mammalian carnivore; mesopredator release; umbrella species.

\section{Introduction}

Habitat fragmentation has been targeted as one of the most serious threats to biological diversity worldwide (Wilcox and Murphy 1985; Soule 1991a), and in areas with increasing urbanization, fragmentation is virtually inevitable (Soulé 1991b). In coastal southern California, intensive development over the past century has destroyed most of the native sage scrub and chaparral habitats. This massive habitat loss, in conjunction with high levels of local endemism of native species, has helped create a "hotspot" of endangerment and extinction in the region (Myers 1990; Dobson et al. 1997).

Mammalian carnivores are particularly vulnerable to extinction in fragmented habitat because of relatively large body sizes, wide ranges, low densities, slow population growth rates, and direct persecution by humans (Terborgh 1974; Williamson 1981; Brown and Gibson 1983; Heany 1986; Pimm et al. 1988; Cox and Moore 1993; Alcover and McMinn 1994; Noss et al. 1996). Top predators such as mountain lions (Felis concolor), bobcats (Felis rufus), and coyotes (Canis latrans) may not be able to persist in habitat fragments, especially small, isolated remnants not connected by movement corridors (Soulé et al. 1988; Beier 1993). Surprisingly little is known, however, on the effects of the widespread habitat destruction in southern California on carnivore populations, or how species might differ in their relative vulnerability to fragmentation.

The disappearance of top predators from fragmented systems may generate trophic cascades that ripple down the food web (Robinson 1953; Linhart and Robinson 1972; Sargeant et al. 1983; Voight and Earle 1983; Schmidt 1986; Johnson et al. 1989; Sovada et al. 1995; Ralls and White 1995). For instance, dominant carnivores can suppress smaller carnivores through both competition and predation (Voight and Earle 1983; Sargeant et al. 1987; Theberge and Wedeles 1989; Harrison et al. 1989). Consequently, the decline of predators in fragmented areas may lead to the ecological release of "opportunistic mesopredators", such as gray foxes (Urocyon cinereoargenteus), raccoons (Procyon lotor), striped skunks (Mephitis mephitis), opossums (Didelphis virginianus), and domestic cats (Felis felis). Such "mesopredator release" (Soulé et al. 1988) has been implicated in the decline and extinction of prey species (Willis and Eisenmann 1979; Matthiae and Stearns 1981; Whitcomb et al. 1981; Sargeant et al. 1983; Wilcove et al. 1986; Soulé et al. 1988; Terborgh 1988; Sovada et al. 1995; Palomares et al. 1995).

Previous workers (Soulé et al. 1988, 1992) have suggested, based on statistical evidence, that the local extinction of coyotes and subsequent mesopredator release may be a significant factor in the observed disappearance of shrub specialist bird species from urban chaparral fragments in San Diego County. Whereas coyotes prey primarily on lagomorphs and rodents (Gier 1975; Bekoff 1977), smaller carnivores are particularly effective predators on birds, bird nests, and other vertebrates (Ewer 1973; Emlen 1974; Weber 1975; Sargeant et al. 1983; Johnson et al. 1989; Sovada et al. 1995). Thus, dominant carnivores such as coyotes in southern California may act as "keystone predators", species whose removal dramatically alters the composition of ecological communities by re- 
sulting in the decline and extinction of some species and marked increase in others (Paine 1969; Mills et al. 1993; Menge et al. 1994).

Since mammalian carnivores are particularly vulnerable to environmental disturbances and may play important structuring roles in the ecological community, they can function as useful conservation tools (Noss et al. 1996). For instance, large predators may act as indicator species - ecologically pivotal organisms whose status is indicative of the structure, function, and composition of the ecosystem. Another tactic to preserve biodiversity is to treat mammalian predators as "umbrella species" for conservation. The rationale of the umbrella species concept is that protection of areas needed for large-bodied, wide-ranging predators will also provide protection for smaller species with more restricted ranges. Few studies, however, have critically evaluated the appropriateness of different predator species to act as indicators for environmental disturbances and as umbrellas species for conserving biodiversity.

In this paper I review my ongoing research on the effects of urban habitat fragmentation on carnivore populations in southern California (Crooks, in preparation). My purpose is to assess the relative sensitivities of mammalian predators to habitat fragmentation across the urban landscape. I then use these differential vulnerabilities to evaluate the utility of mammalian predators as targets for conservation and management plans in southern California.

\section{Study Areas}

San Diego County generally consists of coastal mesas dissected by steep-sided ravines or canyons. Nearly all of the coastal mesas have been developed, leaving these canyons as habitat islands immersed within the urban sea of southern California. In the 1980's Michael Soulé initiated a series of studies investigating the effects of habitat fragmentation on chaparral and sage scrub plants and animals in this system (Soulé et al. 1988). Since then the San Diego canyons have become one of the most wellstudied set of habitat fragments worldwide, yielding research on birds (Soulé et al. 1988; Bolger et al. 1991; Soulé et al. 1992), rodents (Bolger et al. 1997), vegetation (Alberts et al. 1993), nest-predation (Langen et al. 1991), and invertebrates (Suarez et al., in preparation; Bolger et al. in preparation). Indeed, these canyons present an excellent experimental system in which to assess fragmentation effects given their variation in such ecological factors as fragment age, fragment size, fragment isolation, habitat quantity, habitat quality, and interspecific interactions (e.g., predation and competition).

My research focused on the mammalian carnivores in this system (Crooks, in preparation). From summer 1995 through summer 1997 I conducted carnivore surveys in a subset of 28 of the original 37 habitat patches (Fig. 1) originally studied by Soule et al. (1988). In addition, I also surveyed several large, less disturbed areas to provide baseline data and to act as controls to the small, ur-

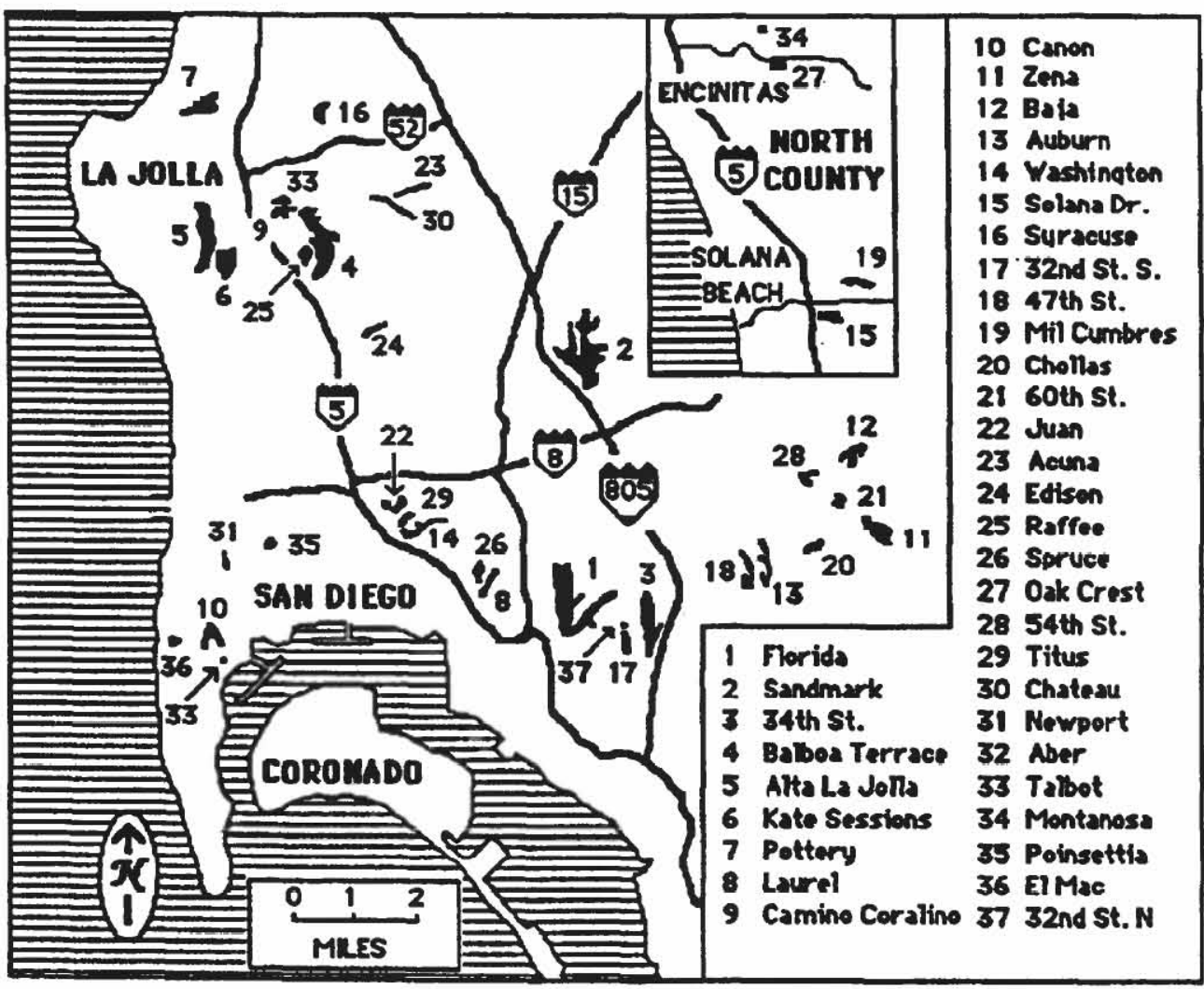

Figure 1. Location of study sites in San Diego County, California (reprinted with permission from Soulé et al. 1988) 
ban habitat isolates. These control areas varied in size, and included sites in San Diego County (Point Loma Ecological Reserve, Torrey Pines State Reserve, Miramar Naval Air Station), Orange County (Starr Ranch Audubon Sanctuary), and Riverside County (Lake Perris Recreation Area).

\section{Multiple Independent Indices}

Mammalian carnivores are inherently difficult to census given their large home ranges, small populations, nocturnality, and extreme wariness due to direct persecution by humans. Absolute density estimates for carnivores are therefore elusive. As a result, indirect survey techniques, such as scat and track indices, have been developed to evaluate the relative abundance of carnivore populations. I have used standard survey methods, as well as new techniques, to survey carnivore populations across the fragmented landscape (Crooks, in preparation). Distribution and relative abundance of predators were assessed using: (1) scat counts along transect lines, (2) species identification of carnivores through analyses of mitochondrial DNA in fresh scats (Foran et al. in press), (3) track counts of animals attracted to scent lures, (4) remotely-triggered cameras established at track stations, (5) questionnaires distributed to residents bordering habitat fragments, and (6) identification of road kills along roadways through natural areas. Target species included mountain lion, bobcat, coyote, gray fox, raccoon, striped skunk, spotted skunk, opossum, domestic dog, and domestic cat.

\section{Sensitivity to Fragmentation}

I used three different landscape variables as descriptors of habitat fragmentation: (1) area - the size of the habitat patch, (2) age - the number of years the patch had been isolated by urban development, and (3) isolation the distance to the nearest habitat patch. I then used two separate, yet complementary measures, Pearson correlation matrices and incidence functions, to evaluate how these landscape descriptors influenced the relative abundance and distribution of carnivore populations (Crooks, in preparation).

The Pearson correlations measured the relationship between landscape variables and carnivore relative abundance, as assessed through a combination of track and scat indices. The correlation matrices generally revealed clear trends in sensitivities to fragmentation (Fig. 2). Mountain lions, spotted skunks, bobcats, and coyotes were classified as fragmentation sensitive species because relative abundance increased with patch size and decreased with patch age and isolation. Raccoons, domestic cats, gray foxes, and opossums displayed an opposite pattern; track
LANDSCAPE VARIABLES v RELATIVE ABUNDANCE DIRECTION OF CORRELATIONS

\begin{tabular}{|c|c|c|c|c|}
\hline & & Age & Area & Isolation \\
\hline \multirow{4}{*}{$\begin{array}{l}\text { Fragmentation } \\
\text { Senultive }\end{array}$} & Mountain Lion & - & + & - \\
\hline & Spotted skunk & - & + & - \\
\hline & Bobcat & - & + & - \\
\hline & Coyote & - & + & - \\
\hline \multirow[t]{5}{*}{$\begin{array}{l}\text { rragmontation } \\
\text { Tolerant }\end{array}$} & Dog & Ns & NS & NS \\
\hline & striped skunk & ws & NS & NS \\
\hline & Raccoon & + & - & NS \\
\hline & Gray Fox & + & - & + \\
\hline & Cat & + & - & NS \\
\hline $\begin{array}{l}\text { rragmentacion } \\
\text { Enhanced }\end{array}$ & Oposaum & + & - & + \\
\hline
\end{tabular}

Figure 2. Direction of Pearson correlations between landscape descriptors and carnivore relative abundance as assessed through scat and track indices (see text). The species are qualitatively ranked by their degree of sensitivity to habitat fragmentation, ranging from fragmentation sensitive to fragmentation enhanced. + represents a significant positive correlation $(p<0.1)$, - rcpresents a significant negative correlation $(p<0.1)$, and NS represents a non-significant correlation (Crooks, unpublished data)

and scat indices generally decreased with patch size and increased with patch age and isolation. The exotic mesopredators, domestic cats and opossums, were particularly associated with urban areas and can be considered fragmentation enhanced. Landscape descriptors had relatively little effect on domestic dogs and striped skunks.

Incidence functions measured the relationship between landscape variables and occupation, defined as the proportion of patches occupied by each species. $\Lambda$ species was classified as "occupying" a particular habitat patch if the suite of survey techniques detected the animal in the patch during the course of the study. Consequently, occupancy in this case does not necessarily imply that the habitat patch is large enough to permanently support a carnivore population. Rather, it measures the ability of each species to at least visit the site. I estimated incidence functions for both native (Fig. 3) and exotic (Fig. 4) species by placing habitat patches into classes based on their size, and then calculating the percent of patches in each size class that were occupied by each species.

Incidence functions yielded trends in vulnerabilities to fragmentation similar to those evident in the correlation matrices. Mountain lions, spotted skunks, and bobcats occurred only in the largest study sites. Coyote occupancy was high in all but the smallest class of habitat 


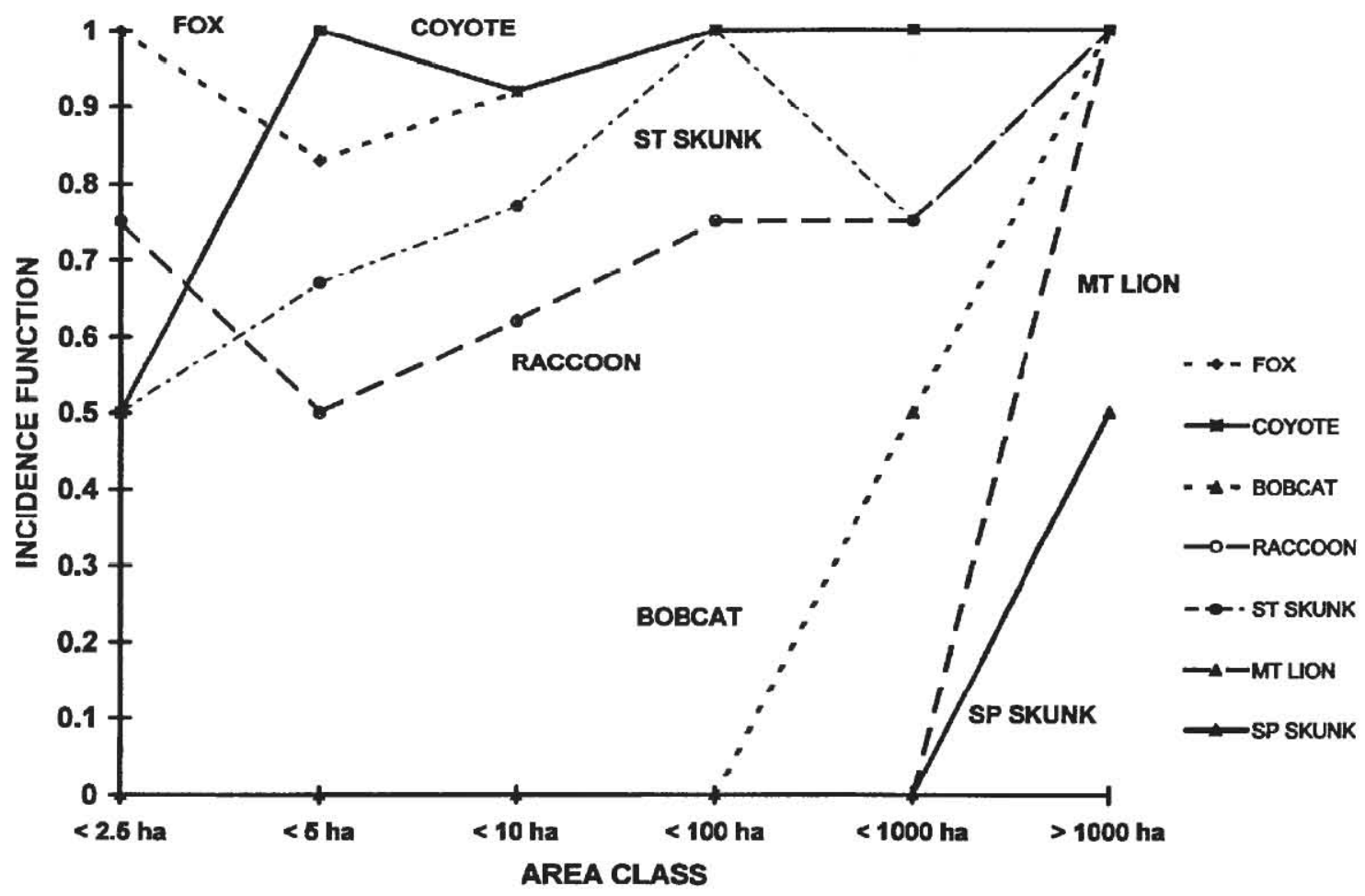

Figure 3. Proportion of habitat patches in each size class occupied by a species (Incidence Function) for native mammals in southern California (from Crooks, unpublished data).

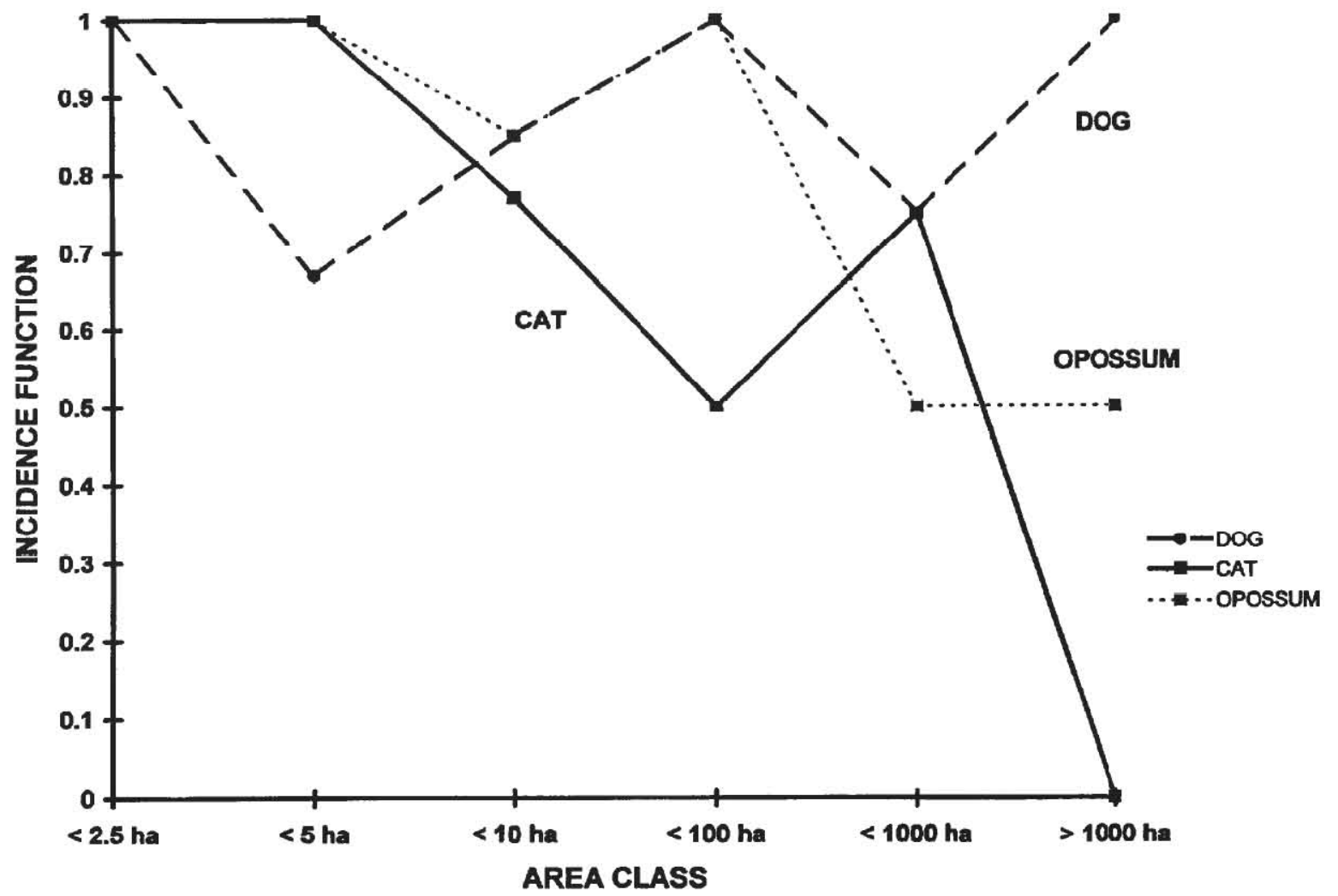

Figure 4. Proportion of habitat patches in each size class occupied by a species (Incidence Function) for non-native exotic mammals in southern California (from Crooks, unpublished data). 
fragments, whereas raccoons, foxes, striped skunks, and domestic dogs were detected in most habitat patches regardless of size. Opossums and cats primarily occupied the small, urban habitat fragments.

\section{Targets for Conservation}

Differential sensitivities to habitat fragmentation are useful as criteria when choosing appropriate carnivore species as indicators and/or umbrellas for conservation planning in southern California. Gencrally, both correlation matrices and incidence functions indicated that mountain lions and spotted skunks were the most sensitive predators to habitat fragmentation; these species were only detected in the largest, least fragmented control areas. Spotted skunks, unlike the larger and more conspicuous striped skunks, are a relatively secretive species (Crooks 1994). The status of the spotted skunk in California is currently unclear and there is growing concern that the species is becoming rare. Although spotted skunks appear sensitive to habitat fragmentation and perhaps are good indicators of environmental disturbances, their restricted ranges and habitat requirements limit their utility as umbrella species.

Mountain lions possess large body sizes and extremely wide ranges and hence are one of the most sensitive predator species to fragmentation effects. Beier (1993) estimated that $1000-2000 \mathrm{~km}^{2}$ of habitat would be necessary to maintain a lion population with a $98 \%$ probability of persistence for 100 years. Many of the fragmented systems in southern California therefore are likely too small and too isolated to permanently support any resident lion populations. Although dispersing lions may occasional enter urban systems (Beier 1993), such events will likely be infrequent and therefore difficult to detect and monitor. Consequently, mountain lions are not an appropriate target species for monitoring and management plans in many disturbed areas in the region. The wide ranges and high sensitivity of lions to environmental perturbations, however, do make them a useful umbrella and indicator species in less fragmented wildlands.

Mesopredators generally were detected most frequently in the smaller, older, and more isolated habitat fragments. Indeed, both our field and questionnaire surveys clearly indicate that these smaller predators are quite insensitive to habitat fragmentation and fare well in urban situations. Although coyote relative abundance generally decreased in older and more isolated fragments, coyotes, like the mesopredators, can travel through the urban matrix to visit relatively isolated habitat patches. During the course of my study, only a few sites, those habitat isolates deep in the center of the city, never had coyote visitations. This relative insensitivity to disturbance limits the effectiveness of coyotes to act as indicator species for habitat fragmentation; their most useful role as an indicator would be in highly fragmented systems that have already lost bobcats and mountain lions. Nevertheless, coyotes can play an important structuring role in ecological communities through their interactions with mesopredators (see below). As such, management plans should target coyotes to ensure their persistence in fragmented landscapes.

Of all the southern California carnivores, bobcats were most intermediate in their vulnerability to habitat fragmentation; they still exist in fragmented and disturbed habitats, but only those with adequate movement corridors. They are therefore less sensitive to disturbance than are mountain lions, which seldom use these fragmented areas, yet are more sensitive than coyotes, which can persist in all but the most disturbed habitat isolates. Bobcats therefore may be excellent target species on which to base future monitoring and management programs in fragmented landscapes at the urban/wildland interface. Bobcats, due to their solitary nature and large ranges, also can function as umbrellas for species with more restricted ranges. Further, they are charismatic animals that likely evoke less public concern than other species of large predators. For instance, bobcats rarely attack and kill humans, and attack and kill fewer pets than do coyotes. Conservation plans for mammalian predators may therefore be easier to justify to both funding agencies and the general public if bobcats are presented as a focal species.

Monitoring is an essential component of any management plan. Multiple detection methods, such as the scat, track, camera, questionnaire, and road kill surveys developed in this study, can be used in concert to develop monitoring programs for carnivores. Mountain lions should be a target species in larger, unfragmented areas, bobcats a target species in most fragmented landscapes in the region, and coyotes a target in highly fragmented urban areas which have already lost lions and bobcats. It should be noted, however, that although top predators have wide ranges and are sensitive to environmental perturbations, these traits do not necessarily ensure that they will be the most effective focal species in the region (Noss et al. 1996). Ryti (1992) found that a conservation plan designed to protect all native plants in southern California would protect $96 \%$ of all vertebrates. In contrast, a reserve designed to ensure mountain lion persistence might not encompass all endemic plant sites and other areas of high biodiversity (Noss et al. 1996). Nevertheless, when choosing targets for conservation, we must not only consider sensitivities to disturbance and the coverage of other species, but also the effectiveness of the target's role as a flagship species. Charismatic animals such as large carnivores can often generate public interest more so than rare, endemic plant species. Moreover, the protection of top predators requires connectivity between discontinuous natural areas, not necessarily a pre-requisite for rare species with restricted ranges. 


\section{Mesopredator Release}

Of all the top predators, coyotes have the most direct impact on populations of urban mesopredators. Distribution and relative abundance of coyotes is consistently negatively related with that of smaller carnivores, especially gray foxes, opossums, and domestic cats in the urban canyons (Crooks, in preparation). However, given that coyotes can persist in many urban habitat fragments, the local extinction of coyotes and subsequent "mesopredator release" is not an immediate threat in many areas. It must be emphasized though, that even in areas where coyotes are present, urban mesopredators still can be a considerable predation threat on native prey populations. Moreover, as coyotes disappear from small habitat isolates, or visit them only infrequently, smaller carnivores can become more active and abundant.

Perhaps the most important interaction between coyotes and smaller carnivores is that between coyotes and domestic cats. Of all the urban mesopredators, domestic cats may be especially devastating because they are maintained far above carrying capacity by nutritional and other subsidics from humans (Ilubbs 1951; Eberhard 1954; Bradt 1949; Erlinge et al. 1983; Churcher and Lawton 1987; Neville 1989; Coleman and Temple 1993). In southern California densities of cats surrounding natural areas can be high; nearly one-third of all respondents to our questionnaires currently owned cats. Further, domestic cats are recreational hunters which can decimate prey populations. They capture prey despite being fed and cared for by people and continue to kill prey even when prey populations are low (Coleman and Temple 1993).

Coyotes can affect both the behavior of cats and their owners (Crooks, in preparation). Coyotes certainly kill domestic cats, as is evident by cat remains both in coyote scat and in study sites with coyotes. Both track surveys and radio-telemetry indicate that domestic cats seldom visit the interior of large fragments supporting coyotes and rather primarily frequent the fragment edges and urban matrix. Many cat owners are well aware of the threat of coyotes to their pets. Nearly half of all cat owners in areas with coyotes reported that coyotes had attacked or killed their cats. Further, cat owners, especially those that have previously lost pets to predation, were less likely to let their cats outdoors in areas with coyotes; about twothirds of all cat owners who believed coyotes to be in their canyons somehow restricted their cat's outdoor activity because of the coyotes presence. Nevertheless, cats still pose a distinct threat to native prey species. Nearly threequarters of all cat owners let out their cats, and cats that were let out brought back prey items to the residence. These prey included a wide variety of native birds, rodents, and lizards (Crooks, unpublished data).

Thus, the presence of coyotes in urban natural areas may be beneficial to native species by reducing numbers and activity of potentially damaging mesopredators. Most importantly, coyotes may act as an important deterrent to cat predation. Consequently, unless strong reasons exist to do otherwise (such as coyote predation on threatened or endangered species), resource managers should oppose the "control" of large carnivores such as coyotes in these systems. Further, it is essential that urban habitat fragments maintain connectivity to large natural areas that currently support source populations of coyotes. One of the most practical and effective measures to maintain wildlife in urban settings is the establishment of linkages that permit dispersal across barriers such as roadways and developments (Noss 1983, 1987; Soulé 1991b; Soulć and Gilpin 1991; Noss et al. 1996). For some species, such "conservation corridors" need not be huge, elaborate structures (although usually the larger the better). Research has shown that amphibians, reptiles, birds, rodents, and small to medium-sized predators (e.g., bobcats, coyotes, foxes, raccoons, and opossums) will use even small culverts and drainages as movement corridors. Bridges or underpasses, however, are often required to accommodate the movement of larger species, such as deer and mountain lions, through the urban environment. Where functional movement corridors are not retained across the urban landscape, many wildlife populations, especially large carnivores, will eventually disappear.

\section{Education and the General Public}

The acceptance by the general public of mammalian carnivores is essential for their protection. This is especially true in urban settings where human-carnivore interactions are intensified. To increase tolerance of carnivores, education programs should be directed at residents bordering natural areas. Kellert et al. (1996) provide general recommendations to instill more positive attitudes towards carnivores. They emphasize that education which solely imparts general information to increase factual knowledge about predators may prove ineffective, sometimes even reinforcing negative attitudes among those already possessing strong views. They emphasize that rather than simply providing more factual information on a species, education should directly target negative attitudes or perceptions concerning carnivores. For instance, in southern California we could focus on the public's negative, and often exaggerated, beliefs concerning the threat of predators to both humans and pets. Potential educational options include information dispersal through the local media, distribution of pamphlets and flyers to residents bordering natural areas, and the development of local school programs. Further, Kellert et al. (1996) stress that education must emphasize all values represented by these species. Although the importance of predators is often couched in terms of their presumed ecological or economic significance, we must also emphasize the many 
aesthetic, visceral, and even spiritual values provided by these charismatic animals.

Encouragingly, the questionnaires generally indicated that the majority of residents liked to have wildlife, including mammalian carnivores, in adjacent wildlands and were concerned for their protection (Crooks, in preparation). Although about two-thirds of residents realized that coyotes were a threat to pets, less then $10 \%$ of respondents did not want them in neighboring natural areas or thought depredating coyotes should be killed. Residents also demonstrated considerable knowledge of the wildlife in their backyards - their responses to the questionnaires corresponded well to our field surveys on the actual distribution and abundance of carnivores in the area. Nevertheless, despite their conservation concern, most cat owners bordering natural areas still let out their cats, and less than half of respondents believed that cats were an important predator in these urban habitat fragments. Education of risks to both cats and native species may help to decrease the negative impacts of cats on natural systems.

In all, the protection of natural areas in southern California requires the collaboration between scientists, resource managers, government agencies, city planners, urban developers, and perhaps most importantly, the general public. Quantitative data on the effects of environmental disturbances such as habitat fragmentation are essential to make informed decisions when developing conservation and management plans to protect native biodiversity. Only through a marriage of science, sound planning, and citizen involvement can we successfully maintain the ecological integrity of fragmented systems across the urban landscape.

Acknowledgments. I thank Michael Soulé for his guidance and inspiration throughout this project. D. Bolger, T. Case, J. Crooks, D. Doak, S. Hathaway, B. Kelly, T. Lynam, S. Minta, P. Raimondi, B. Rice, and A. Suarez all provided helpful advice and assistance during the course of the project. The research would not have been possible without the hard work and dedication of the many assistants who helped me in the field, as well as the cooperation of Torrey Pines State Reserve, Point Loma Ecological Reserve, Naval Air Station Miramar, Lake Perris Recreation Area, and Starr Ranch Audubon Sanctuary. Lastly, I thank R. Sauvajot and J. Keeley for organizing the symposium and inviting me to participate. This research was funded by grants from the American Society of Mammalogists, Dan Brimm, an Environmental Protection Agency STAR Graduate Fellowship, the Mountains Recreation and Conservation Authority, a National Science Foundation Graduate Fellowship, Phi Beta Kappa Honor Society, and Torrey Pines State Reserve.

\section{Literature Cited}

Alberts, A.C., A.D. Richman, D. Tran, R. Sauvajot, C. McCalvin, and D.T. Bolger. 1993. Effects of habitat fragmentation on populations of native and exotic plants in southern California coastal scrub. Pp 103-110 in J.E. Keeley, ed. Interface between ecology and land development in California. Southern California Academy of Sciences, Los Angeles, CA.

Alcover, J.A. and M.McMinn. 1994. Predators of vertebrates on islands. BioScience 44:12-18.

Beier, P. 1993. Determining minimum habitat areas and habitat corridors for cougars. Conservation Biology 7:94-108.

Bekoff, M. 1977. Canis latrans. Mammalian Species, no. 79.

Bolger, D.T., A. Alberts, and M.E. Soulé. 1991. Occurrence patterns of bird species in habitat fragments: sampling, extinction, and nested species subsets. American Naturalist 137:155166.

Bolger, D.T. A.C. Alberts, R.M. Sauvajot,P. Potenza, C. McCalvin, D. Tran, S. Mazzoni, and M.E. Soulé. 1997. Responses of rodents to habitat fragmentation in coastal southern California. Ecological Applications 7:552-563.

Bradt, G.W. 1949. Farm cat as predator. Michigan Conservation 18:25-26.

Brown, J.H. and A.C. Gibson. 1983. Biogeography. C.V. Mosby Company, St. Iouis, MO.

Churcher, J.B. and J.H. Lawton. 1987. Predation by domestic cats in an English village. Journal of Zoology 212:439-456.

Coleman, J.S. and S.A. Temple. 1993. Rural residents' freeranging domestic cats: a survey. Wildlife Society Bulletin 21:381-390.

Cox, C.B. and P.D. Moore. 1993. Biogeography: an ecological and evolutionary approach. Fifth Edition. Blackwell Scientific Publications, Oxford, UK.

Crooks, K.R. 1994. Demography and status of the island fox and island spotted skunk of Santa Cruz Island, California. Southwestern Naturalist 39: 257-262.

Dobson, A.P., J.P. Rodriguez, W.M. Roberts, and D.S. Wilcove. 1997. Geographic distribution of endangered species in the United States. Science 275:550-553.

Eberhard, T. 1954. Food habits of Pennsylvania house cats. Journal of Wildlife Management 18:284-286.

Emlen, J.T. 1974. An urban bird community in Tucson, Arizona: derivation, structure, regulation. Condor 76:184-197.

Erlinge, S.G., G. Goransson, O. Liberg, J. Loman, I. Nilsson, T. von Schantz, and M. Sylvên. 1983. Predation as a regulating factor in small rodent populations in southern Sweden. Oikos 40:36-52.

Ewer, R.F. 1973. The carnivores. Cornell University Press, Ithaca, NY.

Foran, D., K. Crooks, and S. Minta. In press. Species identification: an unambiguous genetic method. Wildlife Society Bulletin.

Gier, H.T. 1975. Ecology and behavior of the coyote (Canis latrans). Pp 247-262 in M.W. Fox, ed. The wild canids. Van Nostrand Reinhold, NY.

Harrison, D.J., J.A. Bissonette, and J.A. Sherburne. 1989. Spatial relationships between coyotes and red foxes in Eastern Maine. Journal of Wildlife Management 53:181-185.

Heany, L.R. 1986. Biogeography of mammals in SE Asia: estimates of rates of colonization, extinction, and speciation. Biological Journal of the Linnean Society 28:127-165.

Hubbs, E.L. 1951. Food habits of feral house cats in the Sacramento Valley. California Fish and Game 37:177-189. 
Johnson, D.H., A.B. Sargeant, and R.J. Greenwood. 1989. Importance of individual species of predators on nesting success of ducks in the Canadian Prairie Pothole Region. Canadian Journal of Zoology 67:291-297.

Kellert, S.R., M. Black, C.R. Rush, and A.J. Bath. 1996. Human culture and large carnivore conservation in North America. Conservation Biology 10:977-990.

Langen, T.A., D.T. Bolger, and T.J. Case. 1991. Predation on artificial bird nests in chaparral fragments. Oecologia 86:395401.

Linhart, S.B. and W.B. Robinson. 1972. Some relative carnivore densities in areas under sustained coyote control. Journal of Mammalogy 53:880-884.

Matthiae, P.E. and F. Stearns. 1981. Mammals in forest islands in southeastern Wisconsin. Pp 55-66 in R. L. Burgess and D. M. Sharpe, eds. Forest island dynamics in man-dominated landscapes. Springer-Verlag, New York, NY.

Menge, B.A., E.L. Berlow, C.A. Blanchette, S.A. Navarrete, and S.B. Yamada. 1994. The keystone species concept: variation in interaction strength in a rocky intertidal habitat. Ecological Monographs 64:249-286.

Mills, L.S., M.E. Soulé, and D.F. Doak. 1993. The keystonespecies concept in ecology and conservation. Bioscience 43:219-224.

Myers, N. 1990. The biodiversity challenge: expanded hot-spots analysis. Environmentalist 10:243-256.

Neville, P.F. 1989. Feral cats: management of urban populations and pest problems by neutering. Pp 261-268 in P.J. Putham, ed. Mammals as pests. Chapman and Hall, London, UK.

Noss, R.F. 1983. A regional landscape approach to maintain diversity. Bioscience 33:700-706.

Noss, R.F. 1987. Corridors in real landscapes: a reply to Simberloff and Cox. Conservation Biology 1:159-164.

Noss, R.F., H.B. Quigley, M.G. Hornocker, T. Merrill, and P.C. Paquet. 1996. Conservation biology and carnivore conservation in the Rocky Mountains. Conservation Biology 10:949963.

Paine, R.T. 1969. A note on trophic complexity and species diversity. American Naturalist 103:91-93.

Palomares, F., P. Gaona, P. Ferreras, and M. Delibes. 1995. Positive effects on game species of top predators by controlling smaller predator populations: an example with lynx, mongooses, and rabbits. Conservation Biology 9:295-305.

Pimm, S.L., H.L. Jones, and J. Diamond. 1988. On the risk of extinction. American Naturalist 132:757-785.

Ralls, L. and P.J. White. 1995. Predation on San Joaquin kit foxes by larger canids. Journal of Mammalogy 76:723-729.

Robinson, W.B. 1953. Population trends of predators and fur animals in 1080 Station Areas. Journal of Mammalogy 34:220-227.

Ryti, R.T. 1992. Effect of the focal taxon on the selection of nature reserves. Ecological Applications 2:404-410.

Sargeant, A.B., S.H. Allen, and R.T. Eberhardt. 1983. Red fox predation on breeding ducks in midcontinent North America. Wildlife Monographs Number 89.

Sargeant, A.B., S.H. Allen, and J.O. Hastings. 1987. Spatial relations between sympatric coyotes and red foxes in North Dakota. Journal of Wildlife Management 51:285-293.

Schmidt, R.H. 1986. Community-level effects of coyote population reduction. American Society for Testing and Materials, Special Technical Publication 920:49-65.

Soulé, M.E. 1991a. Conservation: tactics for a constant crisis. Science 253:744-750.
Soulé, M.E. 1991b. Landuse planning and wildlife maintenance: guidelines for conserving wildlife in an urban landscape. Journal of the American Planning Association 57:313-323.

Soulé, M.E., A.C. Alberts, and D.T. Bolger. 1992. The effects of habitat fragmentation on chaparral plants and vertebrates. Oikos 63:39-47.

Soulé, M.E., D.T. Bolger, A.C. Alberts, R. Sauvajot, J. Wright, M. Sorice, and S. Hill. 1988. Reconstructed dynamics of rapid extinctions of chaparral-requiring birds in urban habitat islands. Conservation Biology 2:75-92.

Soulé, M.E. and M.E. Gilpin. 1991. The theory of wildlife corridor capability. Pp 3-8 in D.A. Saunders and R.J. Hobbs, eds. Nature conservation 2: the roles of corridors. Surrey Beatty and Sons. Chipping Norton, NSW, Australia.

Sovada, M.A., A.B. Sargeant, and J.W. Grier. 1995. Differential effects of coyotes and red foxes on duck nest success. Journal of Wildlife Management 59:1-9.

Terborgh, J. 1974. Preservation of natural diversity: the problem of extinction-prone species. Bioscience 24:715-722.

Terborgh, J. 1988. The big things that run the world - a sequel to E.O. Wilson. Conservation Biology 2:402-403.

Theberge, J.B. and C.H.R. Wedeles. 1989. Prey selection and habitat partitioning in sympatric coyote and red fox populations, southwest Yukon. Canadian Journal ofZoology 67:12851290.

Voight, D.R. and B.D. Earle. 1983. Avoidance of coyotes by red fox families. Journal of Wildlife Management 47:852-857.

Weber, W.C. 1975. Nest-sites of birds in residential areas of Vancouver, British Columbia. Canadian Field-Naturalist 89:457-460.

Whitcomb, R.F., S.S. Robbins, J.F. Lynch, B.I. Whitcomb, M.K. Klimkiewicz, and D. Bystrak. 1981. Effects of forest fragmentation on avifauna of the eastern deciduous forest. Pp 125-292 in R.L. Burgess and D.M. Sharpe, eds. Forest island dynamics in man-dominated landscapes. Springer-Verlag, New York, NY.

Wilcove, D.S., C.H. McLellan, and A.P. Dobson. 1986. Habitat fragmentation in the Temperate Zone. Pp 237-256 in M.E. Soulé, ed. Conservation biology: the science of scarcity and diversity. Sinauer Associates, Sunderland, MA.

Wilcox, B. and D. Murphy. 1985. Conservation strategy: the effects of fragmentation on extinction. American Naturalist 125:879-997.

Williamson, M. 1981. Island populations. Oxford University Press, Oxford, UK.

Willis, E.O. and E. Eisenmann. 1979. A revised list of birds in Barro Colorado Island, Panama. Smithsonian Contributions in Zoology 291:1-31. 


\title{
Distribution and Status of Carnivores in the Santa Monica Mountains, California: Preliminary Results from Radio Telemetry and Remote Camera Surveys
}

\author{
Raymond M. Sauvajot ${ }^{1}$, Eric C. York' ${ }^{1}$ Todd K. Fuller ${ }^{2}$, H. Sharon Kim¹, \\ Denise A. Kamradt ${ }^{1}$, and Robert K. Wayne ${ }^{3}$ \\ ${ }^{1}$ U.S. National Park Service, 401 W. Hillcrest Drive, Thousand Oaks, CA 91360 \\ Tel.805-370-2300; e-mail: ray_sauvajot@nps.gov; denise_kamradt@nps.gov; eric_york@nps.gov; sharon_kim@nps.gov. \\ ${ }^{2}$ Department of Forestry and Wildlife Management, Holdsworth Natural Resources Center, University of Massachusetts, \\ Amherst, MA 01003-4210 \\ Tel. (413) 545-4723; Fax (413) 545-4358; e-mail: tkfuller@forwild.umass.edu \\ ${ }^{3}$ Department of Biology, University of California, Los Angeles, CA 90095-1606 \\ Tel. (310) 206-0334; Fax (310) 206-3987; e-mail: rwayne@biology.lifesciucla.edu
}

\begin{abstract}
Carnivores play critical roles in ecosystem functions and are indicators of ecosystem health. Habitat fragmentation, often caused by urban development, particularly endangers carnivores due to their low population densities and large home range sizes. Very little is known about how habitat fragmentation threatens carnivore survival and how wildlife corridors may help mitigate fragmentation effects. This paper reports on preliminary results from ongoing carnivore research in the Santa Monica Mountains National Recreation Area addressing these issues. The project includes two components: (1) radio telemetry to evaluate home range requirements, habitat needs, and movement patterns for bobcats, coyotes, and gray foxes, and (2) remote camera surveys to evaluate overall carnivore distributions and to assess population sizes of marked animals. From early 1996 to 1998,30 bobcats, 58 coyotes, and 18 gray foxes have been monitored using radio telemetry. During this period, significant mortality factors have included vehicle collisions, interspecific predation, and anticoagulant poisoning. Preliminary data analyses suggest that coyotes travel the greatest distances, exhibit the largest home range sizes, and venture most often into developed areas relative to bobcats and gray foxes. Initial results demonstrate the significance of freeways as obstacles to carnivore movement; only two successful crossings of the Ventura Freeway have been confirmed for radio-collared coyotes. Pressure plate triggered cameras appear effective for determining the presence of most carnivores, and will likely be useful for estimating population sizes for bobcats and gray foxes. Coyotes, however, are difficult to photograph using the pressure plate system. Future plans include continued monitoring of radio-collared animals, more sophisticated analyses of carnivore distributions in the context of habitat variation,
\end{abstract}

urban development, and movement barriers, and ongoing development and implementation of remote camera surveys. Overall results of the project will be incorporated into park planning, land protection, and restoration strategies, and be used to develop wildlife management actions needed to conserve carnivore populations.

Keywords: Bobcats; carnivores; coyotes; gray foxes; habitat fragmentation; habitat linkages; Santa Monica Mountains; wildlife corridors.

\section{Introduction and Objectives}

Carnivores play a critical role in ecosystem functions and are indicators of ecosystem health. Habitat fragmentation, often caused by urban growth encroaching upon natural environments, particularly endangers carnivores due to their low population densities and need for large home ranges. In fact, habitat fragmentation may be the single greatest threat affecting the survival of many wildlife species and thus is a crucial issue for wildlife conservation (Wilcox and Murphy 1985; Lubchenco et al. 1991; Soulé and Kohm 1989). Despite the substantial threats faced by carnivores, very little empirical data exist about how habitat fragmentation affects the distribution and abundance of these species. Since maintaining viable populations of carnivores is important for protecting a wide variety of other species, it is critical that park and resource managers have accurate information on carnivore populations to make effective wildlife conservation decisions.

Wildlife corridors, which are narrower land segments connecting two larger habitat areas for animal movement, 
have been supponed by many biologists as important for long-term wildlife survival in fragmented habitats (e.g., Harris and Gallagher 1989; Beier 1993, 1995). Little field data. however, are available concerning the detailed use of corridors by wildlife and about how landscape fragmentation can influence potential corridor use (Beier and Loe 1992; Hobbs 1992; Simberloff et al. 1992; Rosenberg et al. 1997). As a result, information on wildlife corridor use and design is critically needed to protect wildlife in remaining natural areas (Mann and Plummer 1995).

The $600 \mathrm{~km}^{2}$ Santa Monica Mountains National Recreation Area in southern California provides an excellent opportunity to study these issues. The Santa Monica Mountains, located adjacent to the Los Angeles metropolitan area, provide substantial habitat for a wide variety of carnivores, including mountain lions (Felis concolor), bobcats (Felis rufus), coyotes (Canis latrans), gray foxes (Urocyon cinereoargenteus), and badgers (Taxidea laxus). This habitat exists as large core areas of protected parkland, as well as significant amounts of open space on private lands. While over 90 percent of the land within the recreation area is currently undeveloped, human development pressures are great and formerly continuous habitat is being rapidly encroached upon and fragmented by urbanization. The result is that in the Santa Monica Mountains, carnivores persist in a landscape composed of several large core habitats interspersed by more highly fragmented areas. Numerous potential wildlife movement corridors connect remaining habitat patches including linear habitat linkages (i.e., on the order of tens to hundreds of meters wide), corridors crossing small to medium-sized roads, and narrow underpasses and culverts. which cross a heavily traveled eight to ten lane highway (the Ventura Freeway portion of U.S. Highway 101).

In the Santa Monica Mountains, little is known about the distribution and status of carnivores (National Park Service 1994). Initial studies have indicated, however, that continued fragmentation and habitat loss threatens the persistence of carnivore species in the park (e.g., bobcats and mountains lions, Kamradt 1995; Santa Monica Mountains Conservancy 1990). In order to effectively evaluate the prognosis for long-term carnivore survival in the Santa Monica Mountains and to develop management actions necessary to promote carnivore protection, it is vital that field-based data be collected on camivore distribution and status. Because of this urgent need, we recognize carnivore research as a top priority (National Park Service 1994).

The overall goals of this study are to evaluate the distribution and status of carnivores in the Santa Monica Mountains, and to pursue more detailed work on specific target species. Specific objectives include: assessing the status of carnivores at the population-level, including information about demographics, vital rates, population sizes, and genetics; determining the effects of habitat loss, fragmentation, and urban encroachment on carnivore dis- tribution, activity patterns, and survival; assessing what constitutes a barrier to carnivore movement (e.g., multilane freeways, urban roadways, suburban development patterns, etc.); and finally, determining what constitutes a viable habitat linkage or movement corridor. Ultimately, results from this research will be used to identify important camivore habitats and linkages, to design or restore wildlife movement corridors, and to help develop wildlife management actions necessary to conserve carnivore populations.

Ongoing work has included two specific components: (1) radio telemetry to evaluate home range requirements, habitat needs, movement patterns, and survivorship for target species; and (2) remote camera surveys to evaluate overall camivore distribution patterns and to estimate population sizes of marked (radio-collared and/or eartagged) animals. Currently, detailed field work focuses on bobcats, coyotes, and gray foxes; future work may expand to include badgers, mountain lions, and other species. This paper reports on preliminary findings from ongoing research, including animal survival and mortality information, initial results from radio telemetry analysis, and results from preliminary remote camera surveys. We discuss implications of initial findings for carnivore conservation research in the Santa Monica Mountains, including plans for future work.

\section{Methods}

\section{Study Area}

Radio telemetry data collection and remote camera surveys were initiated in the central portion of the Santa Monica Mountains and in portions of the Simi Hills in southern California (Fig. 1). This study area was selected because it includes contiguous areas of open space and protected areas adjacent to fragmented, human-populated areas. In addition, the eight to ten lane Ventura Freeway and numerous secondary roads intersect the study area, potentially interfering with animal movement across the region.

A variety of vegetation types occur in the study area including mixed chaparral, coastal sage scrub, annual grassland, oak woodland and savanna, and riparian areas. Human-related land uses include urban development, numerous roadways, and a 120 ha landfill (the Calabasas Landfill). This mosaic of natural and human-dominated land cover pmvides an excellent opportunity to assess fragmentation and urban encroachment effects on carnivore distribution, status, and survival.

\section{Animal capture/handling}

Adult coyotes, bobcats, and gray foxes were captured using padded foothold traps (Rolley 1985; Liscombe and 


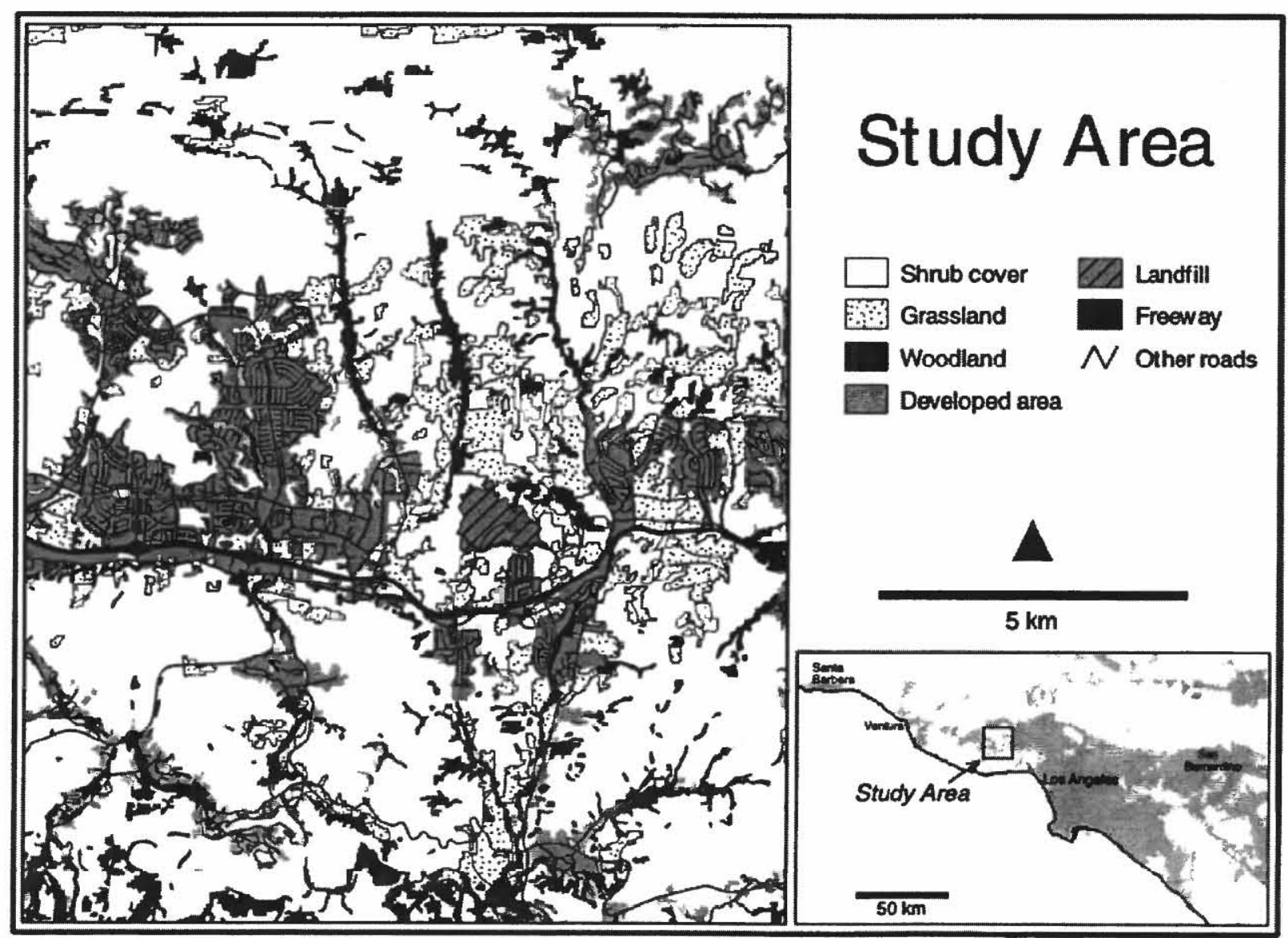

Figure 1. Remote camera survey and radio telemetry study area in the central Santa Monica Mountains and Simi Hills, southern California.

Wright 1988; Skinner and Todd 1990; Linhart and Dasch 1992). Traps were checked at least twice daily either visually or via trap monitoring transmitters to minimize the amount of time a captured animal was confined. Captured animals were restrained using a snare-pole and immobilized with intramuscular injections of ketamine hydrochloride $(10-15 \mathrm{mg} / \mathrm{kg}$ ) and xylazine $(1 \mathrm{mg} / \mathrm{kg}$ ) (Seal and Kreeger 1987; Pond and O'Gara 1994). Some coyotes and foxes were restrained without the use of chemicals by securing their muzzle, forelimbs, and hindlimbs with Velcro wraps.

Immobilized coyotes, bobcats, and gray foxes were fitted with radio transmitters with activity and mortality indicators, and uniquely colored ear tags (Harrison 1992; Litvaitis 1984). Non-target carnivores (raccoons, opossums, badgers, skunks, and a red fox) were immobilized and marked with uniquely colored or numbered ear tags only. Sex, weight, morphological measurements, and age (juvenile/adult) were recorded for each animal, and blood and scat samples were collected. Animals were monitored closely to ensure safe recovery following immobilization. All animals were handled and released at the capture site.

Juvenile coyotes (10 to 16 weeks old) were captured opportunistically and were restrained without the use of immobilants. Sex, weight, morphological measurements, and blood samples were taken from each captured juvenile animal. Juvenile coyotes were equipped with ear tags and radio collars with compressible polyurethane foam inserts to accommodate growth to adulthood (Hallet 1977; Harrison 1992).

\section{Survivorship and radio telemetry}

Radio-collared animals were located and their movements identified via ground triangulation, visual observations, and from a Cessna 182 fixed-wing aircraft equipped with two, four-element yagi antennas (White and Garrot 1990). Ground triangulations were obtained using a hand-held yagi antenna and locations were plotted on 1:24,000 topographic maps. Each ground location was triangulated using two or more bearings, all taken within 30 minutes. Universal Transverse Mercator (UTM) coordinatcs were determined for each location and entered into databases linked to a geographic information system (GIS).

Radio-collared animals were also monitored several times a week to assess survival. If animals could not be located using ground telemetry, aerial telemetry was used to locate radio signals. When mortalities were discovered, attempts were made to determine causes of death in the 
field. If this was not possible, carcasses or tissue samples were collected and sent to the California Department of Fish and Game Wildlife Investigations Laboratory for further analysis. Sex-specific survival and cause-specific mortality rates were calculated from these data for each species and extrapolated to seasonal intervals (summer $=$ March through October; winter = November through February; annual = March through February). Survival and mortality rates were determined for all radio-monitored animals; however, if radio contact was lost, the animal was excluded from the analysis (Heisey and Fuller 1985).

Minimum convex polygon (Hayne 1949) home range sizes were determined for each animal with 20 or more radio locations for summer, winter, and annual data using CALHOME (Kie et al. 1996). Minimum convex polygon home ranges were calculated as the area encompassed by isopleths surrounding $95 \%$ of all locations.

To preliminarily assess relationships between land cover and animal distribution, bobcat and coyote locations were overlaid upon GIS data themes (Koeln et al. 1994). Bobcat or coyote locations were combined to calculate a single $95 \%$ minimum convex polygon for each species to estimate available habitat. This available habitat was then compared to actual habitat utilization by examining the observed locations for each species with respect to various land cover types. Cover types analyzed included chaparral, grassland, woodland, and developed areas, as well as comparisons between core open space (more than $\mathbf{5 0 0}$ $\mathrm{m}$ from development), urban and freeway uses, the Calabasas Landfill, and $500 \mathrm{~m}$ buffers around urban/freeway areas and the landfill.

\section{Remote camera surveys}

Remote camera survey techniques were developed and tested for determining overall carnivore distributions and for estimating population sizes for marked animals. To date, efforts have focused on refining camera station set- ups and on developing sampling techniques for future widescale application. Detailed information on camera station and survey designs can be found in York et al. (unpublished data). Here, we provide general information on the remote camera station design and summary results for four systematic surveys completed in 1997.

\section{Results}

\section{Animal capture/handling}

From February 1996 to November 1997, 58 coyotes ( 28 males, 30 females), 30 bobcats ( 17 males, 13 females), and 18 gray foxes ( 10 males, 8 females) were captured and radio-collared in the Santa Monica Mountains. Of the 58 coyotes, six males and five females were juveniles ( 10 to 16 weeks of age) from five litters captured at rendezvous sites located by howling surveys or monitoring of radio-collared females. Additionally, a small juvenile coyote (approximately 12 weeks old) and four adult gray foxes were tagged with ear tags only. Nontarget captures included two badgers, one red fox (Vulpes fulva), 22 raccoons (Procyon lotor), four striped skunks (Mephitis mephitis), one spotted skunk (Spilogale putorius), and six opossums (Didelphis marsupialis); all nontarget species were ear-tagged only.

\section{Survivorship}

Summer, winter, and annual survival rates were calculated for adult ( 26 months old) bobcats and coyotes from 1996 and 1997 data (Tables 1 and 2). Summer survival rates were also calculated for juvenile coyotes $(<6$ months old) (Table 3) and adult gray foxes (Table 4).

Mortality rates and causes of death were determined for adult and juvenile coyotes (Table 5). Most coyote mortalities were human-related. Primary causes included ve-

Table 1. Summer (March - October), winter (November - February) and annual survival rates of adult ( 26 months) male and female bobcats captured in the Santa Monica Mountains, California, February 1996 to October 1997.

\begin{tabular}{|c|c|c|c|c|c|c|c|c|c|c|c|c|}
\hline \multirow[b]{2}{*}{ Period } & \multicolumn{4}{|c|}{ Males } & \multicolumn{4}{|c|}{ Females } & \multicolumn{4}{|c|}{ Males and females } \\
\hline & $\begin{array}{l}\text { Radio- } \\
\text { days }\end{array}$ & \# deaths & $\begin{array}{l}\text { Survival } \\
\text { rate }^{2}\end{array}$ & $95 \% \mathrm{CI}$ & $\begin{array}{l}\text { Radio- } \\
\text { days }\end{array}$ & $\#$ deaths & $\begin{array}{l}\text { Survival } \\
\text { rate }\end{array}$ & $95 \% \mathrm{Cl}$ & $\begin{array}{l}\text { Radio- } \\
\text { days }\end{array}$ & \# deaths & $\begin{array}{l}\text { Survival } \\
\text { rate }\end{array}$ & $95 \% \mathrm{CI}$ \\
\hline Summer $^{b} 1996$ & 247 & 1 & 0.37 & $0.05-1.0$ & 426 & 0 & 1.00 & - & 673 & 1 & 0.69 & $0.33-1.0$ \\
\hline Winter $1996^{c}$ & 504 & 1 & 0.69 & $0.33-1.0$ & 839 & 0 & 1.00 & - & 1343 & 1 & 0.9 & 0.741 .0 \\
\hline 1996 Total d $^{d}$ & 754 & 2 & 0.25 & $0.03-1.0$ & 1265 & 0 & 1.00 & - & 2019 & 2 & 0.63 & $0.30-1.0$ \\
\hline Summer b 1997 & 1646 & 0 & 1.00 & - & 2354 & 3 & 0.73 & $0.51-1.0$ & +000 & 3 & 0.83 & $0.67-1.0$ \\
\hline All Years $e^{e}$ & 2379 & 2 & 0.72 & $0.45-1.0$ & 3619 & 3 & 0.76 & $0.56-1.0$ & 5998 & 5 & 0.75 & $0.57-0.97$ \\
\hline
\end{tabular}

a Calculated using MICROMORT (Heisey and Fuller 1985).

${ }^{b}$ Pooled monthly survival rate for March - October.

c Pooled monthly survival rate for November 1996 - February 1997

d Pooled monthly survival rate for March 1996 - February 1997.

e Pooled monthly survival rate for March 1996 -October 1997. 
Table 2. Summer (March - October), winter (November - February) and annual survival rates of adult ( $>6$ months) male and female coyotes captured in the Santa Monica Mountains. California. February 1996 to October 1997.

\begin{tabular}{|c|c|c|c|c|c|c|c|c|c|c|c|c|}
\hline \multirow[b]{2}{*}{ Peniod } & \multicolumn{4}{|c|}{. Males } & \multicolumn{4}{|c|}{ Females } & \multicolumn{4}{|c|}{ Males and females } \\
\hline & $\begin{array}{l}\text { Radio- } \\
\text { days }\end{array}$ & \# deaths & $\begin{array}{l}\text { Survival } \\
\text { rate }\end{array}$ & $95 \% \mathrm{CI}$ & $\begin{array}{c}\text { Radio- } \\
\text { days }\end{array}$ & \# deaths & $\begin{array}{c}\text { Survival } \\
\text { rate }\end{array}$ & $95 \% \mathrm{Cl}$ & $\begin{array}{l}\text { Radio- } \\
\text { days }\end{array}$ & \# deaths & $\begin{array}{c}\text { Survival }^{2} \\
\text { rate }\end{array}$ & $95 \% \mathrm{Cl}$ \\
\hline Summer b 1996 & 339 & 0 & 1.00 & - & 633 & 0 & 1.00 & - & 972 & 0 & 1.0 & - \\
\hline Winter $199^{\circ}$ & 1219 & 1 & 0.91 & $0.75-1.0$ & 1408 & 0 & 1.00 & - & 2627 & 1 & 0.96 & $0.87-1.0$ \\
\hline Total $1996^{\circ}$ & 1558 & 1 & 0.91 & $0.75-1.0$ & 2041 & 0 & 1.00 & - & 3599 & 1 & 0.95 & $0.87-1.0$ \\
\hline Surnmer ${ }^{b} 1997$ & 2580 & 3 & 0.76 & $0.56-1.0$ & 3749 & 3 & 0.79 & $0.61-1.0$ & 6329 & 6 & 0.78 & $0.63-0.95$ \\
\hline All years ${ }^{e}$ & 4138 & 4 & 0.70 & $0.51 \div 0.99$ & 5790 & 3 & 0.84 & $0.65-1.0$ & 9928 & 7 & 0.75 & $0.63-0.93$ \\
\hline
\end{tabular}

${ }^{2}$ Calculated using MICROMORT (Heisey and Fuller 1985).

b Pooled monthly survival rate for March - October.

c Pooled monthly survival rate for November 1996 - February 1997

d Pooled monthly survival rate for March 1996 - February 1997

- Pooled monthly survival rate for March 1996 -October 1997.

hicle collisions and poisoning from anticoagulant rodenticide poisons. Poisoning particularly affected young coyotes and was the most common source of mortality for juveniles. For adult coyotes, vehicle collisions were the greatest single source of mortality, primarily occurring on secondary roads. No radio-collared animals were killed on the Ventura Freeway through October 1997. (Since October 1997, two radio-collared coyotes have died attempting to cross the Ventura Freeway.) Based on radio telemetry data, two radio-collared coyotes have successfully crossed the Ventura Freeway (see below).

For gray foxes (Table 4) and bobcats (Table 6), predation was respectively the only or greatest source of mortality. All fox and two bobcat mortalities were caused by other carnivores, most likely coyotes. One of the foxes was completely consumed while two others were left unconsumed or partially consumed after apparently being killed. Since October 1997 two more foxes have been killed and consumed. Fox mortalities were located near trails or open areas, where coyotes frequently traveled. Likewise, both bobcat predation mortalities also occurred in the more open grassland areas. One coyote was killed

Table 3.Summer survival rates of juvenile (3-6 months old) male and fernale coyotes captured in the Santa Monica Mountains, California, June to October 1997.

\begin{tabular}{lcccc}
\hline Sex & Radio-days & \# deaths & Survival rate $^{2}$ & $95 \% \mathrm{CI}$ \\
\hline Males & 390 & 3 & 0.31 & $0.08-1.0$ \\
Females & 165 & + & 0.02 & $0-0.93$ \\
All & 555 & 7 & 0.15 & $0.03-0.60$ \\
\hline
\end{tabular}

a Pooled survival rates for all months calculated using MICROMORT (Heisey and Fuller 1985).
Table 4. Survival rates of aduit ( $>6$ months) male and female gray foxes captured in the Santa Monica Mountains. California. May to October 1997.

\begin{tabular}{lcccc}
\hline Sex & Radio-days & \# deaths & Survival rate & $95 \% \mathrm{Cl}$ \\
\hline Males & 383 & 2 & 0.34 & $0.07-1.0$ \\
Females & 688 & 1 & 0.83 & $0.59-1.0$ \\
All & 1071 & 3 & 0.63 & $0.37-1.0$ \\
\hline
\end{tabular}

a Pooled monthly survival rate calculated using MICROMORT (Heisey and Fuller 1985).

and its remains partially consumed and cached by another predator, possibly a mountain lion.

\section{Radio telemetry}

Minimum convex polygon home ranges were calculated for individual bobcats and coyotes with at least 20 radio locations per season (Tables 7 and 8 ). In all seasons, coyotes exhibited larger home range sizes than bobcats, although differences were not always substantial. In addition, coyote home ranges were much more variable between seasons than those of bobcats. For gray foxes, only summer 1997 data were available for home range analysis. For this species, six individuals ( 2 males, $4 \mathrm{fe}-$ males) had an average home range size of $1.21 \mathrm{~km}^{2}$ with a range of 0.60 to $1.91 \mathrm{~km}^{2}$.

Because minimum convex polygon home ranges are strongly affected by small sample sizes and may include areas within which animals don't actually utilize, location data were used to investigate distribution patterns with respect to land cover types. Total locations for bobcats and coyotes through April 1997 (Fig. 2) were used to determine available habitat for each species and habitat uti- 
Table 5. . 1ortality rates of adult ( $\geq 6$ months old) and juvenile ( $<6$ months old) male and female coyotes captured in the Santa Monica Mountains. California. February 1996 to October 1997.

\begin{tabular}{|c|c|c|c|c|c|c|c|c|c|c|c|c|c|}
\hline \multirow[b]{3}{*}{ Sex } & \multirow{3}{*}{$\begin{array}{l}\text { \# Indiv. } \\
\text { tracked }\end{array}$} & \multicolumn{3}{|c|}{ Roadkill } & \multicolumn{3}{|c|}{ Poisoning ${ }^{b}$} & \multicolumn{3}{|c|}{ Other } & \multicolumn{3}{|c|}{ All } \\
\hline & & \multicolumn{3}{|c|}{ Mortality } & \multicolumn{3}{|c|}{ Mortality } & \multicolumn{3}{|c|}{ Mortality } & \multicolumn{3}{|c|}{ Mortality } \\
\hline & & \# deaths & rate $^{2}$ & $95 \% \mathrm{Cl}$ & \# deaths & rate ${ }^{2}$ & $95 \% \mathrm{Cl}$ & \# deaths & rate ${ }^{2}$ & $95 \% \mathrm{Cl}$ & \# deaths & rate * & $95 \% \mathrm{Cl}$ \\
\hline \multicolumn{14}{|l|}{ ddults } \\
\hline Males & 16 & 2 & 0.15 & 0.0 .34 & 1 & 0.08 & $0-0.22$ & $1^{\mathrm{c}}$ & 0.07 & $0-0.12$ & + & 0.30 & $0.01-0.51$ \\
\hline Females & 20 & 2 & 0.12 & $0-0.27$ & 1 & 0.04 & $0-0.12$ & - & - & - & 3 & 0.16 & $0-0.31$ \\
\hline All & 36 & 4 & 0.16 & $0.01-0.31$ & 2 & 0.05 & $0-0.12$ & 1 & 0.04 & $0-0.11$ & 7 & 0.25 & $0-0.34$ \\
\hline \multicolumn{14}{|l|}{ Juveniles } \\
\hline Males & 7 & - & - & - & 2 & 0.46 & $0-0.92$ & $1^{d}$ & 0.23 & $0-0.63$ & 3 & 0.69 & $0-0.92$ \\
\hline Females & 4 & - & - & - & 1 & 0.24 & $0-0.66$ & $3^{e}$ & 0.73 & $0-0.31$ & 4 & 0.98 & $0.07-1.0$ \\
\hline All & 11 & - & - & - & 3 & 0.36 & 0.040 .69 & 4 & 0.48 & $0.15-0.82$ & 7 & 0.85 & $0.40-0.97$ \\
\hline
\end{tabular}

a Pooled mortality rates calculated using MICROMORT (Heisey and Fuller 1985). Annual mortality rates for adults and summer mortality rates for juveniles.

${ }^{b}$ Anticoagulant poisoning.

'Predation by mountain lion.

${ }^{\mathrm{D}}$ Died of undetermined causes.

' Other causes included predation by domestic dogs $(n \approx 1)$, severe gastritis caused by a fruit pit lodged in the pylorus, and an undetermined cause.

lization was assessed from observed telemetry locations. The proportions of available habitat and animal locations were compared to cvaluate possible habitat preferences and distribution differences between species and among land cover types.

Habitat utilization in natural areas differed somewhat between coyotes and bobcats, with coyotes utilizing grassland areas and bobcats utilizing woodland and chaparral areas at greater proportions than availability (Fig. 3). Both species used developed areas at proportions less than availability, particularly for bobcats (Fig. 3). Habitat within $500 \mathrm{~m}$ of the landfill was utilized to a large degree by both species, while core open space areas (greater than $500 \mathrm{~m}$ from urban or landfill edges) were utilized at pro- portions less than availability (Fig. 4). The proportion of locations found in urban/freeway and landfill areas was less than availability for both species, although this trend was most pronounced for bobcats (Fig. 4).

Although these initial results may suggest interesting patterns, they are very preliminary and analyses were conducted primarily to explore data analysis techniques. Because locations are only included through April 1997, the distribution of animals are strongly affected by initial capture efforts which were focused in areas near urban development and around the Calabasas Landfill. Future spatial analyses using more complete telemetry data will provide more accurate assessments of carnivore habitat utilization in the study area.

Table 6. Annual mortality rates of adult ( $>6$ months) male and female bobcats captured in the Santa Monica Moumtains, California, February 1996 - October 1997.

\begin{tabular}{|c|c|c|c|c|c|c|c|c|c|c|c|c|c|}
\hline \multirow[b]{3}{*}{ Sex } & \multirow{3}{*}{$\begin{array}{l}\text { \# Indiv. } \\
\text { tracked }\end{array}$} & \multicolumn{3}{|c|}{ Roadkill } & \multicolumn{3}{|c|}{ Poisoning ${ }^{b}$} & \multicolumn{3}{|c|}{ Other ${ }^{c}$} & \multicolumn{3}{|c|}{ All } \\
\hline & & \multicolumn{3}{|c|}{ Mortality } & \multicolumn{3}{|c|}{ Mortality } & \multicolumn{3}{|c|}{ Mortality } & \multicolumn{3}{|c|}{ Mortality } \\
\hline & & \# deaths & rate $^{2}$ & $95 \% \mathrm{Cl}$ & \# deaths & rate $^{a}$ & $95 \% \mathrm{Cl}$ & \# deaths & rate ${ }^{a}$ & $95 \% \mathrm{CI}$ & \# deaths & rate & $95 \% \mathrm{Cl}$ \\
\hline Males & 13 & - & - & - & 1 & 0.11 & $0-0.32$ & 1 & 0.17 & $0-0.46$ & 2 & 0.28 & $0-0.55$ \\
\hline Females & 14 & 1 & 0.07 & $0-0.20$ & 1 & 0.08 & $0-0.21$ & 1 & 0.09 & $0-0.25$ & 3 & 0.24 & $0-0.44$ \\
\hline All & 27 & 1 & 0.04 & $0-0.12$ & 2 & 0.10 & $0-0.23$ & 2 & 0.11 & $0-0.27$ & 5 & 0.25 & $0.03-0.43$ \\
\hline
\end{tabular}

a Monthly mortality rates pooled for all years calculated using MICROMORT (Heisey and Fuller 1985)

b Predation by coyotes.

c Other mortalities included megacolon syndrome (male) and an unknown cause (female). 
Table 7. Summer (March - October), Winter (November - February) and annual minimum convex polygon home range size of adult resident male and female bobcats radio-collared in the Santa Monica Mountains, California, 1996-1997.

\begin{tabular}{lccccc}
\hline \multirow{2}{*}{ Season } & \multirow{2}{*}{ \# Animals Monitored } & \multicolumn{2}{c}{ \# locations/animal } & \multicolumn{2}{c}{ Home range size $\left(\mathrm{km}^{2}\right)^{\mathrm{a}}$} \\
\cline { 3 - 5 } & & $\overline{\mathrm{x}}$ & Range & $\overline{\mathrm{x}}$ & Range \\
\hline Summer 1996 & 4 & 44.67 & $37-58$ & 1.86 & $1.01-2.40$ \\
Winter 1996 & 3 & 24.33 & $23-26$ & 1.14 & $0.98-1.43$ \\
Annual 1996 & 4 & 51.45 & $24-81$ & 1.85 & $1.43-2.18$ \\
Summer 1997 & 13 & 27.46 & $20-38$ & 1.98 & $0.57-6.11$ \\
\hline
\end{tabular}

${ }^{a}$ Minimum convex polygon home range calculated using CALHOME (Kie et al. 1996).
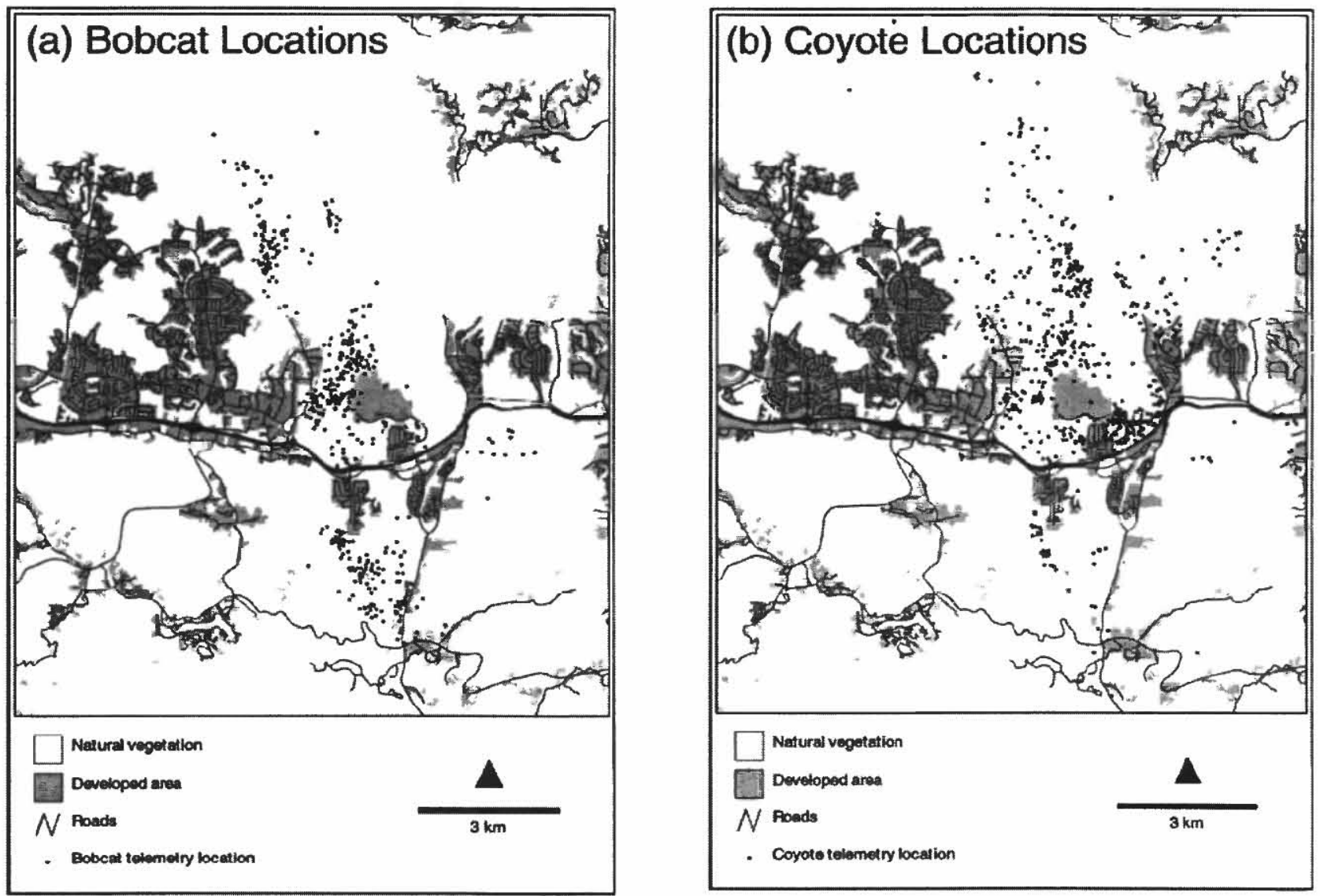

Figure 2. Combined bobcat (a) and coyote (b) radio telemetry locations obtained through April 1997 ( $n=480$ for bobcats; $n=670$ for coyotes).

Table 8. Summer (March-October), winter (November - February), and annual home range size of adult resident male and female coyotes radio-collared in the Santa Monica Mountains, California, 1996-1997.

\begin{tabular}{lccccc}
\hline Scason & \multirow{2}{*}{ \# Animals Monitored } & \multicolumn{2}{c}{ \# locations/animal } & & \multicolumn{2}{c}{ Home range sizc $\left(\mathrm{km}^{2}\right)$} \\
\cline { 3 - 6 } & & $\overline{\mathrm{x}}$ & Range & $\overline{\mathrm{x}}$ & Range \\
\hline Summer 1996 & 3 & 73.67 & $31-99$ & 9.15 & $6.02-11.96$ \\
Winter 1996 & 7 & 26.86 & $23-34$ & 1.30 & $0.66-2.07$ \\
Annual 1996 & 2 & 121.50 & $116-127$ & 9.72 & $8.35-11.08$ \\
Summer 1997 & 7 & 28.29 & $21-46$ & 2.60 & $1.13-4.93$ \\
\end{tabular}

${ }^{\text {a }}$ Minimum convex polygon home range calculated using CALHOME (Kie et al. 1996). 

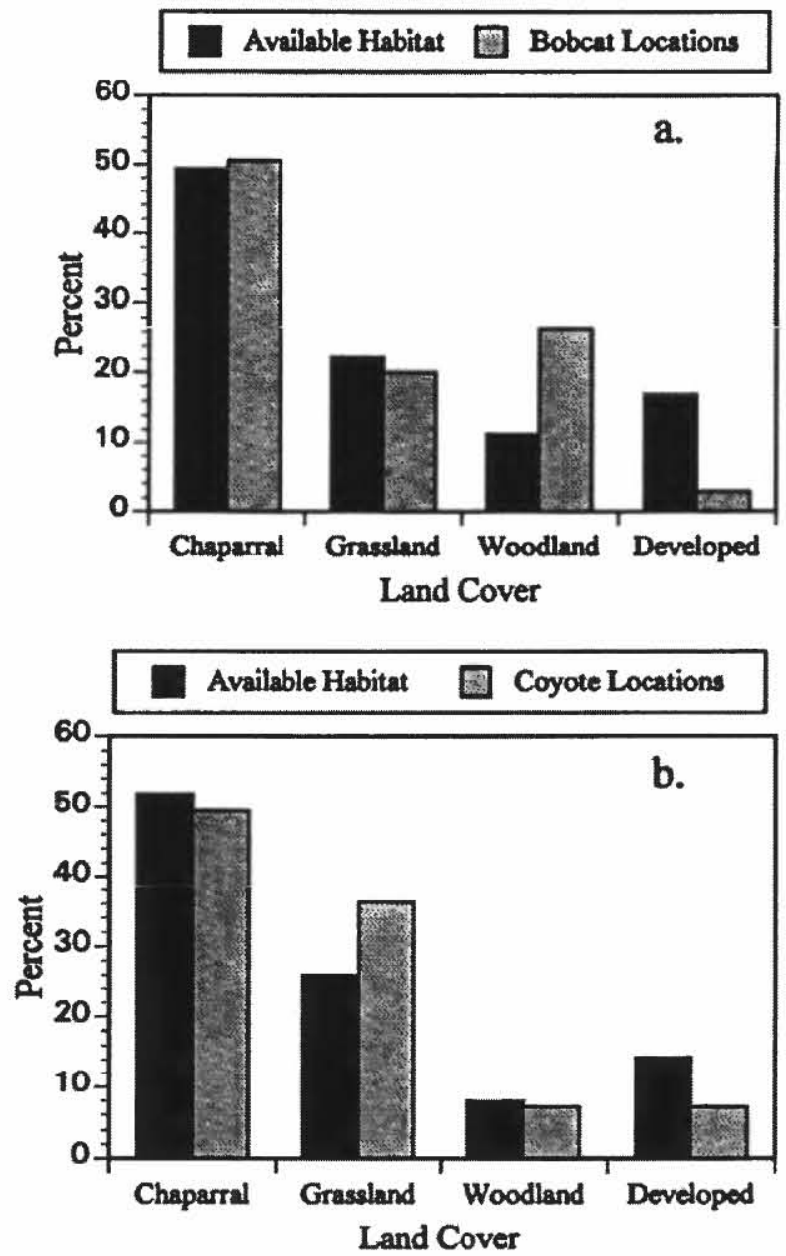

Figure 3. Comparisons between percentage available habitat and percentage habitat utilization from telemetry locations for bobcats (a) and coyotes (b) for chaparral, grassland, woodland, and developed areas. Available habitat was defined as land cover within a single $95 \%$ minumum convex polygon using all telemetry locations for each species. Telemetry data through April 1997 ( $n=480$ for bobcats; $n=670$ for coyotes). Vegetation and land cover data from National Park Service vegetation inventory and Southern California Association of Governments land use assessment.

\section{Camera surveys}

During the summer of 1996, alternative camera station designs were tested to assure that camera setups were effective at capturing photographs of target species. In addition, field trials were used to test sampling schemes for maximizing the number of target species photographed in particular surveys. Results of 1996 field trials are described in Wayne et al. (1997).

Our primary camera station system utilizes a pressure plate triggering mechanism, although we have also utilized cameras equipped with infrared detection devices
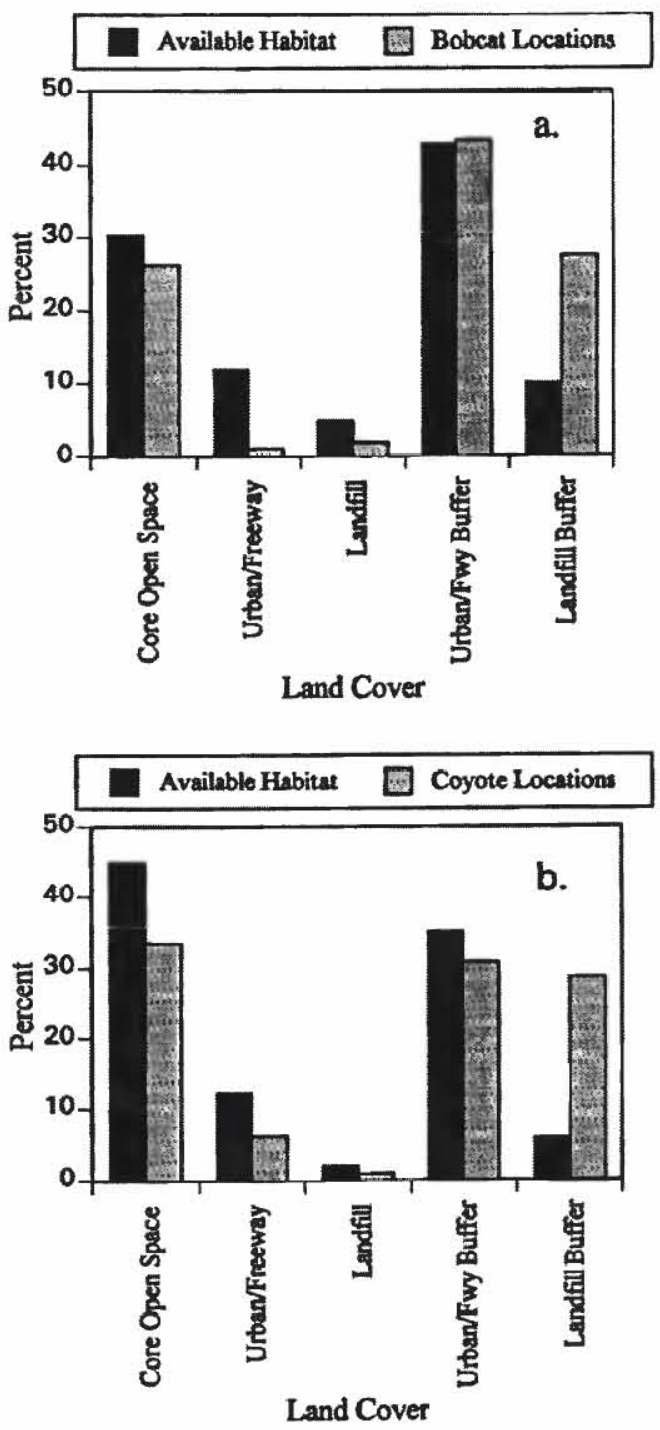

Figure 4. Comparisons between percentage available habitat and percent habitat utilization from telemetry locations for bobcats (a) and coyotes (b) for core open space ( $>500 \mathrm{~m}$ from urban or landfill edges), urban and freeway cover, the Calabasas Landfill, and $500 \mathrm{~m}$ buffers around urban/freeway areas and the landfill. Available habitat was defined as land cover within a single $95 \%$ minumum convex polygon using all telemetry locations for each species. Telemetry data through April 1997 (n $=480$ for bobcats; $n=670$ for coyotes). Vegetation and land cover data from National Park Service vegetation inventory and Southern California Association of Governments land use assessment.

(e.g., Trailmaster or Cam Trakker systems). Because our interests have been to develop an inexpensive and effective remote camera setup using a pressure plate system, we report general results for the pressure plate system here.

Each camera station in the pressure plate system consisted of a 35-mm point-and-shoot camera (Canon Sure Shot Owl) hard-wired to a $20 \times 20 \mathrm{~cm}$ pressure sensitive pad. Camera stations were located in the approximate center of pre-determined grid cells (depending on survey design) within habitat that appeared "attractive" to targeted 
species. Animals were lured to camera stations with fatty acid scent and sun-rendered fish oil. Photos were taken when animals stepped on the pressure sensitive pads and triggered the camera shutter releases. During camera surveys, camera stations remained at each site for two to three weeks and were inspected at 7 to 14 day intervals to ensure that cameras were functioning properly and to replace film, if nccessary. At the conclusion of each survey, camera stations and lures were removed from the area. Resulting photographs were assessed to determine the species photographed and to determine the presence or absence of marks (radio collars or ear tags).

From April to September 1997, four systematic surveys were conducted using this system. One survey consisted of 44 cameras distributed in a grid with density of one camera per $\mathrm{km}^{2}$. This survey targeted all species and was distributed across the study area. Two additional surveys consisted of 25 cameras each with camera densities of one per $0.25 \mathrm{~km}^{2}$. These surveys targeted gray foxes and were located in an area frequented by this species. A fourth survey consisted of 39 cameras at a density of one camera per $0.5 \mathrm{~km}^{2}$. This survey targeted bobcats and coyotes and was distributed where the majority marked individuals of these species occurred.

Based on results from the four surveys, the camera survey system appears effective at obtaining photographs of bobcats, gray foxes, and other carnivores (Table 9). In addition, both marked and unmarked individuals were detected and easily identified. Coyotes, however, were much more difficult to photograph using the pressure plate system and exhibited the lowest number of station visits, total photographs, photos per visit, and the lowest visitation rate. Use of infrared triggering mechanisms on cameras used for other purposes (e.g., monitoring trails and corridors) did result in coyote photographs. Evidence from coyote tracks at pressure plate camera stations suggested that coyotes did approach camera stations but were hesitant to step on the pressure plate triggering mechanisms.

\section{Discussion}

Preliminary results from this project suggest several important conservation implications for carnivores occur- ring in fragmented landscapes and along urban interfaces. In addition, initial work has highlighted the importance of several issues that will be addressed in future research on this project.

\section{Survivorship and radio telemetry}

Perhaps the most important preliminary result is the extent to which carnivore mortality can be attributed to human-caused factors. Because of the substantial road network in the study area, including multi-lane freeways, secondary roads, and suburban roadways, it is not unusual that roadway mortality was identified as a significant cause of mortality. These findings are consistent with results in other areas (Noss 1987; Schonewald-Cox and Buechner 1992; Beier 1995), and may have important implications for long-term carnivore survival in fragmented habitats near urban development. In this study, the effects of roadway mortality on carnivores will continue to be closely monitored.

Of particular interest, however, were mortalities associated with anticoagulant rodenticides. Anticoagulant poisons were found in coyotes and, following recent tests, also in a bobcat. It is not known whether carnivores ingested anticoagulants directly or secondarily, although several types of anticoagulants are readily available at commercial outlets. We are participating in ongoing investigations of anticoagulant mortalities in cooperation with the California Department of Fish and Game Pesticides Unit and several other agencies.

Radio telemetry data analyses have indicated that coyotes are more likely to venture into urban areas than bobcats or gray foxes. In addition, coyotes have larger home ranges and travel greater distances across the study area (e.g., several coyotes traveled over $30 \mathrm{~km}$ from the study area). As a consequence, coyotes may be more likely to encounter urban-associated mortality factors, including vehicle collisions and poison exposure: For bobcats and gray foxes, dispersal periods may also pose the greatest risk, when animals are venturing beyond established home ranges and across human-developed landscapes and unfamiliar areas.

Interspecific interactions and habitat utilization varied between species. In particular, coyotes were more

Table 9. Species photographed, number of visits, and number of photos per visits for four camera surveys conducted in the Santa Monica Mountains, Califomia, April to September 1997.

\begin{tabular}{lcccccc}
\hline Species & $\begin{array}{c}\text { Stations } \\
\text { available }\end{array}$ & $\begin{array}{c}\text { Stations } \\
\text { visited }\end{array}$ & Total visits & Total photos & Photos/visit & $\begin{array}{c}\text { Total visitation rate } \\
\text { (\# visits/ \# stations available) }\end{array}$ \\
\hline Gray fox & 65 & 14 & 22 & 55 & 2.50 & 0.34 \\
Bobcat & 133 & 14 & 19 & 41 & 2.16 & 0.14 \\
Coyote $_{\text {Non-target carnivores }}{ }^{\mathrm{c}}$ & 133 & 733 & 12 & 29 & 61.13 & 0.06 \\
All species & 133 & 47 & 78 & 166 & 2.10 & 0.22 \\
\hline
\end{tabular}

a Based on habitat and range distribution determined from capture and radio telemetry data.

${ }^{b}$ The number of photos or series of photos separated by $>1$ hour.

c. Non-target species include badgers ( 1 visit), raccoons ( 7 visits), skunks ( 8 visits), and opossums ( 13 visits). 
abundant in open habitats while gray foxes were generally confined to areas with dense chaparral or woodland cover. Gray foxes suffered high levels of predation mortality, most likely from coyotes. The interaction between bobcats and coyotes may also be important, but our preliminary data are not yet conclusive.

As habitats are altered along the urban/wildland interface and habitat fragmentation continues, it is possible that habitat changes could favor conditions for coyote population increases or range expansions. As a result, humanassociated land use changes may indirectly reduce gray fox distributions as coyotes expand ranges into more open, modified habitats and adjacent to urbanized areas. These inter-specific interactions, potentially mediated by humanrelated land use changes, will be carefully assessed in future work on this project.

Clearly, coyotes are quite adept at utilizing fragmented habitats interspersed within urbanized areas. The extent to which their long-term persistence across the landscape depends on the availability of intervening natural areas is still unclear. We plan to address this issue in ongoing data collection and analysis efforts.

Bobcats and gray foxes, on the other hand, are less likely to utilize to utilize human-developed areas. As a consequence, the long-term survival of these species in fragmented habitats may be more threatened. For this reason, the persistence of bobcats and gray foxes in southern California habitats may serve as good indicators of ecosystem viability. In ongoing work, we will continue to monitor bobcats, gray foxes, and coyotes, and carefully assess the different reactions these species exhibit to habitat fragmentation and urban encroachment. Results from these efforts will likely suggest habitat conservation, restoration, and wildlife management actions necessary to conserve these species near urbanizing areas.

\section{Camera surveys}

Early results from preliminary camera surveys were encouraging. We believe the pressure plate camera system can be an effective technique for assessing the presence/absence and estimating population sizes for bobcats and gray foxes (York et al., unpublished data). Because coyotes are very wary of the pressure plate camera stations, this system will not likely be effective for this species. We are continuing to refine our camera monitoring systems and will implement broad scale camera surveys throughout 1998.

Overall, we are confident that the combination of pressure plate camera surveys, infrared beam cameras, and radio telemetry data collection will be very effective for assessing carnivore distributions, movement patterns, potential corridor use, and population sizes. Future data collection and analysis will determine how efficient these complementary systems are for determining accurate estimates of carnivore population sizes.

\section{Future research directions}

As of April 1998, 27 coyotes, 15 bobcats, and seven gray foxes were being monitored using radio telemetry. In the coming months, we plan to increase this sample size and continue to monitor animals throughout the study area in the Santa Monica Mountains and Simi Hills. Future research priorities include conducting more detailed analyses of carnivore distributions in the context of urban development, habitat fragmentation, and vegetation cover. We are particularly interested in quantitatively examining what constitutes a movement barrier for these species. In addition, we plan to evaluate behavioral differences between urban-inclined animals and those which remain in the undisturbed core habitats. As more distributional data are collected in combination with population information and GIS data themes, we also hope to model carnivore persistence under alternative future development scenarios. Finally, we are also exploring expanding our efforts to include additional species, particularly mountain lions and badgers.

Using remote camera techniques and radio telemetry, we are also particularly interested in assessing factors that may be important in wildlife corridor design. If carnivores are to persist in the Santa Monica Mountains and other fragmented habitats, it will be critical to determine the characteristics of corridors that facilitate their use by wildlife (Soulé 1991; Rosenberg et al. 1997). With the large number of animals currently radio-collared and the variety of movement corridors and habitat linkages available in the study area, we have an unprecedented opportunity to address this critical conservation question.

Cooperative projects on related issues currently underway include diet analysis from carnivore scat and genetic evaluations of camivores across the study area. These related projects will complement the distribution and population data we are collecting to provide a very comprehensive assessment of carnivores inhabiting fragmented habitats along an urban fringe. As results are obtained from all components of this research, recommendations will be developed and incorporated into park planning and resource management activities to promote carnivore conservation in the Santa Monica Mountains and in other areas facing similar threats.

Acknowledgments. Funding and equipment donations were provided by Canon U.S.A. through the National Park Foundation's Expedition into the Parks program, and by the National Park Service Pacific West Region, the Santa Monica Mountains National Recreation Area, and the Southwest Parks and Monuments Association. Research cooperators include the University of California, Los Angeles, the University of Massachusetts, Amherst, and the Biological Resources Division of the U.S. Geological Survey, UC Davis Field Station. Field assistance was provided by Marianne Batchelder, Susi Bernstein, Jane Brackman, 
Marie Byrd. Jackie Duhon, Veronica Farias, Misty Gonzales, Cathy Herman, Ariana Huemer, Krista Hughes, Don Jones, Robin Kinmont, Eli Marmar, Elise McMahon, Sandy Ng. Cynthia Plummer, Kristin Searcy, Joe Tafur, Kirby Ung, Adam Vashon, and Alona Vizel. Research access and permits were provided by the National Park Service, the California Department of Parks and Recreation, the Mountains Recreation and Conservation Authority, the Rancho Simi Recreation and Park District, the Los Angeles County Sanitation District, the City of Calabasas, the Ahmanson Land Company, and other landowners within the study area. All research was conducted under a Memorandum of Understanding with the Califormia Department of Fish and Game and with approved animal care and handling permits from the National Park Service and the University of California, Los Angeles Chancellor's Animal Research Committee. Special thanks are provided to Arthur Eck and Scott Erickson of the Santa Monica Mountains National Recreation Area for ongoing support of this research.

\section{Literature Cited}

Beier, P. 1995. Dispersal of juvenile cougars in fragmented habitat. Journal of Wildlife Management 59:228-237.

Beier, P. 1993. Determining minimum habitat areas and habitat corridors for cougars. Conservation Biology 7:94-108.

Beier. P. and S. Loe. 1992. A checklist for evaluating impacts to wildlife movement corridors. Wildlife Society Bulletin 20:434 440.

Hallett, D. L. 1977. Post-natal mortality, movements, and den sites of Missouri coyotes. M.S. thesis, University of Missouri, Columbia, $144 \mathrm{p}$.

Harris, L.D. and P.B. Gallagher. 1989. New initiatives for wildlife conservation: the need for movement corridors. Pp. 11-34 in G. Mackintosh, ed. Preserving communities and corridors. Defenders of Wildlife, Washington, D.C.

Harrison, D.J. 1992. Dispersal characteristics of juvenile coyotes in Maine. Journal of Wildlife Management 56:128-138.

Hayne, D.W. 1949. Calculation of size of home range. Journal of Mammalogy 30:1-18.

Heisey, D.M. and T.K. Fuller. 1985. Evaluation of survival and cause-specific mortality rates using telemetry data. Journal of Wildlife Management 49:668-674.

Hobbs, R.J. 1992. The role of corridors in conservation: solution or bandwagon? Trends in Ecology and Evolution 7:389-392.

Kamradt, D. 1995. Evaluating bobcat (Felis rufus) viability in the Santa Monica Mountains, Califomia: GIS modeling and field validation. M.S. thesis. California State University, Northridge, CA. 77 p.

Karanth, K.U. 1995. Estimating tiger populations from cameratrap data using capture-recapture models. Biological Conservation 71:333-338.

Kie, J.G., J.A. Baldwin, and C.J. Evans. 1996. CALHOME: Home range analysis program. Electronic User's manual. USDA Forest Service, Fresno, CA.

Koeln, G.T., L.M. Cowardin. and L.L. Strong. 1994. Geographic information systems. Pp. 540-566 in T.A. Bookhout, ed. Research and management techniques for wildlife and habitats. Fifth edition. The Wildlife Society, Bethesda, MD.

Linhart, S.B. and G.J. Dasch. 1992. Improved performance of padded jaw traps for capturing coyotes. Wildlife Society Bulletin 20:60-66.
Liscombe. R.G. and V.L. Wright. 1988. Efficiency of padded foothold traps for capturing terrestrial furbearers. Wildlife Society Bulletin 16:307-309.

Litvaitis, J.A. 1984. Bobcat movements in relation to prey density. Ph.D. dissertation. Lniversity of Maine, Orono, MN $103 \mathrm{p}$.

Lubchenco, J., A.M. Olson, L.B. Brubaker, S.R. Carpenter, M.M. Holland, S.P. Hubbell, S.A. Levin, J.A. MacMahon, P.A. Matson, J.M. Melillo, H.A. Mooney, C.H. Peterson, H.R. Pulliam, L.A. Real, P.J. Regal, and P.G. Risser. 1991. The sustainable biosphere research initiative: an ecological research agenda. Ecology 72:371-412.

Mann, C.C. and Plummer. M.L. 1995. Are wildlife corridors the right path? Science 270: 1428-1430.

National Park Service, Santa Monica Moumains National Recreation Area. 1994. Resource Management Plan. USDI National Park Service, Thousand Oaks, CA.

Noss, R.F. 1987. Protecting natural areas in fragmented landscapes. Natural Areas Journal 7:2-13.

Pond, D.B. and B.W. O' Gara. 1994. Chemical immobilization of large mammals. Pp. 125-139 in T.A. Bookhout, ed. Research and management techniques for wildlife and habitats. Fifth edition. The Wildlife Society, Bethesda, MD.

Rolley, R.E. 1985. Dynamics of a harvested bobcat population in Oklahoma. Joumal of Wildlife Management 49:283-292.

Rosenberg. D.K., B.R. Noon, andE.C. Meslow. 1997. Biological corridors: form, function, and efficacy. BioScience 47:677687.

Santa Monica Mountains Conservancy. 1990. Preserving the critical link: a discussion of the wildlife corridor from the Santa Susana Mountains to the Santa Monica Mountains via the Simi Hills. Unpublished report, Santa Monica Mountains conservancy, Malibu, CA

Schonewald-Cox, C.M. and M. Buechner. 1992. Park protection and public roads. Pp. 373-396 in P.L. Fiedler and S. Jain. eds. Conservation biology: the theory and practice of nature conservation, preservation and management. Chapman and Hall, New York, NY.

Seal, U.S. and T.J. Kreegar. 1987. Chemical immobilization of furbearers. Pp. 191-215 in M. Novak, J.A. Baker, M.E. Obbard, and B. Malloch, eds. Furbearer management and construction in North America. Ontario Ministry of Natural Resources, Toronto, Canada.

Simberloff, D., J.A. Farr, J. Cox, and D.W. Mehiman. 1992 Movement corridors: conservation bargains or poor invest ments? Conservation Biology 6:493-504.

Skinner, D.L. and A.W. Todd 1990. Evaluating efficiency of footholding devices for coyote capture. Wildlife Society Bulletin 18:166-175.

Soule, M.E. 1991. Theory and strategy. Pp. 91-104 in W.E. Hudson, ed. Landscape linkages and biodiversity. Island Press. Washington, D.C.

Soule, M.E. and Kohm, K.A., ed. 1989. Research priorities for conservation biology. Island Press. Washington, D.C.

Wayne, R.K., T.K. Fuller, R.M. Sauvajot, E.C. York, D. Kamradr, H.S. Kim, A.E. Eck, and S.E. Erickson. 1997. Distribution and status of carnivores in the Santa Monica Mountains, California. 1996 Annual Report. Unpublished Technical Report, U.S. National Park Service, Thousand Oaks, CA.

White, G.C. and R.A. Garrott. 1990. Analysis of wildlife radiotracking data. Academic Press. New York, NY. 383 p.

Wilcox, B.A. and D.D. Murphy. 1985. Conservation strategy: the effects of fragmentation on extinction. American Naturalist $125: 879-887$. 


\title{
Landscape-Level Urbanization Effects on Chaparral Birds: A Santa Monica Mountains Case Study
}

\author{
Diana Stralberg \\ School of Natural Resources and Environment, University of Michigan, Ann Arbor MI 48104 \\ Tel. (313) 936-2097; Fax (313) 936-2195
}

\begin{abstract}
This study uses bird censuses and GIS landcover data to assess the relationships between chaparral bird abundances and urbanization. A set of chaparral-vegetated points across an urbanizing landscape in the eastern Santa Monica Mountains was surveyed for birds and mapped in a GIS. I analyzed the effects of local site conditions versus landscape-level urbanization characteristics on three categories of bird abundance, local and longdistance migrants, chaparral-associated species, and urban-associated species, using a set of nested Poisson regression models. For all groups examined, landscape features significantly improved the fit of bird abundance models containing local site conditions. Migrants and chaparral-associated species decreased with an increase in surrounding urbanization proportion, while urban-associated species increased. For all species groups, urbanization proportion within a $1000 \mathrm{~m}$ radius area explained additional variation in bird abundance not explained by $250 \mathrm{~m}$ radius urbanization levels, indicating that chaparral bird abundance may be closely tied to large-scale landuse patterns. Also supporting this conclusion was the lack of an independent response to urban edge proximity in all groups except urban-associated species. Finally, urbanization-related habitat fragmentation was associated with further reductions in abundance of migrants and chaparral-associated species, suggesting that landscape spatial pattern may affect bird numbers.
\end{abstract}

Keywords: California birds; chaparral; habitat fragmentation; Santa Monica Mountains; urbanization.

\section{Introduction}

Within recent decades, Los Angeles' burgeoning human population and climbing property values have exerted strong development pressures on surrounding open space lands. Post-World War II development has occurred largely in foothills that are too steep, infertile or dry for agriculture, resulting in suburban developments that bor- der on pristine scrub- and woodland-habitats (Scott 1995). In the eastern Santa Monica Mountains, urbanization has occurred primarily along canyon bottoms, creating a mosaic of interspersed suburban development and chaparral-dominated natural areas. While much of the remaining natural habitat in this area is protected in public parks, development has continued at a rapid pace on privatelyowned lands.

The replacement of chaparral with housing tracts has resulted not only in the displacement of wildlife habitat, but also in the fragmentation of remaining natural areas. Referred to as "the single greatest threat to biodiversity" (Noss 1991), habitat fragmentation can cause species extirpations through several mechanisms. The equilibrium theory of island biogeography (MacArthur and Wilson 1963), when extended to habitat fragments, predicts that smaller, more isolated patches will support fewer species, due in part to random extinctions of small populations (Soulé et al. 1992). The insularization of habitat can also result in the exclusion of species with large home ranges (Wilcove et al. 1986) and a reduction in gene flow between isolated populations (Gilpin \& Soule 1986). In addition, habitat fragmentation results in the creation of new edges between natural habitats and urban development, thereby increasing exposure to negative external influences. Edge-related changes in vegetation composition (Saunders et al. 1991) and increased avian nest parasitism and predation rates (Engels and Sexton 1994; Brittingham and Temple 1983) are widely-recognized consequences of increased edge exposure.

Several recent studies have examined the effects of urbanization and habitat fragmentation on birds of southern California's chaparral and coastal sage scrub habitats. Soule et al. (1988) applied the species-area relationship of island biogeography theory to chaparral canyon fragments in San Diego County, demonstrating that the number of "chaparral-requiring" resident bird species increased with fragment size and decreased with fragment age. Bolger et al. (1997) revisited this area with a landscape approach to habitat fragmentation, showing that landscape composition and urbanization pattern were significant pre- 
dictors of occurrence for many species examined, some of which were identified as edge/fragmentation-sensitive. Sauvajut (1997) found anthropogenic habitat disturbances to be more important than urban development proximity for resident bird populations in the eastern Santa Monica Mountains.

Wiens (1994) describes habitat fragmentation as a dynamic process in which habitat continuity is disrupted, producing a variety of patterns, ranging from "small breaks in an otherwise homogeneous habitat" to "widely scattered units of remnant habitat in a transformed matrix." The eastern portion of the Santa Monica Mountains presents just such a range of patterns, along a gradient of increasing urbanization and habitat fragmentation from west to east. The variation in landscape composition-from primarily chaparral to primarily urban development-allows for an examination of landscape-level urbanization influences on chaparral bird abundance.

In this study, I assess the effects of urbanization and habitat fragmentation on resident and migratory birds in the eastern Santa Monica Mountains, taking into account the dynamics of an entire landscape, rather than viewing each habitat patch in isolation. In doing so, I investigate the following questions:

\section{Landscape vs. Local Factors}

Controlling for local site conditions, how do landscape-level urbanization patterns affect chaparral bird abundance?

\section{Landscape Composition}

Do chaparral birds respond differentially to varying proportions of urbanization in the surrounding landscape, and if so, how?

\section{Landscape Fragmentation}

Does fragmentation of the surrounding landscape (within a $1000 \mathrm{~m}$ radius) affect bird abundance?

\section{Edge Effects}

How does proximity to urban development affect chaparral bird abundance?

\section{Scale Differences}

Is bird abundance better predicted by small- or large-scale ( $250 \mathrm{~m}$ radius vs. $1000 \mathrm{~m}$ radius) measures of urbanization?

\section{Methods}

The study was conducted in the eastern portion of the Santa Monica Mountains, which are part of the east-west trending Transverse Ranges of southern California. The study area is bounded by Topanga Canyon to the west, Griffith Park and the Hollywood (101) Freeway to the east, the San Fernando Valley and Ventura (101) Freeway to the north, and western Los Angeles and Sunset Boulevard to the south. The San Diego (405) Freeway bisects

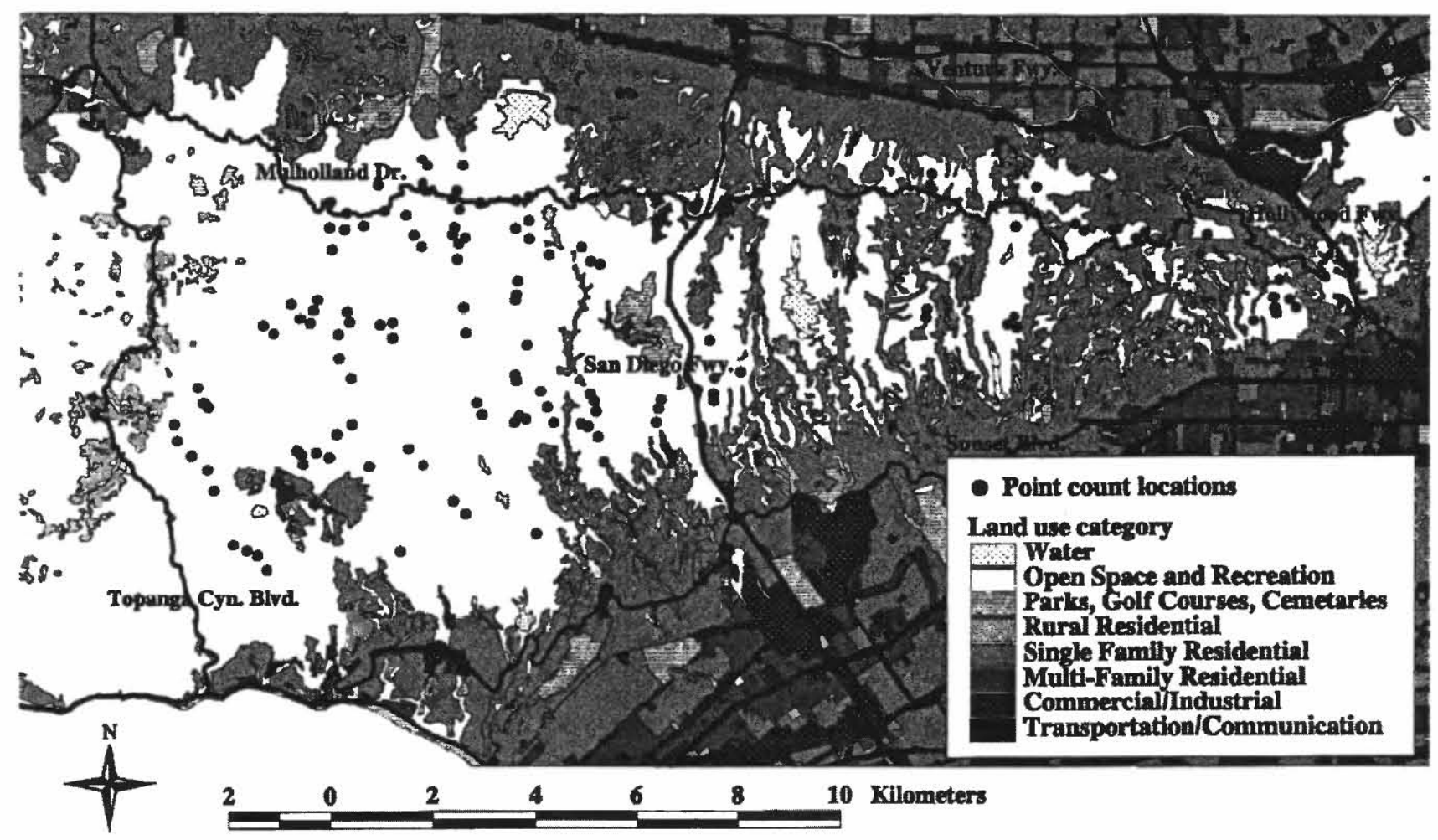

Figure 1. Land use surrounding study area. 
the study area into eastern and western regions, and Mulholland Drive is the ridgeline separating north- and south-trending slopes. Adjacent land use consists primarily of low- and high-density residential development, but a range of residential, commercial and industrial land uses also surround the study area (Fig. 1).

Most of the chaparral vegetation remaining in the Santa Monica Mountains is part of a continuous "core" habitat, fragmented primarily at its margins by encroaching suburban development. East of the San Diego Freeway, however, as suburban development becomes more pervasive, the connections among intact chaparral patches become increasingly tenuous. At the far eastern end of the range, near the Hollywood Freeway, there are several isolated chaparral fragments, two of which are censused in this study.

All bird abundance data were collected along trails and fire roads in northern mixed chaparral vegetation (modified Holland (1986) classification) between 300 and 600 $\mathrm{m}$ elevation, and at least roughly $100 \mathrm{~m}$ from urban development. All sites were dominated by a combination of laurel sumac (Malosma laurina), ceanothus ( $C$. megacarpus and/or $C$. spinosus), and chamise (Adenostoma fasciculatum). Within these bounds, 128 points were selected at random from a GIS (geographic information system) trail map of the study area (GIS trail map based on Tom Harrison trail map for Santa Monica Mountains, supplemented by GPS-recorded trails from eastern part of study site not covered by Harrison map). Ideally, each point represented a 100-meter radius area of chaparral vegetation, spatially distinct from each other area sampled. However, after global positioning system recording of the sites' actual field positions, 15 pairs of sampling areas were found to overlap slightly, and five contained small amounts of urban development. 28 points were located in the more fragmented section east of the 405 Freeway, and 100 points west of the 405 Freeway, in largely contiguous chaparral habitat that is less penetrated by urbanization. The locations of all study sites were recorded with a global positioning system (GPS) and mapped in an ArcInfo Gengraphic Information System (GIS) (Fig. 1).

In the summer of 1996, I conducted two ten-minute fixed-radius $(100 \mathrm{~m})$ point counts (Ralph et al. 1993) at each site, one in June and one in July. Only terrestrial birds, detected on the ground or in vegetation were included. Birds counted included primarily passerines, but also woodpeckers (not included in abundance measures), quail and doves. Raptors, owls, hummingbirds, swallows and swifts were not counted. All point counts were conducted between 05:30 and 10:30 am. Approximate distance $(0-25 \mathrm{~m}, 25-50 \mathrm{~m}$ or $50-100 \mathrm{~m})$ and compass direction were noted for each bird recorded. For each site, local habitat characteristics, including dominant vegetation types, slope aspect and trail width, were also recorded. Dense vegetation and steep terrain prevented quantitative measurement of site vegetation characteristics.

\section{Bird abundance data}

Point counts were categorized as either migrants, chaparral, or urban species (Table 1).

For migrants and chaparral-associated species, two measures of abundance were considered: total number of individuals and number of singing males. For urban-associated species, however, total number of individuals was the only measure used, since only one of the species included, northern mockingbird (Mimus polyglottos), was considered to possess a distinct territorial song.

\section{Site data}

Four site variables, representing censusing and local habitat conditions, were used in this analysis (Table 2). Because breeding activity tends to peak approximately one hour after sunrise, and then decline throughout the morn-

Table 1. Bird abundance categories

Local and long-distance migrants used in this study: species that breed in the study area during the summer months and migrate to Mexico or Central America for the winter (long-distance migrants), or are migratory within California (local migrants) (based on Ehrlich et al. 1988).

Ash-throated flycatcher (Myiarchus cinerascens)

Pacific-slope flycatcher (Empidonax difficilis)
Phainopepla (Phainopepla nitens) Black-headed grosbeak (Pheucticus melanocephalus)

Chaparral-associated species: species closely associated with chaparral and other arid scrub vegetation in southern California, although not necessarily chaparral-specialists (based on Ehrlich et al. 1988, Garrett and Dunn 1981, Brown et al. 1973).

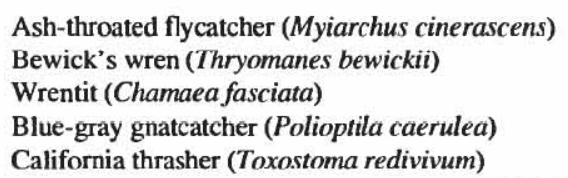

Ash-throated flycatcher (Myiarchus cinerascens)

California thrasher (Toxostoma redivivum)

Urban-associated species: species likely to be found in areas of urban or suburban development (based on Ehrlich et al. 1988, Garrett and Dunn 1981, Brown et al. 1973). The house finch and lesser goldfinch (Carduelis psaltria) were ommited from this category because total abundances wree difficult to quantify in the field.

Mourning dove (Zenaida macroura) American crow (Corvus brachyrhynchos)
Orange-crowned warbler (Vermivora celata)

Rufous-crowned sparrow (Aimophila ruficeps)

Spotted towhee (Pipilo maculatus)

California towhee (Pipilo crissalis) 
Table 2. Site Variables

\begin{tabular}{lll}
\hline Variable Name & Range / Levels & Definition \\
\hline TIME & $05: 30-10: 30$ & Time of day at start of ten-minute point count. \\
\hline DATE & 8 June $96-28$ July 96 & Date of point count. \\
\hline TOPOG & ridge & Site located on ridgetop, with canyons on either side. \\
& canyon & Site located in small canyon; both sides of canyon within point count radius. \\
& slope & Site located on unidirectional slope.
\end{tabular}

ing (Robbins 1981), time of day was presumed to be important in determining bird abundance at a count. The date of the point count was also included, because bird detectability (primarily via territorial male songs) was assumed to decline toward the end of the breeding season.

Another factor thought to affect bird detectability was local site topography, primarily due to differences in acoustic conditions caused by physical sound barriers and enhancements. Three conditions were identified: ridge, slope and canyon.

Finally, vegetation cover within a $100 \mathrm{~m}$ radius was somewhat varied among sites, even though all points were classified as belonging to 'northern mixed chaparral,' according to GIS vegetation data classifed from 1993 satellite images by San Diego State University researchers for Santa Monica Mountains Recreation Area vegetation cover map. Although specific vegetation associations were identified, substantial overlap made qualitative categorization difficult. Three broader categories were used instead: 'mesic,' which occurred primarily on north-facing slopes, but also in small, sheltered canyons; 'intermediate,' which was the most pervasive condition in the study area; and 'dry/disturbed,' which most often occurred on south-facing slopes, and was more prevalent farther east.

\section{Landscape analysis}

The landscape variables, calculated from GIS data, were the primary variables of interest in this study (Table 3).

Urbanization proportion, a measure of landscape composition, was calculated from GIS vegetation data for the areas within two different radii $(250 \mathrm{~m}$ and $1000 \mathrm{~m}$ ) of each point, each representing a different spatial scale. The amount of urban edge within $1000 \mathrm{~m}$ of each point, calculated from GIS land-use data $(1: 24,000$ land use cover map developed by the Southern California Association of Governments (SCAG) for the SMMNRA, based on 1990 aerial photos) was used as an index for surrounding habitat fragmentation (LNED1000). Urban edge proximity was represented by the distance from each point to the nearest urban edge (LNDIST). Variables were natural logtransformed due to curvilinear relationships with the dependent variable examined.

In addition to the urbanization characteristics described above, the geographic coordinates of each point count location (EAST) and (NORTH), obtained from GPS data, were also included with the landscape variables, to incorporate natural spatial variations in habitat throughout the study area.

Table 3. Landscape Variables.

\begin{tabular}{lll}
\hline Variable & Range & Definition \\
\hline URB250 & $0.00-0.78$ & Proportion of the area within a $250 \mathrm{~m}$ radius of the point covered by urban development. \\
\hline URB1000 & $0.00-0.93$ & Proportion of the area within a $1000 \mathrm{~m}$ radius of the point covered by urban development. \\
\hline LNED1000 & $0.00-10.17$ & Natural log of the total length of urban edge contained within a $1000 \mathrm{~m}$ radius of the point. \\
\hline LNDIST & $0.00-7.99$ & Natural log of the distance from the point to the edge of the nearest urban development. \\
\hline EAST & $353681-375679$ & Longitudinal UTM coordinate of point (increasing from west to east). \\
\hline NORTH & $3769998-3778115$ & Latitudinal UTM coordinate of point (increasing from south to north). \\
\hline
\end{tabular}




\section{Statistical methods}

Although counts of animal abundance can often be approximated by a normal distribution, the discrete nature of these data makes the Poisson distribution more appropriate (Dawson 1981). In addition, the Poisson distribution can be positively skewed and has a variance equal to the mean.

To disentangle the effects of correlated independent variables, I fit a sequence of repeated-measures Poisson regression models for each bird abundance measure. A set of nested models was constructed in two stages, using a Poisson distribution and log link function (SAS version 6.12 , proc GENMOD). The change in model deviance (D), evaluated with type 1 chi-square $\left(\neg^{2}\right)$ likelihood ratio tests, was used to determine whether each additional variable contributed significantly to the model fit (SAS Institute 1997). Nested models were compared by examining the percent change in the deviance. The deviance divided by degrees of freedom (D/df) was used to evaluate goodness-of-fit for each final model.

'Site-only' models were constructed first for each measure of bird abundance. These models consisted of site variables that were assumed to influence bird abundance, but could not be experimentally controlled in the study (TIME, DATE, TOPOG, VEG). Type 1 likelihood ratio tests were used to determine whether each term resulted in a significant decrease in model deviance at the $(B=0.05$ significance level. Linear contrasts were used to determine which levels of the categorical variables (TOPOG and VEG) were significantly different.

Next, landscape variables were added to the models, and each variable's added significance to the 'site+landscape' model was assessed with type 1 likelihood ratio tests. First the urbanization variables were added: URB250, to assess the effect of surrounding landscape composition (within a $250 \mathrm{~m}$ radius); and URB1000, to examine the added effect of urbanization proportion at a larger scale of measurement (1000 m radius). Then the two fragmentation variables were inserted: LNED1000, to determine the importance of landscape pattern, or degree of fragmentation in the surrounding landscape, after accounting for urbanization proportion; and LNDIST, to test for the independent influence of urban edge proxim- ity. The last variables added were geographic coordinates (EAST, NORTH), to account for habitat variations along east-west and north-south gradients.

The primary drawback to the Poisson regression model, which is fit with maximum likelihood methods, is the absence of an equivalent to the $\mathrm{R}^{2}$ of least-squares regression, which has an intuitive, linear interpretation (see Bolger et al. 1997). In this analysis, the deviance was used to assess model fit, with a lower deviance indicating a better fit, but all interpretations are relative to other models.

\section{Results}

\section{Bird abundance vs. landscape variables}

As shown in Table 4, bivariate Spearman correlation coefficients revealed significant negative linear relationships between three of the urbanization-related variables (URB250, URB 1000, LNED 1000) and bird abundance for migrants and chaparral-associated species. Abundance of urban-associated species was positively correlated with each of these variables. Edge distance (LNDIST) was negatively correlated with urban-associated species abundance, and positively correlated with all other species abundance measures. With respect to geographic location, urban-associated birds increased with EAST position, while the other groups decreased. Chaparral-associated birds were found to decrease with NORTH position, while urban-associated birds and migrants increased.

These landscape variables are also highly correlated with each other (Table 5), however, indicating that sites with high levels of surrounding urbanization also have high levels of fragmentation, are likely to be located farther east, and tend to be close in proximity to an urban edge. In addition, points located farther north tend to have slightly higher levels of surrounding urbanization, while the most fragmented areas tend to occur farther south.

\section{Site vs. landscape variables}

As expected (and intended), censusing conditions (TIME, DATE) and landscape variables were almost com-

Table 4. Spearman correlation matrix for bird abundance vs. landscape variables for counts 1 and 2 combined. (See Table 3 for description of landscape variables.) All correlations are statistically significant $(P<0.05), n=256)$.

\begin{tabular}{lccccccc}
\hline & Mean \pm S.D. & URB250 & URB1000 & LNED1000 & LNDIST & EAST & NORTH \\
\hline Migrants & & & & & & & \\
$\quad$ Singing males & $0.84 \pm 0.95$ & -0.17 & -0.31 & -0.33 & 0.27 & -0.20 & -0.28 \\
$\quad$ Total & $1.59 \pm 1.61$ & -0.17 & -0.30 & -0.32 & 0.26 & 0.25 \\
\hline Chaparral & & & & & & & \\
$\quad$ Singing males & $8.20 \pm 3.06$ & -0.34 & -0.33 & -0.31 & 0.28 & -0.34 & -0.26 \\
$\quad$ Total & $13.74 \pm 4.60$ & -0.43 & -0.47 & -0.44 & 0.39 & -0.36 & -14 \\
\hline $\begin{array}{l}\text { Urban } \\
\quad \text { Total }\end{array}$ & $2.02 \pm 1.65$ & 0.35 & 0.35 & 0.35 & -0.40 & 0.38 & 0.22 \\
\hline
\end{tabular}


Table 5. Mean and standard deviation and pearson correlation matrix for landscape variables. (See Table 3 for description of landscape variables.) Relationships are statistically significant $(\mathrm{P}<0.05)$, except where indicated $(\mathrm{ns}), \mathrm{n}=256)$.

\begin{tabular}{|c|c|c|c|c|c|c|}
\hline & URB250 & URB1000 & LNED1000 & LNDIST & EAST & NORTH \\
\hline Mean & 0.04 & 0.16 & 6.25 & 6.14 & 361221 & 3774681 \\
\hline S.D. & 0.12 & 0.22 & 3.97 & 1.10 & 5752 & 2054 \\
\hline URB250 & 1.00 & 0.71 & 0.29 & -0.43 & 0.58 & 0.23 \\
\hline URB1000 & & 1.00 & 0.60 & -0.62 & 0.87 & 0.19 \\
\hline LNED1000 & & & 1.00 & -0.65 & 0.51 & -0.15 \\
\hline LNDIST & & & & 1.00 & -0.58 & n.s. \\
\hline EAST & & & & & 1.00 & 0.31 \\
\hline NORTHI & & & & & . & 1.00 \\
\hline
\end{tabular}

pletely uncorrelated, with only weak correlations between URB 1000 and TIME $(r=-0.13)$ and LNED1000 and $\operatorname{DATE}(r=-0.13)$. Likewise, site topography was not significantly associated with any of the landscape variables except NORTH (ANOVA, P < 0.05).

The vegetation (VEG) categories, on the other hand, differed significantly with respect to all of the landscape variables (ANOVA, $\mathrm{P}<0.05$ ). Multiple comparison tests revealed that 'dry/disturbed' sites were localed significantly farther east than 'mesic' and 'intermediate' sites (Fisher's LSD, $\mathrm{P}<0.05$ ), which is consistent with my observation that chaparral vegetation tends to be shorter and patchier in the drier eastern section of my study area. It may also reflect the greater human impact farther east, however, as disturbed sites also tend to be more open and patchy, and contain more California Buckwheat (Eriogonum fasciculatum) and non-native grasses. In addition, 'mesic' sites were located significantly farther north than either 'intermediate' or 'dry/disturbed' sites (Fisher's LSD, $\mathrm{P}<0.05$ ). This relationship was also expected, due to the more mesic, north-slope vegetation found north of the Mulholland ridgeline. 'Intermediate' sites, which best represent typical ceanothus chaparral, had significantly lower surrounding urbanization levels (URB250, URB 1000) than either 'mesic' or 'dry/disturbed' sites, and were significantly less fragmented (LNED1000 lower, LNDIST higher) than 'dry/disturbed' sites (Fisher's LSD, $\mathrm{P}<0.05$ ).

\section{Poisson regression results}

For all six categories of abundance examined, the 'site+landscape' models represented a significant improvement over the 'site-only' models, with at least two landscape variables significant in the type 1 (sequential) analysis of deviance. The signs of all relationships with landscape variables were the same as in the bivariate analyses.

Local and long-distance migrants. Based on type 1 likelihood ratio tests, all four site variables were significant in the 'site-only' model for total migrant abundance; all variables but TIME were significant in the singing male migrants abundance model (Tables 6\& 7). Total migrant abundance was found to increase slightly with TIME, and both measures decreased with DATE. Linear contrasts for TOPOG and VEG indicate that significantly fewer migrants were counted at 'slope' sites than at 'ridge' sites, and that 'dry/ disturbed' sites had significantly lower abundances than either 'mesic' or 'intermediate' sites.

Table 6. Poisson regression results. Migrant abundance (total individuals). Sequential analysis of deviance based on type 1 likelihoodratio tests. Direction of significant effects indicated by $+/$ - for continuous variables, inequality statements for categorical variables. Goodness-of-fit diagnostics summarized for two nested models: site-only and site+landscape. TOPOG levels: $0=$ slope, $1=$ ridge, $2=$ canyon. VEG levels: $0=$ mesic, $1=$ intermediate, $2=$ dry. $* * * \mathrm{P}<0.0005 / * * \mathrm{P}<0.005 / * \mathrm{P}<0.05$

\begin{tabular}{|c|c|c|c|c|c|}
\hline Variable & Deviance & Type 1 & Effect & df & Deviance/df \\
\hline INTERCEPT & 443.38 & & & & \\
\hline TIME & 435.74 & $*$ & + & & \\
\hline DATE & 426.83 & * & - & & \\
\hline TOPOG & 414.17 & $*$ & $1>0$ & & \\
\hline VEG & 383.36 & $* * *$ & $0>2,1>2$ & & \\
\hline Site-Only & & & & 248 & 1.5458 \\
\hline URB250 & 365.42 & $* * *$ & - & & \\
\hline URB1000 & 347.93 & $* * *$ & - & & \\
\hline LNED1000 & 340.77 & $*$ & - & & \\
\hline LNDIST & 340.75 & & & & \\
\hline EAST & 339.31 & & & & \\
\hline NORTH & 315.80 & $* * *$ & + & & \\
\hline Site+Landscape & & & & 242 & 1.3050 \\
\hline
\end{tabular}


Table 7. Poisson regression results. Migrant abundance (singing males). Sequential analysis of deviance based on type 1 likelihoodratio tests. Direction of significant effects indicated by $+/$ - for continuous variables, inequality statements for categorical variables. Goodness-of-fit diagnostics summarized for two nested models: site-only and site+landscape. TOPOG levels: $0=$ slope, $1=$ ridge, $2=$ canyon. VEG levels: $0=$ mesic, $1=$ intermediate, $2=$ dry. $* * * \mathrm{P}<0.0005 / * * \mathrm{P}<0.005 / * \mathrm{P}<0.05$

\begin{tabular}{|c|c|c|c|c|c|}
\hline Variable & Deviance & Type 1 & Effect & df & Deviance/df \\
\hline INTERCEPT & 314.25 & & & & \\
\hline TIME & 310.99 & & & & \\
\hline DATE & 295.65 & $* * *$ & - & & \\
\hline TOPOG & 287.73 & * & $1>0$ & & \\
\hline VEG & 265.06 & $* * *$ & $0>2,1>2$ & & \\
\hline Site Only & \multicolumn{2}{|c|}{265.06} & & 248 & 1.0688 \\
\hline URB250 & 257.69 & * & - & & \\
\hline URB1000 & 247.75 & ** & - & & \\
\hline LNED1000 & 244.22 & & & & \\
\hline LNDIST & 244.19 & & & & \\
\hline EAST & 244.18 & & & & \\
\hline NORTH & 237.08 & $*$ & + & & \\
\hline Site + Landscape & & & & 242 & 0.9797 \\
\hline
\end{tabular}

Addition of landscape variables reduced the deviance by $18 \%$ for the total migrant model, and by $11 \%$ for singing male abundance (Table 11). In the 'site+landscape' models, both urbanization variables (URB250 and URB1000) contributed significantly to the model, based on type 1 likelihood ratio tests. LNED1000 was only significant in the total migrant model, however. Neither LNDIST nor EAST were significant, but NORTH significantly reduced the deviance of both models.

Chaparral-associated species. For total chaparral-associated species, all site variables but TOPOG were significant, based on type 1 likelihood ratio tests; only TIME and VEG were significant in the singing male abundance model (Tables 8 \& 9). Both abundance decreased with TIME, while total increased with DATE, probably reflecting an increase in hatching-year birds throughout the season. Linear contrasts reveal that sites containing the 'intermedi- ate' vegetation type had significantly higher abundances than either the 'dry/disturbed' or 'mesic' sitcs.

Addition of landscape variables reduced the deviance of the total and singing male models by 25 and $22 \%$, respectively (Table 11). In both of the 'site+landscape' models, URB250, URB1000 and LNED1000 all reduced the deviance significantly. No further reductions in model deviance were obtained by adding LNDIST or either of the geographic variables (EAST, NORTH).

Urban-associated species. Site conditions were found to be less important in predicting the abundance of urban-associated species (Table 10). Although they were the first variables to be entered, neither TIME, DATE nor TOPOG provided any significant explanatory power to the model. Vegetation category (VEG) was a significant predictor of abundance, however, with 'dry/disturbed' sites supporting significantly more birds than 'intermediate' sites.

Table 8. Poisson regression results. Chaparral-associated species abundance (total individuals). Sequential analysis of deviance based on type 1 likelihood-ratio tests. Direction of significant effects indicated by $+/$ - for continuous variables, inequality statements for categorical variables. Goodness-of-fit diagnostics summarized for two nested models: site-only and site+landscape. TOPOG levels: 0 = slope, 1 = ridge, 2 = canyon. VEG levels: $0=$ mesic, $1=$ intermediate, $2=$ dry. $* * * P<0.0005 / * * \mathrm{P}<0.005 / * \mathrm{P}<0.05$

\begin{tabular}{|c|c|c|c|c|c|}
\hline Variable & Deviance & Type 1 & Effect & df & Deviance/df \\
\hline INTERCEPT & 395.50 & & & & \\
\hline TIME & 346.16 & $* * *$ & - & & \\
\hline DATE & 294.32 & **** & + & & \\
\hline TOPOG & 292.74 & & & & \\
\hline VEG & 270.59 & $* * *$ & $1>2,1>0$ & & \\
\hline Site-only & & & & 248 & 1.0911 \\
\hline URB250 & 230.14 & $* * *$ & - & & \\
\hline URB 1000 & 210.63 & $* * *$ & - & & \\
\hline LNED1000 & 205.27 & * & - & & \\
\hline LNDIST & 205.16 & & & & \\
\hline EAST & 204.95 & & & & \\
\hline NORTH & 203.36 & & & & \\
\hline Site + Landscape & & & & 242 & 0.8403 \\
\hline
\end{tabular}


Table 9. Poisson regression results. Chaparral-associated species abundance (singing males). Sequential analysis of deviance based on type 1 likelihood-ratio tests. Direction of significant effects indicated by $+/$ - for continuous variables, inequality statements for categorical variables. Goodness-of-fit diagnostics summarized for two nested models: site-only and site+landscape. TOPOG levels: 0 = slope, $1=$ ridge, 2 = canyon. VEG levels: $0=$ mesic, $1=$ intermediate, $2=$ dry. $* * * P<0.0005 / * * \mathrm{P}<0.005 / * \mathrm{P}<0.05$

\begin{tabular}{|c|c|c|c|c|c|}
\hline Variable & Deviance & Type 1 & Effect & df & Deviance/df \\
\hline INTERCEPT & 300.00 & & & & \\
\hline TIME & 288.66 & $* * *$ & - & & \\
\hline DATE & 285.66 & & & & \\
\hline TOPOG & 280.96 & & & & \\
\hline VEG & 261.57 & $* * *$ & $1>2,0>2$ & & \\
\hline Site Only & & & & 248 & 1.0547 \\
\hline URB250 & 227.56 & $* * *$ & - & & \\
\hline URB1000 & 216.16 & $* * *$ & - & & \\
\hline LNED1000 & 215.82 & & & & \\
\hline LNDIST & 215.72 & & & & \\
\hline EAST & 213.87 & & & & \\
\hline NORTH & 204.38 & $* *$ & - & & \\
\hline Site + Landscape & & & & 242 & 0.8445 \\
\hline
\end{tabular}

Addition of landscape variables reduced the deviance of the model by $20 \%$. Both urbanization variables (URB250 and URB1000) contributed significantly to the model in the type 1 analysis of deviance, as did edge proximity (LNDIST) and EAST.

\section{Discussion}

The sequential analysis of nested 'site-only' and 'site+landscape' models allowed me to evaluate the influence of landscape-level urbanization features on chaparral bird abundances, above and beyond the effects of local site conditions, which were forced into the model first. The analyses of deviance were useful in assessing the added contribution of each additional landscape variable, given the assumptions made in determining their insertion order. The retention of the original landscape variables in the model (rather than independent, linear combinations, as can be generated using multivariate ordination techniques) provided for a more direct interpretation of urbanization effects.

\section{Landscape composition}

Across the species categories examined, the urbaniza tion proportion of the surrounding landscape was found to be negatively associated with migrant and chaparralassociated species abundance, and positively associated with urban-associated species. In all cases, urbanization proportion within $250 \mathrm{~m}$ and $1000 \mathrm{~m}$ radius areas explained additional variation in bird abundance not explained by local site conditions (Table 11). Although other studies have demonstrated significant relationships between animal abundance and/or diversity measures and surrounding landscape composition (e.g. Friesen et al.

Table 10. Poisson regression results. Urban-associated species abundance (total individuals). Sequential analysis of deviance based on type 1 likelihood-ratio tests. Direction of significant effects indicated by $+/$ - for continuous variables, inequality statements for categorical variables. Goodness-of-fit diagnostics summarized for two nested models: site-only and site+landscape. TOPOG levels: 0 = slope, 1 = ridge, 2 = canyon. VEG levels: $0=$ mesic, $1=$ intermediate, $2=$ dry. $* * * P<0.0005 / * * \mathrm{P}<0.005 / * \mathrm{P}<0.05$

\begin{tabular}{|c|c|c|c|c|c|}
\hline Variable & Deviance & Type 1 & Effect & df & Deviance/df \\
\hline INTERCEPT & 366.71 & & & & \\
\hline TIME & 366.39 & & & & \\
\hline DATE & 366.39 & & & & \\
\hline TOPOG & 359.72 & & & & \\
\hline VEG & 340.77 & $* *$ & $2>0,2>1$ & & \\
\hline Site Only & \multicolumn{2}{|c|}{340.77} & & 248 & 1.3741 \\
\hline URB250 & 314.68 & $* * *$ & + & & \\
\hline URB 1000 & 293.54 & $* * *$ & + & & \\
\hline LNED1000 & 293.53 & & & & \\
\hline LNDIST & 281.33 & ** & - & & \\
\hline EAST & 274.27 & * & + & & \\
\hline NORTH & 271.80 & & & & \\
\hline Site + Landscape & & & & 242 & 1.1232 \\
\hline
\end{tabular}


Table 11. 'Site-Only' vs. 'Site+Landscape' Models. Change in deviance summarized for each bird abundance category.

\begin{tabular}{lcccc}
\hline Species Category & 'Site-Only' Deviance & 'Site+Landscape' Deviance & Difference & Percent Change \\
\hline MIG-T & 383.36 & 315.80 & 67.56 & $-17.62 \%$ \\
MIG-S & 265.06 & 237.08 & 27.98 & $-10.56 \%$ \\
CIIAP-T & 270.59 & 203.36 & 67.23 & $-24.85 \%$ \\
CHAP-S & 261.57 & 204.38 & 57.19 & $-21.86 \%$ \\
URB-T & 340.77 & 271.80 & 68.97 & $-20.24 \%$ \\
\hline
\end{tabular}

1995; Pearson 1993; Tilghman 1987), relatively few have looked at urbanized landscapes using such a large (1000 m) measurement scale (but see Bolger 1997).

Most of the species examined in this study are prevalent throughout the study area. The Rufous-crowned Sparrow (Aimophila ruficeps) was the only species included in my analyses that has been officially designated a conservation priority (State of California "Species of Special Concern"). Thus, it is noteworthy that such common and widespread species are indeed affected by modifications to the surrounding landscape. Future analyses of individual species relationships are needed to determine whether the observed relationships are driven by particular species.

\section{Landscape fragmentation}

Results indicate that urbanization pattern, as well as extent, may influence breeding bird abundances. Despite its strong correlation with urbanization proportion (Table 5), the amount of urban edge within $1000 \mathrm{~m}$ of a point count location (an index for habitat fragmentation) was found to contribute to significant decreases, beyond that accounted for by simple urbanization proportion, in total number of migrants and chaparral-associated species. Until recently, most studies of habitat fragmentation in urbanized landscapes have focused on distinct habitat islands (Soulé et al. 1988; Tilghman 1987; Dickman 1987; Friesen et al. 1995), rather than largely contiguous habitat interspersed with urban development. The results of this study suggest that the effects of habitat fragmentation may be manifest before the traditional fragmentation scenario habitat islands in a sea of inhospitable environment -is reached. In other words, urban encroachment may cause population declines in areas that are not yet completely isolated.

The decrease in total individuals, but not singing males, of these two species groups, suggests that territory size and breeding bird density may not be affected by habitat fragmentation. Perhaps the birds that decline with habitat fragmentation are juvenile birds, implicating reproductive success, rather than habitat occupancy, as the mechanism by which habitat fragmentation affects bird abundance. An investigation of reproductive success in fragmented areas, involving territory mapping and nest site monitoring, is needed to evaluate this potential mechanism.

\section{Edge effects}

Urban-associated species were the only group to demonstrate a significant independent response to urban edge proximity. Urban-associated avian nest predators have been correlated with songbird declines near urban developments (Engels and Sexton 1994). The western scrubjay (Aphelocoma californica), one of the urban-associated species in this study, has been implicated as a songbird nest predator (Ehrlich and McLaughlin 1988), suggesting that enhanced abundances near urban edges could detrimentally affect songbird reproductive success.

The edge-insensitivity of migrant species is initially surprising, given that, in the eastern United States, many neotropical migrants are considered edge-averse, forest interior species (Whitcomb et al. 1981; Flather and Sauer 1996). However, the few migrant species in the chaparral avifauna are all relatively common specics that do not appear to be particularly edge-averse (personal observations).

The edge-insensitivity of chaparral-associated species is consistent with Sauvajot's (1997) results, which, in this same area, found no significant relationships between proximity to urban development and resident bird species richness or abundance. Bolger et al. (1997) also identified most of the chaparral-associated species examined in this study as edge-insensitive.

These results (for migrants and chaparral-associated species) may be due to the hardiness of chaparral vegetation, and its resistance to invasion by non-native plant species, as well as its relative impenetrability to humans (Sauvajot 1997). Indeed, much of the chaparral-development interface appears to be characterized by a distinct "edge," rather than transitional vegetation (personal observations).

Another possible explanation is that reproductive success is indeed lower near urban edges, but source-sink dynamics keep abundances high. Previous studies have suggested that habitat fragmentation reduces reproductive success of migratory songbirds, resulting in source-sink dynamics that may not be detected in simple surveys of species abundance (Donovan et al. 1995; Brawn and Robinson 1996). Again, studies of reproductive success 
near urban edges could increase understanding of these dynamics.

\section{Scale differences}

For each species category examined, the type 1 analysis of deviance indicated that urbanization of the surrounding landscape ( $1000 \mathrm{~m}$ radius) explains additional variation in bird abundance not explained by local urbanization levels ( $250 \mathrm{~m}$ radius). These results suggest that largescale urbanization descriptors are better predictors of chaparral bird abundance than similar measures computed at a smaller spatial scale. Considered with the absence of edgerelated declines in abundances, these two findings suggest that breeding bird numbers may be more closely tied to overall landscape composition and pattern than local urbanization characteristics.

The relative importance of large-scale urbanization patterns suggests that urbanization and resulting landscape modifications may affect birds at the level of the population, rather than the individual. Soule et al. (1988) postulated that the low vagility of "chaparral-requiring" species makes small, isolated populations particularly susceptible to random extinctions. While this scenario does not directly apply to largely interconnected chaparral habitat, reductions in suitable habitat may still limit dispersal and make populations more vulnerable to environmental and demographic stochasticity. Long-term population monitoring, including the tracking of individual birds, would be needed to further investigate this hypothesis.

\section{Landscape vs. local factors}

As reported in previous sections, landscape variables significantly improved the fit of each bird abundance model, indicating that landscape-level land-use patterns are indeed important predictors of chaparral bird abundance, independent of local habitat effects. This is consistent with several recent studies that have taken a landscape ecological approach to habitat fragmentation (e.g., Pearson 1993; Bolger 1997).

Contrary to the findings of several studies of eastern birds (Whitcomb et al. 1981; Flather and Sauer 1996), my results did not indicate that migrants are more susceptible to changes in landscape pattern than are resident species. Migrant species in this study actually appeared to be less affected by landscape features than chaparral- or urbanassociated species, based on the smaller percentage change in deviance between 'site-only' and 'site+landscape' models (Table 11), although this observation could not be tested statistically. Eastern and western migrants may respond differently to landscape fragmentation, based on differences in life-history traits (Hansen and Urban 1992). Indeed, none of the local or long-distance migrants included in this analysis possess the combination of lifehistory traits typical of fragmentation-sensitive species (e.g., closed forest specialist, open nests near ground, low reproductive effort) (based on Whitcomb et al. 1981), although Hansen and Urban (1992) considered the blackheaded grosbeak (Pheucticus melanocephalus) sensitive to landscape change.

In contrast, chaparral-associated species appeared to be somewhat more susceptible to the effects of habitat tragmentation and urban encroachment, based on the relatively large $>20 \%$ changes in deviance between 'site-only' and 'site+landscape' models (Table 11). With the exception of the ash-throated flycatcher (Myiarchus cinerascens), all birds in this category are year-round residents, which are often considered less vulnerable to landscape-level changes than migrant species. At least two of these species, however, have been identified as fragmentation-sensitive in other studies: the orange-crowned warbler (Vermivora celata) (Hansen and Urban 1992), and the rufous-crowned sparrow (Bolger et al. 1997).

Urban-associated species abundance also appears to be predicted largely by landscape-level factors, as evidenced by the $20 \%$ decrease in deviance between the 'siteonly' and 'site+landscape' models (Table 11). For these species, this difference scems to be largely attributable to urban edge proximity, as well as surrounding urbanization proportion, indicating that they tend to follow encroaching urbanization.

My results do not necessarily imply that landscape features are more important than local habitat considerations, as my study did not emphasize local habitat variables to the extent that other similar studies (e.g., Bolger 1997; Pearson 1993) have done. Microclimate, vegetation and topography clearly play an important role in determining where birds nest and forage. The presence of a single coast live oak tree (Quercus agrifolia), for example, may attract birds such as the orange-crowned warbler or blue-gray gnatcatcher (Polioptila caerulea). Similarly, small rocky outcrops may entice other species, such as the canyon wren (Catherpes mexicanus) or rufouscrowned sparrow (Aimophila ruficeps). Such microhabitat differences may indeed explain a large part of the variation in bird abundance.

The collection of additional habitat variables may enable the building of better-fitting models. Such factors would be unlikely to diminish the effect of landscape pattern, however, unless they were highly correlated with the landscape variables, in which case they might actually represent human-induced habitat modifications. Rather than quantifying and incorporating habitat differences, I attempted to control for them to the greatest extent practically possible, by choosing all of my point count locations to be contained in northern mixed chaparral vegetation within 300-600 m elevation. 


\section{Caveats and suggestions}

This observational study examines relationships between a set of independent variables and several measures of bird abundance, identifying overall patterns of abundance. Without experimental manipulation, causal relationships can only be inferred, and the mechanisms responsible for these patterns remain speculative. Given the difficulty of conducting experimental studies at such a large scale, the development and testing of predictive models can produce results valuable to land-use planners and researchers alike. Although I will not be able to evaluate the models' predictive abilities with independent data sets, a second field season will supply additional data with which to replicate the analysis.

Robinson et al. (1992) warn that aggregate measures such as species richness and evenness may obscure the responses of individual species and populations. In grouping like species into broader categories, my study sacrifices species-specific information for a more manageable data set and the ability to capture general patterns that may not be apparent for sparsely-distributed species, given the large number of independent variables and relatively small sample size. However, individual species relationships will be examined in future analyses.

The increase in urbanization from west to east within the study area complicates the interpretation of my results. Although the categorical vegetation variable incorporates some of the natural variation along this east-west gradient, the effects of urbanization and fragmentation are difficult to disentangle from the effects of geographic location, given the potential variations in climate generated by proximity to the Pacific Ocean. The east-west location variable was included in the models to test for these potential differences, but its lack of significance for all but urban-associated species may just indicate a high degree of correlation with the urbanization variables. In my continuing research efforts, I have attempted to address this problem by selecting additional eastern sites that are less urbanized, and additional western sites that are more urbanized. Given the urbanization characteristics of this particular landscape, however, eastern sites with low surrounding urbanization are few and far between.

Also varying from east to west is human disturbance, which is generally higher in the east, where recreational use is concentrated in a few small public parks. Since all point counts were conducted along trails or fire roads, which varied in their traffic levels and recreational uses, human disturbance is a potential confounding factor in this study. Unfortunately, there are no comprehensive data on trail use over the entire study area.

Finally, although geographic coordinates were explicitly included in the models, point count locations were assumed to be independent for statistical purposes. Given the lack of variation in avifauna among scrub vegetation types in southern California (Small 1974), this assump- tion may indeed be reasonable. It is likely, though, that spatial autocorrelation, i.e. greater similarities between points that are closer in proximity to one another, plays some role in determining bird abundance at a point. Geostatistics, while more often used on continental or regional scales (see Villard and Maurer 1996), may be useful in assessing and incorporating spatial autocorrelation within this system.

\section{Conclusion}

While many of the factors influencing this system remain unidentified, a consistent theme emerging from this study is the importance of landscape-level urbanization characteristics in explaining bird abundances in the eastern Santa Monica Mountains. Controlling for site conditions, increasing urbanization and fragmentation of the surrounding landscape is associated with significantly lower abundances of migrant and chaparral-associated species at chaparral-vegetated sites. Chaparral-associated (mostly resident) species appear to be the most sensitive to surrounding landscape changes. Urban-associated species increase in the chaparral with proximity to urban development, as well as surrounding urbanization proportion.

Even when apparently suitable chaparral habitat is present, surrounding urbanization appears to be reducing chaparral bird numbers. The influence of large-scale urbanization patterns on chaparral bird abundance suggests that conservation and land use planning efforts would benefit by incorporating regional, as well as local perspectives, to help ensure that sufficiently large, intact areas of chaparral are maintained. Such planning is possible because chaparral habitat still remains largely unfragmented throughout large sections of the Santa Monica Mountains, and elsewhere in southern California. The relationships observed in this study highlight that planning and forethought will help preserve chaparral habitat before crisis proportions are reached.

Acknowledgments. I wish to thank my advisor, Dr. Terry Root, for her advice and assistance with this project, which is part of my master's thesis research. I am also grateful to Michelle Petit, for field assistance, and to Thomas Dietsch, Michael Burger, Dea Armstrong and Daniel Cooper for providing valuable comments on this manuscript. Dr. Douglas Bolger provided helpful feedback on initial results. Bridget Fahey, Lisa Sorensen, Russ Butler, and David Kershner have provided assistance and support at various stages in my research. Thanks are also extended to Dr. Gary Fowler and Kathy Welch for statistical consultation, and to John Fay for GIS support. Special thanks to Dr. Raymond Sauvajot and Denise Kamradt of the National Park Service, Santa Monica Mountains National Recre- 
ation Area, for project assistance and equipment use. Funding for this project was provided by the Southwest Parks and Monuments Association; and the Population-Environment Dynamics Project, Rackham Graduate School and School of Natural Resources and Environment at the University of Michigan.

\section{Literature Cited}

Bolger, D.T., T.A. Scott, and J.T. Rotenberry. 1997. Breeding bird abundance in an urbanizing landscape in coastal southern California. Conservation Biology 11:406-421.

Brawn, J.D. and S.K. Robinson. 1996. Source-sink population dynamics may complicate the interpretation of long-term census data. Ecology 77:3-12.

Brittingham, M.C. and S.A. Temple. 1983. Have cowbirds caused forest songbirds to decline? BioScience 33:31-35.

Brown, V., H.G. Weston, and J. Buzzell. 1973. Handbook of California birds. Naturegraph Publishers, Healdsburg, CA.

Dawson, D.G. 1981. Experimental design when counting birds. Studies in Avian Biology 6:392-398.

DeSante, D. 1982. Nests and nest predation in landbirds. PRBO Newsletter 59:1-5.

Dickman, C.R. 1987. Habitat fragmentation and vertebrate species richness in an urban environment. Journal of Applied Ecology 24:337-351.

Donovan, T.M., F.R. Thompson, J. Faaborg, and J.R. Probst. 1995. Reproductive success of migratory birds in habitat sources and sinks. Conservation Biology 9:1380-1395.

Ehrlich, P.R., D.F. Dobkin, and D. Wheye. 1988. The birder's handbook: A field guide to the natural history of birds. Simon \& Schuster. New York, NY.

Ehrlich, P.R. and J.F. McLaughlin. 1988. Scrub jay predation on starlings and swallows: attack and interspecies defense. Condor 90:503-505.

Engels, T.M. and C.W. Sexton. 1994. Negative correlation of blue jays and golden-cheeked warblers near an urbanizing area. Conservation Biology 8:286-290.

Flather, C.H. and J.R. Sauer. 1996. Using landscape ecology to test hypotheses about large-scale abundance patterns in migratory birds. Ecology 77:28-35.

Friesen, L.E., P.F. Eagles, and R.J. Mackay. 1995. Effects of residential development on forest-dwelling Neotropical migrant songbirds. Conservation Biology 9:1408-1414.

Garrett, K. and J. Dunn. 1981. Birds of southern California. Los Angeles Audubon Society, Los Angeles, CA.

Gilpin, M.E. and M.E. Soulé. 1986. Minimum viable populations: processes of species extinctions. Pp. 19-34 in M.E. Soulé, ed. Conservation biology: The science of scarcity and diversity. Sinauer Associates, Sunderland, MA.

Hansen, A.J. and D.L. Urban. 1992. Avian response to landscape pattern: the role of species' life histories. Landscape Ecology 7:163-180.

Holland, R.F. 1986. Preliminary descriptions of the terrestrial natural communities of California. State of California, The Resources Agency, Department of Fish and Game, Natural Heritage Division, Sacramento, CA.

Langen, T.A., D.T. Bolger, and T.J. Case. 1991. Predation on artificial bird nests in chaparral fragments. Oecologia 86:395401.
MacArthur, R.H. and E.O. Wilson. 1963. An equilibrium theory of insular zoogeography. Evolution 17:373-387.

Noss, R.F. 1991. Landscape connectivity: different functions at different scales. Pp. 27-39 in W.E. Hudson, ed. Landscape linkages and biodiversity. Island Press, Washington, DC.

Pearson, S.M. 1993. The spatial extent and relative influence of landscape-level factors on wintering bird populations. Landscape Ecology 8:3-18.

Ralph, C.J., G.R. Geupel, P. Pyle, T.E. Martin, and D.F. DeSante. 1993. Handbook of field methods for monitoring landbirds. USDA Forest Service Gencral Technical Report PSW-GTR144.

Robbins. C.S. 1981. Effect of time of day on bird activity. Studies in Avian Biology 6:275-286.

Robinson, G.R., R.D. Holt, M.S. Gaines, S.P. Hamburg, M.L. Johnson, H.S. Fitch, and E.A. Martinko. 1992. Diverse and contrasting effects of habitat fragmentation. Science 257:524526.

SAS Institute Inc. 1997. SAS/STAT(r) Software: Changes and enhancements through release 6.12. SAS Institute Inc., Cary, NC.

Saunders, D.A., R.J. Hobbs, and C.R. Margules. 1991. Consequences of ecosystem fragmentation: a review. Conservation Biology 5:18-32.

Sauvajot, R.M. 1997. The influence of urban edge effects and anthropogenic disturbance on chaparral mammals and birds. Oecologia, in review.

Scott, T.A. 1995. Prefire management along California's wildland/urban interface: introduction and session overview. Pp. 3-10 in Keeley, J.E. and T.A. Scott, eds. Brushfires in California wildlands: ecology and resource management. International Association of Wildland Fire, Fairfield, WA.

Small, A. 1974. The birds of California. Winchester Press, New York, NY.

Soulé, M.E., A.C. Alberts, and D.T. Bolger. 1992. The effects of habitat fragmentation on chaparral plants and vertebrates. Oikos 63:39-47.

Soulé, M.E., D.T. Bolger, A.C. Alberts, R. Sauvajot, J. Wright, M. Sorice, and S. Hill. 1988. Reconstructed dynamics of rapid extinctions of chaparral-requiring birds in urban habital islands. Conservation Biology 2:75-92.

Tilghman, N.G. 1987. Characteristics of urban woodlands affecting breeding bird diversity and abundance. Landscape and Urban Planning 14:481-495.

Villard, M. and B.A. Maurer. 1996. Geostatistics as a tool for examining hypothesized declines in migratory songbirds. Ecology 77:59-68.

Whitcomb, R.F., C.S. Robbins, J.F. Lynch, B.L. Whitcomb, K. Klimkiewicz, and D. Bystrak. 1981. Effects of forest fragmentation on avifauna of the eastern deciduous forest. Pp. 125-205 in R.L. Burgess and D.M. Sharpe, eds. Forest island dynamics in man-dominated landscapes. Springer-Verlag, New York, NY.

Wiens, J.A. 1994. Habitat fragmentation: island vs. landscape perspectives on bird conservation. Ibis 137:S97-S104.

Wilcover, D.S., C.H. McLellan, and A.P. Dobson. 1986. Habitat fragmentation in the temperate zone. Pp. 237-256 in M.E. Soulé, ed. Conservation biology; the science of scarcity and diversity. Sinauer, Sunderland, MA. 


\title{
Distribution of the Herpetofauna of Coastal Southern California with Reference to Elevation Effects
}

\author{
Robert N. Fisher* and Ted J. Case \\ Department of Biology, University of California at San Diego, La Jolla, CA 92093 \\ *Present address: USGS Biological Resources Division and Biological Field Stations \\ Department of Biology, San Diego State University, San Diego, CA 92182-4614 \\ Tel. (619) 594-8026; e-mail: rfisher@sunstroke.sdsu.edu
}

\begin{abstract}
We are conducting an intensive study of the herpetofauna of the low elevation scrubland communities of the California Floristic Province between the Santa Ana River and the Mexican Border. Our research focuses on autecology and the effect of habitat fragmentation on species distributions. We utilize pit-fall traps with drift fences to trap species at 21 study sites, consisting of multiple sampling stations, ranging over an environmental gradient of habitat, elevation, and climate. The trapping design captures $40+$ species of reptiles and amphibians. It is an effective way to sample the majority of the terrestrial fauna, particularly those that are difficult to inventory because of nocturnal, fossorial, and cryptic habits. We found that most species occur broadly over this area, and that there is a core group of 14 species that occurs evenly at the majority of the study sites in each county. Several of the sensitive species are widespread across the region, and if proactive conservation steps are taken, many of these could be brought out of risk for future listings.
\end{abstract}

Keywords: Amphibians; coastal southern California; community structure; pit-fall trapping; reptiles.

\section{Introduction}

The herpetofauna of coastal southern California is very diverse due to a variety of factors including topography, geological and biogeographic history, and a diversity of climates over a relatively small area (Peabody and Savage 1958; Savage 1960). This herpetofauna consists of over 70 species in 19 families, of which 24 are considered sensitive at the state or federal levels (Stebbins 1985; Jennings and Hayes 1994; Fisher and Case 1997). Much of the remaining open space in coastal southern Califor- nia is highly fragmented and the future of the herpetofaunal diversity in southern California will depend on an understanding of the distribution and abundance of these species within this fragmented landscape.

We began an autecological study of the herpetofauna of coastal southern California to identify which reptile and amphibian species were present, when they were active, and what habitats they are in. One goal was to identify any immediate management needs regarding the maintenance of these species. Specifically our study set out to address the following four questions:

(1) What are the regional patterns of herpetofaunal diversity across coastal southern California?

(2) What is the autecolngy of some of the sensitive herpetofaunal species?

(3) How can we best maintain the herpetofaunal diversity on reserve lands?

(4) What species may need additional regulatory attention, and which species are adequately protected in the current planning of permanently preserved habitats?

Our study is still ongoing, however, in this paper we can address some preliminary conclusions on the first question: the regional patterns of herpetofaunal diversity. We will focus our attention on community structure, analyzing which species appear to be the more consistent elements across the region. Few studies have looked at community structure in reptiles and amphibians in California in general, and most attention has been on the desert communities (Pianka 1986). Notable non-desert exceptions are the work of Fitch (1949) and Klauber (1939) on snakes, 
Fuentes (1976) on lizards, Drost and Fellers (1996) and Fisher and Shaffer (1996) on amphibians, and Morafka and Banta (1976) on reptiles and amphibians.

\section{Materials and Methods}

In 1995 we began an intensive study of the diversity and autecology of the herpetofauna of the California portion of the California Floristic Province. To date we have established 26 study sites geographically ranging from the San Bernardino Mountains (Big Bear Region) in the north, to the Mexican Border at the Tijuana Estuary and Marron Valley. These sites range in elevation from sea level to 2,500 meters. We have established 313 pit-fall drift-fence arrays within these 26 sites. They are distributed across various habitats including oak woodland, coniferous forest, coastal sage scrub, grassland, sand dune, and chaparral. Each array consists of seven 5 gallon buckets as pit fall traps, connected by shade cloth drift-fences ( 15 meter arms), in the shape of a Y. Each arm of the $Y$ has a bucket on the end, one in the middle, and the arms connect to a center bucket. A meter long hardware cloth funnel trap is placed along each of the three arms for capturing large snakes and lizards. Sampling is conducted at each study site for 10 consecutive days every 6 weeks, for a total of 50 to 60 days a year, spread evenly across all seasons. The traps are kept closed between the sampling periods. Sampling was begun at most sites in the summer of 1995 .

The animals captured are individually marked (except for slender salamanders) either by toe-clipping or scaleclipping (snakes) and then released. We process the reptiles and amphibians in the field and released any other animals. Processing includes marking, weighing, and measuring the body length; we keep the toe-clips and tail tips from snakes in ethanol for future molecular systematic work. The vegetation has been recorded in the vicinity of most arrays following established protocols of the California Native Plant Society, and various local landscape features have also been recorded and entered into a GIS database.

The results and discussion to follow rely heavily on the results from 21 low elevation study sites of the 26 sites total (we excluded Camp Pendleton as we have only sampled it for one year). To identify regional patterns of species diversity we pooled the low elevation sites within each county for San Diego, Orange, and Riverside counties. Four of the remaining sites (San Bernardino Mountains, San Jacinto Mountains, Palomar Mountains, and Japatul Valley) are mid to high elevation and will be used to analyze the relationship of elevation to diversity and abundance of the herpetofaunal community in general. For this analysis we included data for these four mid to high elevation scrub and forest study sites, and data from the twelve largest low elevation sites. As a proxy for abundance we plotted the average capture rate per array per day across sample periods for each site. The capture rate plotted is the total number of captures of reptiles and amphibians during the sample period, divided by the number of arrays at the site, and the number of days we sampled each period (typically 10 ).

Mathematically the capture rate of species $i$ at a site $j$ is:

$$
\mathrm{CR}_{\mathrm{ij}}=\mathrm{n}_{\mathrm{ij}} /\left[\left(\mathrm{A}_{\mathrm{j}}\right)\left(\mathrm{d}_{\mathrm{j}}\right)\right]
$$

where:

$$
\begin{aligned}
\mathrm{CR}_{\mathrm{ij}}= & \text { mean capture (per array per day) rate of spe- } \\
& \text { cies } i \text { at site } j \\
\mathrm{n}_{\mathrm{ij}}= & \text { TOTAL number of individuals captured of } \\
& \text { species } i \text { at site } j \\
\mathrm{~A}_{\mathrm{j}}= & \text { total number of arrays at site } j \\
\mathrm{~d}_{\mathrm{j}}= & \text { number of days site } j \text { was sampled (summed } \\
& \text { over sample periods) }
\end{aligned}
$$

And the total capture rate for site $\mathrm{j}$ summed across all reptile and amphibian species is:

$$
\mathrm{TCR}_{\mathrm{J}}=\sum_{\mathrm{i}=1}^{\text {all species }} \mathrm{CR}_{\mathrm{ij}}
$$

Elevation was estimated as the average across all arrays at a site, and diversity was calculated as simply the total number of species captured at a study site.

\section{Site distribution within counties}

Orange County: We have established three study sites in this county. The two large sites are associated with the foothills of the Santa Ana Mountains and the one smaller site is located in the northern San Joaquin Hills. No sites occurred north of the Santa Ana River or south of San Juan Creek.

San Diego County: We have established 12 study sites in this county; seven are considered small and five large. The northern-most site was at the San Diego Wild Animal Park, several sites were along the coast between Torrey Pines State Reserve and the Tijuana Estuary, and several others were inland from the eastern slope of Otay Mountain to the northern boundary of Miramar Marine Corps Base.

Riverside County: We established six study sites in western Riverside County. Five of these sites are considered large. The study sites were distributed from the northern edge of the Perris Valley south to the northern bank of the Santa Margarita River. No sites were located in the Elsinore Plain or near the Santa Ana River. 
Table 1. Species by county matrix for 21 study sites. Shaded boxes represent species that occurred in $50 \%$ or more sites in that county.

\begin{tabular}{|c|c|c|c|c|c|c|c|c|}
\hline \multirow[b]{2}{*}{ Species } & \multirow[b]{2}{*}{$\begin{array}{l}\text { Total \# } \\
\text { of sites }\end{array}$} & \multirow[b]{2}{*}{$\begin{array}{c}\text { Total \# } \\
\text { individuals }\end{array}$} & \multicolumn{3}{|c|}{$\begin{array}{l}\text { Number of Sites per County } \\
\text { with species vccurrences }\end{array}$} & \multicolumn{3}{|c|}{$\begin{array}{l}\text { Percentage of Sites per County } \\
\text { with species occurrences }\end{array}$} \\
\hline & & & $\begin{array}{c}\text { Orange } \\
\text { County } \\
3 \text { sites } \\
39 \text { arrays } \\
\end{array}$ & $\begin{array}{c}\text { San Diego } \\
\text { County } \\
12 \text { sites } \\
148 \text { arrays }\end{array}$ & $\begin{array}{c}\text { Riverside } \\
\text { County } \\
6 \text { sites } \\
69 \text { arrays } \\
\end{array}$ & $\begin{array}{c}\text { Orange } \\
\text { County } \\
3 \text { sites } \\
39 \text { arrays }\end{array}$ & $\begin{array}{c}\text { San Diego } \\
\text { County } \\
12 \text { sites } \\
148 \text { arrays }\end{array}$ & $\begin{array}{c}\text { Riverside } \\
\text { County } \\
6 \text { sites } \\
69 \text { arrays } \\
\end{array}$ \\
\hline Batrachoseps pacificus & 17 & 339 & 3 & 8 & 6 & $100 \%$ & $67 \%$ & 1005 \\
\hline Aneides lugubris & 5 & 10 & 2 & 3 & & $67 \%$ & $25 \%$ & \\
\hline Ensatina eschscholtzii & 3 & 25 & 2 & 1 & & $67 \%$ & $8 \%$ & \\
\hline $\begin{array}{l}\text { Batrachoseps nigriventris } \\
\text { Taricha torosa* }\end{array}$ & 2 & 31 & 2 & & & $67 \%$ & & \\
\hline Hyla regilla & 18 & 339 & 2 & 10 & 6 & $67 \%$ & $83 \%$ & $100 \%$ \\
\hline Scaphiopus hammondii* & 12 & 65 & 1 & 5 & 6 & $33 \%$ & $42 \%$ & $100 \%$ \\
\hline Bufo boreas & 12 & 1127 & 2 & 4 & 6 & $67 \%$ & $33 \%$ & $100 \%$ \\
\hline Hyla cadaverina & 4 & 4 & 2 & 1 & 1 & $67 \%$ & $8 \%$ & $17 \%$ \\
\hline \multicolumn{9}{|l|}{ Bufo microscaphus* } \\
\hline \multicolumn{9}{|l|}{ Bufo punctatus } \\
\hline \multicolumn{9}{|l|}{ Rana aurora* } \\
\hline Clemmys marmorata* & 1 & obs. only** & & & 1 & & & $17 \%$ \\
\hline Uta stansburiana & 21 & 1456 & 3 & 12 & 6 & $100 \%$ & $100 \%$ & $100 \%$ \\
\hline Elgaria multicarinatus & 21 & 696 & 3 & 12 & 6 & $100 \%$ & $100 \%$ & $100 \%$ \\
\hline Sceloporus occidentalis & 20 & 2330 & 3 & 12 & 5 & $100 \%$ & $100 \%$ & $83 \%$ \\
\hline Cnemidophorus hyperythrus* & 19 & 3471 & 2 & 11 & 6 & $67 \%$ & $92 \%$ & $100 \%$ \\
\hline Eumeces skiltonianus* & 19 & 875 & 3 & 10 & 6 & $100 \%$ & $83 \%$ & $100 \%$ \\
\hline Cnemidophorus tigris* & 16 & 869 & 2 & 8 & 6 & $67 \%$ & $67 \%$ & $100 \%$ \\
\hline Phrynosoma coronatum* & 15 & 349 & 2 & 7 & 6 & $67 \%$ & $58 \%$ & $100 \%$ \\
\hline Sceloporus orcutti & 10 & 83 & 1 & 3 & 6 & $33 \%$ & $25 \%$ & $100 \%$ \\
\hline Eumeces gilberti & 7 & 77 & 1 & 3 & 3 & $33 \%$ & $25 \%$ & $50 \%$ \\
\hline Coleonyx variegatus* & 7 & 87 & 1 & 2 & 4 & $33 \%$ & $17 \%$ & $67 \%$ \\
\hline Anniella pulchra* & 7 & 13 & & 6 & 1 & & $50 \%$ & $17 \%$ \\
\hline Xantusia henshawi* & 5 & 11 & & 4 & 1 & & $33 \%$ & $17 \%$ \\
\hline Gambelia wislizenii & 1 & obs. only & & & 1 & & & $17 \%$ \\
\hline Lampropeltis getulus & 20 & 145 & 3 & 12 & 5 & $100 \%$ & $100 \%$ & $83 \%$ \\
\hline Masticophis lateralis & 20 & 327 & 2 & 12 & 6 & $67 \%$ & $100 \%$ & $100 \%$ \\
\hline Pituophis melanoleucas & 20 & 122 & 3 & 11 & 6 & $100 \%$ & $92 \%$ & $100 \%$ \\
\hline Crotalus viridis & 18 & 48 & 2 & 12 & 4 & $67 \%$ & $100 \%$ & $67 \%$ \\
\hline Crotalus ruber* & 15 & 33 & 2 & 7 & 6 & $67 \%$ & $58 \%$ & $100 \%$ \\
\hline Masticophis flagellum & 13 & 111 & 1 & 6 & 6 & $33 \%$ & $50 \%$ & $100 \%$ \\
\hline Leptotyphlops humilis & 12 & 74 & 1 & 5 & 6 & $33 \%$ & $42 \%$ & $100 \%$ \\
\hline Diadophis punctatus* & 11 & 42 & 2 & 7 & 2 & $67 \%$ & $58 \%$ & $33 \%$ \\
\hline Salvadora hexalepis* & 11 & 38 & 2 & 4 & 5 & $67 \%$ & $33 \%$ & $83 \%$ \\
\hline Hypsiglena torquata & 10 & 22 & 1 & 6 & 3 & $33 \%$ & $50 \%$ & $50 \%$ \\
\hline Rhinocheilus lecontei & 9 & 25 & & 5 & 4 & & $42 \%$ & $67 \%$ \\
\hline Lichanura trivirgata* & 9 & 10 & & 3 & 6 & & $25 \%$ & $100 \%$ \\
\hline Thamnophis hammondii* & 8 & 52 & 1 & 6 & 1 & $33 \%$ & $50 \%$ & $17 \%$ \\
\hline Tantilla planiceps & 8 & 32 & & 5 & 3 & & $42 \%$ & $50 \%$ \\
\hline Crotalus mitchellii & 5 & 4 & & 3 & 2 & & $25 \%$ & $33 \%$ \\
\hline Trimorphodon biscutatus & 5 & 3 & 1 & I & 3 & $33 \%$ & $8 \%$ & $50 \%$ \\
\hline Coluber constrictor & 3 & 28 & 1 & 2 & & $33 \%$ & $17 \%$ & \\
\hline Lampropeltis zonata* & 1 & obs. only & 1 & & & $33 \%$ & & \\
\hline \multirow{2}{*}{\multicolumn{9}{|c|}{$\begin{array}{l}\text { Arizona elegans } \\
\text { Thamnophis sirtalis* }\end{array}$}} \\
\hline & & & & & & & & \\
\hline \multicolumn{9}{|l|}{ Exotics } \\
\hline Xenopus leavis & 3 & 196 & & 3 & & & $25 \%$ & \\
\hline Rana catesbeiana & 3 & obs. only & 1 & 1 & 1 & $33 \%$ & $8 \%$ & $17 \%$ \\
\hline Trachemys scripta & 1 & obs. only & & & I & & & $17 \%$ \\
\hline Sceloporus magister & 1 & obs. only & & 1 & & & $8 \%$ & \\
\hline
\end{tabular}

Total number of native species $=40$

* = considered sensitive or protected by USFWS or CDFG

** obs. only $=$ species observed at a site but not in a trap 


\section{Results and Discussion}

A total of 16,650 captures have occurred, representing 13,570 total individuals across a total of 37 species of native reptiles and amphibians over the 21 study sites (Table 1). The three counties had between 32 and 36 species recorded from the study sites. Twenty-seven species were shared by all three counties (Table 1). Eight of the species occurred at 19-21 of the 21 study sites, indicating that many species were in fact widespread within the study region. Table 1 indicates the number of sites a species occurred in per county, and in a second column we present the proportion of sites within the county at which a species occurred. There was one salamander, one frog, seven lizards, and five snake species that occurred in $50 \%$ or more of the study sites across each of the three counties. These species could be viewed as the core elements of the low-elevation herpetofaunal community in coastal southern California. Five of these species are considered sensitive by the California Department of Fish and Game or the United States Fish and Wildlife Service and are identified in bold on Table 1. An average of eight species were captured at each array with a range from 4 to 17 species (Fig. 1).

\section{Salamanders}

The diversity of salamanders was greatest in Orange County with four species recorded as occurring in two of the three study sites. San Diego followed with three species of salamanders recorded, and Riverside County only had the Pacific slender salamander (Batrachoseps pacificus). The four species captured (Aneides lugubris, Ensatina eschscholtzii, Batrachoseps nigriventris, Batrachoseps pacificus) are all member of the family Plethodontidae. They thus are lungless, lack the larval stage and can occur in areas without standing water. These

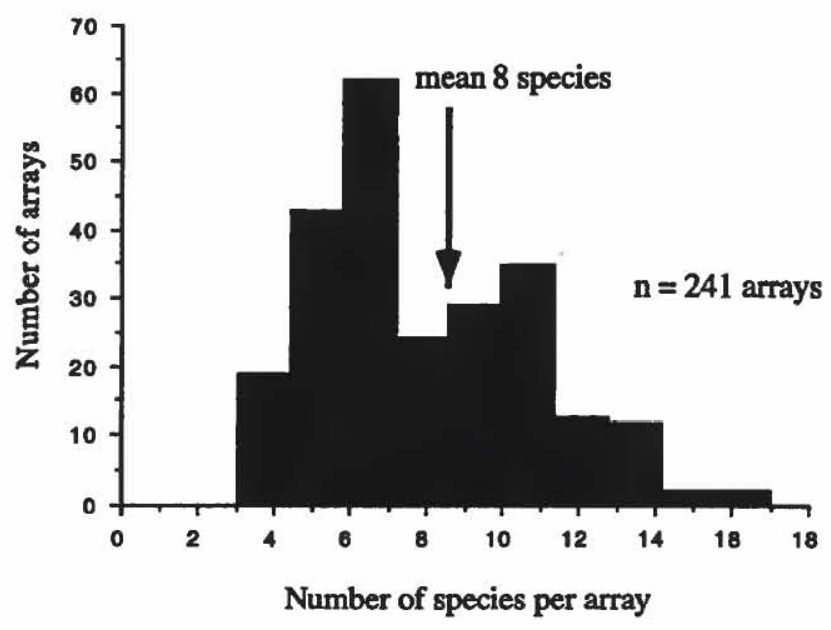

Figure 1. Abundance of pit fall drift fence arrays with varying number of species. are generally mesic-adapted species, except for Batrachoseps pacificus which, was found across the majority of our study sites (17 of 21), and is typically the only salamander present in scrublands of coastal southern California. This species is also a common urban vertebrate element in southern California, with one published field study of a population in an urban garden in Santa Monica (Cunningham 1959). Individuals are often captured in urban settings in San Diego (Fisher, personal observations). The black-bellied slender salamander (Batrachoseps nigriventris) is not known from San Diego County (Wake 1996), and restricted to only mountain canyons in Riverside County (Glaser 1970), thus we would not have expected to capture it in our study sites in these two counties.

\section{Frogs and Toads}

All three counties had the same four species. The Pacific treefrog (Hyla regilla) was the most common, occurring in 18 of the 21 study sites, followed by the western toad (Bufo boreas) and the western spadefoot toad (Scaphiopus hammondii), each occurring in 12 sites. These three species are often associated with temporary pools and ponds (Fisher and Shaffer 1996), and thus are not restricted to areas of permanent water. The fourth species recorded was the California treefrog (Hyla cadaverina), which is restricted to rocky streams and rivers typically associated with canyons (Stebbins 1985) and was found uncommonly at our study sites. Most of our study sites consisted of upland habitat and were not necessarily associated with canyons, the main breeding sites for frogs and toads in temporary pools and ponds. Consequently, typical scrubland habitats across coastal southern California have a community consisting of Hyla regilla, Bufo boreas, and Scaphiopus hammondii.

\section{Turtles}

The only native species of turtle in California is the Pacific pond turtle (Clemmys marmorata) and although it was historically widespread in various habitats, it generally occurs in proximity to permanent water. We observed it at only one study site in Riverside County and did not expect to capture them in our traps. They utilize upland habitats seasonally, especially for nesting. We did find an introduced red-eared slider (Trachemys scripta) at a trap in Riverside County, and this exotic species is becoming widespread throughout southern California (Holland 1997; Fisher, personal observations).

\section{Lizards}

The diversity of lizards was lowest in Orange County, contrary to the results for salamanders, and highest in Riverside County, with all possible species recorded (Table 
1). Seven of these species occurred in over $50 \%$ of the sites in each county, including four of the sensitive species. We found 10 species of lizards occurring across all three counties; half of these species are considered sensitive (Table 1). The side-blotched lizard (Uta stansburiana) and southern alligator lizard (Elgaria multicarinatus) were the only two reptile or amphibian species to occur at all 21 study sites. Four "sensitive" species (Cnemidophorus hyperythrus, Cnemidophorus tigris, Eumeces skiltonianus, Phrynosoma coronatum) occurred within 15 to 19 study sites and were thus widespread. The leopard lizard (Gambelia wislizenii) is not known from Orange County, or the region of our study sites in San Diego County, thus we only expected to observe it in Riverside County.

\section{Snakes}

We found that the snake diversity is highest at our study sites in San Diego County, with a total of 17 of a possible 20 species recorded, one more than Riverside County and three more than Orange County. There were 12 species that were recorded across all three counties, four of which are considered sensitive (Table 1). Three snake species occurred in 20 sites each, and most species occurred in $\mathbf{1 0}$ or more sites. Two species were not recorded at any sites, although there are historic records for one of these (Arizona elegans) at several of our sites. The other species (Thamnophis sirtalis) is primarily riparian and therefore its microhabitats are not covered by our trap design. Snakes were the only group where there were not nested subsets of species across counties. The California mountain kingsnake (Lampropeltis zonata) is only known from high elevations in San Diego and Riverside counties, but it occurs in low elevation riparian forest in Orange County, thus we expected it only in traps from this county.

\section{Exotic species}

We found four introduced species across the 21 study sites. Three were aquatic species as would be expected due to the generally higher degradation of aquatic habitats versus upland habitats. Two of the species found were frogs (Rana catesbeiana, and Xenopus leavis), one a turtle (Trachemys scripta), and the fourth was the desert spiny lizard (Sceloporus magister). Only the last species (Sceloporus magister) may represent an isolated introduction, and not an established population, but this is not firmly established.

\section{Analysis for diversity and abundance by elevation}

We looked at the distribution of total species diversity, and species abundance across all the study sites by elevation. We found that across the 12 lower study sites and the four higher elevation sites, species diversity was

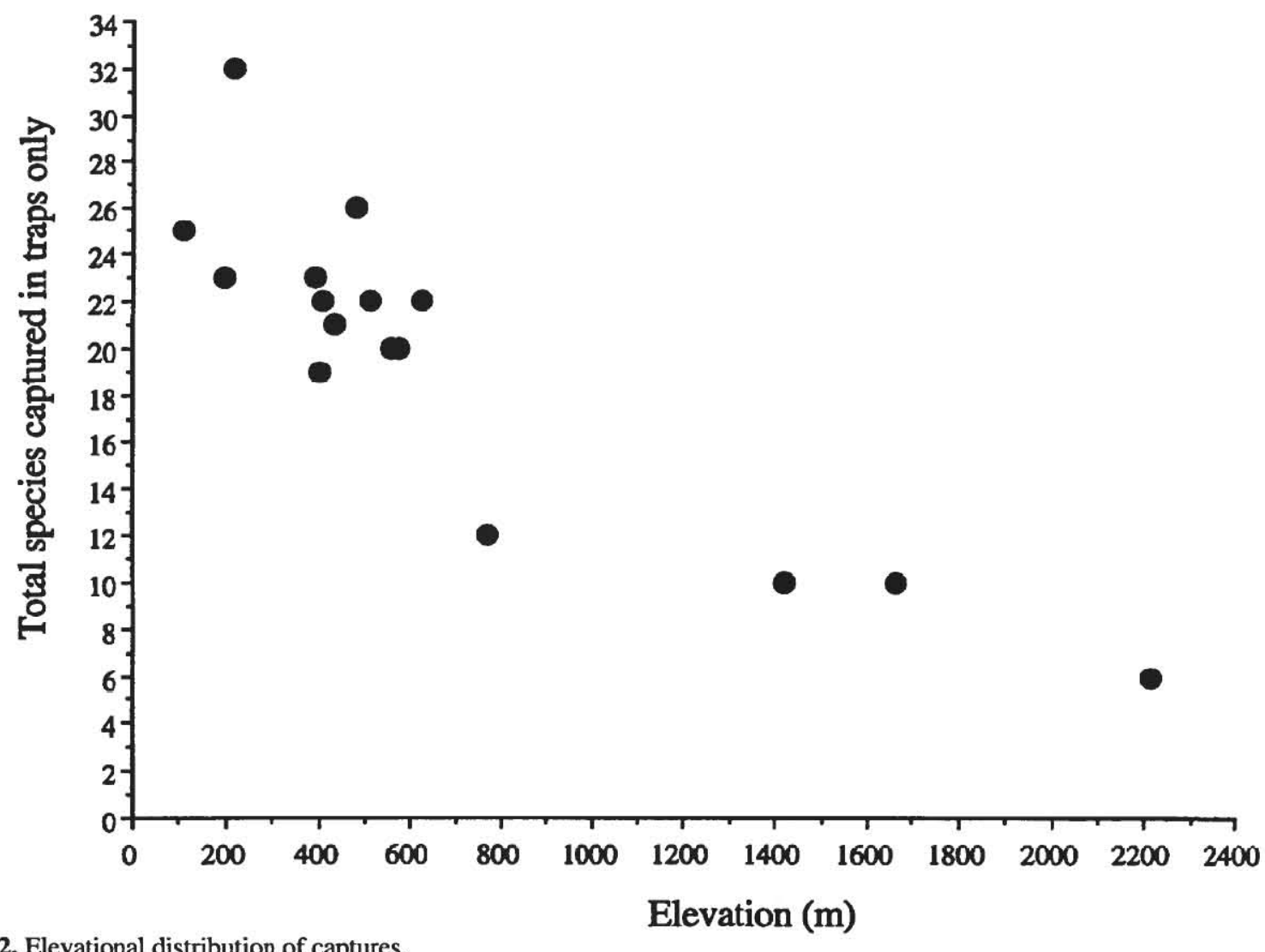

Figure 2. Elevational distribution of captures. 


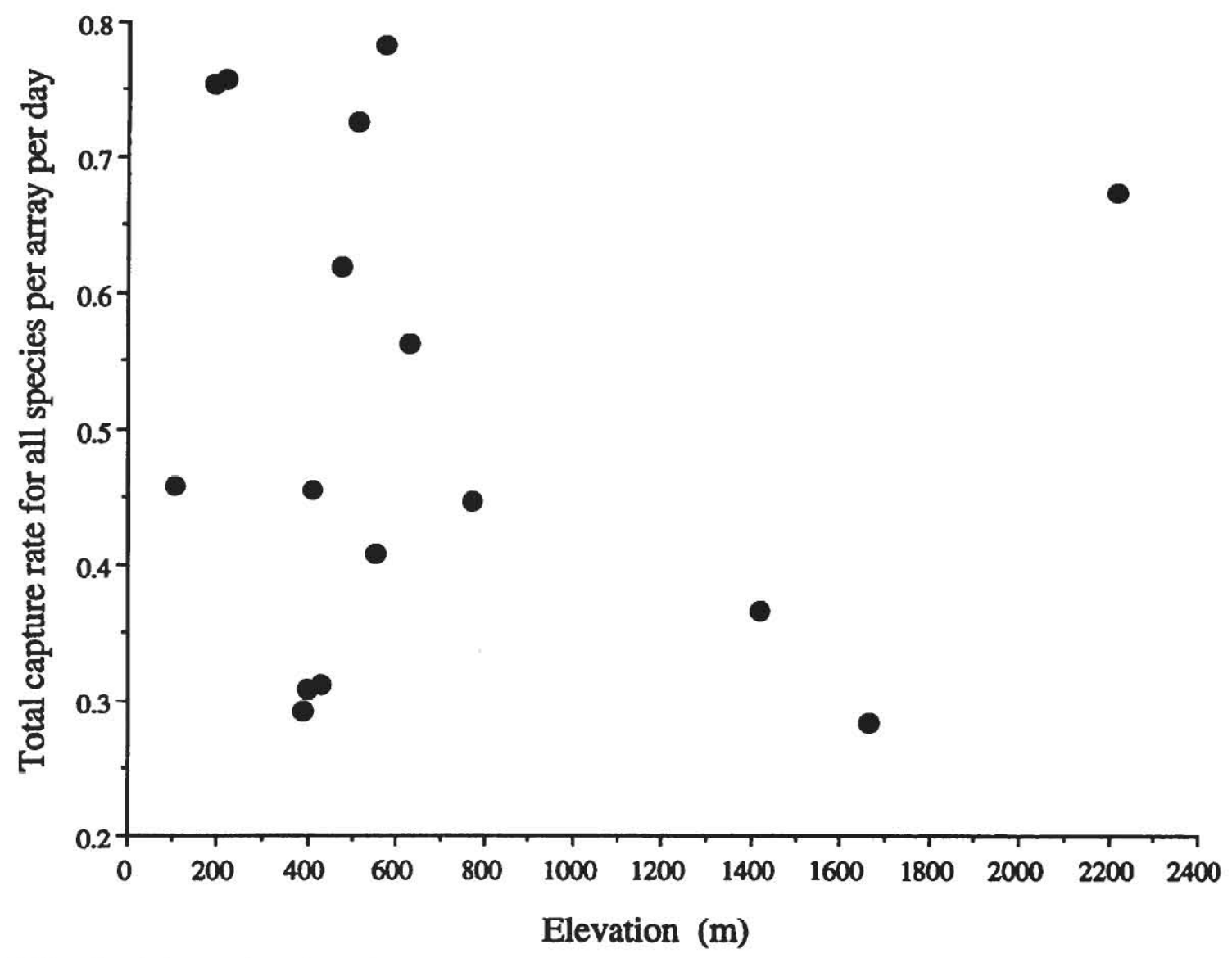

Figure 3. Elevational changes in capture rate.

greatest at lower elevations and decreased with elevation gain (Figure 2). Total summed abundance within each study site was unrelated to elevation and showed a twofold difference across the mountain sites, and within other sites as well (Figure 3). An interesting finding was that one mountain site had a very high capture rate, although it also had the lowest species diversity (Figure 2).

\section{Summary}

We found that study sites in low elevation coastal sage scrub and chaparral habitats across southern California support a minimum of 40 species total, with 32 to 36 species per county. Twenty seven species were shared between all three counties, and fourteen of these occurred in $50 \%$ or more of the sites per county. All of these 14 species are widespread throughout much of California in the California Floristic Province, except for two species that represent Baja California elements (Stebbins 1985; Welsh 1988). These two species are considered sensitive. They are the orange-throated whiptail (Cnemidophorus hyperythrus) and the red diamond rattlesnake (Crotalus ruber). These two species and Batrachoseps pacificus are the only species of the four- teen core species to not be recorded from the early Holocene of the La Brea Tar Pits (Jefferson 1991). Recent molecular data supports the hypothesis that Cnemidophorus hyperythrus and Crotalus ruber both might be recent post-glacial invaders of southern California (Murphy et al. 1995; Radtkey et al. 1997). The lack of Batrachoseps fossils from anywhere in California (Jefferson 1991) may be an artifact of their small size resulting in difficulty in detection as fossils, although their tracks are known from the Pliocene of the Sierra Nevada (Peabody 1940). Thus the evidence from the tar pits supports that most of this core group of species has been persistent in coastal southern California for the last 10,000 to 40,000 years.

The 27 species that occur in all three counties also all occur in the coastal slope sites of a survey transect across Baja California, 200 kilometers to the south of the Mexican Border from San Diego County (Welsh 1988). This strongly implies that the herpetofaunal community of 27 species we have identified in coastal southern California across these counties is stable for approximately $400 \mathrm{ki}$ lometers from the Santa Ana River south to the transect in Baja California. The lack of previous studies on the herpetofaunal community structure in coastal southern 
California, however, limits our ability to make many comparisons.

The 13 species that we recorded from only one or two counties basically divide into mesic adapted and xeric adapted species (Stebbins 1985). Two of the mesic species only occurred in Orange County, and three were shared between Orange and San Diego Counties (Table 1). One of the xeric species occurred only in Riverside County, and six were shared between Riverside and San Diego counties (Table 1). The last species, the Pacific pond turtle (clemmys marmorata), was recorded from along the Santa Margarita River in Riverside County.

The suite of lizards that we found to be widespread across our study sites included all of the species that Fuentes (1976) studied within his plots in San Diego County. The suite of snakes we recorded as widespread was a subset of the species that Klauber (1939) had captured commonly across southern California, implying that some species are now absent or rare. Further detailed analysis of historic records from field notes and museums for this southern California herpetofauna will enable us to determine the population trends across species.

We identified low elevation habitats in southern California as supporting the highest diversities of reptiles and amphibians compared to our high elevation study sites. Unfortunately, the low elevation habitats are typically altered by development and land use change. Thus, the biodiversity of the herpetofauna of southern California is at risk of decline unless proactive conservation planning efforts are successful.

Acknowledgments. These surveys would not have been possible without the day to day sampling by Chris Brown, Ed Ervin, Bob Haase, Adam Backlin, and the many students and volunteers over the last few years. Many land owners, and agencies have granted use of their properties for our study. This work was supported by funding from the California Department of Fish and Game, Biological Resources Division of the USGS, Metropolitan Water District, California State Parks, United States Forest Service, and United States Fish and Wildlife Service.

\section{Literature Cited}

Cunningham, J.D. 1959. Aspects of the ecology of the Pacific slender salamander, Batrachoseps pacificus, in southern California. Ecology 41:88-99.

Drost, C.A. and G.M. Fellers. 1996. Collapse of a regional frog fauna in the Yosemite area of the California Sierra Nevada, USA. Conservation Biology 10:414-425.

Fisher, R.N. and T.J. Case. 1997. A field guide to the reptiles and amphibians of coastal southern California. Unpublished $48 \mathrm{p}$.

Fisher, R.N. and H.B. Shaffer. 1996. The decline of amphibians in California's great Central Valley. Conservation Biology 10:1387-1397.
Fitch, H.S. 1949. Study of snake populations in central California. American Midland Naturalist 41:513-579.

Fuentes, E.R. 1976. Ecological convergence of lizard communities in Chile and California. Ecology 57:3-17.

Glaser, H.S.R. 1970. The distribution of amphibians and reptiles in Riverside County, California. Riverside Museum Press. Riverside, CA. 40 p.

Holland, D. 1997. Draft report on the reptiles and amphibians of Camp Pendelton MCB.

Jefferson, G.T. 1991. A catalogue of late quaternary vertebrates from California: Part one, nonmarine lower vertebrate and avian taxa. Natural History Museum of Los Angeles County, Technical Reports, Number 5, I os Angeles, CA.

Jennings, M.R. and M.P. Hayes. 1994. Amphibian and reptile species of special concern in California. Final report under Contract 8023, California Department of Fish and Game, Inland Fisheries Division, Rancho Cordova, CA.

Klauber, L.M. 1939. Studies of reptile life in the arid southwest. Bulletin of the Zoological Society of San Diego 14:4-100.

Morafka, D.J. and B.H. Banta. 1976. Ecological relationships of the recent herpetofauna of Pinnacles National Monument, Monterey and San Benito Counties, California. Wasmann Journal of Biology 34:304-324.

Murphy, R.W., V. Kovac, O. Haddrath, G.S. Allen, A. Fishbein, and N. Mandrak. 1995. MTDNA gene sequence, allozyme, and morphological uniformity among red diamond rattlesnakes, Crotalus ruber and Crotalus exsul. Canadian Journal Zoology 73:270-281.

Peabody, F.E. 1940. Trackways of Pliocene and recent salamandroids of the Pacific Coast of North America. M.A. thesis, University of California, Berkeley, CA.

Peabody, F.E. and J.M. Savage. 1958. Evolution of a coast range corridor in California and its effects on the origin and dispersion of living amphibians and reptiles. American Association for the Advancement of Science, Publication 51:159-186.

Pianka, E.R. 1986. Ecology and natural history of desert lizards: analyses of the ecological niche and community structure. Princeton University Press, Princeton, NJ.

Radtkey, R.R., S.M. Fallon, and T.J. Case. 1997. Character displacement in some Cnemidophorus lizards revisited: a phylogenetic analysis. Proceedings of the National Academy of Sciences 94:9740-9745.

Savage, J.M. 1960. Evolution of a peninsular herpetofauna. Systematic Zoology 9:184-212.

Stebbins, R.C. 1985. A field guide to western reptiles and amphibians. The Peterson Field Guide Series. Houghton Mifflin Co, New York, NY.

Wake, D.B. 1996. A new species of Batrachoseps (Amphibia: Plethodontidae) from the San Gabriel Mountains, southern California. Contributions in Science, Los Angeles Natural History Museum, 463:1-12.

Welsh, H.H. 1988. An ecogeographic analysis of the herpetofauna of the Sierra San Pedro Martir region, Baja California, with a contribution to the biogeography of the Baja California herpetofauna. Proceedings of the California Academy of Sciences 46:1-72. 


\title{
Alien Species in the Flora and Vegetation of the Santa Monica Mountains, California: Patterns, Processes, and Management Implications
}

\author{
Philip W. Rundel \\ Department of Biology, University of California, Los Angeles, CA 90095 \\ Tel. (310) 825-4072; Fax (310) 825-9433; e-mail: rundel@biology.ucla.edu
}

\begin{abstract}
Naturalized alien species make up $26.8 \%$ of the flora of the Santa Monica Mountains, a level higher than that for California as a whole. Monocotyledonae, particular grasses, are a significant component of this high occurrence of alien species. The largest numbers of aliens occurs in the Poaceae (56 alien species), Asteraceae (35), and Brassicaceae (23). Compared to the flora of natives, alien species in the Santa Monica Mountains show a high frequency $(56 \%)$ of annuals, and low frequencies of woody species. Approximately half of the alien flora of the Santa Monica Mountains is restricted at the present time to strongly disturbed habitats such as roadsides, cleared land and wasteplaces. In the absence of major disturbance, mature chaparral communities are relatively free of invasive alien species, while invasive alien annual grasses may form an important element in more open coastal sage scrub. Oak woodlands and grasslands have been altered dramatically from their original structure and are dominated by annual grasses and forbs from the Mediterraean Basin. Riparian communities include more invasive alien species than any other native ecosystem, and explosive expansion of Arundo donax in this habitat in recent years has the potential to dramatically alter their structure and biodiversity. Coastal and salt marsh habitats also harbor many aggressive invaders. The management and control of invasive alien species in the Santa Monica Mountains and elsewhere in California presents a critical issue of resource management for the future.
\end{abstract}

Keywords: California grasslands; chaparral; invasibility; invasive species; Mediterranean-climate.

\section{Invasive Alien Plants in Mediterranean-Climate Ecosystems}

Invasions of alien species into mediterranean-climate regions throughout the world have become a problem of increasing environmental focus and concern (Mooney and Drake 1986; Kruger et al. 1989; di Castri et al. 1990; Groves 1991; Rundel 1998; Rundel et al. 1998). While thousands of alien plant species have been planted horticulturally in each region, only about $10 \%$ of these have become naturalized. About $1 \%$ of these introductions have become invasive with respect to becoming established in native plant communities.

Comparative studies of alien plant species that have become naturalized within the five mediterranean-climate regions have provided important lessons for resource management because of the similarities of the physical environment of these ecosystems and the common phylogenetic origin of many of the problem weeds. While the compositions of invasive alien plant species within each of these regions show patterns related to the history of human colonization, the nature of settlement patterns, and the nature of trade routes for agricultural and livestock products, there is a strong predominance of European species in these invasive floras. This pattern applies even within the Mediterranean Basin itself, where more than half of the introduced flora of the western Mediterranean comes either from northern Europe or from other areas of the Mediterranean Basin (Guillerm et al. 1990). Moreover, there is a surprising dominance of species of four families in invasive alien floras of mediterranean-climate regions - Poaceae, Asteraceae, Brassicaceae, and Fabaceae.

\section{Patterns of Life History in Invasive Species}

There are two features of mediterranean-climate ecosystems that have been hypothesized to be significant in promoting the invasion of alien plant species (Groves 1991). The first of these is the nature of open habitats available for colonization with the first autumn rains falling after a long summer drought. The majority of herbaceous invaders in Mediterranean-type ecosystems effectively invade such habitats by responding rapidly with germination from soil seed pools once adequate moisture conditions occur and temperatures are suitable. While dormancy mechanisms are often present, these are only suf- 
ficient to maintain dormancy from the time of seed maturation in late spring to the onset of rains in autumn.

The second important component of the invasion of alien annuals species in mediterranean-type ecosystems is the evolutionary origin of many of these species under a long history of human disturbance in the Mediterranean Basin (Le Houérou 1981). As human populations in this region slowly developed large population centers and agricultural economies over a period of thousands of years, there was a natural selection process for biological attributes in weedy species that could adapt to such conditions. Annual cultivation for cropping, grazing, deforestation, and changing frequencies and intensities of fire all introduced selective forces on the life history attributes of native grasses and forbs.

\section{Naturalized Alien Species in the Flora of the Santa Monica Mountains}

The flora of the Santa Monica Mountains in southern California includes 640 native species of vascular plants plus an additional 234 alien species that have become naturalized (Raven et al. 1986). Aliens, therefore, form 26.8\% of the total flora. These aliens are largely species native to other mediterranean-climate regions, although this total includes a few naturalized species that are native to other parts of California (e.g., Romneya coulteri). This proportion of aliens can be compared (Fig. 1) with the flora of Sonoma County with $28.5 \%$ aliens (Best et al. 1996), San Diego County with $23.4 \%$ aliens (Beauchamp 1986), and all of California with $21.1 \%$ aliens (Hickman 1993). Considering alien species of Dicotyledonae and Monocotyledonae separately, the Santa Monica Mountains are notable in comparison to these other areas in the large proportion of aliens (42\%) among monocots (Fig.1). In evaluating these numbers, it is important to remember that there has been a sharp increase in the number of alien

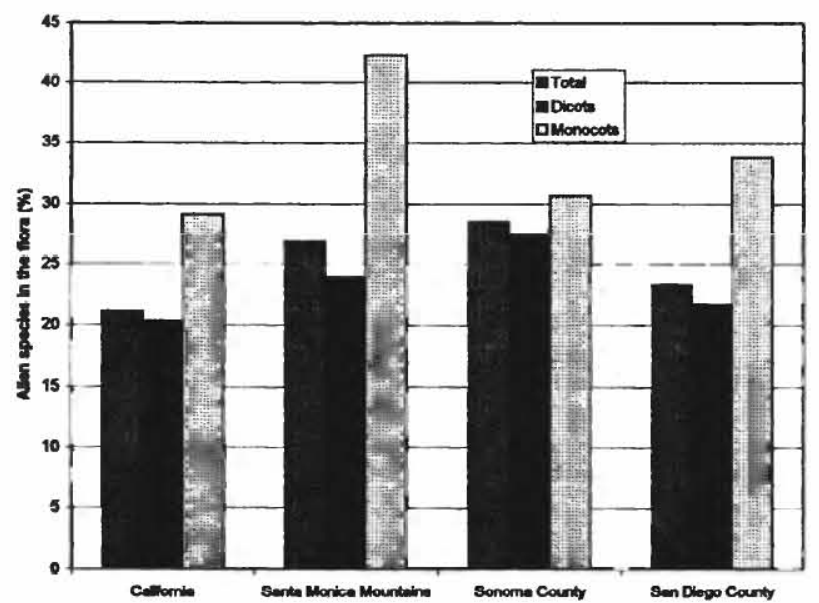

Figure 1. Relative frequencies of naturalized alien species in the total flora of California and within regional areas of the Santa MonicaMountains, Sonoma County andSan Diego County. Data from Hickman (1993), Raven et al. (1986), Best et al. (1996), and Beauchamp (1986).

species naturalized in California over the past two centuries (Frenkel 1970). Future surveys will undoubtedly add to this list of aliens for the Santa Monica Mountains and other areas. Rejmanek and Randall (1994) have recently published a thorough summary of invasive alien plants in California.

Nearly $60 \%$ of the alien species in the Santa Monica Mountains are members of just five families (Table 1). The greatest number of alien species is found in the Poaceae with 56 species (57\% of all Poaceae), followed by the Asteraceae with 35 species ( $27 \%$ of all Asteraceae), the Brassicaceae with 23 species (53\% of all Brassicaceae), the Chenopodiaceae with 13 species $(46 \%$ of all Chenopodiaceae), and the Fabaceae with 12 species (21.0\% of all Fabaceae). Alien species are notably few or absent in a number of the largest families in the flora of the Santa Monica Mountains - the Onagraceae (no

Table 1. Distribution of naturalized alien species within important families in the flora of the Santa Monica Mountains. Families are arranged in order of the number of native species. Data from Raven et al. (1986).

\begin{tabular}{|c|c|c|c|c|}
\hline Family & Total species & Native species & Alien species & Percent aliens \\
\hline \multicolumn{5}{|l|}{ Largest Families } \\
\hline Asteraceate & 131 & 97 & 35 & 26.7 \\
\hline Poaceae & 98 & 42 & 56 & 57.1 \\
\hline Fabaceae & 57 & 45 & 12 & 21.0 \\
\hline Scrophulariaceae & 36 & 33 & 3 & 8.3 \\
\hline Onagraceae & 22 & 22 & 0 & 0.0 \\
\hline Brassicaceae & 43 & 20 & 23 & 53.4 \\
\hline Hydrophyllaceae & 21 & 21 & 0 & 0.0 \\
\hline Cyperaceae & 21 & 19 & 2 & 9.5 \\
\hline Polygonaceae & 25 & 18 & 7 & 28.0 \\
\hline Apiaceae & 24 & 16 & 8 & 33.3 \\
\hline \multicolumn{5}{|l|}{ Other families } \\
\hline Chenopodiaceae & 28 & 15 & 13 & 46.4 \\
\hline Solanaceae & 14 & 5 & 9 & 64.2 \\
\hline Total flora & 874 & 640 & 234 & 26.8 \\
\hline
\end{tabular}


aliens), Hydrophyllaceae (no aliens), Scrophulariaceae (3 alien species), and Cyperaceae ( 2 alien species; Table 1).

The relative distribution of naturalized alien species among plant life-forms compared to the distribution within native species shows distinct patterns of difference (Fig. 2). Annuals make up $56 \%$ of alien species, compared to only $36 \%$ of natives. While the relative frequencies of herbaceous perennials are similar in the two groups, with $38 \%$ and $35 \%$ respectively, there are very few subshrubs and shrubs among aliens in the Santa Monica Mountains.

\section{Alien Species in Ecosystems of the Santa Monica Mountains}

Natural ecosystems in the Santa Monica Mountains, as in other areas of southern California, have experienced changing forms and levels of disturbance associated with human settlement. Such impacts begin with indigenous populations several thousand years ago (Anderson 1993). The nature and extent of human disturbance, however, has accelerated over the past 150 years. Some ecosystems have remained relatively pristine in their floristic composition and vegetation composition, while the structure and diversity of others have been strongly affected by human activities. Almost invariably, strong anthropogenic disturbance since European settlement has been associated with an increasing number and dominance of invasive alien species in native communities.

\section{Highly disturbed habitats}

Distinctive assemblages of alien species and a few weedy natives characterize highly disturbed habitats in California along roads and trails in vacant parcels of land that have been cleared. Frenkel (1970) has broadly discussed the floristic composition of roadside vegetation in

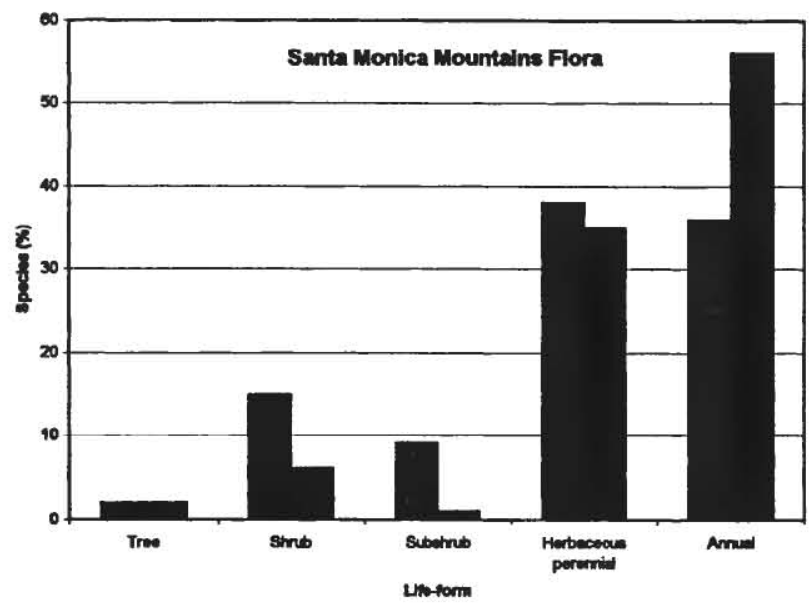

Figure 2. Relative distribution of naturalized alien species among five life-forms in the flora of the Santa Monica Mountains. Data adapted from Raven et al. (1986).
California, and Vessel and Wong (1987) have described the natural history and ecology of vacant lots in the state.

$\Lambda \mathrm{s}$ in other parts of Califonia and mediterranean-climate regions throughout the world (Rundel et al. 1998), there is a strong correlation between the occurrence of alien species in the Santa Monica Mountains and landscape disturbance. More than half of the alien species in the Santa Monica Mountains are weedy taxa strongly associated with disturbed habitats such as roadsides, trails, cleared areas, and wasteplaces. These species have not invaded semi-natural plant communities to any significant extent nor become aggressive outside of highly disturbed habitats of this type. Requirements for disturbed soil microenvironments, low competition, or high microhabitat availability for water or nutrient resources are the likely primary causes of this pattern of limited distribution. Nevertheless, there is potential for some of these species to become more invasive in the future, particularly if seed dispersal more than microhabitat is a factor in distribution.

\section{Chaparral and coastal sage scrub}

Mature chaparral ecosystems in the Santa Monica Mountains are remarkably free of alien species in the absence of major anthropogenic disturbance. Only 19 alien species are commonly associated with chaparral (Fig. 3). And the majority of these are generalist annuals that become briefly established on open sites in the first few years after fire. Examples of such species include Hypochaeris glabra (Asteraceae), Brassica nigra, Lepidium virginicum, Sisymbrium altis and S. officinale (Brassicaceae), Stellaria media (Caryophyllaceae), Erodium cicutarium (Geraniaceae), and Bromus diandrus, B. hordaceus and B. madritensis (Poaceae). Unlike the situation with native post-fire annuals, soil seed pools of alien annuals typically do not survive fires and thus these species become established through seed dispersal from populations outside burned areas. As a result, open areas created by chaparral fires are invaded less strongly by aliens than are chaparral areas cleared or disturbed in other manners. Recent studies of post-fire aerial spraying of seeds of both native and alien species in the Santa Monica Mountains have shown relatively insignificant establishment compared to native regeneration (Keeley 1996).

Woody aliens in chaparral are rare in southern California, although these may be aggressive invaders in more mesic conditions in northern and central parts of the state. There are local areas in the Santa Monica Mountains, as in Cold Creek Canyon, where Spanish broom (Spartium junceum; Fabaceae), has become established on disturbed chaparral sites. This species should be monitored for possible expansion of its range outside of these local areas, as it is known to be an aggressive invader with the potential to reduce community diversity in grasslands and shrublands (Chiarucci et al. 1995). As a legume with ni- 


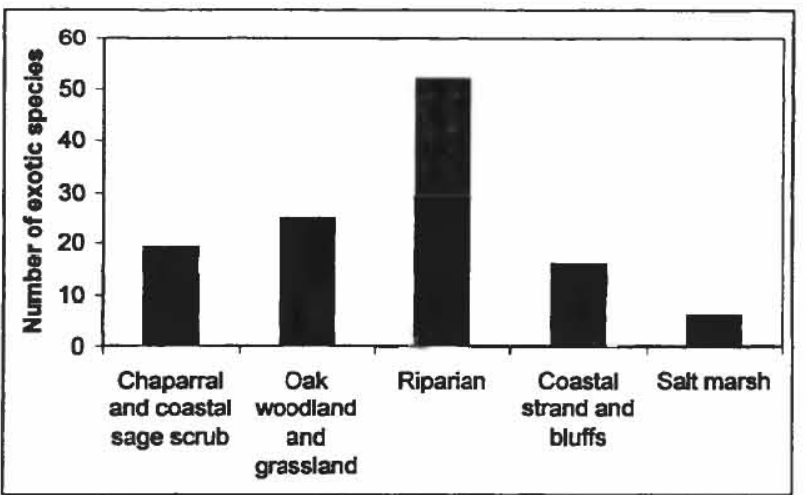

Figure 3. Numbers of naturalized alien species commonly associated with native plant communities in the Santa Monica Mountains. Data from Raven et al. (1986) and personal observations.

trogen-fixing root nodules, $S$. junceum has the potential to significantly alter soil nutrient characteristics beneath its canopy and thereby provide favorable habitat for alien herb species (Maron and Connors 1996). A related species of legume, Cytisus scoparius, has become an invasive problem in shrublands of northern California (Bossard and Rejmanek 1994)

The South American wild tree tobacco, Nicotiana glauca (Solanaceae), has become widely established on landslide slopes and roadsides in many chaparral areas of the Santa Monica Mountains, but has not to date become a problem in mature chaparral. It has become invasive in riparian habitats, however, as described below. Tree-ofheaven, Ailanthus altissima (Simaroubaceae), was brought to California from Asia more than a century ago by Chinese laborers, and has become locally established at a number of sites along north slopes of the Santa Monica Mountains. This tree has the potential to become an increasingly aggressive invader on moist chaparral slopes and riparian corridors.

The open stand structure and light penetration to the ground surface in coastal sage scrub communities makes these more invasible to alien species than chaparral. Most of the same annual invaders described above for chaparral may also be found in open areas of coastal sage scrub, particularly in areas subject to habitat disturbance of any kind. Moreover, alien annuals in these stands may serve as sources for seed distribution to adjacent chaparral stands following fires in the former. Alien annual grasses in coastal sage scrub also inhibit regeneration of native shrub species by competing for soil moisture, thereby promoting a slow conversion from shrubland to grassland (Zink et al. 1995; Eliason and Allen 1997).

\section{Oak woodland and grasslands}

The most dramatic example of altered ecosystem structure in California following disturbance has occurred with the oak woodlands and grasslands of the state. These com- munities have become totally modified from a system largely dominated by native perennial grasses to one in which introduced European annual grasses and forbs provide almost all of the herbaceous plant cover (Heady 1977; Huennecke and Mooney 1989). The sources of these invaders are reasonably well documented, with both deliberate and accidental introductions involved (Mooney et al. 1986; Rejmanek et al. 1991). Flexible life-history characteristics with high reproductive effort, low root to shoot ratios, and large seed banks have pre-adapted these species to habitats with strong grazing pressure and frequent human disturbance (Jackson 1985; Maranon and Bartolome 1993). It is interesting to note that grasslands on edaphically-challenging soil substrates in California, such as serpentine-derived or heavy clay soils, retain a dominance of native annuals and herbaceous perennials, indicating that the widespread introduced annuals are not as competitive in these habitats. Species diversities of native grasslands are commonly higher than those of grasslands dominated by introduced species.

There have been a number of studies establishing the manner in which changes from dominance by perennial bunchgrasses to alien annual grasses have affected woodland and grassland ecosystems in California. One major impact has been changing soil moisture regimes that alter the patterns of seasonal soil water availability (Holmes and Rice 1996). Alien annual species compete strongly with oak seedlings for soil moisture in surface horizons, thereby affecting population dynamics of tree establishment (Bicak and Sternberg 1993; Gordon and Rice 1993).

There seems no question that past and ongoing anthropogenic disturbance has been a factor in allowing invasions of Mediterranean grasses and forbs into Californian woodlands and grasslands (Heady 1977; Huennecke and Mooney 1989; Stromberg and Griffin 1996). Although some disturbance regimes are less damaging to native species than others, almost all forms of disturbance ultimately favor aliens over native species (Kotanen 1997). Management strategies to increase populations of native bunchgrasses and forbs in these habitats have typically involved reducing or eliminating such disturbances, especially from grazing and agricultural activities. Nevertheless, disturbance regimes are important for the persistence of many native grassland species (Schiffman 1994; Kotanen 1997). While it has long been assumed that species-rich communities of native grasslands are less invasible than low diversity communities (Rejmanek 1993), this generalization may not always be true (Rohinson et al. 1995). While many of the dominant alien grasses in grassland communities today will likely always be parts of these ecosystems, newer invaders are cause for concern. Star thistle (Centaurea solstitalis; Asteraceae) has become increasingly invasive in recent years, presenting serious problems for control (Roche et al. 1994). 


\section{Riparian habitats}

Riparian communities and associated wetland habitats make up less than $1 \%$ of the land area of the Santa Monica Mountains of Southern California, but surprisingly are the primary habitat for $20 \%$ of the native flora (Rundel and Sturmer 1998). This remarkable biodiversity is consistent with that found in other riparian communities. $\mathrm{Ri}$ parian habitats form unusually dynamic ecosystems in southern California. These areas are subject to impacts of fluvial disturbances from flooding and associated sediment deposition and/or erosion, as well as nonfluvial impacts from adjacent upland areas in the form of fire, landslides, and other alterations to their physical structure.

More than fifty species of aliens may be found in riparian corridors of the Santa Monica Mountains, nearly half of all alien species in the region. These species include some strongly aggressive invaders that have the potential to dramatically impact the structure and biodiversity of riparian ecosystems. The species of greatest concern among these is Arundo donax (Poaceae), the giant reed. This bamboo-like grass of European origin has rapidly expanded its distribution and abundance in the Santa Monica Mountains in recent years. Arundo is thought to lack functional sexual reproduction in our area, but instead spreads readily by vegetative propagation from stem or root fragments. Once established in a watershev\$ it expands its range rapidly following disturbance associated with strong hydrological flow in streams and creeks.

There are two primary ways in which the spread of Arundo donax can affect the structure and diversity of riparian communities. Thick stands of Arundo crowd out and shade native riparian species, particularly keystone woody species such as sycamores, willows, and alders. Such Arundo stands also provide a large hiomass of highly flammable plant material. Under these conditions, chaparral fires, which commonly jump over or stop along riparian corridors, will burn intensely through these areas, seriously weakening or killing native species. Arundo, however, readily resprouts after fire to regain and expand its previous dominance.

Several other woody plant species may become locally abundant invaders in riparian habitats in the Santa Monica Mountains. Ricinus communis (Euphorbiaceae), the castor bean, forms dense thickets along both small runoff channels and larger streams such as Malibu Creek. These thickets often crowd out competing native species, but seem to be associated primarily with areas of heavy site disturbance. Ageratina adenophora (Asteraceae), an escapee from gardens, has become widely established in riparian corridors in the eastern third of the Santa Monica Mountains from Pacific Palisades to Griffith Park. It frequently forms the dominant understory shrub in shaded sites under the canopies of native tree species. Nicotiana glauca is often locally abundant in riparian habitats where disturbance has occurred. This species forms dense monospecific stands in disturbed flood plains in other areas of riparian habitat in southern California and northwestern Baja California, suggesting that it may become increasingly invasive along some of the larger streams such as Topanga and Malibu Creeks in the Santa Monica Mountains. Ailanthus altissima is locally established in riparian habitats of the mountains, and also has the potential to become much more aggressive.

One herbaceous species, the milk thistle Silybum marianum (Asteraceae), has become established in a number of riparian habitats and may become an aggressive weedy invader with strongly negative impacts on native species. The biology and life history of this and other invasive thistle species has been described in some detail (Gabay et al. 1994; Bruzzese 1996; Sheppard 1996). The bull thistle, Cirsium vulgare (Asteraceae), has been shown to competitively suppress the growth of adjacent tree seedlings (Randall and Rejmanek 1993).

\section{Coastal dunes and bluffs}

The structure and function of coastal dune and bluff communities in many parts of central and northern of California have been dramatically changed by the introduction of invasive alien species. The most significant change has resulted from the widespread introduction of Ammophila arenaria (Poaceae) from Europe for dune control. This aggressive species changes the nature and structure of the dunes through geomorphic impacts on dune stability and by the shading out of native species (Buell et al. 1995). Once established, it is very difficult to remove. Carpobrotus edulis (Aizoaceae) from South Africa, originally planted for dune cover and erosion control along the coast, also has become a widespread invader, crowding out native species (D'Antonio 1993; D'Antonio et al. 1993).

Ammophila and Carpobrotus have not had a significant impact in the Santa Monica Mountains where the relative paucity of dune areas and sandy soils limits their spread. Carpobrotus chilensis, C. edulis, Mesembryanthemum crystallinum (Aizoaceae), and Cakile maritima (Brassicaceae) are all well-established invaders on coastal dunes and beaches. Patterns of extensive disturbance of coastal bluffs have led to herbaceous communities in which aliens commonly outnumber native species.

Pampas grass, Cortaderia atacamensis (Poaceae), has become locally established along the Malibu Coast in areas with seepage, and has the potential to become a serious invader as it is along large areas of the central California coast. Similarly, fountain grass (Pennisetum setaceum; Poaceae) may be a serious problem as well in these habitats. 


\section{Salt marsh}

Although salt marsh habitats at Point Mugu and Malibu Lagoon in the Santa Monica Mountains have retained a dominance of native perennial species, the largest portions of the total floras of these areas are composed of alien species. Approximately $60 \%$ of the vascular plant species sampled in transect studies carried out at Malibu Lagoon were aliens (Manion and Dillingham 1989). Many of these aliens, however, are associated with disturbed upland sites with relatively low soil salinity. Kuhn and Zedler (1997) have investigated the differential effects of salinity and soil saturation on native and alien plants in a coastal salt marsh further south in southern California. They found that although Polypogon monspeliensis (Poaceae) was an aggressive invader of salt marshes where salinity was reduced by urban runoff or unwanted freshwater inflows, this species grew poorly at higher salinities that were readily tolerated by native species. Invasions of Spartina alterniflora (Poaceae), a major problem in northern California, have not occurred along the Malibu Coast, perhaps because of a paucity of suitable habitats.

\section{Aliens that have not naturalized}

In considering the large number of alien species in the Santa Monica Mountains, and in particular those that are highly invasive, it is worth noting a number of species that have not become established. Acacia cyclops, Pinus halapensis, and P. radiata, for example, are all widely planted in the area but do not seem to have become naturalized. These species are highly invasive in other mediterranean-climate regions (Kruger et al. 1989).

\section{Resource Management for the Future}

There can be no simple recommendation for resource management responses to problems of alien species invasions in the Santa Monica Mountains. With limited resources available, it is difficult to know how such resources should be best utilized with our limited present knowledge. Oak woodlands and grasslands appear to be permanently altered to a dominance of alien annual species, with little practical hope of restoring these communities to their natural state. Nevertheless, there is a need for management policies to protect rare and endangered native species within these habitats, and native bunchgrass communities can be maintained on low nutrient or eroded sites. Some species such as Arundo donax are expanding explosively and present a difficult but important problem for control. Other potentially invasive species need careful monitoring or control before they become a serious management problem.
Three critical questions that are now being addressed broadly by researchers with respect to invasive species deserve careful study.

1. Which species make good invaders? While we know something about the life history characteristics of many invasive species, we are only now beginning to be able to predict potential future problems of this nature (Tucker and Richardson 1995; Reichard and Hamilton 1997; Rejmanek and Richardson 1996).

2. Which communities are most easily invaded? It is clear in California and throughout the world that some ecological communities are far more easily invaded by others, but we still do not understand the nature of competitive interactions and life-history characteristics that allows this to occur (Perrins et al. 1992; Rejmanek 1993; Planty-Tabacchi et al. 1996).

3. What will be the rate of spread of invading species? New advances in demographic modeling are allowing a greatly improved basis for making predictions for the rate of spread of newly invasive species (Andow et al. 1993; Shigesada and Kawasaki 1997). Such a capability will be critical to effective resource mangement policies in the future.

\section{Literature Cited}

Anderson, K. 1993. Native Californians as ancient and contemporary cultivators. Pp. 151-174 in T.C. Blackburn and K. Anderson, eds. Before the wilderness: environmental management by native Californians. Ballena Press, Menlo Park, CA.

Andow, D.A., P.M. Kareiva, S.A. Levin, and A. Okubo. 1993. Spread of invading organisms: patterns of spread. Pp. 219-242 in K. Kim and B.A. McPheron, eds. Evolution of insect pests: patterns of variation. John Wiley, New York, NY.

Aschmann, H. 1973. Man's impact on the several regions with mediterrancan climates. Pp. 363-371 in F. di Castri and H.A. Mooney, eds. Mediterranean-type ecosystems: origin and structure. Springer-Verlag, New York, NY.

Beauchamp, R.M. 1986. A flora of San Diego County. Sweetwater River Press, San Diego, CA.

Best, C., J.T. Howell, W. Knight, I. Knight, and M. Wells. 1996. A flora of Sonoma County. California Native Plant Society, Sacramento, CA.

Bicak, C.J. and D. Sternberg. 1993. Water relations of an annual grass, Bromus diandrus, in the Central Valley of California. Bulletin of the Southern California Academy of Sciences 92:54-63.

Bossard, C.C. and M. Rejmanek. 1994. Herbivory, growth, seed production, and resprouting of an exotic invasive shrub Cytisus scoparius. Biological Conservation 67:193-200.

Bruzzese, E. 1996. Ecology of Cirsium vulgare and Silybum marianum in relation to biological control. Plant Protection Quarterly 11: 245-249. 
Buell, A.C., A.J. Pickart, and J.D. Stuart. 1995. Introduction history and invasion patterns of Ammophila arenaria on the north coast of California. Conservation Biology 9:15871593.

Chiarucci, A., I. Bonini, S. Maccherini, and V. De Dominicis. 1995. Influence of colonizing Spartium junceum scrub on Bromus erectus grassland in a biancana badland of the Orcia Valley, Tuscany. Archivio Geobotanico 1:127-134.

D’Antonio, C.M. 1993. Mechanisms controlling invasion of coastal plant communities by the alien succulent Carpobrotus edulis. Ecology 74:83-95.

D'Antonio, C.M., D.C. Odion, and C. M. Tyler. 1993. Invasion of maritime chaparral by the introduced succulent Carpohrotus edulis the roles of fire and herbivory. Oecologia 95:14-21.

di Castri F., A.J. Hansen, and M. Debussche M. eds. 1990. Biological invasions in Europe and the Mediterranean Basin. Kluwer, Dordrecht, The Netherlands.

Eliason, S.A. and E.B. Allen. 1997. Exotic grass competition in suppressing native shrubland re-establishment. Restoration Ecology 5:245-255.

Else, J.A. and P. Zedler. 1996. Dynamics of the flood disturbed zone of a riparian system: Vegetative establishment and resprouting of woody native species and the exotic, Arundo donax. Bulletin of the Ecological Society of America 77:129.

Esler, K.J., P.W. Rundel, and R.M. Cowling. 1998. Biodiversity and conservation biology of coastal transition zones from mediterranean to desert ecosystems: an intercontinental comparison. in P.W. Rundel, G. Montenegro and F. Jaksic, eds. Landscape disturbance and biodiversity in mediterraneantype ecosystems. Springer-Verlag, Berlin (in press).

Frenkel, R.E. 1970. Ruderal vegetation along some California roadsides. University of California Publications in Geography 20:1-163.

Gabay, R., U. Plitmann, and A. Danin. 1994. Factors affecting the dominance of Silybum marianum L. (Asteraceae) in its specific habitats. Flora (Jena) 189:201-206.

Gordon, D.R. and K.J. Rice. 1993. Competitive effects of grassland annuals on soil water and blue oak (Quercus douglasii) seedlings. Ecology 74:68-82.

Groves, R.H. 1991. The biogeography of mediterranean plant invasions. Pp. 427-438 in R.H. Groves and F. di Castri, eds. Biogeography of mediterranean invasions. Cambridge University Press, Cambridge, UK.

Guillerm, J.L., E. Le Floc'h, J. Maillet, and C. Boulet. 1990. The invading weeds within the western Mediterranean Basin. Pp. 61-84 in F. di Castri, A.J. Hansen, and M. Debussche, eds. Biological invasions in Europe and the Mediterranean Basin. Kluwer, Dordrecht, The Netherlands.

Heady, H.F. 1977. Valley grassland. Pp. 491-514 in M. G. Barbour and J. Major, eds. Terrestrial vegetation of California. John Wiley, New York, NY.

Hickman, J. ed. 1993. The Jepson manual: higher plants of California. University of California Press, Berkeley, CA.

Holmes, T.H. and K.J. Rice. 1996. Patterns of growth and soilwater utilization in some exotic annuals and native perennial bunchgrasses of California. Annals of Botany 78:233-243.

Huennecke, L.F. and H.A. Mooney. eds. 1989. Grassland structure and function: California annual grassland. Kluwer, Dordrecht, The Netherlands.

Jackson, L.E. 1985. Ecological origins of California's mediterranean grasses. Journal of Biogeography 12:349-361.
Keeley, J.E. 1996. Postfire vegetation recovery in the Santa Monica Mountains under two alternative management programs. Bulletin of the Southern California Academy of Sciences 95:103-119.

Kotanen, P.M. 1997. Effects of experimental soil disturbance on revegetation by natives and exotics in coastal Californian meadows. Journal of Applied Ecology 34:631-644.

Kruger, F.J., G.J. Breytenbach, I.A.W. MacDonald and D.M. Richardson. 1989. The characteristics of invaded mediterranean-climate regions. Pp. 181-213 in Drake, J.H. A. Mooney, F. di Castri, R. Groves, F.J. Kruger, M. Rcjmanck, and $\mathrm{M}$. Willamson, eds. Biological invasions: a global perspective. Wiley \& Sons, New York, NY.

Kuhn, N.L. and J.B. Zedler. 1997. Differential effects of salinity and soil saturation on native and exotic plants of a coastal salt marsh. Estuaries 20:391-403.

Le Houérou, H.N. 1981. Impact of man and his animals on mediterranean vegetation. Pp. 479-521 in F. di Castri, D. W. Goodall, andR.L. Specht, eds. Mediterranean-type shrublands. Elsevier, Amsterdam.

Manion, B.S. and J.H. Dillingham. 1989. Malibu Lagoon: a baseline ecological survey. Topanga-Las Virgenes Resource Conservation District, Topanga, CA.

Maranon, T. and J.W. Bartolome. 1993. Reciprocal transplants of herbaceous communities between Quercus agrifolia woodland and adjacent grassland. Journal of Ecology 81:673-682.

Maron, J.L. and P.G. Connors. 1996. A native nitrogen-fixing shrub facilitates weed invasion. Oecologia 105:302-312.

Mooney H.A. and J.A. Drake, eds. 1986. Ecology of biological invasions of North America and Hawaii. Springer-Verlag. New York, NY.

Mooney, H.A., S.P. Hamburg, and J.A. Drake. 1986. The invasions of plants and animals into California. Pp. 250-272 in H.A. Mooney and J.A. Drake, eds. Ecology of biological invasions of North America and Hawaii. Springer-Verlag, New York, NY.

Perrins, J., M. Williamson, and A. Fitter. 1992. A survey of differing views of weed classification: implications for regulation of introductions. Biological Conservation 60:47-56.

Planty-Tabacchi, A., E. Tabacchi, R. J. Naiman, C. Deferrari, and H. Decamps. 1996. Invasibility of species-rich communities in riparian zones. Conservation Biology 10:598-607.

Randall, J.M. and M. Rejmanek. 1993. Interference of bull thistle (Cirsium vulgare) with growth of ponderosa pine (Pinus ponderosa) seedlings in a forest plantation. Canadian Journal of Forest Research 23:1507-1513.

Raven, P.H., H.J. Thompson, and B.A. Prigge. 1986. Flora of the Santa Monica Mountains, California, 2nd edition. Southern California Botanists Special Publication No. 2, Univeristy of California, Los Angeles.

Reichard, S.H. and K. Hamilton. 1997. Predicting invasions of woody plants introduced into North America. Conservation Biology 11:193-203.

Rejmanek, M. 1993. Species richness and resistance to invasions. Pp. 153-172 in Orians, G.H., R. Dirzo, and J.H. Cushman, eds. Biodiversity and ecosystem processes in tropical forests. Springer-Verlag, Berlin.

Rejmanek, M. 1996. A theory of seed plant invasiveness: the first sketch. Biological Conservation 78:171-181.

Rejmanek, M. and J.M. Randall. 1994. Invasive alien plants in California: 1993 summary and comparison with other areas in North America. Madroño 41:161-177. 
Rejmanek, M. and D.M. Richardson. 1996. What attributes make some plant species more invasive? Ecology 77:1655-1661.

Rejmanek, M., C.D. Thomsen, and L.D. Peters. 1991. Invasive vascular plants in California. Pp. 81-101 in R.H. Groves and F. di Castri, eds. Biogeography of mediterranean invasions. Cambridge University Press, Cambridge, UK.

Robinson, G.R., J.F. Quinn, and M.L Stanton. 1995. Invasibility of experimental habitat islands in a California winter annual grassland. Ecology 76:786-794.

Roche, B.F. Jr; C.T. Roche, and R.C. Chapman. 1994. Impacts of grassland habitat on yellow star thistle (Centaurea solstitialis L.) invasion. Northwest Science 68:86-96.

Rundel. P.W, 1998. Landscape disturbance in mediterraneantype ecosystems: an overview. Pp. 3-22 in P. W. Rundel, G. Montenegro and F. Jaksic, eds. Landscape disturbance and biodiversity in mediterranean-type ecosystems. SpringerVerlag, Berlin 45: 93-100.

Rundel, P.W. and S. Sturmer. 1998. Vascular plant diversity in riparian communities of the Santa Monica Mountains, California. Madroño.

Schiffman, P.M. 1994. Promotion of exotic weed establishment by endangered giant kangaroo rats (Dipodomys ingens) in a California grassland. Biodiversity and Conservation 3:524-
537.

Sheppard, A.W. 1996. Weeds in the Cardueae: biological control and patterns of herbivory. Pp. 291-306 in P.D.S. Caligari and D.J.N. Hind, eds. Compositae: biology and utilization. Volume 2. Royal Botanic Gardens, Kew, London.

Shigesada N. and K. Kawasaki. 1997. Biological invasions: theory and practice. Oxford University Press, Oxford.

Stromberg, M.R. and J.R. Griffin. 1996. Long-term patterns in coastal California grasslands in relation to cultivation, gophers, and grazing. Ecological Applications 6:1189-1211.

Tucker, K.C. and D.M. Richardson. 1995. An expert system for screening potentially invasive alien plants in South African fynbos. Journal of Environmental Management 44:309-338.

Vessel, M.F. and H.H. Wong. 1987. Natural history of vacant lots. University of California Press, Berkeley, CA.

Vitousek, P.M., C.M. D'Antonio, L.L. Loope, M. Rejmanek, and R. Westbrooks. 1997. Introduced species: a significant components of human-caused global change. New Zealand Journal of Ecology 21:1-16.

Zink, T.A., M.F. Allen, B. Heindl-Tenhunen, and E.B.Allen. 1995. The effect of a disturbance corridor on an ecological reserve. Restoration Ecology 3:304-310. 


\title{
Mammal Burrowing, Erratic Rainfall and the Annual Lifestyle in the California Prairie: Is it Time for a Paradigm Shift?
}

\author{
Paula M. Schiffman \\ Biology Department and Center for the Study of Biodiversity, California State University, Northridge, CA 91330-8303 \\ Tel. (818) 677-3350; Fax (818) 677-2034; e-mail: paula.schiffman@csun.edu
}

\begin{abstract}
California's valley "grassland" (prairie) is characterized by chronic soil disturbance and climatic unpredictability. Active gopher, kangaroo rat and ground squirrel burrows can occupy as much as one third of the total land area, and the behaviors of several other historically important grassland mammals (badgers, kit foxes, coyotes and grizzly bears) also include soil excavation. In addition, rainfall occurs sporadically throughout the winter and annual accumulations can vary enormously. The vast extent and persistent nature of these mammal-caused soil disturbances combined with brief and erratic rainfall strongly favors plants with annual lifestyles. Despite the current abundance of alien (Mediterranean) annual plants in California's prairies, a great diversity of native annuals exists, indicating that the annual lifestyle was important in the pre-European settlement flora. The collective ecological importance of these native annuals is seldom considered when doing grassland restoration or conservation, however. Instead, since Clements' time, scientists have focused on perennial bunchgrasses, especially Nassella (Stipa), as the most historically important vegetation constituents. Given the great importance of erratic rainfall and mammal burrowing in determining species composition in thisecosystem, the emphasis on perennials seems illogical. Therefore, I suggest that a paradigm shift is required if southern California's prairies are to be adequately conserved and restored. Efforts should emphasize the enhancement of a diversity of native annual forbs, rather than just one or two perennial bunchgrass species which may never have been dominant components of the vegetation.
\end{abstract}

Keywords: Alien; annual; bunchgrass; California; Carrizo Plain; Clements; conservation; forb; gopher; grizzly bear; ground squirrel; Los Angeles Basin; Mediterranean climate; Muir; Nassella; perennial; prairie; restoration; Sacramento Valley; San Fernando Valley; San Joaquin Valley; Stipa; valley grassland.

\section{Introduction}

Prior to European settlement, a unique ecosystem called "valley grassland" covered about $13 \%$ of California (Barbour and Major 1977). Found on relatively flat xeric terrain where the soils tend to be clayey and where moisure input is largely limited to winter rains, this ecosystem occurred throughout much of the San Joaquin and Sacramento Valleys and extended into many parts of southern California (including the Los Angeles Basin and the San Fcrnando and San Gabriel valleys). Today, virtually all of this historical ecosystem has been converted to agricultural and urban uses. Only small scattered fragments remain. European settlement was accompanied by invasions by alien plants (mostly of Mediterranean Basin origin; Sauer 1988; Rejmanek and Randall 1994). Spreading rapidly, alien species displaced natives and came to dominate valley grassland vegetation (Heady 1977; Keeley 1990). This massive compositional shift occurred before accurate and detailed descriptions of the pristine vegetation could be compiled (Wester 1981). Consequently, very little is known of the structure and composition of the presettlement valley grassland vegetation. The insufficiency of the historical information poses significant problems for environmental groups and government agencies that are trying to conserve and restore the few fragments of valley grasslands that remain in existence. Which species were important and which were not?

Early in the twentieth century, Frederic E. Clements noticed that perennial bunchgrasses, particularly species in the genus Nassella (=Stipa; botanical nomenclature in this paper follows Hickman 1993) occurred in small patches (Clements 1920,1934). These bunchgrass patches were found in narrow strips along railroad and automobile rights-of-way and under the protective canopies of prickly pear cactus (Opuntia sp.). Clements suggested that these patches were relicts of the vast historical grass- 
land. By extrapolating from them, he hypothesized that the valley grasslands of California had been dominated by bunchgrasses, particularly Nassella spp. Like many early ecological hypotheses, this one had a rather tenuous foundation as it was based completely on a few descriptive accounts rather than on experimental or comparative data (Hamilton 1997). Despite an obvious need for further study and the assessment of alternative hypotheses (Twisselmann 1967; Wester 1981; Keeley 1990; Blumler 1992; Hamilton 1997), most scientists since Clements' time have viewed his relict hypothesis almost as gospel and have assumed that, in their pristine state, all of California's valley grasslands was once dominated by perennial bunchgrasses (e.g., Burcham 1957; 1961; Heady 1977; Baker 1989; Heady et al. 1992; Dyer et al. 1996; Stromberg and Griffin 1996). The nearly unquestioning adherence to this hypothesis is quite remarkable given the fact that most of Clements' other major ecological ideas (e.g., the organismic community, succession as a unidirectional predictable process and the climax association) have been widely studied and found to be simplistic (McIntosh 1985). The persistence of Clements' relict bunchgrass hypothesis is curious and reflects an odd parochialism among California ecologists. Perhaps it is an intellectual manifestation of California's insularity (Bakker 1984; Polk 1991) and floristic uniqueness (Raven and Axelrod 1978).

\section{An Alternative Hypothesis: Native Annual Dominance}

Dominance by perennial bunchgrasses seems illogical for three reasons. First, California's grasslands abound with burrowing mammals (gophers, ground squirrels, kangaroo rats and many other species) such that the terrain is riddled with burrow holes and piles of excavated soil (Burcham 1957; Schiffman 1994; Hobbs and Mooney 1995; Stromberg and Griffin 1996; Kneitel 1997). By chronically disturbing grassland soils, these animals would have created conditions unconducive to dominance by perennials. Second, the region of California that was historically occupied by valley grasslands is characterized by unpredictable rainfall and water stress (Keeley 1990). These climatic conditions may not be favorable for the survival and recruitment of perennial plants in the numbers needed for community dominance (Twisselmann 1967; Jackson and Roy 1986; Dyer et al. 1996). Third, the few significant fragments of grassland that still exist today are inhabited by large numbers of native annuals, particularly forbs (e.g., Butterworth and Chadwick 1995). Although alien grasses now dominate, the persistent diversity of "weedy" native annuals suggests that the environmental opportunism offered by the annual lifestyle was of great adaptive value in environments characterized by widespread chronic soil disturbance and limited unpre- dictable rainfall (Raven and Axelrod 1978). These three trains of thought, which are discussed below in more detail, form the basis for my contention that, historically, California's arid valley grasslands were dominated by a diversity of opportunistic and ruderal native annuals rather than the perennial bunchgrasses that Clements hypothesized.

\section{Burrowing mammals were abundant}

I propose that the very high density and diversity of burrowing mammals native to the valley grasslands were the primary reasons for annual dominance. Some of these animal species were completely fossorial (pocket gophers). Others created burrows for nesting and shelter (kangaroo rats, pocket mice, ground squirrels, voles, kit foxes, coyotes), and/or dug up the soil as they searched for food (badgers, grizzly bears). The patchy soil disturbances that these animals produced were extremely widespread (Cronise 1868; Bryant 1929; Burcham 1957; Lidicker 1989) and would have served as habitat for oppurtunistic annual plants (Grime 1977; Schiffman 1994; Hobbs and Mooney 1995; Kneitel 1997). The abundance and chronic nature of these mammal-caused soil disturbances would have created habitat conditions in which dominance by perennial bunchgrasses could not have been maintained. The bunchgrasses, Nassella pulchra, N. cernua and Elymus multisetus (=Sitanion jubatum), have been shown to be measurably reduced in areas occupied by pocket gophers or kangaroo rats (Hobbs and Mooney 1995; Schiffman 1995; Stromberg and Griffin 1996).

Burrowing animals are common in California's largest remaining grassland, the Carrizo Plain Natural Area, an 81,000 ha preserve in San Luis Obispo County (Holing 1988). In some parts of the plain, giant kangaroo rat (Dipodomys ingens) burrows comprise up to $32 \%$ of the grassland (Schiffman 1994). In other parts, valley pocket gopher mounds (Thomomys bottae) polka-dot the landscape and, on average, occupy $28 \%$ of the terrain (Kneitel 1997). Gophers continually dig new burrows such that the surface soil in their grassland habitats gets completely turned over approximately every 15 years (Kneitel 1997). Interestingly, the rate of soil turnover by pocket gophers in another California grassland was found to be considerably more rapid (3-5 years; Hobbs and Mooney 1995). The impressive extent of the excavation by just two species, giant kangaroo rats and valley pocket gophers, indicate that burrowing had to have been a major form of disturbance in the historic grasslands. In addition, it is important that several other burrowing mammal species also inhabited this ecosystem (Lidicker 1989). For example, there are records of the following burrowers at the Carrizo Plain (R. van de Hoek, unpublished data): Fresno and Heermann kangaroo rats (Dipodomys nitritoides and $D$. heermanni), San Joaquin pocket mice (Perognathus inornatus), California pocket mice (Chaetodipus 
californicus), California ground squirrels (Spermophilus beecheyi), California voles (Microtus californicus), coyotes (Canis latrans), kit foxes (Vulpes macrotis), badgers (Taxidea taxus), and grizzly bears (Ursus arctos). Moreover, several nonburrowing grassland animals (e.g. Burrowing Owls [Athene cunicularia], longtail weasels [Mustela frenata], San Joaquin antelope squirrels [Ammospermophilus nelsoni], and numerous reptiles) also relied on animal burrows for habitat. These secondary burrow users are further evidence of the evolutionary importance of burrowing to the development of the valley grassland ecosystem.

Despite a fairly strong body of evidence suggesting that burrowing mammals are (and were) common, inhibiting bunchgrasses and encouraging annual plants, a nagging question remains. Do the high densities of small burrowing mammals that we see today reflect ecological conditions of the past, or have these populations been inflated by nearly a century of intensive predator suppression in California? If, historically, burrowing mammals were less important than they are today, because predators limited their populations, perhaps bunchgrasses could have been grassland dominants afterall.

Several early written accounts of California's natural history specifically noted the abundance of burrowing animals in California. For example, in 1775-76, Pedro Font, a member of Anza's second expedition through California, remarked in his diary about a barren landscape that had been "mined by ground squirrels" and about the numerous "almondigones" or hummocks (probably gophercreated mima mounds; Cox and Scheffer 1991) which made cross-country trekking difficult (pp. 410 and 481 in Bolton 1966). Similarly, Hugo Reid, an early settler in southern California, noted in his 1832 journal that burrowing mammals "so honeycombed the ground as to make it dangerous to ride anywhere off the roadway faster than a walk" (p. 4 in Dakin 1939). In 1853, the craters produced by the burrowing of "thousands of ground squirrels" were among the things that reminded Harris Newmark, another early southern California settler, of being on "another planet" (p. 24 in Newmark and Newmark 1916). Likewise, in 1862, William H. Brewer, a botanist and member of the Whitney Survey field party, wrote that "often for miles we see nothing... except birds or insects, reptiles, and ground squirrels" (p. 283 in Farquhar 1966), and John Muir (1894) wrote that "spermophiles showed themselves in considerable numbers" throughout the Central Valley (p. 342).

The ecological importance of grizzly bear diggings in valley grasslands also should not be underestimated. In 1860 , the zoologist, Janos Xantus, noted that the grizzly bear "sometimes amuses himself with digging, like the pigs, and sometimes during a moon-light night, he will dig up many acres of lands, [so] that not one [blade of] grass is to be found" (p. 20 in Storer and Tevis 1955). The writings of the Font, Reid, Newmark, Brewer and
Muir all mentioned the abundance of grizzlies as well. According to Storer and Tevis (1955), historically, large numbers of grizzlies occurred in the valleys of the coast ranges, on the plains of southern California and in the Sacaramento and San Joaquin Valleys. In other words, grizzly bears occurred throughout the region that was once occupied by grassland. From these written accounts, it seems clear that, historically, there was a great diversity of burrowers in valley grasslands and that the spatial extents and chronic nature of their disturbances were impressive. Given the vast amounts of soil that burrowing mammals would have excavated, it seems unlikely that dominance by perennial bunchgrasses would have been possible. Furthermore, it seems unlikely that extant patches of Nassella are relicts of a historical bunchgrassdominated grassland. Rather, it is probable that such patches exist in unusual microhabitats that, for whatever reason, lack significant disturbance by burrowing mammals.

Additional evidence of the great historical ecological importance of burrowing emerges when valley grassland animal life is viewed within a trophic interaction-energy flow framework (Fig. 1). California grasslands were habitat to an impressive diversity of vertebrate carnivores. Moreover, the diets of 23 of these animals relied heavily on burrowing mammalian herbivores. From the "topdown" perspective (McLaren and Peterson 1994), it is evident that the development of an ecosystem with such a great diversity of different carnivores could have occurred only if an enormous food base had been available.

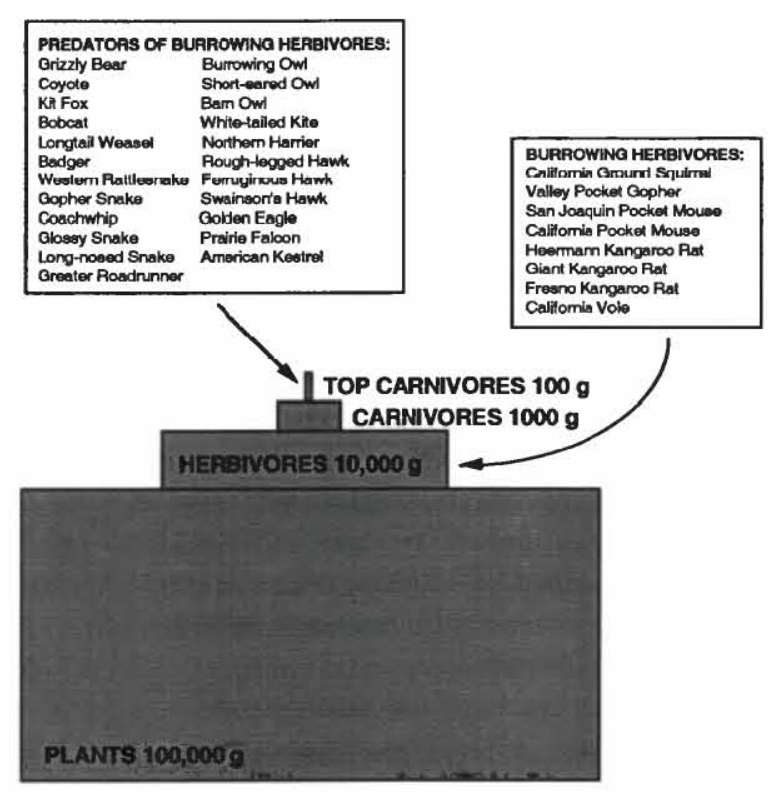

Figure 1. A simple model of trophic relationships in a California prairie. Burrowing herbivores and the incredible diversity of carnivores that eat them are emphasized. Species lists reflect records for the Carrizo Plain (San Luis Obispo County). 
This logical link between biodiveristy and the second law of thermodynamics strongly suggests that very large numbers of burrowing mammals must have existed in California's valley grasslands prior to modern-day predator suppression.

Storer and Tevis $(1955$; p. 56) stated that "only the badger could vie with the bear in digging rodents from the soil." But, approximately how many rodent herbivores would be required to maintain the 23 different mammal-eaters native to California's valley grasslands? A very simple ecosystem model can be used to answer this question. For the sake of computational simplicity, this model relies on three assumptions: (1) the efficiency of energy flow between trophic levels is $10 \%$, (2) California ground squirrels constitute the entire diet of these predators, and (3) each predator species exists wholly within the top carnivore trophic level and is represented by a single individual of median biomass. Despite the crudeness of these "back of the envelope" calculations, this model's results are very suggestive. For example, it would have taken 43,349 California ground squirrels (biomass $=726.5 \mathrm{~g}$ / individual; Burt and Grossenheider 1976) to support just a single individual of each of the 23 grassland carnivores (collective biomass = 314,933 g; Burt and Grossenheider 1976; Dunning 1993; C. Rudolph personal communication 1997). Moreover, 103 ground squirrels would be required to sustain one gopher snake (Pituophis melanoleucus), 158 ground squirrels for one Ferruginous Hawk (Buteo regalis) and 577 ground squirrels for one Golden Eagle (Aquila chrysaetos). Although this model is extremely simplistic (cf; Pearson 1964; Scott 1979; Slobodkin 1987), the take-home message is clear. An ecosystem with such a diverse array of carnivores could not have existed without a significant food base. Burrowing mammals were prominent members of the trophic level that comprised that food base and their prolific soil excavations would have negatively affected perennial bunchgrasses. While some individual bunchgrasses certainly would have endured despite so much disturbance to the soil, it seems extremely unlikely that they could have been the widespread community dominants that Clements described.

\section{Rainfall varied greatly}

It might be argued that soil disturbances by mammalian burrowers alone may not have been sufficient to prevent bunchgrass dominance. After all, the perennial grasslands of the Great Plains are also habitat for gophers, prairie dogs, badgers and other burrowers (Platt 1975; Huntly and Inouye 1988; Whicker and Detling 1988). The climatic regime of California's grasslands, however, is radically different from the climatic regimes of other North American grasslands. I suggest that the climatic unpredictability and overall aridity of California's grasslands, in combination with the extensive mammal-caused soil disturbances, prevented bunchgrass dominance. Unlike the Great Plains, the regions in California that were once occupied by valley grasslands have mediterranean climates (Keeley 1990). Long, hot, dry summers are the norm and rainfall is essentially limited to the winter and early spring with accumulations varying considerably from year to year (Fig. 2). During 1971-72 (July to June), for example, the southern San Joaquin Valley (Bakersfield) received only $7.6 \mathrm{~cm}$ of precipitation. The following year, $20.3 \mathrm{~cm}$ of rain fell. The timing of rainfall within any given "rainy season" is also highly variable (Fig. 3). Although rain might fall steadily over a period of 3 or 4 months, as it did in Bakersfield in 1991-92 (Fig. 3), in some years, precipitation is largely restricted to a single month. In 1990-91, for example $61.2 \%(11.0 \mathrm{~cm})$ of the entire season's rainfall occurred in March (Fig. 3). In still other years (such as 1989-90), little appreciable precipitation happens during any month. It is well known that the amount and timing of rainfall can strongly influence annual species composition (Talbot et al. 1939; Mulroy and Rundel 1977; Pitt and Heady 1978; Bartolome 1979). In the Bakersfield area, three compositionally different suites of grassland annuals were favored by the three very different rainfall patterns experienced in 1989-90, 199091 and 1991-92. Perennials are not so opportunistic and thus the ability of bunchgrasses to dominate under such a varied rainfall regime is much less certain (Twisselmann 1967; Jackson and Roy 1986; Dyer et al. 1996).

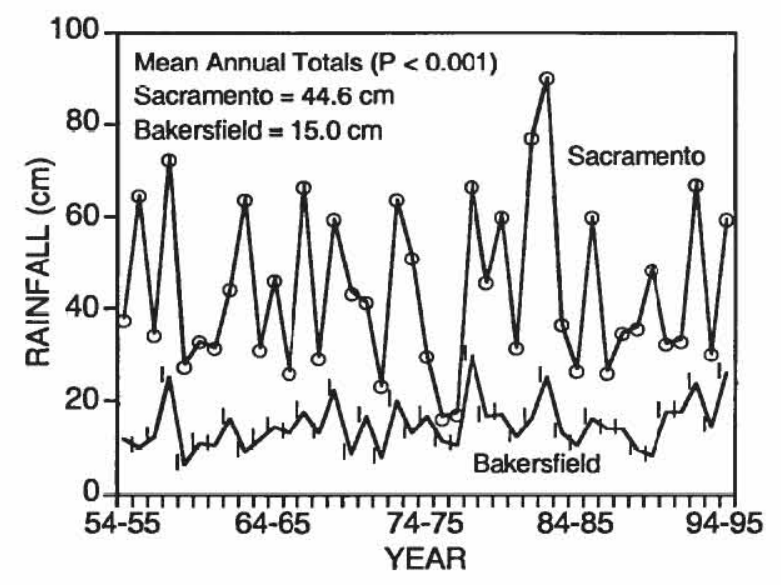

Figure 2. Annual rainfall in Sacramento and Bakersfield from 1954-55 to 1994-95. Despite large inter-year variance at both locations, Sacramento consistently received more rain than Bakersfield. P-value refers to Mann-Whitney U-test.

While rainfall amounts do vary both within-years and between-years in the northern reaches of the historical California grasslands as well, it is important to note that, on average, the Sacramento Valley receives significantly more rainfall than does the San Joaquin Valley (Figs. 2 and 4). Therefore, if Nassella pulchra and other bunch- 
grasses ever dominated valley grasslands, it would have been most likely in the more mesic northern part of the latitudinal range, where moisture conditions corresponded best with the prolonged survival and recruitment of perennials. Again, it is important to note that the limited and unpredictable nature of rainfall experienced by the more arid southern valley grasslands would not have completely precluded bunchgrasses. Scattered extant patches of Nassella individuals and others (e.g. Poa secunda, Elymus elymoides) testify to the fact that some bunchgrasses can tolerate xeric conditions. Given the region's chronic moisture limitations, however, it is doubtful that these perennials would have been capable of the recruitment and survivorship required to maintain vegetation dominance over the long term (Twisselmann 1967; Wester 1981; Jackson and Roy 1986; Dyer et al. 1996).

\section{Most native species were annuals}

Annual alien grasses currently dominate much of California. Because they were annuals, these Mediterranean species were preadapted to the high degree of soil disturbance (Schiffman 1994) and varied climatic regime (Jackson 1985; Jackson and Roy 1986) of valley grasslands. The fact that grassland floras still include very large numbers of native annual species is a clear indication that the annual lifestyle also had been extremely important in this community prior to European settlement. At the Carrizo Plain, for example, in addition to 30 alien annuals, the grassland includes at least 106 native annual species (Butterworth and Chadwick 1995). Similarly, Talbot et al. (1939) found that the San Joaquin Experimental Range grassland (Madera County) included 109 uncommon annuals, most of which were native forbs.

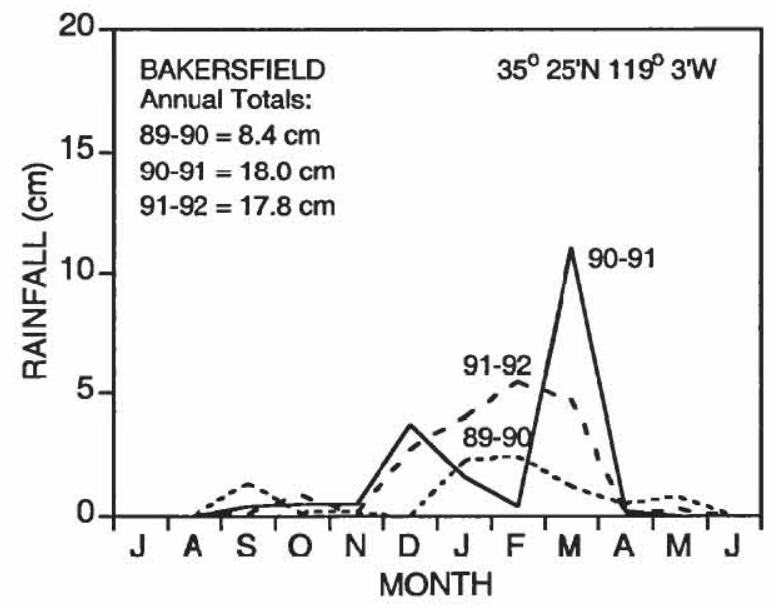

Figure 3. Monthly rainfall for 1989-90, 1990-91 and 1991-92 (July - June) in Bakersfield, CA. Note the relatively low annual totals and the high degree of within-year and between-year variability.

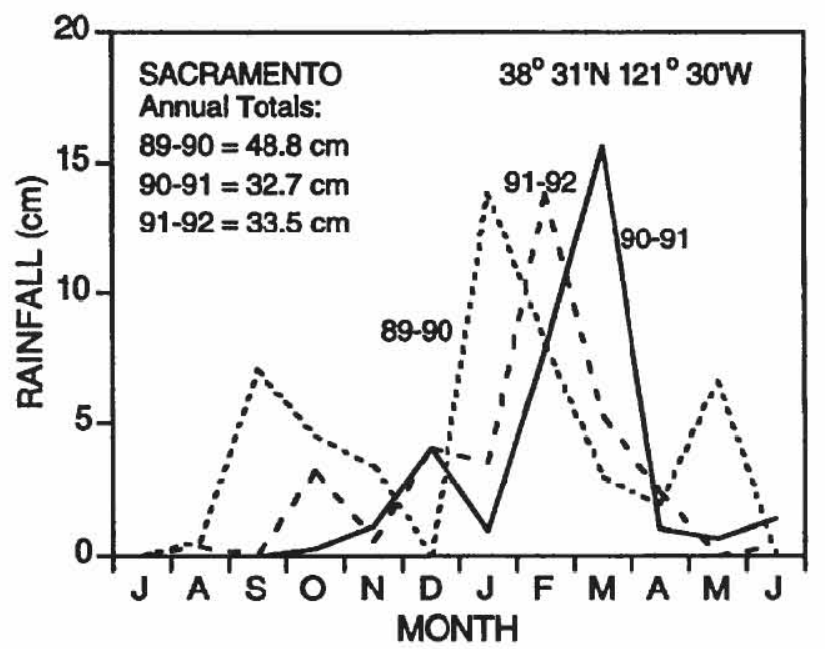

Figure 4. Monthly rainfall for 1989-90, 1990-91 and 1991-92 in Sacramento, CA. Note the relatively high annual totals and the high degree of within-year and between-year variability.

In addition, the finding that some native grassland annuals (e.g. Tropidocarpum gracile, Amsinckia tessellata, Lotus subpinnatus, Hesperevax [=Evax] sparsiflora, Caulanthus californicus, Uropappus lindleyi, Guillenia lasiophylla, Nemophila menziesii) occur most often on soils excavated by small mammals (Schiffman 1994; Hobbs and Mooney 1995; Cypher and Williams 1996; P. Schiffman, personal observations) is additional support for the view that the annual lifestyle was of great adaptive value in California's valley grasslands. This short list of burrow-loving plants is probably "just the tip of the iceberg." The historic grasslands must have included many burrowing-adapted native ruderals. Furthermore, because annual plants are short-lived and often form longlasting seed banks, it can be surmised that a significant proportion of the flora was somewhat flexible in terms of timing germination, growth and reproduction to correspond with annual rainfall peculiarities (Mulroy and Rundel 1977; Rice 1989). Populations of opportunistic annual plants would have been much more capable of persisting in an environment characterized by extensive and chronic soil disturbance (Grime 1979; Hobbs and Mooney 1995; Kneitel 1997), prolonged dry periods (Stine 1994) and erratic rainfall (Talbot et al. 1939; Raven and Axelrod 1978; Wester 1981; Jackson and Roy 1986; Dyer et al. 1996) than populations of perennial bunchgrasses would have been.

Given the obvious importance of annuals to California's grassland flora and the difficulties that bunchgrasses would have had surviving in this heavily disturbed and often dry environment, could native annuals have once dominated? A natural community dominated by annuals certainly would have been an ecological anomaly. Is there another community anywhcre in the world in which annuals have maintained dominance? I know of none. However, California is floristically unique and, in particular, 
is characterized by an unusually large proportion of "weedy" annual forbs (Raven and Axelrod 1978). I contend that these floristic attributes along with extensive mammalian soil disturbance and erratic rainfall combined to produce a vegetation type dominated by annuals. I see no reason to abandon the hypothesis of annual dominance merely because analogous vegetations did not evolve elsewhere. After all, the general climatic similarities between California and other regions with Mediterranean climates are not reflected by high degrees of ecological similarity among these various regions (Jackson 1985; Arroyo et al. 1995; Davis and Richardson 1995; Cowling et al. 1996). Moreover, the body of ecological evidence that supports the annual dominance hypothesis is much greater than the small number of observations that served as the basis for Clements' relict bunchgrass hypothesis.

\section{Coda: It was a Prairie of Forbs}

In 1894, John Muir published extensive observations of the importance of native annual forbs to California's vast valley grassland. For example, he said: "The Great Central Plain of California, during the months of March, April, and May, was one smooth continuous bed of honeybloom, so marvelously rich that, in walking from one end of it to the other, a distance of more than 400 miles, your foot would press about a hundred flowers at every step. Mints, gilias, nemophilas, castilleias, and innumerable compositae were so crowded together that, had ninetynine percent of them been taken away, the plain would still have seemed to any but Californians extravagantly flowery" (p. 339). Interestingly, Muir's vividly detailed descriptions of this historic ecosystem made absolutely no mention of bunchgrasses. In fact, he noticed that "all of the ground was covered, not with grass and green leaves, but with radiant corollas, about ankle-deep next to the foothills, knee-deep or more five or six miles out" (p. 342).

I believe that the time has come for a paradigm shift. Not only was Clements' vision of a vast perennial bunchgrass-dominated community apparently inaccurate, this historic vegetation type was probably not dominated by grasses of any sort. Descriptions, such as Muir's, of breathtaking expanses of native annual forb cover, along with evidence of the continucd importance of these species in extant floras (e.g. Talbot et al. 1939; Beetle 1947; Burcham 1957; Keeley 1990; Butterworth and Chadwick 1995), point to an obvious logical inconguity: the word "grassland." Given the great importance of forbs, an alternative term is required if the historical vegetation of California's valleys is to be described accurately. I suggest that "California prairie" be used instead of "California grassland." According to Webster's New Universal Unabridged Dictionary (2nd edition), the word "prairie" is French for "meadow." While meadows can include grasses, the word "grass" is not a structural part of the word itself. Other California scientists, including Clements (1934), have used the word, "prairie," (Burcham 1957 ; Heady et al. 1992) but just as a synonym for "grassland." To fit the unique California context and to emphasize the compositional importance of annual forbs, the name of the vegetation type must be altered somewhat. While this may lead to some initial confusion, refining the ecological definition of "prairie," a word in common usage, should be far easier than attempting to coin a new descriptive term, such as "forb field" or "dicot sward."

Lastly, perhaps my attempt to develop a more accurate picture of the species composition of California's once vast prairie is of no practical importance. Afterall, only small fragments of this ecosystem now remain and all are dominated by alien grasses. Despite these problems, I think that trying to imagine what this vegetation was like is more than just a pleasant ecological day-dream. The remaining prairie fragments are habitat for hundreds of plant and animal species, some which are listed as threatened or endangered. For this reason, several preserves have been established (e.g. Carrizo Plain, Santa Rosa Plateau, Jepson Prairie) and "grassland" conservation and restoration is receiving much attention throughout California. It is my view that, to be effective, plans for the restoration and conservation of California's prairies should consider three important issues more fully: (1) mammal burrowing, (2) limited and erratic rainfall, and (3) the diversity of native annual forbs. The restoration of several hundred annual forbs and the burrowing mammals that maintain their habitat is a much more daunting task than simply "reestablishing" Nassella pulchra. In the end, however, a unique, diverse and breathtakingly beautiful ecosystem will be saved, and we will know a great deal more about our natural heritage.

Acknowledgments. Thanks are due Jamie Kneitel, Roy van de Hoek and Craig Rudolph for sharing their data with me, and Paul Wilson for reviewing and commenting on the manuscript. In addition, countless conversations with my colleagues at CSUN and the Carrizo Plain were invaluable in getting my ideas to gel.

\section{Literature Cited}

Arroyo, M.T.K., P.H. Zedler, and M.D. Fox, eds. 1995. Ecology and biogeography of Mediterranean ecosystems in Chile, California and Australia. Springer-Verlag, New York, NY.

Baker, H.G. 1989. Sources of naturalized grasses and herbs in California. Pp 29-38 in L.F. Huenneke and H.A. Mooney, eds. Grassland structure and function: California annual grassland. Kluwer Academic Publishers, Boston, MA

Bakker, E. 1984. An island called Califorina. 2nd ed. University of California Press, Berkeley, CA.

Barbour, M.G. and J. Major, eds. 1977. Terrestrial vegetation of California. California Native Plant Society Special Publication no. 9, Sacramento, CA. 
Bartolome, J.W. 1979. Germination and seedling establishment in California annual grassland. Journal of Ecology 67:273281.

Beetle, A.A. 1947. Distribution of the native grasses of California. Hilgardia 17:309-357.

Blumler, M.A. 1992. Some myths about California grasslands and grazers. Fremontia 20(3):22-27.

Bolton, H.E. 1966. Anza's California expeditions (Vol. IV), Font's complete diary of the second Anza expedition. Russell and Russell, New York, NY.

Bryant, H.C. 1929. Outdoor heritage. Powell Publishing Co., San Francisco, CA.

Burcham, L.T. 1957. California range land: a historico-ecological study of the range resource of California. State of California, Department of Natural Resources, Division of Forestry, Sacramento, $\mathrm{CA}$.

Burcham, L.T. 1961. Cattle and range forage in California 17701880. Agricultural History 35:140-149.

Burt, W.H. and R.P. Grossenheider. 1976. A field guide to the mammals of America north of Mexico. Houghton Mifflin Co., Boston, MA.

Butterworth, G. and A. Chadwick. 1995. Checklist of plants of the Carrizo Plain Natural Area. USDI Bureau of Land Management, Bakersfield, CA.

Clements, F.E. 1920. Plant indicators. Carnegie Institution of Washington, Washington, DC.

Clements, F.E. 1934. The relict method of dynamic ecology. Journal of Ecology 22:39-68.

Cowling, R.M., P.W. Rundel, B.B. Lamont, M.K. Arroyo, and M. Arianoutsou. 1996. Plant diversity in mediterranean-climate regions. Trends in Ecology and Evolution 11:362-366.

Cox, G.W. and V.B. Scheffer. 1991. Pocket gophers and mima terrain in North America. Natural Areas Joumal 11:193-198.

Cronise, T.F. 1868. The natural wealth of California. H.H. Bancroft and Co., New York. NY.

Cypher, E.A. and D.F. Williams. 1996. Influence of endangered giant kangaroo rats on the dispersion and fitness of two endangered plant species in central California. Bulletin of the Ecological Society of America (Supplement) 77:100.

Dakin, S.B. 1939. A Scotch paisano: Hugo Reid's life in California, 1832-1852 derived from his correspondence. University of California Press, Berkeley, CA.

Davis, G.W. and D.M. Richardson (eds). 1995. Mediterraneantype ecosystems: the function of biodiversity. SpringerVerlag, New York, NY.

Dunning, J.B., ed. 1993. CRC Handbook of avian body masses. CRC Press, Ann Arbor, MI.

Dyer, A. R., H. C. Fossum, and J. W. Menke. 1996. Emergence and survival of Nassella pulchra in a California grassland. Madroño 43:316-333.

Farquhar, F.P., ed. 1966. Up and down California in 1860-1864: the journal of William $\mathrm{H}$. Brewer, professor of agriculture in the Sheffield Scientific School from 1864-1903. University of California Press, Berkclcy, CA.

Grime, J.P. 1979. Evidence of the existence of three primary strategies in plants and its relevance to ecological and evolutionary theory. American Naturalist 111:1169-1194.

Hamilton, J.G. 1997. Changing perceptions of pre-European grasslands in California. Madroño 44:311-333.

Heady, H.F. 1977. Valley grassland. Pp.491-514 in M.G. Barbour and J. Major, eds. Terrestrial vegetation of California. California Native Plant Society Special Publication No. 9, Sacramento.
Heady, H.F., J.W. Bartolome, M.D. Pitt, G. D. Savelle, and M. C. Stroud. 1992. California prairie.Pp.313-335 in R. T. Coupland, ed. Natural grasslands. Elsevier Science, Amsterdam.

Hickman, J.C., ed. 1993. Jepson manual: higher plants of California. University of California Press, Berkeley, CA.

Hobbs, R.J. and H.A. Mooney. 1995. Spatial and temporal variability in California annual grassland: results from a longterm study. Journal of Vegetation Science 6:43-56.

Holing, D. 1988. California wild lands: a guide to the Nature Conservancy preserves. Chronicle Books, San Francisco, CA.

Huntly, N. and R. Inouye. 1988. Pocket gophers in ecosystems: patterns and mechanisms. Bioscience 38:786-793.

Jackson, L.E. 1985. Ecological origins of California's mediterranean grasses. Journal of Biogeography 12:349-361.

Jackson, L.E. and J. Roy. 1986. Growth patterns of mediterranean annual and perennial grasses under simulated rainfall regimes of southern France and California. Acta Oecologica/Oecologia Plantarum 7:191-212.

Keeley, J.E. 1990. The California valley grassland. Pp. 2-23 in A. A. Schoenherr (ed.) Endangered plant communities of southern California. Southern California Botanists Special Publication No. 3, Claremont, CA.

Kneitel, J.M. 1997. The effects of fire and pocket gopher (Thomomys bottae) disturbances on a California valley grassland. M.S. thesis, California State University, Northridge, CA.

Lidicker, W.Z. 1989. Impacts of non-domesticated vertebrates on California grasslands. Pp. 135-150 in L. F. Huenneke and H.A. Mooney, eds. Grassland structure and function: California annual grassland. Kluwer Academic Publishers, Boston, MA.

McIntosh, R.P. 1985. The background of ecology: concept and theory. Cambridge University Press, Cambridge, U.K.

McLaren, B.E. and R.O. Peterson. 1994. Wolves, moose, and tree rings on Isle Royale. Science 266:1555-1558.

Mulroy, T.W. and P.W. Rundel. 1977. Annual plants: adaptations to desert environments. Bioscience 27:109-114.

Muir, J. 1894. The mountains of California. Ten Speed Press, Berkeley, CA.

Newmark, M.H. and M.R. Newmark, eds. 1916. Sixty years in southern California, 1853-1913, containing thereminiscences of Harris Newmark (reprinted in 1970). Zeitlin and Ver Brugge, Los Angeles, CA.

Pearson, O.P. 1964. Carnivore-mouse predation: an examplc of its intensity and bioenergetics. Journal of Mammalogy 45:177188.

Pitt, M.D. and H.F. Heady. 1978. Responses of annual vegetation to temperature and rainfall patterns in northern California. Ecology 59:336-350.

Platt, W.J. 1975. The colonization and formation of equilibrium plant species associations on badger disturbances in tall-grass prairie. Ecological Monographs 45:285-305.

Polk, D.B. 1991. The island of California: a history of the myth. University of Nebraska Press, Lincoln, NB.

Raven, P.H. and D.I. Axelrod. 1978. Origin and relationships of the California flora. University of California Press, Berkeley, CA.

Rejmanek, M. and J.M. Randall. 1994. Invasive alien plants in California: 1993 summary and comparison with other areas in North America. Madroño 41:161-177. 
Rice, K.J. 1989. Impacts of seed banks on grassland community structure and population dynamics. Pp. 221-230 in M.A. Leck, V.T. Parker, R.L. Simpson, eds. Ecology of soil seed banks. Academic Press, New York, NY.

Sauer, J.D. 1988. Plant migration: the dynamics of geographic patterning in seed plant species. University of California Press, Berkeley, CA.

Schiffman, P.M. 1994. Promotion of exotic weed establishment by endangered giant kangaroo rats (Dipodomys ingens) in a California grassland. Biodiversity and Conservation 3:524537.

Schiffman, P.M. 1995. Impact of endangered giant kangaroo rats on grassland restoration. Bulletin of the Ecological Society of America (Supplement) 76:238.

Scott, J.A., N.R. French, and J.W. Leetham. 1979. Patterns of consumption in grasslands. Pp. 89-105 in N. R. French, ed. Perspectives in grassland ecology. Springer-Verlag, New York, NY.
Slobodkin, L.B. 1987. Glosses on Lindeman - the ramifications of an innocent physicalism. Evolutionary Ecology 1:189-196.

Stine, S. 1994. Extreme and persistent drought in California and Patagonia during mediaeval time. Nature 369:546-549.

Storer, T.I. and L.P. Tevis. 1955. California grizzly. University of California Press, Berkeley, CA.

Stromberg, M.R. and J.R. Griffin. 1996. Long-term patterns in coastal California grasslands in relation to cultivation, gophers, and grazing. Ecological Applications 6:1189-1211.

Talbot, M.W., H.H. Biswell, and A.L. Hormay. 1939. Fluctuations in the annual vegetation of California. Ecology 20:394402.

Twisselmann, E.C. 1967. A flora of Kern County, California. Wasmann Journal of Biology 25:1-395

Wester, L.L. 1981. Composition of native grasslands in the San Joaquin Valley, California. Madroño 28:231-241.

Whicker, A.D. and J.K. Detling. 1988. Ecological consequences of prairie dog disturbances. Bioscience 38:778-785. 


\section{NCCP and Land Planning}

"Train wrecks!" was the expression Secretary of Interior Bruce Babbitt used to describe confrontations beween the Endanagered Species Act and development, which "stopped projects dead in their tracks." On Earth Day 1991 the governor of California presented an environmental agenda that promised to create partnersips between land owners and environmentalists, ones that would guarantee the protection of endangered species. Out of this grew the pioneering initiative known as the Natural Communities Conservation Planning (NCCP) Program 


\title{
Natural Community Conservation Planning: A 1997 Interim Report
}

\author{
Dan Silver \\ Endangered Habitats League, 8424A Santa Monica Blvd., \#592, Los Angeles, CA 90069 \\ Tel. (213) 654-1456; Fax (213) 654-1456; e-mail: ensilver@aol.com
}

\begin{abstract}
The Natural Community Conservation Planning (NCCP) program seeks to conserve a wide array of threatened wildlife in the global biodiversity "hotspot" of southern California. Over the last six years, there have been substantial achievements as well as lessons learned about the pitfalls and limitations of this potential model. These considerations are summarized, and tentative conclusions made regarding the place of the NCCP in the overall context of land use planning.
\end{abstract}

Keywords: Endangered species; habitat conservation plans; land use planning; Natural Community Conservation Planning.

\section{Introduction}

The goal of the State of California Natural Community Conservation Planning (NCCP) Act of 1991 is to resolve environmental-economic conflicts over endangered species on private lands. Rather than deal with species one at a time, an NCCP seeks to meet Endangered Species Act (ESA) standards for multiple species simultaneously. Typically, a mix of listed and declining, though as-yet-unlisted, species are conserved on a habitat or "natural community" basis-while, from the standpoint of biological impacts, development is facilitated outside the preserve. The object of the NCCP "pilot project" is southern California's Mediterranean-climate ecosystem, consisting of coastal sage scrub and associated habitats - a global biodiversity and extinction "hotspot."

The NCCP program began with controversy, after being marketed by the Wilson Administration as a substitute for listing, under the California Endangered Species Act, of the California gnatcatcher, a resident of otherwise highly developable coastal sage scrub. Since NCCP participation was voluntary for all parties, progress was variable and overall insufficient until 1993, when the listing of the gnatcatcher as a "threatened" species under the federal Endangered Species Act gave essential backbone and impetus to the program. In fact, the federal listing formally linked itself to the NCCP via a "special rule": the incentive of expedited "interim take" of the gnatcatcher was offered to program participants subscribing to a set of "Conservation Guidelines." While it seems clear to most parties that voluntary programs do not obviate the need to list species, this debate has been a continuing source of tension.

Under the NCCP umbrella, seven "sub-regional" efforts, all with local jurisdictions as lead agencies, are either completed or underway across a largely contiguous $17,000 \mathrm{~km}^{2}$ planning area. To understand why the NCCP has "taken off" in southern California, it is necessary to understand what motivates each of the primary participants. For conservationists, a comprehensive plan based upon ESA standards appears the best hope of rescuing a decimated ecosystem. For developers, the assurances an NCCP provides against future listings are perceived as vital to a predictable business environment. For local governments, it is a way to retain autonomy over land use in the face of impending listings and to better balance future growth with natural open space - which contributes to quality of life. For the wildlife agencies, it is a way to improve upon project-by-project mitigation and a way to avert the regulatory nightmare of a succession of overlapping listings. While the benefits of NCCP are thus quite different for each party - ranging from regulatory efficiency to land protection - there has been enough common ground to advance a politically difficult process.

\section{Overview of the plans}

\section{Orange County plans}

In Orange County, there are two programs; the Central/Coastal NCCP is complete. In this section of Orange County, a single, massive ownership - that of the Irvine Co. - allowed a relatively orderly pattern of sprawl to occur. Consequently, apart from two newly constructed tollroads that bisect it, the reserve also contains relatively unfragmented lands. The reserve design process involved a "gap analysis" between already-planned open space (exactions obtained through the land use process and earlier purchases) and maps of overall habitat quality and "tar- 
get species" presence. The result - a preserve of 15,133 ha "covering" 39 species - combined the pre-existing open space with smaller, though important, new additions (about 2000 ha). As well, there are connectivity improvements and new management obligations.

The covered species list of the Central/Coastal NCCP relies upon umbrella species methodologies, upon variable amounts of survey data, and upon judgements of habitat sufficiency. When planned restoration of agricultural lands is factored in, the result is particularly defensible for coastal sage scrub. As in all the NCCP plans, monitoring and adaptive management are major program components. The purported conservation of the endangered Pacific pocket mouse is disputed, though.

Another huge Orange County ownership is involved in the southern NCCP. An absence of already-planned land uses in this area makes it a test case for the NCCP program. This effort is progressing very slowly but has excellent conservation potential.

\section{San Diego County plans}

In San Diego, the logistically complex and politically daunting Multiple Species Conservation Program, or MSCP, pre-dates the NCCP itself and involves multiple jurisdictions and hundreds of landowners. After extensive public participation, a 69,635 ha preserve, "covering" 85 species across a full range of habitats, has been approved at the framework level and by two of the five jurisdictions involved. Included are 36,500 ha of currently private lands, two thirds of which will derive from development exactions, and the remainder acquired at an estimated cost of $\$ 300,000,000$ (to be shared by local, state, and federal sectors). In some jurisdictions, pre-existing "Resource Protection Ordinances" serve as the underpinning for program implementation.

The preserve design process appropriately began with the compilation of standards and guidelines for preservation of vegetation communities and for maintaining "viable populations" of 90 target species of plants and animals. Due to incomplete survey data, a habitat quality map was prepared using a matrix of indices, and then a useful map of "biological core areas and linkages" was produced. After adding in local land use factors, preserve design alternatives were developed, and evaluated for species coverage. The final rationales for species coverage, though, do not well-reflect this considerable groundwork, and suffer from a disturbing lack of supporting scientific analysis.

Largely corresponding to preexisting constraints, the MSCP preserve is weaker in some areas and stronger in others. All together, about 3/4's of the best remaining habitat is slated for protection, and maintaining connectivity across an already fragmented landscape is a major potential benefit. A new San Diego National Wildlife Refuge will be created in the most intact remaining land- scape. Uncertainties in preserve assembly still need resolution, however: While some preserve areas have "hardlines" derived from project-specific negotiations, others have "softlines" where the preserve is to be assembled over time according to pre-determined criteria.

A companion plan amongst several cities in northern San Diego County, the Multiple Habitat Conservation Program, is proceeding at a slower pace. Preexisting fragmentation has severely restricted preserve design and connectivity options, and the treatment of farming operations also needs resolution.

\section{Other plans}

In Riverside County, a Planning Agreement is nearing completion to begin an NCCP. This County is rebounding from what all parties agree was an unsatisfactory experience with a highly regulatory, solely developerfinanced single species plan for the Stephens' kangaroo rat (SKR). Incorporated into the new plan will be the combination of SKR reserves and multiple species plans done for major Metropolitan Water District construction projects, totalling about 16,200 ha. Integration of agricultural lands, as buffers for example, may occur in the Riverside plan, but these landowners request not only conservation "incentives" but maintenance of development options. In a rapidly growing region like this, with little previous history of preserving open space through the land use process, an NCCP can make a considerable difference.

In the Palos Verdes Peninsula, in Los Angeles County, a smaller NCCP is underway. San Bernardino County, facing a possible San Bernardino kangaroo rat listing, is also initiating a "Valley-Wide" program.

A purpose of the ESA is to conserve "the ecosystems upon which ... species depend." The NCCP program uses the ESA as leverage to apply the principles of conservation biology over a wide area, and is the most realistic option to salvage, connect, and manage the best habitat remaining on private lands within the vast, numbing sprawl of coastal southern California. But despite overwhelming practical benefit, controversy still exists over whether there are sufficient scientific grounds to believe the plans will deliver the species protections they promise.

\section{Lessons}

So far, what has been learned from the NCCP experience?

\section{- Listings play an essential role.}

The ESA can indeed be parlayed into significant multiple species conservation, far beyond what would otherwise occur. But as proven by potentially disastrous project 
approvals by NCCP-participating jurisdictions - actions which directly contravened wildlife agency advice-voluntary programs in and of themselves are inadequate substitutes for actual listings. In southern California, the listing of the California gnatcatcher remains an indispensable driving force.

\section{- Public participation must be sought.}

Public input is very likely to be essential if an acceptable conservation result is to be achieved. "Collaborative" stakeholder groups, as employed in the NCCP, have made many substantial contributions, particularly in preserve implementation and finance. Consensus is not common, but very powerful when it does occur. For final arbitration of contentious issues, however, the composition of local decision-making bodies remains of utmost importance.

\section{- Partnerships with local government are powerful.}

The key advantage of an NCCP over the ESA alone is that local government is an active partner. The application of local land use authority allows accomplishments state or federal agencies could not manage alone. For example, wildlife movement corridors through habitat unoccupied by a listed species can be protected. Also, implementation tools are much more effective when local government steps in. The City of San Diego, for example, uses an "open space zone," within which development of $25 \%$ of a parcel is permitted, to effect part of its plan.

\section{- Assurances are part of the equation.}

The trade-off for proactive planning, and, indeed, for the very involvement of local government and landowners, is assurances - assurances that in the event species "covered" by the plan subsequently become listed or suffer unanticipated decline, additional mitigation will not be required on the applicants' part. (The assumption by the federal government of the financial burden for unforeseen circumstances has been called the "No Surprises" policy.) The most pertinent question is whether the biological robustness of the NCCP preserves is commensurate with the iron-clad assurances. In particular, the policy of "habitat-based" assurances, in which no additional mitigation is required for subsequently listed species if these are dependent upon habitats predetermined to be "sufficiently conserved," exceeds prudent bounds. Admittedly, though, due to the pace of permanent habitat loss, there is less risk of foreclosing future conservation options through these policies in southern California than in managed landscapes, like northwest forests.

\section{- There is "spill-over" into better planning in general.}

The NCCP programs have allowed local governments to understand the many benefits of natural open space to their communities, and to act. Furthermore, fiscal analyses have demonstrated positive economic effects, not only in terms of regulatory efficiency but also in furthering more compact patterns of development.

\section{- State delegation is unwise.}

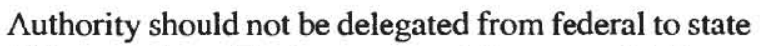
wildlife agencies. Further removed from special interests and representing the national interest, the U.S. Fish and Wildlife Service has a singular role to play.

\section{- Scientific accountability is still insufficient.}

Since the dissolution of the early NCCP scientific panel, which prepared a general set of "Conservation Guidelines," the program has suffered from a serious deficiency of independent scientific input and review. A comparison with the high level of expertise present on an ESA species Recovery Team is instructive. While it should not be inferred that the plans are necessarily unsound, neither are they as yet fully credible. Averse to potential delay and to "second-guessing" of decisions, the biggest obstacle to independent scientific input (and therefore to resolution of controversy over science) has been the wildlife agencies themselves. As time goes on, this deficiency is being partially remedied, as the individual efforts are putting in place their own advisory panels. Formal scientific review of the NCCP pilot project would now be appropriate.

A dilemma in regard to the role of science in the NCCP has been the overarching biological imperative to protect large blocks of habitat quickly, before they disappear, even in the absence of detailed data on a species level. This has forced the use of practical reserve design, habitat-oriented, and "umbrella species" methodologies, which urgently need more study and validation.

\section{- Recovery objectives are paramount.}

A critical unresolved issue is that of standards. These regional plans must be considered de facto species recovery plans, as mandated by the ESA. At a minimum, therefore, they must assure healthy populations across the species' range, which goes beyond the "not appreciably reduce the likelihood of survival and recovery" standard typically applied to smaller, individual projects under section 10(a) of the Act. (The NCCP Act itself contains no standards, although the Conservation Guidelines specifically prepared for coastal sage scrub call for no-net-loss of habitat value as defined by viable populations.) The failure to explicitly address the recovery objectives of the 
ESA is the most cogent conservation criticism of the NCCP plans to date. In this regard, recent testimony by the Regional Director of the U.S. Fish and Wildlife Service that the San Diego MSCP supported or contributed to the recovery of all covered species establishes a vital policy precedent.

\section{- Local land use factors limit program effectiveness.}

The specific deficiencies of current plans are often due to irremediable zoning constraints or project entitlement actions by local government. It should be emphasized that the ESA alone cannot undo local General Plans or reverse long-standing, anti-environmental policies. To the contrary, on private lands, the local land use authorities create the legal and economic parameters within which all other parties operate. Habitat Conservation Plans (including segments of the NCCPs) are too frequently the result of negotiations in which, figuratively, the wildlife agencies are dealt a pair of deuces and the developer a full house.

\section{-Vital acquisition funding remains unavailable.}

Funding for land acquisition which goes beyond development project exaction is essential for most programs. Sufficient funds are not currently available, and will not be unless the political roadblocks to meaningful funding at both state and federal levels are reversed. The lack of acquisition funds early in the planning process is a huge, truly fatal flaw in achieving recovery objectives. Perhaps, setting positive recovery objectives would in and of itself engender greater support for endangered species funding.

\section{Conclusion}

Safeguards are needed if NCCP is codified into the Endangered Species Act. Imperative elements are: massively increased acquisition funding as well as landowner and tax incentives, independent scientific input, public participation, non-delegation to state agencies, and welldefined recovery objectives.

The most important conclusions about NCCP pertain to context. Rather than viewing the southern California experience as an off-the-shelf "national model," the role and form of multiple species planning should be individualized to each locale. For example, rather than a defined preserve, land management practices may be superior for less developed areas.

Even more fundamental is the issue of when use of minimal ESA standards - upon which NCCPs are currently based - is appropriate. Coastal southern California, with highly depleted ecosystems under immediate threat from continued population growth, and governed by local jurisdictions unwilling to protect the landscape on their own, is a case in point. There are undoubtedly many other urbanizing areas where the NCCP is an appropriate model. But in more intact landscapes, where merely "viable" populations" is a low standard, the future balance between conservation and development should be determined otherwise, and the potential of other land use tools not undermined.

Ideally, the primary land use tools should remain the traditional ones, growth management and sound local General Plans. From this perspective, NCCPs could play individualized roles in creating meaningful conscrvation elements for General Plans, and thereby also integrate with land use, housing, open space, circulation, and agriculture elements. It should be recognized, though, that in southern California, the biologically-driven NCCPs may, perhaps ironically, stimulate better planning in general. More compact urban forms and agricultural preservation may be facilitated, either indirectly through implementation of the preserve or simply as a result of citizens facing problems they would otherwise have avoided. Indeed, in some areas, a multiple species plan may be the best entrée to improved planning available.

But how to avert a "southern California solution" in which the Endangered Species Act steps in as de facto land use planning after a virtual holocaust? As already noted, the strongest tools available - infrastructure limits, zoning, ordinance - belong to local government. This same political process is also the vehicle whereby communities can create and implement a vision for the future. The development industry regularly commandeers these forces, however, and the environmental community shows little indication of applying itself to the remedy, the hard work of politics and of building coalitions with other constituencies. But let there be no doubt over the legislative potential of local government, so under-utilized, to advance natural open space as part of the public welfare. According to the U.S. Supreme Court (Berman v. Parker, 348 U.S. 26 (1954)):

The concept of the public welfare is broad and inclusive. ...The values it represents are spiritual as well as physical, aesthetic as well as monetary. It is within the power of the legislature to determine that the community should be beautiful as well as healthy, spacious as well as clean, well-balanced as well as carefully patrolled. 


\title{
Research Guidance to Address the Needs of Land Managers: Coastal Sage Scrub Natural Community Conservation Planning (NCCP)
}

\author{
Peter A Stine \\ Western Ecological Research Center, USGS Biological Resources Division, \\ California State University, 6000 J St., Placer Hall, Sacramento, CA 95819-6129 \\ Tel. (916) 278-3251; Fax (916) 278-3700; e-mail: Peter_Stine@usgs.gov
}

\begin{abstract}
Several federal, state, and private organizations with responsibility for land use and resource management in southern California are cooperating to protect coastal sage scrub areas through the development and implementation of Natural Community Conservation Planning (NCCP) programs in San Diego, Orange, and Riverside counties. The representatives of the state and federal agencies charged with oversight of the NCCP appointed a Science Research Committee to coordinate research and related land management activities. This committee in turn selected an ad hoc Core Group of representative researchers and managers from differing regions, sectors, and perspectives to advise them regarding improved methods for developing and disseminating ecological information needed for planning and management. The following draft report was prepared by the NCCP Core Group, whose members are listed below.
\end{abstract}

Keywords: Research needs; resource managers; southern California.

\section{Introduction}

The "Core Group" of representative land managers and researchers from federal, state, local, and private organizations worked together to build recommendations and a report on how to coordinate the development and dissemination of ecological information needed by all parties involved in implementing the Natural Community Conservation Planning (NCCP) areas for coastal sage scrub in Southern California. The group explored various mechanisms for addressing the ecological information needs of managers and decision makers involved in the NCCP program. Their goals were to (1) reassess the research agenda intended to supply important new information to manag- ers and (2) determine the most effective means for synthesizing new and existing ecological information into appropriate guidance for decision makers.

Through a series of working meetings, the group reached consensus on the general information needs most important to resource managers and identified the gaps in current research efforts needed to address those needs. They also made recommendations on how to develop more coordinated and effective organization and processes to enhance the ongoing coordination of research activities and the dissemination of the resulting information.

The group attempted to identify the general information needs of the managers and policy makers involved in the coastal sage scrub NCCP. They also listed the many recent and ongoing research activities that are relevant to coastal sage scrub. By mapping the research activities to the information needs, the group identified gaps in which key information needs are not being addressed by current research. The group also prioritized the broad areas of information needs to help guide future research agendas. This is discussed further below.

There currently is no broadly recognized formal mechanisms for research coordination and communication of existing and new information to managers. A team of four individuals (including representatives from USDI Fish and Wildlife Service, California Department of Fish and Game, The Nature Conservancy, and the Biological Resources Division of U.S. Geological Survey) constitute a Science Research Coordinating Committee for the NCCP program. However they have insufficient time to carry out all the work identified for research corrdination and information dissemination. Therefore, the Core Group recommended that a more focused function or office be established to coordinate research and information dissemination activities related to the coastal sage scrub NCCP. The proposed functions would be to: 
- Facilitate the identification of priority information needs of managers and the research and other efforts required to address those needs

- Provide assessment and synthesis of ongoing research and its ability to address management needs

- Communicate research results to managers and policy makers to effectively inform their decisions

- Assist in the development and coordination of databases needed to implement land management programs.

The crucial need that the focal point function would fill is to enhance the collective ability of participants of the NCCP program to address and gain access to the best scientific information available. Ideally this proposed function would interact with both public and private sector agencies and would have adequate budget to carry out its facilitation role. It would not, however, fund specific research projects, but simply serve to coordinate new and ongoing research and facilitate the exchange of information between research and management. It should be staffed both by people with research experience and with management expertise.

\section{Background}

The organizations responsible for managing lands associated with the Natural Community Conservation Planning (NCCP) are faced with the challenge of breaking new ground in managing large, fragmented areas for multispecies protection at the population and ecosystem scales. Many of the habitat management decisions to be made have no precedent and there is limited technical information on which they can be based.

There are limited resources available for management of the ecological reserves established under the NCCP program and for research of coastal sage scrub ecosystems. Therefore, representatives from key federal and state agencies and from The Nature Conservancy initiated an effort to coordinate relevant research activities and facilitate the production of technical information that can inform management decisions. The Science Research Committee-in collaboration with local governments, public utilities, the San Diego Zoological Society, and othersheld a conference in September 1996 to share information on ongoing research activities related to coastal sage scrub and to discuss how this research relates to managers' information needs.

A Core Group of fourteen representative researchers, land managers, and planners was selected by the Science Research Committee to provide a cross section of perspectives on these issues. The group was convened at the
September conference to further identify land managers' information needs and examine how research can address those needs. Science \& Policy Associates, Inc. was asked to facilitate the Core Group based on their extensive experience in assisting similar groups to link research with decision making. They acted as a neutral broker with no vested interest in the NCCP issues or role in research or management. Their activities were sponsored by Southern California Edison, the Metropolitan Water District of Southern California, and the Electric Power Research Institute.

At the Core Group's first meeting during the September 1996 conference they unanimously identified their mission as follows:

To redefine the existing research agenda and develop a strategy for more effectively applying science to implementing NCCP policy and management.

The Core Group held a two day working session 31 October - 1 November 1996 to forge ahead with this mission. At a third meeting on 20 December 1996, the group refined and revised its conclusions and recommendations.

\section{Objectives}

The Core Group had three primary objectives:

(1) To identify and rank the priority information needs of decision makers responsible for managing the land and resources of coastal sage scrub and adjoining habitats.

(2) To develop guidance for how research can address those information needs and inform the decisions of managers.

(3) To recommend a function and process for ensuring ongoing communication between and among the research and management organizations involved in the NCCP program.

\section{Approach}

When the Core Group was convened at the September conference, two members agreed to complete key tasks in preparation for the October-November meeting. Larry Eng of the California Department of Fish and Game talked with "on-the-ground" managers to develop a framework list of information needs. Peter Stine of the Biological Resources Division of the U.S. Geological Survey (formerly the National Biological Service) organized a preliminary list of existing research activities and mapped them to the information needs elicited by Eng. Stine was 
assisted in his effort by staff from the San Diego NCCP office of the California Department of Fish and Game.

At the Core Group meeting, the preliminary list of managers' information needs was refined, reorganized, and prioritized. The list was then framed as potential research questions more completely mapped to the existing or recently completed research activities. This resulted in guidance on what research is needed to inform management decisions, and highlights those research needs not addressed by current research.

Finally the group developed recommendations for a needed function and process for coordinating research and information dissemination activities to serve each other most efficiently and effectively. This outcome was enhanced by the diverse perspectives and concerns of the group and by their willingness to discuss challenges, weaknesses, and opportunities candidly and openly.

\section{Findings on Research and Management Information Needs}

\section{Research/management categories and priorities}

The Core Group reorganized the framework list of managers' information needs into a taxonomy that would be useful to relate the needs of natural resource managers with distinct categories familiar to research funders and managers. The group developed the following list of categories (Table 1) of managers' research needs. The resource managers in the group assigned broad priorities to the categories using two considerations: urgency (short-term requirements) and importance (requirements related to issues with great potential impact).

As with any list of priorities, those described in Table 1 should be qualified. The categories of management information needs, the specific information needs, and the priorities assigned to them should be considered only in the context of the following qualifiers:
(1) They are the result of consensus generalizations by a diverse group. For specific sites or issues, priorities may vary.

(2) They represent a range of required research commitment. Some could be addressed by a single one-year study, while others could take decades.

(3) They are stated broadly so that they can be tailored to specific situations.

(4) The information needs and associated priorities will change over time as gaps are filled, needs refined, and new gaps identified.

\section{Broad research gaps}

Past and ongoing research partially addresses a small percentage of the managers' questions identified by the Core Group and others. Few, if any, managers' needs are fully addressed by current and planned research. For some of the broad areas listed above there are no research activities specifically related to the managers' needs.

Based on the priorities assigned to the categories of information needs and the lack of relevant research activities, the most significant information gaps are the following categories.

- Inventory and Monitoring

- Administration, Socioeconomic Considerations, and Implementation

- Species Persistence/Demographics/Genetics

- Fire

Table 1. Core Group's recommendatoins for resource manager's reserach needs. Rankings for each, with 1 signifying the higherst priority and 3 the lowest.

\begin{tabular}{lcc}
\hline Information Need & \multicolumn{2}{c}{ Ranking } \\
& Urgency & 1 \\
\hline Fire & 1 & 1 \\
Inventory and Monitoring & 1 & 1 \\
Species Persistence/Demographics/Genetics & 1 \\
Administration, Socioeconomic Considerations, and Implementation & 1 \\
Exotics and Invasives & 2 & 1 \\
Public Use & 2 & 1 \\
Biophysical Processes/Ecosystem Function & 3 \\
Reserve Design/Biogeography/Landscape Processes & 2 & 1 \\
Restoration and Enhancement & 2 \\
General Species, Program-Wide, and Regional Concerns & 3 \\
Historical Land Use/Succession & 2 \\
Habitat Management Practices & 2 \\
Influence of Adjacent Land Uses & 3 & 2 \\
\hline
\end{tabular}


The ongoing research activities identified to the information needs elicited from managers is reported in the full report of the Core Group. For each information need, relevant research activities are listed. Many of the information needs under the highest priority categories listed above are being addressed by none or only a few of the research projects reported. For instance, one of the fire questions is being addressed by several projects, but the remainder have only one activity that even partially addressed the need.

\section{Findings on Organization, Process, and Communication}

The Core Group examined the existing capacities for effectively accomplishing the primary objectives summarized earlier. This was a difficult issue because it was clearly not the intention of the group to support any additional bureaucratic layers or to supplant the discretion of local authorities or individual organizations developing and/or using new scientific information. However, we believe that if land managers and planners are to obtain the maximum potential value from existing and future scientific research, some additional means of enhancing communication and cooperation between and among both researchers and managers/planners is desirable.

In light of this, the Core Group considered some possible options to enhance our collective ability to achieve the stated objectives. A set of recommendations and additional steps were developed that could help fulfill the potential that research and information exchange offers to implementation of the NCCP program. We believe, in fact, that these recommendations could be applicable to the generic issue of effective communication between the ecological researchers and the land managers/land planners in other areas. There is no simple solution; however, the group of researchers and managers/planners involved in this effort discovered some useful common ground in the course of our discussions.

\section{Status and opportunities}

Existing mechanisms for addressing ecological information necds related to the NCCP currently have the following characteristics:

- Ad hoc organization

- Variable research budget

- No formal coordination of research or management

- No formal leadership

- A bottom-up approach

- Jurisdictional subdivisions

- Insufficient funding for processes, assessments, synthesis, or communication
- An emerging set of guidelines that is diffuse and inconsistent.

The strengths of NCCP research coordination, as currently operated, include the attention that top-level policy makers and experienced managers have given to the program. Although the structure is informal, there has been good cooperation and commitment, to the extent possible, from the involved parties. The program also has broad public support at the regional and state levels. The Core Group believes it is important to maintain strong coordination between policymakers and the research initiative.

The lack of a formal structure of the research initiative, however, presents a number of challenges. The people involved in implementing the program are too busy with other responsibilities to invest adequate time into the research and information dissemination efforts intended to assist the NCCP program. The lack of a well-defined process for sharing information limits the effectiveness and impact of the program and its many valuable contributions. The program is also making the transition from reserve design to management, and is still in the process of evolving into that new role.

The opportunities presented by the NCCP are:

- To develop a unified research agenda

- To enhance communication between land managers and researchers

- To meld scientific/management/policy objectives

- To coordinate effective adaptive management implementation with research feedback on a regional basis

- To create a model for similar programs elsewhere.

\section{Recommendations}

The NCCP program involves an intricate system of cooperation between several types of organizations and individuals, including researchers, research managers, land managers, planners, policy makers, and the general public. There is an obvious need for communication within and among these groups.

The Core Group recommended the establishment or designation of a research coordinator to oversee or facilitate the coordination and communication of research and information dissemination activities related to the NCCP program. This should be situated within an institution with direct access (in both directions) to managers and other consumers of the needed information. The Core Group did not believe it is in a position to determine where or how this function should be established. This will be a decision to be lead by the resource and land management agencies in cooperation with planning partners. However, the group recommended that the research coordinator function should meet the following criteria: 
- Act as an efficient central clearinghouse for technical information, rather than an additional bureaucratic layer

- Have research AND land management expertise

- Offer adequate time commitment of program officer-level director and administrative support

- Have adequate budget and resources from one or more sources (preferably a mix of public and private sector funders) to carry out facilitation functions

- Coordinate and link research ideas and funding from a variety of sources

The Core Group recommended that the individual or group responsible for coordination should have the following roles and responsibilities:

- Assess, synthesize, and communicate information from research results to managers and other users

- Keep and coordinate databases

- Identify ongoing management needs and research to address those needs

- Staff the Science Research Committee of the NCCP

- Maintain communication between sectors and communities and to the public (e.g., through Web pages, newsletters, conferences, and other fora)

- Promote the continuity of long-term research funding

- Assist with recovery plans and activities.

\section{Next Steps}

The long-term effect of this effort and the resulting full report of the Core Group greatly depends on whether or not its principal recommendation is implemented: establishment of a coordinator function to facilitate execution of the prioritized research agenda. The coordinator(s), in addition to fulfilling the above-listed functions, will play a much needed role in assisting local land entities in achieving their land management goals efficiently and cost-effectively. Local preserve managers face the challenge of making daily decisions that are potentially very costly in terms of dollars as well as the natural resources under their charge. They can be greatly assisted in their ground-breaking efforts through information sharing with researchers and managers of other preserves, and cost- sharing in gathering information of common value to managers region-wide. Many of the most prioritized management questions will benefit from field investigations outside the specific locations where they might be applied, such as information on recreation impacts on habitat. Other topics require pooling of resources over broad geographic areas because of the long-term nature or relative expense of collecting sufficient data. The coordinator function is intended to facilitate these kinds of cost-saving strategies. Rather than an added bureaucratic layer, or command and control research management, the role is conceived as an available resource to facilitate managers in finding the best way to obtain information they need.

Establishment of the coordinator function will ensure ongoing maintenance of a clearinghouse for data that will provide three important running lists: (1) of relevant past, ongoing, and planned research and research results, (2) of managers' information needs, activities, priorities, and lessons learned and (3) of the research still needed to address those needs. These will change over time, and the report will be revised to reflect that evolution. The lists will be made available on a World Wide Web home page so that they will be living documents to help coordinate and guide research and management efforts. Once again, where and how this function will be realized is a decision for the resource management agencies to make.

The effort and the resulting report also will provide a blueprint and a rationale for the more formalized structure and process recommended. Through publication and briefings, the findings and recommendations of the Core Group will be communicated to the public and private sector decision makers with a stake in the success of the NCCP program and the resources to further support the effort.

Acknowledgments. This effort and the attending results, including this summary report, were the product of many people and their dedicated contribution. I acknowledge the participation of the Core Group members which included the following people; Ed Almanza, Jon Atwood, Peter Bowler, Ted Case, Larry Eng, Gail Kobetich, Rod Meade, Patrick Mock, Mike O'Connell, Tom Oberbauer, John Rotenberry, JerreStallcup, MikeStroud, and Sherry Teresa. I also acknowledge the professional assistance the group had from the facilitators of the effort, Chris Bernabo and Tom Carter from Science \& Policy Associates. Finally we would like to thank those organizations which provided the needed funding to support the effort of the group, Southern California Edison, the Metropolitan Water District, and the Electric Power Research Institute. 


\title{
Gnatcatchers and the NCCP: Will We Know When the Species Should be Delisted?
}

\author{
Jonathan L. Atwood \\ Manomet Center for Conservation Sciences, P.O. Box 1770, Manomet, MA 02345 \\ Tel. (508) 224-6521; Fax (508) 224-9220; e-mail: jatwood@ manomet.org
}

\begin{abstract}
Federal listing of the California gnatcatcher as a Threatened species under the Endangered Species Act is generally acknowledged as a major factor in the evolution of the Natural Community Conservation Planning (NCCP) process, and the species continues to play a central role in land-use decisions throughout most of coastal southern California. With the establishment of various NCCP reserves, has conservation concern over the gnatcatcher been alleviated to the point that formal endangered species protection is no longer necessary? Various approaches to answering this question have been suggested, including (a) comparing authorized "take" of gnatcatchers under NCCP agreements with maximum levels established at the time of listing, and (b) annual census efforts aimed at detecting population trends. The first of these approaches wrongly assumes the existence of correct baseline estimates of regional population sizes of gnatcatchers. The second approach may effectively detect population declines, but only if monitoring sites are adequately distributed throughout an NCCP subregion. Monitoring protocols for the Orange County Central/ Coastal NCCP plan and the Multiple Species Conservation Program (MSCP) will sample gnatcatcher populations on plots representing $2 \%-4 \%$, respectively, of each reserve system. Whether this level of coverage will provide an adequate basis for determining if the NCCP program has successfully conserved even this "flagship" species is unknown.
\end{abstract}

Keywords: California gnatcatcher; endangered species; conservation planning; NCCP; HCP; monitoring.

\section{Introduction}

Since 1990, when protection under the U.S. Endangered Species Act (hereafter, ESA) was petitioned for the California gnatcatcher's northernmost, nominate subspecies (Polioptila c. californica) (Atwood 1993; USFWS 1993b), this small songbird has played a central role in one of the nation's most significant conservation initiatives, the State of California's Natural Community Conservation Planning (NCCP) program. Not only did anticipated protection of the species by the federal government act to catalyze passage of the NCCP Act in 1991 (Reynolds 1993), but issuance of a Special Rule under Section 4(d) of the ESA encouraged voluntary participation in the NCCP process by private landowners and local jurisdictions (USFWS 1993a). Subsequently, gnatcatcher distribution, habitat requirements, and behavior have continued to be focal issues determining the specific details of NCCP plans in coastal southern California; in fact, the Special Rule requires "that final NCCP plans meet the standards set forth under 50 CFR 17.32(b)(2) [Code of Federal Regulations]" (USFWS 1993a). DeSimone and Silver (1993) concluded that "NCCP would have little chance of ever culminating plans for successful wildlife resource protection without the regulatory teeth of a threatened or endangered listing under the CESA [California Endangered Species Act] or the ESA ... federal listing of the gnatcatcher is the sole reason the NCCP process retains the potential for effectively protecting coastal sage scrub."

Given the centrality of concerns about gnatcatcher conservation in the evolution and implementation of the NCCP program, it is not unreasonable to use this species' status as one indicator of how the planning process has succeeded to date. Certainly the NCCP program has much more sweeping objectives than conservation of the California gnatcatcher (Atwood and Noss 1994; Reid and Murphy 1995; O'Connell and Johnson 1997). Nonetheless, while successful protection of viable gnatcatcher populations would be insufficient proof of the NCCP's overall success, any failure to adequately protect the program's flagship species (Noss 1991) might well indicate broader flaws in the overall planning process. It is difficult to imagine a definition of NCCP success that would exclude effective conservation of gnatcatchers in coastal southern California. 
In this paper I evaluate two ways that have been suggested, to date, for using status of the California gnatcatcher as an index of the NCCP's success. Furthermore, I discuss the question of whether existing monitoring programs will effectively indicate when the gnatcatcher should be removed from the federal endangered species list.

\section{Methods}

This paper makes use of data collected by Manomet Center for Conservation Sciences from 1993 - 1996 on the Palos Verdes Peninsula, Los Angeles County, California. All major areas of natural habitat on the Peninsula were repeatedly surveyed for breeding California gnatcatchers during February - July of each year of the study. Because natural areas on the Peninsula are isolated from other areas of coastal sage scrub by the extensive urban megalopolis of greater Los Angeles, and because the amount of natural habitat remaining on the Peninsula is extremely limited, these surveys are believed to provide accurate estimates of the annual distribution of breeding pairs and year-to-year survivorship of banded birds. Assessment of annual reproductive success was based on detailed observation of 9 pairs during 1993, 20 pairs during 1994,21 pairs during 1995 , and 18 pairs during 1996. Although the Palos Verdes Peninsula gnatcatcher population contrasts with other southern California populations of the species in its degree of isolation and consequent lack of emigration from neighboring populations, there is no evidence to date that it significantly differs in reproductive success or survivorship (Ogden Environmental and Energy Services 1992; Braden and Powell 1994; Bontrager et al. 1995; Atwood et al. 1997). Additional information regarding the Palos Verdes study area and general methodology is provided in Atwood et al. (1997). Banding, nest monitoring, and survey activities were conducted under U.S. Fish and Wildlife Service Endangered Species recovery permit PRT-800922, U.S. Fish and Wildlife Service Master Bird-Banding Permit 09996, State of California Scientific Collecting Permits, and a California Department of Fish and Game Memorandum of Understanding dated 25 August 1992 (as amended).

\section{Results}

Two approaches have been suggested as ways to evaluate success of the NCCP program based on status of the California gnatcatcher. These include (1) comparison of gnatcatcher "take" allowed during the NCCP planning period with regulatory limits associated with baseline population estimates, and (2) analysis of population trends based on annual surveys of breeding pairs.
Gnatcatcher "take" compared to baseline population size

An important factor that prompted many representatives of the southern California building industry to participate in the NCCP program was the Section 4(d) Special Rule that allowed limited, continued impacts to occur on gnatcatcher-occupied habitat during the period that specific NCCP plans were being prepared and approved (USFWS 1993a). In fact, without the flexibility allowed by this interim "take" provision, implementation of the NCCP concept in southern California would likely have failed, since voluntary participation in the program would not have conferred any immediate benefits to most landowners. Only through the Special Rule could on-going or imminent land development projects continue without confronting the regulatory red tape typically associated with Section 10(a) permitting under the ESA. By acting as a nexus between the State's NCCP program and provisions of the federal ESA, the Special Rule provided a legal context in which preparation of NCCP plans might proceed.

However, the Special Rule also included language that opened to legal criticism the basic assumption that levels of interim "take" would comply with the ESA's 10(a) permitting standards. The Special Rule stated that "Under the provisions of the NCCP Conservation Guidelines, up to 5 percent of existing coastal sage scrub habitat could be lost, and an estimated 66 to 116 pairs of gnatcatchers could be incidentally taken under the provisions of the special rule during the planning period ... The Service has conducted an internal consultation under section 7 of the Act to evaluate the effects of the proposed special rule on the gnatcatcher during the interim planning period and has concluded that the rule is not likely to jeopardize the continued existence of the species ... The Service will monitor the implementation of the NCCP Conservation and Process Guidelines as a whole, and will conduct a review every 6 months to determine whether the guidelines, as implemented, are effective in progressing toward or meeting regional and subregional conservation objectives during the interim planning period. If the Service determines that the guidelines are not effecting adequate progress ... the Service may revoke the interim take provisions of this special rule on a subregional or subarea basis ... Revocation would result in the reinstatement of the take prohibitions set forth under 50 CFR 17.31(a) and (b) in the affected NCCP area" (USFWS 1993a; italics added for emphasis). By setting an upper limit on gnatcatcher "take" at 116 pairs, the Special Rule implied a criterion for NCCP success that nearly jeopardized the program's future; failure to comply with this limit could result in loss of the flexibility that was important to continued participation in the process by many landowners.

In 1996 this scenario came close to fulfillment. Conservation advocates who were critical of the Orange County Central/Coastal NCCP process concluded that 
"take" of gnatcatcher pairs in this planning area alone had apparently exceeded the 116 pair limit given in the Special Rule (L. Klippstein, personel communication). On June 24, 1996 the Spirit of the Sage Council filed a 60day notice of intent to sue the U.S. Fish \& Wildlife Service (USFWS) over various issues, including a request "that the FWS notify all NCCP program participants to cease activities until a formal consultation has been completed." On October 18, 1996 the Carlsbad Field Office of the U.S. Fish and Wildlife Service complied with the required review of the Special Rule's effects on the California gnatcatcher - the first such review to be conducted since publication of the Special Rule in 1993. Based on analysis of sightings reported subsequent to listing the species in 1993, the Service concluded that the earlier estimate of 2,562 gnatcatcher pairs should, instead, have been 3,430 pairs, and furthermore concluded that "the anticipated loss of 80 gnatcatcher pairs (in Orange and San Diego Counties, and in the Rancho Palos Verdes area of Los Angeles County) in addition to the 116 pairs addressed in the original 1993 biological opinion will not affect the viability of the gnatcatcher population" (USFWS 1996).

How did USFWS first arrive at the conclusion that take of more than 116 gnatcatcher pairs should trigger re-evaluation of the Special Rule (and whether the NCCP program was effectively conserving the species as required by the ESA)? What was the biological basis for this value? More generally, how certain are the population estimates used by the Service (or others) in calculating limits of acceptable take or potential impacts of NCCP agreements on the species?

When the NCCP process was inaugurated, one of the first actions taken by the State Resources Agency was appointment of a blue-ribbon panel of widely respected conservation biologists who were charged with the task of preparing a set of conservation guidelines to serve as a broad template for subsequent planning efforts (California Department of Fish and Game and California Resources Agency 1993). These guidelines concluded that "total interim loss should be limited to $5 \%$ of [coastal sage scrub] habitat in any individual subregion" (California Department of Fish and Game and California Resources Agency 1993). The Scientific Review Panel took what was generally considered a biologically conservative and politically necessary approach; by allowing loss of a limited amount of existing coastal sage scrub, they hoped to maintain future conservation planning options while also retaining necessary participation in the NCCP process by the development community and local jurisdictions.

The situation was complicated when the Special Rule was issued one month later. The authors of this rule clearly recognized that the Scientific Review Panel's conservation guidelines had described an interim "take" limit not for California gnatcatchers but rather for coastal sage scrub habitat. Nonetheless, presumably because ESA 10(a) per- mitting is typically linked to anticipated project impacts on listed species, the Special Rule went on to state that no more than 116 pairs ( $4.5 \%$ of the estimated U.S. population size of 2,562 pairs at the time of listing) could be "taken" within the NCCP planning area during the interim planning effort. The same approach was repeated in 1996, when the Service revised the acceptable limit on "take" to include an additional 70 pairs (based on a newly-estimated population size of $3,340(116+70=186 ; 186 \div$ $3,430=0.05$ ) (USFWS 1996).

The underlying problem with this issue revolves around methods used to obtain regional estimates of California gnatcatcher population size. With rare exceptions, such as on the Palos Verdes Peninsula, NCCP subregions or subareas include extensive amounts of coastal sage scrub habitat, making it difficult to perform complete and thorough surveys of all areas of habitat potentially occupied by gnatcatchers in a single year. While use of location data acquired over multiple years is appropriate for identifying suitable habitat and core gnatcatcher populations, there has also been a dangerous tendency to misuse these data for estimating population sizes. For example, USFWS (1996) calculated population sizes in Orange County based on data obtained from 1987 - 1996; estimates for San Diego and Riverside Counties were based on data collected from "the 1980s" - 1996. Despite efforts to avoid over-estimates of gnatcatcher population size caused by multi-year observations of what are putatively the same birds (USFWS 1996), pair sightings from previously unsurveyed localities have generally been considered to represent additional pairs, as have pairs found in new locations within areas that previously had been surveyed. Inherent to such cumulative analyses is the assumption that gnatcatcher distribution in the landscape is relatively static from year-to-year, and that observations obtained over multiple years can therefore be used legitimately as indices of population size.

I evaluated the validity of this assumption by examining the spatial distribution of gnatcatcher breeding territories on the Palos Verdes Peninsula from 1993 - 1995. Following the general approach taken by other efforts to calculate gnatcatcher numbers in various regions of southern California, locations that were mapped within $250 \mathrm{~m}$ of each other in different years were assumed to represent the same breeding pair; sites that were separated by more than $250 \mathrm{~m}$ were assumed to represent different pairs, as were all sites known to be simultaneously occupied within a single year.

A total of 73 distinct pair locations were identified during these 3 years of study (Fig. 1). Of these, 17 (23\%) were occupied for all three years, $29(40 \%)$ were occupied for two years, and $27(37 \%)$ were occupied in only one year. During 1993 - 1995, the true population size in any year ranged from 26 - 56 pairs (Atwood et al. 1997). In other words, use of a 3-year, cumulative approach to determine total gnatcatcher population size on the Palos 


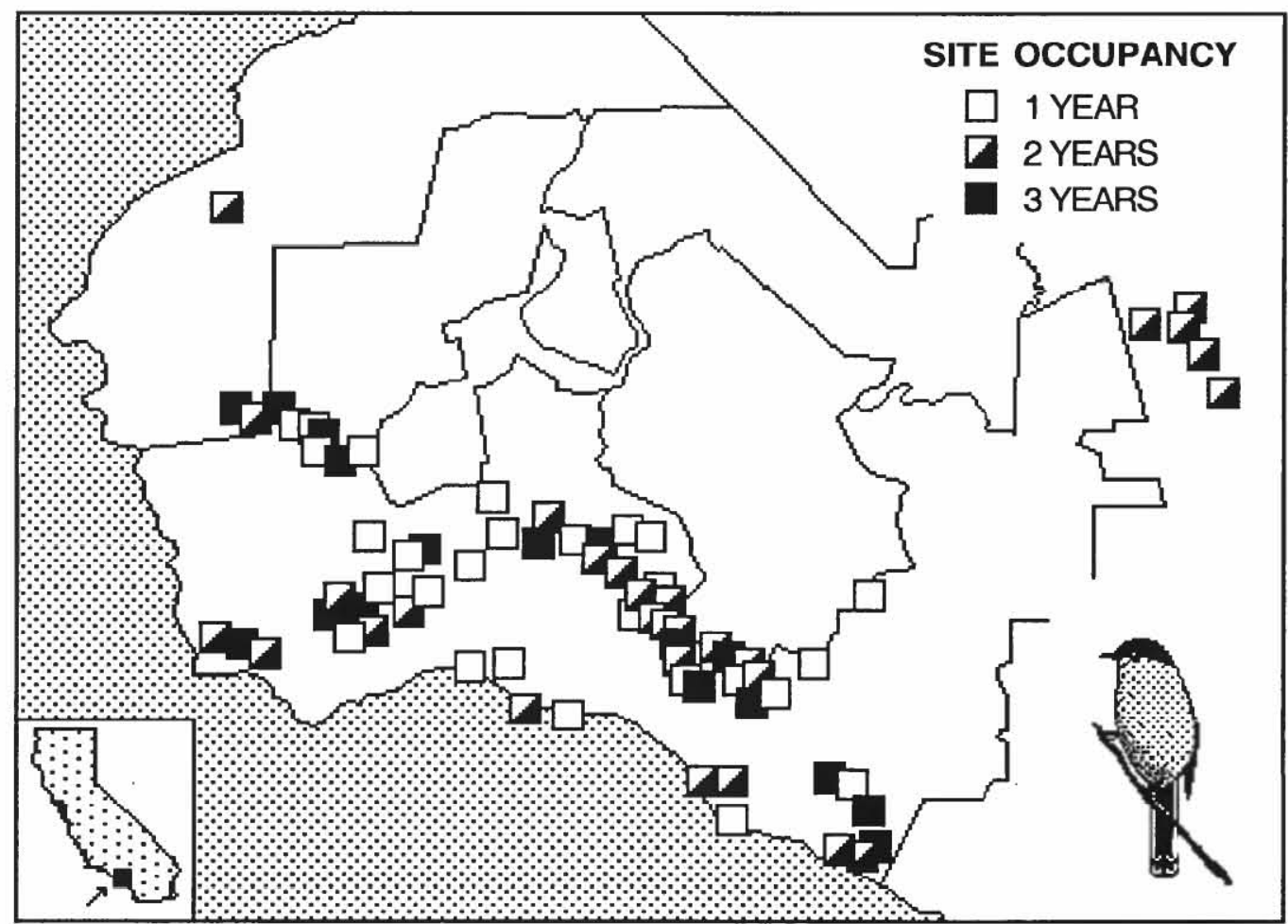

Figure 1. Year-to-year variation in occupancy of California gnatcatcher breeding sites on the Palos Verdes Peninsula. Lines represent boundaries of various civil jurisdictions.

Verdes Peninsula could potentially have yielded over-estimates ranging from $130 \%-281 \%$ of the actual number of pairs present in any single year.

These results suggest that population estimates derived from survey data collected during multiple years may exceed, perhaps substantially, the actual number of gnatcatcher pairs present in any given year. This means that for all NCCP planning areas other than the intensivelystudied (and limited in size) Palos Verdes Peninsula, regional estimates of gnatcatcher population size should be considered little more than crude guesses. Furthermore, comparison of gnatcatcher "take" authorizations against baseline population estimates, such as occurred during fall 1996 , is not a particularly useful means by which to evaluate the effectiveness of the NCCP program in conserving the species. Instead, permit issuance by regulatory authorities should continue to focus on the conservation of regionally important, core gnatcatcher populations rather than protection of specific pairs or reference to a probably inaccurate baseline population size.

\section{Analysis of population trends based on counts of breed- ing pairs}

A second approach that has been suggested regarding how to assess the effectiveness of NCCP reserves at conserving the California gnatcatcher is to conduct successive counts of breeding pairs and use these data to moni- tor population trends over time. In other words, is there any empirical evidence to indicate that the species is declining within the reserve system? Such declines might warrant changes in habitat management efforts, or, in a worst-case scenario, indicate inadequacies in the location or configuration of the habitat reserve system.

Two major NCCP plans have, to date, made specific recommendations regarding monitoring protocols for California gnatcatcher populations: the Orange County Central/Coastal plan and the Multiple Species Conservation Program in southwestern San Diego County (hereafter, MSCP). In the first case, the intent of the monitoring effort is "to determine how well the NCCP/HCP adaptive management program is addressing the goal of maintaining net habitat value of [coastal sage scrub] habitat" for the Orange County Central/Coastal NCCP subregion (Neely 1997). Specifically, the required protocol identified "six survey sampling areas (three in the Central subarea and three in the Coastal subarea) that are representative of core reserve, non-core reserve, and linkage areas" (Neely 1997). Each of these $40-100$ acre plots, which represent, at most, $2 \%$ of the total NCCP reserve, will be surveyed 3 times per year following accepted USFWS survey protocols for California gnatcatcher (USFWS 1997). The objective of these surveys is to produce a single estimate of the number of gnatcatcher breeding pairs present on each plot during that year. The duration of monitoring activities for the Orange County Central/ 
Coastal NCCP subregion is not explicitly stated, although Neely (1997) indicates that the program "may be extended [beyond its first year] depending on available funding."

The MSCP monitoring program, as described by Ogden Environmental and Energy Services (1996), is intended to evaluate " . . . whether the preserve system is meeting subarea plan conservation targets for covered plant and animal species and their habitats, identify threats to covered species and habitats, and help prioritize management needs ... The goal . . . is to implement a monitoring program that is sufficient to detect significant longterm declines in population levels of focal species within the preserve system." The MSCP monitoring plan identifies 31 plots, of approximately 200 acres each, where gnatcatcher surveys will be conducted every three years following USFWS protocols (Ogden Environmental and Energy Services 1996); these monitoring sites will cover approximately $4 \%$ of the total area included within the habitat reserve. At least 22 of these sites are expected to be accessible for monitoring purposes within the first five years of implementation of the MSCP plan (P. Mock, pers. comm.).

The Orange County Central/Coastal sampling scheme does not clearly identify the basic hypotheses that it hopes to examine. One section of the bid solicitation suggests that results from three sites will form the basis for inferences about gnatcatcher population status in each of two large, isolated geographic areas: (1) the Central NCCP reserve, and (2) the Coastal NCCP reserve (Neely 1997). Another section of the same solicitation implies that the basic units to be compared are (1) core reserve, (2) noncore reserve, and (3) linkage areas, with each of these types apparently to be represented by two sites (one located in the Central NCCP reserve and one in the Coastal NCCP reserve). The MSCP protocol more directly states that the monitoring design is simply intended to address the gnatcatcher's status throughout the overall reserve system, with monitoring areas situated in localities that attempt to reflect the regional diversity in habitat, landscape context, and geography.

To examine the likely effectiveness of these two monitoring plans I used the software program MONITOR, which is designed to estimate the ability of population monitoring programs to detect trends in plant or animal abundance (Gibbs 1995). After the user provides values for various, interacting variables that define the structure of a monitoring program, the software uses Monte Carlo procedures to show how often trends of varying magnitude would be detected by such a monitoring effort (Gibbs 1995). In all cases, the results described here were based on 500 iterations with $P=0.1$. Use of this relatively large significance level, which may, in practice, result in occasionally "crying wolf" when, in fact, no true population decline has occurred, is justified given that waiting for statistically more certain results may delay recognition of a problem to the point that a population has collapsed or that various management options have been precluded. In all simulations I assumed a linear (as opposed to exponential) trend, and I calculated significance using a onetailed t-test (although there is no a priori expectation of the direction of future trends in the population, the intent of NCCP monitoring programs are primarily to identify negative trends that might warrant changes in ongoing management practices). Although both the Orange County Central/Coastal NCCP and MSCP monitoring programs prescribe three survey visits per year, the objective of these multiple visits in each case is to produce a single, annual estimate of population size (rather than an average calculated from 3 separate estimates) (USFWS 1997); consequently, I used the rounding option in MONITOR to yield whole (integer) numbers in each iteration. In these analyses, the contributions of all plots to the average trend estimate were equally weighted. Similarly, because there is no information regarding the degree of spatial correlation that may exist among sampling areas, I used a standard deviation for "trend variation" of zero. All simulations were run for a 10-year period (including the initial year). Each simulation calculated power estimates, expressed as the number of trials in which $5 \%$ population declines were detected divided by the total number of trials run.

I used empirical data on gnatcatcher population variability as the basis for all simulations. On the Palos Verdes Peninsula, gnatcatcher numbers have varied from 26-56 pairs during $1993-1996(\mathrm{x}=42.25$, s.d. $=13.77)$ (Atwood et al. 1997). For the simulations performed here, I used the coefficient of variation from the Palos Verdes data to calculate a comparable standard deviation (s.d. $=3.3$ ) for an arbitrary initial sample size of 10 pairs per study plot. This index of variability "determines how much 'noise' will be present in the simulated data" (Gibbs 1995). Other important variables that were altered in different simula-

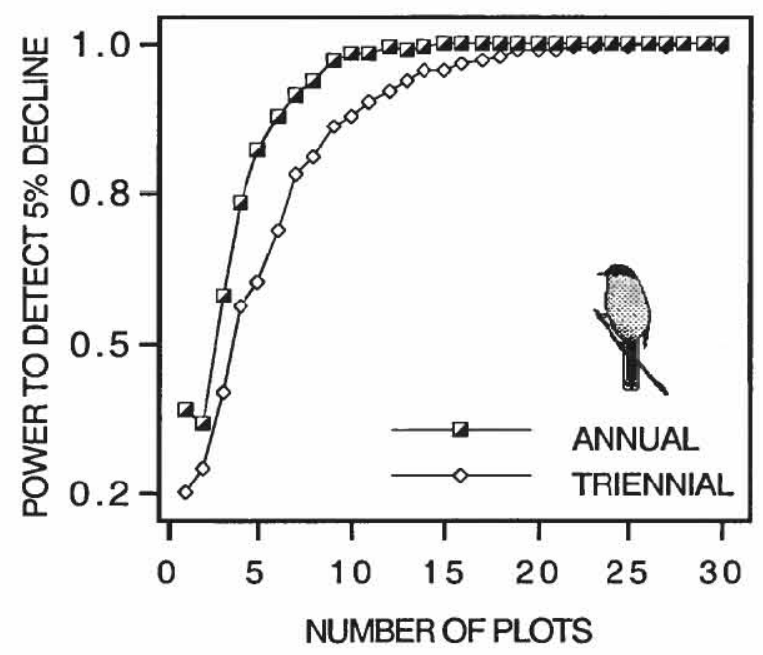

Figure 2. Influence of number of sample plots on ability to detect 5\% declines based on Annual and Triennial surveys of California gnatcatcher population size. 
tions included (a) number of sample plots, and (b) survey frequency (annual vs. triennial).

As expected, the number of sample plots strongly influenced the ability of monitoring simulations to detect small (5\%) annual declines in population size, with at least 5 independent sites being necessary to obtain power values of $80 \%$ or greater (Fig. 2). Use of a triennial (every three years) vs annual monitoring scheme effectively detected 5\% declines as long as approximately 10 independent sampling units were included.

I also used MONITOR to examine two additional parameters that might be useful in monitoring California gnatcatcher population status: annual reproductive success and survivorship of breeding adults, again using field data obtained from the Palos Verdes Peninsula as the basis for all simulations. Mean reproductive success (number of fledglings produced per pair) varied from 2.62 3.89 from $1993-1996(x=2.98$, s.d. $=0.61, n=4)$, and adult survivorship rates varied from $0.19-0.52(x=0.395$, s.d. $=0.179, n=3$ ) (Atwood et al. 1997). Each simulation used 500 iterations, conducted at $\mathrm{P}=0.1$ for detection of a $5 \%$ decline in each variable being evaluated (pair counts, adult survivorship, and reproductive success). An annual sampling effort was simulated over a 10 -year period. MONITOR's rounding option was not implemented for reproductive success or adult survivorship. Number of study plots was varied from $1-30$.

Monitoring based on reproductive success, because this parameter was less variable than either pair counts or adult survivorship (coefficients of variation $=20.5,32.6$, and 45.3 , respectively), was most likely to successfully detect a small $(5 \%)$ decline over a 10 -year period with the fewest sampling plots (Fig. 3). However, simulations

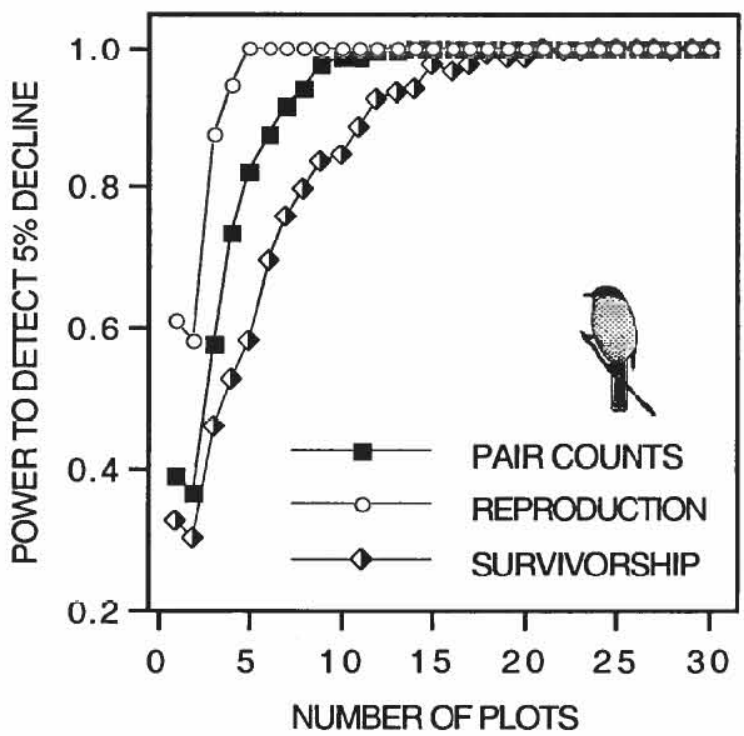

Figure 3. Detection of $5 \%$ declines in number of breeding pairs, reproductive success, and adult survivorship in simulated monitoring of California gnatcatchers. based on all three parameters yielded power estimates of at least $80 \%$ when 10 or more sample areas were included in the protocol.

\section{Discussion}

California's Natural Community Conservation Planning (NCCP) program is proactive, innovative, and widely portrayed as a national model for resolving conflicts between conservation and economic concerns ( $\mathrm{O}^{\prime}$ Connell and Johnson 1997). The program is also largely untested, and is now at a stage in its evolution where the need for scientific validation of approved or proposed conservation plans has never been greater.

NCCP has much greater objectives than simply conserving viable populations of California gnatcatchers. Nonetheless, because this species has been central in virtually all southern California NCCP planning decisions, and because compliance with federal recovery standards for the gnatcatcher represents a definite criterion by which NCCP plans are formally evaluated, it is not unreasonable to use gnatcatcher status as an important, albeit narrow, measure of the program's success. Successful implementation of the NCCP process should, presumably, provide for recovery of California gnatcatchers in the United States. Is this goal being realized? Is information being collected that will allow regulatory authorities to decide whether it is appropriate to remove the gnatcatcher from the federal List of Threatened and Endangered Species?

Most discussion about the gnatcatcher's status in southern California has revolved around estimates of the species' population size (Jones 1991; RECON 1991; Atwood 1992; USFWS 1996). Large numbers of focused surveys have been required, on a project-by-project basis, throughout the southern California NCCP planning region since the early 1990's, and there is no doubt that information regarding the distribution of the species in the United States is much more complete than at the time of listing. Because of this recent emphasis on population size and distribution, it is perhaps not surprising that the most typical concept of how to use the gnatcatcher to evaluate the success of regional conservation planning has been to suggest additional survey work aimed at counting pairs. Whether for purposes of comparison with a past, baseline population size, or as a means for assessing population trend, counting of gnatcatcher pairs seems to have become an almost de facto method for evaluating the species' status, and, perhaps more importantly, success of the NCCP.

This analysis lends tentative support to monitoring programs that focus on using pair counts to assess population trends, with the important caveat that these efforts must be of adequate scope to address the geographic and ecological diversity found within each NCCP planning area. The MSCP monitoring scheme includes approxi- 
mately 30 sampling localities, approximately 81 ha each, spread over a reserve system that will ultimately encompass approximately 66,000 ha. The Orange County Central/Coastal NCCP plan, which establishes a reserve system composed of two isolated units that together total approximately 15,000 ha, will attempt to monitor gnatcatcher populations based on six sampling areas of approximately 40 ha each. Given the relatively high level of annual variability in gnatcatcher population sizes that has been documented to date (Atwood et al. 1997; Ogden Environmental and Energy Services 1992), plus the likely possibility of differences in parameters affecting population size among various monitoring sites established within a single NCCP reserve, it is possible that monitoring associated with neither the Orange County Central/Coastal NCCP plan or the MSCP plan will effectively detect small, annual declines in gnatcatcher numbers. On the other hand, as additional information about gnatcatcher population variability becomes available, both efforts may prove perfectly adequate to determine if gnatcatchers are being effectively protected by the NCCP reserve system.

Creating a suitable monitoring protocol must, obviously, incorporate not only available biological information about the species of concern but also a recognition of logistic and financial limitations. Although studies of a relatively stable parameter such as reproductive success are most likely to detect small annual declines that might ultimately cause the population to crash, such detailed, focused research is labor-intensive and, consequently, financially costly. And, although I consider potential threats to California gnatcatcher reproductive success as the most likely focus of conservation concern for the species, and therefore the parameter that $\mathrm{I}$ believe is most important to monitor, it is impossible at this time to rule out other more subtle effects on population dynamics that might also be critical to study (Akçakaya and Atwood 1997). For example, investigation of factors affecting survivorship and juvenile dispersal behavior may eventually prove necessary in order to understand California gnatcatcher population dynamics. Given these various uncertainties, monitoring based on repeated counts of breeding pairs, if nothing else, has the advantage of simultaneously reflecting the influence of all parameters that might contribute to overall population trends.

The greatest difficulty with using pair counts as a means of evaluating the gnatcatcher's status is simply that if a population decline were detected, reserve managers and regulatory authorities would have no immediate way to know what factor was causing such a trend. By the time that new research aimed at understanding the cause(s) of the decline had been initiated and completed, the population may have dwindled to the point that corrective measures in reserve design or habitat management would be impossible or impractical.

Because research funding is always limited, it only seems prudent to encourage a dual focus to any studies of
California gnatcatchers within the NCCP planning region. Wherever possible, simple censuses of breeding pairs should be augmented by focused studies of reproductive success, survivorship, and dispersal, and efforts should especially be taken to maintain existing long-term studies located in southern California. Unless this approach is taken, regulators and policy makers 10 years from now may be faced with the embarrassing possibility that, despite thousands of hours and millions of dollars spent toward planning efforts, still no one is sure if the NCCP's flagship species has been successfully conserved - or if it is declining, what to do about the problem.

Acknowledgments. I am grateful for the assistance of my outstanding research team, and for their many important contributions to coastal sage scrub conservation efforts on the Palos Verdes Peninsula and elsewhere. Pat Mock and Mike Fugagli provided useful comments on an initial draft of this manuscript. Financial support was provided by the U.S. Navy (Dawn Lawson), Southern California Edison (John Palmer), National Fish and Wildlife Foundation, Homeland Foundation, Ed Almanza and Associates, and the trustees and members of Manomet Center for Conservation Sciences.

\section{Literature Cited}

Akçakaya, H. R., and J. L. Atwood. 1997. A habitat-based metapopulation model of the California gnatcatcher. Conservation Biology 11:422-434.

Atwood, J. L. 1992. A maximum estimate of the California gnatcatcher's population size in the United States. Western Birds 23:1-9.

Atwood, J. L. 1993. California gnatcatchers and coastal sage scrub: the biological basis for endangered species listing. Pp. 149-169 in J. E. Keeley, ed. Interface between ecology and land development in California. Southern California Academy Sciences, Los Angeles, CA.

Atwood, J. L., M. R. Fugagli, C. H. Reynolds, J. C. Luttrell, and S. H. Tsai. 1997. Distribution, dispersal, and population dynamics of California gnatcatchers on the Palos Verdes Peninsula, 1993-1995. CalGnat Proceedings, submitted.

Atwood, J. L., and R. F. Noss. 1994. Gnatcatchers and development: a "train wreck" avoided? Illahee 10:123-132.

Atwood, J. L., S. H. Tsai, and A. M. L. Miller. 1996. California gnatcatchers, cactus wrens, and conservation of coastal sage scrub on the Palos Verdes Peninsula. Progress Report No. 4 (1996). Unpublished report, Manomet Observatory for Conservation Sciences, Manomet, MA. 15 p. + appendices.

Bontrager, D. R., A. L. Gorospe, and D. K. Kamada. 1995. 1995 breeding biology of the California gnatcatcher in the San Joaquin Hills, Orange County, California. Unpublished report no. SP-95-04, The Superpark Project, Laguna Beach, CA. 
Braden, G., and S. Powell. 1994. Draft report: Nesting biology of the California gnatcatcher (Polioptila californica californica) in western Riverside County. Unpublished report, prepared for Southwestern Riverside County Multi-species Reserve Management Committee and The Metropolitan Water District; January 1994.

California Department of Fish and Game and California Resources Agency. 1993. Southern California coastal sage scrub: Natural Community Conservation Planning conservation guidelines. Unpublished report, California Department of Fish and Game, Sacramento, California. 19 p.

DeSimone, P. and D. Silver. 1993. The Natural Community Conservation Plan: Can it protect coastal sage scrub? Fremontia 23:32-36.

Gibbs, J. P. 1995. Monitor: Software for estimating the power of population monitoring programs to detect trends in plant or animal abundance. Version 6.2. Prepared for Department of Biology, Yale University. April 15, 1995.

Jones, H. L. 1991. A rangewide assessment of the California gnatcatcher (Polioptila californica). Unpublished report, prepared for Building Industry Assoc. of Southern California, Santa Ana, CA.

Neely, T. 1997. Solicitation of bids for target species survey sampling and monitoring. The Nature Reserve of Orange County; Santa Ana, CA. 6 p.

Noss, R. F. 1991. From endangered species to biodiversity. Pp. 227-246, in K. Kohm, ed. Balancing on the brink of extinction: the Endangered Species Act and lessons for the future. Island Press; Washington, D.C.

O'Connell, M. A. and S. P. Johnson. 1997. Improving habitat conservation planning: the California natural community conservation model. Endangered Species Update 14:1-3,14.

Ogden Environmental and Energy Services. 1992. Unpublished job report: Ecology of the California gnatcatcher at Rancho San Diegn. Prepared for Home Capital Development Corporation, San Diego, CA; December 1992.
Ogden Environmental and Energy Services. 1996. Biological monitoring plan for the Multiple Species Conservation Program. Project No. 110921000. Unpublished report, prepared for City of San Diego, California Department of Fish and Game, and U.S. Fish and Wildlife Service. Revised April 23, 1996.

RECON. 1991. Distribution and population estimates of the California gnatcatcher (Polioptila californica) in Baja California, Mexico. Number 2168C. Unpublished report, prepared for Building Industry Associates of Southern California. June 26, 1991.

Reid, T. S. and D. D. Murphy. 1995. Providing a regional context for local conservation action. BioScience Supplement, Science and Biodiversity Policy S-84 - S90.

Reynolds, J. R. 1993. Singing on the brink: can a songbird save our southern coast? Land Use Forum (Summer 1993). Continuing Education of the Bar, Berkeley, CA.

USFWS. 1993a. Endangered and threatened wildlife and plants; Special Rule concerning take of the threatened coastal California gnatcatcher. Final rule. Federal Register 58:6508865096.

USFWS. 1993b. Endangered and threatened wildlife and plants; Threatened coastal California gnatcatcher; Final Rule and Proposed Special Rule. Federal Register 58:16742-16753.

USFWS. 1996. Reinitiation of formal consultation on implementation of the Special Rule for the coastal California gnatcatcher (1-6-93-FW-37R1). Unpublished report, prepared for USFWS, California State Supervisor, Sacramento, CA. October 18, 1996.

USFWS. 1997. Coastal California gnatcatcher (Polioptila californica californica) presence/absence survey guidelines. Unpublished report, prepared for USFWS Carlsbad Field Office. February 28, 1997. 


\title{
Transferable Credit Programs as Land Preservation Tools in the Santa Monica Mountains National Recreation Area
}

\author{
Bryan D. Stumpf \\ Monroe County Planning Department, Courthouse Room 306, Bloomington, IN 47404 \\ Tel. (812) 349-2560; Fax (812) 349-2967
}

\begin{abstract}
High land values and increased competition for funding has made money for land acquisition scarce. The National Park Service is searching for other land use tools to accomplish its land preservation goals in the highly fragmented Santa Monica Mountains National Recreation Area. This project focused on two regulatory market programs that preserve environmentally sensitive lands: transferable development credits and conservation banking. The results of the study indicate that a combination of the two programs would be the most successful in reaching the preservation goals within the study area. A voluntary transferable development credits program would successfully reduce the number of inholdings within the National Recreation Area boundary and focus development in areas more appropriate for higher intensity use. Conservation banking would successfully provide rapid protection to areas containing significant habitat resources in need of immediate attention.
\end{abstract}

Keywords: Conservation banks; habitat fragmentation; habitat linkages; inholding reduction; land preservation; National Park Service; Santa Monica Mountains; transferable development credits.

\section{Introduction}

Unlike other lands managed by the National Park Service, such as Yosemite or Yellowstone, the Santa Monica Mountains National Recreation Area is a young park established after many land development activities had begun. As a result, the area within the National Recreation Area boundary is extremely fragmented. As development pressures in the region continue to increase, development within the National Recreation Area boundary threatens to impact or destroy significant ecological habitat and sever important habitat linkages (USDI National Park Service 1984; Yelin 1995).

The Santa Monica Mountains are one of the few eastwest trending mountain ranges in North America. The range averages $12 \mathrm{~km}$ ( 7 miles) in width and is approximately $75 \mathrm{~km}$ ( 45 miles) in length. At its eastern end, the mountains bisect the Los Angeles metropolitan area. The complex topography includes steep north-south oriented canyons between mountain slopes that rise abruptly from the coastline. Mountain peaks often reach altitudes over $600 \mathrm{~m}$ (2000 feet). Twenty-six different natural communities are found in the mountains' south coast mediterranean ecosystem. The wildlife living in these communities are equally abundant and diverse. Many of the species and communities in the Santa Monica Mountains are identified as ecologically significant by local, regional, state, and federal agencies. Eighteen species of federal or state listed endangered or threatened species occur in the mountains.

The Santa Monica Mountains National Recreation Area boundary encompasses 60,700 hectares $(50,000$ acres). The larger Santa Monica Mountains zone that encompasses all of the mountains and its watersheds covers 91,100 ha $(225,000$ acres). The National Park Service owns approximately 8,500 ha (21,000 acres) of this land, all within the National Recreation Area boundary.

In the Santa Monica Mountains National Recreation Area, over half of the land is privately owned. Of this land, it is estimated that only one-fourth has been developed. Meanwhile, development pressures continue providing the greatest threat to resource protection in the Santa Monica Mountains.

In addition to its physical and ecological complexity, providing comprehensive management of the area is difficult due to interagency complexity (Wiechec 1995). Over 20 public agencies from the local to federal level own land within the Santa Monica Mountains National Recreation Area. Adding in the thousands of private land owners makes maintaining the ecological integrity and recreation opportunities of the area a daunting task.

To test the applicability of a transferable development credits or conservation banking program to the Santa Monica Mountains, a study area within the federally-designated Santa Monica Mountains Zone was selected. The 2448 ha $(6,047$ acre) study area is bounded on the south 
by the coastal zone boundary, on the west by Mulholland Highway and Kanan Road, on the north by the Ventura Freeway, and on the east by the Agoura Hills City Limit extended southward (Planning Network 1993). The study area was selected because it typifies the conditions and issues found throughout the Santa Monica Mountains National Recreation Area; a strong threat of development putting significant habitat areas and recreation opportunities at risk.

\section{Existing land uses}

Figure 1 indicates the existing land uses within the study area (County of Venture 1994a, 1994b, 1995). As with other areas in the Santa Monica Mountains, land within the study area faces a high threat of development. The Southern California Association of Governments (1995), the area's regional planning body, has projected growth trends for the area in the Growth Management chapter of the Regional Comprehensive Plan and Guide published in May 1995.

The 1990 census indicates that the cities of Agoura Hills and Westlake Village had a population of 138,000 with approximately 52,000 housing units (Southern California Association of Governments 1990). Based on projections by the Southern California Association of Gov- ernments, in 2010 these two cities will have a population of 225,000 with approximately 80,000 housing units. Assuming the current development trend, by 2010 the physical size of the developed portion of the region could be up to $33 \%$ larger than its current size. This additional growth will consume a large portion of the remaining private land in the region. Vacant lands in outlying areas, currently perceived as open space, will come under significant development pressures.

Regarding the study area specifically, the projections indicate increased urban build-up along the Ventura Freeway corridor and interior highways. The Existing Land Use Map (Fig. 1) indicates the current land use designations within the study area. Note the increased zoning densities along the Ventura Freeway and on Mulholland Highway near Malibu Lake.

These two roads create distinct problems for habitat preservation. The Ventura Freeway creates a hard, highly impassable edge that separates the Santa Monica Mountains from the Simi Hills to the north. This is an important connection because the Simi Hills provide a bridge from the Santa Monica Mountains to the Santa Susanna Mountains and Los Padres National Forest. Land values and development potential are high in areas flanking the freeway. The key issue for areas adjoining the freeway is retaining the few regional wildlife habitat linkages.

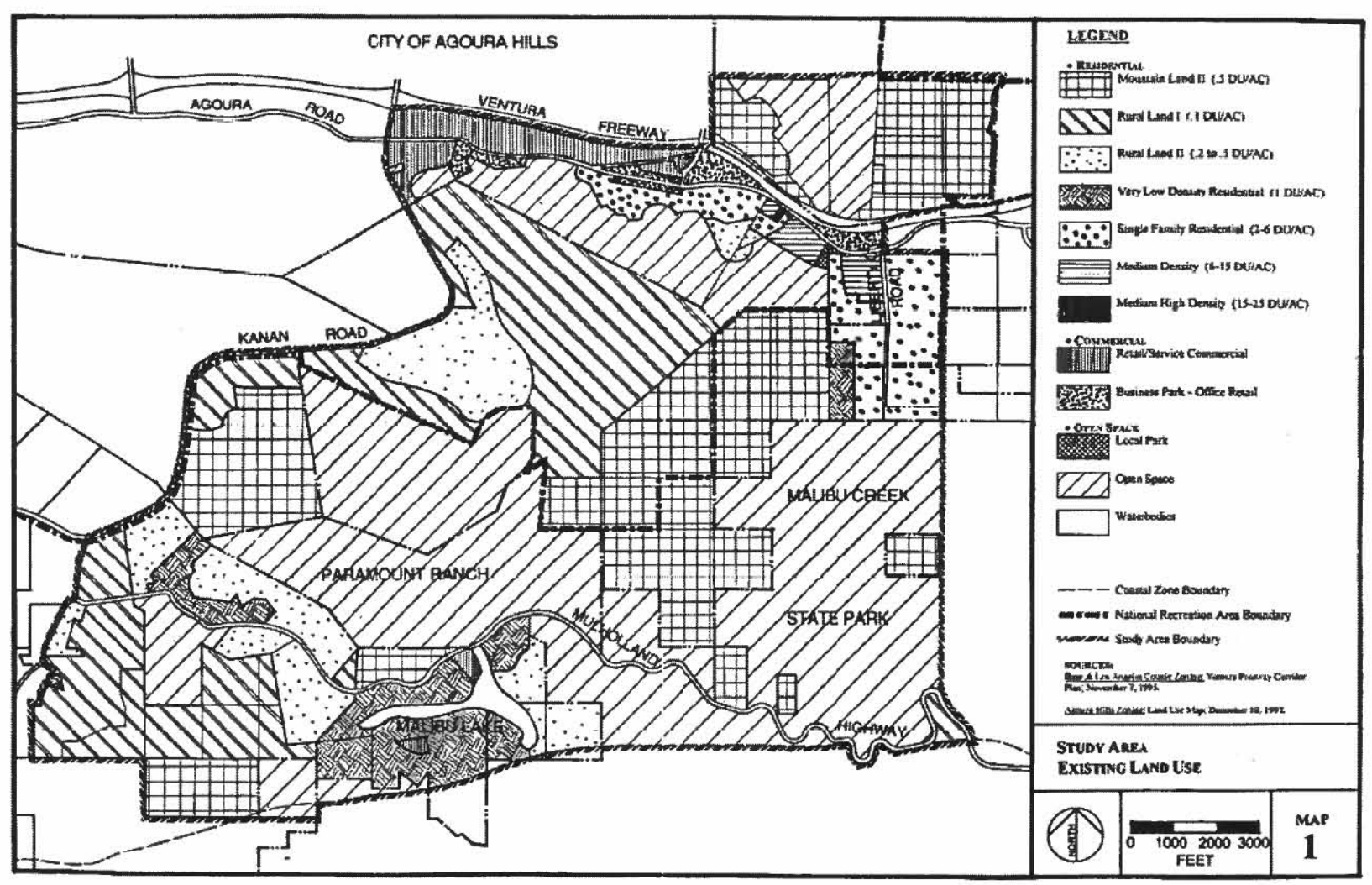

Figure 1. Exisiting land uses within the study area in the Santa Monica Mountains 
Mulholland Highway, which follows the spine of the Santa Monica Mountains, creates a different type of problem. It provides access to many small residential lots. These "mountain estates" are typically five-acre lots with high development potential. While buildout of an individual lot has little significant impact on the mountains, the aggregate buildout of a substantial number of mountain estate lots will bifurcate the park's habitat.

Contained within the study area are two significant habitat areas designated by the National Park Service. The Liberty Canyon linkage connects Malibu Creek State Park located south of the freeway with Palo Comado and Cheeseboro Canyons (National Park Service protected land north of the freeway). This linkage is one of two primary habitat linkages remaining along the Ventura Freeway corridor.

The National Park Service has designated a Special Natural Area covering a large portion of Malibu Creek State Park and extending into the private land to the north. The area contains resources that represent sensitive, vital, or critical components of the existing environment. The area includes habitat of rare, endangered, or threatened plant and animal species, biotic resources that are of scientific interest because they exist at an extreme physical or geographical limitation, or habitat that provides for the preservation of relatively undisturbed examples of natural biotic communities in Los Angeles County.

The study area also contains recreation opportunities that help meet the increased demand for recreation in Los Angeles County. The additional growth projected for the area places further strain on the capacity of the existing parks and public campgrounds, many of which are already showing signs of overuse. The gap between demand and services provided will continue to grow as the population increases.

The study area contains hiking and equestrian trials, as well as bicycle routes that are part of a regional network weaving through the Santa Monica Mountains. The study area also contains Paramount Ranch, a National Park Service operated area containing hiking trails, a western town movie set, picnic areas, a ranger station, and other facilities. Paramount Ranch is typical of the park's more active recreation sites.

\section{Desired land protection}

Figure 2 indicates the desired land protection within the study area. This map is based upon the National Park Service's Santa Monica Mountains Land Protection Plan Map and the research that accompanies the plan. In areas

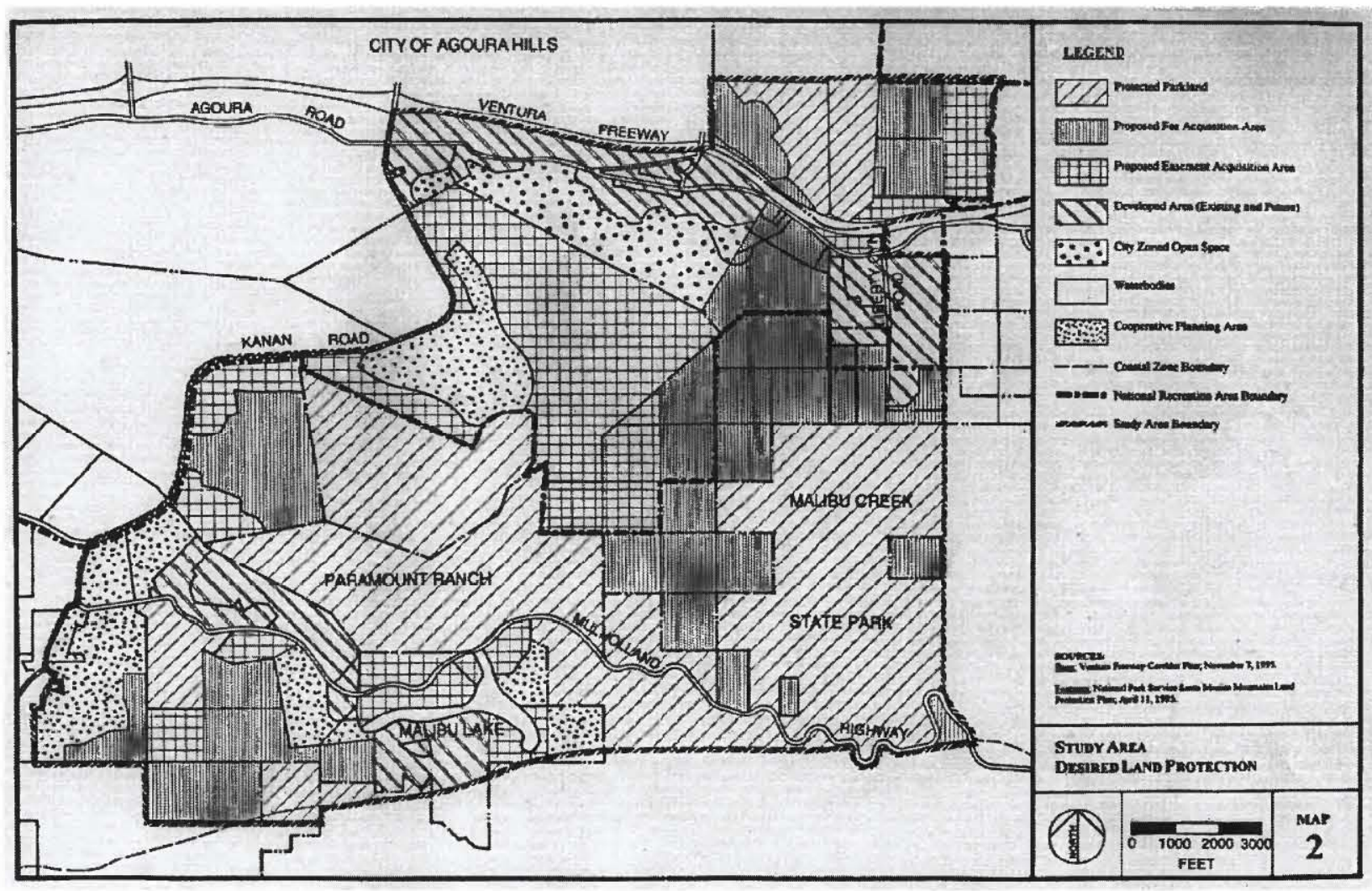

Figure 2. Desire land protection within the study area in the Santa Monica Mountains. 
slated for acquisition, a distinction is made between fee and easement acquisition. Fee acquisition is done when other methods of protection are inadequate, ineffective, or inefficient to meet management goals. The Land Protection Plan specifies the limited conditions under which fee acquisition is used by the National Park Service.

Easement acquisition ensures that the rural character of the mountains is preserved while allowing private uses of land to continue. Two types of easements are used by the National Park Service: conservation easements and right-of-way easements. A conservation easement is a legal agreement a property owner makes to restrict the type and amount of development that may take place on the property. Each easement's restrictions are tailored to the particular property and the interests of the individual owner. The National Park Service uses conservation easements to reduce the level of development near park boundaries and to protect significant habitat areas on private land. Conservation easements do not allow public use of the land unless requested by the owner. Right-of-way easements are used to create trail connections that cross private land. As inferred by their purpose, right-of-way easements allow public access across private property along a narrow corridor.

Despite what is shown on the Desired Land Protection Map (Fig. 2), the limited resources available for fee acquisition do not make this option very feasible. It was this ineffectiveness that encouraged the National Park Service to look at regulatory market programs for alternatives (e.g., City of San Diego 1994; California Department of Fish and Game 1995). The key question of the study was "What alternative programs to fee acquisition best provide the land protection desired in the Santa Monica Mountains?" To determine the extent and areas of coverage for the case study programs, four variables were applied to each of the zoning areas: threat of development, connectivity to protected land, acquisition and maintenance costs, and recreation opportunities.

\section{Transferable Development Credits}

Transferable development credits are part of a density transfer program that provides resource protection by transferring the development potential from a sending site where a resource to be protected is located to a receiving site more appropriate for accommodating new development (Tietenberg 1992). This program benefits the community by helping reach resource preservation goals with little or no expenditure (Roddewig and Ingham 1997). The program also provides property owners with compensation for restrictions on development within sending sites. Communities are usually hesitant to apply heavy restrictions on private property without providing compensation through public funding. This is one reason why the Ex- isting Land Use Map (Fig. 1) and the Desired Land Protection Map (Fig. 2) do not look the same.

Land use restrictions or physical site constraints usually make it difficult to attain the maximum economic use of sending sites. Transferable development credits allow these property owners to obtain some or all economic return that would have occurred from developing the sending site.

On the other end of the transfer, owners of receiving sites can increase their economic return through additional development on their property. Developers will continue to purchase credits as long as the marginal profit from higher density development is greater than the cost of acquiring the additional development credits.

This program is successful when it allows communities to adopt the land use regulations needed to preserve important community resources while providing property owners and developers the opportunity to build additional development on receiving sites that yield at least as much economic return as the opportunity to develop the sending site (Pruetz 1993).

There are two main types of transferable development programs: mandatory and voluntary. A mandatory program is highly restrictive and prohibits development on the sending site whether or not transfers occur. A voluntary program is non-restrictive with few or no restrictions on the sending site. Property owners in a voluntary program can decide to develop on the sending site or transfer the development credits elsewhere. Most of the transferable development credits programs established in the United States fall somewhere between these two extremes based on the level of community support for the resource that the program strives to protect (Pruetz 1993).

The development restrictions on sending sites are a key factor to determining the degree to which the goals of the transferable development credits program are achieved. The locations of receiving sites play an important role because they create the community connection to the program, a necessity for generating public support for the program.

The overall success of the program depends on the demand for additional development on receiving sites and the ability to achieve that density primarily using transferable development credits. If the demand for additional development at the receiving site can be met in a manner cheaper or faster than using credits, developers have little incentive to purchase them. Also, if the receiving site zoning allows higher densities than desired by developers, they will not need transferable development credits for their projects.

\section{Program elements}

The elements of a transferable development credit program fall into one of two categories: implementation tools or program management issues. Implementation tools are 
incentives designed within the transferable development credit program to encourage its use. Transfer ratios, requirement exemptions, and transferable development credit banks are the most common implementation tools found in transferable development credit programs.

Transfer ratios encourage use of credits by assuring receiving site developers that they can make at least as much profit from development at the higher density allowed by the transfer, even after paying for the credits that made the higher density possible. The ratio should be set higher than the break-even point, the point at which the ratio generates the same profit using credits as a developer would receive for developing the receiving site at its currently allowed density without using them. According to Pruetz (1993), there are three main factors to consider when determining the transfer ratio:

1. Characteristics of the sending site. If the sending site contains many small parcels under separate ownership, then a high transfer ratio may be needed to motivate property owners to use credits.

2. Effectiveness of other elements of the program. If other parts of the program are working successfully, a high transfer ratio is not as important to a project.
3. Community commitment to the program. If a community is supportive of a program's goals, it will want a program that maximizes transfer activity.

Exemptions from requirements are another common incentive. These exemptions may include waivers from fees or other development requirements, such as building permit caps. Exemptions should streamline the approval process to make credits an attractive alternative to the standard approval process.

The most important tool is the transferable development credit bank. A bank purchases credits from sending sites and holds them until a developer buys them in order to build on a receiving site. A bank facilitates transfers by eliminating the need for buyers and sellers to find each other and participate in case-by-case negotiations. The bank also makes the process more effective by providing certainty and speed to developers, influencing credit prices, and providing transaction services.

The bank's ability to influence and stabilize prices is important. If the price of credits is too high, receiving site developers will not purchase them. Conversely, if the price is too low, sending site owners will not be motivated to sell credits. By controlling the amount of cred-

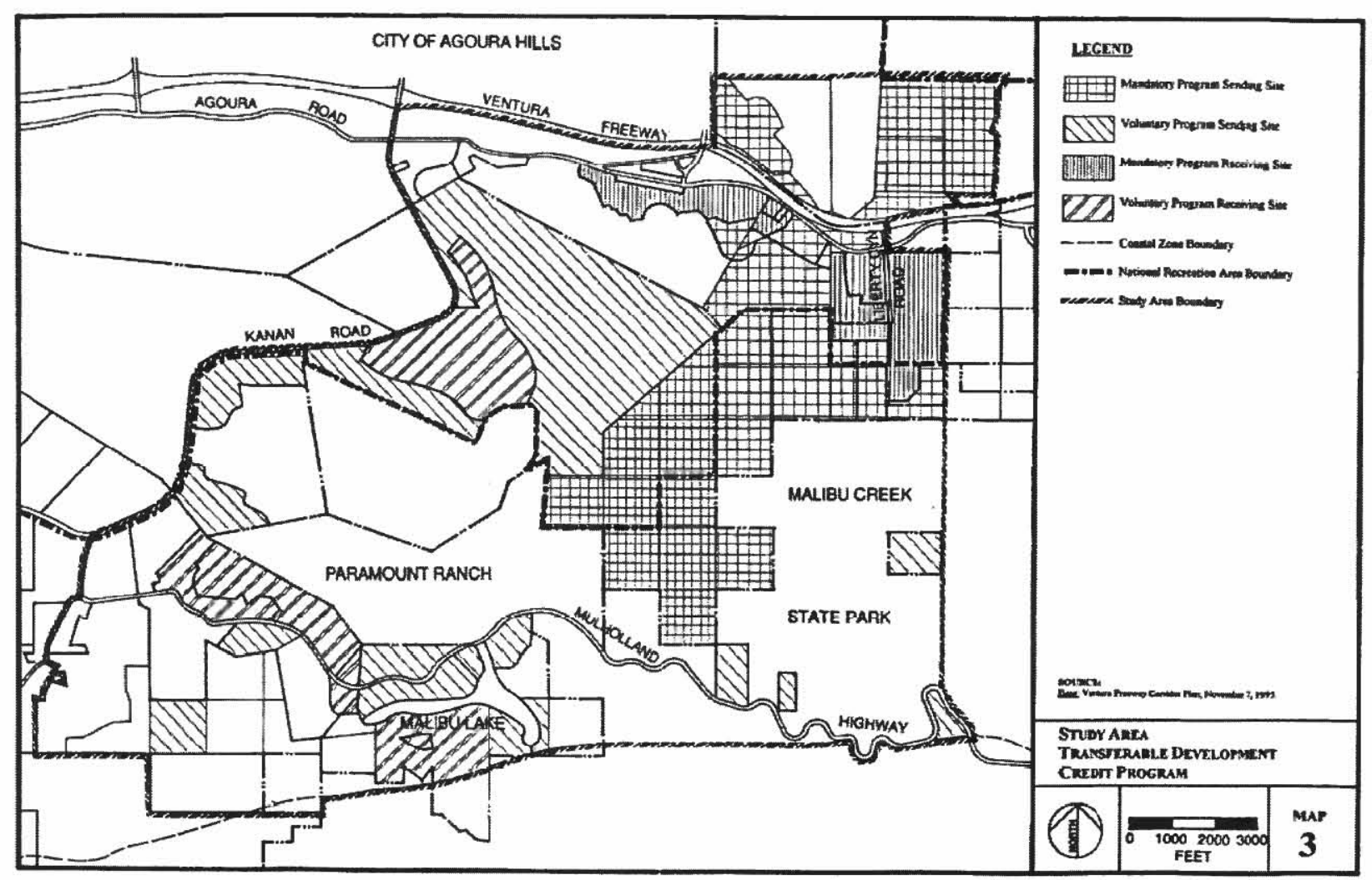

Figure 3. Possible voluntary and mandatory transferable credit programs in the Santa Monica Mountains Study area. Sending sites are credits purchased and held by a bank i order to build on a receiving site. 
its, a bank influences their price. Without stable prices, developers have a difficult time determining the cost-revcnuc flows of proposed projects.

A bank also provides important transaction services. If they think they will get no assistance, developers and property owners will avoid the transferable development credit process. A bank can provide assistance in the process, educate the public about the program, and promote the use of credits.

Program management issues comprise the other elements of the program. The proper program management requires substantial commitment and continuing support through assistance to the development community, public education, and monitoring of the program with a devotion to make necessary improvements.

Assistance to the development community increases transfer activity. A program that emphasizes cooperation with developers and property owners, involves them in the design of the program, encourages their use of it, and provides assistance through the process will generate more transfers.

Public education and involvement is important to achieving the ultimate resource protection goals. Public input helps develop and promote the program while the discussion can generate support for the protection of resources.

Finally, these programs are complex and require review on a regular basis to refine and improve the program. Periodic review may also reveal that other techniques are better suited to achieving the community's goals.

\section{Application of these programs to the study area}

Figure 3 depicts how a transferable development credit program could be established within the study area. Two levels of sending and receiving sites are depicted on the map. This gradation reflects the habitat significance of certain areas and provides flexibility for the proposed program. A mandatory program was used to protect the habitat linkage at Liberty Canyon and the significant habitat area north of Malibu Creek State Park. Due to the regional importance of this linkage, no future development should be allowed along the linkage that would have an adverse impact on motion along the corridor. The mandatory program forces the development to occur elsewhere.

The goal of the voluntary program is to reduce the number of inholdings within the National Recreation Area boundary. Limited development on the sending sites will occur, but at a lower density than if the program did not exist. Sending sites of this zone cover only areas designated as easement acquisition areas on the Desired Land Protection Map (Fig. 2). Areas that were designated for fee acquisition were not included due to their likelihood of containing significant habitat that would be in conflict with limited development.

Using a credit program similar to the California Coastal Commission's program where transfers are required to build new residential units, the study area contains enough potential sending and receiving sites for both the mandatory and voluntary programs. However, the level of community support and the legal mandate for protection of land within the National Recreation Area boundary is not as strong as the area around Malibu where the Coastal Commission's program operates. Therefore, it is likely that a standard program that encourages transfers through the use of density bonuses would be used within the study area. Using this type of program, there are not enough receiving sites within the study area. The amount of receiving sites along the Ventura Freeway corridor would need to be increased. However, the additional receiving sites would need to be close to the study area to retain a rational relationship between the sending sites and receiving sites.

\section{Conservation Banking}

Environmental laws, such as the Federal Endangered Species Act, the California Environmental Quality Act, and the California Endangered Species Act, that require mitigation for the impacts created by development have generated a need for methods to provide mitigation (California Environmental Protection Agency 1995). The mitigation measures used to satisfy these laws often have insufficient impact because they are undertaken at the same site as the development itself, require in-kind compensation, and do not address the broader conservation objectives of the project's region. When mandated on a projectby-project basis, mitigation is often burdensome and costly to landowners. Determining the application of state and federal laws and the specific mitigation requirements that apply to a project can be very difficult. The cumulative total of the mitigation requirements may be extremely expensive. The process of designing new mitigation projects for each development project can also be time consuming and costly. Most commercial and residential developers do not have the expertise nor willingness to make the best mitigation area they can. Mitigation is simply another element they must comply with to receive approval of their project.

Conservation banking provides a means to further regional habitat conservation goals in a manner not permitted by traditional on-site mitigation practices. A conservation bank is a single parcel, or a series of contiguous or noncontiguous parcels, of habitat that is managed for its natural resource values. The resource benefits are sold as "credits" to project proponents who seek mitigation opportunities to compensate for resource impacts elsewhere (California Environmental Protection Agency 1995). 
Conservation banking rewards the bank owner for the quality of habitat present on the site. It creates a strong financial incentive to maximize the habitat quality of the property. The higher the habitat quality, the more credits and subsequent revenue generated from the sale of credits can be made.

Conservation banking plays an important role in the Natural Communities Conservation Planning program (NCCP), a program designed to conserve multiple species and their habitat while providing for the utilization of private land. The program seeks to reconcile the demands of resource conservation and economic development through ecosystem management. The goal of NCCP is to conserve in reserves large enough to ensure their existence in perpetuity, plants and animals native to California and, importantly, the habitats on which they depend.

Any individual or entity, public or private, can establish a conservation bank. The bank must posses land determined by authorized resource agencies to meet the following criteria: the land contains substantial regional habitat value; it is in need of preservation or restoration; and it is worthy of permanent protection.

Credit generation is based on habitat acreage, habitat quality, the contribution to the regional conservation strat- egy approved by the appropriate regulatory agencies, or any other basis acceptable to the regulatory agencies. Credits may be sold prior to the realization of the targeted resource value of the bank in accordance with the agreed upon performance criteria for the development of resource value. This gives the bank owner the opportunity to make improvements to the bank, raise the quality of the habitat it contains, and possibly generate more credits from restored habitat areas. Property owners can sell credits or apply credits against any multi-species mitigation applicable to other properties within the credit area. The bank owner has the exclusive right to determine the price of any and all credits offered for sale or transfer.

After all credits are sold, the property owner must execute a grant deed naming the state as grantee and place a conservation easement over the entire site. The conservation easement prohibits future development of the site, including building construction, clearing, grubbing, grading, or disturbance of natural vegetation.

\section{Conservation banking program elements}

As is the case with transferable development credit programs, the transfer ratio plays an important role in the operation of a conservation banking program. Credits are

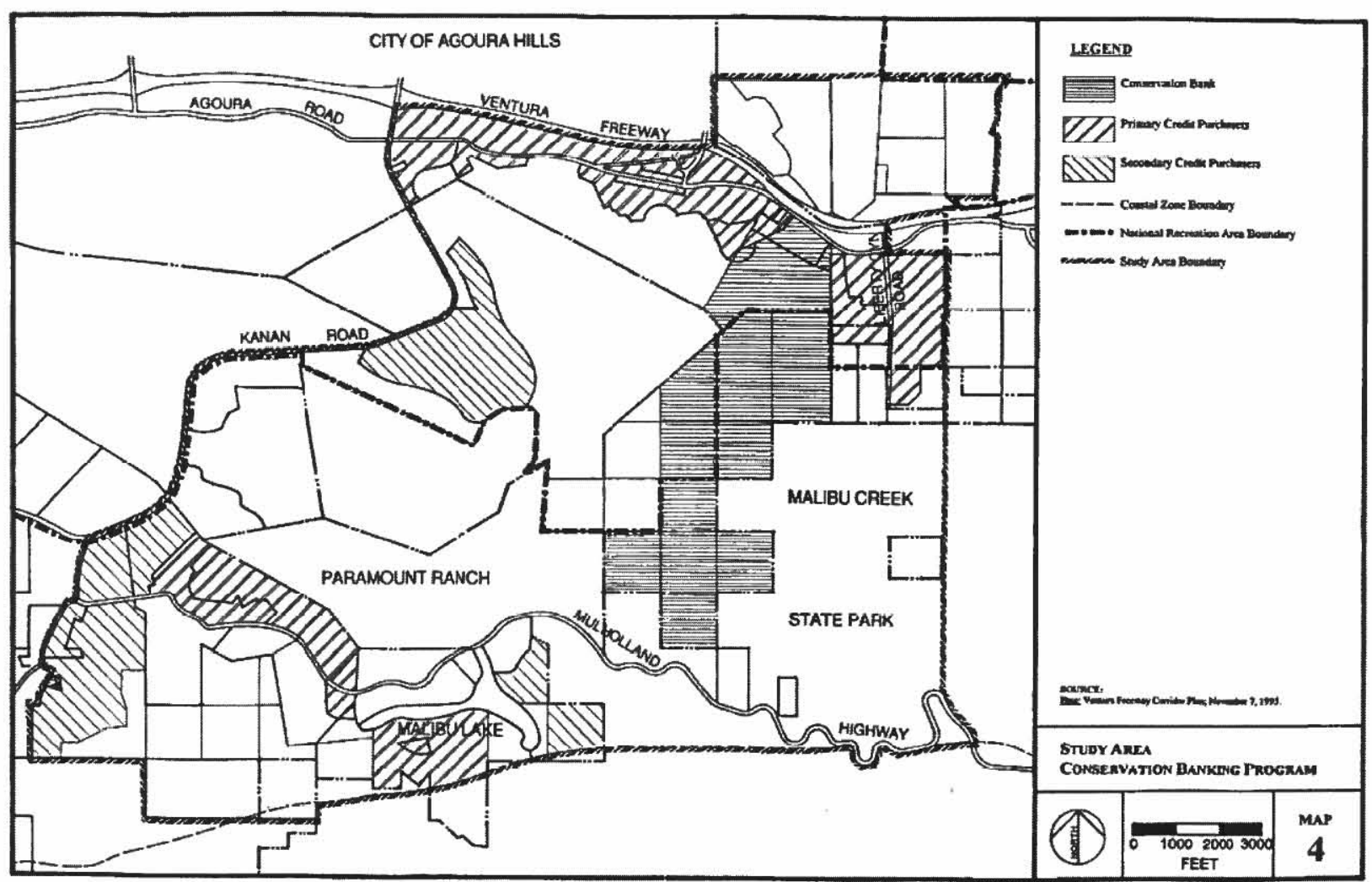

Figure 4. Possible conservation banking program in the Santa Monica Mountains study site. Primary credits are in areas planned for development and secondary credits are areas where development may occur. 
typically generated on a 1:1 ratio, one hectare of land within a conservation bank equals one hectare of multispecies mitigation. Credits cannot be generated from land that resource agencies specifically determine have a highly unique occurrence of certain species or habitats. These areas must be protected. The transfer ratio may change based on whether the mitigation is in-kind or out-of-kind. Out-of-kind mitigation may have a higher ratio as a deterrent to prevent too much loss of a specific habitat type. Some out-of-kind mitigation may be at the same ratio of in-kind mitigation if a regional conservation program encourages the protection of a specific natural resource priority. A higher ratio may be used for land that would be difficult to develop. This prevents overvaluation and the generation of credits from land that is not likely to be developed.

To use credits, the affected areas that are in need of mitigation must have lower or equivalent habitat value than the habitat contained on the bank property.

Management and endowment funds are critical to establish the bank in perpetuity. Until a property owner has deposited a predetermined amount of money into a management/ endowment fund, all net proceeds from the sale of credits are given to the Board of Trustees for the conservation bank or an authorized third party manager with written notice to the resource agencies. Management deposits are used to pay for fencing and other current habitat management activities. The aggregate of the endowment deposits creates an endowment fund to be used to defray the costs of managing the conservation bank after all of the credits are sold. The property owner's sole obligation with respect to the management of the conservation bank is the obligation to make all of the management and endowment fund deposits.

\section{Application of conservation banking program to the study area}

Figure 4 illustrates how a conservation bank could be applied to the study area. The map designates two categories of credit purchasers. Primary credit purchasers are those located in areas planned for increased development that will likely require mitigation in order to develop. Secondary credit purchasers refers to a smaller group of zones in which development is not encouraged, but may occur with mitigation requirements.

The simplicity of the map reflects the relative geographic simplicity of conservation banking programs. The conservation bank covers significant habitat areas north of Malibu State Park and the critical wildlife habitat linkage at Liberty Canyon. The bank also provides a stron-

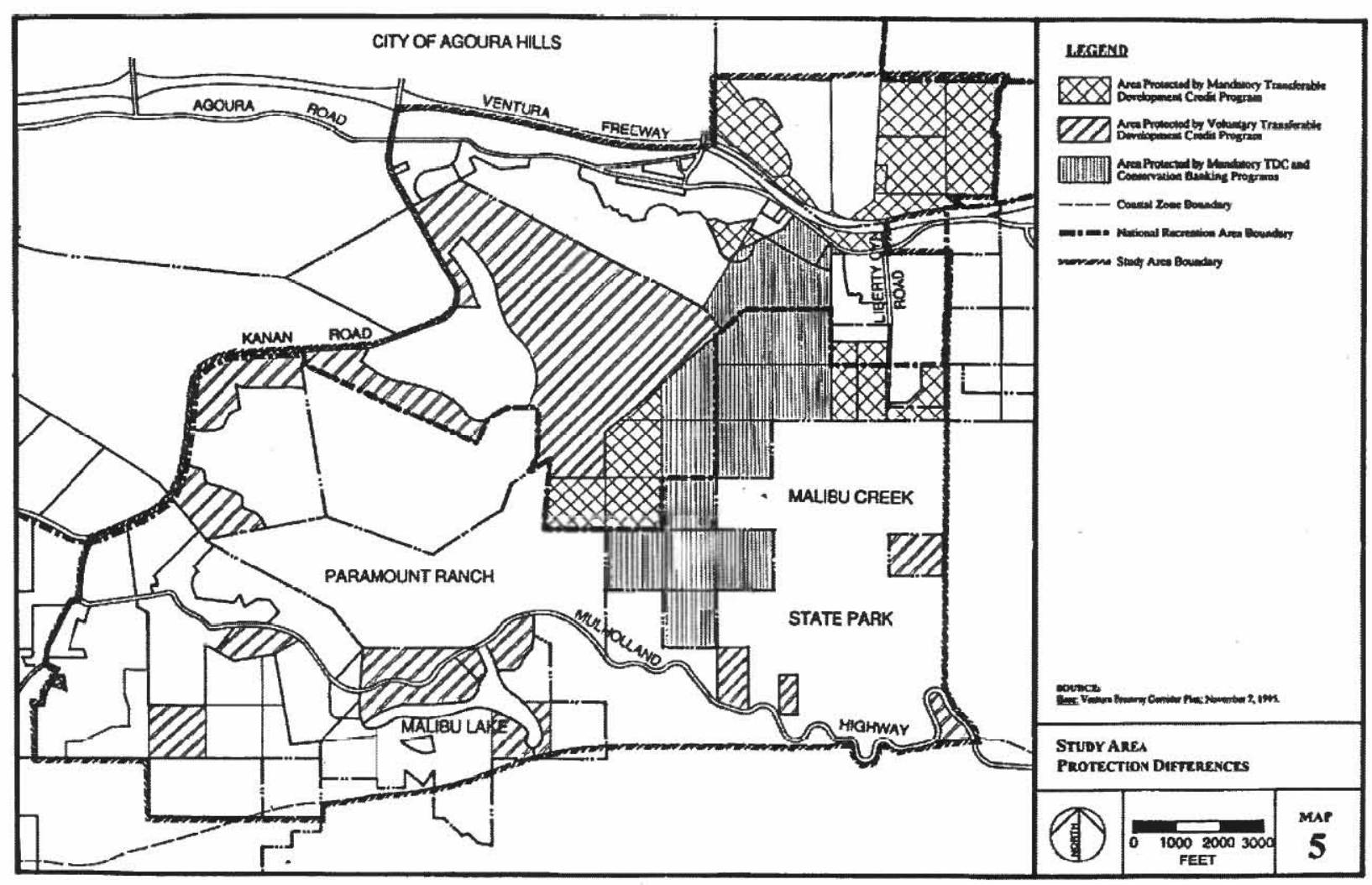

Figure 5. Comparison of transferable development credit programs and conservation banking, as applied to the Santa Monica Mountains study area. 
Table 1. Comparison of Programs

\begin{tabular}{|c|c|c|c|}
\hline & $\begin{array}{l}\text { Mandatory Transfer } \\
\text { Development Program }\end{array}$ & $\begin{array}{l}\text { Voluntary Transfer } \\
\text { Development Program }\end{array}$ & Conservation Banking \\
\hline \multicolumn{4}{|c|}{ Program Elements } \\
\hline Operation & $\begin{array}{c}\text { Preserves significant } \\
\text { habitat from development }\end{array}$ & $\begin{array}{l}\text { Redirects the } \\
\text { location of development }\end{array}$ & $\begin{array}{l}\text { Preserves significant } \\
\text { habitat from development }\end{array}$ \\
\hline Level of Protection & $\begin{array}{l}\text { Complete protection } \\
\text { of sending site }\end{array}$ & $\begin{array}{l}\text { Incomplete protection } \\
\text { of the sending site }\end{array}$ & $\begin{array}{l}\text { Complete protection } \\
\text { of the bank area }\end{array}$ \\
\hline Achievements & $\begin{array}{l}\text { Protects key parcels } \\
\text { of significant habitat }\end{array}$ & $\begin{array}{l}\text { Reduces or } \\
\text { removes inholdings }\end{array}$ & $\begin{array}{l}\text { Protects large areas } \\
\text { of significant habitat }\end{array}$ \\
\hline Scope & $\begin{array}{c}\text { Focuses on } \\
\text { many small parcels }\end{array}$ & $\begin{array}{c}\text { Focuses on } \\
\text { many small parcels }\end{array}$ & $\begin{array}{l}\text { Focuses on } \\
\text { large parcels }\end{array}$ \\
\hline $\begin{array}{l}\text { Preservation of } \\
\text { Undisturbed Land }\end{array}$ & Moderate to high & Low to moderate & High \\
\hline \multicolumn{4}{|c|}{ Economic Aspects } \\
\hline Compensation & $\begin{array}{l}\text { Direct payment for } \\
\text { each credit transferred }\end{array}$ & $\begin{array}{l}\text { Direct payment for } \\
\text { each credit transferred }\end{array}$ & Direct fee simple purchase \\
\hline Initial Costs & Little capital required & Little capital required & Expensive fee acquisition costs \\
\hline Management Costs & Moderate & Moderate & High \\
\hline Enforcement Costs & Potentially high & Potentially high & Low \\
\hline Land Taxation & Land remains on tax rolls & Land remains on tax rolls & $\begin{array}{l}\text { Land removed from tax roles } \\
\text { if acquired by a public agency }\end{array}$ \\
\hline \multicolumn{4}{|c|}{ Management and Legal Aspects } \\
\hline $\begin{array}{l}\text { Time to } \\
\text { Maximum Protection }\end{array}$ & $\begin{array}{l}\text { Long time to complete } \\
\text { protection of desired land }\end{array}$ & $\begin{array}{l}\text { Long time to complete } \\
\text { protection of desired land }\end{array}$ & $\begin{array}{l}\text { Relatively short time } \\
\text { to program protection goals }\end{array}$ \\
\hline $\begin{array}{l}\text { Chance of } \\
\text { Legal Challenge }\end{array}$ & High & Low to moderate & Low \\
\hline Liability Exposure & Low & Low & $\begin{array}{l}\text { Moderate to high: public use } \\
\text { insurance is needed. Low if } \\
\text { land is not open to the public. }\end{array}$ \\
\hline
\end{tabular}

ger protected connection between Malibu Creek State Park and Paramount Ranch. The size of the conservation bank is only a little smaller than the aggregate acreage of the potential purchasers within the study area. This indicates that the study area is too small to support the conservation bank. Because not all of the potential purchasers will require mitigation on their projects, and assuming the potential purchaser areas are developed, purchasers from other areas of the watershed should be able to buy credits from this bank.

\section{Comparative Analysis}

After generating the maps describing the geographic application of a transferable development credit program and a conservation banking program to the study area, pattern matching was conducted to determine which program would be more successful in fulfilling the land protection goals of the area. First, the maps were compared to the continuum created by the Existing Land Use Map (Fig. 1) and Desired Land Protection Map (Fig. 2). Then, protection differences between the programs were analyzed based on structure and operation; implementation elements; economic elements; and management and legal aspects. Table 1 presents a synopsis of the findings regarding the four categories.

\section{Comparison of program application to the study area}

Figure 5 provides an illustration of the geographic differences in the amount of land protection each program provides. The conservation banking program preserves the smallest area, about 237 ha (586 acres). The mandatory transferable development credit program covered the same area protected by the conservation bank plus additional land to the north, east, and west for a total area of 472 ha (1,167 acres). The voluntary credit program did not overlay any areas of the conservation bank. Since this program was geared toward the reduction of inholdings within the National Recreation Area boundary, it covered many small areas protecting a total of 383 ha (948 acres). In total, the transferable development credit programs cover approximately $31 / 2$ times the 
amount of land protected by the conservation bank. This reflects the difference in the credit markets and initial monetary requirements of the programs.

\section{Policy Recommendations}

Fee acquisition remains the preferable alternative to protecting significant habitat areas in the Santa Monica Mountains. It provides clear, unconstrained acquisition of the property and conveys all of its corresponding rights. However, the economic reality of the funding for fee acquisition makes it an unlikely method to obtain the desired land protection goals of the area. This inability lead to research on regulatory market programs. For the property within the study area, a hybrid program using both conservation banking and a voluntary credit program would best meet the desired land protection goals.

The hybrid program, illustrated on Figure 6, uses a conservation bank to protect significant habitat areas and the critical wildlife habitat corridor at Liberty Canyon. It then utilizes a voluntary transfer credit program to reduce the number of inholdings within the National Recreation Area boundary and direct development to locations more appropriate to handle higher density development. Receiving sites are mainly located along the Ventura Free- way corridor and along Mulholland Highway in the Malibu Lake area. This provides a strong connection between the program's sending and receiving sites. Some fee acquisition of parcels is still required to reach the Land Protection Plan goals. The areas for fee acquistion are mostly located west of Malibu Lake.

The hybrid program does not preclude other conservation organizations from protecting the areas it covers. The program maximizes the strengths of both the conservation banking and transfer credit programs and increases the chances of obtaining the desired land protection goals. The conservation banking program strengths are its ease of operation, immediate protection of the resource, and its legal clarity. The land is purchased through fee simple acquisition and then the mitigation credits are sold. Initial funding remains the largest obstacle to implementing such a program.

Why not use a mandatory transfer credit program rather than conservation banking? A mandatory credit program has better coverage without the up-front expenses. The issue here is a legal one which returns to the use of credits as mitigation or as full compensation for restrictions on land use. A mandatory program would require that the price paid per credit was sufficient to provide full compensation for the extreme restrictions on the sending sites. Full compensation is not likely to be provided by transfer

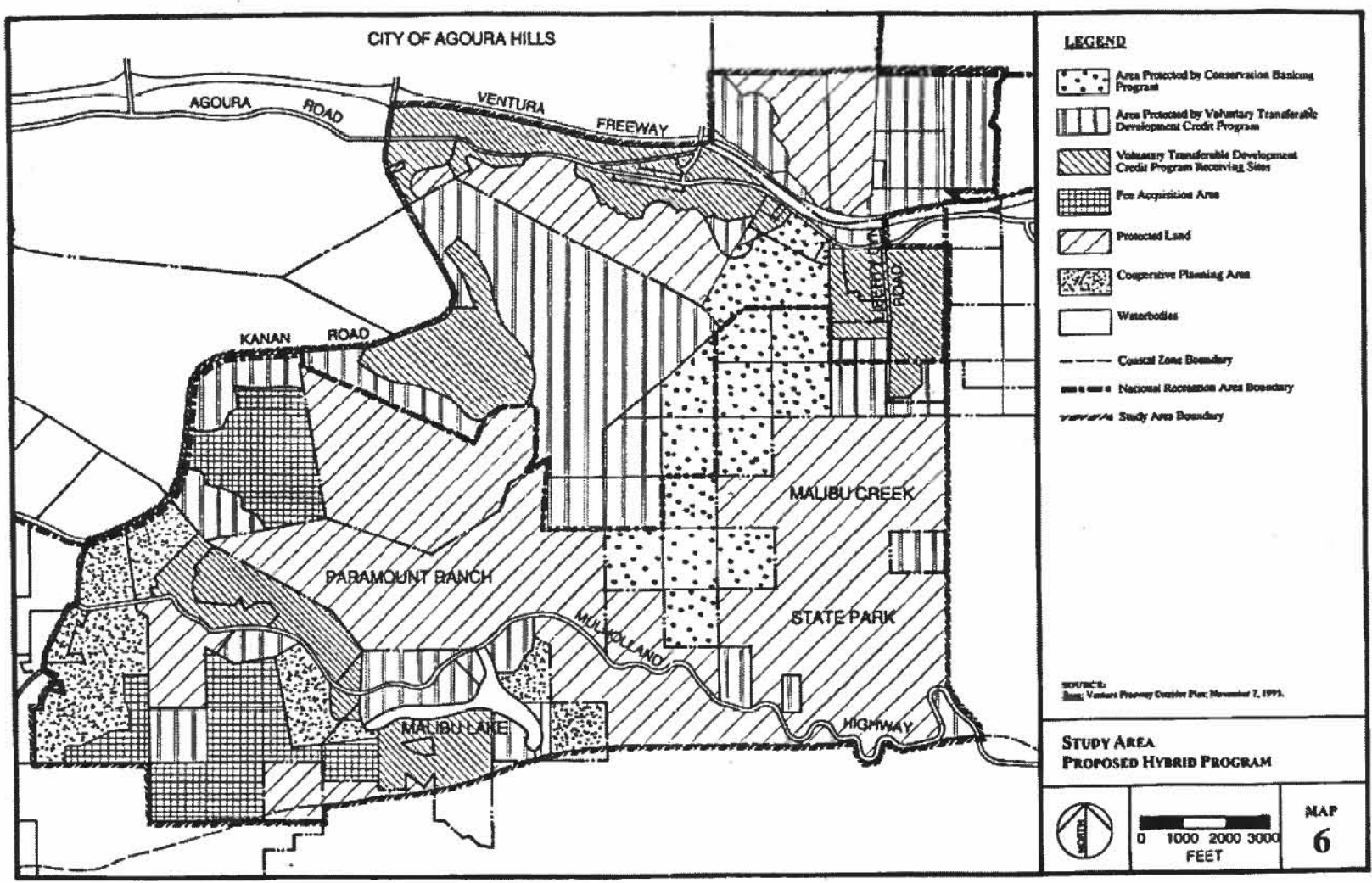

Figure 6. Proposed hybrid conservation programs in the Santa Monica Mountains study area. 
credits. A credit price that would provide the sending site owner full compensation would be prohibitively expensive to a recciving sitc owner secking development credits. Therefore, the prices that have traditionally been paid for credits only reflects the value of the ability to develop on the sending sites and do not accurately reflect full compensation for all of the property rights of the sending site.

The voluntary program applies to areas designated as proposed easement acquisition areas on the Desired Land Protection Map (Fig. 2). These areas do not have the same sense of urgency for protection that accompanies critical habitat areas. Private inholdings within the National Recreation Area boundary are typically not a problem until the owners want to develop them. Until they are developed, the property is perceived as open space.

The proposed hybrid program would be ministerial. This means that as long as the program requirements are met, credit transfers can occur with little or no discretion from the administrator of the program. Due to the Coastal Commission's transfer credit program, many people in the area are familiar with how such a program operates, an element important in generating ample community support.

The hybrid program would have to be run by a third party on behalf of the National Park Service. Federal policy prevents the National Park Service and other federal agencies from owning land that has conditions or restrictions attached to it. The conservation easements that are crucial to protecting the desired resource in perpituity preclude the National Park Service from owning any of the areas protected by the hybrid program.

\section{Areas for further study}

The next step toward implementing the hybrid program is a series of detailed economic and biological studies. First, a study of the regulatory market needs regarding transfer credits needs to be done. The study should focus on the residential development market to determine if the exact level of demand within the watershed in which the study area is located is sufficient to drive the credit portion of the hybrid program.

Second, a similar study is necessary to estimate the demand for mitigation credits in the area. This study would include a determination of how may credits the conservation bank within the study area would generate. Also included in the study should be a biological assessment of the potential purchase sites that would fund the conservation bank.

The final element of the study would be to determine how many of the potential purchaser areas would be lost to development and the amount of mitigation that would be required.

Answers to these questions need to be found before the hybrid program could be properly designed and implemented.

\section{Literature Cited}

California Department of Fish and Game. 1995. Carlsbad conservation bank implementation agreement. Carlsbad, CA.

California Environmental Protection Agency. 1995. Official Policy on Conservation Banks. Sacramento, CA.

City of Calabasas, General Plan. 1993. Community Issues. Calabasas, CA.

City of Calabasas. 1995. General Plan: Agenda for the 21st Century. Riverside, CA.

City of San Diego. 1994. Mitigation Bank Agreement. San Diego, CA.

County of Ventura, California. 1994a. Ventura County General Plan: Resources Appendix. Ventura, CA.

County of Ventura, California. 1994b. Ventura County General Plan: Public Facilities and Services Appendix. Ventura, CA.

County of Ventura, California. 1995. Ventura County General Plan: Land Use Appendix. Ventura, CA.

Planning Network. 1993. VenturaFreeway Areawide Plan. Rancho Cucamonga, CA.

Pruetz, R. 1993. Putting Transfer of Development Rights to Work in California. Solano Press, Point Arena, CA.

Roddewig, R.J., and C.A. Inghram. 1987. Transferable Development Rights Programs: TDRs and the Real Estate Marketplace. American Planning Association, Planning Advisory Service Report Number 401, Chicago, IL.

Southern California Association of Governments. 1990. Economic Profile of the SCAG Region. Los Angeles, CA.

Southern California Association of Governments. 1995. Regional Comprehensive Plan and Guide. Los Angeles, CA.

Tietenberg, T. 1992. Environmental and Natural Resource Economics. Harper Collins, New York, NY.

USDI National Park Service. 1984. Santa Monica Mountains National Recreation Area: LandProtection Plan. SantaMonica Mountains National Recreation Area, Agoura Hills, CA.

Wiechec, M.E. 1995. Transfer of development in the Malibu Coastal Zone. Prepared for Santa Monica Mountains Conservancy, Malibu, CA.

Yelin, J.R. 1995. A Survey of criteria and strategies for regional conservation. Report Prepared for Santa Monica Mountains National Recreation Area, Agoura Hills, CA. 


\section{Restoration Ecology}

California's vast expanse of seemingly endless resources has traditionally been viewed as justification for abusive land use practices. The modern day recognition that resources are finite has led to greater concern, not only for conserving what is left, but restoring abused landscapes. Ecological restoration is a new science devoted to returning disturbed environments to a semblance of their pristine state. Based on principles of "revegetation," restoration goes far beyond simple replanting. The ambition of ecological restoration is to return landscapes to functioning ecosystems. 


\title{
Climate, Vegetation, and Considerations for Restoration
}

\author{
Nathan L. Stephenson \\ U.S. Geological Survey, Western Ecological Research Center, Sequoia-Kings Canyon Field Station, Three Rivers, CA \\ 93271-9651 \\ Tel. (559) 565-3176; Fax (559) 565-3177; e-mail: nstephenson@usgs.gov
}

\begin{abstract}
Climate is one of the master controllers of the distribution of individual plants and of assemblages of plants (vegetation) across landscapes. Restoration ecologists need to understand climate, plant distribution, and their relationships in order to (1) understand how to manipulate local conditions to favor or disfavor certain species, (2) choose species appropriate for revegetation, given the local conditions, and (3) select appropriate case studies from similar climate and vegetation types in order to learn from previous successes or failures. Climate is best described in terms of the seasonal interactions of water supply and evaporative demand (potential evapotranspiration); this is done by calculating the climatic water balance. The main elements of the water balance are actual evapotranspiration (an estimate of simultaneous "warm and wet," related to potential for plant growth); deficit (an cstimatc of drought stress); and surplus (an estimate of water that runs off, unused). There are a number of ways, ranging from simple to complex, for calculating and illustrating site water balances.

Factors affecting the water balance can be broken into those that affect water supply (or available water) and those that affect evaporative demand (potential evapotranspiration), and by the spatial scale upon which they act regional, local, or micro scales. On the local and micro scales, some of the most important factors affecting the water balance are slope aspect, slope steepness, waterholding capacity of the soil, and the presence or absence of nearby plants. Restoration ecologists can, within limits, manipulate water balances at the local and micro scales.

For continental and global scales, several authors have described the distribution of vegetation types relative to mean annual temperature, precipitation, or water balance parameters. Actual evapotranspiration and deficit form the pair of parameters most highly correlated with vegetation distribution. One author, Walter, has taken a different approach by dividing the globe into nine zones defined by climatic types, and listing their most commonly associated vegetation types. Each of the earth's climatic types offers different challenges to restoration ecologists, ranging from
\end{abstract}

extreme drought stress and highly variable precipitation (arid climates) to potential for severe flooding (monsoonal and tropical rain climates).

Keywords: Actual evapotranspiration; biogeography; physiognomy; potential evapotranspiration; spatial scale; water balance; water deficit; water supply.

\section{Introduction}

Climate is the major shaper of the terrestrial world, profoundly affecting the distribution and properties of soils, plants, and animals. Because it is largely plants that determine the structure and function of terrestrial communities, restoration ecologists need especially to understand the effects of climate on plants and vegetation. Armed with such an understanding, restorationists will be in a position to (1) manipulate local conditions to favor or disfavor certain species, (2) choose species appropriate for revegetation, given the regional climate, and (3) select appropriate case studies from similar climatic and vegetation types, in order to learn from previous successes or failures.

One of the basic axioms of physiological ecology is that an organism interacts with its environment through the exchange of mass, energy, and momentum. Most of this exchange depends on what we call "climate." Wind, through transfer of momentum, can bend a plant or knock it down. Wind, humidity, solar radiation, and air temperature, by affecting leaf temperature and rate of water loss, can strongly influence a plant's metabolic and photosynthetic rates. Solar radiation supplies the energy that is stored in carbon compounds by photosynthesis, and, like temperature, can act as a cue for important events in a plant's life history, such as flowering and leaf fall. Finally, precipitation plays the all- important role of supplying the water needed to maintain cell function in a drying aerial environment. Each of these topics has been examined in great detail by botanists, physiologists, and 
ecologists (e.g., Galston et al. 1980; Etherington 1982; Jones 1992; Larcher 1995; Campbell and Norman 1998; I ambers et al. 1998; Barbour et al. 1999).

Here I focus on the most important climatic factors determining the distribution of plants across landscapes: those that affect water and energy exchange between plants and their environment. The organizing principle is that the only way to understand the effects of energy and water on plants is to consider their interactions. After a brief discussion of the importance of scale, the concept of the climatic water balance is introduced - a useful way of describing the interactions of energy and water. Sources of site-specific climate and water balance summaries are given, along with methods for calculating the water balance. Of particular importance to restorationists is knowing what factors affect the water balance at different spatial scales. These factors are introduced, along with some of the ways in which they might be manipulated to achieve certain ends.

To provide restorationists with a broader perspective, I then provide a global overview of the world's major vegetation types and the important features of the world's major climatic types. Of particular relevance to restoration is the observation that the association between vegetation types and climate is relatively predictable.

\section{Scale}

At first it may not be apparent why restorationists need to consider climate, and the factors affecting climate, across a broad range of spatial scales. After all, what re- ally matters to a plant is microclimate - the climate immediately contacting the plant. It makes no difference to a plant whether it avoids frost damage hy growing in a region that never experiences frost, or by receiving radiant heat from a nearby rock in a region otherwise prone to frost. In both cases, the plant's microclimate never falls below freezing.

However, a plant's microclimate is a product of successive modification of climatic factors operating at larger spatial scales. At the largest scale we will consider in detail, regional climate is that averaged over several unsheltered sites on level ground in a defined area - for example, the average climate of a coastal plain (see Major 1951; Linacre 1992). It is controlled by large-scale atmospheric circulation and is, by definition, independent of local variations in topography. Local climate is regional climate as it is modified by topography - for example, the different climates found on the north-facing and southfacing slopes of a hill. Finally, microclimate - that which directly affects a plant - is the local climate as it is modified by nearby plants, rocks, or other relatively small objects. Microclimate, which determines the success or failure of plant establishment, growth, and reproduction, thus depends on factors working at regional, local, and micro scales (Table 1).

Restorationists must also consider climate at different temporal scales. Even though climate is constantly changing at scales of years to millennia (Schneider and Londer 1984; Bradley 1990), climatic data are nearly always presented as averages of weather data spanning a few decades to a little more than a century. These averages mask short-term climatic changes and weather extremes, giv-

Table 1. Factors affecting the water balance. The factors have been grouped by the spatial scale at which their effect is most important (though they may be important at more than one scale), and by whether they affect water supply (or available water) or evaporative demand (potential evapotranspiration).

\begin{tabular}{|c|c|c|c|}
\hline & Regional Scale & Local Scale & Micro Scale \\
\hline Water supply & $\begin{array}{c}\text { Annual precipitation } \\
\text { Seasonality of precipitation } \\
\text { Form of precipitation (liquid or solid) } \\
\text { Duration and intensity of precipitation events } \\
\text { Year-to-year variation in precipitation } \\
\text { Cloud seeding }\end{array}$ & $\begin{array}{l}\text { Slope position (upper middle, lower) } \\
\text { Slope steepness } \\
\text { Slope configuration (concave, flat, } \\
\text { convex, or terraced) } \\
\text { Depth to water table } \\
\text { Water-holding capacity of the soil } \\
\text { Irrigation }\end{array}$ & $\begin{array}{l}\text { Soil microtopography (concave, } \\
\text { convex, flat, or terraced) } \\
\text { Fog and dew drip } \\
\text { Snow retention } \\
\text { Water-holding capacity of the soil } \\
\text { Irrigation } \\
\text { Uptake of soil water by nearby plants } \\
\text { Mulching }\end{array}$ \\
\hline $\begin{array}{l}\text { Evaporative } \\
\text { demand }\end{array}$ & $\begin{array}{c}\text { Annual potential evapotranspiration } \\
\text { (temperature, humidity, wind speed, } \\
\text { solar radiation) } \\
\text { Seasonality of potential } \\
\text { evapotranspiration (temperature, } \\
\text { humidity, wind speed, solar radiation) } \\
\text { Year-to-year variation in potential } \\
\text { evapotranspiration (temperature, humidity, } \\
\text { wind speed, solar radiation) }\end{array}$ & $\begin{array}{l}\text { Slope aspect and steepness } \\
\text { Slope position (upper, middle, lower) } \\
\text { Exposure (shading, or protection } \\
\text { from wind by other slopes, wind- } \\
\text { breaks, or shelterbelts) }\end{array}$ & $\begin{array}{l}\text { Shading by nearby plants or objects } \\
\text { Protection from wind by nearby } \\
\text { plants, objects, or by snowpack } \\
\text { Reflection and radiation from soil, } \\
\text { plants, or nearby objects }\end{array}$ \\
\hline
\end{tabular}


ing the false impression that climate is constant. Weather extremes often have more influence on plant distribution than climatic means. The saguaro cactus of Arizona, for example, usually is killed when air temperature remains below freezing for 36 hours or more, and the cactus reaches the northern and eastern limits of its distribution where these conditions are occasionally met (Hastings and Turner 1965, in Begon et al. 1986). These frost periods would be invisible in climatic means, which would falsely imply that freezing temperatures are never reached at the distributional limits of the cactus.

This is not to say that climatic means have no value; on the contrary, they are quite valuable. First, climatic means and climatic extremes are usually correlated; for example, high average temperatures and high extreme temperatures usually go hand in hand. Second, the average climate of the immediate past, not weather extremes, is usually our best predictor of climate in the immediate future. This chapter focuses more on climatic means than weather extremes.

\section{The Climatic Water Balance}

Most of us tend to think of climate in the same way that weather agencies and news media report daily weather: how warm it was (a measure of energy) and how much rain or snow fell (a measure of water). By simple extension, regional climate (that is, the average weather of an area) often is summarized as mean annual temperature and precipitation. This approach to thinking about climate is simple, familiar, and widely used. However, when it is applied toward understanding ecological patterns and processes, it inadvertently introduces a false assumption - the assumption that the effects of energy and water are independent.

Energy and water do not act independently. For example, for a plant to use external energy for growth, water must be available; otherwise the energy will act only to heat and stress the plant. Similarly, for a plant to use water for growth, energy must be available; otherwise water simply will percolate through the soil or run off, unused. Clearly, the effects of climate on plants (as well as on most ecological patterns and processes) are not determined simply by average annual totals of energy and water, but rather by the seasonal interactions of the two (Stephenson 1990, 1998). This demands that we think of climate in some less traditional ways.

The climatic water balance (or water budget) better describes climate as it affects most natural patterns and processes than simple measures of energy and water. Water-balance parameters estimate (1) the simultaneous availability of energy and water in the environment ("warm and wet"), (2) evaporative demand not met by available water (a term related to excess energy - "warm and dry"), and (3) the amount of water that runs off or percolates through the soil (excess water). A few definitions serve to introduce the concept of the water balance.

Energy, rather than being expressed in terms of temperature, is expressed in terms of evaporative demand, or potential evapotranspiration. By convention, potential evapotranspiration is defined as the evaporative water loss from a site covered by a standard crop - a continuous sward of short green plants that completely shade the ground, supplied with unlimited water (see Rosenberg et al., 1983, for a more detailed discussion). While modified by wind speed and atmospheric humidity, potential evapotranspiration generally increases with increasing energy (heat and solar radiation); that is, the more energy present in the environment, the greater the evaporative demand. Though it is a measure related to energy, potential evapotranspiration, by definition, is measured in units of water depth - the depth of water that could be evaporated by a given amount of energy. This allows for meaningful comparisons of water supply and evaporative demand. For example, in Portland, Oregon, where January precipitation and potential evapotranspiration typically are $140 \mathrm{~mm}$ and $20 \mathrm{~mm}$, respectively, it is quickly apparent that about $120 \mathrm{~mm}$ of January precipitation (140 minus 20) will run off as excess in creeks and rivers (assuming that soils are saturated and the vegetation around Portland transpires at more or less the same rate as the "standard crop" used to define potential evapotranspiration).

Precipitation is the amount of water, liquid or solid, that falls to the ground in a given period. Water supply, in contrast, is the amount of liquid water that reaches the soil surface in a given period; it consists of rain and meltwater. Snow is precipitation at the time it falls, but not a part of water supply until it melts. The distinction is important because liquid water, unlike snow, can penetrate the soil, be taken up and transpired by plants, or run off in creeks and rivers. Barring irrigation or other overland transport of water, or significant loss of snow to sublimation, annual precipitation equals annual water supply, though their seasonal timing may differ.

The fate of water at a site cannot be completely understood without considering soil, which acts as a moisture reservoir. When water supply exceeds evaporative demand, a portion of the water supply is stored in the soil. In times of drought, when plants draw on soil water, their actual water use may exceed the amount of rain and meltwater reaching the soil surface. Available water is the total amount of water that potentially can be used by plants; it is the total amount of liquid water reaching the soil (water supply), minus the net change in water stored in the soil.

Having considered energy (potential evapotranspiration) and water availability, we are now in a position to consider the seasonal interactions of the two - the essence of the climatic water balance. Understanding the interrelationships of the water balance parameters is greatly aided by diagrams of the seasonal dynamics of 
available water and potential evapotranspiration at a site, showing the annual totals for all parameters as areas under curves (Fig. 1).

Actual evapotranspiration can be viewed as a measure of the simultaneous availability of biologically usable energy and biologically usable water in the environment (Major 1963; Rosenzweig 1968). It is usually defined as the evaporative water loss from a site covered by a standard crop, given the prevailing water availability. Actual evapotranspiration equals available water or potential evapotranspiration, whichever is less. When potential evapotranspiration exceeds available water, actual evapotranspiration is limited by water, and actual evapotranspiration equals available water; when available water exceeds potential evapotranspiration, actual evapotranspiration is limited by energy, and actual evapotranspiration equals potential evapotranspiration. For a discussion of confusion surrounding the definition and meaning of actual evapotranspiration, see Stephenson (1990).

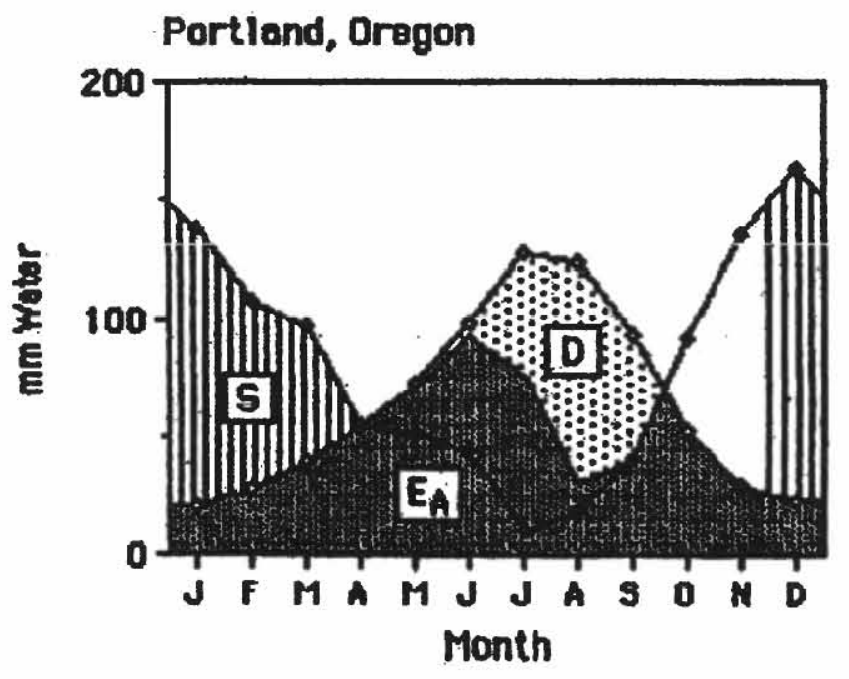

Fig. 1. The water balance of Portland, Oregon - a locality supporting coniferous forest. From October to April, precipitation (solid diamonds) - the best available estimate of water supply (see Approaches to calculating the water balance in text) - exceeds potential evapotranspiration (open diamonds). During this period, actual evapotranspiration $\left(\mathrm{E}_{\mathrm{A}}\right.$, dense stippling) is limited by energy and equals potential evapotranspiration. In October and November, excess water replaces soil water used during the summer; the white area between precipitation and potential evapotranspiration curves represents soil-water recharge. From December to April, after soil water has been replenished, the difference between precipitation and potential evapotranspiration is surplus (S, stripes). From April through September, potential evapotranspiration exceeds precipitation. During this period, actual evapotranspiration is limited by water and equals available water, precipitation plus water extracted from the soil (shown as the curve between the precipitation and potential evapotranspiration curves). Deficit (D, sparse stippling) is the difference between potential evapotranspiration and available water. Redrawn from Stephenson (1990).
Deficit is evaporative demand not met by available water - a measure of how much more water could have been evaporated or transpired from a site covered by a standard crop, had the water been available. It is the difference between potential evapotranspiration and actual evapotranspiration. Deficit is related to the magnitude and length of drought stress experienced by plants - heat stress that cannot be regulated by transpiration, metabolic costs that cannot be met by active photosynthesis, and potential for cell damage or death (e.g., Jones 1992; Larcher 1995). Finally, surplus is a measure of excess water in the environment. It is the amount of water that leaves a site covered by a standard crop - through runoff or subsurface flow - without being evaporated or transpired. It is the difference between available water and actual evapotranspiration when the soil is saturated.

The relationships among the water balance parameters can be expressed in two equations: $\mathrm{W}=\mathrm{E}_{\mathrm{A}}+\mathrm{S}$ and $\mathrm{E}_{\mathrm{P}}=$ $\mathrm{E}_{\mathrm{A}}+\mathrm{D}\left(\mathrm{W}=\right.$ available water, $\mathrm{E}_{\mathrm{A}}=$ actual evapotranspiration, $\mathrm{S}=$ surplus, $\mathrm{E}_{\mathrm{P}}=$ potential evapotranspiration, $\mathrm{D}=$ deficit). The first describes conservation of water; the second, conservation of energy.

\section{Approaches to calculating the water balance}

Restorationists can gain much by examining site water balances and the factors that control them. What practical alternatives are there for getting water balance data for a particular site? At a very coarse scale, maps are available showing general patterns in the distribution of annual means of water balance parameters for all continents (e.g., USSR National Committee for the International Hydrological Decade 1977). On a much finer scale, sitespecific water balances have been calculated for thousands of individual sites around the world, mostly for towns or cities with relatively long weather records (e.g., Mather 1962, 1963a, 1963b, 1963c, 1964a, 1964b, 1964c, 1965; Eagleman 1976). But what should a restorationist do if, as will often be the case, water balance data have not already been calculated for a particular location of interest?

Much of the time, a qualitative understanding of how local and microsite factors affect water balances is all one needs for a restoration project. It might be enough to know that, within a region, the most drought-tolerant plants at a given elevation are found on sunward slopes, shallow soils, or ridgetops (where water deficits are highest), that loss of available soil water can be slowed by applying mulch, and so on (see the next subsection). Thus there may be no need to summarize weather data and calculate local water balances. On the other hand, a restorationist may wish to gain knowledge of the success or failure of restoration efforts carried out in similar climates, determine which of several available species are most appropriate to a particular site, and so on. These goals require a quantitative understanding of climate. 
Walter and his colleagues, recognizing the limitations inherent in describing climate as annual means of temperature and precipitation, took a simple graphic approach to representing the seasonal interactions of energy and water at a site (Walter and Lieth 1967; Walter et al. 1975a, 1975b; Walter 1985). Using an approximation that each degree Celsius above zero equals $2 \mathrm{~mm}$ of potential evapotranspiration, they created climate diagrams with temperature and precipitation axes arranged such that the temperature curve provided a crude approximation of a potential evapotranspiration curve (Fig. 2). In practice, the temperature curves of Walter-type climate diagrams drastically underestimate potential evapotranspiration - and therefore the length and magnitude of deficit periods at all but lowest temperatures (compare Figs. 1 and 2). Recognizing this limitation, Walter sometimes plotted a "reduced supplementary precipitation curve" where $1{ }^{\circ} \mathrm{C}$ equalled $3 \mathrm{~mm}$ precipitation (Fig. 2; Walter 1985). However, the fact remains that the temperature curves are poor substitutes for potential evapotranspiration curves. Additionally, Walter diagrams do not take into account the dynamics of soil water use and soil water recharge, both of which are important aspects of a site's water balance.

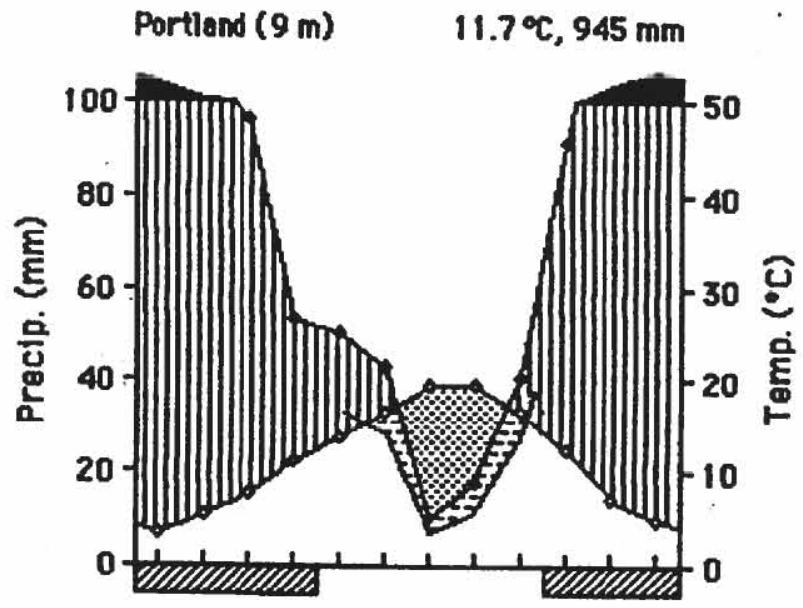

Fig. 2. A Walter-type climate diagram for Portland, Oregon (compare with Fig. 1). Divisions on the $\mathrm{x}$-axis are months, January through December (July through June for stations in the southern hemisphere). The mean monthly precipitation curve (solid diamonds) and mean monthly temperature curve (open diamonds) are arranged so that $1^{\circ} \mathrm{C}=2 \mathrm{~mm}$. Top left, station name and elevation. Top right, mean annual temperature and precipitation. Black part of precipitation curve, mean monthly precipitation $>100 \mathrm{~mm}$ (scale reduced by a factor of 10 relative to the rest of diagram). Vertical stripes, the "relative humid season" (precipitation curve above temperature curve). Stippling, the "relative period of drought" (temperature curve above precipitation curve). Dashed area, drought period as defined by a "reduced supplementary precipitation curve" $\left(1^{\circ} \mathrm{C}=3 \mathrm{~mm}\right.$ precipitation). Diagonal shading below $x$-axis, months with absolute minimum temperature below $0^{\circ} \mathrm{C}$ (that is, months with potential for frost). Data from Walter and Lieth (1967) and Eagleman (1976); see also Walter (1985).
In spite of these drawbacks, Walter-type climate diagrams are excellent for giving an impression of climate at a glance, and for making quick between-site comparisons of climates. A distinct advantage of Walter diagrams an advantage that has led to their popularity - is that the temperature data needed to create them are more readily available than the potential evapotranspiration data needed to create a water-balance diagram. Additionally, atlases are available of climate diagrams for thousands of sites around the world (Walter and Lieth 1967; Walter et al. 1975a, 1975b). Visual inspection of Walter diagrams can be used to group similar climates, determine the usual vegetation type for a given climatic type, choose appropriate species for revegetation, and so on. Some examples of the use of the diagrams can be found in di Castri (1973), Jackson (1985), and Walter (1985).

If one needs a more accurate representation of site water balance than is possible with Walter diagrams, other simple methods are available for estimating potential evapotranspiration from temperature data alone - most notably the Thornthwaite (Thornthwaite 1948; Thornthwaite et al. 1957) and Holdridge (1967) methods. Reflecting their geographic origins, the Thornthwaite method traditionally has been used most extensively in the temperate latitudes, the Holdridge method in the tropics. While more accurate than Walter's climate diagrams, both methods still tend to underestimate potential evapotranspiration as it is estimated by more sophisticated methods and by actual measurements of evaporative water loss (Sellers 1965; Eagleman 1976; Rosenberg et al. 1983). The two methods are most accurate in humid regions, but may underestimate potential evapotranspiration by as much as a factor of two in arid regions.

The remaining methods for calculating the water balance, while more accurate, require data that are less commonly available. Of these, the Eagleman method (Eagleman 1976) is the simplest, requiring only measurements of temperature and humidity. The most accurate methods, such as the Penman method and its relatives (see Rosenberg et al. 1983), require measurements of temperature, humidity, solar radiation, and wind speed. These latter methods represent an ideal that should be strived for, but which will rarely be reached in practice. Most often, the approaches of Walter, Thornthwaite, or Holdridge will be the only practical alternatives for a given location.

Finally, a word of caution is in order regarding estimating water supply for water balance calculations. Snow does not become a part of water supply until it melts. Thus, for environments in which a significant amount of annual precipitation forms a snowpack lasting a month or more, the seasonal march of precipitation does not accurately reflect the seasonal march of water supply. This is of little consequence for regions in which precipitation exceeds potential evapotranspiration year-round; then only the relative timing of water surplus would be affected by using precipitation as an estimate of water supply. For snowy 
regions with a significant summer water deficit, however, using precipitation as a substitute for water supply may result in overestimating annual deficit and underestimating annual actual evapotranspiration. This is because some of the annual water supply will be delayed until spring melt, keeping soils moist longer than indicated by the precipitation curve. In practice, data on the timing and amount of snow melt often are difficult to obtain or are unavailable, hence precipitation curves are almost always used as a less-than-perfect substitute for water supply curves (as in the figures presented in this paper).

\section{Factors affecting the water balance}

Factors affecting the climatic water balance have two important attributes to consider: (1) the spatial scale at which the factors operate, and (2) whether the factors influence water supply, evaporative demand, or both (Table 1). Understanding both attributes helps restorationists decide how to modify the environment to favor or disfavor certain species. For example, if restorationists know that the seedling stage of a particular species is drought-intolerant, yet wish to establish the plant in an area that suffers significant climatic water deficits, they may choose to reduce water deficits at the micro scale. They might accomplish this by reducing evaporative demand by shading, or increasing water supply by irrigation; both actions will reduce water deficits. Though many (if not most) site manipulations in terrestrial restoration projects will be aimed at favoring or disfavoring certain plant species by modifying water supply, evaporative demand, or both, climate can affect plant success by other means, such as through wind damage and temperature extremes (especially frost damage). Wind damage and temperature extremes can be controlled in many of the same ways as evaporative demand, as discussed below.

Water supply at the regional scale. When considering the match between a plant and its environment, one of the first and most obvious things to consider is annual precipitation at a regional scale (Table 1). This point is so obvious it barely warrants mention; clearly, it would be foolish to try to establish a plant adapted to $1000 \mathrm{~mm}$ annual precipitation in a region receiving only $100 \mathrm{~mm}$ annual precipitation (not to mention that the plant from the former environment is almost certainly not native to the latter). Equally important is the seasonality of precipitation. Two regions can have identical annual precipitation and yet, because the seasonal timing of precipitation differs, support a very different flora and vegetation. For example, the northeastern United States - where annual precipitation is distributed fairly evenly throughout the year - supports deciduous forest, whereas areas of the Pacific Northwest - where the same amount of annual precipitation falls mostly in winter - support coniferous forest (Waring and Franklin 1979). The form of precipi- tation (liquid or solid) determines when liquid water enters the soil and becomes available to plants. Rain reaches the soil surface immediately, whereas water held in snow may not reach the soil surface as liquid until months after the snow was deposited. The slow melt of a snowpack allows ample time for water to percolate deeply into the soil, whereas much of the same amount of precipitation coming as a sudden burst of rain might run downslope without entering the soil. Likewise, a rainstorm of long duration and low intensity is more likely to recharge the soil than the same amount of rain coming in a sudden downpour. (Rainfall intensity, usually measured in $\mathrm{mm}$ / $\mathrm{h}$, is greatest in regions where convective storms dominate - usually the warmer latitudes [Linacre 1992].) The term "precipitation effectiveness" has sometimes been used to distinguish among types of precipitation (form, duration, and intensity) on the basis of their ability to recharge the soil with water (Oosting 1956; Barbour et al. 1999).

The climatic element that typically causes the greatest year-to-year variation in site water balance is precipitation (Eagleman 1976). Reestablishing natural communities may be particularly challenging in areas of extreme variability, such as areas prone to severe or unpredictable floods or droughts. Those regions receiving the lowest mean annual precipitation have, proportionally, the highest year-to-year and within-year variation therein; that is, precipitation is least predictable (most variable) in arid regions (Fig. 3; also see Eagleman 1976). Eagleman (1976) has presented a 25-year series of water-balance diagrams for Kansas City, Missouri, and Topeka, Kansas, demonstrating that actual evapotranspiration, deficit, and surplus all can vary severalfold from year to year. At the regional scale, precipitation is controlled by large-scale atmo-

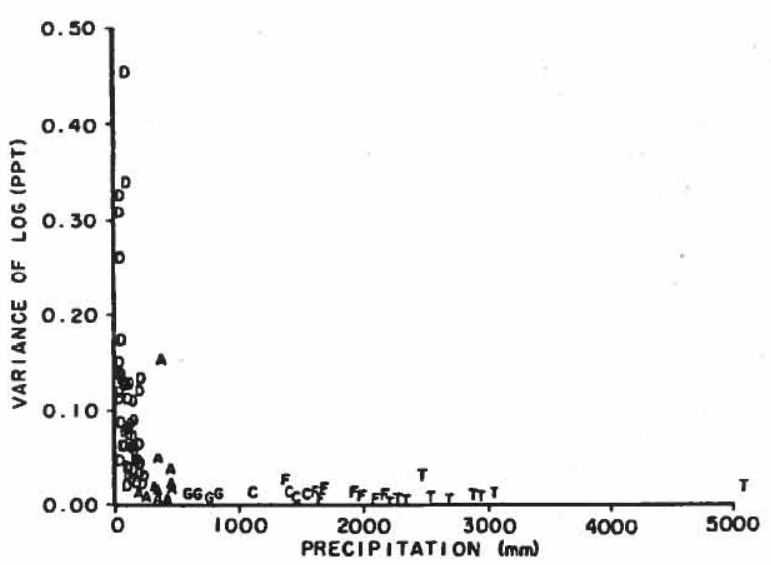

Fig. 3. Variance of the logarithm of annual precipitation versus mean annual precipitation for various weather stations around the world. Year-to-year variation in precipitation is greatest where mean annual precipitation is least. D, desert; A, tundra; G, grassland; C, coniferous forest; F, deciduous forest; T, tropical rain forest. Taken, with permission, from MacMahon (1980). 
spheric circulation which, for the most part, is beyond human control (Trewartha 1968; Henderson-Sellers and Robinson 1986; Barry and Chorley 1998). However, some modification can be achieved by cloud seeding; the resulting increase in regional water supply results in an increase in regional actual evapotranspiration, surplus, or both, accompanied by a decrease in water deficit. Regional changes resulting from the human-induced accumulation of atmospheric greenhouse gasses are far less predictable. Depending on the magnitude of large-scale warming and the resulting shifts in atmospheric currents, oceanic currents, and cvaporation, some regions of the globe will likely receive more precipitation, others less. These changes will largely be accidental and, unless strict measures are taken, uncontrollable. The consequences of greenhouse warming over the next century may be profound, potentially causing massive ecological change at a pace unrivalled in human experience (Wyman 1991; Peters and Lovejoy 1992; Kareiva et al. 1993; Solomon and Shugart 1993; Walker and Steffen 1996; Watson et al. 1996).

Evaporative demand at the regional scale. The flip side of water supply is evaporative demand. Several factors affect the evaporative loss of water, most notably temperature, solar radiation, wind speed, and humidity; their interactions are expressed as potential evapotranspiration (see the definitions presented earlier). Therefore, the following discussions of factors affecting potential evapotranspiration (and the effects of changing potential evapotranspiration) could just as easily be applied individually to temperature, solar radiation, wind speed, or humidity.

As a necessary complement to considering water supply at a regional scale, a restorationist's decision-making process needs to include annual potential evapotranspiration, seasonality of potential evapotranspiration, and yearto-year variation in potential evapotranspiration (Table 1). To chose what and when to plant, one must know the magnitude of evaporative demand in a region as well as the seasonal timing of the demand relative to water supply; for example, it may be unwise to plant immediately before or during periods when evaporative demand is likely to exceed water supply. While potential evapotranspiration tends to be less variable from year to year than precipitation (Eayleman 1976), it is still important to know the likely extremes encountered in an area. Humans have little control of potential evapotranspiration at a regional scale; however, the worldwide increase in atmospheric greenhouse gasses could drastically increase evaporative demand in some areas of the globe in the coming decades.

Water supply at the local scale. Narrowing our focus to the local scale, we find that water supply and available water, while strongly reflecting regional climate, may be modified by several factors (Table 1). Slope position can modify water supply, with slope bottoms and flats at the bases of hills sometimes receiving substantial runoff from upslope. Water may run off steep slopes more rapidly than shallow slopes, allowing less time for percolation into the soil, and concave or terraced slopes may collect more water than convex slopes. The water table may be near the soil surface in areas such as river floodplains, meaning that once plants have rooted to a sufficient depth their water source is relatively independent of atmospheric inputs.

Perhaps most important to restorationists at the local scale are variations in the water-holding capacity of the soil. In regions where water supply significantly exceeds evaporative demand year-round, variations in soil waterholding capacity are of little importance; soils remain wet year-round. However, where evaporative demand exceeds water supply for part of the year, site-to-site variation in soil depth and texture (relative proportions of sand, silt, clay, and organic matter) can lead to severalfold differences in available water between sites (Brady 1974).

The easiest ways for a restorationist to control water supply and availability at the local scale are by irrigation and by terracing to retain water.

Evaporative demand at the local scale. Local topographic modifications of evaporative demand are of great importance to restoration efforts (Table 1). In the northern hemisphere, south-facing slopes receive more solar radiation than north-facing slopes (Geiger 1965); the reverse holds in the southern hemisphere. The result (in the northern hemisphere) is warmer soils and greater evaporative demand on south-facing slopes (e.g., Cantlon 1953; Cooper 1961), leading to higher water deficits. Slope steepness also affects evaporative demand to the extent that it modifies how directly a slope faces the sun. Thus, in the northern hemisphere, north-facing slopes often have wetter soils than south-facing slopes. It is worth emphasizing, however, that soils on north- facing slopes are wetter because local evaporative demand is less, not because they receive more water than south-facing slopes (Stephenson 1998). Differences between slopes can be large enough that establishment of a particular species is successful on one slope but not the other.

The success or failure of a planting can also be determined by slope position. Cold air flows downslope at night, meaning nighttime temperatures usually are colder at the base of slopes than on upper slopes (Geiger 1965). In addition, slope exposure (the relative sheltering of one slope by another from direct sunlight or wind) can influence local temperature and evaporative demand. Both evaporative demand and wind damage can be reduced locally by establishing windbreaks or by planting "shelterbelts"-rows of plants that reduce wind speed near the soil surface (Lowry 1969).

We must be wary of a trade-off: methods that reduce evaporative demand by reducing temperature can also put plants at risk of frost damage. Regardless of the source of 
low temperatures, plants can be protected from frost in many ways, most of which are labor- or resource-intensive (Rosenberg et al. 1983). Among the most practical is placing caps of insulating materials over plants at night, removing the caps during the day. Alternatively, covers can be placed over soil late in the day, when the soil is warmest, and removed near dawn, when the chance of frost is greatest and reradiation of heat from the soil is most critical. Networks of oil, kerosene, or gas-burning heaters can be used to heat the air locally. Irrigation, by flooding or sprinkling with water, will sometimes protect plants from frost, because water releases heat as it freezes, maintaining its temperature at $0^{\circ} \mathrm{C}$. Finally, and perhaps most expensive, engine-driven propellers mounted on towers often will protect plants from frost by mixing warm upper air (when it is present) with cold surface air. More detailed discussions of frost protection can be found elsewhere (Rosenberg et al. 1983).

Water supply at the micro scale. Microclimates can vary enurmously within relatively small geographic areas (e.g., Wolfe et al. 1949), meaning that successful establishment of a plant will depend quite heavily upon its particular microsite. Fortunately, water supply and availability are easy to manipulate at the micro scale. At this scale, water supply and availability can be either increased or decreased by modifying soil microtopography, such as by terracing or creating small diversions of surface water (Table 1). Soil water can be increased by the interception of fog or condensation of dew on the foliage of nearby plants, followed by dripping. Fog drip can increase precipitation by a factor of 1.5 or more (Azevedo and Morgan 1974; Walter 1985), and in some arid regions dew drip is the primary source of water available to plants (Rosenberg et al. 1983). In snowy regions, water supply can be increased by erecting artificial or natural plant barriers that retain drifting snow until spring melt. Soil water-holding capacity can be increased by adding to soil depth, decreased by subtracting from soil depth, and either increased or decreased by manipulating the soil's relative proportions of sand, silt, clay, and organic matter (Brady 1974). Finally, the most obvious (and perhaps most ancient) method of increasing water supply, at both local and micro scales, is by irrigation.

Another way to maintain water availability, besides increasing water supply, is to prevent water loss. For example, available soil water can be decreased by the transpiration of nearby plants; these transpirational losses can be reduced by weeding. Direct loss of soil water by evaporation from the soil surface, in turn, can be reduced by covering the soil with a mulch (this is not the same as controlling the evaporative demand experienced by the plant).

Evaporative demand at the micro scale. Like water supply, evaporative demand varies greatly among micro- climates. For example, Wolfe et al. (1949) measured tenfold differences in summertime evaporative demand among different microclimates in a small valley in Ohio. Evaporative demand, like water supply, can be manipulated effectively at the micro scale. Shading, whether by nearby rocks, shade cloth, or other plants, reduces temperature and solar radiation, therefore evaporative demand (Table 1). The effects are particularly evident in arid regions, where certain plant species become established almost exclusively in the shade of adjacent "nurse plants" (Barbour et al. 1999). Similarly, nearby objects can protect plants from damage or desiccation by wind. At the opposite extreme, when low temperatures jeopardize a planting, rocks can be placed on the side of a plant opposite the sun to reflect extra sunlight onto a plant during the day, and to radiate heat during the night (Lowry 1969). In snowy regions, artificial or natural plant barriers can retain drifting snow around a plant, protecting it from extreme cold and desiccating winds.

As at the local scale, we must be wary of increasing the risk of frost damage if we reduce evaporative demand by reducing temperature. Regardless of the source of low temperatures, plants can be protected from frost at the micro scale using the same methods as at the local scale.

A final note of caution highlights why it is useful to separate factors affecting the water balance into those affecting water supply and availability and those affecting evaporative demand. Plants appropriate to sites that are arid because of low water availability, such as soils with low water-holding capacity, may not be appropriate to sites that are arid because of high evaporative demand, such as sunward slopes - the two forms of "arid" are not equivalent (Stephenson 1998). Low water supply or availability usually causes a decrease in actual evapotranspiration that is exactly matched by an increase in deficit. On the other hand, high evaporative demand, in addition to increasing deficit, either does not affect or increases actual evapotranspiration (Stephenson 1998).

\section{The water balance as a controller of natural patterns and processes}

The utility of the climatic water balance in explaining many natural patterns is well established. One water balance parameter - actual cvapotranspiration - has been shown to be highly correlated, over a broad range of ecosystems, with tree species richness (Currie and Paquin 1987; Currie 1991), organic litter decomposition rates (Meentemeyer 1978; Berg et al. 1993) and ecosystem productivity (Rosenzweig 1968; Lieth 1975, 1976). The water balance has proven useful in explaining the organic content, acidity, weathering rates, and distribution of soil types (Arkley 1967). And, because it traces the fate of water at the surface of the earth (the timing and amount of water reaching the surface, entering the soil, evaporating, or running off), the water balance is central to any 
study of hydrology. It is because the water balance describes climate as the interactions of energy and water, and not just their absolute amounts, that it so successfully explains patterns and processes in nature.

In the following section we will examine one of the patterns of greatest interest to restorationists: the distribution of vegetation types as it is controlled by the climatic water balance.

\section{Climate and Vegetation}

One of the oldest and broadest generalizations in ecology is so familiar that it is commonly taken for granted: that the distribution of terrestrial vegetation types is strongly controlled by climate. Here I briefly review the approaches people have used to understand the relationship between climate and vegetation, then provide an overview of the spectrum of climatic and vegetation types found on the earth today. Since restoration efforts might be needed in any of the earth's diverse vegetation types, it is useful to be familiar with what particular climatic features are associated with which vegetation types. More detailed discussions of the world's vegetation types and their associated climates can be found elsewhere (e.g., Dansereau 1957; Eyre 1971; Whittaker 1975; Barbour and Billings 1988; and especially Walter 1968, 1973, 1985).

\section{Background}

The correlation between vegetation type and climate exists because (1) much of the way a plant looks (its life form or growth form) is determined by its approach to capturing and fixing carbon from the atmosphere, and especially by its approach to coping with the inevitable water loss that accompanies carbon uptake; and (2) different climates strongly select among these different approaches. For example, the most successful plants in arid regions often have small, thick leaves which minimize water loss. In contrast, the most successful plants in the interior of wet tropical forests, where carbon gain is less constrained by water loss, usually have large, thin leaves which maximize photosynthetically active surface area. Plants exhibit a multitude of other physiological and morphological adaptations to coping with their environments (Horn 1971; Grime 1979; Etherington 1982; Chabot and Mooney 1985; Givnish 1986; Jones 1992; Larcher 1995).

The life-form composition of vegetation is called its physiognomy, and the major physiognomic types are called formations (or biomes, when the associated fauna is also considered). For example, "broad-leaved deciduous tree" defines a life form, whereas "broad-leaved deciduous forest" (a collection of many plants of the "broad-leaved deciduous tree" life form) defines a formation.

As an aid to understanding the relationship between climate and the physiognomy of vegetation, some authors

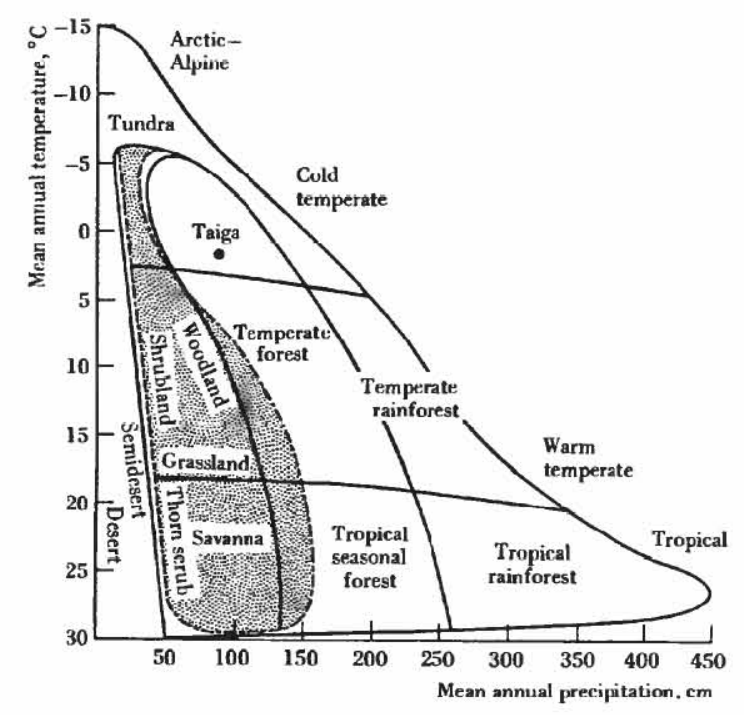

Fig. 4. Whittaker's diagram showing the distribution of the world's major plant formations relative to mean annual temperature and precipitation (see also Lieth 1956). Boundaries delineating formations are approximate; the shaded region encloses a range of environments in which either grasslands or woody formations may dominate. Taken, with permission, from Krebs (1978).

have plotted the distribution of plant formations relative to measures of mean annual energy (temperature or potential evapotranspiration), water supply, or their ratios (see Stephenson, 1990, for a more complete review). Lieth (1956) plotted the distribution of the world's major plant formations relative to mean annual temperature and precipitation; Whittaker (1975) popularized this approach in the English-language literature (Fig. 4). Holdridge (1967) published another popular diagram in which the world's major plant formations were plotted relative to mean annual precipitation, potential evapotranspiration, and a "potential evapotranspiration ratio" (potential evapotranspiration divided by precipitation) (Fig. 5). The complexity of Holdridge's diagram is deceptive; the graph's axes have been twisted from the familiar right angles of Cartesian coordinates to form a triangle, and the "third factor," potential evapotranspiration ratio, is an inconsequential artifact of plotting mean annual precipitation and potential evapotranspiration on logarithmic scales.

The pioneering works of Lieth, Whittaker, and Holdridge were useful in that they focused attention on energy and water as the primary controllers of plant distribution, and offered a framework for describing and exploring the relationship between climate and plant distribution. However, these approaches shared an important problem: they could not distinguish between climates that were similar in annual energy and water supplies but different in their seasonal timing. As a result, Whittaker's approach, for example, could not distinguish well between 


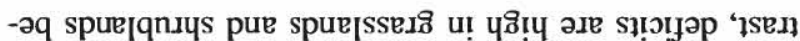

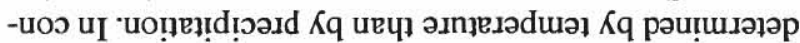

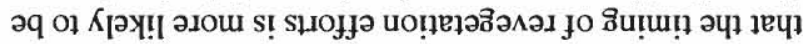
SMOIIOI HI '

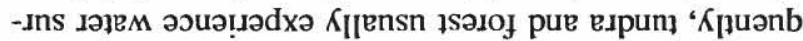

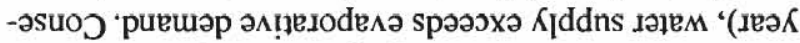

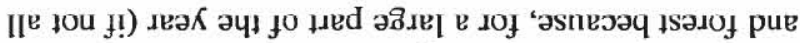

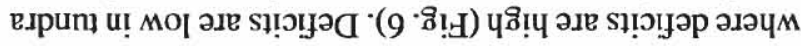

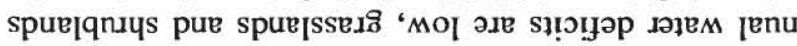

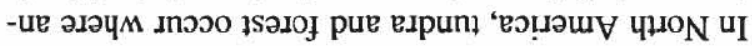

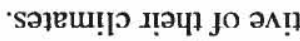

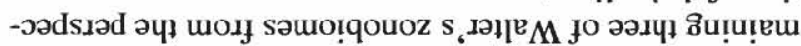

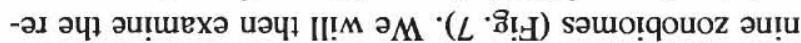

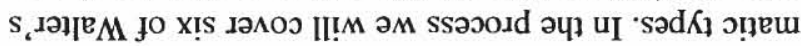

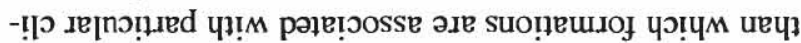

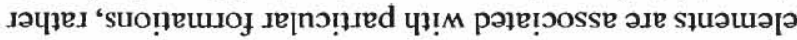

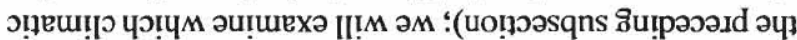

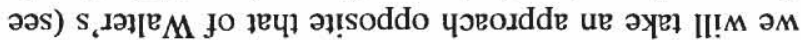

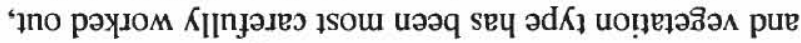

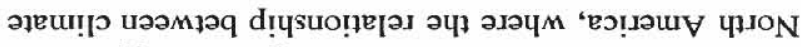

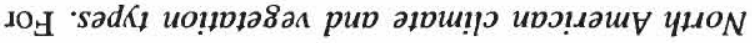

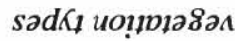

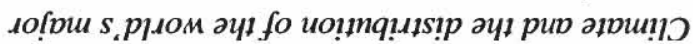

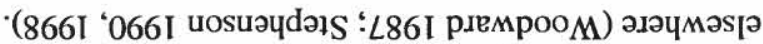

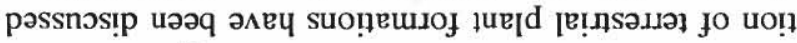

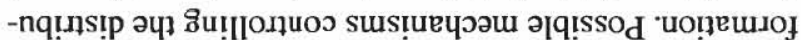

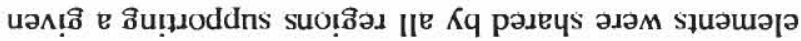

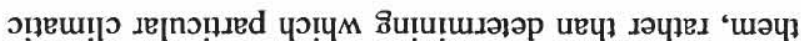

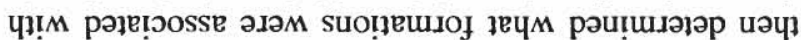

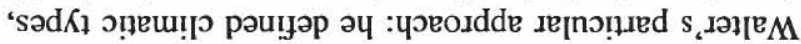

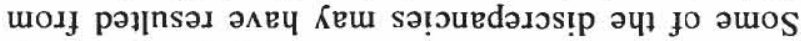

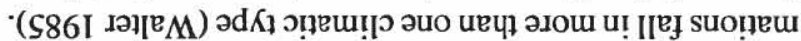

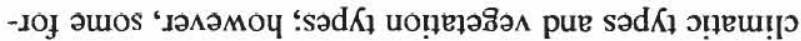

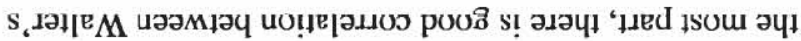

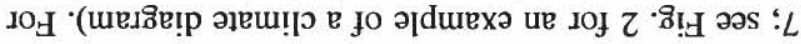

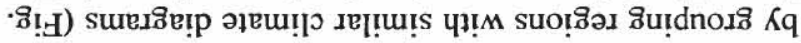

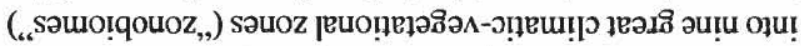

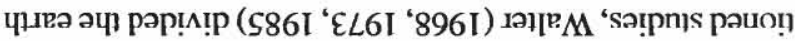

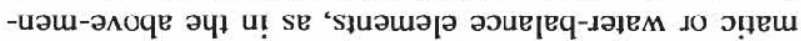

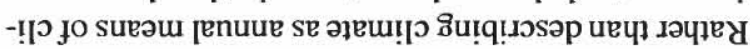

$\cdot(866 \mathrm{I}$

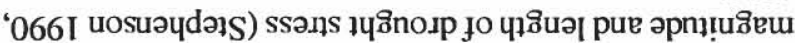

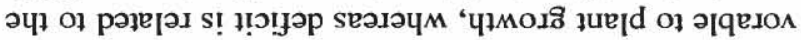
- שృ Suо!!

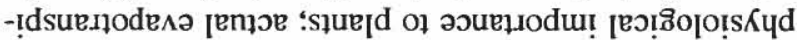

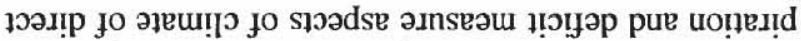
-suenode八ә [епџе ' '

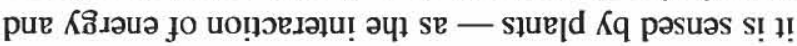

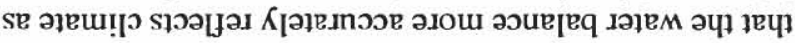

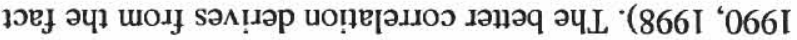

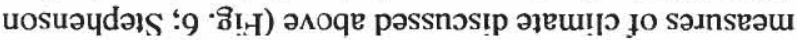

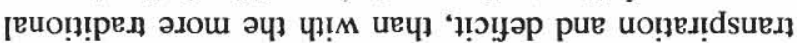

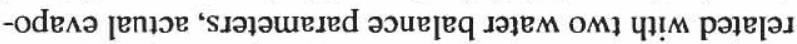
-ı0ว К КЧ

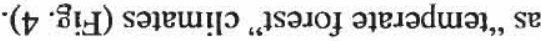

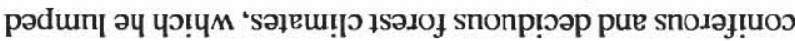

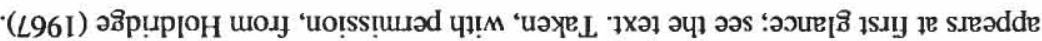

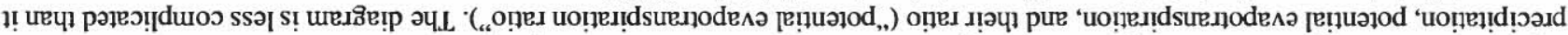

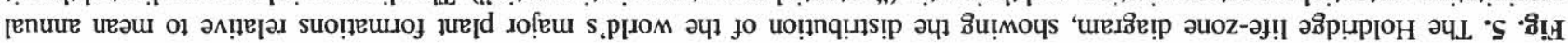

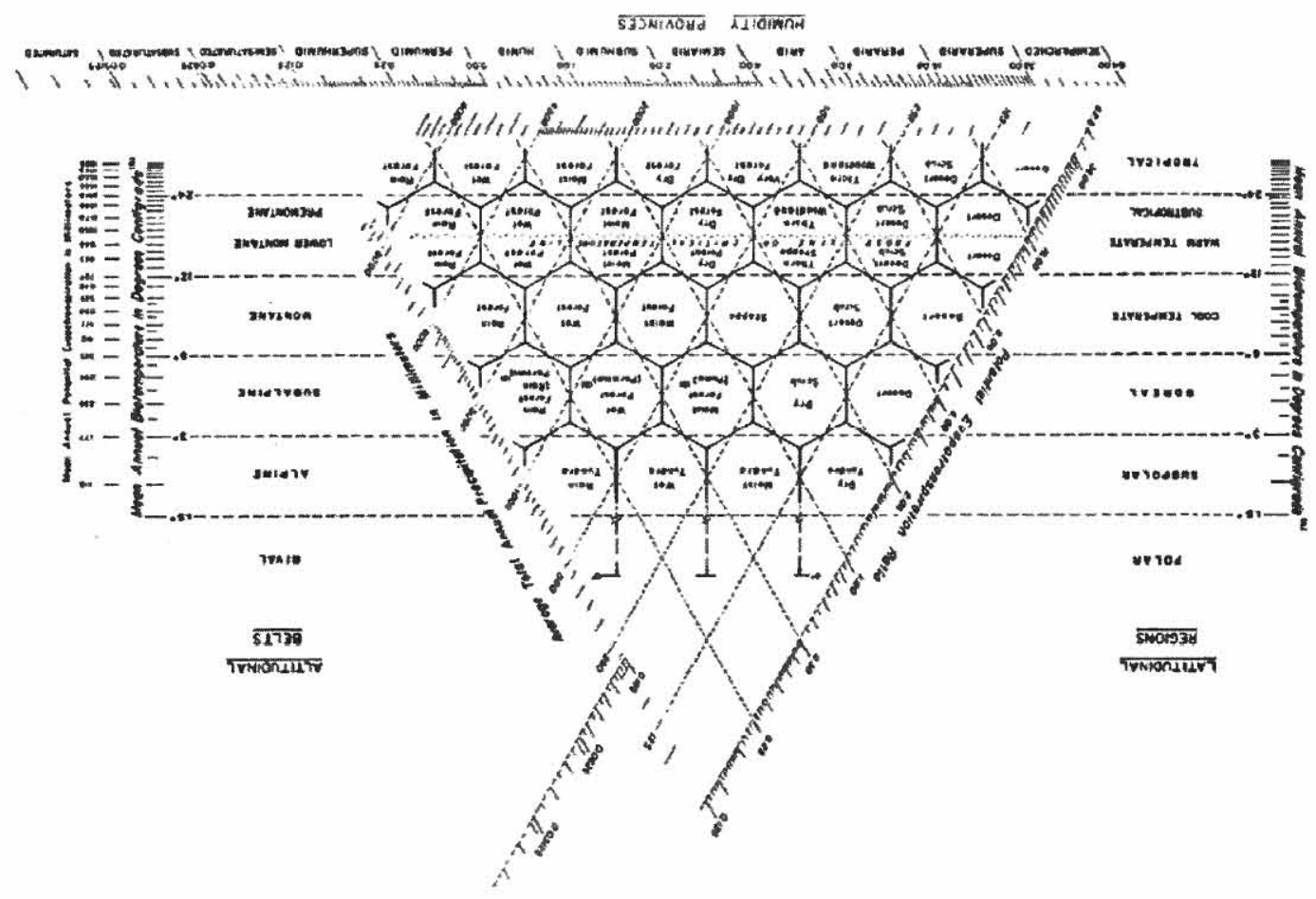

'T"N ‘uosuəudəIS 


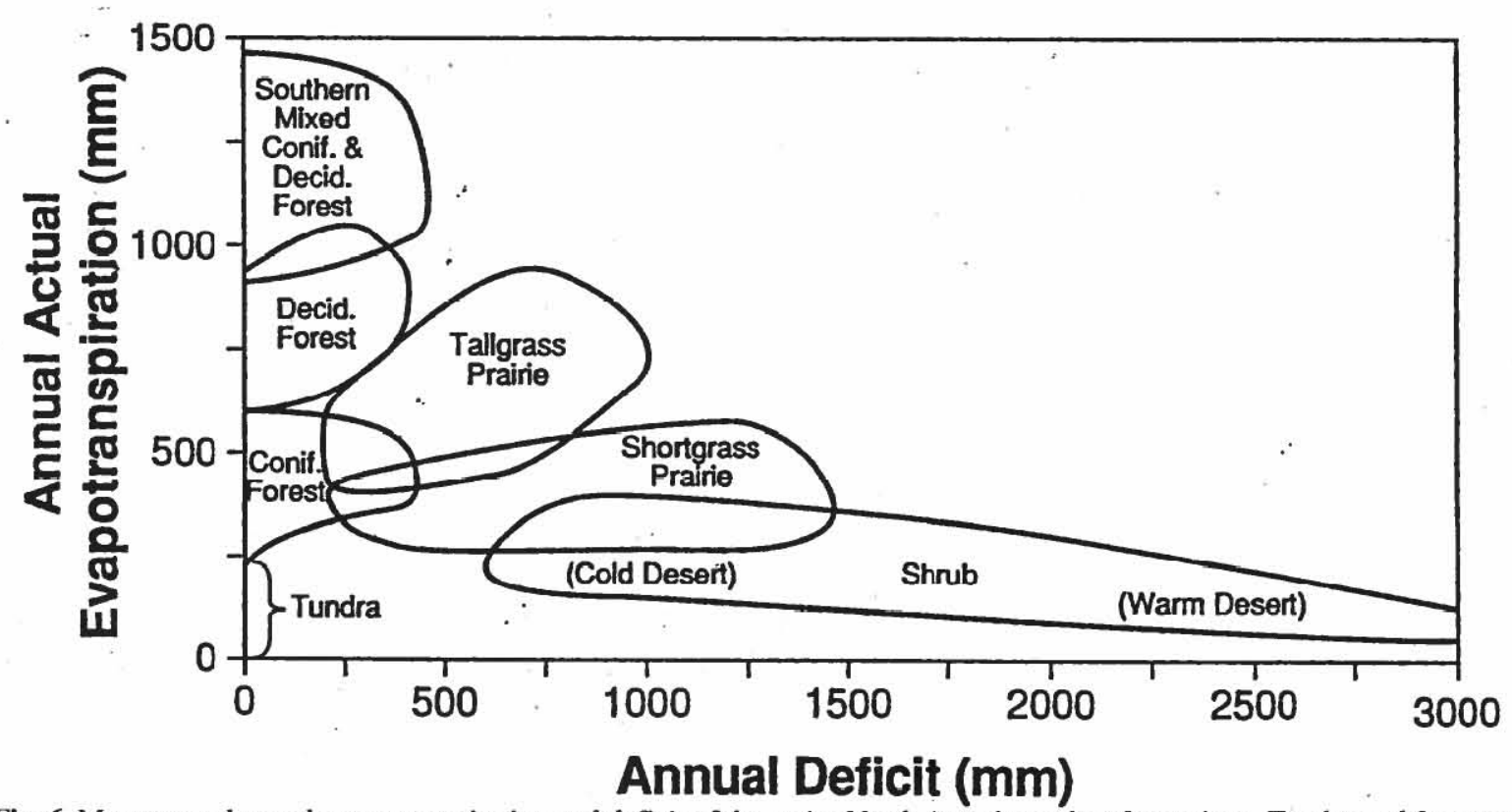

Fig. 6. Mean annual actual evapotranspiration and deficit of the major North American plant formations. Tundra and forest occur where annual water deficits are low; grasslands and desert shrublands where they are high. Diagonal lines connecting equal values of actual evapotranspiration and deficit represent isolines of potential evapotranspiration $\left(E_{p}\right)$, since $E_{P}=E_{A}+D$ (see the text). Thus, movement along a diagonal line connecting aclual evapotranspiration of $1000 \mathrm{~mm}$ and a deficit of $1000 \mathrm{~mm}$ represents a transect of increasing aridity (decreasing actual evapotranspiration, increasing deficit) at approximately constant annual energy (potential evapotranspiration $=1000$ $\mathrm{mm}$ ). These changes in the water balance are found along an east-to-west transect straddling $40^{\circ} \mathrm{N}$ latitude in North America, where a sequence of deciduous forest, tallgrass prairie, shortgrass prairie, and cold desert are encountered with increasing aridity. From Stephenson (1990).

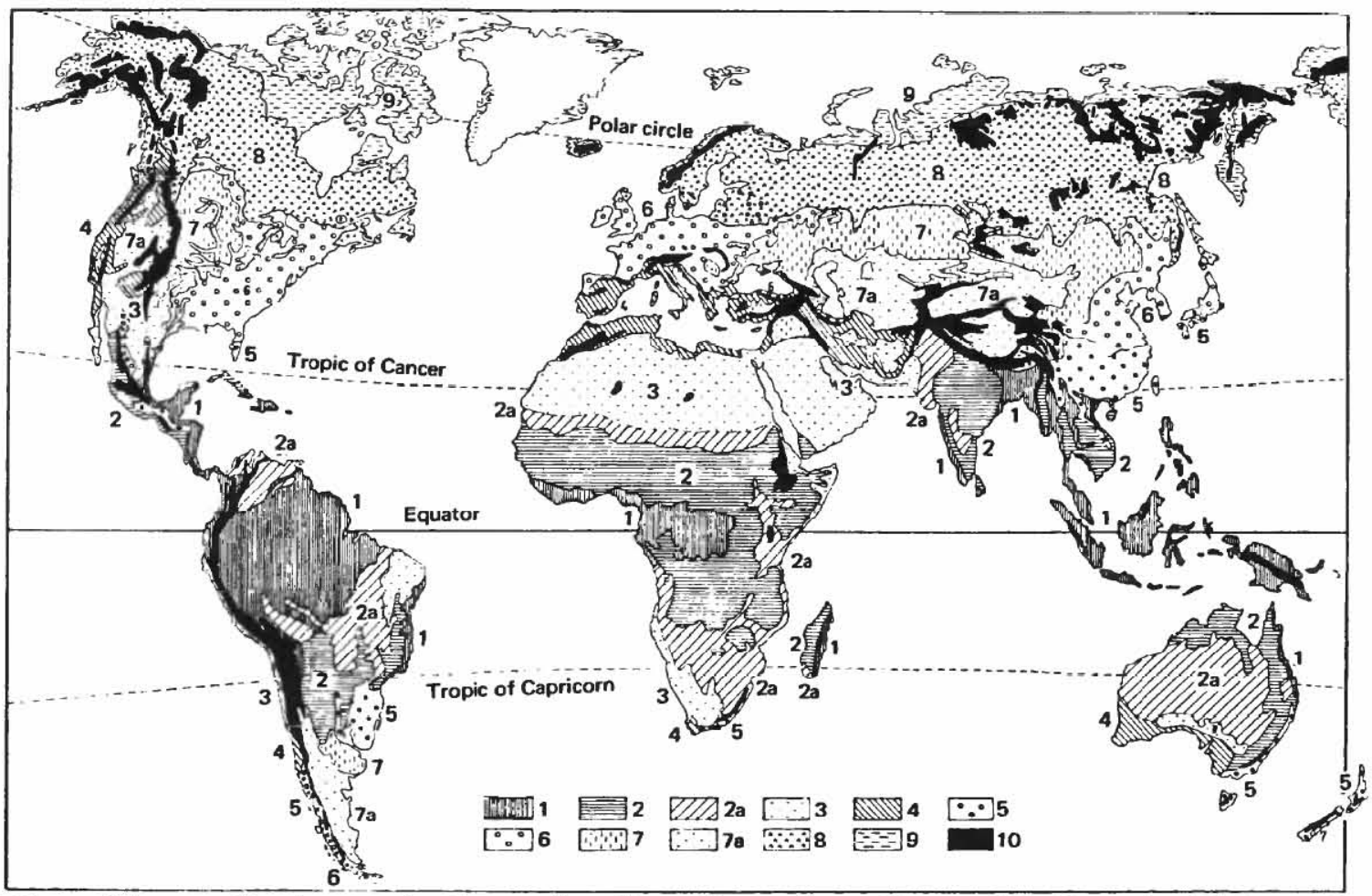

Fig. 7. The world's great climatic-vegetational zones ("zonobiomes") according to Walter (1985). Tropical and Subtropical Zones: (1) tropical rain climate (evergreen rain forest), (2) tropical summer-rain climate (semievergreen and deciduous forest, and 2a, dry woodland, savanna, or grassland), (3) subtropical arid climate (hot desert and semidesert). Temperate and Arctic Zones: (4) winter-rain climate (sclerophyllous woodland), (5) warm moist-temperate climate (temperate woodland), (6) typical temperate climate (deciduous forest), (7) arid-temperate climate, with cold winters (temperate steppe [grassland], and 7a, semidesert and desert), (8) cold-temperate climate (boreal coniferous forest), (9) arctic and antarctic climate (tundra), (10) mountains (complex mosaic of climate and vegetation types). Taken, with permission, from Walter (1985). 
cause, for a large part of the year (if not all year), evaporative demand exceeds water supply. Consequently, grasslands and shrublands rarely experience large water surpluses, and the timing of revegetation efforts is more likely to be determined by precipitation than by temperature. These patterns are more easily understood when selected site water halances are examined, below.

At low deficit, a sequence of tundra, coniferous forest, deciduous forest, and mixed forest is encountered with increasing annual actual evapotranspiration (Fig. 6). The outstanding climatic feature of tundra environments (Walter's zonobiome 9), and the one most likely to influence the timing of revegetation efforts, is their low temperature. The average annual temperature of Nome, Alaska, is $-3{ }^{\circ} \mathrm{C}$, and only five months of the year have average temperatures above freezing. Evaporative demand at Nome is correspondingly low. Thus, in spite of relatively low annual precipitation $(455 \mathrm{~mm}$ ), potential evapotranspiration exceeds precipitation in only one month; as a result, water deficits are insignificant and about $60 \%$ of annual precipitation runs off as surplus (Fig. 8a). Annual actual evapotranspiration averages $175 \mathrm{~mm}$, below the minimum of about $240 \mathrm{~mm}$ typical of coniferous forest environments. The world's largest expanses of tundra are confined to the Northern Hemisphere (Fig. 7).

At Moosonee, Ontario, both evaporative demand and water supply are greater. Annual actual evapotranspiration still is limited by energy, and water deficits are insignificant or nonexistent (Fig. 8b). However, warmer temperatures and correspondingly greater evaporative demand boost Moosonee's annual actual evapotranspiration to 345 $\mathrm{mm}$, past the threshold for coniferous forest (Walter's zonobiome 8). Not all coniferous forests are energy-limited like those at Moosonee, however; actual evapotranspiration may alternate seasonally between energy-limitation and water-limitation (such as at Portland, Oregon Walter's zonobiome 5; see Fig. 1), or may in some cases be water-limited all year (such as at Flagstaff, Arizona; see Stephenson 1990). The common denominator among coniferous forest climates is low annual deficit (less than a. Nome, Alaske (tundra)

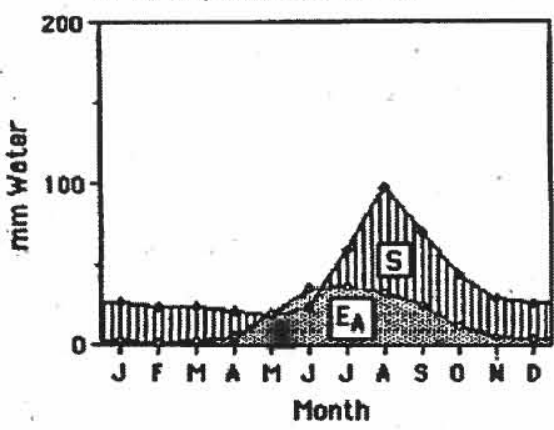

b. Moosonee, Onterlo (conif. forest)

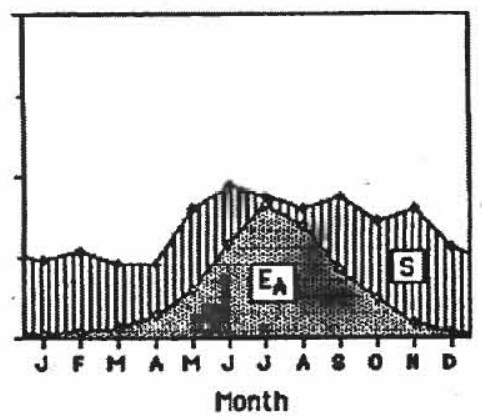

\section{c. Erle, Pennsylyonio (decid. forest)}

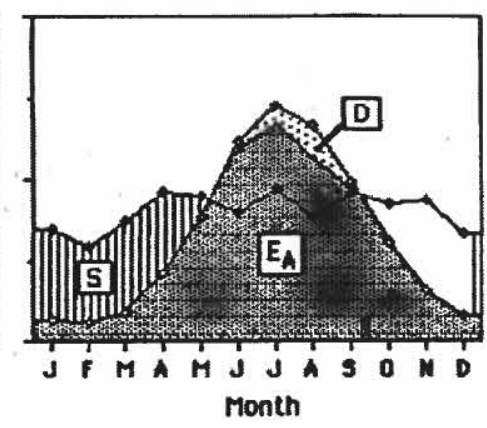

d. Goodland, Kansas (grassiand)

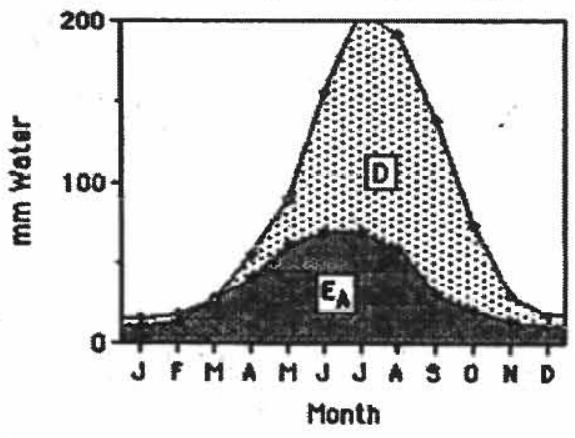

8. Phoenix, Arizona (desert shrub)

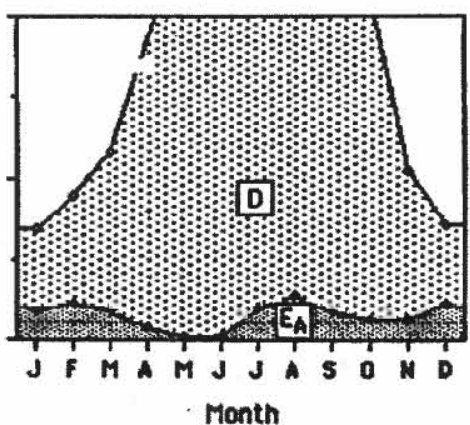

Fig. 8. Water balances of selected sites representing some of the major North American plant formations (see Fig. 1 for a further explanation of water-balance diagrams). Data on the timing and amount of snowmelt were unavailable, so water supply was estimated from precipitation (solid diamonds) (open diamonds are potential evapotranspiration). Actual evapotranspiration $\left(\mathrm{E}_{\mathrm{A}}\right.$, dense stippling) most often is limited by energy in tundra and forest environments (a-c); consequently water deficits (D, sparse stippling) are low and much of annual precipitation runs off as surplus ( $\mathrm{S}$, stripes). (While the long-term average water balances in diagrams $a$ and $b$ show no period of water deficit, deficits can occur in individual years of low precipitation at these sites.) Actual evapotranspiration usually is limited by water in grassland and shrub environments ( $\mathrm{d} \& \mathrm{e}$ ), leading to high deficits and little or no surplus. (While the long-term average water balances in diagrams $d$ and $e$ show no period of water surplus, surplus can occur in individual years of heavy precipitation.) Data from Eagleman (1976); b and c redrawn from Stephenson (1990). 
about $400 \mathrm{~mm}$ ) and annual actual evapotranspiration between about 240 and $600 \mathrm{~mm}$ (Fig. 6; also see Stephenson, 1990, 1998 for more complete discussions). Most of the world's coniferous forests are found in vast expanses of boreal forest in the Northern Hemisphere (Fig. 7).

Annual energy and water supplies continue to increase south of Moosonee. At Erie, Pennsylvania, potential evapotranspiration slightly exceeds precipitation in the summer months, leading to a summertime drawdown of soil water and mild water deficits ( $40 \mathrm{~mm}$ annually; Fig. 8c). At $725 \mathrm{~mm}$, annual actual evapotranspiration at Erie exceeds the $600 \mathrm{~mm}$ threshold for deciduous forest (Walter's zonobiome 6). Interestingly, the coniferous forest climate of Portland (Fig. 1) and the deciduous forest climate of Erie (Fig. 8c) have nearly identical annual precipitation ( $945 \mathrm{~mm}$ and $960 \mathrm{~mm}$ ) and potential evapotranspiration (760 mm and $765 \mathrm{~mm}$ ). But, unlike Erie, energy and water supplies are seasonally asynchronous in Portland, leading to an annual actual evapotranspiration of 560 $\mathrm{mm}$, below the threshold for deciduous forest.

To the south of Erie, in the southeastern United States, pines are pioneer species following disturbance in what is otherwise a deciduous forest (indicated as "southern mixed coniferous and deciduous forest" in Fig. 6). In the absence of disturbance, a mostly deciduous forest would dominate the region. Annual actual evapotranspiration in these southern mixed forests usually exceeds $1000 \mathrm{~mm}$, but water deficits still remain low (usually less than 400 $\mathrm{mm}$ ).

Now moving west, we enter grassland and shrubland environments - those characterized by high water deficits. At Goodland, Kansas, average evaporative demand equals or exceeds average precipitation year-round, and actual evapotranspiration is now limited by available water (Fig. 8d). On an average year, there is no surplus period. Timing of precipitation will therefore play a large role in the timing of revegetation efforts. Although Goodland's annual actual evapotranspiration $(420 \mathrm{~mm})$ is comparable to that of coniferous forest environments, its annual water deficit $(590 \mathrm{~mm})$ is ton high to support forest. Goodland lies in the midst of shortgrass prairie (Walter's zonobiome 7). The world's great temperate steppes (grasslands) are found in the centers of the North American and Eurasian continents, and on the east coast of southern South America (Fig. 7).

At Phoenix, Arizona, evaporative demand far outstrips precipitation year-round (Fig. 8e). Annual actual evapotranspiration $(185 \mathrm{~mm})$ is limited by annual precipitation (also $185 \mathrm{~mm}$ ), and the climate is overwhelmingly dominated by a year-round water deficit totalling $2315 \mathrm{~mm}$ annually. As for grassland climates, timing of revegetation efforts will be closely linked to timing of precipitation. The region is dominated by desert shrub vegetation (Walter's zonobiome 3). Hot deserts are found on all continents (except Antarctica) in subtropical regions (Fig. 7).
Other climate and vegetation types. Leaving North America, we will briefly examine four climatic types associated with Walter's three remaining zonobiomes. Tropical summer-rain climates (Walter's zonobiome 2), including the famous monsoonal climates of southern Asia, are usually characterized by sharply defined wet and dry seasons. More than $99 \%$ of annual precipitation can fall in less than half the year, leading to periods of alternating extreme drought and extreme water surplus. Bombay, for example, has a substantial annual surplus (1020 mm), mostly occurring from July through October, followed by a deficit totalling $720 \mathrm{~mm}$ from November through May (Fig. 9a). Average precipitation at Bombay is virtually zero in April, peaking at an astonishing $620 \mathrm{~mm}$ in July, only three months later. Depending on associated soils and the length and magnitude of the deficit period, tropical summer-rain climates can support mixed broadleaf deciduous and broadleaf evergreen forest, broadleaf deciduous forest, dry woodland, savanna, or grassland. These climates and formations are found in the tropics and subtropics, on all continents except Antarctica (Fig. 7).

Highly seasonal precipitation also occurs in the winter-rain climates (also called "mediterranean climates") - those typically found on the west sides of continents between about $30^{\circ}$ and $40^{\circ}$ latitude (Walter's zonobiome 4; Fig. 7). However, in contrast to monsoonal climates, most annual precipitation comes during the cool winter months. Precipitation is least in the hot summer months, leading to high water deficits. In Santiago, for example, $90 \%$ of annual precipitation falls during the six coldest months (Fig. 9b). The remaining $10 \%$ of annual precipitation is far too little to meet summertime evaporative demand, leading to an annual deficit of $410 \mathrm{~mm}$. The vegetation of mediterranean climates often is dominated by evergreen sclerophyllous (hard-leaved) woodlands (di Castri and Mooney 1973; Mooney 1977).

As their name implies, bimodal climates are characterized by two distinct rainy seasons annually. While they are most frequently associated with the vegetation types of Walter's zonobiome 2, bimndal climates span vegetation types usually associated with other zonobiomes (such as hot desert, zonobiome 3). In Nairobi, an area dominated by savanna vegetation, a brief wet season in November breaks an otherwise uninterrupted drought that started in June or July, and precedes the main wet season from March through May (Fig. 9c). As for much of the tropics, potential evapotranspiration is relatively constant year-round in Nairobi, where temperature and net radiation (two of the most important determinants of evaporative demand) are relatively constant year-round. In general, tropical seasons are less defined by temperature than by precipitation. Bimodal climates are mostly limited to the tropics and subtropics.

Tropical rain climates are characterized by relatively constant warm temperatures, heavy rain, low (or no) water deficits, and large surpluses (Walter's zonobiome 1). 
o. Bombay, India (monsoonal)

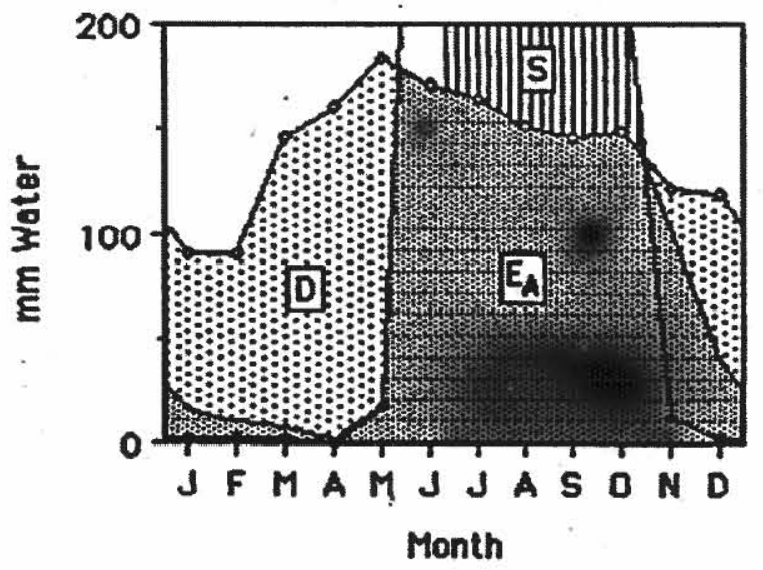

c. Nairobi, Kenya (bimadal)

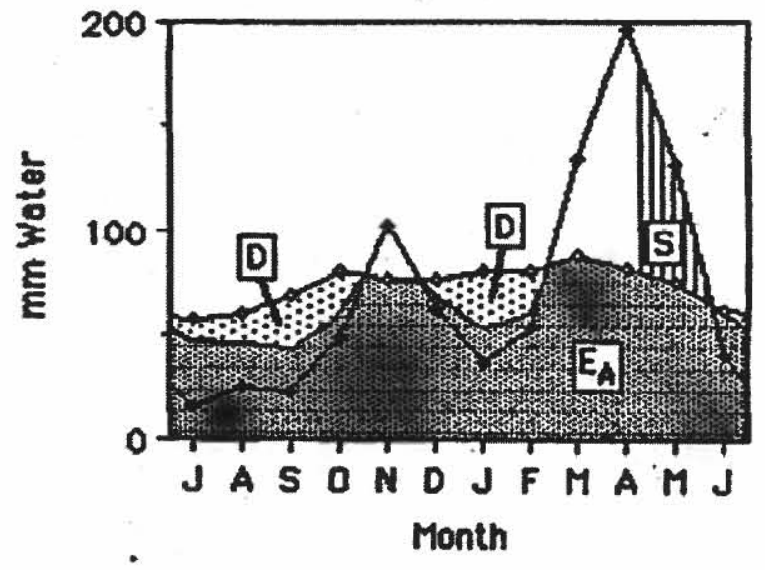

b. Santiago, Chile (mediterraneen)

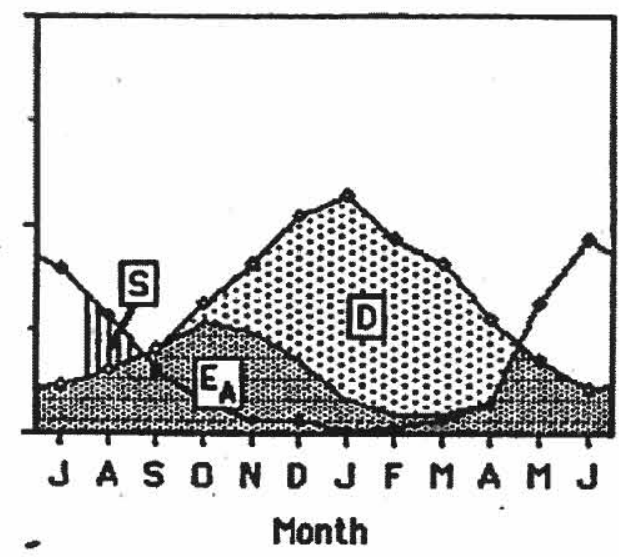

d. Hilo, Hawail (tropical rain)

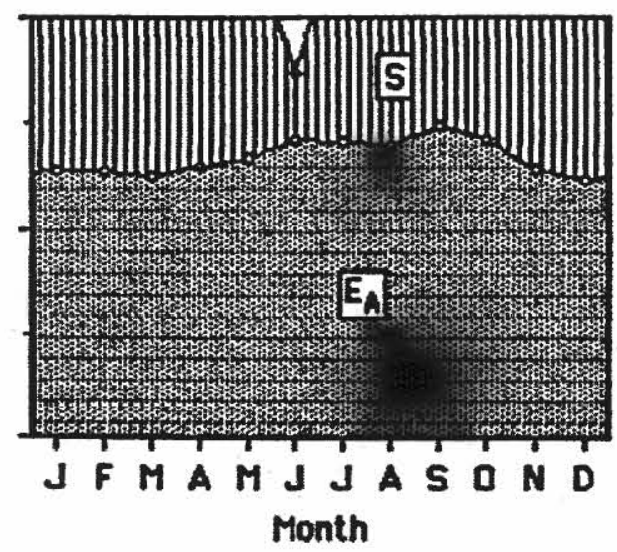

Fig. 9. Water balances of selected sites representing other major climate types of the world (see Fig. 1 for a further explanation of waterbalance diagrams). For consistency of arrangement of seasons among diagrams, sites south of the equator (Santiago and Nairobi) have months ordered from July through June, so that the warmest months are at the center of the diagram. Data for $a, b$, and $c$ are recalculated from Mather (1962, 1963a, 1965), to reflect soil water-holding capacities of $150 \mathrm{~mm}$. Data for $d$ are from Eagleman (1976).

For example, at Hilo annual precipitation is nearly 3500 $\mathrm{mm}$, and only one month has precipitation less than 200 mm (Fig. 9d). These humid climates support lush rain forests of broadleaf evergreen trees, noted especially for their high species richness (Richards 1973; Whitmore 1998). Even though this is the stereotypic tropical climate for many people living at higher latitudes (who often picture the tropics as dominated by dripping, steaming jungles), tropical areas where precipitation exceeds evaporative demand all year (or nearly all year) are relatively limited, mostly to the Amazon basin, equatorial West Africa, and parts of southeast $\Lambda$ sia (Fig. 7). $\Lambda$ s at Nairobi, evaporative demand at Hilo is nearly constant year-round.

\section{Conclusions}

An understanding of the climatic controls of plant and vegetation distribution can assist restorationists in their tasks. Two fundamental principles are that climate acts on plants largely through the interactions of energy and water (evaporative demand and water availability), and that the factors affecting evaporative demand and water availability vary with spatial scale. There are several predictable relationships between climate and vegetation distribution. Each of the earth's climates offers different challenges to restoration ecologists, ranging from extreme drought stress and highly variable precipitation (arid climates) to potential for severe flooding (monsoonal and tropical rain climates). 
Acknowledgements. I thankE. Allen, J. Keeley, Z. Naveh, and an anonymous reviewer for helpful comments on the manuscript. Special thanks go to Edie Allen for supplying some key references.

\section{Literature Cited}

Arkley, R.J. 1967. Climates of some great soil groups of the western United States. Soil Science 103:389-400.

Azevedo, J. and D.L. Morgan. 1974. Fog precipitation in coastal California forests. Ecology 55:1135-1141.

Barbour, M.G. and W.D. Billings (eds). 1988. North American Terrestrial Vegetation. Cambridge University Press, Cambridge.

Barbour, M.G., J.H. Burk, W.D. Pitts, F.S. Gilliam, and M.W. Schwartz. 1999. Terrestrial Plant Ecology. 3rd edition. Benjamin/Cummings, Menlo Park, CA.

Barry, R.G. and R.J. Chorley. 1998. Atmosphere, weather, and climate. 7th edition. Routledge, Chapman and Hall, NY.

Begon, M., J.L. Harper, and C.R. Townsend. 1986. Ecology: individuals, populations, and communities. Sinauer Associates, Sunderland, MA.

Berg, B., M. P. Berg, P. Bottner, E. Box, A. Brcymcycr, R. Calvo de Anta, M. Couteaux, A. Escudero, A. Gallardo, W. Kratz, M. Madeira, E. Mälkänen, C. McClaugherty, V.Meentemeyer, F. Muñoz, P. Piussi, J. Remacle, and A. Virzo de Santo. 1993. Litter mass loss rates in pine forests of Europe and eastern United States: some relationships with climate and litter quality. Biogeochemistry 20:127-159.

Bradley, R.S. (ed). 1990. Global changes of the past. University Corporation for Atmospheric Research, Office of Interdisciplinary Earth Studies, Boulder, CO.

Brady, N.C. 1974. The nature and properties of soils. 8th edition. Macmillan, New York, NY.

Campbell, G.S. and J.M. Norman. 1998. An introduction to environmentalbiophysics. 2nd edition. Springer-Verlag, New York, NY.

Cantlon, J.E. 1953. Vegetation and microclimates on north and south slopes of Cushetunk Mountain, New Jersey. Ecological Monographs 23:241-270.

Chabot, B.F. and H.A. Mooney (eds). 1985. Physiological ecology of North American plant communities. Chapman and Hall, New York, NY.

Cooper, A.W. 1961. Relationship between plant life-forms and microclimate in southeastern Michigan. Ecological Monographs 31:31-59.

Currie, D. J. 1991. Energy and large-scale patterns of animal-and plant-species richness. American Naturalist 137:27-49.

Currie, D.J. and V. Paquin. 1987. Large-scale biogeographical patterns of species richness of trees. Nature 329:326-327.

Dansereau, P. 1957. Biogeography: an ecological perspective. Roland Press, New York, NY.

di Castri, F. 1973. Climatographical comparisons between Chile and the western coast of North America. Pp. 21-36 in F. di Castri and H.A. Mooney, eds. Mediterranean-type ecosystems: origin and structure. Springer-Verlag, New York, NY.

di Castri, F. and H.A. Mooney (eds). 1973. Mediterranean-type ecosystems: origin and structure. Springer-Verlag, New York, NY.
Eagleman, J.R. 1976. The visualization of climate. Lexington Books, Lexington, MA.

Etherington, J.R. 1982. Environment and plant ecology. 2nd edition. John Wiley \& Sons, New York, NY.

Eyre, S.R. (ed). 1971. World vegetation types. MacMillan, London.

Galston, A.W., P.J. Davies, and R.L. Satter. 1980. The life of the green plant. 3rd edition. Prentice-Hall, Englewood Cliffs, NJ.

Geiger, R. 1965. The climate near the ground. 4th edition. Harvard University Press, Cambridge, MA.

Givnish, T.J. (ed). 1986. On the economy of plant form and function. Cambridge University Press, Cambridge, U.K.

Grime, J.P. 1979. Plant strategies and vegetation processes. John Wiley \& Sons, New York, NY.

Hastings, J.R. and R.M. Turner. 1965. The changing mile. University of Arizona Press, Tucson, AZ.

Henderson-Sellers, A. and P.J. Robinson. 1986. Contemporary climatology. Addison Wesley Longman, Essex, England.

Holdridge, L.R. 1967. Life zone ecology. Revised edition. Tropical Science Center, San Jose, Costa Rica.

Horn, H.S. 1971. The adaptive geometry of trees. Princeton University Press, Princeton, NJ.

Jackson, L.E. 1985. Ecological origins of California's mediterranean grasses. Journal of Biogeography 12:349-361.

Jones, H.G. 1992. Plants and microclimate. 2nd edition. Cambridge University Press, Cambridge, U.K.

Kareiva, P.M., J.G. Kingsolver, andR.B. Huey (eds). 1993. Biotic interactions and global change. Sinauer, Sunderland, MA.

Krebs, C.J. 1978. Ecology: the experimental analysis of distribution and abundance. Harper \& Row, NY.

Lambers, H., F.S. Chapin, and T. Pons. 1998. Plant physiological ecology. Springer-Verlag, NY.

Larcher, W. 1995. Physiological plant ecology. 3rd edition. Springer-Verlag, Berlin.

Lieth, H. 1956. Ein Beitrag zur Frage der Korrelation zwischen mittleren Klimawerten und Vegetationsformationen. Berichte der Deutschen Botanischen Gesellschaft 69:169-176.

Lieth, H. 1975. Modeling the primary productivity of the world. Pp. 237- 263 in H. Lieth and R.H. Whittaker, eds. Primary productivity of the biosphere. Springer-Verlag, New York, NY.

Lieth, H. 1976. The use of correlation models to predict primary productivity from precipitation or evapotranspiration. Pp. 392 - 407, in O.L. Lange, L. Kappen, and E.-D. Schulze, eds. Water and plant life. Springer-Verlag, New York, NY.

Linacre, E. 1992. Climate data and resources: a reference and guide. Routledge, London.

Lowry, W.P. 1969. Weather and life: an introduction to biometeorology. Academic Press, New York, NY.

MacMahon, J.A. 1980. Ecosystems over time: succession and other kinds of change. Pp. 27-58, in R. Waring, ed. Forests: fresh perspectives from ecosystem analyses. Oregon State University Press, Corvallis, OR.

Major, J. 1951. A functional, factorial approach to plant ecology. Ecology 32:392-412.

Major, J. 1963. A climatic index to vascular plant activity. Ecology 44:485-498.

Mather, J.R. 1962. Average climatic water balance data of the continents. Part I. Africa. Publications in Climatology 15:115287. 
Mather, J.R. 1963a. Average climatic water balance data of the continents. Part II. Asia (excluding U.S.S.R.). Publications in Climatology 16:5-262.

Mather, J.R. 1963b. Average climatic water balance data of the continents. Part III. U.S.S.R. Publications in Climatology 16:267-378.

Mather, J.R. 1963c. Average climatic water balance data of the continents. Part IV. Australia, New Zealand, and Oceania. Publications in Climatology 16:383-476.

Mather, J.R. 1964a. Average climatic water balance data of the continents. Part V. Europe. Publications in Climatology 17:5229.

Mather, J.R. 1964b. Average climatic water balance data of the continents. Part VI. North America (excluding the United States). Publications in Climatology 17:235-414.

Mather, J.R. 1964c. Average climatic water balance data of the continents. Part VII. United States. Publications in Climatology 17:419-615.

Mather, J.R. 1965. Average climatic water balance data of the continents. Part VIII. South America. Publications in Climatology 18:297-433.

Meentemeyer, V. 1978. Macroclimate and lignin control of litter decomposition rates. Ecology 59:465-472.

Mooney, H.A. (ed). 1977. Convergent evolution in Chile and California: mediterranean climate ecosystems. Dowden, Hutchinson, and Ross, Stroudsburg, PA.

Oosting, H.J. 1956. The study of plant communities. 2nd edition. W. H. Freeman, San Francisco, CA.

Peters, R.L. and T.E. Lovejoy (eds). 1992. Global warming and biological diversity. Yale University Press, New Haven, CT.

Richards, P.W. 1973. The tropical rain forest. Scientific American 229(6):58-67.

Rosenberg, N.J., B.L. Blad, and S.B. Verma. 1983. Microclimate: the biological environment. 2nd edition. Wiley, New York, NY.

Rosenzweig, M.L. 1968. Net primary productivity of terrestrial communities: prediction from climatological data. American Naturalist 102:67-74.

Schneider, S.H. and R. Londer. 1984. The coevolution of climate and life. Sierra Club Books, San Francisco, CA.

Sellers, W.D. 1965. Physical climatology. University of Chicago Press, Chicago, IL.

Solomon, A.M. and H.H. Shugart. 1993. Vegetation dynamics and global change. Chapman \& Hall, New York, NY.

Stephenson, N.L. 1990. Climatic control of vegetation distribution: the role of the water balance. American Naturalist 135:649-670.

Stephenson, N.L. 1998. Actual evapotranspiration and deficit: biologically meaningful correlates of vegetation distribution across spatial scales. Journal of Biogeography 25:855-870.

Thornthwaite, C.W. 1948. An approach toward a rational classification of climate. Geographical Review 38:55-94.

Thornthwaite, C.W., J.R. Mather, and D.B. Carter. 1957. Instructions and tables for computing potential evapotranspiration and the water balance. Publications in Climatology 10:183311.

Trewartha, G.T. 1968. An introduction to climate. 4th edition. McGraw-Hill, New York, NY.

USSR National Committee for the International Hydrological Decade. 1977. Atlas of World Water Balance. UNESCO Press, Paris.
Walker, B. and W. Steffen (eds). 1996. Global change and terrestrial ecosystems. Cambridge University Press, Cambridge, U.K.

Walter, H. 1968. Die Vegetation der Erde in Oko-physiologischer Betrachtung. Vol. II. Die Gemässigten und Arktischen Zonen. Gustav-Fischer Verlag, Jena, Germany.

Walter, H. 1973. Die Vegetation der Erde in Öko-physiologischer Betrachtung. Vol. I. Die Tropischen und SubtropischenZonen. 3rd edition. Gustav-Fischer Verlag, Stuttgart, Germany.

Walter, H. 1985. Vegetation of the Earth and Ecological Systems of the Geo-Biosphere. 3rd edition. Springer, New York, NY.

Walter, H., E. Harnickell, and D. Mueller-Dombois. 1975a. Klimadiagramm-Karten der einzelen Kontinente und okologische Klimagliederung der Erde. Gustav-Fischer Verlag, Stuttgart, Germany.

Walter, H., E. Harnickell, and D. Mueller-Dombois. 1975b. Climate-Diagram Maps of the Individual Continents and the Ecological Climate Regions of the Earth. Springer, New York, NY. (English translation of the preceding reference.)

Walter, H. and H. Lieth. 1967. Klimadiagramm-Weltatlas. GustavFischer Verlag, Jena, Germany.

Waring, R.H. and J.F. Franklin. 1979. Evergreen coniferous forests of the Pacific Northwest. Science 204:1380-1386.

Watson, R.T., M.C. Zinyowera, and R.H. Moss (eds). 1996. Climate change 1995 - Impacts, adaptations and mitigation of climate change: scientific-technical analyses. Cambridge University Press, Cambridge, U.K.

Whitmore, T.C. 1998. An introduction to tropical rain forests. 2nd edition. Oxford University Press, Oxford, U.K.

Whittaker, R.H. 1975. Communities andecosystems. 2nd edition. MacMillan, New York, NY.

Wolfe, J.N., R.T. Wareham, and H.T. Scofield. 1949. Microclimates and macroclimate of Neotoma, a small valley in central Ohio. Ohio Biological Survey, Bulletin 41 (Volume 8, No. 1):1-267.

Woodward, F.I. 1987. Climate and plant distribution. Cambridge University Press, Cambridge, U.K.

Wyman, R.L. (ed). 1991. Global climate change and life on Earth. Routledge, Chapman, and Hall, New York, NY. 


\title{
Population Genetic Theory and Data in Restoration of Rare Plants: Examples from Serpentine and Vernal Pool Taxa
}

\author{
Diane R. Elam \\ U.S. Fish and Wildlife Service, 3310 El Camino Ave., Suite 130, Sacramento, CA 95821 \\ Tel. (916) 979-2120; Fax (916) 979-212; e-mail: diane_elam@mail.fws.gov
}

\begin{abstract}
Population genetic data may improve selection of donor populations and design of restorations for rare plant taxa. However, population genetic data will usually be lacking for taxa of concern. Understanding when and how evolutionary factors (such as genetic drift, inbreeding, gene flow and selection) structure genetic variation may help biologists make preliminary guesses about levels and distribution of genetic variation in unstudied plant taxa. I discuss how approximate predictions of genetic structure may be made and used to help restoration practitioners avoid mistakes that may jeopardize the success of a restoration. I use vernal pool and serpentine endemic plant taxa to illustrate these concepts.
\end{abstract}

Keywords: Genetic drift, mating system, gene flow, Limnanthes, Clarkia, endangered, conservation

\section{Introduction}

Understanding population genetic structure will help maximize the likelihood of successfully designing and implementing the restoration of rare plant species. For example, considering population genetic structure (i.e. levels and distribution of genetic variation within and among populations) may allow design of restorations that minimize the probability that progeny of introduced individuals will suffer from inbreeding depression, that introduced individuals will die due to lack of local adaptation to the restoration site, and that mating of local and nonlocal individuals in the restoration will disrupt the genetic integrity of natural populations (i.e. will lead to genetic contamination) (Millar and Libby 1989; Knapp and Rice 1994; Linhart 1995).

Despite the recognition that population genetic principles may play a role in planning and implementing successful restorations, the widespread use of genetics in restoration has been limited. The infrequent use of genetics may be due in part to the lack of available data for most species. My paper addresses how understanding population genetic structure may be important in planning and implementing restoration programs for rare plants. I emphasize the role of population genetics (1) in selection of suitable donor populations and (2) in designing restorations. Where data are available for species targeted in the restoration, I discuss how knowledge of population genetic structure may help practitioners design the best restoration, and in the absence of data, how considering population genetic principles may still be important in helping practitioners avoid mistakes. The examples I use to illustrate these concepts are from serpentine and vernal pool endemic plants.

\section{Selection of Donor Populations}

A critical step in designing any restoration is the evaluation of potential sources of individuals, seeds or other propagules (donors). When restoration emphasizes rare plant species, the evaluation focuses on a limited number of a vailable populations. Population genetic questions to consider include (1) how much genetic variation is contained within populations (level of genetic variation) and (2) how that genetic variation is distributed among populations.

Selecting donor populations with relatively high levels of genetic variation might be important to increase the likelihood of success in a restoration if, as theory has suggested, levels of genetic diversity influence current or future persistence of populations. Reduced levels of variation are thought to limit the potential for persistence of populations or species over the long-term as the biotic or abiotic environment changes (Soulé 1980; Frankel and Soule 1981) or over the short-term such as during herbivore or pathogen outbreaks, drought or other extreme conditions (Huenneke 1991). In addition, it has been suggested that decreased levels of variation may influence population persistence in the short-term if heterozygosity per se has a direct impact on fitness (Frankel and Soulé 1981; Mitton and Grant 1984 and references therein). If populations with higher levels of genetic diversity are more persistent in the face of biotic and abiotic challenges, 
then using donor populations with high levels of genetic variation may increase the likelihood that restored populations are persistent. Even if genetic diversity is not highly associated with population viability, considering which donor populations have high levels of genetic variation may be important in ensuring that species level variation is represented in restoration efforts. However, genetically depauperate populations may also play a role in ensuring representation of species level variation if they contain high frequencies of rare alleles (as may result from genetic drift in small populations).

Considering how genetic diversity is distributed among populations of a rare species may also be important in restoration planning. Genetic variation is likely to be structured locally and/or regionally (Linhart and Grant 1996). For species with high levels of among-population genetic differentiation (i.e., where populations are genetically very different from one another), selecting donor material appropriate to the restoration site may be especially critical. "Mismatched" material (i.e., material from an unsuitable donor population) may die, or if it survives, contaminate local natural populations of the species causing outbreeding depression and disruption of local adaptation (see below and references). Knowledge of the distribution of variation among populations may also be valuable in ensuring sampling of species level variation in restoration efforts. If taxa of concern have high levels of among-population genetic variation, then more populations need to be sampled to ensure adequate representation of allelic and genotypic diversity within the taxon.

\section{Examples: Using available population genetic data in selecting donor populations}

In a limited number of cases, population genetic data for rare plant species will be available to help guide decisions about donor populations. Two examples which illustrate how available data may be used to select donor populations are Limnanthes floccosa ssp. californica (Limnanthaceae) and Clarkia franciscana (Onagraceae). For each, the available study measured levels and distribution of electrophoretically-detectable isozyme variation. Quantitative variation (Lande and Barrowclough 1987; Hamrick 1989) and DNA-based molecular markers such as chloroplast DNA and mitochondrial DNA (Avise 1994; Furnier and Stine 1995) may exhibit different patterns. To what extent neutral variation (i.e., molecular variation) is organized differently than adaptive variation is the subject of active research (Avise 1994).

Limnanthes floccosa ssp. californica is a state-and federally-listed endangered vernal pool endemic that is restricted to Butte County, California (Skinner and Pavlik 1994). Vernal pools, which are found throughout California (Holland and Jain 1988; Keeler-Wolf et al. 1996), are seasonally flooded landscape depressions underlain by a drainage-limiting subsurface layer of hardpan, clay- pan, basalt or other material. Pools support a specialized biota that contains an abundance of threatened and endangered species (Thorne 1981; Zedler 1987; Holland and Jain 1988) such as $L$. floccosa ssp. californica.

Dole and Sun (1992) estimated population genetic structure from 28 isozyme loci of 15 enzyme systems for nine of the eleven known populations of $L$. floccosa ssp. californica. They defined a population to be a group of plants separated from others by at least 100 meters or by an obvious dispersal barrier. The results of the isozyme analysis showed that $L$. floccosa ssp. californica is highly monomorphic (i.e. has very little genetic variation). Six of the nine populations were fixed (i.e. showed no variation) at all loci examined. The results also showed that $96 \%$ of the total genetic variation was distributed among populations $\left(G_{S T}=0.96\right)$. This value of $G_{S T}$ is among the highest recorded for local, conspecific populations of plants. The corresponding average number of successful migrants per generation $(\mathrm{Nm})$, calculated from $G_{S T}$, is 0.01 , suggesting gene flow among populations is quite low. Additionally, Dole and Sun (1992) used genetic distance estimates to identify three "centers of diversity" and two distinct populations that deserve special consideration in conservation efforts because they may have high frequencies of locally adapted alleles. Genetic distance also corresponded to geographic distance.

The population genetic structure of $L$. floccosa ssp. californica suggests some effective restoration strategies for the species. Especially important is the distribution of genetic variation among populations. Selection of donor populations ought to involve consideration of the location of the restoration site with respect to the centers of diversity identified by isozyme analysis. To the extent that patterns of genetic variation at isozyme loci are representative of patterns of variation throughout the genome and lacking any additional data, moving plant material among geographic regions that appeared genetically different in Dole and Sun's 1992 study would probably be imprudent. In addition, the data suggest that adequate representation of species level variation would require sampling from each center of diversity as well as from the distinct populations outside those centers.

Like Limnanthes floccosa ssp. californica , Clarkia franciscana is a state- and federally- listed endangered plant. It is a serpentine (edaphic) endemic restricted to San Francisco and Alameda counties in California (Skinner and Pavlik 1994). Serpentine substrates are characterized by high levels of magnesium and low levels of calcium and often contain heavy metals such as cobalt, nickel and iron. In California, approximately 215 species, subspecies and varieties of plants are endemic to serpentine substrates (Kruckeberg 1984).

Of the five known occurrences of $C$. franciscana, three are in the Oakland Hills of Alameda County and two are on the Presidio in San Francisco County (CNDDB 1997). Gottlieb and Edwards (1992) used isozyme electrophore- 
sis to examine the genetic relationship between plants at the two locations; they sampled one population from the Oakland Hills and one population from the Presidio. Despite low levels of genetic variation, they found substantial differences between the two populations. As with $L$. floccosa ssp. californica, these differences suggest that the location of the restoration might influence the selection of donor material. That is, if patterns of genetic variation at isozyme loci are representative of patterns of genetic variation throughout the genome, restorations planned for the Oakland Hills probably ought to utilize Oakland Hills material. In addition, these data suggest that to adequately represent species level variation sampling needs to be conducted at both locations.

\section{Population genetic structure of unstudied plant taxa}

These examples are exceptional because for many plant taxa of concern, genetic data will not be available. Most often, obtaining the necessary genetic data will not be feasible within the time frame of concern. Because genetic data will most often be lacking, it makes sense to consider whether there are circumstances in which it may be possible to make predictions about the probable genetic structure of unstudied plant taxa. Because theory suggests that evolutionary factors such as genetic drift, inbreeding, gene flow and natural selection are important in structuring genetic variation (Futuyma 1986; Hartl and Clark 1989), the discussion below is based upon predictions related to these factors.

Genetic drifi. Genetic drift can be defined as the random change in allele frequencies that occurs because only a subset of alleles present in the parental generation is transmitted to the next generation. Genetic structure is expected to be most influenced by genetic drift in populations that are continually small in size (e.g. $<100$ individuals) or that occasionally fluctuate to small size, as in population bottlenecks or founder/colonization events (Frankel and Soulé 1980; Futuyma 1986). Theory predicts that genetic drift will substantially alter population genetic structure when $1 / 4 N_{e}$ is much greater than the mutation rate $(\mu)$ and the selection coefficient $(s)$ where $N_{e}$ is the effective population size. Effective population size, the number of individuals in an ideal population that would have the same genetic response to random processes as a real population of size $N$ (Wright 1931; Crawford 1984), is difficult to measure accurately in nature but is generally expected to be less than the census size, $N$ (e.g. Nunney and Elam 1994). Factors that can lower $N_{e}$ relative to $N$ include population size fluctuations, unbalanced sex ratios and variance in reproductive success among individuals (Wright 1938).

Allele frequencies may undergo large and unpredictable fluctuations in small populations due to genetic drift. One can expect (1) genetic variation to decrease within populations (exhibited by loss of heterozygosity and eventually fixation of alleles) and (2) differentiation among populations to increase (i.e. populations become genetically more different from each other) (Futuyma 1986; Falconer 1989). In populations that undergo substantial population size fluctuations, allelic variation is likely to decrease (i.e. alleles are likely to be lost) while expected heterozygosity often is relatively unchanged as long as population size rebounds rapidly (Futuyma 1986; Barrett and Kohn 1991). The specific effects of drift on genetic diversity in small plant populations (Ellstrand and Elam 1993) and the population genetic consequences of bottlenecks and founder events (Barrett and Kohn 1991) have been discussed elsewhere.

The available data suggest that patterns of genetic variation in some rare plant taxa are consistent with the predictions of genetic drift (e.g. Ellstrand and Elam 1993). However, patterns consistent with genetic drift may not be caused by genetic drift. Mating systems, gene flow, natural selection and other factors are also likely to influence patterns of genetic variation. In particular, it has been suggested that seed banks may play a role in the maintenance of genetic variation as well as in buffering large changes in genetic composition (Baker 1989).

Inbreeding/mating system. Inbreeding is the mating of related individuals (Falconer 1989). In plants, mating system strongly influences the level of inbreeding. Selfing is the most extreme form of inbreeding. Some plants are habitually selfing. In others, selfing may be (1) reduced by patterns of flower development such as protandry (where anther dehiscence precedes stigma receptivity) or (2) prevented by breeding systems which ensure outcrossing (e.g. self-incompatibility). Inbreeding in plants can also occur through mating of two related individuals (biparental inbreeding) when populations are small (Barrett and Kohn 1991 and references therein) or exhibit spatial genetic structure (e.g. Turner et al. 1982) as many populations do (Linhart and Grant 1996).

Inbreeding leads to increases in homozygosity and among-population differentiation. Smaller populations are expected to lose heterozygosity faster than larger ones because heterozygosity is lost at a rate of $1 / 2 N_{e}$ per generation. Frequencies of heterozygotes are expected to approach zero in populations characterized by continuous inbreeding (Wright 1931; Futuyma 1986). Because inbreeding levels are closely related to mating system, the particular genetic structure of a plant population is highly influenced by the plant's mating system (Hamrick 1989). Habitually selfing species tend to have low within-population genetic variation and high among-population differentiation (Hamrick and Godt 1990). Because mating systems play a crucial role in shaping population genetic structure, knowledge of a plant's mating system may provide clues to its genetic structure. 
Inbreeding may also affect fitness (viability and/or fecundity). Inbreeding depression is expressed as a loss of fitness with increasing homozygosity. The precise mechanism of inbreeding depression is not fully understood but is an area of active research. Increased homozygosity due to inbreeding may result in a loss of fitness because (1) heterozygotes are superior at loci affecting fitness (overdominance) or (2) increased homozygosity leads to expression of deleterious recessive alleles. In the latter case, selection in typically inbreeding (e.g., selfing) populations is expected to remove deleterious recessives responsible for fitness losses, resulting in populations that exhibit little inbreeding depression (Charlesworth and Charlesworth 1987). Nevertheless, the observation that some selfing species suffer from strong inbreeding depression suggests that the relationship between selfing rate (mating system) and inbreeding depression is not precise (Barrett and Kohn 1991).

Gene flow. Geographically discrete plant populations may not be reproductively isolated due to gene flow between populations. Gene flow, which occurs by interpopulation mating or by migration of seeds or vegetative propagules (Ellstrand and Elam 1993), can be substantial but is highly variable among species, populations, individuals and years (Ellstrand 1992). Even in predominantly selfing species, gene flow may occur at significant rates and considerable distances (Wagner and Allard 1991). In general, species with restricted pollen and seed movement (i.e., low levels of gene flow) are expected to exhibit greater levels of among-population genetic differentiation than those with more widely dispersed pollen and seeds (Hamrick 1989). Techniques and difficulties associated with measurement of gene flow are discussed by Slatkin (1987) and Ellstrand (1992).

Potential henefits of interpopulation gene flow in conservation (e.g., Huenneke 1991) include increasing the effective size of populations, and thereby, reducing the threat of depletion of genetic variation and inbreeding depression. One immigrant every second generation or one interpopulation mating per generation $(\mathrm{Nm}=0.5)$ is expected to prevent substantial differentiation among populations (Slatkin 1987).

However, gene flow may also be detrimental for at lcast threc rcasons (Ellstrand 1992). (1) Local variation in a target population may be reduced by substantial gene flow from a genetically depauperate source. (2) Local adaptation may be prevented by gene flow of alleles from populations in different locations if selection favors different alleles in the source populations than in the target population (Ellstrand and Elam 1993). (3) Gene flow among populations may lead to fitness reductions in target populations through "outbreeding depression" (sensu Templeton 1986). Such reductions, which have been attributed to disruption of co-adaptation to local conditions (Templeton 1986), may be common in plants and may occur over distances as small as 10-15 meters in herbaceous plants (e.g., Waser 1993).

The beneficial or detrimental role of gene flow is expected to depend largely upon its role in the recent evolutionary history of the species. Where levels of gene flow have been historically high, decreases in gene flow are a greater concern than increases are. Alternatively, where levels of gene flow have been historically low, genetic structure is likely to be little affected by decreased gene flow (or increased isolation). However, increased gene flow may be deleterious (e.g., it may cause outbreeding depression in target populations) (Ellstrand and Elam 1993). Details of how changes in gene flow might be identified, possible management alternatives, and problems associated with interspecific gene flow are reviewed elsewhere (Ellstrand 1992; Ellstrand and Elam 1993).

Selection. Natural selection is differential survival and reproduction of genotypes in a specific environment. Alleles that promote higher fitness increase in frequency in succeeding generations because of selection. Selection can influence population genetic structure as a result of its potential to alter allele frequencies (Futuyma 1986; Hartl and Clark 1989).

In general, selection is expected to be important in structuring genetic variation when the effects of genetic drift and gene flow are small (Futuyma 1986; Hartl and Clark 1989). In populations likely to be influenced by genetic drift (i.e., small populations or those fluctuating to small size), advantageous alleles may be lost or deleterious alleles fixed despite selection. Similarly, gene flow may prevent local adaptation when $m>s$ where $m$ is the fraction of immigrants per generation and $s$ is the local selective coefficient. However, as this relationship implies, selection may influence population genetic structure even in the presence of significant gene flow if selection is strong (Slatkin 1987).

When selection is important in structuring genetic variation, the precise outcome will depend upon the mode of selection involved. Directional selection may reduce levels of variation while stabilizing or diversifying selection may maintain levels of variation (Futuyma 1986; Hartl and Clark 1989). In this context, heterogeneous habitats may be good predictors of genetic heterogeneity (Linhart and Grant 1996). Spatial variation in physical components of the environment (e.g. soil conditions, moisture) may produce differentiation between adjacent populations while biotic components of the environment (e.g. herbivores) usually produce differentiation within populations (Linhart 1995 and references therein). Modes of selection and their potential outcomes are discussed in detail by Futuyma (1986) and Hartl and Clark (1989).

Level of genetic variation. Because knowledge of the level of genetic variation may influence the selection and use of donor populations, it is useful to consider whether we 
can identify circumstances in which populations may be genetically depauperate (i.e., have low levels of genetic diversity). These include situations when (1) populations are continually small in size or substantially fluctuate in size over time (size is ideally measured as effective population size, $N_{e}$ ), (2) the taxon is highly inbreeding (as when predominantly selfing), (3) gene flow from genetically richer sources is absent, (4) gene flow from genetically depauperate sources is substantial and/or (5) local variation is reduced by strong directional selection. It is crucial to recognize that these are expectations. Because other factors may influence levels of genetic variation within populations (e.g., the presence of seed banks) and because interactions among evolutionary factors may alter expectations about population genetic structure, the situation in natural populations may be extremely complex. Estimating levels of genetic variation empirically is necessary to determine a population's structure with any certainty. For most restoration and other conservation efforts, obtaining empirical estimates. using isozymes, PCR (polymerase chain reaction)-based molecular markers or measures of quantitative genetic variation under uniform environmen- tal conditions will not be feasible because of cost, time, tractability and similar difficulties.

Distribution of genetic variation. Knowing that populations may be genetically distinct is likely to influence the choice and use of donor populations for restoration. Therefore, it is also important to consider whether we can identify circumstances in which we expect high levels of genetic differentiation among populations (i.e. large values of $G_{S T}$ ). These include situations when (1) populations are continually small in size or substantially fluctuate in size over time (size is ideally measured as effective population size, $N_{e}$ ), (2) the taxon is highly inbreeding (as when predominantly selfing), (3) populations are very isolated (i.e., the level of gene flow among populations is very low) and/or (4) selection leads to the development of local or regional variation (e.g. due to heterogeneous habitats and biotas of herbivores, parasites and soil microorganisms). Recognizing the preliminary nature of these predictions is crucial because complex, site-specific interactions among factors are likely to be the rule. For this reason, empirical estimation is the only way to be certain

Table 1: Available information for selected federally-listed plants in California

\begin{tabular}{|c|c|c|c|c|c|c|c|}
\hline $\begin{array}{l}\text { Species } \\
\text { Family }\end{array}$ & Counties+ & $\begin{array}{l}\text { Number of } \\
\text { populations }\end{array}$ & $\begin{array}{l}\text { Geographic } \\
\text { isolation of } \\
\text { poplulations }\end{array}$ & $\begin{array}{l}\text { Population } \\
\text { Sizes }\end{array}$ & $\begin{array}{c}\text { Population } \\
\text { Size } \\
\text { fluctuates }\end{array}$ & $\begin{array}{l}\text { Mating } \\
\text { system }\end{array}$ & Dispersal** \\
\hline $\begin{array}{l}\text { Acanthomintha duttonii } \\
\text { (Lamiaceae) }\end{array}$ & SMT & 2 & $\sim 1 \mathrm{~km}$ & $\begin{array}{l}\text { one large, } \\
\text { one }<100\end{array}$ & no & selfing & $\begin{array}{c}\mathrm{p} \text { - bumblebees } \\
\mathrm{s}-?\end{array}$ \\
\hline $\begin{array}{l}\text { Castilleja affinis ssp. neglecta } \\
\text { (Scrophulariaceae) }\end{array}$ & $\begin{array}{l}\text { MRN } \\
\text { NAP } \\
\text { SCL }\end{array}$ & 6 & 1 to $\sim 100 \mathrm{~km}$ & $\begin{array}{c}<1000 \\
\text { some small }\end{array}$ & $?$ & $?$ & $\begin{array}{l}\mathrm{p}-\text { bee? } \\
\mathrm{s}-?\end{array}$ \\
\hline $\begin{array}{l}\text { Clarkia franciscana* } \\
\text { (Onagraceae) }\end{array}$ & $\begin{array}{l}\text { ALA } \\
\text { SFO }\end{array}$ & 5 & $\begin{array}{l}2 \text { locations } \\
\sim 20 \mathrm{~km} \text { apart }\end{array}$ & some small & yes & $\begin{array}{l}\text { primarily } \\
\text { selfing }\end{array}$ & $\begin{array}{c}\mathrm{p} \text { - halictid bees } \\
\mathrm{s}-?\end{array}$ \\
\hline $\begin{array}{l}\text { Dudleya setchellii } \\
\text { (Crassulaceae) }\end{array}$ & SCL & $\sim 20$ & $<\sim 10 \mathrm{~km}$ & 100 -1000's & $?$ & $?$ & $\begin{array}{c}\mathrm{p}-? \\
\mathrm{~s}-\text { wind }\end{array}$ \\
\hline $\begin{array}{l}\text { Limnanthes floccosa ssp. californica* } \\
\text { (Limnanthaceae) }\end{array}$ & BUT & 11 & up to $\sim 17 \mathrm{~km}$ & $200-45,000$ & yes & $\begin{array}{l}\text { highly } \\
\text { selfing }\end{array}$ & $\begin{array}{c}\mathrm{p}-? \\
\mathrm{~s} \text { - gravity }\end{array}$ \\
\hline $\begin{array}{l}\text { Hesperolinon congestum } \\
\quad \text { (Linaceae) }\end{array}$ & $\begin{array}{l}\text { MRN } \\
\text { SFO } \\
\text { SMT }\end{array}$ & $\sim 20$ & up to $\sim 12 \mathrm{~km}$ & some small & sometimes & $?$ & $\begin{array}{c}\text { p - beeflies, } \\
\text { beetles } \\
\mathrm{s}-?\end{array}$ \\
\hline $\begin{array}{l}\text { Streptanthus niger } \\
\text { (Brassicaceae) }\end{array}$ & SMT & 2 & $<3 \mathrm{~km}$ & sometimes & yes & $?$ & $\begin{array}{l}\mathrm{p}-? \\
\mathrm{~s}-?\end{array}$ \\
\hline
\end{tabular}

* Population genetic data available (Dole and Sun 1992; Gottlieb and Edwards 1992)

$+\mathrm{ALA}=$ Alameda, $\mathrm{BUT}=$ Butte, $\mathrm{MRN}=$ Marin, NAP $=\mathrm{Napa}, \mathrm{SCL}=\mathrm{Santa}$ Clara, $\mathrm{SFO}=$ San Francisco, $\mathrm{SMT}=\mathrm{San}$ Mateo

$* * \mathrm{p}=$ pollen, $\mathrm{s}=$ seed

References: Dole and Sun 1992; Lewis and Raven 1958; Heckard in litt. 1989; Gottlieb and Edwards 1992; Robison and Morey 1992; McCarten 1993; Steeck 1995; CNDDB 1997 
that substantial among-population differentiation exists (or does not).

\section{Selecting donor populations in the absence of population genetic data}

Using population genetic theory to make preliminary guesses about probable population genetic structure may help avoid mistakes in selecting donor populations for restorations. Evaluating relevant available information about the taxon of concern is the first step. Most often, this information is likely to include observed population sizes and year-to year fluctuations in population size, mating system, pollinators if the taxon is outcrossed, pollen and seed dispersal mechanisms, and geographic distribution. Less frequently information may also be available to allow evaluation of the evolutionary history of the taxon and populations of concern (e.g., were populations of the taxon formerly geographically isolated?) and the presence or absence of a substantial seed bank.

Table 1 summarizes available information for several rare plant taxa. These taxa can be used to illustrate how the hypotheses of population genetic theory might be used to select donor populations for restoration. The table also illustrates that, in most cases, much relevant information will be lacking. Only location, geographic distribution and population size are consistently available. Where some populations occur on private land, even population size information may be unavailable or anecdotal. It is prudent to recognize this lack of information in the decision-making process. The best way to avoid making a mistake that might jeopardize the success of a restoration is to make a conservative decision based on the information that is available. Below I use some examples to show how population genetics may be used as a guide in selection of donor populations.

Level of genetic variation. Acanthomintha duttonii (Lamiaceae) is a serpentine endemic annual (CNDDB 1997; Table 1) for which no genetic data are available. The species is found in two natural populations approximately $1 \mathrm{~km}$ apart in San Mateo County, California (CNDDB 1997). One of the extant populations is large, and one is small. The latter has typically contained fewer than 100 individuals (Steeck 1995). We expect, based strictly on current population size, that the larger population is likely to have higher levels of genetic variation than the smaller one (e.g., van Treuren et al. 1991; Ellstrand and Elam 1993 and references therein; Elam 1994). Therefore, if sampling for restoration is meant to capture species level variation for this taxon, concentrating most effort on the larger population is a reasonable strategy. Collecting some material from the smaller population may also be desirable because it is possible that rare alleles may be present at high frequencies due to genetic drift in this population. However, because the spe- cies is thought to be inbreeding (Steeck 1995), we expect the populations may contain relatively low levels of variation compared to outcrossing species. We also expect significant genetic differences may exist between the populations if the species is inbreeding.

Distribution of genetic variation. Castilleja affinis ssp. neglecta (Scrophulariaceae) is a perennial serpentine endemic with six known populations in California (CNDDB 1997; Table 1). Four of the populations are in Marin County, one is in Napa County, and one is in Santa Clara County. The geographic distribution of the species suggests that gene flow is probably low between some of the populations (i.e. there is some isolation of populations). The populations in Marin County are approximately 1 to $5 \mathrm{~km}$ apart and are at least $5 \mathrm{~km}$ from the Napa County population. The Santa Clara County population is at least $100 \mathrm{~km}$ south of the Marin County populations. This distribution, along with small population sizes, may lead to genetic differentiation among populations, especially for the Santa Clara County population. The possibility of genetic differentiation among populations (e.g. due to lack of gene flow or different types of selection among sites) may be an important consideration in choosing donor populations for the species. If ensuring representation of species level variation is a concern, then populations from each county probably should be sampled. However, lacking any other information, moving material among regions for restoration is probably not prudent if maximizing the likelihood of success of the restoration is important. Another consideration in restoration of $C$. affinis ssp. neglecta is its hemiparasitic nature. Heckard (1962) showed that the presence of a host plant increases the survivorship of C. affinis ssp. neglecta. Choosing a restoration site lacking host plants or failing to introduce host plants may result in an unsuccessful restoration for this species.

Like $C$. affinis ssp. neglecta, Hesperolinon congestum (Linaceae) occurs in several counties and in relatively disjunct locations (CNDDB 1997; Table 1). Although the geographic gaps between $\boldsymbol{H}$. congestum populations (or groups of populations) are a tenth of those in $C$. affinis ssp. neglecta, they are large enough (up to $\sim 12 \mathrm{~km}$ ) to warrant care in moving material among regions. Possibly exacerbating the relative geographic isolation is low vagility of the observed potential pollinators (beeflies and beetles) (Robison and Morey 1992). In addition, small population sizes and population size fluctuations suggest among-population differentiation may be a concern for the species.

\section{Examples: Returning to Limnanthes and Clarkia}

Because genetic data are available for Limnanthes floccosa ssp. californica and for Clarkia franciscana, it is instructive to revisit them and evaluate whether we might have correctly predicted their population genetic 
structures using the considerations above. Limnanthes floccosa ssp. californica is highly selfing, with substantial population size fluctuations and restricted gene flow (self-pollination and gravity dispersed capsules) (Dole and Sun 1992). These characteristics suggest low levels of genetic variation and high among-population differentiation. The genetic data corroborate these expectations. However, the genetic data also indicate the presence of three centers of diversity. Mating system and population size data alone would have been unlikely to suggest genetic structure at this level of detail. Similarly, Clarkia franciscana is predominantly selfing, occurring sometimes in small populations and in populations that fluctuate in size (Lewis and Raven 1958; CNDDB 1997). These characteristics suggest that levels of genetic variation in the taxon are likely to be low. The population genetic data are consistent with this prediction. In addition, the mating system and population size data, as well as the geographic separation (CNDDB 1997) between the Presidio and the Oakland Hills locations (at least $20 \mathrm{~km}$ across San Francisco Bay), suggest that among-population differentiation in the species is likely to be relatively high. To the extent that we know that the Presidio and Oakland Hills populations are genetically different based on sampling of one population in each location, the expectation that genetic differentiation has occurred among populations is also borne out by the isozyme data.

These examples suggest that making preliminary guesses about population genetic structure based on available information is not unreasonable. However, it is crucial to recognize that patterns are relatively straightforward for the species discussed. Evaluating probable population genetic structure for other species, perhaps most other species, will be more difficult. The difficulty will be especially obvious when evolutionary factors interact and when prediction requires determining which factor is most important in structuring variation.

\section{Design of Restoration}

In addition to guiding donor choice, population genetic theory may suggest other ways that mistakes can be avoided in restoration design. For example, population genetic principles may guide selection of donors, not just in general as discussed above, but with respect to particular restoration sites. Where high levels of local adaptation (e.g., to particular soils, Linhart and Grant 1996) and/ or high levels of among-population differentiation are expected, it is especially prudent to select donors from local populations to maximize the likelihood of success of the restoration as well as to avoid contamination of local populations with foreign material. Lacking any other information about a taxon, a local source that "matches" the restoration site in terms of biotic and abiotic factors (to the extent this can be determined) is the most conser- vative choice for donor material (Millar and Libby 1989; Knapp and Rice 1994; Linhart 1995). In addition, designing a restoration with relatively higher levels of genetic variation may be valuable if high levels of variation increase the probability that the population will survive in the short-term (e.g. Frankel and Soulé 1980; Mitton and Grant 1984; Huenneke 1991) or the long-term (Soulé 1980; Frankel and Soulé 1980). Using large population sizes in a restoration may minimize genetic drift, loss of fitness due to demographic stochasticity and other potential problems associated with small populations (Barrett and Kohn 1991; Ellstrand and Elam 1993).

Evaluating the mating system of the species is also important in avoiding mistakes in restoration design. Dioecious and self-incompatible species require special consideration. For example, one natural population of 2000 individuals of dioecious Nolina interrata contained no male individuals following a fire in 1984. Electrophoretic studies showed that all rosettes in the population were identical at 15 loci, suggesting that the population might be composed of a single clone (Dice 1988 as cited in Bauder 1993). In the absence of a male clone, sexual reproduction would depend upon pollen from other populations. Similarly, the self-incompatible mating system of Eriodictyon capitatum may limit sexual reproduction, at least in two populations that appear to be composed of single clones (Elam 1994). Failure to introduce sufficient $\mathrm{S}$-allele variation in restorations of self-incompatible plants (e.g. Byers and Meagher 1992; Reinartz and Les 1994; Karron 1997) or failure to consider sex ratio in restoration of dioecious plants may limit reproductive output, and hence persistence, of restored populations. Although the above examples both involve clonal species, the concern also applies to self-incompatible and dioecious species that do not vegetatively reproduce.

\section{Summary}

Population genetic data for rare plant taxa may provide insight into how donor populations might best be selected and how restorations might best be designed. However, most often, population genetic data will be unavailable for rare plant species. In this situation, population genetics may still be useful to help restoration practitioners avoid mistakes that may jeopardize the success of a restoration. Understanding when and how evolutionary factors (such as genetic drift, inbreeding, gene flow and selection) structure genetic variation can help biologists make preliminary guesses about levels and distribution of genetic variation in unstudied plant taxa.

In general, as many aspects of life history as possible, reflecting factors such as mating system, dispersal mechanisms, and ecological setting, should be considered (Linhart 1995) when making decisions about selection of donors and restoration design. Most often, the available 
information will be limited to population sizes (and sometimes population size fluctuations), geographic distribution, and mating system (rarely). Information on population size and the frequency and magnitude of population size fluctuations may be useful in evaluating the magnitude of genetic drift. Where genetic drift is likely to be substantial, levels of genetic variation are expected to be low and among population differentiation high (Futuyma 1986; Falconer 1989). The geographic distribution of populations may provide clues to whether populations are genetically isolated (and hence perhaps genetically different) from one another. Although genetic isolation may also be influenced by the frequency and magnitude of gene flow, data quantifying gene flow will almost never be available. Because mating systems play an important role in shaping population genetic structure, utilizing or obtaining mating system data will be useful. Selfing species tend to have low within-population variation and high among-population differentiation.

While having an idea about the level and distribution of genetic variation may be useful in selecting donor populations and in designing restorations for unstudied plant taxa, critical to basing decisions on preliminary guesses about population genetic structure is the recognition that the guesses may be substantially wrong. This does not mean preliminary guesses ought never to be used, only that they be used conservatively.

Acknowledgments. The manuscript was improved by comments from P.E. Arriola, N.C. Ellstrand, K.W. Fuller, K. Goodell, J.D. Karron, Y.B. Linhart and A. Montalvo.

\section{Literature Cited}

Avise, J.C. 1994. Molecular markers, natural history and evolution. Chapman and Hall, New York, NY.

Baker, H.G. 1989. Some aspects of the natural history of seed banks. Pp. 9-21 in M.A. Leck, V.T. Parker and R.L. Simpson, eds. Ecology of soil seed banks. Academic Press, New York, NY.

Barrett, S.C.H. and J.R. Kohn. 1991. Genetic and evolutionary consequences of small population size. Pp. 3-30 in D.A. Falk and K.E. Holsinger, eds. Genetics and conservation of rare plants. Oxford University Press, New York, NY.

Bauder, E.T. 1993. Genetic diversity: esoteric or essential? Pp. 35-41 in J.E. Keeley, ed. Interface between ecology and land development in California. Southern California Academy of Sciences, Los Angeles, CA.

Byers, D.L. and T.R. Meagher. 1992. Mate availability in small populations of plant species with homomorphic sporophytic self-incompatibility. Heredity 68:353-359.

Charlesworth, D. and B. Charlesworth. 1987. Inbreeding depression and its evolutionary consequences. Annual Review of Ecology and Systematics 18:237-268.

CNDDB. 1997. Rarefind. California Natural Diversity Data Base, Natural Heritage Division, California Department of Fish and Game, Sacramento, CA.
Crawford, T.J. 1984. What is a population? Pp.135-174 in B. Shorrocks, ed. Evolutionary ecology. Blackwell Scientific, Oxford.

Dole, J.A. and M. Sun. 1992. Field and genetic survey of the endangeredButte County meadowfoam-Limnanthes floccosa subsp. californica (Limnanthaceae). Conservation Biology 6:549-558.

Elam, D.R. 1994. Genetic variation and reproductive output in plant populations: effects of population size and self-incompatibility. Ph.D. dissertation, University of California, Riverside, CA.

Ellstrand, N.C. 1992. Gene flow by pollen: implications for plant conservation genetics. Oikos 63:77-86.

Ellstrand, N.C. and D.R. Elam. 1993. Population genetic consequences of small population size: implications for plant conservation. Annual Review of Ecology and Systematics 24:217242.

Falconer, D.S. 1989. Introduction to quantitative genetics. Wiley, New York, NY.

Frankel, O.H. and M.E. Soulé. 1980. Conservation and evolution. Cambridge University Press, New York, NY.

Furnier, G.R. and M. Stine. 1995. Interpopulation differentiation of nuclear and chloroplast loci in white spruce. Canadian Journal of Forest Research 25:736-742.

Futuyma, D.J. 1986. Evolutionary biology. Sinauer Associates, Sunderland, MA.

Gottlieb, L.D. and S.W. Edwards. 1992. An electrophoretic test of the genetic independence of a newly discovered population of Clarkia franciscana. Madroño 39:1-17.

Hamrick, J.L. 1989. Isozymes and the analysis of genetic structure in plant populations. Pp. 87-105 in D.E. Soltis and P.S. Soltis, eds. Isozymes in plant biology. Dioscorides Press, Portland, OR.

Hamrick, J.L. and M.J.W. Godt. 1990. Allozyme diversity in plant species. Pp. 43-63 in A.D.H. Brown, M.T. Clegg. A.L. Kahler and B.S. Weir eds. Plant population genetics, breeding, and genetic resources. Sinauer Associates, Sunderland, MA.

Hartl, D.L. and A.G. Clark. 1989. Principles of population genetics. Sinauer Associates, Sunderland, MA.

Heckard, L.R. 1962. Root parasitism in Castilleja. Botanical Gazette 124:21-29.

Heckard, L. 1989. Letter to Pete Bonadelli, California Department of Fish and Game, Sacramento, CA.

Holland, R.F. and S.K. Jain. 1988. Vernal pools. Pp. 515-531 in M.J. Barbour and J. Major, eds. Terrestrial vegetation of California. California Native Plant Society Special Publication No. 9, Sacramento, CA.

Huenneke, L.F. 1991. Ecological implications of variation in plant populations. Pp. 31-44 in D.A. Falk and K.E. Holsinger, eds. Genetics and conservation of rare plants. Oxford University Press, New York, NY.

Karron, J.D. 1997. Genetic consequences of different patterns of distribution and abundancc. Pp.174-189 in W.E. Kunin and K. Gaston, eds. The biology of rarity. Chapman and Hall, London, UK.

Keeler-Wolf, T., D.R. Elam and S.A. Flint. 1996. Draft California vernal pool assessment preliminary report. State of California, The Resources Agency, Department of Fish and Game, Sacramento, CA. 
Knapp, E.E. and K.J. Rice 1994. Starting from seed: genetic issues in using native grasses for restoration. Restoration \& Management Notes 12(1):40-45.

Kruckeberg, A.R. 1984. California serpentines: flora, vegetation, geology, soils, and management problems. University of California Press, Berkeley, CA.

Lande, R. and G.F. Barrowclough. 1987. Effective population size, genetic variation, and their use in population management. Pp. 87-123 in M.E. Soulé, ed. Viable populations for conservation. Cambridge University Press, New York, NY.

Lewis, H. and P. Raven. Clarkia franciscana, a new species from central California. Brittonia 10:7-13.

Linhart, Y.B. 1995. Restoration, revegetation, and the importance of genetic and evolutionary perspectives. Pp. 271-287 in B.A. Roundy, E.D. McArthur, J.S. Haley, and D.K. Mann, eds. Proceedings: wildland shrub and arid land restoration symposium. USDA Forest Service. General Technical Report INT-GTR-315.

Linhart, Y.B. and M.C. Grant. 1996. Evolutionary significance of local genetic differentiation in plants. Annual Review of Ecology and Systematics 27:237-277.

McCarten, N.F. 1993. Petition to the State of California Fish and Gamc Commission: Dudleya setchellii. Natural Ileritage Division, California Department of Fish and Game, Sacramento, CA.

Millar, C.I. and W.J. Libby. 1989. Disneyland or native ecosystem: genetics and the restorationist. Restoration \& Management Notes 7(1):18-24.

Mitton, J.B. and M.C. Grant. 1984. Associations among protein heterozygosity, growth rate and developmental homeostasis. Annual Review of Ecology and Systematics 15:479-499.

Nunney, L. and D.R. Elam. 1994. Estimating the effective size of conserved populations. Conservation Biology 8:175-184.

Reinartz, J.A. and D.H. Les. 1994. Bottleneck induced dissolution of self-incompatibility and breeding system consequences in Aster furcatus (Asteraceae). American Journal of Botany 81:446-455.

Robison, R.A and S. Morey. 1992. Report to the Fish and Game Commission on the status of Marin dwarf flax (Hesperolinon congestum). Status Report 92-2. Natural Heritage Division, California Department of Fish and Game, Sacramento, CA.

Skinner, M.W. and B.M. Pavlik. 1994. California Native Plant Society's inventory of rare and endangered plants of California. 5th edition. California Native Plant Society Special Publication No. 1, Sacramento, CA.
Slatkin, M. 1987. Gene flow and the geographic structure of natural populations. Science 236:787-792.

Soulé, M.E. 1980. Thresholds for survival: maintaining fitness and evolutionary potential. Pp. 151-169 in M.E. Soulé, ed. Conservation biology: an evolutionary-ecological approach. Sinauer Associates, Sunderland, MA.

Steeck, D.M. 1995. Reproductive biology of a rare California annual, Acanthomintha duttonii, and its congener, Acanthomintha obovata ssp. cordata. M.S. thesis, University of California, Davis, Davis, CA.

Templeton, A.R. 1986. Coadaptation and outbreeding depression. Pp. 105-116 in M.E. Soulé, ed. Conservation biology: the science of scarcity and diversity. Sinauer Associates, Sunderland, MA.

Thorne, R.F. 1981. Are California's vernal pools unique? Pp. 18 in S.K. Jain and P.B. Moyle, eds. Vernal pools and intermittent streams. Institute of Ecology Publication No. 28, University of California, Davis, CA.

Turner, M.E., J.C. Stephens, and W.W. Anderson. 1982. Homozygosity and patch structure in plant populations as a result of nearest-neighbor pollination. Proceedings of the National Academy of Science USA 79:203-207.

van Treuren, R., R. Bijlsma, W. van Delden and N.J. Ouborg. 1991. The significance of genetic erosion in the process of extinction. I. Genetic differentiation in Salvia pratensis and Scabiosa columbaria in relation to population size. Heredity 66:181-189.

Wagner, D.B. and R.W. Allard. 1991. Pollen migration in predominantly self-fertilizing plants: barley. Journal of Heredity $82: 302-304$.

Waser, N.M. 1993. Population structure, optimal outbreeding and assortative mating in angiosperms. Pp. 173-199 in N.W. Thornhill, ed. The natural history of inbreeding and outbreeding: theoretical and empirical perspectives. University of Chicago Press, Chicago, IL.

Wright, S. 1931. Evolution in Mendelian populations. Genetics 16:97-159.

Wright, S. 1938. Size of population and breeding structure in relation to evolution. Science 87:430-431.

Zedler, P.H. 1987. The ecology of southern California vernal pools: a community profile. U.S. Fish and Wildlife Service Biological Report 85 (7.11). 


\title{
Evolutionary Factors Affecting the Probability of Local Adaptation or Should We Expect to See Ecotypes Behind Every Rock?
}

\author{
Kevin J. Rice and Eric E. Knapp \\ Department of Agronomy and Range Science and the Center for Population Biology, University of California, Davis. \\ One Shields Ave., Davis CA 95616-8515 \\ Tel. (916) 752-8529; e-mail: kjrice@ucdavis.edu
}

\begin{abstract}
When restoring a site, the proper selection of plant material is critical. After selection of species appropriate for the site has been made, the next step should be to determine whether natural selection has created locally adapted populations such that there is a "home team" advantage for the populations growing on or near the site. Appreciation for the potential importance of locally adapted ecotypes in restoration has grown in recent years. In fact, the current philosophy in many State and Federal agencies is to assume that very localized adaptation has occurred and that "local" material must be used whenever possible. Given the paucity of information on patterns of adaptation of many species used in restoration, this conservative view may be justified. However, this view that selection is "allpowerful" may be incorrect for certain species because other evolutionary factors such as gene flow may effectively prevent the development of locally adapted populations. We will discuss how gene flow, founder effects and the ability of plants to acclimate to a wide range of environments (i.e., phenotypic plasticity) may reduce the probability that local adaptation may occur. We will also discuss how the breeding system of a plant may influence patterns of gene flow and thus the probability that local adaption will arise.
\end{abstract}

Keywords: Breeding system; common garden; ecotypes; founder effects; gene flow; genetic drift; genetic variation; local adaptation; natural selection; phenotypic plasticity.

\section{Evolutionary Causes of Genetic Differentiation Among Populations}

A great deal of genetic variation is found within most plant species. It is only recently that the importance of this variability has been widely recognized by restorationists. Unfortunately, protocols for collecting seed of native plant species such that natural patterns of this intraspecific variation are maintained have yet to he developed and implemented for most species used in restoration (Knapp and Rice 1994).
How did all this variation arise and why is it so important to consider? The genetic variation found within plant species often reflects the tremendous environmental heterogeneity that can exist within the species' geographic range. Because of their sessile nature, plants are forced to cope with environmental conditions at the site where germination occurs. Over time, the action of natural selection, through differential survival and reproduction, can result in the formation of ecotypes adapted to local environmental conditions. Selection imposed by physical factors such as soil gradients or climatic variation and selection by biotic factors such as competition or disease can be quite strong and can cause major morphological and physiological differences among populations. In some sense, the local population represents a "genetic memory" that integrates the effects of selection that may vary from one year to the next. Because of this "genetic memory" of historical environmental variability, planting at a particular site is often most successful when local populations are used.

A recent review of the plant literature on adaptation concludes that selection, when strong and consistent in direction, can result in local adaptation over very small spatial scales and often within short periods of time (Linhart and Grant 1996). However in other situations local adaptation may not occur because selection is not strong or is not consistent, or both. Especially over smaller spatial scales, the presence of a particular genotype on a site might be attributed to chance alone, and not due to any type of adaptive superiority. For example, a founding event where a few seeds are deposited into a new area and form a new population can cause genetic differentiation among populations. By chance, the one or few plants which founded this new population may not have the same allele frequencies as the original source population and thus will be genetically different from the original population. This random change in gene frequency is known as genetic drift. Formation of genetically distinct subpopulations due to these chance colonization events can create the appearance of local adaptive differences, when 
in fact, none exist. As an example, such "bogus adaptation" might result from the chance dispersal of a genetically distinct immigrant into an open habitat with few competitors. If the new immigrant can self-fertilize, it can propagate and colonize the open habitat. Even though it rapidly spreads, this new sub-population of related genotypes is not necessarily better adapted to this open habitat than the surrounding population. This sub-population's dominance of the site reflects the action of chance colonization, not the action of natural selection.

While natural selection and genetic drift can both lead to population divergence and spatial patterns in genetic variation, such differentiation is countered by another evolutionary force known as gene flow. Gene flow is a function of the movement of pollen and seeds among populations and acts to reduce genetic differentiation. Both theory and experimental work in population genetics have shown that gene flow can be as important as selection in shaping the genetic structure of populations. The importance of gene flow on the spatial scales of adaptation and the extent to which plant populations can become genetically differentiated is addressed below in the discussion of plant breeding system.

\section{The Role of Genes and Environment in Shaping the Plant Phenotype}

A mistake often made by well meaning restorationists is to assume that all intraspecific variation observed in the field has a genetic basis. However, the situation is more complex than that. Observable intraspecific variation, or phenotypic variation, represents the interaction of a particular genotype with environmental conditions present during the organism's development (Antonovics 1971; Lewontin 1974; Sultan 1987) . Much of this observable phenotypic variation may therefore reflect the influence of environmental variation rather than genetic "hardwiring". One only has to observe the often dramatic difference in morphology and physiology between shade and sun leaves on a single tree to realize that a single genotype may express strikingly different phenotypes depending on micro-environmental conditions.

The capacity for a single genotype (or closely-related genotypes) to express different phenotypes in different environments is called phenotypic plasticity. Phenotypic plasticity can be especially pronounced in plants because modular construction (Harper 1977) gives plants a tremendous capacity to respond developmentally to spatial and temporal changes in environmental conditions. Understanding the genetic basis for intraspecific phenotypic variability therefore depends on knowing something about the potential influence of the environment in shaping phenotypes.

Conversely, when trying to predict adaptive response along an environmental gradient, it is important to remem- ber that the effectiveness of selection depends critically on the amount of genetic variation existing within populations. Selection can be very strong but if there is no genetic variation within the population there will be no selective response and no genetic differentiation. Whereas ecotypic differentiation among populations represents the products of selection, within-population genetic variation represents the potential for population response to future selective challenges, either natural or human-induced. In a very real sense, within-population genetic variation is "evolutionary grist" for the "mill" of natural selection.

How this genetic variation is maintained within populations has long been an area of intense interest in evolutionary biology (Levene 1953; Levins 1968; Gillespie 1974). Numerous theoretical studies have suggested that spatial and temporal variation in the direction of selection may act to maintain genetic variation within populations. Phenotypic plasticity may also provide a means by which variation within populations is preserved, especially in highly patchy environments (Sultan 1987). To understand how plasticity may work in this fashion, it is important to first remember that natural selection can act only on "visible" phenotypic variation. Even if selection is strong, microenvironmental variability in resources within a heterogeneous landscape may have more to do with how well a plant grows than underlying genetic factors. When microenvironmental variation is low, genotypes that are relatively less fit are "seen" by selection and removed with a resultant decrease in genetic variation. However, under natural conditions, soil properties or competitive pressure may be highly variable in both space and time. Let us suppose that a normally less fit genotype, by chance, colonizes a resource-rich patch. If that individual exhibits highly plastic growth and reproduction in response to the high resource levels within the patch, it will contribute large numbers of offspring to the next generation. In essence, selection has been ineffective in removing "suboptimal" genotypes. In natural environments where this scenario is repeated many times, phenotypic plasticity might buffer populations from the loss of currently suboptimal genotypes and thus help to maintain within-population genetic diversity. These "ugly duckling" genotypes that are currently sub-optimal may, however, be very important for adaptation to changed conditions in the future.

\section{Measuring Genetic Differentiation and Adaptation}

Given that the phenotype represents this complex interaction of genotype and environment, how does one try to partition the relative contributions of genetic and environmental variation to the variation seen in the phenotype? Actually, in some sense, this is an impossible task because the phenotype is the interaction of genotype and environment and this intimate interaction can never be 
truly partitioned (Lewontin 1974). However, from a practical standpoint, it is possible to roughly assess the relative importance of genetic and environmental factors in causing phenotypic variation.

The contribution of genetic and environmental variation to phenotypic variation can be represented by the following simple expression:

$$
\mathrm{V}_{\mathrm{P}}=\mathrm{V}_{\mathrm{G}}+\mathrm{V}_{\mathrm{E}}
$$

where $V_{P}$ is the amount of phenotypic variation, $V_{G}$ represents the contribution to this variation from genetic sources, and $\mathrm{V}_{\mathrm{E}}$ indicates the magnitude of environmental variation. This is actually an overly simplified version of the usual model used by geneticists. (An additional term taking into account some of the interactive effects of genetic and environmental factors (i.e., $V_{G} \times E$ ) may be included and the genetic component of variation is often further broken down into heritable (e.g., additive, $V_{\mathrm{A}}$ ) variation and non-heritable (e.g. dominance effects, $V_{D}$ ) variation.) Even in the above simplified form, this expression provides a useful way to illustrate how a common garden can be used to evaluate the relative contribution of genetic variation to variation in the phenotype. In common garden studies, seeds or other types of plant material (e.g., tillers) collected from populations growing in the wild under different environmental conditions are planted into the one environment of the garden. Within this common environment, the contribution of environmental variation to phenotypic is assumed to be nil (i.e., $\mathrm{V}_{\mathrm{E}}=0$ ). With this assumption the already simple expression further simplifies to:

$$
\mathrm{V}_{\mathrm{P}}=\mathrm{V}_{\mathrm{G}}
$$

The potential power of the common garden approach is then obvious. Any observable phenotypic variation should now reflect underlying genetic variation. The results may be complicated somewhat if small scale environmental variation exists within the garden or biased if genotype by environment interactions are significant. In general, however, the common garden represents a simple and valid approach to teasing out the genetic components of intraspecific variation. It can be used to examine genetic differences among populations by planting seeds from different populations together within a single garden. In addition, it can also be used to roughly estimate the amount of genetic variation within populations if several seeds collected from each plant growing in the wild (e.g., maternal families) are planted within the garden.

Thus, the common garden technique is a valuable tool for evaluating genetic differences among populations and genetic variation within populations. Of the most interest to restorationists seeking to match genotypes to the environment of a particular planting site are adaptive differences that can be attributed to the action of selection.
However, as discussed in the previous section, not all genetic differences are due to selection. So, how does one determine whether genetic differences detected in a common garden are adaptive? The key to demonstrating local adaptation is to detect a particular type of interaction between genotype and environment which we might call the "home team" or perhaps more appropriately "home field" advantage in terms of relative fitness. To do this usually requires the establishment of a reciprocal transplant experiment, where common gardens containing the different populations are planted at each of the home sites. For example, populations from a low and a high clevation site are planted (reciprocally) into both low and high elevation sitcs. Local adaptation is indicated if the low elevation population has a relative fitness advantage in its home site (low elevation site) and the high elevation population is relatively more fit in its home site (high elevation site). A convincing demonstration of local adaptation requires that a home team fitness advantage is detected at both sites. Classic studies by Clausen, Keck and Heisey (1940) on local adaptation in native plants along elevation gradients in the Sierra Nevada used this reciprocal transplant technique extensively and this approach still remains the most direct and powerful technique for demonstrating local adaptation. The primary drawback to this approach is that it is time consuming and labor intensive, especially if several populations and sites are studied.

\section{Patterns of Genetic Variation: Molecular Markers vs. Quantitative Traits}

Molecular markers have become a popular means of evaluating population differences, partially due to the difficulties inherent in demonstrating local adaptive differentiation, and perhaps also partially due to the lure of new technologies. Genetic differences for molecular markers can often be evaluated relatively cheaply, quickly and easily. However, whether population differences detected by molecular markers can be used to develop guidelines for translocating genotypes in restoration, remains to be seen.

In studies where molecular markers have been used to assay patterns of genetic variation, there often is an implicit assumption that spatial patterns in molecular traits reflect spatial patterns in potentially adaptive traits such as seed production, plant size and growth rate etc. of interest to restorationists. However, there is no a priori reason to expect that patterns of molecular marker variation should be correlated with adaptive genetic variation.

Molecular markers and quantitative traits may not be correlated because these different marker types may be measuring the effects of very different evolutionary forces (e.g., genetic drift versus selection) (Knapp and Rice 1998). Most adaptive variation resulting from the action 
of natural selection is polygenic (i.e. quantitative), with the genetic basis for the observed phenotypic variation caused by the interacting effect of many genes. In contrast, molecular markers such as isozymes, RAPDs, RFLPs, or microsatellites that allow us to detect variation at a single genetic loci, and this variation is thought to be neutral or nearly neutral to selection. Molecular variation can be considered hidden or neutral/nearly-neutral because genetic differences (e.g., alternate alleles) at these single loci do not usually result in a significant change in the expressed phenotype. Due to the weak or non-existent selection on many molecular genetic markers, cvolutionary forces such as genetic drift may play a larger role in shaping pattcrns of variation for these traits than would be expected for most quantitative traits. Thus, comparing patterns of molecular marker and quantitative trait variation may be like comparing apples and oranges.

An exception to this generalization occurs when the molecular markers are closely linked with blocks of genes underlying quantitative traits; in this case a correlation of patterns of among population variation detected by the two methods is expected. It cannot be emphasized too strongly that molecular markers are measuring a particular type of genetic variation, not all of the genetic variation of a population or species. Unfortunately, in some molecular studies, even if the authors are careful in a paper's introduction to make the point that molecular markers may be poor indicators of genetic variation in traits under selection, by the discussion section they are often blithely using their results to describe overall genetic variation.

As noted above, the validity of using molecular markers as indicators of overall patterns of genetic variation depends on the degree of correlation between molecular markers and quantitative traits. Unfortunately relatively few studies have examined patterns of both molecular marker variation and quantitative trait variation simultaneously in order to test whether such a correlation exists. From the studies that have been conducted, evidence for such a correlation is mixed at best. For example, Price et al. (1984), found a statistically significant association between molecular marker variation and quantitative trait variation for two out of four species studied. The two species that showed a significant association were selfpollinating. This observation led the authors to suggest that the degree of association between isozyme and quantitative markers may depend on the breeding system. These authors argued that this association within self-pollinating species reflects the fact that linkage disequilibrium or the development of a coadapted gene complex (Allard et al. 1972) is more likely to occur in selfing species. Such linkage disequilibrium would increase that probability that, by chance, molecular markers would be associated with blocks of genes coding for quantitative traits. However, the small number of species evaluated, and the fact that the breeding system of the species stud- ied was confounded with very different evolutionary histories (the two self-pollinating species which exhibited an association were a colonizing weed (Avena barbata) and a crop species (Hordeum vulgare) - both exotic grasses, while the one outcrossing species (Clarkia williamsonii) was a native dicot. The fourth species, a native selfing grass (Hordeum jubatum), did not exhibit the association.) Other studies on both plants and animals (Patton et al. 1975; Bryant 1984; Lagercrantz and Ryman 1990) have suggested that the degree of association between quantitative traits and molecular markers may be related to the evolutionary history of the populations cvaluated. In several of the studies which have demonstrated an association betwcen the two types of traits, population differentiation was attributed to bottlenecks and founder effects, evolutionary events that tend to influence molecular marker and quantitative trait variation in a similar way.

The potential importance of understanding, for restoration, this association between molecular and quantitative traits might best be illustrated by an example from our own research. Using common garden and electrophoretic techniques, we recently completed a study of both quantitative trait and molecular marker variation in the native bunchgrass Nassella pulchra (Knapp and Rice 1998). Nassella pulchra has a wide geographic range within California and is a species used extensively for ecological restoration and re-vegetation. At the time we initiated the study very little information was available on the patterns of genetic variation found in N. pulchra at regional or local scales. Within the range of the species, we sampled populations growing in both coastal and interior grassland habitats from northern to southern California. For each population, quantitative traits such as plant size, number of seeds produced, and leaf shape were measured within a common garden planting and starch gel electrophoresis was used to evaluate molecular marker variation. Indices of genetic differentiation among populations were then calculated for both types of traits. The relationship between plant trait values and the geographic distance between populations as well as the environmental "distance" (as measured by an aggregate index of climatic variables) was also calculated. We found no significant correlation between patterns of variation for molecular genetic markers and quantitative traits. Our results indicated that molecular genetic differences increased with increasing geographic distance between populations, but were not correlated with a strong climatic gradient found between interior and coastal sites. This is exactly the kind of result that one would expect for loci which are largely neutral to selection. Population genetic theory predicts that genetic differentiation for neutral or "nearly neutral" loci occurs through a predominance of random processes associated with "isolation by distance" (Wright 1969) and not from the action of natural selection. In contrast, quantitative trait variation in our study (i.e., variation that one would expect to be "visible" to the action of 
selection) was strongly correlated with climatic variation. Selection imposed by climatic variables is therefore suggested as an important force shaping variation for these quantitative traits. Thus, selection was likely a stronger force affecting differentiation for quantitative traits while genetic drift likely had a greater impact on patterns of differentiation for molecular markers. Although easier and quicker to obtain, molecular marker data do not, in this case, provide much information about adaptive variation. Rather, evaluating quantitative trait variation may have a more immediate benefit for predicting whether a plant population might grow in a new location, due to the more obvious link between these traits and adaptive responses.

Although molecular markers may be poor indicators of the effects of selection, it does not mean that they cannot be useful tools for understanding evolutionary forces shaping genetic variation in natural plant populations. In fact, it is precisely because of this lack of response to selection that neutral or nearly neutral molecular markers are very valuable indicators of genetic drift and gene flow. These molecular markers can complement quantitative markers to provide a more comprehensive description of the evolutionary forces shaping the genetic structure of a species.

\section{The Plant Breeding System and How it May Influence Spatial Scale and Extent of Population Differentiation.}

Because pollen dispersal is directly linked to gene flow, the breeding system of a plant can have a major influence on both the intensity and spatial scale of local adaptation. In cross-pollinating (outcrossing) species, gene flow is often much greater than in species with a breeding system of predominant selfing because outcrossing promotes more extensive movement of pollen. Theoretical and empirical work has shown that when gene flow among populations is high, local adaptation is unlikely to occur even if selection is moderately strong (Jain and Bradshaw 1966; Slatkin 1981). To illustrate this concept, imagine that there is a small pond within an otherwise dry habitat and that selection favors genotypes that are adapted to wet conditions near thw pond, and favors genotypes adapted to dry conditions away from the pond. Imagine also that the number of plants in the dry habitat is far greater than in the novel wet habitat. If the plant is outcrossing and gene flow is high, cross-pollination among plants in the two habitats may rapidly homogenize any genetic differences resulting from selection, thereby preventing the formation of locally adapted ecotypes. If the species is selfpollinating, however, genetic differences among populations growing in these habitats may persist, due to lack of gene flow. Thus, genetic differentiation among populations is expected to be greater in self-pollinating species (Hamrick and Godt 1989). In such species, the spatial scale over which populations are adapted is potentially more restricted and thus restorationists may wish to be more careful about widespread translocations. In addition, the extent of local adaptive differentiation across the same spatial scale is likely greater in selfing species, thus the consequences of such translocations for survival of a planting might be more severe.

Evaluating the breeding system of a plant can provide us with valuable insight into the extent of genetic differentiation and the scale at which it might be expected (Clegg 1980). In this regard, molecular markers have proven to be extremely valuable because their general neutrality with respect to selection makes them excellent indicators of gene flow (Brown et al. 1989). Although more labor intensive, controlled crosses can also give estimates of outcrossing rates (Jain 1979). The practical application of this information on potential gene flow patterns is in the designation of seed transfer guidelines for restoration of native species. Although seed transfer zones from conifer species may provide an initial model for herbaceous species, most conifers are highly outcrossed. As a result, conifer transfer zones are probably too broad for many herbaceous species that have mixed or predominantly self-pollinating mating systems. In many native species where quantitative analyses on outcrossing rates are currently unavailable, relatively simple observations on flower morphology or phenology can still provide very useful information. As an example, for species with flowers that do not open before pollination (cleistogamous flowers), fertilization is likely accomplished by selfing and gene flow would therefore be expected to be relatively restricted. In addition to general flower morphology, other reproduction related observations can provide qualitative estimates of outcrossing rates. For example, pollen to ovule number ratios have been found to provide information on breeding system because species producing large amounts of pollen relative to the number of ovules are more likely to be outcrossing than species with low pollen to ovule ratios (Cruden 1977). Admittedly, these observations may give only rough, qualitative clues about breeding system parameters. However, given the importance of breeding system in structuring genetic variation, even this rudimentary information is very valuable in helping to understand the balance between gene flow and selection in native species and developing guidelines for translocating seed for restoration. Given the lack of knowledge of gene flow patterns for most species used in restoration, planning species-specific transfer zones will be greatly assisted by any information on plant breeding system and gene flow.

\section{Summary Statements}

- A balanced view of the impact of evolutionary forces (i.e., selection, gene flow, and drift) on patterns of ge- 
netic variation is needed in order to predict the importance of local adaptation when restoring populations of native species.

- Especially in small populations, founder effects and genetic drift may cause genctic differentiation that reflects chance events and not the action of natural selection (i.e., "bogus adaptation").

- Gene flow is a very powerful cvolutionary force that acts to homogenize genetic variation and reduce the probability for selection to produce locally adapted ecotypes.

- Patterns of genetic variation in a species may depend critically on the type of trait evaluated. Molecular genetic markers, because they are usually neutral or nearly neutral to selection, may be a poor choice if one is interested in patterns of variation that reflect local adaptation. Examining quantitative traits within common gardens is often more useful (although more time consuming) because these traits may more readily predict patterns of adaptive variation, and thus provide a better means of estimating the spatial scales over which populations can be translocated and still be well adapted.

- Ecotypic variation among-populations represents the result of natural selection, whereas genetic variation within-populations represents the potential for future response to selection. Although most emphasis in restoration of genetic structure has been on among-population variation, the long-term persistence of restored populations may depend critically on the genetic potential within populations.

- Patterns of gene flow among populations are strongly influenced by the breeding system of a species. If gene flow is low, populations are more likely to become genetically differentiated and seed transfer zones may therefore need to be more restricted. Any information that can be obtained about a species' breeding system is important for both restoration practice and policy.

\section{References}

Allard, R.W., G.R. Babbel, M.T. Clegg, and A.L. Kahler, 1972. Evidence for coadaptation in Avena barbata. Proceedings of the National Academy of Sciences. 69:3043-3048.

Antonovics, J. 1971. The effects of a heterogeneous environment on the genetics of natural populations. American Scientist 59: 593-599.

Brown, A.H.D., J.J. Burdon, and A.M. Jarosz. 1989. Isozyme analysis of plant mating systems. Pp. 73-105 in D. E. Soltis, and P. S. Soltis, eds. Isozymes in plant biology. Dioscorides Press, Portland, OR.
Bryant, E.H. 1984. A comparison of electrophoretic and morphometric variability in the face fly, Musca autumnalis. Evolution 38:455-458.

Clausen, J., D.D. Keck, and W.M. Heisey. 1940. Experimental studies on the nature of species. I. The effect of varied environments on western North American plants. Carnegie Institution of Washington Publication 520. Washington, D.C.: Carnegie Institution of Washington.

Clegg, M.T. 1980. Measuring plant mating systems. BioScience 30:814-818.

Cruden, R.W. 1977. Pollen-ovule ratios: a conservative indicator of breeding systems in flowering plants. Evolution 31:32-46.

Gillespie, J. 1974. The role of environmental grain in the maintenance of genetic variation. American Naturalist 108:831-836.

Hamrick, J.L. and M.J.W. Godt. 1989. Allozyme diversity in plant species. Pp. 43-63 in A.H.D. Brown, M.T. Clegg, A.L. Kahler, and B.S. Weir, eds. Plant population genetics, breeding, and genetic resources. Sinauer Associates Inc., Sunderland, MA.

Harper, J.L. 1977. Population biology of plants. Academic Press, New York, NY.

Jain, S.K. 1979. Estimation of outcrossing rates: some alternative procedures. Crop Science 19:23-26.

Jain, S.K., and A.D. Bradshaw. 1966. Evolutionary divergence among adjacent plant populations. I. The evidence and its theoretical analysis. Heredity 21:407-441.

Knapp, E.E. and K.J. Rice. 1994. Starting from seed: genetic issues in using native grasses for restoration. Restoration \& Management Notes 12:40-45.

Knapp, E.E. and K.J. Rice. 1998. Comparison of isozymes and quantitative traits for evaluating patterns of genetic variation in purple needlegrass (Nassella pulchra). Conservation Biology 12:1031-1041.

Lagercrantz, U. and N. Ryman. 1990. Genetic structure in Norway spruce (Picea abies): concordance of morphological and allozymic variation. Evolution 44:38-53.

Lewontin, R.C. 1974. The analysis of variance and the analysis of causes. American Journal of Human Genetics 26:400-411.

Levene, H. 1953. Genetic equilibrium when more than one ecological niche is available. American Naturalist 87:331333.

Levins, R. 1968. Evolution in changing environments. Princeton University Press, Princeton, NJ.

Linhart, Y.B., and M.C. Grant. 1996. Evolutionary significance of local genetic differentiation in plants. Annual Review of Ecology and Systematics 27:237-277.

Patton, J.L., S.Y. Yang, and P. Meyers. 1975. Genetic and morphologic divergence among introduced rat populations (Rattus rattus) of the Galapagos archipelago, Ecuador. Systematic Zoology 24:296-310.

Price, S.C., K.M. Shumaker, A.L. Kahler, R.W. Allard, and J.E. Hill. 1984. Estimates of population differentiation obtained from enzyme polymorphisms and quantitative characters. Journal of Heredity 75:141-142.

Slatkin, M. 1981. Estimating gene flow in natural populations. Genetics 99:323-335.

Sultan, S.E. 1987. Evolutionary implications of phenotypic plasticity in plants. Evolutionary Biology 21:127-176.

Wright, S. 1969. Evolution and the genetics of populations. Volume 2. The theory of gene frequencies. University of Chicago Press, Chicago, IL. 


\title{
Fitness Consequences of Non-local Transplantation: Preliminary Tests of the Home Team Advantage and Outbreeding Depression Hypotheses
}

\author{
Arlee M. Montalvo ${ }^{1,2}$ and Norman C. Ellstrand ${ }^{2}$ \\ ' Pacific Southwest Research Station, USDA Forest Service, Riverside, CA 92507 \\ Tel. (909) 787-5405; Fax (909) 787-4437; e-mail: montalvo@citrus.ucr.edu \\ ${ }^{2}$ Department of Botany and Plant Sciences, University of California, Riverside, CA 92521-0124 \\ Tel. (909) 787-4194; Fax (909) 787-4437
}

\begin{abstract}
The long-term success of restored plant populations may be affected by the collection locality of transplants. Our research evaluates two hypotheses about effects of non-local transplantation: (1) the relative success of introduced populations from different locations depends on their genetic similarity to the local native population; and (2) the relative performance of progeny from crosses among local and non-local transplants is affected by the genetic similarities of the parents. In common garden studies of the geographically variable shrub, Lotus scoparius, survival and growth of transplants was inversely related to the genetic distance between source and resident populations. The success of cross pollinations among greenhouse-grown plants originating from six sites, and the germination of seeds from the crosses was also inversely related to the genetic distance of the crossed populations. These data suggest that use of non-local seed sources in restoration can lower the fitness of augmented populations.
\end{abstract}

Keywords: Coastal sage scrub; common garden experiment; ecological genetics; genetic distance; germplasm transfer; habitat restoration; Lotus scoparius; outbreeding depression; post-fire seeding.

\section{Introduction}

With large scale urban expansion and encroachment on wildlands, there is an increasing level of damage to wildland habitats. The mandate to protect endangered species and natural biodiversity has resulted in a concordant increase in the use of native plant species for habitat restoration projects, or in the seeding of steep hillslopes near urban areas after wildfire. The potential benefits of using native rather than introduced plant species are numerous. For example, natives are likely to be pre-adapted to the habitat in question, and their use discourages habi- tat conversion to communities dominated by non-natives. Native plant use in restoration can also aid in managing biodiversity through preservation of biological interactions, such as those between plants and their pollinators, seed dispersers, mycorrhizae, and herbivores (Handel et al. 1994; Montalvo et al. 1997).

Although the problems associated with using native plants are mostly logistical, and potentially solvable, indiscriminate collection of transplants may have an impact on the long-term viability and evolutionary potential of restored populations. The native plants used for seeding and restoration projects are frequently of unknown genetic or ecological origin, non-local, low in genetic diversity, or even have evolutionarily diverged after generations of un-intentional selection under cultivation (Montalvo et al. 1997). The genetic background of restored populations may be important to their long-term survival because local populations are often better adapted to their home environments than foreign ones and because reproductive success and performance of progeny can be affected by the genetic similarity of mates (Millar and Libby 1989; Barrett and Kohn 1991; Fenster and Dudash 1994; Guerrant 1992, 1996; Montalvo 1995; Knapp and Rice 1994; Montalvo et al. 1997). In this paper, we concentrate on these two potential problems associated with using non-local sources of seeds in restoration.

Many species of plants used for restoration have natural distributions spanning a variety of habitats and environmental conditions. Such species frequently exhibit variation in morphology and physiology, especially among populations from different ecological zones. Nlthough some population differences can be attributed to plastic development, many differences may have an adaptive genetic basis such that the populations can be recognized as distinct ecotypes (Turesson 1922, 1925, 1930; Clausen et al. 1940, 1947, 1948; Clausen and Hiesey 1958; Bradshaw 1965, 1984). Since the classic works of Turesson $(1922,1925,1930)$, many wild species have been 
used in classical experiments designed to examine morphological and physiological differences among individuals from different populations. In these studies, individuals originating from several different habitats have been grown together in "common garden" plots at reciprocal locations. Plants typically performed best in the environment most similar to their home (Clausen et al. 1940, 1947, 1948; Bradshaw 1984; Schmidt and Levin 1985; Silander 1985; Millar and Libby 1989, 1991; Huenneke 1991; Wang et al. 1997). Such results suggest that when plants are introduced from a distance for restoration, even if the appropriate native species are chosen, the introduced individuals may be poorly adapted to the transplant site and suffer unusually high mortality or lowered reproductive success. Thus, inappropriate, long-distance seed sources may frustrate restoration attempts.

Using non-local genotypes in seeding and restoration can also create problems after the initial transplanted generation. If non-local transplants and their progeny survive to flowering age, they can hybridize with native local individuals. Many studies of wild plant species have shown that, compared to crosses among individuals from the same population, mating between geographically distant populations of the same species results in reduced seed production, survival, and growth of progeny (Waser 1993). This reduction in fitness caused by distant crosses is known as outbreeding depression (Templeton 1986; Lynch 1991). If transplanted populations are genetically distant enough to result in outbreeding depression after crossing with local plants, then the long-term success of restorations may be lower than if local or genetically similar populations were used to provide seeds for restoration.

We can begin to examine the potential for outbreeding depression in wild populations by examining the genetic distance of populations in relation to the success of their crossed progeny (Fenster and Dudash 1994; Montalvo 1995; Montalvo et al. 1997). Fenster and Dudash (1994) note that the severity and persistence of outbreeding depression into future generations may depend both on the cause of genetic divergence and on the type of gene interaction responsible for the outbreeding. A better understanding of the mechanisms and potential for outbreeding depression upon non-local transplantation of plant populations can be gained by assessing: (1) if populations have diverged genetically; (2) if populations are adapted to different environments; and (3) establishing if there is a link between genetic distance and progeny success.

The question of the appropriateness of seed source location for restoration is not a new concept. The USDA Forest Service has long recognized the value of using local sources of tree seeds in reforestation (McCall 1939; Schubert et al. 1971; Kitzmiller 1990). The U.S. Department of Agriculture adopted seed transfer policy as early as 1939 (McCall 1939) in which it was recommended that seeds be collected and used for reforestation only within a specified area or "seed collection zone." Tree seed collection zones for California were first established in 1946 and were further subdivided into the current zones in 1970 (Fowells 1946; Schubert et al. 1971). However, the importance of using local populations of shrubs and herbs was often overlooked until recently (Millar and Libby 1991; Knapp and Rice 1994; Montalvo 1995; Montalvo et al. 1997). Several government agencies including the California Department of Parks and Recreation (Anonymous 1992) and the USDA Forest Service (unpublished memo, Pacific Southwest Region, 1994) now have seed transfer policies designed to increase the initial success of plantings and also to preserve the "evolutionary potential" of restored populations (Montalvo 1995; Knapp and Rice 1994). These policies encourage practices that (1) assure the presence of genetic variation in planting stock; (2) maintain sufficient numbers of individuals to minimize potentially damaging stochastic processes that can result in survival of genotypes without regard to their adaptedness; and (3) maintain the genetic integrity of populations by discouraging both severe inbreeding and outbreeding that can result in inbreeding and outbreeding depression. Guidelines were based on population genetics theory and a large body of literature ranging from classic evolutionary systematics studies of wild plant species (Clausen et al. 1940, 1948; reviews in Bradshaw 1984; Millar and Libby 1989; Huenneke 1991), to applied studies on the performance of economically important forest trees in contrasting environments (Baron and Schubert 1963; reviews in Kitzmiller 1990).

To the dismay of many land managers, seed transfer guidelines require more careful source tracking and planning in obtaining seeds and plants for revegetation and seeding than when source is not a consideration. It is not always practical to obtain locally collected seeds of all species desired for a seeding or restoration project. Many managers do not feel that there is enough evidence that preservation of the local genetic composition of populations is important enough to justify the extra work, planning, and cost that may be associated with use of local seeds. The possible unnecessary "rigidity" of the guidelines calls for some empirical tests of the fundamental principles upon which the guidelines are based. We need to understand when guidelines can be relaxed and for what kinds of species. Otherwise, restoration practitioners who find guidelines difficult and restrictive will distrust their importance and ignore them.

Our research examines the potential effects of nonlocal transplantation of plants in postfire seeding and restoration of three species common to coastal sage scrub vegetation, including Lotus scoparius, Eriogonum fasciculatum, and Salvia mellifera. Although it is possible to make predictions about the relative performance of non-local seed transplants based on allozyme data and some observed correlations between life-history traits and population genetic statistics (Hamrick et al. 1991; Elam 
this volume), these predictions have not been adequately tested. Our goal is to eventually assemble enough relevant studies of species that represent a variety of life forms, life-histories, mating systems, and potential for gene flow so that we can create a set of general, realistic, and tractable recommendations for the practitioner.

This paper reports preliminary results of tests of two hypotheses evaluating the fitness effects of using non-local genepools in restoration of $L$. scoparius: (1) the "home team advantage' hypothesis predicts that when growing together, the success of populations from different locations depends on their genetic similarity to the local native population; and (2) the 'outbreeding depression' hypothesis predicts that performance of the progeny of crossed transplants and residents is a function of the genetic similarity of the parents.

\section{Methods}

\section{Study species}

Lotus scoparius (Nutt.) Ottley (Fabaccac) is a widely distributed subshrub in Californian coastal sage scrub and chaparral (Hickman 1993). The seeds have hard seed coats and typically germinate after scarification by fire or in open disturbed sites. One of the dominant perennial species after fire, it becomes less abundant within 5 to 10 years. Plants are facultatively drought-deciduous, selfcompatible, and insect-pollinated (Moldenke 1976; Hickman 1993). Bumblebees are among the primary flower visitors (Montalvo, personal observations). The two varieties, $L$. $s$. var. brevialatus Ottley and $L$. $s$. var. scoparius, in southern California are distinguished primarily by a floral characteristic (in the former, the keel is longer than the wings; in the latter, it is about as long as the wings) and geographical location (Isely 1981; Steppan 1991). Of the two varieties, $L$. s. brevialatus is the more restricted in distribution, occurring primarily in the interior regions of western Riverside and San Diego Counties. The two varieties have been used indiscriminately in many restoration and seeding projects (Montalvo, personal observations).

\section{Study habitat}

We chose to work in coastal sage scrub vegetation for multiple reasons. First, it is an endangered habitat under constant pressure of urbanization and associated disturbances in densely populated southern California. The community is characterized by frequent fire and the presence of facultatively drought-deciduous shrubs, several of which are highly aromatic (Kirkpatrick and Hutchinson 1977). Many of these shrub species can regenerate after fire, either from the seed bank or by resprouting. Because of frequent fires, and other disturbances, including prox-

imity to urban areas, the habitat undergoes frequent restoration and post-fire seeding.

Second, coastal sage scrub occurs in a heterogeneous Mediterranean climatic zone generally characterized by summer drought and equable temperatures. However, both precipitation and summer temperatures vary markedly within this zone. Together with soil composition and topographic differences, these factors influence the composition of the different floristic associations seen within this plant community (Westman 1983). The resulting variation in community composition allows recognition of four major floristic units in southern California: the Diablan, Venturan, Riversidian, and Diegan formations (Westman 1983). The extensive variation in environmental factors and plant associations occurring in coastal sage scrub suggests that the more ubiquitous and wide-ranging species may develop ecotypic differences over a relatively small region.

\section{Study sites}

We chose 12 study populations, distributed from Santa Barbara County south to southern San Diego County, California (Fig. 1), representing three different associations of coastal sage scrub (sensu Westman 1983). All sites had substantial populations of $L$. scoparius, and all 12 populations served as sources of seeds for experimental work. Three of the 12 populations (MR, LS, and J, Fig. 1) were $L$. $s$. var. brevialatus. The rest were $L$. $s$. var. scoparius. To provide seeds for our experiments and leaf tissue for population genetic surveys, we sampled 60 individuals from every population. Plants were randomly selected at about $10 \mathrm{~m}$ intervals along arbitrarily arranged transects. Fruits were collected into paper coin envelopes in summer 1994; leaves were collected in spring 1995. Leaf samples were placed immediately in plastic bags in coolers and kept on ice or refrigerated until processing. We did not collect from areas that were known to have been previously restored or seeded.

Lotus scoparius Site Locations

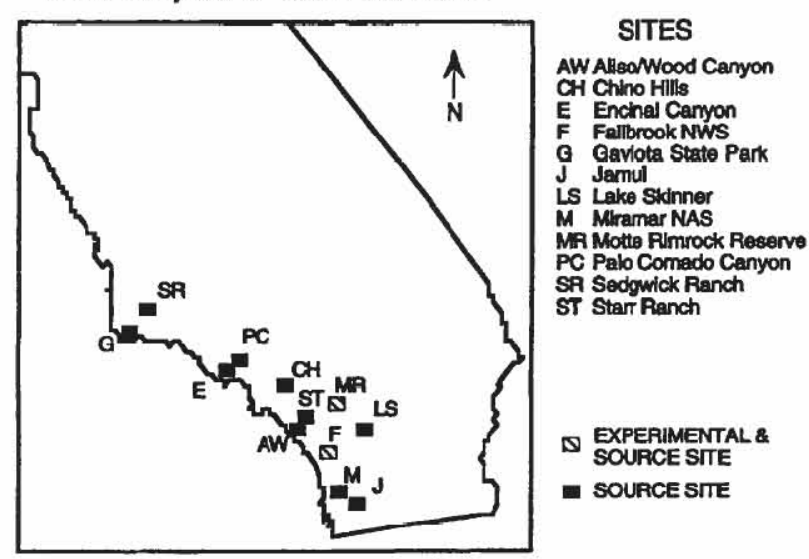

Figure 1. Southern California sites of Lotus scoparius populations used in this study. 
Two common garden plots were established in native coastal sage scrub vegetation at two of the 12 source site locations. One was at the University of California, Motte Rimrock Reserve in western Riverside County, California and is home to $L$. scoparius var. brevialatus. The second experimental site was at the Fallbrook Naval Weapons Station in northwestern San Diego County, California and is home to L. scoparius var. scoparius. The former site is hotter in summer, receives less rainfall, and experiences cooler winters than the relatively coastal Fallbrook site. Experimental plots were fenced to exclude large vertebrates, and gophers were routinely removed from the area.

\section{Electrophoresis}

Starch gel electrophoresis was used to provide allozyme data for calculating genetic distances. We ground $50 \mathrm{mg}$ of fresh leaf material from each sample in 5 drops of chilled $0.1 \mathrm{M}$ Tris- $\mathrm{HCl} \mathrm{pH} 8.0$ extraction buffer with $10 \%$ by wt of PVP-40 and $0.075 \%$ by wt dithiothreitol. We soaked extracts onto filter paper wicks (Whatman \#3) and stored them at $-80^{\circ} \mathrm{C}$ until electrophoresed on horizontal $10 \%$ starch gels. Ten enzyme systems were resolved (malic dehydrogenase, $\mathrm{MDH}$; isocitrate dehydrogenase, IDH; phosphoglucose isomerase, PGI; phosphoglucomutase, PGM; shikimate dehydrogenase, SKDH; aspartate alpha-ketogluconate aminotransaminase, AAT; aconitase, ACO; alcohol dehydrogenase, $\mathrm{ADH}$; triose phosphate isomerase, TPI; menadione reductase, MNR); 13 loci were consistently scorable. The following buffer systems were used: histidine citrate $\mathrm{pH} 6.0$ run at $25 \mathrm{~mA}$ for $5 \mathrm{hr}$ for $\mathrm{IDH}, \mathrm{ADH}$, $\mathrm{MNR}$, and TPI; morpholine-citrate $\mathrm{pH} 8$ run at $30 \mathrm{~mA}$ for $5 \mathrm{hr}$ for $\mathrm{MDH}, \mathrm{ACO}$, and $\mathrm{SKDH}$; and a discontinuous $\mathrm{LiOH}$-horate system run at $75 \mathrm{~mA}$ for $3.5 \mathrm{hr}$ or until the borate front had migrated $8 \mathrm{~cm}$ from the origin for PGI, PGM, and AAT (Ellstrand 1984). Gels were stained using standard assays (Weeden and Wendel 1989).

\section{Seed planting}

To produce seedlings for use in both Experiments I (test of the home team advantage hypothesis) and II (test of the outbreeding depression hypothesis), we combined equal numbers of wild collected seeds from each of 60 maternal parents, by site, and planted them in plug flats in a randomized blocks design in the greenhouse at the USDA Forest Service's Fire Laboratory in Riverside on February 8-9, 1995. Boiling water was poured over the planted seeds to stimulate germination. A random subset of the resulting seedlings were used in each experiment. Equal numbers of seedlings from each of the 12 source populations were designated for planting in Experiment I, while 60 individuals from each of 6 populations were transplanted into $1 \mathrm{gal}$ pots and used in Experiment II.
Experiment I - Test of the home team advantage hypothesis: On March 20-21, 1995, we planted 60 seedlings from each source site into each of the two experimental gardens for a total of 1,440 transplants. The plots were not tilled, but vegetation was trimmed to near ground level to allow planting and monitoring. Seedlings were planted about $7 \mathrm{~cm}$ apart in groups of three at the center of $0.75 \mathrm{x}$ $0.75 \mathrm{~m}$ cells in a random grid design. To plant seedlings, we removed $3 \mathrm{~cm}$ diameter plugs of native soil, and placed plugs containing single seedlings into the holes. Exotic plants were cut down or pulled if they were within $5 \mathrm{~cm}$ of the transplants. Grid positions were tagged with writeon aluminum tags, and individual seedlings were marked by placing colored plastic toothpicks in the ground. Plants were watered minimally the first growing season to prevent catastrophic mortality by transplant shock and to encourage root growth into the native soil before the onset of summer drought. We monitored survival and growth of seedlings within the first month of transplanting and again at the end of the growing season in June. After the dry dormant season, we monitored plants for survival after the onset of the 1996 growing season in early March 1996. All scoring was accomplished "blind" in that the source identity of individual plants was unknown to the persons doing the monitoring. Monitoring continued into the current 1997 growing season with the intention of harvesting plants in August 1997; however, this paper reports the results of size obtained at the end of the first growing season and survival through the first full year in the experimental garden. We measured plant height, number of branches, and length and width of largest leaf, number of leaves, and basal stem diameter on the primary branch. We measured the same response variables on a random subset of extra greenhouse seedlings, dried them, weighed them and examined the relationship between response variables and dry above ground biomass to determine the best correlate of overall plant size. Plant height was the best indicator of above ground size in juvenile plants (Pearson's $r=0.84 ; P=0.0001 ; \mathrm{N}=99$ ).

Experiment II - Test of the outbreeding depression hypothesis: We used six of the original 12 source populations in this experiment. Two of the original source populations from each of the three major floristic associations were represented (Venturan-E and SR; Diegan- AW and F; and Riversidian- LS and MR, Fig. 1) including the source populations from the two experimental sites. A random subset of 60 seedlings from each source population was grown to maturity in an insect excluded greenhouse at the Riverside Fire Lab. Original seed collections were made from each of 3 plots at the source populations and we grew 20 individuals from each plot. We randomly selected 25 plants from each source population to serve as maternal parents (pollen recipients), with the remaining plants serving as paternal parents (pollen donors). The crossing design involved crosses among indi- 
viduals from different populations as well as from the same population such that individuals from all possible combinations of populations were crossed. Pollen donors (fathers) were randomly selected from among paternal parents, and all within population crosses were done among individuals originating from different plots so as to minimize inbred matings and potential inbreeding depression. On each day of pollinations, the sequence of pollen donors used was randomized and every type of pollination was done within one hour. Order of incorporation of maternal parents was also random. Each maternal parent was pollinated on 3-5 separate days, each time achieving a full set of pollinations. A pollination set incorporated a single inflorescence on each of seven separate branches, each assigned a different pollen donor population (except that two were assigned to the self population). All flowers in an inflorescence were pollinated with freshly collected pollen from a single pollen donor (usually 2-5/infl). This resulted in 36 different types of pollinations, including reciprocals of e.g., Fallbrook female x Motte Rimrock male and Motte Rimrock female x Fallbrook male, etc. (Fig. 2). The design used a total of 21 different population combinations, and a total of 13,973 flowers were pollinated.

We monitored the potential for outbreeding depression in terms of production of filled seeds and seedling emergence. To determine the effect of parental cross on seed production, we tracked each pollinated flower from several days after pollination to fruit maturity (about 8 weeks). Fruits and seeds were scored as filled if seeds were plump and of mature color. To examine the effect of cross type on seed germination, we planted seeds in a randomized block design in the greenhouse on December $18-19,1996$. All seeds were treated by pouring boiling water over them in a glass beaker and soaking them for exactly 10 minutes. We planted 6 replicates of 15 seeds per row for each cross type, except for within population

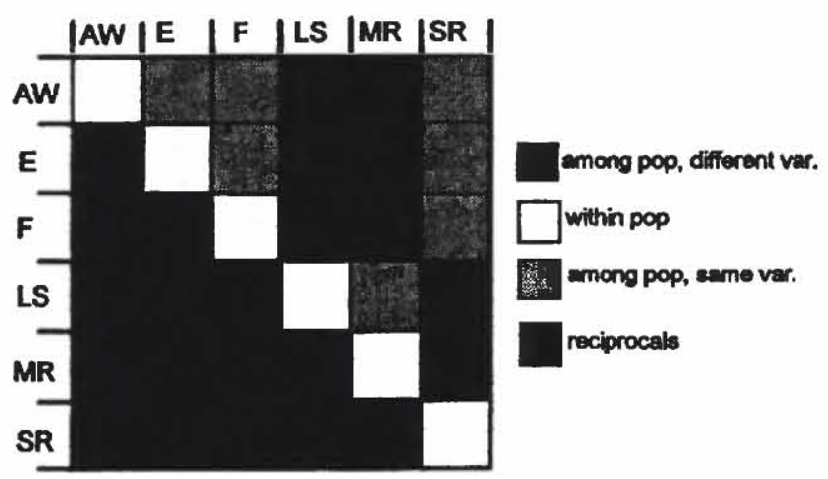

Figure 2. Experimental crossing design for test of the outbreeding depression hypothesis in Lotus scoparius. See Figure 1 for key to site abreviations. Plants in the populations listed across the top of the diagram served as mothers, while those on the vertical axis served as fathers. The black cells (below the diagonal) represent the reciprocal of those crosses shown above the diagonal. crosses in which we planted 12 replicate rows. Flats were placed in the greenhouse at ambient temperatures except that night- and daytime extreme temperatures were kept to within a range of $4-29^{\circ} \mathrm{C}$, respectively. We rotated flats and scored emergences "blind" every other day until February 12.

\section{Data analysis}

Genetic diversity and distance - To calculate genetic distances among all 12 source populations, mean expected heterozygosity, and mean alleles per locus, we used BIOSYS-1 for PC (cf. Swofford and Selander 1981).

Experiment I: To test the hypothesis that performance of transplanted populations decreases as the genetic distance among each of the 12 source sites and the recipient population (either Motte Rimrock or Fallbrook) increases, we ran two analyses. The first examined the relationship between height of individuals at the end of the first growing season (mid-June 1995) and genetic distance using a simple linear regression model with the square root of height as the dependent variable. Plant height was transformed to improve normality of residuals. Second, we tested if there was a negative correlation between the proportion of individuals surviving to February 1996, after one complete annual cycle of growth in the common gardens, and genetic distance by using a Spearman's rank order correlation test. In all cases, the test for a decreasing relationship of fitness relative to genetic distance is one-tailed. We used SAS for Windows, version 6.08 for these analyses.

Experiment II: To test for the occurrence of outbreeding depression upon crossing of individuals from genetically differentiated populations, we ran two analysis of covariance (ANCOVA) models. We used ANCOVA instead of simple linear regressions because differences among mothers from different sites in their ability to produce viable seeds can potentially reduce the error variance of the model. An ANCOVA model that considers the joint effect of genetic distance as a covariate (the regression part of the model) with the mother's source site as a main effect would then allow a better view of the relationship between genetic distance of the crosses and crossing success. For any particular cross, we used the mean proportion of flowers setting mature seeds over all mothers originating from the same plot within a source population. In the first model, mean proportion of flowers setting mature seeds was the dependent variable, site of mother was the main effect, and genetic distance of the crossed populations was the covariate. Site of mother was included to partition potentially strong maternal effects. The analysis was then weighted by the number of mothers represented in each mean. The use of plot means for proportion of flowers setting mature seeds improved normality 
of residuals in the ANCOVA compared to use of individual counts. In the second model, the dependent variable was the proportion of seeds in each replicate planting that produced seedlings (EMERG), transformed with an arcsine of the square root to improve normality of residuals. For all models, we first tested for the hypothesis of equal slopes by including the site of mother $\mathrm{x}$ genetic distance interaction term to the above. Because this was always non-significant, it was removed from the final models. In all cases, the test for a decreasing relationship of fitness relative to genetic distance is one-tailed, while tests for the effect of site are two-tailed. We used Proc GLM, with type III sums of squares for the final models, from SAS for Windows, version 6.08 (SAS Institute 1986).

\section{Results}

\section{Genetic diversity and distance}

Analysis of electrophoretic data for the 12 source populations revealed high genetic diversity over the geographic area sampled. The mean number of alleles per locus was 5.6, mean expected heterozygosity $\left(\mathrm{H}_{\mathrm{e}}\right)$ was 0.26 , and 12 of 13 loci were polymorphic (loci with more than one allele). This high diversity and large sample size of 60 individuals per source population, provided confident estimates of genetic distance. An unweighted pairgroup method analysis (UPGMA) clustergram of Nei's (1972) genetic distances (Fig. 3 ) shows that the populations of L. s. brevialatus cluster distinctly from those of $L$. s. scoparius. Because of this strong genetic differentiation among these two varieties, we analyzed results of the common garden experiments in two ways: (1) we lumped the varieties together in analyses (the way practitioners of post-fire seeding and restoration frequently view them); and (2) we analyzed data for the nine $L$. s. scoparius source populations alone (it was the only variety represented by enough source populations to analyze statistically).

Lotus Scoparius SIte Locations

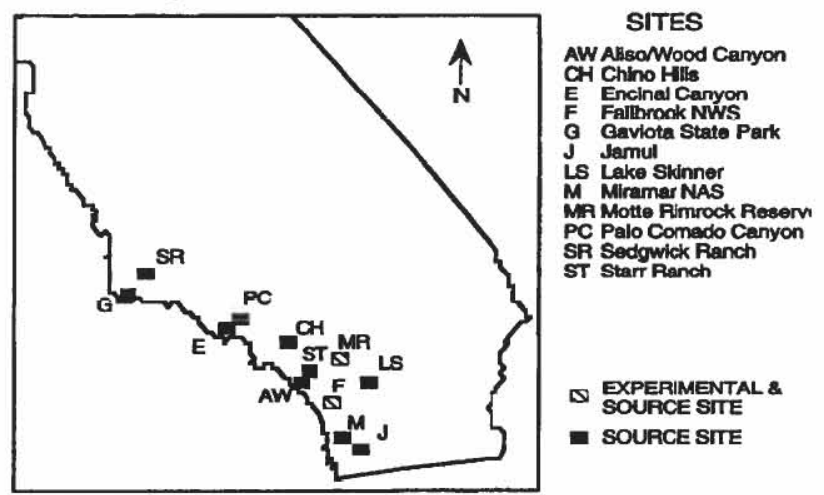

Figure 3. UPGMA clustergram of genetic distances among source populations.

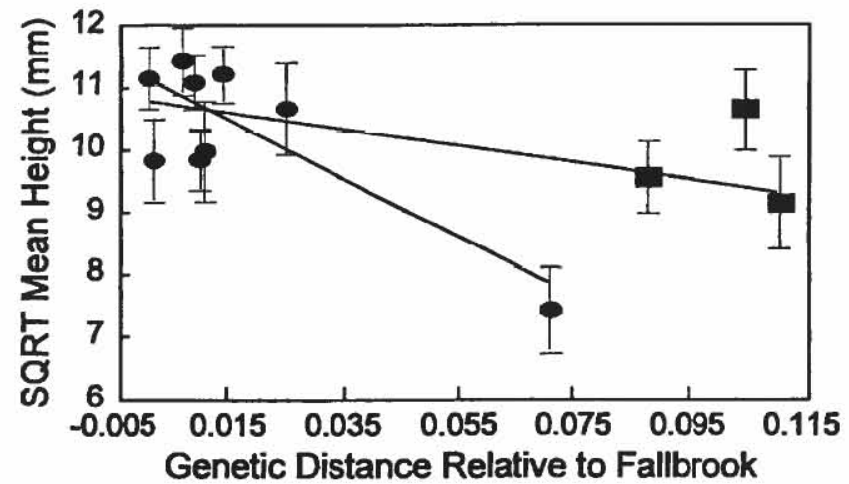

Figure 4. Mean height attained at the Fallbrook experimental garden at the end of the first growing season. The square root of mean height is the dependent variable, and genetic distance is the independent variable in regression analyses. Vertical bars are standard errors for the mean values for the performance of progeny from each source population in the Fallbrook experimental garden. Means are plotted by the genetic distance of the source population and the population indigenous to Fallbrook. The regression line with the shallow slope is for the analysis that lumps the two varieties, $L$. scoparius var. scoparius (ovals) and $L$. scoparius var. brevialatus (rectangles), while the steeper line is for the analysis based on only $L$. s. var. scoparius source.

Experiment I - Test of the home team advantage hypothesis: At both experimental sites, there was general support for the home team advantage hypothesis as measured by plant height at end of first growing season. At Fallbrook, analysis of both varieties of $L$. scoparius together (Fig. 4), showed that the height of individuals obtained by the end of the first growing season decreased significantly with increasing genetic distance of source site to the Fallbrook indigenous population $(\mathrm{F}=9.1 ; \mathrm{P}=$ 0.0014). At Motte, there was no significant negative slope

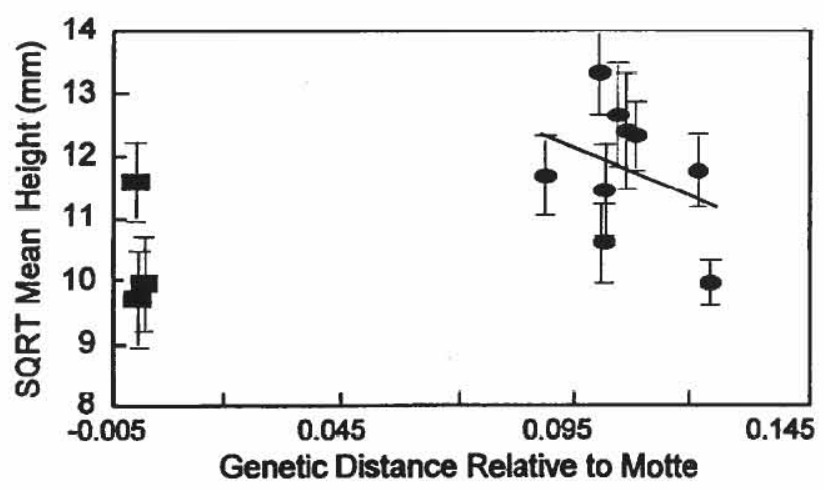

Figure 5. Mean height attained at the Motte experimental garden at the end of the first growing scason. Regression plot in which the square root of mean height is the dependent variable, and genetic distance is the independent variable. Vertical bars are standard errors for the mean values for the performance of progeny from each source population in the Motte experimental garden. Means are plotted by the genetic distance of the source population and the population indigenous to Motte. The regression line is for the analysis based on only L. scoparius var. scoparius source populations (oval symbols). 


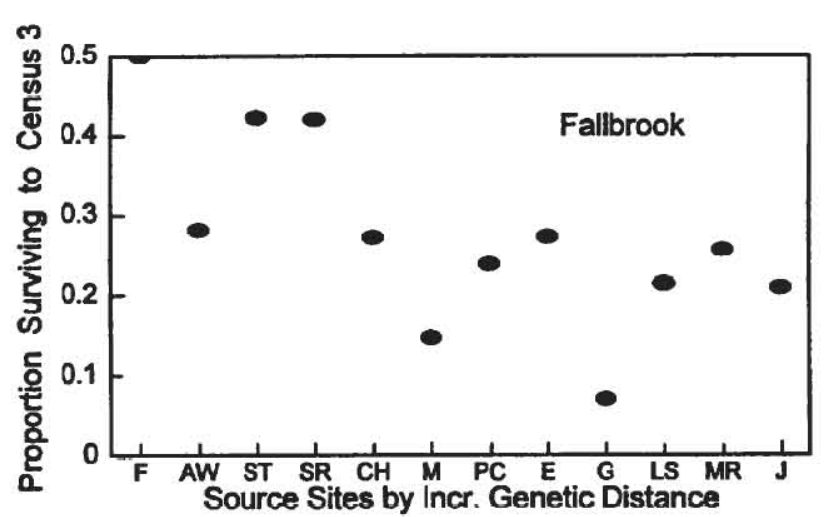

Figure 6. The proportion of individuals from each source population surviving for one year in the Fallbrook experimental plot. Source populations are arranged by rank order of increasing genetic distance of each source population relative to the population indigenous to Fallbrook.

(Fig. 5). When the data for only L. s. scoparius were analyzed, plants in both experimental plots showed a significant decrease in height with increasing genetic distance (Fallbrook, $F=13.16 ; P=0.0002$; Motte, $F=2.88 ; P=$ 0.0455 ). In models with only L. s. scoparius (Figs. 4 and $5), 6.4 \%$ and $1.4 \%$ of the total variance in height was explained by genetic distance.

Analyses of survival for the combined data for $L . s$. brevialatus and $L$. s. scoparius showed a significant decrease in the proportion of individuals surviving with increasing genetic distance for 1 year at Fallbrook ( $r=-$ $0.76 ; P=0.0020$ ), but this trend was not significant at Motte $(r=-0.031 ; P=0.1595)$. However, in the separate analyses of transplant survival of the nine $L$. s. scoparius populations, there was a significant decrease at both Fallrook $(r=-0.86 ; P=0.0014)$ and Motte $(r=-0.62 ; P=$ 0.0366 ). Overall survival was low but was much better at Fallbrook (median $=26.5 \%$, range $7.1 \%-50 \%$ ) than at the Motte (median $=13.5 \%$, range 3.6-34.6\%) (Figs. 6 and

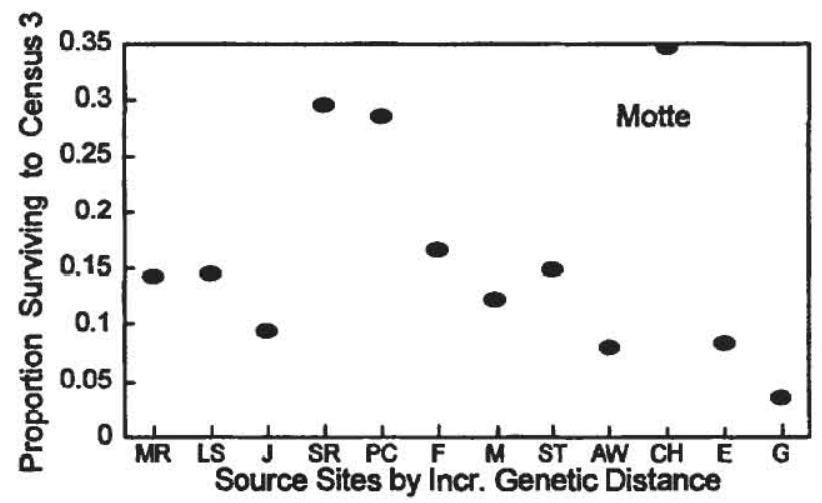

Figure 7. The proportion of individuals from each source population surviving for one year in the Motte experimental plot. Source populations are arranged by rank order of increasing genetic distance of each source population relative to the population indigenous to Motte.

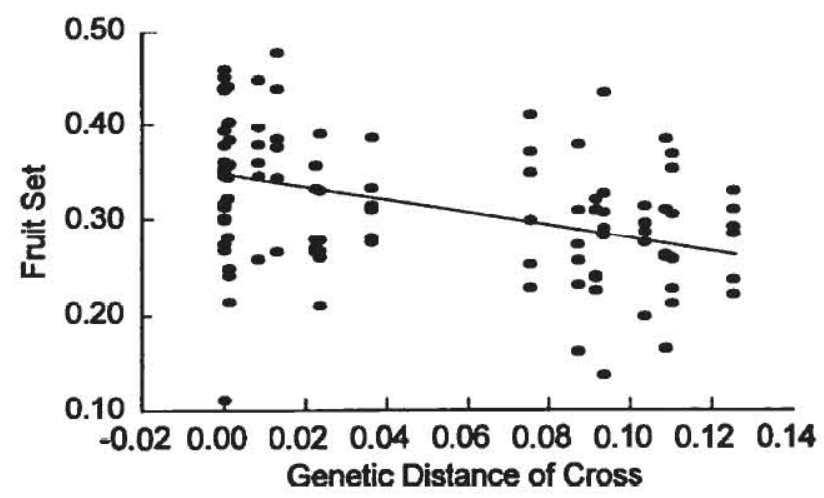

Figure 8. Mean $\%$ fruit set (FSET) resulting from experimental crosses arranged by increasing genetic distance of the crossed populations. Each data point has been adjusted by the effect of SITE (from the ANCOVA results).

7). The relative performance of the different source populations shifted among two experimental sites. For example, the source population from Gaviota State Park had the lowest survival at both locations. However, Fallbrook source plants had the highest survival at Fallbrook with Chino Hills source plants ranked fourth, but their survival ranks were reversed at Motte. Ranked success of the $L$. $s$. brevialatus plants was somewhat higher at Motte, shifting from ranks 7,9 , and 10 to 6,5 , and 9 .

Experiment II - Test of the outbreeding depression hypothesis: Analysis of the fitness components of fruit set and seedling emergence showed a significant potential for outbreeding depression when local and non-local populations of $\boldsymbol{L}$. scoparius were crossed. For both parameters, fitness decreased with increasing genetic distance of the crossed populations. Mean fruit sets (adjusted for site) were $28.9 \%$ from among variety crosses and $34.7 \%$ for within variety crosses, revealing a $16.7 \%$ relative advantage to within variety crosses. In the ANCOVA of fruit

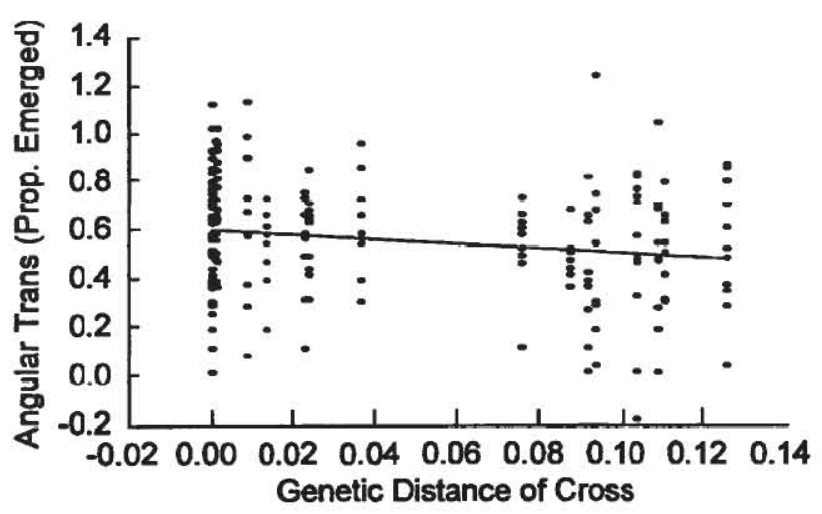

Figure 9. The proportion of seeds producing seedlings arranged by increasing genetic distances of their parental populations. Each data point has been adjusted by the effect of SITE (from the ANCOVA results). 
set, the highly significant site effect explained $32.8 \%$ of the total variance $\left(F_{[5,107]}=12.75 ; P=0.0001\right)$ showing a strong effect of maternal population, presumably because there were large differences among mothers from different sites in ability to produce seeds under our growing conditions. In the same model, genetic distance explained $11 \%$ of the variation such that fruit set decreased significantly with increasing genetic distance $(F=20.00, d f=1$; $P<0.0001)$. This relationship is best observed by plotting the relationship of fruit set and genetic distance after removing the effects of maternal site (Fig. 8). In a separate ANOVA model that included a main effect of cross type (within population, among population but within variety, versus among variety), instead of the covariate genetic distance, we found that most of the fitness difference in fruit set was a result of significant differences for within versus among variety crosses (apriori contrasts: among variety crosses versus others, $d f=1, \mathrm{~F}=14.14, P$ $=0.004$; within population versus among population and within variety, $d f=1, F=0.36, P=0.560$ ).

The proportion of seeds resulting in emerged seedlings also decreased significantly with increasing genetic distance of the crossed parental populations (Fig. 9), but the relationship was quite weak. In the ANCOVA, the site effect explained a highly significant $15.8 \%$ of the total variance in emergence $\left(F_{[5,251]}=8.85 ; P=0.0001\right)$, while genetic distance explained a significant $3.1 \%$ of the variance $(F=9.47 ; d f=1 ; P=0.0012)$. Again, in a separate ANOVA model that included a main effect of cross type (within population, among population but within variety, versus among variety) instead of the covariate genetic distance, we found that most of the significant difference in seedling emergence was due to within versus among variety crosses (apriori contrasts: among variety crosses versus others, $d f=1, F=19.04, P=0.001$; within population versus among population and within variety, $d f=$ $1, F=0.27, P=0.615$ ). Site-adjusted means for percentage emergence were $15.7 \%$ lower for seeds from within variety compared to among variety crosses (that is, with respect to the fitness component of seedling emergence, among variety seeds were $84.3 \%$ as fit as within variety seeds).

\section{Discussion}

Experiment I - Test of the home team advantage hypothesis:

Differences in initial survival and growth of plants in restorations are important to both the short- and long-term success of the restoration projects. Our data suggest that success rates will be higher if genetically local populations are used to supply seeds for restoration and postfire seeding of specific sites. At the end of a single season of growth, there was a significant home team advantage for $L$. s. scoparius at both common garden locations for both plant size and survival. However, when the data for both varieties of $L$. scoparius were lumped, this relationship became clouded at the Motte garden site. In this preliminary analysis, we examined survival through one complete growing season, the long dry season, and the early part of the 1996 growing season. Survival is only one of several major components of fitness needed to examine overall fitness. We also examined height of plants attained in a single growing season (proxy for size). Although plant size is not a major component of fitness, it is a fitness related trait that sometimes correlates with flower production (Primack and Kang 1989; Devlin and Ellstrand 1990). We have continued to monitor these plants through three entire growing seasons to obtain more direct measures of the reproductive potential of these plants, including flower production, and will incorporate these data into future tests of the home team advantage hypothesis. Eventually, we will multiply survival and reproductive success components to obtain more complete estimates of cumulative relative fitness.

\section{Experiment II - Test of the outbreeding depression hypoth-} esis:

Significant outbreeding depression observed in both fruit production and seedling emergence suggests that there will be outbreeding depression in nature if flower visitors successfully cross pollinate flowers of non-local transplants and residents. In our study species, the potential for outbreeding depression is highest when the two varieties are crossed. Mean fruit set of among variety crosses was $83.3 \%$ that of within variety crosses. Similarly, emergences of among variety seeds were $84.3 \%$ of within variety crosses. These two components of fitness (relative fruit set and relative emergence) can be multiplied together to determine cumulative fitness of the cross types through the stage of seedling emergence. The cumulative fitness of among relative to within population crosses is $70 \%$ representing a substantial level of outbreeding depression. Because flowers of both varieties are visited, and presumably pollinated by bumblebees, there is potential for natural hybridization when the two varieties are interplanted. However, the success of cross pollination in nature remains to be studied.

The seedlings from our crosses have been transplanted into the two common garden sites. Future analyses will incorporate data from the relative survival of seedlings of different crossing distances in two contrasting environments.

Although we found significant outbreeding depression in the first progeny generation after outcrossing, we do not know its genetic basis or its potential to persist into future generations. Persistence and total fitness deficits will depend both on the initial relative frequencies of nonlocal and local parents and on the genetic basis of the outbreeding depression (e.g., Fenster and Dudash 1994). 


\section{Other analyses}

We are also planning to examine our hypotheses with respect to environmental distance of populations. We are basing environmental distance on climatological and soil factors and will also examine correlations between geographic distance, environmental distance, and measures of distance based on floral morphology. These analyses will help to determine if the patterns in differential success of source populations and the presence of outbreeding depression is, in part, the result of local adaptive differences among populations (e.g., Manly 1985; Knapp and Rice 1997). These analyses may also clarify potential seed collection zones and provide traits that are more easily observed than allozymes.

\section{Conclusions}

The preliminary results of this study suggest that the fitness of $L$. scoparius populations can be adversely affected when non-local populations are used for seeding and restoration. There is a potential for both lower fitness of foreign transplants and outbreeding depression if nonlocal seeds are used in emergency post-fire seeding and habitat restoration. The effect is strongest when non-local varieties are mixed. Future analyses will reveal if ecological data from the source habitats can provide easily defined seed-collection zones than can be obtained with allozyme data. Existing Pacific Southwest Region 5 genetic transfer guidelines should be used in the meantime, with the caution that varieties be kept separate whenever they actually occur in the same seed collection zone.

Acknowledgments. We thank Andrew Cortez, Tasha LaDoux, Kelcy Kemp, Jenni Kempton, Rick Miranda, Deborah Weaver, and Lynn Wolden for assisting with greenhouse and field work; Janet Clegg and Elizabeth Franzino for running gels; Haiganoush Preisler,Len Nunney, Matt Brooks, and Jud Monroe for comments on an earlier draft of the manuscript; and Len Nunney and Susan Conard for logistical support. This research was supported in part by a grant from the USDA National Research Initiative Competitive Grant Program (No. 94-37101-0385) and the Southwestern Riverside County Multi-Species Reserve Management Committee (Agreement No. 1551).

\section{Literature Cited}

Anonymous. 1992. Guidelines for management of genetic resources in the Califurnia Stale Park System. Prepared by Sycamore Associates for the California Department of Parks and Recreation, Lafayette, CA.
Baron, F.J. and G.H. Schubert. 1963. Seed origin and size on ponderosa pine planting stock grown at several California nurseries. USDA Forest Service, Research Note PSW No. 9.

Barrett, S.C.H. and J.R. Kohn. 1991. Genetic and evolutionary consequences of small population size in plants: implications for conservation. Pp. 3-30 in D.A. Falk and K.E. Holsinger, eds. Genetics and conservation of rare plants. Oxford University Press, New York, NY.

Bradshaw, A.D. 1965. Evolutionary significance of phenotypic plasticity in plants. Advances in Genetics 13:115-155.

Bradshaw, A.D. 1984. Ecological significance of genetic variation between populations. Pp. 213-228 in R. Dirzo and J. Sarukhan, eds. Perspectives on plant population ecology. Sinauer, Sunderland, MA.

Clausen, J. and W.M. Hiesey. 1958. Experimental studies on the nature of species. IV. Genetic structure of ecological races. Carnegie Institute of Washington Publication 615, Washington, DC.

Clausen, J., D.D. Keck, and W.M. Hiesey. 1940. Experimental studies on the nature of species. I. Effect of varied environments on western North American plants. Carnegie Institution of Washington Publication 520, Washington, DC.

Clausen, J., D.D. Keck, and W.M. Hiesey. 1947. Heredity of geographically and ecologically isolated races. American Naturalist 81:114-133.

Clausen, J., D.D. Keck, and W.M. Hiesey. 1948. Experimental studies on the nature of species. III. Environmental responses of climatic races of Achillea. Carnegie Institution of Washington Publication 581, Washington, D.C.

Devlin, B. and N.C. Ellstrand. 1990. Male and female fertility variation in wild radish, a hermaphrodite. American Naturalist 136:87-107.

Elam, D.R. 1999. Using population genetic theory and data in restoration of rare plants in California. Pp. 211-219 in J.E. Keeley, M.B. Keeley, and C.J. Fotheringham, eds. 2nd Interface between ecology and land development in California. International Association of Wildland Fire, Fairfield, WA.

Ellstrand, N.C. 1984. Multiple paternity within the fruits of the wild radish, Raphanus sativus. American Naturalist 123:819828.

Fenster, C.B. and M. R. Dudash. 1994. Genetic considerations for plant population restoration and conservation. Pp. 34-62 in M.L. Bowles and C.J. Whelan, eds. Restoration of endangered species: conceptual issues, planning, and implementation. Cambridge University Press, Cambridge, UK.

Fowells, H.A. 1946. Forest tree seed collection zones in California. USDA Forest Service, Research Note 51.

Guerrant, E.O., Jr. 1992. Genetic and demographic considerations in the sampling and reintroduction of rare plants. Pp. 321-344 in P.L. Fiedler and S.K. Jain, eds. Conservation biology: the theory and practice of nature conservation, preservation, and management. Chapman and Hall, New York, NY.

Guerrant, E.O., Jr. 1996. Designing populations: demographic, genetic, and horticultural dimensions. Pp. 171-207 in D.A. Falk, C.I. Millar, and M. Olwell, eds. Restoring diversity: strategies for reintroduction of endangered plants. Island Press, Covelo, CA.

Hamrick, J.L., M.J.W. Godt, D.A. Murawski, and M.D. Loveless. 1991. Correlations between species traits and allozyme diversity: implications for conservation biology. Pp.75-86 in D.A. Falk and K.E. Holsinger, eds. Genetics and conservation of rare plants. Oxford University Press, New York, NY. 
Handel, S.N., G.R. Robinson, and A.J. Beattie. 1994. Biodiversity resources for restoration ecology. Restoration Ecology 2:230241.

Hickman, J.C., editor. 1993. The Jepson manual: higher plants of California. University of California Press, Ltd., London, UK.

Huenneke, L.F. 1991. Ecological implications of genetic variation in plant populations. Pp. 31-44 in D. A. Falk and K. E. Holsinger, eds. Genetics and conservation of rare plants. Oxford University Press, New York, NY.

Isely, D. 1981. Leguminosae of the U.S. III: subfamily Papilionoideae: tribes Sophoreae, Podalyryeae, Loteae. Memoirs of the New York Botanical Garden 25:1-264.

Kirkpatrick, J.B. and C.F. Hutchinson. 1977. The community composition of California coastal sage scrub. Vegetatio 35:21-33.

Kitzmiller, J.H. 1990. Managing genetic diversity in a tree improvement program. Forest Ecology and Management 35:131-149.

Knapp, E.E. and K.J. Rice. 1994. Starting from seed: genetic issues in using native grasses for restoration. Restoration $\&$ Management Notes 12(1):40-45.

Knapp, E.E. and K.J. Rice. 1997. Comparing isozymes and quantitative traits for evaluating patterns of genetic variation in purple needlegrass (Nassella pulchra). Conservation Biology, 12:1031-1041.

Lynch, M. 1991. The genetic interpretation of inbreeding depression and outbreeding depression. Evolution 45:622629.

Manly, B.F.J. 1985. The statistics of natural selection on animal populations. Chapman and Hall, New York, NY.

McCall, M.A. 1939. Forest tree seed policy of the U. S. Department of Agriculture. Journal of Forestry 37:820-821.

Millar, C.I. and W.J. Libby. 1989. Disneyland or native ecosystem: genetics and the restorationist. Restoration and Management Notes 7(1):18-24.

Millar, C.I. and W.J. Libby. 1991. Strategies for conserving clinal, ecotypic, and disjunct population diversity in widespread species. Pp. 149-170 in D.A. Falk and K.E. Holsinger, eds. Genetics and conservation of rare plants. Oxford University Press, New York, NY.

Moldenke, A.R. 1976. California pollination ecology and vegetation types. Phytologia 34:305-361.

Montalvo, A.M. 1995. Restauracion de habitats con plantas nativas: consideraciones geneticas que afectan a la viabilidad de la poblacion. Pp. 179-192 in A. Pastor-Lopez and E. Seva, eds. Restauracion de la Cubierta Vegetal en Ecosistemas Mediterraneos. Coleccion Seminarios. Volume 7. Instituto de Cultura Juan Gil-Albert. EXCMA, Diputacionde Alicante, Espana.

Montalvo, A.M., S.L. Williams, K.J. Rice, S.L. Buchmann, C. Cory, S.N. Handel, G.P. Nabhan, R. Primack, and R.H. Robichaux. 1997. Restoration biology: a population biology perspective. Restoration Ecology, 5:277-290

Nei, M. 1972. Genetic distance between populations. American Naturalist 106:283-292.

Primack, R.B. and H. Kang. 1989. Measuring fitness and natural selection in wild plant populations. Annual Review of Ecology and Systematics 20:367-396.

Schmidt, K.P. and D A. Levin. 1985. The comparative demography of reciprocally sown populations of Phlox drummondii Hook. I. Survivorships, fecundities, and finite rates of increase. Evolution 39:396-404.
Schubert, G.H., R.S. Adams, and L.A. Moran. 1971. Reforestation practices for conifers in California. State of California, The Resources Agency, Department of Conservation, Division of Forestry, Sacramento, CA.

Silander, J.A. 1985. The genetic basis of the ecological amplitude of Spartina patens II. Variation and correlation analysis. Evolution 39:1034-1052.

Steppan, S.J. 1991. Geographic distribution of flower morphological traits in subspecies of Lotus scoparius. Journal of Biogeography 18:321-331.

Swofford, D.L. and R B. Selander. 1981. BIOSYS-1: a FORTRAN program for the comprehensive analysis of electrophoretic data in population genetics and systematics. Journal of Heredity 72:281-283.

Templeton, A.R. 1986. Coadaptation and outbreeding depression. Pp. 105-116 in M.E. Soule, ed. Conservation biology: the science of scarcity and diversity. Sinauer, Sunderland, MA.

Turesson, G. 1922. The genotypical response of the plant species to the habitat. Hereditas 3:211-350.

Turesson, G. 1925. The plant species in relation to habitat and climate. Hereditas 6:147-236.

Turesson, G. 1930. The selective effect of climate upon the plant species. Hereditas 14:99-152.

Wang, H., E.D. McArthur, S.C. Sanderson, J.H. Graham, and D.C. Freeman. 1997. Narrow hybrid zone between two subspecies of big sagebrush (Artemisia tridentata Asteraceae). IV. Reciprocal transplant experiments. Evolution 51:95-102.

Waser, N.M. 1993. Population structure, optimal outbreeding, and assortative mating in angiosperms in N.W. Thornhill, ed. The natural history of inbreeding and outbreeding: theoretical and empirical perspectives. University of Chicago Press, Chicago, IL.

Weeden, N.F. and J.F. Wendel. 1989. Visualization andinterpretation of plant isozymes. Pp 5-45 in D.E. Soltis and P.S. Soltis, eds. Isozymes in plant biology. Dioscorides Press, Portland, OR.

Westman, W.E. 1983. Xeric mediterranean-type shrubland associations of Alta and Baja California and the community/ continuum debate. Vegetatio 52:3-19. 


\title{
Assessing Success of Restoration Attempts: What Can Terrestrial Arthropods Tell Us?
}

\author{
Kathy S. Williams \\ Department of Biology, San Diego State University, San Diego, California, USA 92182-4614 \\ Tel. (619) 594-6767; Fax (619) 594-5676; e-mail : kwilliam@sunstroke.sdsu.edu
}

\begin{abstract}
A major problem for restoration ecology is how to assess success. Agencies may be satisfied with restoration efforts if the area has native plants that remain green over time or if certain birds or mammals are observed there, although those criteria may inaccurately represent ecosystem conditions. Terrestrial arthropods are particularly appropriate for evaluating environmental quality and serving as warning indicators, since they represent tremendous biodiversity and roles as herbivores, pollinators, decomposers, predators, and prey for vertebrates are critical to ecosystem functions. Examples from several habitats demonstrate benefits and potential problems of various methods of monitoring arthropods for habitat quality assessment.
\end{abstract}

Keywords: Insects; terrestrial arthropods; riparian restoration; indicators; biodiversity; habitat management and monitoring; San Luis Rey River; San Diego River; San Diego County.

\section{Introduction}

A major problem for restoration ecology is assessing progress or succcess of restoration efforts (Andersen 1990; PERL 1990; Kremen et al. 1993; Williams 1993a; Kremen 1994). Some agencies may be satisfied with restoration efforts if the area contains plants that remain green over time or if certain birds or mammals are observed there, although those criteria may inaccurately represent ecosystem conditions (Jordan et al. 1987; Landres et al. 1988; Majer 1989; Noss 1990; Kremen et al. 1993). Insects and related terrestrial arthropods represent tremendous taxonomic and morphological diversity, which also is reflected in their functional diversity. Terrestrial arthropods play essential roles as predators, parasites, herbivores, pollinators, decomposers, scavengers, and as prey for many other organisms (Wilson 1987; Handel 1997; Majer 1997; Williams 1997). These attributes of morphological and ecological diversity, in addition to short generation times, dramatic population dynamics, and high population densities make insects and other terrestrial arthropods par- ticularly appropriate to serve as indicators of biodiversity, habitat quality, and disturbance (Refseth 1980; Kremen 1992; Williams 1993; Handel 1997; Majer 1997; Williams 1997).

Unfortunately, often monitoring programs or habitat analyses exclude insects, in part, because their diversity may be overwhelming. However, insects in many of the orders, or members of families within diverse orders, share ecologically informative characteristics. For example, members of the suborder Homoptera (including aphids and planthoppers) are all herbivores (Borror et al. 1989), many families of Diptera (flies) have larvae that require aquatic conditions for development (Cole 1969), and all spiders are predators (Comstock 1940). Thus, identification to taxonomic levels above species, such as order or family, can provide valuable ecological information about many insects. In this paper I would like to demonstrate how insect diversity can be used to provide valuable information for restoration and management, and how various arthropod sampling methods can affect the quality of data and subsequent conclusions.

\section{Variation Among Sampling Methods}

When using diverse insects to answer questions about restoration or management of habitats, differences among groups must be considered and sampling methods selected to answer specific questions. Since terrestrial arthropods are so diverse, most methods collect some types more frequently than others, yielding biased samples (Southwood 1978). Therefore, collection techniques must be selected carefully to obtain accurate answers to urgent ecological questions dealing with habitat restoration and management. The following review describes some of the benefits and biases of a few standard methods of collecting terrestrial arthropods.

\section{Interceptors}

Interceptors are traps that can be set up and left unattended for periods of time, and include Malaise traps, 
sticky traps, pitfall traps, emergence traps, and water traps (Southwood 1978). A major advantage of these traps is that they collect large numbers of insects and spiders with relatively small efforts. These techniques are used to collect Coleoptera, Diptera, Hemiptera, Hymenoptera, Lepidoptera, but mainly collect those species that are relatively active and vagile (Southwood 1978; Penny and Arias 1982; New 1984; Zelanzny and Alfiler 1987; Sutton 1989; Hutcheson 1990). Thus, collections are influenced by insect phenologies and weather conditions. In addition, the variety of insects caught may reflect specific trap location.

\section{Vegetation sampling}

Collections from vegetation can be made by sweeping or beating insects and spiders off of vegetation or even by using suction devises (Southwood 1978). Sampling insects from vegetation allows association of insects with particular plants, and both large and small insects may be collected in this way. A wide variety of insect taxa can be censused from vegetation, including Coleoptera, Diptera, Hemiptera, Hymenoptera, Lepidoptera, and Orthoptera (Janzen 1973a, 1973b; Janzen and Pond 1975; Southwood 1978; Kemp et al. 1990). As is the case with sampling using inteceptors, vegetation collections can be influenced strongly by insect phenologies, weather conditions, ability of active insects to escape capture, and also by the condition of the plants.

\section{Soil and litter sampling}

Ground-dwelling arthropods like millipedes, centipedes, Collembola (springtails) and termites can be sampled using cores or Berlaise funnels to process soils and litter (Lussenhop 1973; Southwood 1978; Penny and Arias 1982; Stork 1987a, 1987b), While these animals represent critical components of ecosystem function, their survey usually involves labor-intensive methods and active animals can escape collection. Paradoxically, effectiveness of funnels to separate soil arthropods depends on the ability of animals to move (Southwood 1978). However, any problems of sampling and processing are far outweighed by the valuable information that can be gathered from studying soil arthropods, which can number over 200 species per square meter of forest soil in the Pacific Northwest (Moldenke 1990).

\section{Attractants}

Frequently insect sampling methods use attractants, such as light or baits, since they may be left unattended and can collect many individuals of particular taxa (Southwood 1978). Light trapping is widely used to census Lepidoptera and Coleoptera, since it is a relatively easy method to collect flying insects, even from tree cano- pies (Penny and Arias 1982; New 1984; Holloway 1990; McGeachie 1989; Sutton 1989). However, there are several potential problems associated with light trapping. For example, light trap samples are biased to collect highly mobile insects with high degrees of phototaxis, both variable characteristics among taxa. Thus, light traps may "oversample" abundant or light sensitive species. Furthermore, light trap collections may be affected by incident light in the neighborhood of traps and weather conditions, which can vary among sampling dates. Baited traps are successfully used to sample Coleoptera, Diptera, Lepidoptera, and spiders (Southwood 1978; Penny and Arias 1982; Zelanzny and Alfiler 1987; Sutton 1989). Baits, such as sugars, carrion, $\mathrm{CO}_{2}$, and pheromones, typically are selective for particular taxa, and for groups exhibiting certain phenologies and behavior. For example, often only adult insects are collected at baits, since juveniles may not be attracted to baits, like pheromones, and often have limited mobility. Pheromone baits can be species-specific, providing an excellent tool for detection or presence/absence assays. In addition, attractants like baits and lights may attract individuals from long distances, limiting assessments of population distributions.

By reviewing a variety of standard methods, I have attempted to demonstrate that not all collection techniques can possibly answer all ecological questions, since most methods collect different insects and related terrestrial arthropods. Therefore, differences among groups must be considered and sampling methods selected to answer specific questions. Examples of how this theory can be put into practice follow.

\section{Putting Theory Into Practice}

How do we turn this theory about arthropod indicators into practice and select appropriate collection methods? In southern California, preservation and maintenance of habitat for threatened species of birds, like the lightfooted clapper rail (Rallus longirostrus levipes) and the California gnatcatcher (Polioptila californica californica), drives much of the habitat restoration and management, and in riparian areas the target species is least Bell's vireo (Vireo bellii pusillus) (Baird 1989; Baird and Rieger 1989; IIendricks and Rieger 1989; Kus 1997). IIere I present data from studies of riparian habitats in San Diego County where woodlands were managed as habitat for least Bell's vireo.

\section{Study sites}

The following data come from seven years of quantifying terrestrial arthropod communities along two river drainages in San Diego County. In 1989 planting was completed at a restoration site along the San Luis Rey River, near Oceanside, CA (Williams 1993, 1997). This 
small site had an area of $3 \mathrm{ha}$ and an adjacent site, $3 \mathrm{~km}$ away, was studied as a reference, or more natural, site. Least Bell's vireo had nested there each year since monitoring began in 1989 (B. Kus, personal communication). Another restoration site CalTrans planted is along the San Diego River, near Santee, CA, and encompassed about 20 ha and bordered existing riparian vegetation. On the north side of the river, a 14 ha section of the riparian drainage north was almost completely replanted. On the south side of the river, native riparian vegetation was transplanted to portions of a 7 ha area that had been used as a public campground. Reconstruction there involved removal and revegetation of campsites in the woodland. Since disturbance and revegetation was relatively limited at the south site, it was considered to be a relatively undisturbed area and used as reference for a restoration site north of the river.

\section{Methods}

Terrestrial arthropods - including insects, spiders, and isopods - were collected every 4 to 6 weeks in spring and summer, and once each fall and winter when weather allowed. Data presented here represent collections made during spring and summer months (April through July) when insect and avian breeding activities were intense. Insects and spiders were collected using sweep netting and pan trapping techniques (Williams 1993, 1997). Traps and sweep sampling stations were placed in regular arrangements at the sites to insure coverage. At the San Luis Rey River, 47 pan traps and 17 sweep sampling stations were used during 1989-1992, and at the San Diego River, 49 pan traps and 29 sweep sampling stations were used during 1991-1995 (Williams 1993, 1997).

Mean numbers of individuals per sample unit were compared between sites and within years using one-way analyses of variance (Abacus Concepts, Statview II 1.04, and SuperANOVA 1.11). When necessary, data were first transformed to achieve normality. Data are presented here in the non-transformed form, but statistical differences refer to transformed data.

\section{Quantifying Food Resources For Foliage Gleaning Birds}

\section{Analyses based on the complete arthropod community}

Least Bell's vireo was the target species for the riparian habitat restoration discussed here, so one way of evaluating success of these restoration efforts is to examine avian food resources. Least Bell's vireo and many other riparian birds are insectivores that glean prey from vegetation (Kus 1997). Therefore, an ecological question to be asked in such situations is whether restoration sites provide food resources for avian insectivores that are equivalent to those at more natural reference sites. An initial approach might be to sample using gross methods to quantify all arthropods and draw inferences about food availability, but quantifying total abundance (quantified as numbers or biomass) without considering the composition of collections and possible sampling biases may give misleading answers. For example, a simple method of collecting relatively large numbers of diverse terrestrial arthropods is to use pitfall or pan traps. Considering data from fluid-filled pan traps at Restoration and Reference sites along the San Luis Rey River (Williams 1993), the conclusion would be that on many dates during springsummer of the first four years after restoration was attempted total arthropod abundance was greater at the Restoration site (Fig. 1A).

However, when the data were reanalyzed with numbers of only one taxon, Collembola, removed, the conclu-
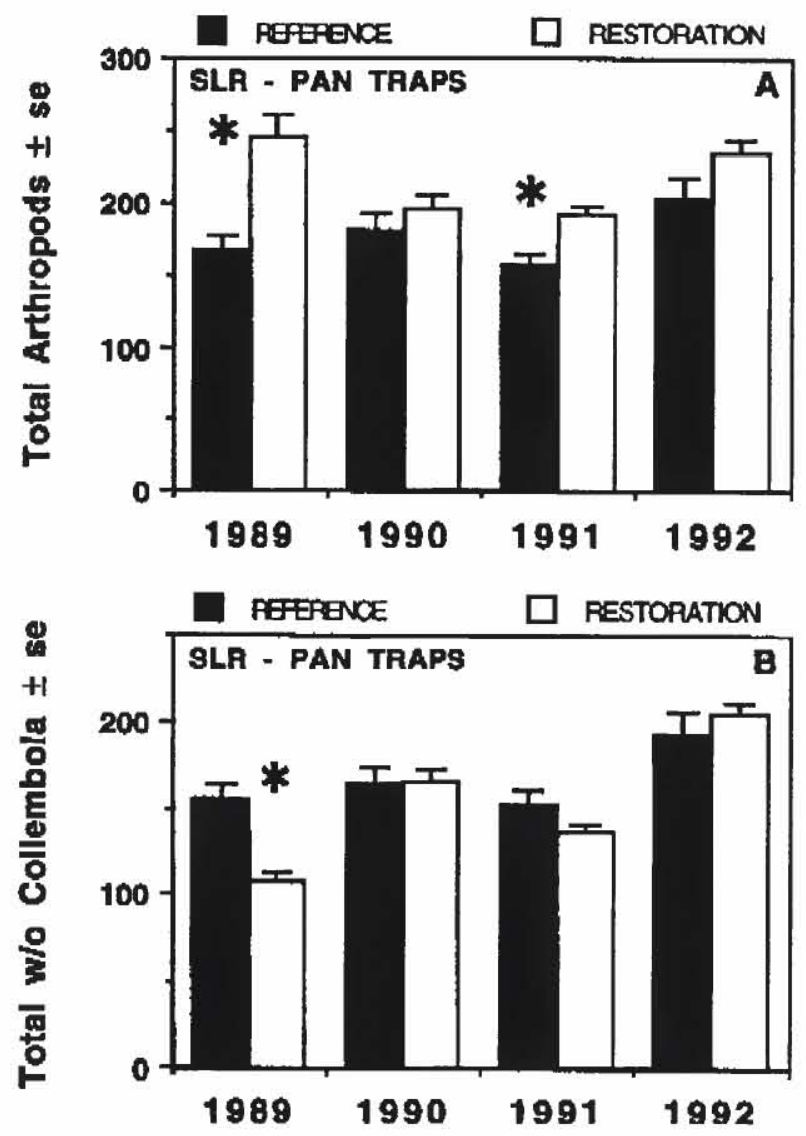

Figure 1. Total terrestrial arthropods collected in pan traps at $S a n$ Luis Rey sites. (A) Total individuals collected per pan trap compared to (B) total number excluding Collembola (mean/ sample \pm S.E.; reference $n=63$ pan traps in 1990-1992, 84 in 1989; restoration $n=78$ pan traps in 1990-1992, 104 in 1989). In all figures, significant differences between means (at $\mathrm{P}<0.05$ ) are represented by an asterisk *.

sions were different. Comparing total arthropods per pan trap without Collembola (Fig. 1B), the abundance of arthropods at the restoration site appeared to be less than or equal to that at the reference site until at least late 1991. Collembola, or springtails, are ground-dwelling arthropods that live in relatively moist conditions and feed on dead 
and decaying plant material (Essig 1958; Borror et al. 1989). Their obvious super-abundance at the restoration site (Williams 1993) probably resulted from the management practice of covering the newly planted site with bark chips to conserve moisture and provide decaying material to improve soil nutrients. The bark chips apparently provided a rich food source supporting Collembola population growth. However, foliage gleaning birds should not even encounter Collembola, so including them in an analysis of food availability could produce erroneous conclusions.

\section{Analyses based on high-quality bird food-Lepidoptera}

While it may be appealing to quantify total abundance of insects and spiders collected by passive interceptors as an indicator of food availability for birds, examining a subset of taxa collected with more selective sampling methods can provide different and more accurate answers. Lepidoptera, especially juvenile stages - caterpillars are high-quality food items for foliage gleaning birds (Ehrlich et al. 1988). So abundances of Lepidoptera can be used as an indicator of avian food resources (Holmes et al. 1979; Pollard 1979; Heinrich and Bell 1995). If abundances of Lepidoptera collected during spring-summer months in pan traps at the San Luis Rey River sites are compared, relative abundances between restoration and reference sites appeared to be similar, except in 1989 , when they were significantly more abundant at the newlyplanted restoration site (Fig. 2A).

However, gleaning birds forage on vegetation (Ehrlich et al. 1988), so more appropriate methods should focus on quantifying Lepidoptera on plants. The method used in these studies was to make equal numbers of sweeps with standard-sized insect nets through four dominant types of riparian vegetation at the sites (Williams 1997): baccharis (Baccharis gluttinosa), cottonwood (Populus fremontii), willow (including Salix goodingii, Salix hindsiana, Salix laevigata, and Salix lasiolepis), and annual and perennial herbaceous vegetation (including Eschscholzia californica, Lupinus bicolor, Oenothera hookeri, Raphanus sativus, Phacelia parryi, Taraxacum officinale, and Trifolium sp.) (Williams 1993, 1997). Comparing abundances of Lepidoptera collected from vegetation showed that Lepidoptera were relatively more abundant at the reference site in 1989, 1991, and 1992 (Fig. 2B), a different conclusion than that resulting from pan trap data.

\section{Analyses based on assemblages of potential prey}

Although insectivorous birds may favor Lepidoptera as high-quality food, many other kinds of insects are included in their diets. Another method of quantifying abundances of avian prey is to assign certain taxa to an assemblage, considering foraging behavior, to be used as an in-

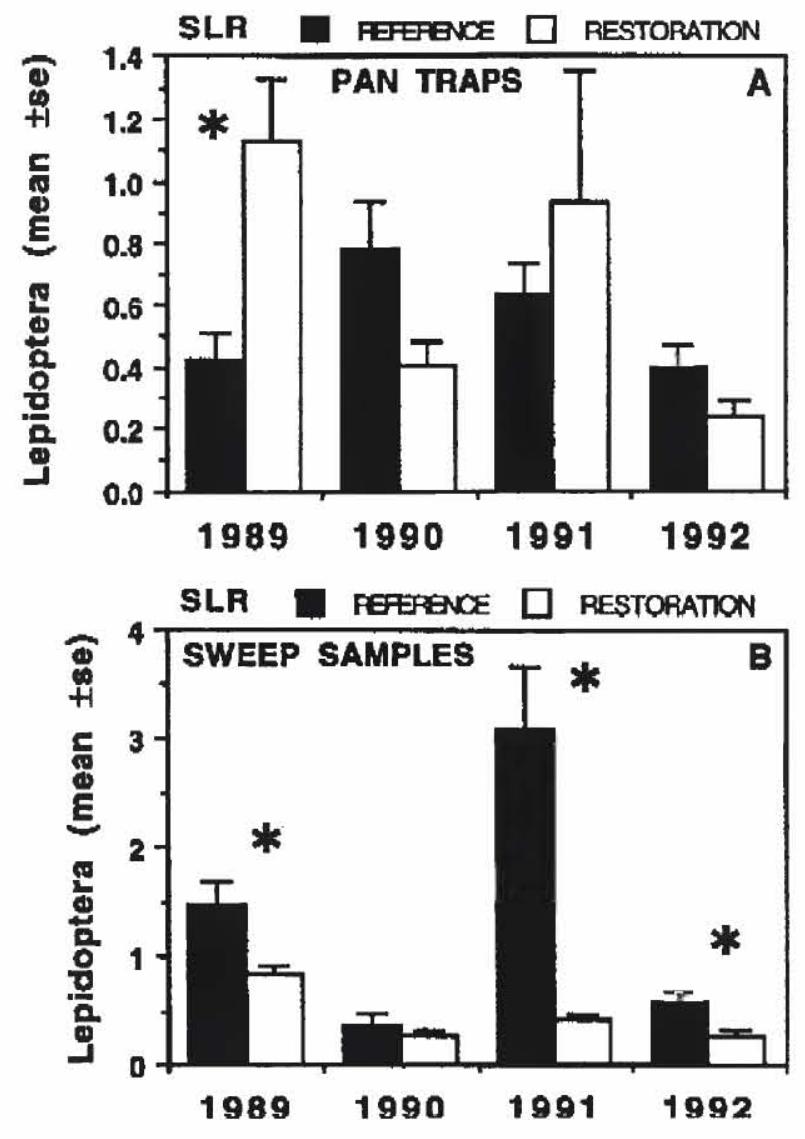

Figure 2. Abundance of Lepidoptera collected in (A) pan traps and (B) swecp samples collected at San Luis Rey sites. (mean/ sample \pm S.E.; reference site $n=78-84$ pan traps per $y r$, 50 sweep samples per yr, restoration sitc $\mathrm{n}=78-104$ pan traps per yr, 130 sweep samples per yr).

dicator of potential prey (Noss 1990; Kremen 1992). Some insects are not available to certain foraging guilds; gleaners typically will not "sally" off a branch and catch flying prey, such as Odonata (dragonflies) (Ehrlich et al. 1988). Arthropods considered as food for least Bell's vireo and other insectivorous passerines in this study included those larger than $0.5 \mathrm{~cm}$ body length ("large prey"): Araneida (spiders), Orthoptera (grasshoppers), Homoptera (planthoppers), Heteroptera (true bugs), Coleoptera (beetles), Lepidoptera (butterflies), and Hymenoptera (bees, wasps), and those smaller than $0.5 \mathrm{~cm}$ body length ("small prey"): Araneida (spiders), Ephemeroptera (mayflies), Homoptera (planthoppers), Heteroptera (true bugs), Coleoptera (beetles), Lepidoptera (butterflies), Neuroptera (lacewings), and Tricoptera (caddisflies) (Miner 1989; Kus personal communication).

\section{Relationship of insect abundance to bird activity}

Comparing relative abundances of large and small prey assemblages between San Diego River reference and restoration sites vegetation during spring-summer seasons of 
1991-1993 indicated that abundances of large prey were not significantly different except in the second year after the restoration site was created, 1992, when restoration site abundances were greater (significant only for small prey; Fig. 3). Thus, the prey assemblage data suggest that food resources, as measured by prey assemblages, were relatively similar at the two sites, and even slightly more abundant at the restoration site in 1992.
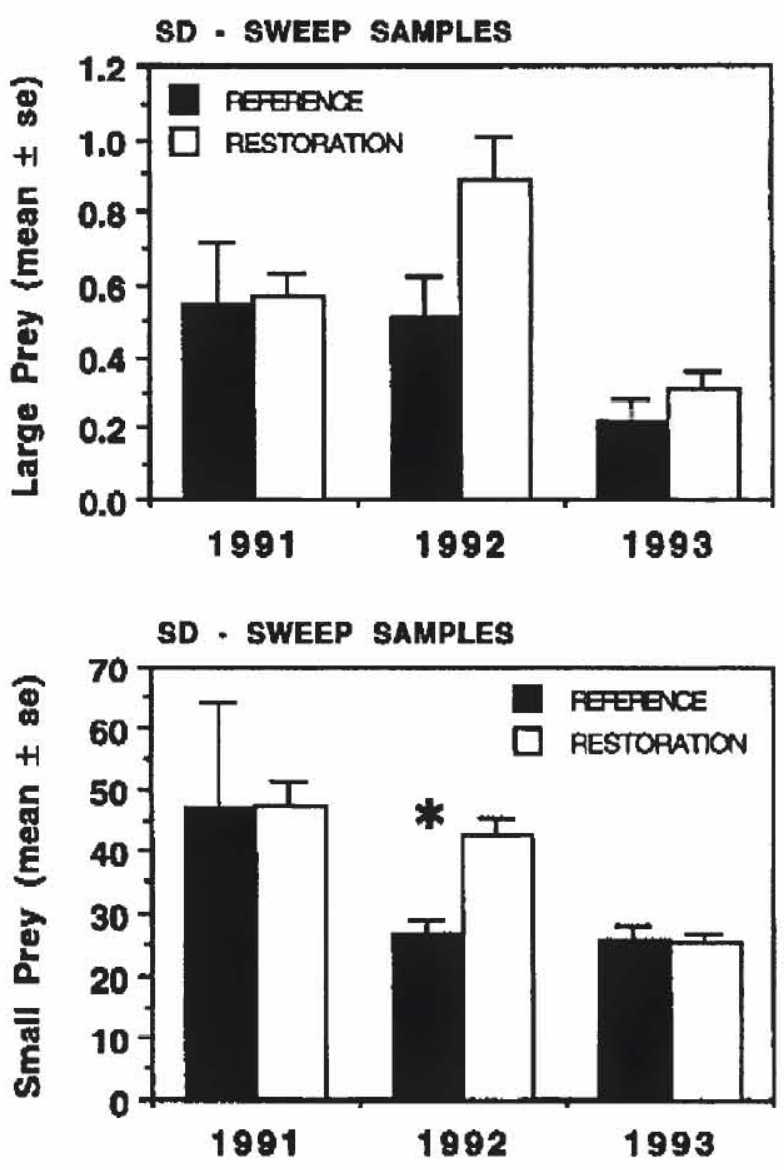

Figure 3. Potential prey assemblages collected in sweep samples at San Luis Rey sites. (A) Large prey compared to (B) Small prey assemblages (mean/sample \pm S.E.; reference site $n=50$ sweep samples, restoration site $n=130$ sweep samples).

Next, we can ask whether prey assemblage results reflect bird use of the sites. Initially, least Bell's vireo used the restoration site for territories less frequently than they used the reference site, but use increased in subsequent years (Kus 1997; Fig. 4). Since the restoration site was heavily disturbed in 1991 by replanting the entire site, this seems to indicate that while food resources may be necessary for establishment of vireo territories, other habitat features, such as plant size or architecture, are critical also (Holmes and Robinson 1984; Kus 1997).

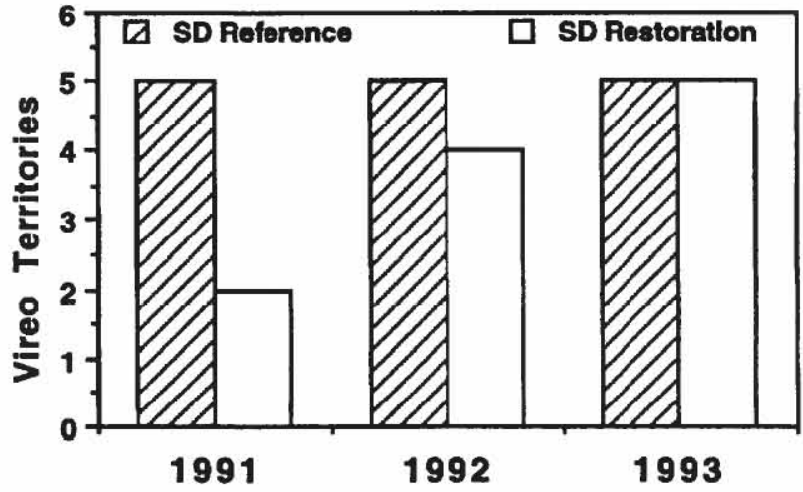

Figure 4. Number of territories of least Bell's vireo extending into San Diego River reference and restoration sites, 1991-1993. Data from Kus (1997).

\section{Arthropods as Indicators For Habitat Management}

Many terrestrial arthropods have relatively short generation times, often producing more than one generation per year, and populations can undergo dramatic fluctuations reflecting variations in habitat conditions (Duviard and Pollet 1973; Wolda 1978; Erwin and Scott 1980; New 1984; Price 1984; Brown and Hyman 1986; Wolda 1988; Sutton 1989). Thus, insects may serve as "early warning indicators" and be used to formulate management recommendations (Noss 1990; Kremen 1992; Kremen et al. 1993).

For example, abundances of Diptera reflected initial drainage problems at the San Diego River restoration site. In 1991 and 1992, low-lying sampling locations within the restoration site were under water on 5 out of 7 sampling dates during rainy periods of spring and early summer. Similar problems did not appear at the reference site. By 1993, drainage improved such that no sampling sites were inundated even on sampling dates after rains. Many free-living Diptera, such as mosquitoes, have aquatic larval stages and population densities increase

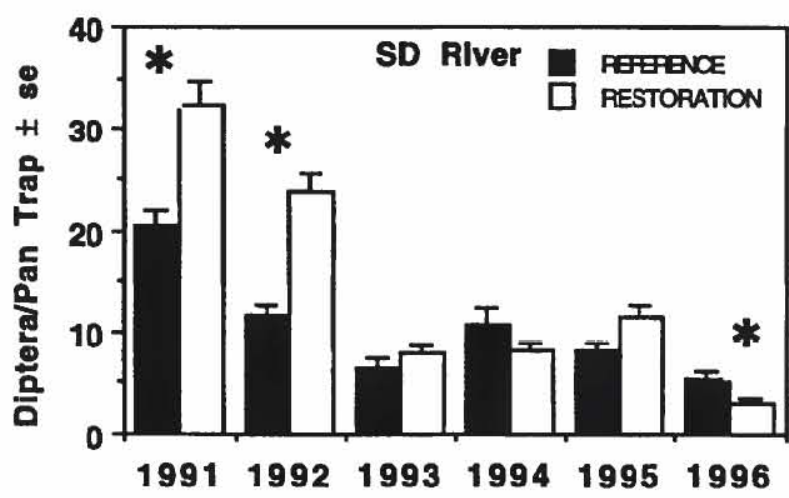

Figure 5. Relative abundances of Diptera (mean/pan trap \pm S.E.) collected at San Diego River sites (reference $n=45-60$ pan traps per $\mathrm{yr}$, restoration $\mathrm{n}=\mathbf{9 6 - 1 3 3}$ per $\mathrm{yr}$ ). 


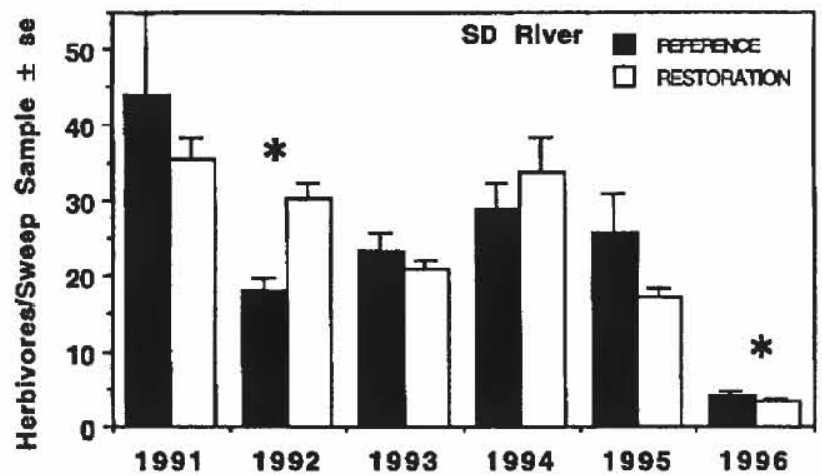

Figure 6. Relative abundances of Herbivore assemblages (mean/ sample \pm S.E.) collected in sweep samples at San Diego River sites. Reference site $n=48-100$ per yr; restoration site $n=222$ -

when standing water is present (Cole 1969). Abundances of small Diptera, including midges and mosquitoes, were significantly greater at the restoration site in spring-summer, 1991 and 1992 (Fig. 5), years when standing water was present at the site. The subsequent decline indicated that the problem had been resolved. While willows growing within the restoration site did not show immediate effects of drainage problems, by 1994 , patchy mortality indicated that many of those individuals had apparently failed to become established. Therefore, this appears to be a case in which insects responded to variations in environmental conditions before plants showed negative effects.

\section{Arthropods as Indicators of System Resiliency}

Many herbivores are attracted to and proliferate on newly-planted or otherwise stressed plants (White 1984; Louda 1988 and references therein). Abundances of the assemblage of herbivores (including Lepidoptera, Orthoptera, Homoptera, and herbivorous families of Coleoptera) collected from vegetation were significantly greater at the restoration site in 1992 (Fig. 6), quantifying an observed abundance of herbivores on newly-transplanted vegetation. In a healthy, functioning ecosystem, the dynamics of predator populations may be expected to increase following a pulse of prey (herbivores, in this case; Hassell 1978). In the San Diego River collections from vegetation, Homoptera were the most abundant herbivores, sometimes comprising as much as $20 \%$ of all arthropods collected. Spiders represent major arthropod predators, in this system as in many others (Comstock 1940; Simmonds et al. 1994), so could be expected to respond in abundance to herbivores like Homoptera (numerical response to increasing prey densities; Hassell 1978). In fact, that pattern appeared when abundances of Homoptera and spiders (Araneida) collected from vegetation at the San Diego River site were plotted over years 1992-1995 (Fig. 7). Dynamics such as this demonstrate one form of system resiliency that is a goal of many habitat restoration efforts (Baird and Rieger 1989; Rieger 1992).

\section{Conclusions}

Terrestrial arthropods are diverse and sometimes difficult to identify, but examining their communities can help ecologists and managers evaluate progress towards the urgent goal of providing habitat for sensitive species of animals and plants, and towards the long-term goal of creating ecological systems that are resilient and self-maintaining (Baird 1989; Rieger 1992). While there is a myriad of ways to collect and count insects and their relatives some very detailed, some very gross - all have biases and should be selected carefully to answer questions of interest. In selecting collection methods, strengths and weak-

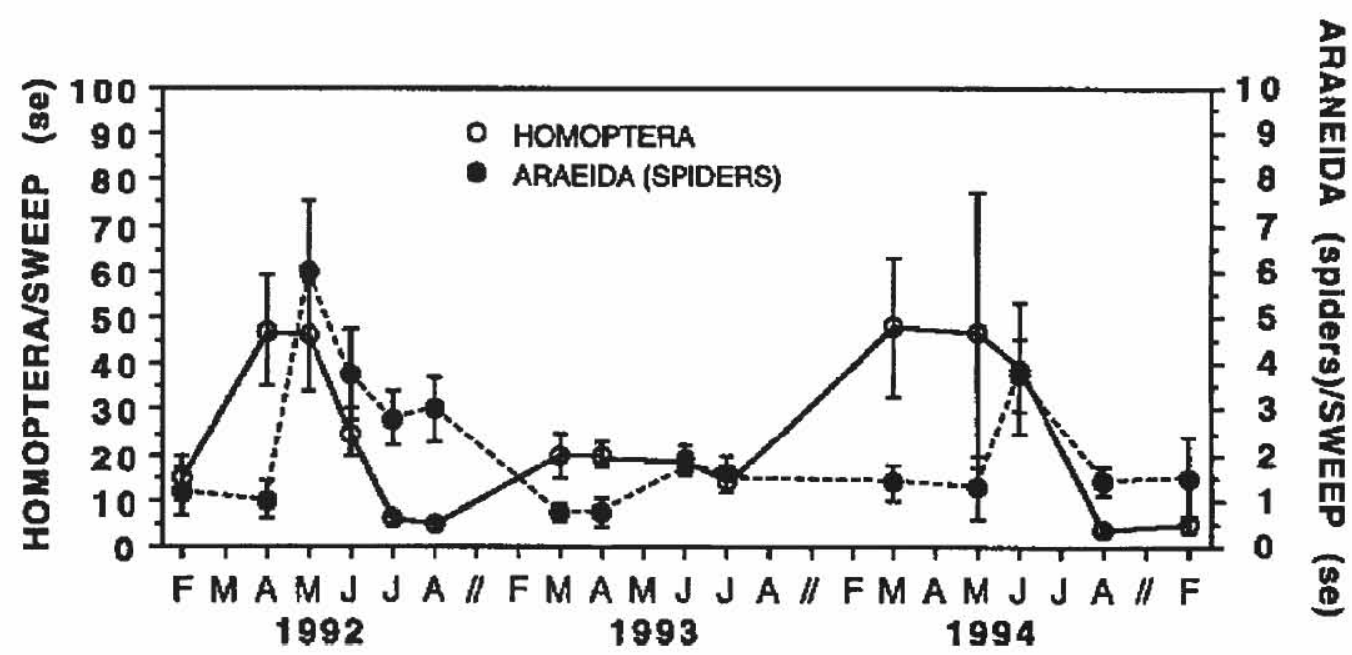

Figure 7. Relative abundances of Homoptera and Araneida (spiders) (mean/sample \pm S.E.) collected in sweep samples at the San Diego River restoration site; restoration site $n=23$ sweep sampling stations; restoration site $n=6$ stations. Means within a date were significantly different when error bars did not overlap, see text for statistical methods. 
nesses of each must be considered to ensure that rigorous answers and conclusions will be obtained. Many humans, including scientists, share a primal fear of insects - or at least avoid them because they cannot name them all, but when that aversion is overcome we can use arthropods to help solve problems of habitat preservation, restoration, and management.

Acknowledgments. Projects were funded by awards from the California Department of Transportation and California State University. Bruce April, Gina Moran, and J. Rieger of CalTrans provided assistance and support. Many graduate and undergraduate students assisted with collections and identification of hundreds of thousands of arthropods.

\section{Literature Cited}

Andersen, A.N. 1990. The use of ant communities to evaluate change in Australian terrestrial ecosystems: a review and a recipe. Proceedings of the Ecological Society of Australia 16:347-57.

Baird, K. 1989. High quality restoration of riparian ecosystems. Restoration \& Management Notes 7:60-64.

Baird, K. and J.P. Rieger. 1989. A restoration design for least Bell's vireo hahitat design in San Diego County. Pp. 462-466 in Proceedings of the California riparian systems conference: Protection, Management, and Restoration for the 1990s. USDA Forest Service, General Technical Report PSW-110.

Borror, D.J., C.A. Triplehorn, and N.F. Johnson. 1989. An introduction to the study of insects. Saunders College Publishers, Philadelphia, PA.

Brown, V.K. and P.S. Hyman. 1986. Successional communities of plants and phytophagous Coleoptera. Journal of Ecology 74:963-975.

Cole, F.R. 1969. The flies of western North America. University of California Press, Berkeley, CA.

Comstock, J.H. 1940. The spider book. Doubleday, Doran and Company, New York, NY.

Duviard, D. and A. Pollet 1973. Spatial and seasonal distribution of Diptera, Homoptera, and Hymenoptera in a moist shrub savanna. Oikos 24:42-57.

Ehrlich, P.R., D.S. Dobkin, and D. Wheye. 1988. The birder's handbook: A field guide to the natural history of North American birds. Simon and Schuster, New York, NY.

Erwin, T.F. and J.C. Scott. 1980. Seasonal and size patterns, trophic structure, and richness of Coleoptera in the tropical arboreal ecosystem: the fauna of the tree Luehea seemannii Triana and Planch in the CanalZone of Panama. Coleopterists Bulletin 34:305-22.

Essig, E.O. 1958. Insects and mites of Western North America. The Macmillan Company, New York, NY.

Handel, S.N. 1997. The role of plant-animal interactions in restoration. Pp. 111-132 in K.M. Urbanska, N.R.Webb, and P.J.Edwards, eds. Restoration ecology and sustainable development. Cambridge University Press, Cambridge, UK.

Hassell, M.P. 1978. The dynamics of arthropod predator-prey systems. Princeton University Press, Princeton, NJ.
Heinrich, B. and R. Bell. 1995. Winter food of a small insectivorous bird, the Golden-crowned Kinglet. Wilson Bulletin 107:558-561.

Hendricks, B.J. and J.P. Rieger. 1989. Description of nesting habitat for the least Bell's vireo in San Diego County. Pp. 285292 in Proceedings of the California riparian systems conference: protection, management, and restoration for the $1990 \mathrm{~s}$. USDA Forest Service, General Technical Report PSW-110.

Holloway, J.D. 1970. Moths. Pp. 437-453 in H. Lieth and J.J.A. Werger eds. Tropical raiforest ecosystems; Biogeographical and ecological studies. Ecosystems of the world, Volume 14B. Elsevier Science, Amsterdam.

Holmes, R.T. and S.K. Robinson. 1984. Effects of plant species and foliage structure on the foraging behavior of forest birds. Auk 101:672-684.

Holmes, R.T., J.C. Schultz, and P. Nothnagle. 1979. Bird predation on forest insects: an exclosure experiment. Science 206:462-463.

Hutcheson, J. 1990. Characterization of terrestrial insect communities using quantified, Malaise-trapped Coleoptera. Ecological Entomology 15:143-151.

Janzen, D.H. 1973a. Sweep samples of tropical foliage insects: description of study sites, with data on species abundances and size distributions. Ecology 54:659-666.

Janzen, D.H. 1973b. Sweep samples of tropical foliage insects: effects of seasons, vegetation types, elevation, time of day, and insularity. Ecology 54:687-708.

Janzen, D.H. and C.M. Pond 1975. A comparison, by sweep sampling, of the arthropod fauna of secondary vegetation in Michigan, England, and Costa Rica. Transactions of the Royal Entomological Society of London 127:33-50.

Jordan, W.R. III, M.E. Gilpin, and J.D. Aber. 1987. Restoration ecology. Cambridge University Press, Cambridge, UK.

Kemp, W.S., S.J. Harvey, and K.M. O'Neill. 1990. Patterns of vegetation and grasshopper community composition. Oecologia 83:229-308.

Kremen, C. 1992. Assessing the indicator properties of species assemblages for natural areas for monitoring. Ecological Applications 2:203-217.

Kremen, C. 1994. Biological inventory using target taxa: a case study of the butterflies of Madagascar. Ecological Applications 4:407-422.

Kremen, C., R.K. Colwell, T.L. Erwin, D.D. Murphy, R.F. Noss, and M.A. Sanjayan. 1993. Terrestrial arthropod assemblages: their use in conservation planning. Conservation Biology 7:796-808.

Kus, B.E. 1997. Use of restored riparian habitat by the endangered least Bell's vireo (Vireo bellii pusillus). Restoration Ecology, in press.

Landres, P.B., J. Vemer, and J.W. Thomas. 1988. Ecological uses of vertebrate indicator species: a critique. Conservation Biology 2:316-328.

Louda, S.M. 1988. Insect pests and plant stress as consideration for revegetation of disturbed ecosystems. Pp. 51-67 in J. Cairns, ed. Rehabilitating damaged ecosystems. Volume 2. CRC Press, Boca Raton, FL.

Lussenhop, J. 1973. The soil arthropod community of a Chicago expressway margin. Ecology 54:1124-1137.

Majer, J.D. ed. 1989. Animals in primary succession: the role of fauna in reclaimed lands. Cambridge University Press, Cambridge, UK. 
Majer, J.D. 1997. Invertebrates assist the restoration process: an Australian perspective. Pp. 212-237 in K.M. Urbanska, N.R.Webb, and P.J. Edwards, eds. Restoration ecology and sustainable development. Cambridge University Press, Cambridge, UK.

McGeachie, W.J. 1989. The effects of moonlight illuminance, temperature and wind speed on light-trap catches of moths. Bulletin of Entomological Research 79:185-192.

Miner, K.L. 1989. Foraging ecology of the least Bell's vireo, Vireo bellii pusillus. M.S. thesis. San Diego State University, San Diego, CA.

Moldenke, A. 1990. One hundred twenty thousand little legs. Wings 15:11-14.

New, T.R. 1984. Insect conservation - an Australian perspective. Dr. W. Junk, Dordrecht, The Netherlands.

Noss, R.F. 1990. Indicators for monitoring biodiversity: a hierarchial approach. Conservation Biology 4:355-364.

Penny, N.D., and A.R. Arias 1982. Insects of an Amazon forest. Columbia University Press, New York, NY.

PERL (Pacific Estuarine Research Laboratory). 1990. A manual for assessing restored and natural coastal wetlands with examples from southern California. Report No. T-CSGCP-021. California Sea Grant, La Jolla, California, USA.

Pollard, E. 1979. Population ecology and change in range of the white admiral butterfly Ladoga camilla L. in England. Ecological Entomology 4:61-74.

Price, P.W. 1984. Insect ecology. John Wiley and Sons, New York, NY.

Refseth, D. 1980. Ecological analyses of carabid communities potential use in biological classification for nature conservation. Biological Conservation 17:131-141.

Rieger, J. 1992. Western riparian and wetland systems. Restoration \& Management Notes 10:52-55.
Simmonds, S.J., J.D. Majer, and O.G. Nichols. 1994. A comparative study of spider (Aranae) communities of rehabilitated bauxite mines and surrounding forest in the southwest of western Australia. Restoration Ecology 2:247-60.

Southwood, T.R.E. 1978. Ecological methods. Chapman and Hall, London.

Stork, N. 1987a. Guild structure of arthropods from Bornean rain forest trees. Ecological Entomology 12:69-80.

Stork, N. 1987b. Arthropod faunal similarity of Bornean rain forest trees. Ecological Entomology 12:219-226.

Sutton, S.L. ed. 1989. The spatial distribution of flying insects. Elsevier Science, Amsterdam.

White, T.C.R. 1984. The abundance of invertebrate herbivores in relation to the availability of nitrogen in stressed food plants. Oecologia 63:90-105.

Williams, K.S. 1993. Use of terrestrial arthropods to evaluate restored riaprian woodlands. Restoration Ecology 1:107-118.

Williams, K.S. 1997. Terrestrial arthropods as ecological indicators of habitat restoration in southwestern North America. Pp. 238-258 in K.M. Urbanska, N.R.Webb, and P.J. Edwards eds. Restoration ecology and sustainable development. Cambridge University Press, Cambridge, UK.

Wilson, E.O. 1987. The little things that run the world (the importance of conservation of invertebrates). Conservation Biology 1:344-346.

Wolda, H. 1978. Seasonal fluctuations in rainfall, food and abundance of tropical insects. Journal of Animal Ecology 47:369-381.

Wolda, H. 1988. Insect seasonality: why? Annual Review of Ecology and Systematics 19:1-18.

Zelanzny, B., and A.R. Alfiler 1987. Ecological methods for adult populations of Oryctes rhinoceros (Coleoptera, Scarabaeidae). Ecological Entomology 12:227-238. 


\title{
Improving the Design of Fish Habitat Mitigation Projects in Southern California
}

\author{
Julie S. Desmond ${ }^{1}$, Gregory D. Williams ${ }^{1}$, and Joy B. Zedler,"* \\ Pacific Estuarine Research Laboratory, San Diego State University, San Diego, CA 92182-4625 \\ Tel. (619) 594-7436; Fax (619) 594-2035
}

\begin{abstract}
Southern California's rate of loss of coastal wetlands is very high. In many places less than $10 \%$ of the historical area remains. Impacts to the region's wetland remnants continue, and several mitigation projects have been built or planned to replace lost or damaged fish habitat. Designs for these projects haveemphasized subtidal basins or large channels, both of which are quickly colonized by fish. However, the functional equivalency between these habitats and natural wetlands is questionable, because the constructed habitats lack complex tidal creek networks and connectivity with the upland landscape. Designs should be improved by incorporating greater habitat complexity at both the landscape and fine scales. We recommend using natural coastal marsh systems as models for future habitat creation efforts. Policies for assigning mitigation credit might be changed to allow more fish habitat mitigation credit for projects integrating a variety of estuarine habitats. We also recommend that future projects facilitate research on the benefits of habitat complexity to fishes.
\end{abstract}

Keywords: Coastal wetlands; estuaries; fish habitat; habitat complexity; habitat function; southern California; wetland mitigation.

\section{Introduction}

The coast of southern California, with one of the highest population densities in the nation (over 16 million people), has experienced severe losses of wetland habitat. Three tidal wetlands near San Diego (San Diego Bay, Tijuana Estuary, and Mission Bay) have collectively lost $87 \%$ of their salt marsh, $84 \%$ of their intertidal flats, and $69 \%$ of their shallow subtidal habitat since the earliest maps were prepared (1856 ff.); at the same time, these three sites have seen major gains in deeper subtidal habitat due to dredging (Macdonald 1990).

*Present address: Arboretum and Botany Department, University of Wisconsin, 430 Lincoln Dr., Madison, WI 53706. Tel. (606)2628629; e-mail: jbzedler@facstaff.wisc.edu
With a $90 \%$ loss of coastal wetlands statewide (NOAA 1990), local increases in deep-water habitat, and continuing requests to permit filling of or modification to both shallow- and deep-water coastal habitats, a regional view of the most appropriate kinds of restoration and mitigation projects is needed (Zedler 1996). In the past 25 years, various habitat-modification projects have been implemented (or are being planned) to mitigate for damage to wetlands or to populations of endangered wetland species. Several involve the creation of fish habitat. For example, fish populations have been damaged by the release of cooling waters from the San Onofre Nuclear Generating Station (MEC Analytical Systems, Inc. 1993) and wetland habitat is required as mitigation (CCC 1997). Filling activities in large harbors (Long Beach: MEC Analytical Systems, Inc. 1995; Los Angeles: City of Carlsbad and US. Army Corps of Engineers 1990) have altered habitat for coastal fish populations, and requirements for mitigation have included dredging in or near coastal wetlands. Modifications to habitat for the California least tern (Sterna antillarum browni), an endangered species that uses wetland areas for foraging, have also generated requirements for wetland mitigation.

In this paper we discuss selected fish habitat mitigation approaches in southern California. Based on published reports and our own experiences with natural and constructed wetlands in San Diego County, we provide recommendations for future research and for the design of projects related to the support of coastal fishes in southern California.

\section{Fish Habitat Creation in Southern California: Basins} and Channels

Basin designs

Three projects have provided habitat for fishes by excavating large, primarily subtidal basins, which are tid- 
ally flushed. We describe them as basins, because they are steep-sided and have little intertidal habitat (i.e., mudflat or salt marsh) or connectivity with salt marshes. The first of these, at San Dieguito Lagoon, was intended to increase the volume of tidal flows; it was a tidal restoration project, not a habitat mitigation project. Like many of San Diego's coastal lagoons, San Dieguito Lagoon has been subject to increasing sedimentation over the past century due to the development of its watershed. In 1982, a subtidal basin was excavated to remove recently deposited sediments and re-create tidal habitats (California State Coastal Conservancy 1989). The -10 -ha basin was excavated from historic wetland and upland areas (MEC Analytical Systems, Inc. 1993); it contained an island of intertidal marsh habitat but was primarily surrounded by upland and remnants of salt marsh.

In 1990, four subtidal basins totalling 46.2 ha were excavated within the Seal Beach National Wildlife Refuge in Anaheim Bay, as out-of-kind mitigation for filling a nearby deepwater harbor area. The basins were excavated from upland and historical wetland areas that had little or no tidal influence. They are bordered on all sides by uplands, roads and railroad tracks and have steeply sloping sides. They are linked to the intertidal marshes and mudflats of Anaheim Bay by culverts. Six small intertidal islands (totalling $7.5 \mathrm{ha}$ ) were constructed or already existed within two of the basins (MEC Analytical Systems, Inc. 1995); the edges of these islands are gently sloped.

In 1994-1995, the basin design was used in a project intended to mitigate for damages to fish habitat in San Diego Bay. The rectangular subtidal basin was excavated from the D Street Fill area of the Sweetwater Marsh National Wildlife Refuge, a historical wetland which had been filled decades before. The small $(<1 \mathrm{ha})$ excavation has very steep walls; it adjoins a tidal channel but is surrounded by upland on three sides. The remaining area of the $\sim 5$-ha mitigation site will eventually be modified, depending on mitigation credit needs, but there is no overall habitat design.

\section{Channel design}

A different approach for creating fish habitat was undertaken in a mitigation project at Sweetwater Marsh National Wildlife Refuge, San Diego Bay. In 1984, a series of islands and a new tidal channel (the Connector Marsh) were created within the Refuge as mitigation for jeopardizing endangered species habitat. The expansion of Interstate Freeway 5, the construction of a new freeway interchange, and the excavation of a flood control channel that diverted the Sweetwater River generated the need for mitigation of damages to foraging habitat of the California least tern (Sterna albifrons browni) and salt marsh habitat for the light-footed clapper rail (Rallus longirostris levipes) and the salt marsh bird's beak (Cordylanthus maritimus ssp. maritimus). Thus, the $\sim 5$-ha project was designed to incorporate subtidal channel habitats adjacent to intertidal marshes. The eight large marsh islands were built in a row, with a historical, straight channel on one side, adjacent to the freeway, and a new, deeper channel on the opposite side, adjacent to a railroad. Smaller crosschannels were excavated between the islands, like a ladder. The channels have since developed meanders within the constraints of the linear site, and some islands have merged due to sedimentation and marsh plant expansion. All islands have relatively smooth edges, but with a greater amount of marsh-water interface than the basin designs described above. None of the islands has upland habitat; collectively, they support a range of salt marsh habitats, from cordgrass (Spartina foliosa) at the water's edge to high marsh with salt marsh bird's beak near the upper intertidal limit.

The design for a second mitigation site at the Refuge was inspired by a natural salt marsh and large meandering channel at San Quintín Bay, Baja California. At the San Diego site the 8-ha Marisma de Nación, southeast of the Connector Marsh, has a centrally placed, wide, sinuous channel that was excavated to retain water at low tide. It was opened to tidal flushing in 1990 . The area to the east is a powerline right-of-way, which limits potential for connectivity with the upland; also a straight chain-link fence has been constructed at the edge of the marsh, in order to reduce disturbance by humans and feral animals. To the north is a dirt road and the steep-sided flood control channel. To the west is a large dredge spoil deposit, some of which is set aside for future mitigation (D-Street Fill area mentioned above).

These channel designs are similar to natural estuarine systems, in that subtidal habitats are bordered by intertidal habitats. The ladder design has a high degree of water-marsh interface, but linkages between the wetland and adjacent habitats were not possible, due to the confines of the freeway and railroad. The sinuous design allows for more marsh edge per unit area than a straight channel, but the edges between the wetland and the adjacent upland are abrupt.

\section{Success of excavated projects}

Fish quickly colonized all of these basins and channels, but it is difficult to judge whether or not they have actually succeeded in improving habitat function and/or creating functional fish habitats. In some cases, this is simply due to a lack of information. Post-excavation studies were performed at San Dieguito Lagoon (Greenwald 1985), but little was known about the fish fauna prior to excavation, so changes or improvements are difficult to quantify. In other cases, extensive pre- and post-excavation studies were performed, but the assessments focus on compliance with specific criteria. For reasons of efficiency, mitigation criteria are usually based on easily 
measured parameters, such as species richness or total fish abundance.

These parameters may not be the best indicators of ecosystem function. Even though the channels of Connector Marsh and Marisma de Nación were constructed for least tern foraging habitat and easily met mitigation standards set by the USFWS, least terns were more often observed foraging in the nearby flood control channel than in the habitats designed to produce tern foods (Boland 1991). Whether or not the constructed channels support fish populations important to the terns is unknown.

In creating functional habitat for fishes, studies of fish growth (e.g., Schreffler et al. 1990) or fish feeding (e.g., Moy and Levin 1991; Schreffler et al. 1992) would allow a much more direct assessment of a system's performance. Other recommendations for improving mitigation assessment have included setting regional standards for the selection and use of reference sites against which to compare new habitats (Brinson and Rheinhardt 1996), and allowing projects to develop over longer time scales (i.e., $15-20$ years rather than 5 years) before judging success (Mitsch and Wilson 1996).

\section{How Can Project Designs Be Improved?}

Ideally, design standards should reflect more accurately the habitat functions of the target system. Studies from other regions, as well as our own experiences with natural and constructed wetlands in southern California, show that details of habitat structure and complexity, at landscape and finer scales, can have a strong influence on habitat function.

\section{Complexity at the landscape scale-Providing links between subtidal and intertidal habitats}

Researchers around the nation recognize the importance of linkages between habitats, especially in the effective management of estuaries, which are characterized by multiple habitat types (Fonseca et al. 1994; Irlandi and Crawford 1997). Incorporating more links between subtidal and intertidal habitats at restoration sites and using natural coastal landscapes and habitats as models in mitigation projects could provide multiple benefits for estuarine fish. The fish could move into the marshes more readily if there were high connectivity, e.g., interdigitating tidal creeks. Studies in other regions have shown that marsh habitats are important for fish, which move from subtidal habitats onto the marsh surface at high tide to feed (Harrington and Harrington 1961; Miller and Dunn 1980; Rozas and LaSalle 1990) and to seek refuge from predation (Boesch and Turner 1984).

Greater connectivity of habitats would also allow the products of the marsh to move into the channels more readily. Salt marsh vegetation, especially in its decom- posed form (detritus), has long been thought to fuel estuarine food webs (Teal 1962; Odum et al. 1973). While there have been fewer studies documenting direct use of California marshes by fish, there is some evidence that fishes in West Coast estuaries benefit from the presence of salt marsh habitats. At two southern California wetlands, Kwak and Zedler (1997) used stable isotope analysis to trace estuarine food webs. They found that microalgae, intertidal macro-algae and salt marsh cordgrass (Spartina foliosa), producers which occupy regularly flooded marsh habitats, provide organic material that supports estuarine fishes and invertebrates. Cordgrass, abundant at Tijuana Estuary but not at San Dieguito Lagoon, was identified as the major organic matter source for fishes in the former wetland (Kwak and Zedler 1997). This study indicates a strong link between subtidal channel and intertidal marsh habitats for these fish. Proximity to intertidal marsh primary producers may explain the very high productivity of southern California estuarine fish assemblages (Horn and Allen 1985) which are dominated by herbivores/detritivores such as topsmelt and striped mullet. Fish productivity may suffer in restoration projects which lack links to intertidal marsh areas.

\section{Smaller scale complexity - Attention to channel network configurations, channel morphology}

Complexity on a smaller (habitat-level) scale should also be an important consideration in creating fish habitats. Natural wetlands are intricately dissected by channel systems, which provide habitats widely varying in depth and morphology. Small first and second-order creeks (Horton 1945), which are almost completely intertidal, comprise over $70 \%$ of the total channel length of the northern arm of the Tijuana Estuary in southern California (Fig. 1) and make up a similarly high proportion of total creek length in other California wetlands (Pestrong 1965; Coats et al. 1995). However, small creeks are generally lacking in newly constructed systems, which are usually excavated with one or two large channels. While the integrated creek-marsh designs of Connector Marsh and Marisma de Nación were more similar to natural areas than to tidal basins, they still lack much of the habitat complexity of natural wetlands.

Small intertidal creeks serve several functions for fish. On the Atlantic Coast, estuarine fishes have been found to use small intertidal creeks for foraging at high tide (Allen et al. 1994; Kleypas and Dean 1983), and in tidal freshwater marshes in Virginia, fishes preferentially used small creeks (as opposed to banks of larger channels) to access the marsh surface when it flooded (Rozas et al. 1988). In Albrae Slough, at the south end of San Francisco Bay, small (approximately $0.4 \mathrm{~m}$ deep and $0.8 \mathrm{~m}$ wide) mosquito ditches were excavated to provide tidal flushing to isolated marsh ponds. A comparison of the fish communities of this marsh with a nearby, unditched 

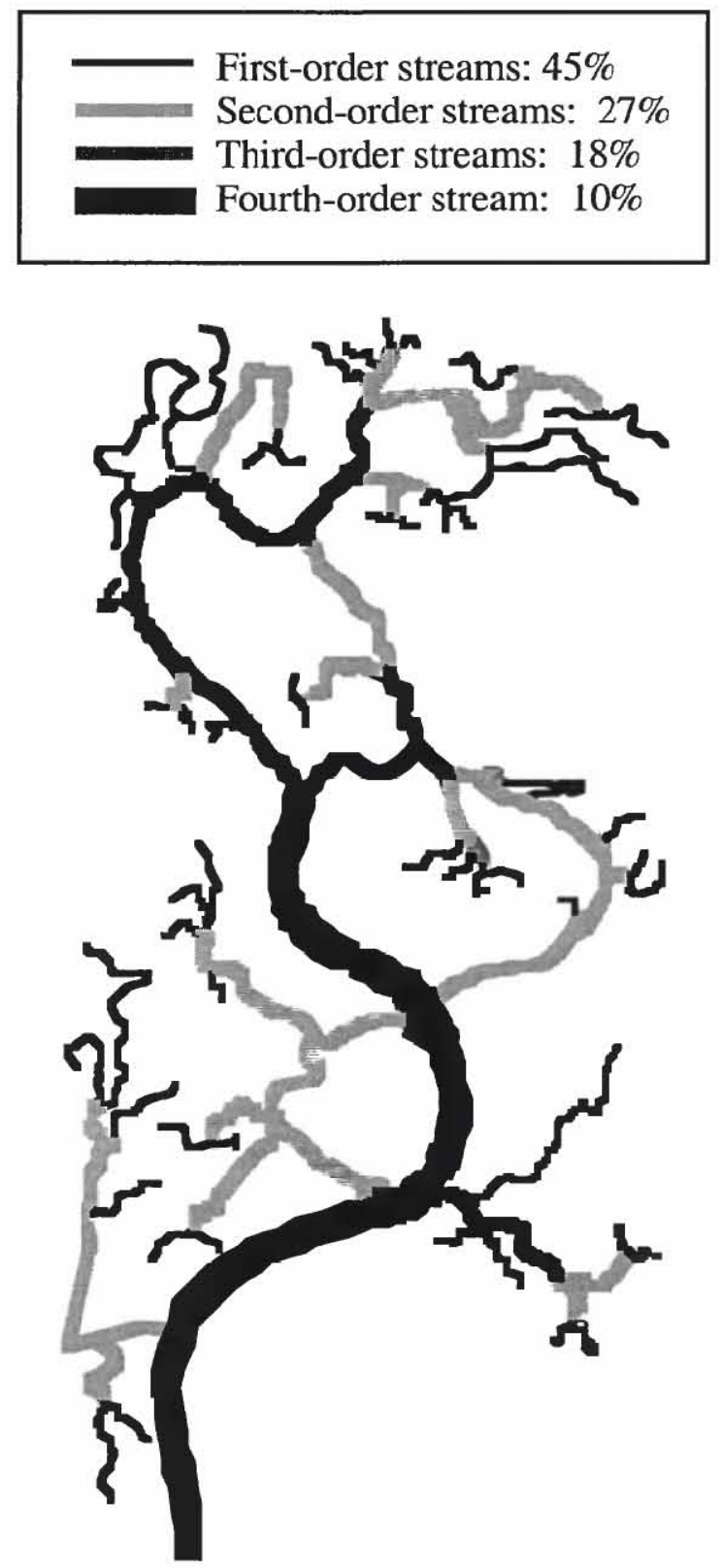

Figure 1. Creek network of Tijuana Estuary's North Arm, with channels separated by order based on Horton's (1945) system. Proportion of total creek length accounted for by each order is shown (modified from Desmond 1996).

marsh showed that the ditched marsh harbored twice as many species (10 vs. 5). Increasing the length of small creeks (ditches) allowed more species access to marsh habitats (Balling et al. 1980). In southern California coastal wetlands, shallow habitats may be important as nursery areas for estuarine species such as the California killifish. For example, Desmond (1996) found that killifish collected from shallow first-order creeks were generally smaller (mean total length $=29 \mathrm{~mm}$ ) than those collected from large third- and fourth-order channels (size $=49 \mathrm{~mm}$, t-test, $\mathrm{P}<0.001$ ); likewise, small juvenile killifish made up a significantly higher proportion of the catch from low-order creeks (Fig. 2). These studies indicate that marshes with more complex creek networks may provide multiple benefits for fish that may be lacking from more simple, homogeneous habitats.

On an even smaller scale, details of habitat morphology strongly influence fish distribution and abundance patterns, and likely reflect their functional relevance. For example, proximity and type of channel vegetation and depth are important factors influencing the distribution of small fishes in Gulf Coast marshes (Baltz et al. 1993). McIvor and Odum (1988) found that fish abundance was significantly higher at sites adjacent to shallow, sloping depositional banks than sites with steeper, erosional banks in tidal freshwater marshes in Virginia. In constructed and natural habitats San Diego Bay, Williams and Zedler
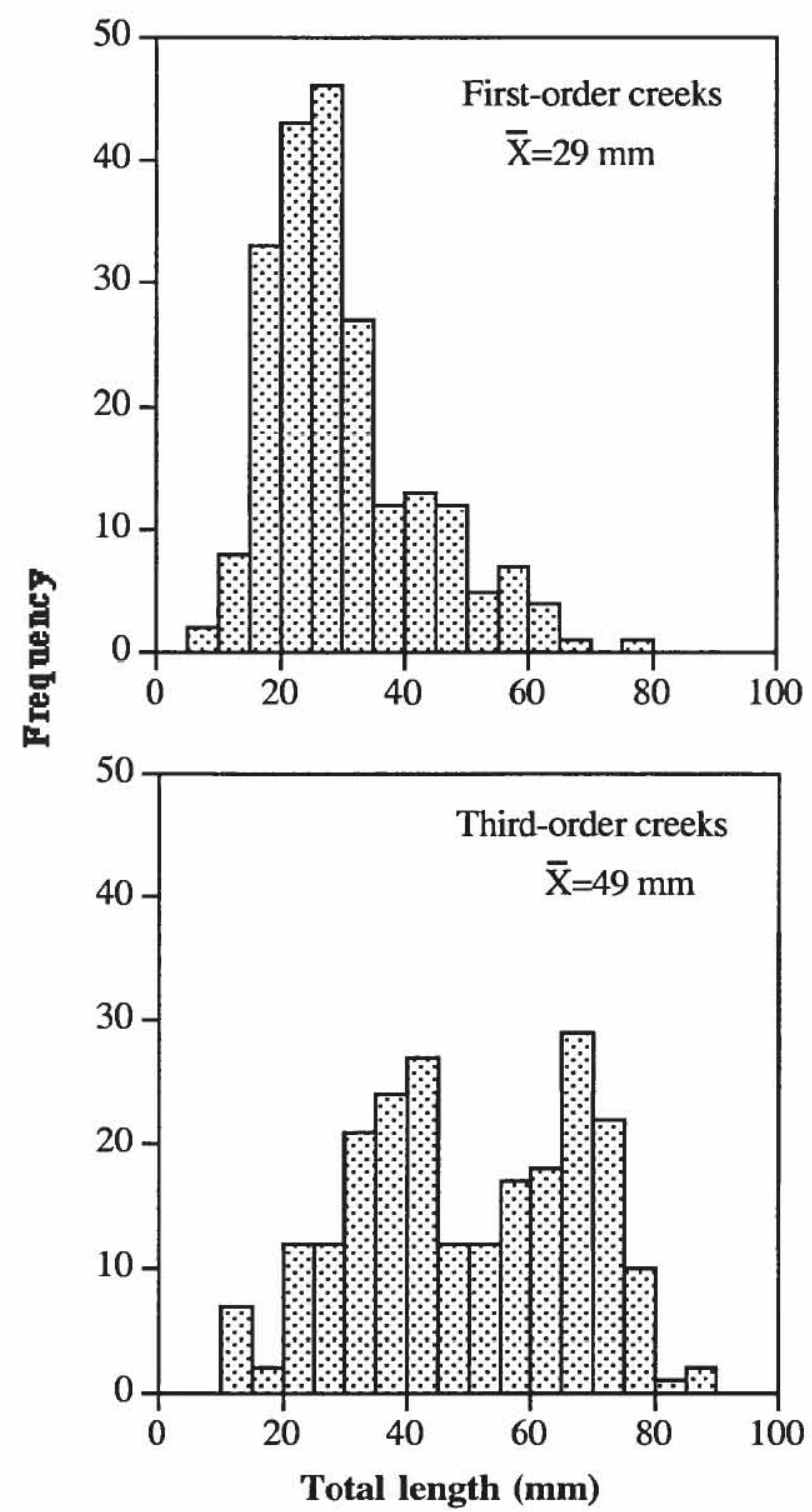

Figure 2. Length-frequency histograms of Fundulus parvipinnis from first- and third-order creeks at Sweetwater Marsh and Tijuana Estuary, October, 1995 (modified from Desmond 1996). 


\section{Channel Morphology}

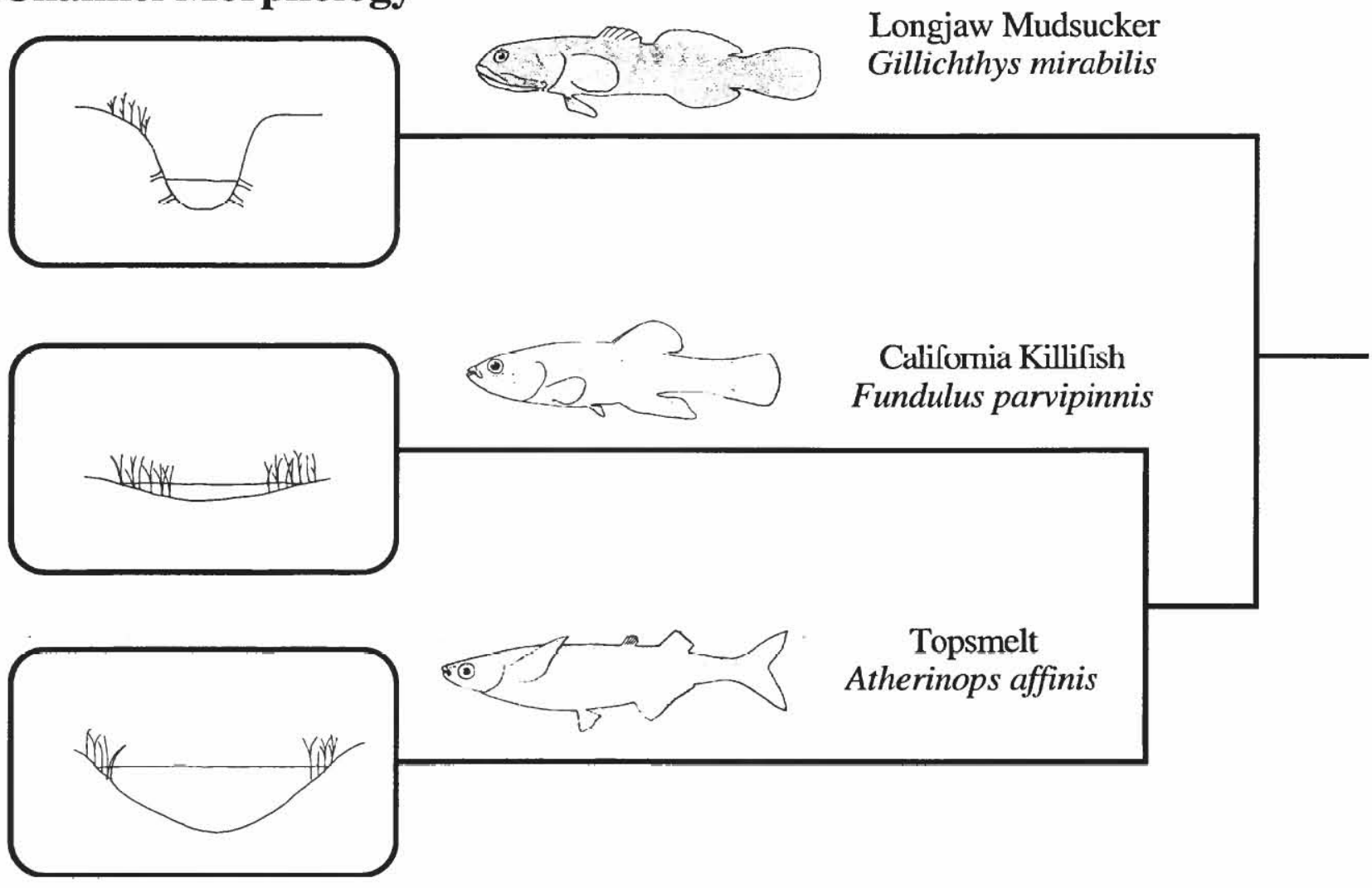

Figure 3. Relationship between channel morphology and the numerically dominant species in seine catches during summer sampling periods in Sweetwater Marsh National Wildlife Refuge (modified from Williams and Zedler, in press).

(in press) observed a general relationship between saltmarsh channel morphology and fish assemblage composition. Narrow channels with deeply incised banks were dominated by longjaw mudsuckers, shallow-sloping channels bordered with emergent vegetation were dominated by killifish, and the deepest channels were dominated by topsmelt (Fig. 3). Morphological details like these should be considered in the design of restoration projects.

\section{Conclusions}

Several habitat creation/restoration projects have been judged in compliance with their stated goals, and the speed with which fish colonize newly created habitats is encouraging. However, a broader view of the changes to coastal landscapes and a more in-depth analysis of ecosystem functioning is needed, because most of southern California's coastal wetland acreage has been filled or otherwise degraded. Harbors have replaced estuaries as the main inshore habitat for fish, and Horn and Allen (1985) caution that while harbors do support diverse fish assemblages, these fish assemblages are substantially different from those found in California's natural estuaries.
Given the extent of habitat loss, we believe emphasis should be placed on restoring habitats to their more natural condition and on recreating more natural landscape features. Perhaps more mitigation credit could be given to projects that include both subtidal and intertidal habitats than for those with strictly subtidal areas. Allowing more credit for habitats that mimic natural wetland systems of the region, i.e., marshes with complex tidal creek networks, could also be beneficial. Knowlege of how basins, channels, and more complex tidal creek networks function in fish support would be aided by projects designed to compare different habitat designs. For example, an 8-ha model marsh has been designed for construction at Tijuana Estuary; it incorporates replicate areas with and without tidal creek networks, with research to compare a wide range of ecosystem processes (Entrix et al. 1991).

Even with all of the pieces in the correct places, wetland creation still involves uncertainty. Detailed understanding of a site's hydrologic characteristics will not prevent some self-modification over time, and extreme flooding could substantially modify the outcome of any restoration project. At Puyallup Bay in Washington, channels excavated as habitat for juvenile salmon in the Gog-Le$\mathrm{Hi}$-Te estuarine wetland are sedimenting in, while a more 
complex network of shallow creeks is developing (Simenstad and Thom 1996). In San Diego Bay, a portion of the marsh at Marisma de Nación is eroding and converting to mudflat, possibly because the marsh plain was excavated too deeply (Haltiner et al. 1997). Settling upon a design that allows for self-modification (in the best case, steering modification in a particular direction), is the difficult goal of habitat restorationists.

Recommendations for future fish habitat restoration projects:

(1) Use natural systems as a model, incorporating complexity at several scales:

- Increase linkages between subtidal and intertidal habitats

- Include topographic complexity (i.e., small creek networks) from the onset

- Mimic the details of habitat morphology (i.e., channel morphology)

(2) Construct experimental wetlands with different habitat designs so that the performance of basins, channels, and tidal creek networks can be compared.

(3) Consider allowing more fish habitat mitigation credit for projects that include intertidal habitat along with subtidal habitat.

(4) Require evaluation of a greater range of ecosystem functions (food production, food transfer to fish, fish reproduction, fish growth) and comparison with a range of reference ecosystems (3-5 sites that have comparable, long-term data).

\section{Literature cited}

Allen, E.A., P.E. Fell, M.A. Peck, J.A. Gieg, C.R. Guthke, and M.D. Newkirk. 1994. Gut contents of common mummichogs, Fundulus heteroclitus L., in a restored impounded marsh and in natural reference marshes. Estuaries 17:462471.

Balling, S.S., T. Stochr, and V.H. Resh. 1980. The effects of mosquito control recirculation ditches on the fish community of a San Francisco Bay salt marsh. California Fish and Game 66:25-34.

Baltz, D.M., C. Rakocinski, and J.W. Fleeger. 1993. Microhabitat use by marsh-edge fishes in a Louisiana estuary. Environmental Biology of Fishes 36:109-126.

Boesch, D.F. and R.E. Turner. 1984. Dependence of fishery species on salt marshes: the role of food and refuge. Estuaries 7:460-468.

Boland, J. 1991. Avian community, emphasizing Marisma de Nación and the intertidal lagoon. Addendum to 1991 Annual Report on Sweetwater Marsh to Caltrans. Pacific Estuarine Research Laboratory, San Diego State University, San Diego, CA.

Brinson, M.M. and R. Rheinhardt. 1996. The role of reference wetlands in functional assessment and mitigation. Ecological Applications 6:69-76.
California Coastal Commission. 1997. Staff Recommendation Proposed Findings and Conditions: Permit Amendment and Condition Compliance, Permit \# 6-81-330-A. California Coastal Commission, San Francisco, CA.

California State Coastal Conservancy. 1989. The coastal wetlands of San Diego County. 65 p.

City of Carlsbad and U.S. Army Corps of Engineers. 1990. Batiquitos Lagoon enhancement project final EIR/EIS. US Army Corps of Engineers, Los Angeles, CA.

Coats, R.N., P.B. Williams, C.K. Cuffe, and J.B. Zedler. 1995. Design guidelines for tidal channels in coastal wetlands. Report prepared for the US Army Corps of Engineers Waterways Experiment Station. Philip Williams and Associates, Ltd., San Francisco, CA.

Desmond, J.S. 1996. Species composition and size structure of fish assemblages in relation to tidal creek size in southern California coastal wetlands. M.S. thesis, San Diego State University, San Diego, CA. 70 p.

Entrix, Inc., PERL, and Phil Williams Associates, Ltd. 1991. Tijuana Estuary tidal restoration program. Volumes I-III. California Coastal Conservancy (SCC) and US Fish and Wildlife Service, Lead Agencies. SCC, Oakland, CA.

Fonseca, M.S., G.W. Thayer, D.L. Meyer, and V.G. Thayer. 1994. Effect of habitat heterogeneity in planted saltmarsh and seagrass on system linkages and faunal development. Report 1, prepared for the US Army Corps of Engineers and monitored by Environmental Laboratory, US Army Engineer Waterways Experiment Station, Vicksburg, MS.

Greenwald, G.M. 1985. Final report: San Dieguito Lagoon fish/ plankton project. Unpublished report prepared for the County of San Diego Department of Planning and Land Use, Fish and Wildlife Advisory Committee. 33 p.

Haltiner, J., J.B. Zedler, K.E. Boyer, G.D. Williams, and J.C. Callaway. 1997. Influence of physical processes on the design, functioning, and evolution of restored tidal wetlands in California (USA). Wetlands Ecology and Management 4:73-91.

Harrington, R.W., Jr. and E.S. Harrington. 1961. Food selection among fishes invading a high subtropical salt marsh: From onset of flooding through the progress of a mosquito brood. Ecology 42:646-666.

Horn, M.H. and L.G. Allen. 1985. Fish community ecology in southern Californiabays and estuaries. Pp. 169-188 in YañezArencibia, ed. Fish community ecology in estuaries and coastal lagoons: towards an ecosystem integration. UNAM Press, Mexico City, Mexico.

Horton, R.E. 1945. Erosional development of creeks and their drainage basins. Bulletin of the Geological Society of America 56:275-370.

Irlandi, E.A. and M.K. Crawford. 1997. Habitat linkages: the effect of intertidal saltmarshes and adjacent subtidal habitats on abundance, movement, and growth of an estuarine fish. Oecologia 110:222-230.

Kleypas, J. and J.M. Dean. 1983. Migration and feeding of the predatory fish, Bairdiella chrysura Lacepede, in an intertidal creek. Journal of Experimental Marine Biology and Ecology 72:199-209.

Kwak, T.J. and J.B.Zedler. 1997. Food web analysis of southern California coastal wetlands using multiple stable isotopes. Oecologia 110: 262-277. 
MacDonald, K.B. 1990. South San Diego Bay enhancement plan, volume one: Resources atlas. Report prepared for the San Diego Unified Port District and the California State Coastal Conservancy. Michael Brandman Associates, Inc., San Diego, CA.

Mclvor, C.C. and W.E. Odum. 1988. Food, predation risk, and microhabitat selection in a marsh fish assemblage. Ecology 69:1341-1351.

MEC Analytical Systems, Inc. 1993. San Dieguito Lagoon restoration project biological baseline study, March-August 1992. Report submitted to Southern California Edison. Carlsbad, CA.

MEC Analytical Systems, Inc. 1995. Anaheim Bay biological monitoring project. Volume 2: Survey Data. Report submitted to the Port of Long Beach. Carlsbad, CA.

Miller, J.M. and M.L. Dunn. 1980. Feeding strategies and patterns of movement in juvenile estuarine fishes, Pp. 437448 in V.S. Kennedy, ed. Estuarine Perspectives. Academic Press, New York, NY.

Mitsch, W.J. and R.F. Wilson. 1996. Improving the success of wetland creation and restoration with know-how, time, and self-design. Ecological Applications 6:77-83.

Moy, L.D. and L. A. Levin. 1991. Are Spartina marshes a replaceable resource? A functional approach to evaluation of marsh creation efforts. Estuaries 14:1-16.

NOAA. 1990. Estuaries of the United States: Vital statistics of a national resource base. Special 20th Anniversary Report. Rockville, MD.

Odum, W.E., J.C. Zieman, and E.J. Heald. 1973. The importance of vascular plant detritus to estuaries. Pp. 91-135, in R.H. Chabreck, ed. Proceedings of the coastal marsh and estuary management symposium. Louisiana State University Division of Continuing Education, Baton Rouge, LA.
Pestrong, R. 1965. The development of drainage patterns on tidal marshes. Stanford University Publications, Volume X, Number 2. School of Earth Sciences, Stanford University, Stanford, CA. 96 p.

Rozas, L.P., C.C. McIvor, and W.E. Odum. 1988. Intertidal rivulets and creekbanks: corridors between tidal creeks and marshes. Marine Ecology Progress Series 47:303-307.

Rozas, L.P. and M.W. Lasalle. 1990. A comparison of diets of gulf killifish, Fundulus grandis Baird and Girard, entering and leaving a Mississippi brackish marsh. Estuaries 13:332336.

Schreffler, D.K., C.A. Simenstad, and R. M. Thom. 1990. Temporary residence by juvenile salmon in a restored estuarine wetland. Canadian Journal of Fisheries and Aquatic Sciences 47:2079-2084.

Schreffler, D. K., C. A. Simenstad, and R. M. Thom. 1992. Foraging by juvenile salmon in a restored estuarine wetland. Estuaries 15:204-213.

Simenstad, C.A. and R.M. Thom. 1996. Functional equivalency trajectories of the restored Gog-Le-Hi-Te estuarine wetland. Ecological Applications 6:38-56.

Teal, J.M. 1962. Energy flow in a salt marsh ecosystem in Georgia. Ecology 43:614-624.

Williams, G.D. and J.B. Zedler. 1999. Fish assemblage composition in constructed and natural tidal marshes of San Diego Bay: Relative influence of channel morphology and restoration history. Estuaries 22 (in press).

Zedler, J.B. 1996. Coastal mitigation in southern California: the need for a regional restoration strategy. Ecological Applications 6:84-93. 


\title{
What are the Limits to Restoration of Coastal Sage Scrub in Southern California?
}

\author{
Edith B. Allen', Scott A. Eliason', Viviane J. Marquez ${ }^{2}$, Gillian P. Schultz', \\ Nancy K. Storms', Cathlyn Davis Stylinski², Thomas A. Zink ${ }^{2}$, Michael F. Allen' \\ 'Department of Botany and Plant Sciences, University of California Riverside, Riverside, California 92521-0124 \\ Tel. (909) 787-2123; Fax (909) 787-4437; e-mail: edith.allen@ucr.edu \\ ${ }^{2}$ Department of Biology, San Diego State University, San Diego, California 92182-0057
}

\begin{abstract}
The coastal sage scrub vegetation of southern California is becoming one of the most intractable vegetation types to restore. It is subject to weed invasion, fragmentation, frequent fire, nitrogen deposition, and other disturbances that have reduced the shrub density and increased the frequency of Mediterranean weeds. Natural recolonization of native shrubs and forbs back into disturbed coastal sage scrub is often slow, especially where exotic weed abundance and disturbance frequency are high.

Where natural regeneration is slow, restoration will be necessary to return the native shrub and forb cover. Restoration trials with six species of shrubs showed that they would not establish from seed unless the Mediterranean annual grasses were removed. However, establishment of seedlings of Artemisia californica was successful if they were initiated as three month old greenhouse transplants. Transplant survival and growth rate were increased by weeding, and those transplants that survived the first growing season with grass competition survived into the second season. Thus, weed management, including weed seedbank control, is the most critical factor for shrub establishment.
\end{abstract}

An additional problem related to weed invasion may be nitrogen deposition from automobile exhaust, which is up to $45 \mathrm{~kg} / \mathrm{ha} / \mathrm{yr}$ in the Los Angeles air basin. Anthropogenic $\mathrm{N}$ deposition causes increased weed productivity in other areas around the globe, and may in part explain the vegetation type conversion of coastal sage shrubland to annual grassland in southern California. Thus, even our best efforts at restoration may fail in the most polluted areas, where we have measured extractable soil $\mathrm{N}$ up to $87 \mu \mathrm{g} / \mathrm{g}$.

Reestablishing biodiversity is one of the most important goals of many restoration projects, but even the best stands of restored coastal sage scrub have low biodiversity. This vegetation type contains 600 sensitive species, but restoration of many of these is limited by insufficient availability of seed, lack of knowledge of propagation, and of course the high cost associated with handling so many species. However, the greatest threats to biodiversity for coastal sage scrub restoration are competition from weeds and possibly also elevated soil $\mathrm{N}$ in regions with $\mathrm{N}$ deposition. A restoration strategy for the region will include an understanding of what sites are most likely to respond to restoration, given problems inherent in areas that suffer from the highest air pollution and greatest weed invasion.

Keywords: Artemisia californica; biodiversity; exotics; fire; nitrogen deposition.

\section{Introduction}

The coastal sage scrub vegetation of southern California is among the most intensively human-affected vegetation types in the United States. For this reason it has become a focus for mitigation and restoration (Bowler 1990), driven by the legal requirements of the Endangered Species Act (Berger 1991). It contains about 200 sensitive plant species (Skinner and Pavlik 1994) and has lost both floral and faunal diversily in urban fragments (Soulé et al. 1988; Alberts et al. 1993). Coastal sage scrub has been subject to urbanization, agriculture, and invasion by exotic annuals to such a large extent that one estimate gives only $10 \%$ of the original vegetation in good condition (Westman 1981). Other estimates suggest approximately $40 \%$ has been lost to urban development and agriculture (Klopatek et al. 1979), and a more recent estimate puts coastal sage scrub loss at 66\% (O'Leary et al. 1992). The differences among the estimates may lie in the inability to estimate accurately how much of the natural potential vegetation is coastal sage scrub. Alternatively, it may lie in the condition of the remaining vegetation, which is often very weedy. Estimates for various southern California counties indicate that up to $50 \%$ of the remaining coastal sage scrub is degraded (O'Leary et al. 1992). Large 
expanses have been invaded by annual Mediterranean grasses and forbs (Freudenberger et al. 1987), and in many areas the shrub understory is dominated by exotic rather than native annuals (Davis 1994). The conversion of shrubland to Mediterranean annual grassland has occurred primarily in the last 60 years, with $90 \%$ loss in shrub cover close to urban areas in western Riverside County with replacement by annual grasses (Minnich and Dezzani 1998).

The large extent of degraded coastal sage scrub, along with its diminishing land area and many sensitive species, has made it a target for restoration. While there are many restoration efforts, they are not so successful that they emulate the original vegetation (Bowler 1990). The objective of this report is to understand the ecological limitations to restoration of coastal sage scrub. First we will examine the causes of vegetation type conversion in coastal sage scrub, including anthropogenic disturbance, weed invasion, and their interactions. Then we will describe the processes of succession in coastal sage scrub, especially as they have been modified by human influences. Succession is frequently used as a tool to promote restoration, so modifications in the successional process will necessarily require changes in management for restoration. Finally, we will focus on competition from weeds, inability to replace lost biodiversity, and nitrogen eutrophication as major limiting factors for restoration.

\section{Causes of Vegetation Type Conversion in Coastal Sage Scrub}

For restoration to be successful, the causes of vegetation conversion must be identified and remedied. The historic vegetation must also be known to set a restoration goal (White and Walker 1997). The causes of change in coastal sage scrub are multiple; the most direct of these, urbanization and agriculture, have already taken $40 \%$ or more in southern California (Klopatek et al. 1979; O'Leary et al. 1992). Decline of the remaining stands that are in poor condition is more complex to understand, and may be largely due to weed invasions. The invasion by Mediterranean annuals is given as a cause of loss of biodiversity in California grasslands (Pavlik et al. 1993), and may also be a cause for biodiversity losses in coastal sage scrub. Invasive weeds in coastal sage scrub include annual grasses in the genera Bromus, Avena, Vulpia, and Hordeum. Bromus madritensis is especially widespread, either present or abundant in virtually all stands across southern California (O'Leary personal communication). Other problem weeds include Cynara cardunculus, Carpobrotus edulis, and Chrysanthemum coronarium, which occur near the coast, species of Brassica, Erodium, and Centauria, Foeniculum vulgare, Nicotiana glauca, and others. The restoration efforts reported here are in areas dominated by annual grasses because they are widespread and better represented in the published literature, although research and management on the other species is ongoing. Invasions of natural plant communities do not typically occur without some imposed disturhance (Fox and Fox 1986). Remnant stands of coastal sage scrub have been subject to fragmentation, historic grazing by domestic livestock, increased fire frequency, and two major forms of air pollution, ozone and nitrogen deposition. Each of these causes of disturbance is briefly considered below.

Fragmentation by urbanization and agriculture may have promoted the spread of Mediterranean annuals in coastal sage scrub. This is a naturally fragmented vegetation type, with patches surrounded by chaparral, native grassland, and oak savanna (Westman 1981). However, these adjacent native vegetation types would not promote the invasion of exotic species into scrub, as they themselves are native species. Many of them have herbaceous understory species in common with coastal sage scrub. However, in some cases the surrounding native vegetation has become weedy, such as oak savannas with annual grass understorys that could act as seed sources for invasion to adjacent coastal sage scrub. Urban weedlots and agricultural fields are primary sources of invasive weeds. Coastal sage scrub fragments surrounded by nonnative vegetation are subject to invasion of weeds, the extent of the invasion being related to the size of fragment, time since fragmentation, the biological characteristics of invading and invaded vegetation, and the disturbance regime (Alberts et al. 1993; Forman 1995). In one study, a pipeline corridor through the Santa Margarita Ecological Reserve (northern San Diego County) was cited as the cause of weed invasion into the reserve (Zink et al. 1995). Extensive fragmentation and disturbance corridors are relatively recent in their impact on southern California vegetation, compared to grazing that has occurred for several centuries.

Ecologists in southern California have discussed the impacts of grazing on coastal sage scrub with little more than anecdotal information to back up competing hypotheses, since little published information is available. Burcham (1957) wrote that ranchers used fire in California sagebrush as a management tool, and may have induced past vegetation type conversion to annual grass by frequent burning. Fire was coupled with seeding by Bromus hordeaceous and other annuals in some areas. Some coastal sage scrub may have been converted to grass long before local botanists and naturalists took note. However, the most intensive sheep and cattle grazing ended by the turn of the century (Robinson and Risher 1993), and any large scale effects of grazing were over hy then. Shrub reinvasion has been observed where grazing was excluded (Wells 1962), so many grazed areas may have recovered after the animals were removed. However, not all areas that are dominated by exotic grasses returned to their original shrub vegetation (Freudenberger et al. 1987; Davis et al. 1994), and the current vegetation of historically grazed shrublands may be the product of past graz- 
ing. For instance, the historically grazed Motte Rimrock Reserve and Sycamore Canyon Parks in western Riverside County have both large stands of exotic annual grasses and patchy shrublands with grass understory. Other areas that were ranches in the past and are reserves today, such as the Western Riverside Multispecies Reserve or the Audubon Starr Ranch, have extensive stands of shrubland with primarily native species in the understory - but also extensive stands with weeds in the understory.

In addition to direct effects of vegetation consumption and trampling, grazing animals also disperse seed (Burcham 1957; Malo and Suarez 1995). It is likely that grazers dispersed the weed seeds at a more rapid rate and to greater distances than other dispersal modes. Mediterranean annuals were already widespread in California grasslands by the mid-1800's and likely even earlier (Heady 1977). Because coastal sage scrub was grazed by the earliest European settlers, weed seed also likely arrived in this vegetation type early on. However, the extensive type changes occurred primarily after the 1930's, after the heaviest grazing had been removed (Minnich and Dezzani 1998). These observations were based on the Forest Service "Vegetation Type Map" historic data from the 1930's, and on aerial photographs from that time (Minnich and Dezzani 1998). The grazing animals may have "primed" the system by assuring that seeds were widely dispersed, but the extensive reproduction of weeds within a site may have continued after cattle and sheep were removed. Weed abundance may have increased in recent decades simply because it took the annuals several decades to become locally abundant after their seeds were dispersed. However, other factors in addition to time may have interacted to promote their reproduction and increase in local abundance in recent decades. Two additional important factors to consider for this region are fire and air pollution.

Increased fire frequency is another cause of decline of shrublands. A number of studies noted that short fire intervals cause conversion of shrubland to grassland (Zedler et al. 1983; Malanson 1985; Callaway and Davis 1993). The normal fire interval in coastal sage scrub is about 30 years (Keeley and Keeley 1984; Westman and O'Leary 1986), but when the fire frequency becomes 2-3 years, the shrubs cannot regenerate. Urban parks in western Riverside County, such as Box Springs Mountain and Mt. Rubidoux, that were dominated by coastal sage scrub only 20 years ago are now largely annual grasslands because of fires that burn at 2-3 year intervals (Minnich 1988 and personal communication). Thus frequent fire can be blamed for the loss of shrubland in urban reserves where ignition sources are frequent. However, most remaining coastal sage scrub does not burn this frequently, and even areas that have not burned in 30 years have apparently experienced shrub loss (Minnich and Dezzani 1998). This leaves air pollution as the final discussion point to explain shrub loss.

Air pollution in southern California has two major components, ozone and nitrogen oxides. The ozone response of conifers has been well studied because they suffered mortality in the Transverse Ranges adjacent to the Los Angeles Air Basin (Miller et al. 1963). Coastal sage scrub shrubs are less sensitive to ozone than conifers (Westman 1990), but still responsive to ozone injury. Well-watered seedlings of shrubs had reduced growth with $24 \mathrm{hr}$ exposures of $150 \mathrm{ppb}$ ozone, while lower exposures to ozone caused no measurable effects (Westman 1990). In another study, populations of Bromus madritensis that were collected from areas with a history of ozone exposure showed no sensitivity to the same level of ozone, while populations from areas with clean air were sensitive (Westman 1991). These studies suggest that ozone could contribute to scrub decline. But in fact, ozone levels are at their highest in summer when shrubs are dormant, and are lower in spring. Most of the shrubs shed $50-90 \%$ of their leaves in the summer, and would not be affected by summer ozone highs of $150 \mathrm{ppb}$. While wellwatered seedlings in the greenhouse with open stomates would be affected by ambient summer ozone levels, dormant shrubs in the field are unlikely to be affected. Therefore, ozone is not likely to be the most important component of air pollution affecting coastal sage scrub.

Nitrogen deposition has not previously been examined as a contributor to coastal sage scrub decline, but up to 45 $\mathrm{kg} / \mathrm{ha} / \mathrm{yr} \mathrm{N}$ are deposited in the mountains adjacent to the Los Angeles Basin (Bytnerowicz and Fenn 1996). Nitrogen deposition is known to cause vegetation type conversions to low diversity grasslands in other regions, notably the Netherlands (Bobbink and Willems 1987), which have up to $85 \mathrm{~kg} / \mathrm{ha} / \mathrm{yr}$ of $\mathrm{N}$ deposited. In southern California $90 \%$ of the $\mathrm{N}$ arrives as dry fall (particulate and ion deposition to surfaces) during the dry mediterranean-climate summer. Of the total $\mathrm{N}$ deposited, $80-90 \%$ of this is nitrate that originates from internal combustion engines, the remainder is ammonium from agricultural origins (Bytnerowicz et al 1987). $\mathrm{N}$ deposition is so high that soils with more than 80 ppm extractable $\mathrm{N}$ occur in the polluted regions near Riverside during the dry season, an extremely high value that is unknown from natural wildland soils (Allen et al. 1996). In greenhouse experiments both the annuals and the shrubs had rapid rates of growth and $\mathrm{N}$ uptake at higher fertilization rates, but two shrub species, Artemisia californica and Encelia californica, began to die after 6-12 months in soil with $30-50 \mathrm{ppm} \mathrm{N}$ (Allen et al. 1996; P. Padgett, unpublished data). Although we have yet to explain this effect of high $\mathrm{N}$ on the shrubs, they apparently suffer from the physiological effects of high soil N. First individual leaves turn brown and die, then branchlets, then entire branches in the greenhouse. In the field we have anecdotal observations that shrub 
mortality in native stands is higher in polluted than unpolluted regions. This corroborates the findings that shrub loss since the 1930's was also greater in urban than rural areas (Minnich and Dezzani 1998). Thus, among the several causes of loss of coastal sage scrub in natural reserves, $\mathrm{N}$ deposition may be important in air-polluted regions. Nitrogen deposition would be most noticeable in those reserves that do not burn frequently or are not subject to other forms of frequent disturbance.

For restoration to be successful, $\mathrm{N}$ deposition will need to be reduced and $\mathrm{N}$ levels that have been built-up in soils will need to be immobilized. Along with ozone, concentrations of nitrogen oxides in the atmosphere are becoming lower (EPA 1997), although $\mathrm{N}$ eutrophication continues to be a problem. High levels of $\mathrm{N}$ deposition are less of a problem in the coastal than inland areas of southern California (EPA 1997), because onshore breezes move the pollution inland. Thus the inland sage scrub of Riverside County is likely more threatened by $\mathrm{N}$ deposition than the scrub vegetation near the coast. Nitrogen must be removed or immobilized for restoration of eutrophied soils, as discussed below.

\section{Succession in Coastal Sage Scrub}

To understand the processes and limits of restoration of coastal sage scrub, we must study succession. Many restorationists use succession as a tool to enhance their restoration activities, which can be termed passive restoration if natural succession is the only method used (Fig. 1). Conversely, in situations where natural processes will not return the system to the desired state, or where natural processes, such as recolonization, are too slow, active restoration is required. Succession in coastal sage scrub has been studied primarily in the context of fire (Zedler et al. 1983; Westman and O'Leary 1986; O'Leary 1990; Keeley and Keeley 1984). Recovery from fire that oc-

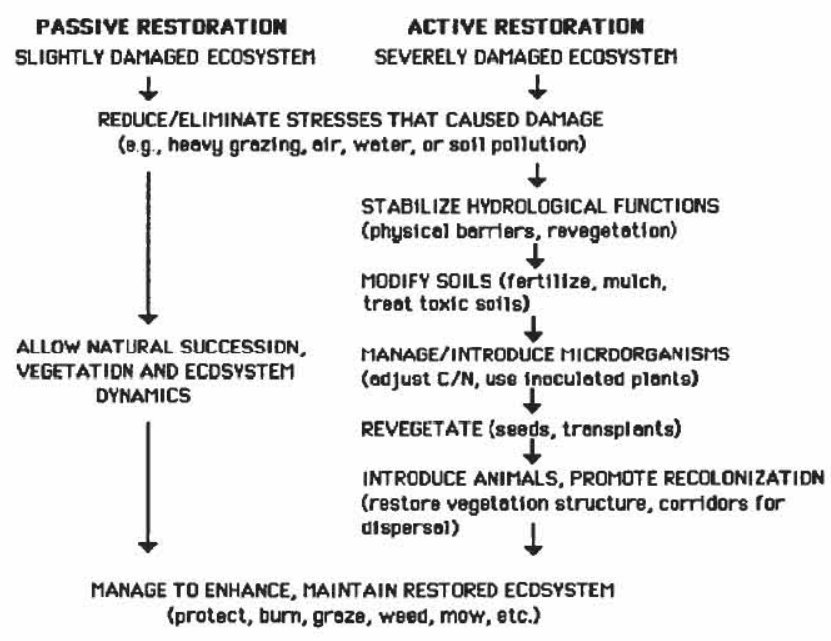

Fig. 1. Comparison of active vs. passive restoration. curs at natural, decades-long intervals is rapid. A flush of native annual forbs (sometimes mixed with exotic grasses and forbs) during the first year or two is followed by recovery of native shrubs from the seed bank, seed dispersal, resprouting, and seeds produced by the resprouters. Ecologists would normally not propose restoration after such a burn, because the natural regeneration is rapid enough. Active restoration is needed if natural processes will not return the desired vegetation, or if natural processes are too slow for the management goal.

Sometimes land managers seed exotic perennial grasses in a mistaken attempt to hasten reestablishment of vegetative cover (Conard et al. 1995). This is done on steep slopes at the edge of urban/suburban areas where soil erosion is feared, but the natural ability of native mediterranean shrublands to regenerate after fire is very high (Westman and O'Leary 1986). Experiments in chaparral have shown no conclusive evidence that seeding with exotic grasses either helps or hinders native vegetation establishment, or decreases soil erosion (Conard et al. 1995). Similar results are not available for coastal sage scrub, so it is not known whether seeding exotic grasses will reduce the ability of native shrubs to regenerate after fire.

Although scrub recovery from fire is rapid, recovery from other disturbances that cause type conversion to annual grassland is slow or does not occur. Some of the instances of this were cited above, e.g., the grasslands of Los Angeles and Riverside County have only been slowly recolonized (Freudenberger et al. 1987). The pipeline through the Santa Margarita Reserve was dominated by exotic annuals for 20 years (Zink et al. 1995). The first author of this paper revisited the reserve in 1997, and noted that Eriogonum fasciculatum is higher in density and cover than when Zink et al. (1995) did their observations in 1992. However, Eriogonum is still virtually the only native shrub, and the understory is still dominated by exotic annuals. Thus, it is premature to say the pipeline is dominated by native vegetation. Succession has not returned this pipeline to its former undisturbed vegetation composition.

In a larger scale study of 23 anthropogenically disturbed sites throughout San Diego County, none of the sites were statistically similar to adjacent stands of native shrubs even 71 years after disturbance (Davis 1994). The study compared each disturbed site to an adjacent undisturbed site (Fig. 2), and concluded that the similarity index between disturbed and undisturbed sites did not increase over time. The sites included chaparral and coastal sage scrub, which both behaved similarly under anthropogenic disturbance. Two native shrub species were abundant on a few of the sites, Eriogonum fasciculatum which typically is a component of both chaparral and sage scrub, and Baccharis sarothroides, which colonizes natural edges of riparian disturbances. All 23 sites had a dense ground layer dominated by Mediterranean annual grasses and 


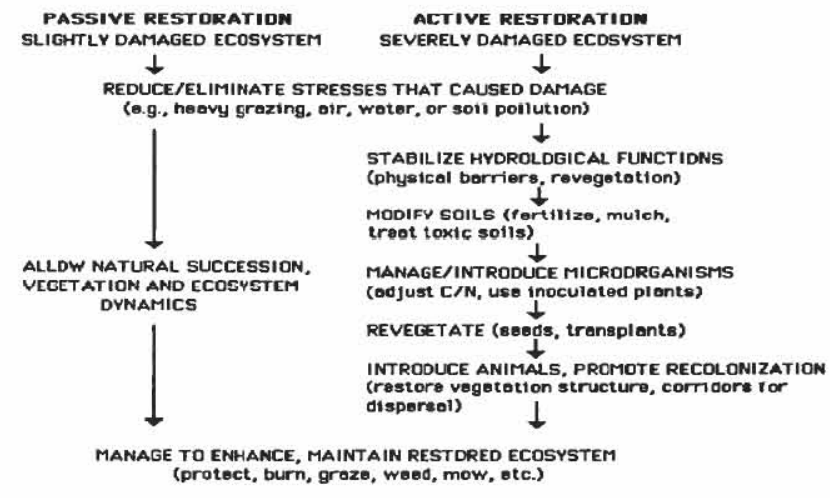

Fig. 2. Similarity index (Czekanowski's) for adjacent disturbed and undisturbed CSS and chaparral sites ranging in 1-71 years since disturbance. Data from Davis (1994).

forbs. The disturbances included earthen fills, compaction, scraping, and tillage. They were all chosen as intensive or long term disturbances that largely removed the seed bank and also altered the soils. Thus, there was no evidence of traditional "Clementsian" succession to a prior vegetation type. The combination of loss of seed bank, invasive annuals, and possibly also altered soils appears to have caused a vegetation type conversion in coastal sage scrub as well as chaparral at these 23 sites.

Certainly there are examples, both published and anecdotal, of coastal sage scrub shrubs recolonizing disturbed areas after tillage or grazing (Freudenberger et al. 1987; Wells 1962). Superficially, these areas may even look like coastal sage scrub if the shrub density is high enough, especially from aerial photographs. Some areas of San Diego County that were farmed in the early part of this century had shrub cover equal to surrounding unplowed hillsides after several decades (T. Scott unpublished aerial photographs). However, ground truth surveys have shown that the understory is not nearly as diverse as the surrounding undisturbed vegetation, and has a high cover of Mediterranean annuals. Eriogonum fasciculatum and Baccharis sarothroides appear to be exceptional shrubs that can invade the dense annual grasses, as noted in other areas (Kirkpatrick and Hutchinson 1977; Williams and Hobbs 1989), but the resultant plant community cannot be described as native coastal sage scrub. Even less disturbed scrub may have a high cover of exotics, such as in nature reserves with high foot traffic. In fact, some of the "undisturbed" stands that Davis (1994) studied were quite weedy, having a relatively high cover of exotic annuals. They differed from the disturbed in that native herbaceous species were also abundant in the understory and there was a higher diversity of native shrubs. Coastal sage scrub may often be a weedy vegetation type, even where it has not been subject to intensive disturbance. Large scale surveys have not been done to show where the best and poorest condition occur, so it is not possible to speculate the extent and location of poor condition scrub. However, our preliminary observations during travels throughout the region suggest that the weedier stands tend to occur inland under higher $\mathrm{N}$ deposition as well as drier (lower humidity) summer conditions. This stands as a hypothesis to be tested using large scale surveys and remote sensing techniques. For the purposes of restoration, we are interested in selecting reference areas as goals for restoration. If the native areas have a large proportion of exotic species, they do not serve well as a reference area. In addition, if natural stands are weedy, then it will be difficult for the restorationist to improve upon natural conditions. Restored lands may initially have a low proportion of weeds because of the efforts of restorationists, but how do we keep the weeds out without sustained and expensive effort?

\section{Limitations to Restoration in Coastal Sage Scrub}

During the last five years we have undertaken numerous restoration trials that will be used to illustrate the limits to restoration. Among these are studies on weed competition, restoring biodiversity, and problems of high soil nitrogen. These are the ecological limitations. Even before facing these there are political, economic, and social limitations. However, we will not consider these here, and will discuss only the ecolugical limitations.

\section{Competition}

Restorationists have long considered nurse plants for restoration, especially where the native species are too slow growing for rapid establishment to stabilize soil. One of the dilemmas of restorationists who work with steep slopes is that they must get both a rapid cover to prevent erosion, and establish native plants. Many native plant species are slow growing compared to the horticultural plants used to stabilize soil. A few years ago we were approached by the California Department of Transportation to determine whether Trifolium hirtum, a fast-growing, non-native legume, acts as a nurse plant to establish coastal sage scrub vegetation on roadsides. Trifolium hirtum is used throughout the state to stabilize roadsides, but in southern California this annual typically persists only for a few years. Thus, it seems like it should be a good nurse plant, in addition to the fact that as a legume that could contribute $\mathrm{N}$ to the poor soils often created by the road building process. We tested the interactions of Artemisia californica with $T$. hirtum, and learned that $T$. hirtum acted as a competitor even under the lowest density of one plant of each species per $25 \times 25 \mathrm{~cm}$ (Marquez and Allen 1996). Competition from $T$. hirtum was so intense even at the lowest density that $A$. californica biomass was reduced by an order of magnitude. Noncompetitive, mechanical means must be taken where slope stabilization is an issue, such as mulching or furrowing, to as- 
sure the establishment of slower growing shrubs and at the same time reduce soil erosion.

Artemisia californica was not only a poor competitor with $T$. hirtum, but also with Mediterranean annual grasses. Active restoration is the only practical means of recreating the former shrublands where Mediterranean grasses have colonized, so experiments in restoration of grasslands back to shrublands are at the same time experiments in competition. In a grass thinning experiment, increasing density of grasses from 0 to 500 per $\mathrm{m}^{2}$ caused increased mortality and decreased biomass of transplanted seedlings of A. californica (Eliason and Allen 1997). During the first year there were no differences between biomass of $A$. californica in plots ranging from 25 to 500 grasses per $\mathrm{m}^{2}$, but when all grasses were removed, the shrubs were significantly larger (Fig. 3). Grasses are so plastic in their growth, that the thinned individuals responded rapidly by increasing their size. Thus, to assure survival of transplanted $A$. californica a very high proportion of the grasses need to be removed, leaving fewer than 25 plants per $\mathrm{m}^{2}$. In this study the annual grasses included primarily Bromus madritensis, B. diandrus, and Avena fatua.

Transplanted seedlings suffered from competition in stands of annual grasses, and germinants from planted seed fared even more poorly. In a seeding experiment with six shrub species (Eriogonum fasciculatum, Salvia mellifera, S. apiana, Lotus scoparius, Encelia farinosa, Artemisia californica) there were no survivors unless the annual grasses were cleared (Schultz 1996), and the same pattern was seen for germinants of A. californica (Eliason and Allen 1997). Conversely, all six seeded species survived at rates of $1-5 \%$ of seedlings per $10 \times 10 \mathrm{~cm}$ plot if the grasses and all other vegetation was cleared (Schultz 1996). The study by Schultz (1996) was done in Riversidean sage scrub, while that of Eliason and Allen (1997) was in Diegan sage scrub. However, both studies produced the same conclusions regarding the need to remove grasses if seeding, rather than transplanting, is the

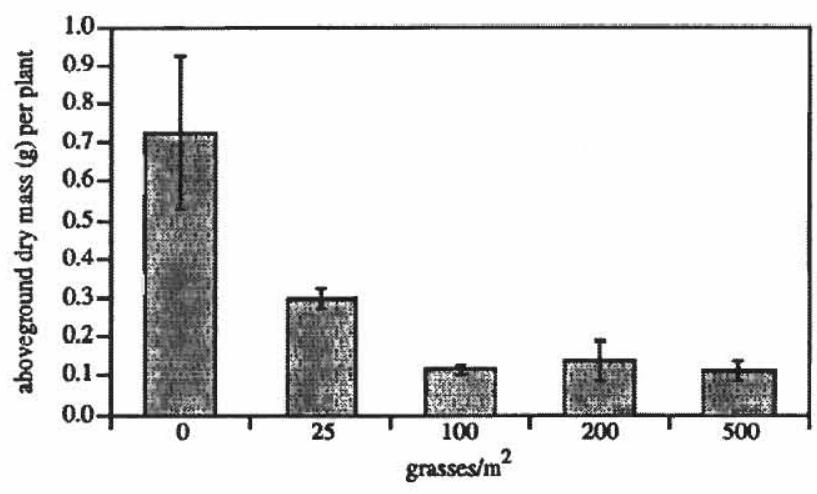

Fig. 3. Growth responses of Artemisia californica to different manipulated densities of Mediterranean annual grasses after one growing season in a field experiment. Data from Eliason and Allen (1997). preferred technique for restoration. Weeding is seldom done adequately because of the high cost. In one example where weeding was part of the planning process, the California Department of Transportation removed all exotics for 2-3 years from planted stands at a mitigation site in Santee (John Rieger, personal communication). This resulted in a healthy stand of coastal sage scrub shrubs with little herbaceous understory that has persisted for more than 7 years in this condition.

Results of these grass/shrub competition experiments help to explain why reinvasion of scrub species is so slow in many converted grasslands. The annual grasses are dense and highly competitive, and native seeds that disperse into these grasslands have a diminished chance of survival. Some researchers have hypothesized that they may invade natural disturbances, such as animal diggings. Comparisons between gopher exclosures and control plots showed no increase in shrub germinant survival with gopher digging (Schultz 1996). However, these were small scale plots measured over two growing seasons. In large annual grasslands over many years some establishment of shrubs would be expected, as was seen by Davis (1994) with the recolonization of Eriogonum fasciculatum. Schultz (1994) also measured the dispersal of shrub seeds into grassland, and of the six species only $E$. fasciculatum dispersed any seed at all beyond the canopy of the parent shrub. Of these six, E. fasciculatum has the only winged seed that might be wind dispersed. Seed dispersal is poorly known for coastal sage scrub shrubs (Keeley 1991), but appears, like many other vegetation types, to be largely limited to the immediate surroundings of the parent plant. Thus, competition from annual grasses is one of the greatest limitations to restoration, but these studies and other anecdotal restoration studies (Bowler 1990; Hillyard and Black 1987) indicate that shrubs can be reestablished if sufficient efforts are made.

\section{Biodiversity}

A larger problem than shrub establishment may be restoration of the diverse understory of coastal sage scrub. Most of the species declared sensitive by the California Native Plant Society are herbaceous annuals and perennials, including some fire following annuals (Skinner and Pavlik 1994). These have been included in restoration seed mixes, but with varied success. For instance, some large stands of Lasthenia spp. were seeded successfully at Crystal Cove State Park (Hillyard and Black 1987; D. Hillyard, personal communication). At several sites throughout San Diego County, less common species such as Lessingia fasciculatum, Eriophyllum confertifolia, and others were successfully seeded, or species including Chamaesyce albomarginata, Solanum douglasii, Gnaphthalium califonicum, and Heliotropum curassavicum, appeared in the soil seedbank from salvaged topsoil (Marquez, personal observation), but most restored 
sites are largely dominated by shrubs with an understory of non-native annual grasses.

For the most part, seeded sites contain only a fraction of the biodiversity of natural coastal sage scrub stands, which may have 60-70 species per hectare. The low diversity is in part related to the low numbers of species prescribed in the seed mix, but also because of competition from exotic annuals, possibly coupled with $\mathrm{N}$ deposition in some areas. Thus, our main goal of restoring biodiversity is thwarted by the high cost and low availability of seed, the lack of mandate to use more than a few species in the seed mixture, and weed competition. Inability to collect, process, and germinate seed is another limitation, but California botanists have learned much about native seed germination (e.g., Keeley 1991), and even more unpublished information is available from local botanical gardens and firms that process and sell seed. To improve the chances of increasing diversity, the restorationist needs to take advantage of soil seed banks and of the ability of seeds to disperse naturally.

Even though some coastal sage scrub sites have been nearly replaced by exotic annual grasses for 20 years or more (Minnich and Dezzani 1998), they may still have a native seedbank. Richard Minnich observed vegetation recovery after a May burn in the Box Springs Mountains, Riverside, compared to a fall burn. These mountains lost most of their native vegetation cover during the last 20 years, but primarily native species came up after the spring burn (Minnich, unpublished observations). This may have occurred because the current year standing crop of weed seed burned almost completely, since the seeds had not yet shattered from their seedheads. For the fall burn, the seeds had already shattered, and enough were in soil cracks and protected from the fire that they germinated in large numbers at the onset of the winter rains. The longevity of native seed banks is well known for coastal sage scrub and chaparral, since these vegetation types have decadeslong fire cycles. The restorationist may be able to take advantage of this knowledge and promote diversity by using prescribed fire in the spring. This poses two problems. One is obtaining permission for prescribed fire in a pyrophobic society, and the other is keeping the grasses from recolonizing over the longer term. This would require longterm maintenance, which is seldom available. Thus, a high diversity stand may not be possible except in special circumstances where grass competition is controlled.

The second chance that the restorationist has to improve diversity is to take advantage of natural colonization. From the many examples given above, it should be clear that this can occur only if weed competition can be reduced, because only a few unusual species colonize dense stands of annual grasses. In a study of roadside restoration on Interstate 15 in San Diego County, we examined sites up to 18 years old to determine how many native species would colonize and increase stand richness.

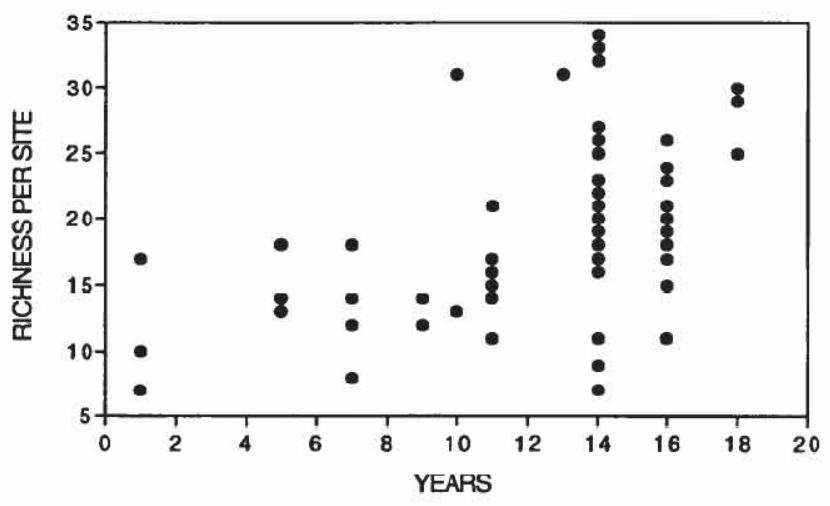

Fig. 4. Richness of native plant colonization over time on a revegetated California roadside. Data from Allen et al. (1993)

The advantage of using a roadside for an ecological experiment, is that topsoil is not saved and there is no seedbank of any species initially. Of 36 locations, no site had more than 12 species planted originally. After 10 years, a few sites had 15-16 additional colonizing species that were not among the planted species (Fig. 4, Allen et al. 1993). These included such native annuals as Cryptantha intermedia, Filago arizonica, Plantago spp., and others. Not all sites had native colonizers, only those that were adjacent to native vegetation. Sections of the roadside that ran through the city or suburbs had only exotic colonizing species, which occurred throughout. Thus, we can expect native species to colonize only in those restoration sties that are surrounded by native vegetation. Isolated restoration or mitigation sites will have low richness even with the greatest efforts, as do small isolated natural patches of coastal sage scrub and chaparral (Soulé et al. 1988).

\section{Nitrogen eutrophication}

Soils that have been eutrophied by nitrogen deposition may also prove a formidable task for restorationists. Obviously the first task would be to reduce the production of nitrogen oxides, and this is occurring to some degree (EPA 1996). However, the amount of nitrogen that is coming down is still at agricultural levels, and is not likely to decline rapidly. We still know relatively little about the effects of high soil $\mathrm{N}$ on shrub longevity, and in addition nitrogen oxides have direct detrimental effects on leaf cuticles (Wellburn 1990; Allen et al. 1996). Thus, we would not choose those sites that have the highest $\mathrm{N}$ deposition for restoration sites, but the upper limits of $\mathrm{N}$ deposition for negative effects on coastal sage scrub communities are not known.

In the Netherlands where the $\mathrm{N}$ deposition rate is as much as $90 \mathrm{~kg}$ per ha per $\mathrm{yr}$, annual haying in the early summer has been used successfully to increase pasture biodiversity (Bobbink and Willems 1997). However, cutting later in the growing season was not as effective. This 
technique was successful because pastures have become dominated by one species of perennial grass native to Europe, Brachypodium pinnatum, which when removed allows other species to grow. Haying could potentially be used as a restoration technique in type-converted coastal sage scrub, but only if done early enough in the season to remove the current year contribution to the seedbank. Once the shrubs are reestablished, haying is of course no longer possible.

Where soils have high available $\mathrm{N}$, the overriding restoration goal is to immobilize it and make it unavailable to plants. In our semiarid system external additions of organic matter may help to solve the excess fertility problem by immobilizing the high levels of inorganic N. This was accomplished by using mulch with a high $\mathrm{C} / \mathrm{N}$ ratio in a restoration plot on a pipeline disturbance with relatively high extractable N. Bark mulch, with high $\mathrm{C} / \mathrm{N}$, was more effective than straw mulch in promoting the growth of planted seedlings of Artemisia californica (Zink and Allen 1998). Bark also promoted growth of soil saprobic fungi more than straw or unmulched soil, and the fungi are responsible for immobilization of nitrogen. At this time the mechanisms by which $\mathrm{N}$ immobilization promoted shrub growth over grass growth are not clear. Changes in forms of $\mathrm{N}$ (ammonium vs. nitrate) with mulching, differential abilities of shrubs and grasses to take up different $\mathrm{N}$ forms, or ability to take up $\mathrm{N}$ in soils with lower concentrations of $\mathrm{N}$, may all come into play.

Obviously it will not be possible to apply bark mulch to vast expanses of scrub that have excesses of nitrogen. It is possible that excess nitrate may eventually be lost, if air pollution can be decreased. For soil $\mathrm{N}$ to increase permanently, there must be an increase in organic matter plus soil microorganisms to bind the nitrogen. Our measurements of southern California soils do not show significant increases in soil organic matter in high $\mathrm{N}$ sites (E. Allen et al., unpublished data). Wedin and Tilman (1996), working in a mesic grassland, also have shown no accumulation of organic matter even after years of fertilization. The most likely reason for this is increased rates of mineralization in high $\mathrm{N}$ soils, which keeps carbon from building up in the soil. Thus, many soils that have been affected by $\mathrm{N}$ deposition will have higher levels of inorganic $\mathrm{N}$, but organic $\mathrm{N}$ buildup will be slow and small. An exception to this is sites that are invaded by nitrogen fixing plants, such as Myrica faya in the poor volcanic soils of Hawaii (Vitousek and Walker 1989). These soils have permanently increased organic $\mathrm{N}$, but in this case the source of $\mathrm{N}$ input is organic litter rather than inorganic $\mathrm{N}$ deposition.

There is a great deal of reason to hope that vegetation that has been altered by $\mathrm{N}$ deposition can be at least partially restored, because inorganic $\mathrm{N}$ may be lost from the system after inorganic input declines. Studies on $\mathrm{N}$ deposition and $\mathrm{N}$ fertilization can give us some clues about how restoration of these may begin. Available $\mathrm{N}$ and $\mathrm{N}$ mineralization rates are typically higher under grasses than shrubs (Ingham et al. 1989). Practices that slow mineralization and bind inorganic nitrogen, such as mulching, and planting with species that promote slower mineralization (Wedin and Tilman 1996) would push the system back to a lower available $\mathrm{N}$. Thus revegetation efforts need to consider more than reestablishing the vegetation, they need to manage and restore $\mathrm{N}$ dynamics.

\section{Conclusions}

The overriding limitation to restoration of coastal sage scrub is replacing the biodiversity. This will become increasingly difficult as competition from exotics becomes greater, and as nitrogen deposition possibly makes the exotics even more competitive. Limitations of seed dispersal and remnant native soil seed bank must also be taken into consideration if restoration of a community high in richness is to succeed. Sometimes this will take a better understanding of community and ecosystem dynamics than we now have. For example, it may require a better understanding of the nitrogen dynamics of native and cxotic species than we have now. Restoration of coastal sage scrub is a relatively recent activity, and as argued by Bowler (1990), we will not know whether we have truly restored coastal sage scrub until it has matured to the point where we can reapply the natural fire regime. The resultant community must then respond to fire as does a natural community. We can use these limitations in a positive sense to choose those sites that have the best potential for restoration. For instance, sites with a potential native seed bank, sites that are adjacent to existing vegetation and can receive dispersed seed, sites with relatively low $\mathrm{N}$ deposition, and sites where weed invasion can be kept under control, are the best potential candidates for restoration. Sites that have more severe environmental problems may be chosen for political or social reasons as restoration sites, but these cannot be truly restored given the limitations discussed here.

Acknowledgments. The research synthesized here was supported by the National Science Foundation Division of Environmental Biology, USDA Competitive Grants Program, and the California Department of Transportation.

\section{Literature Cited}

Alberts, A.C., A.D. Richman, D. Tran, R. Sauvajot, C. McCalvin, and D.T. Bolger. 1993. Effects of habitat fragmentation on populations of native and exotic plants in southern California coastal scrub. Pp. 103-110 in J.E. Keeley, ed. Interface between ecology and land development in California. Southern California Academy of Sciences, Los Angeles, CA. 
Allen, E.B., B.I. Heindl-Tenhunen, and J. P. Rieger. 1993. Trajectories of succession on restored roadsides in southern California. Annual Meeting of the Society for Ecological Restoration, Irvine, California, June 1993.

Allen, E.B., P.E. Padgett, A. Bytnerowicz, and R.A. Minnich. 1998. Nitrogen deposition effects on coastal sage vegetation of southern California. Air pollution and climate change effects of forest ecosystems. USDA Forest Service, PSWRUU-4451. (www.rfl.pswfed.us/pubs/psw-gtr-164/ index.html).

Berger, J. 1991. The federal mandate to restore: laws and policies on environmental restoration. Environmental Professional 13:195-206.

Bobbink, R. and J.H. Willems. 1987. Increasing dominance of Brachypodium pinnatum (L.) Beauv. in chalk grasslands: a threat to a species-rich ecosystem. Biological Conservation 40:301-314.

Bowler, P.A. 1990. Coastal sage scrub restoration-I: The challenge of mitigation. Restoration \& Management Notes 8:7882.

Burcham, L.T. 1957. California range land: an historico-ecological study of the range resource of California. Department of Natural Resources, Division of Forestry, State of California, Sacramento, CA.

Bytnerowicz, A. and M.E. Fenn. 1996. Nitrogen deposition in California forests : A review. Environmental Pollution 92:127146.

Bytnerowicz, A., P.R. Miller, D.M. Olszyk, P.J. Dawson, and C.A. Fox. 1987. Gaseous and particulate air pollution in the San Gabriel mountains of southern California. Atmospheric Environment 21:1805-1814.

Callaway, R.M. and F.W. Davis. 1993. Vegetation dynamics, fire, and the physical environment in coastal central California. Ecology 74:1567-1578.

Conard, S.G., J.L. Beyers, and P.M. Wohlgemuth. 1995. Impacts of postfire grass seeding on chaparral systems - what we know and where do we go from here? Pp. 149-161 in J.E. Keeley and T.A. Scott, eds. Brush fires in California wildlands: ecology and resource management. International Association of Wildland Firc, Fairficld, WA.

Davis, C.M. 1994. Changes in succession after anthropogenic mechanical disturbance in coastal sage scrub. M.S. thesis. San Diego State University, San Diego, CA.

Eliason, S.A. and E.B. Allen. 1997. Exotic grass competition in suppressing native shrubland reestablishment. Restoration Ecology 5: 245-255.

Environmental Protection Agency. 1996. Breathing easier: 1996. A report on air quality in EPA Region 9. http://www.epa.gov/ region09/air/breath96/index.html.

Forman, R.T.T. 1995. Land mosaics: the ecology of landscapes and regions. Cambridge University Press, Cambridge, UK.

Fox, M.D., and B.J. Fox. 1986. The susceptibility of natural communities to invasion. Pp. 57-67 in R.H. Groves, and J.J. Burdon, eds. Ecology of biological invasions. Cambridge University Press, Cambridge, U.K.

Freudenberger, D.O., B.E. Fish, and Keeley J.E. 1987. Distribution and stability of grasslands in the Los Angeles basin. Bulletin of the Southern California Academy of Sciences 86:13-26.
Heady, H.F. 1977. Valley grasslands. Pp. 491-514 in G. Barbour and J.Majors, eds. Terrestrial vegetation of California. Wiley and Sons, New York, NY.

Hillyard, D. and M. Black. 1987. Coastal sage scrub restoration (California). Restoration \& Management Notes 5:96.

Ingham, E.R., D.C. Coleman, and J.C. Moore. 1989. An analysis of food-web structure and function in a shortgrass prairie, a mountain meadow, and a lodgepole pine forest. Biology and Fertility of Soils 8:29-37.

Keeley, J.E. and S.C. Keeley. 1984. Postfire recovery of California coastal sage scrub. American Midland Naturalist 111:105-117.

Keeley, J.E. 1991. Seed germination and life history syndromes in the California chaparral. Botanical Review 57:81-116.

Kirkpatrick, T.B. and C.F. Hutchinson. 1977. The community composition of California coastal sage scrub. Vegetatio 35: 21-33.

Klopatek, J.M., R.J. Olsen, C.J. Emerson, and J.L. Joness. 1979. Land use conflicts with natural vegetation in the United States. Environmental Conservation 6:191-199.

Malanson, G.P. 1985. Simulation of competition between alternative shrub life history strategies through recurrent fires. Ecological Modeling 27:271-283.

Malo, J.E. and F. Suarez. 1995. Cattle dung and the fate of Biserrula pelecinus L. (Leguminosae) in a Mediterranean pasture: seed dispersal, germination and recruitment. Botanical Journal of the Linnean Society 118:139-148.

Marquez, V.J. and Allen, E.B. 1996. Ineffectiveness of two annual legumes as nurse plants for establishment of Artemisia californica in coastal sage scrub. Restoration Ecology 4:4250.

Miller, P.R., J.R.J. Parmeter, O.C. Taylor, and E.A. Cardif. 1963. Ozone injury to the foliage of Pinus ponderosa. Phytopathology 53:1072-1076.

Minnich, R.A. 1988. The biogeography of fire in the San Bernardino Mountains of California. University of California Publications, Geography 28:36-40.

Minnich, R.A. and R.J. Dezzani. 1998. Historical decline of coastal sage scrub in the Riverside-Perris Plain, California. In T.A. Scott and J.T. Rotenberry, eds. Proceedings of the Symposium on the California Gnatcatcher. Studies in Avian Biology, Monograph Series. Cooper Ornithology Society, in press.

O'Leary, J.F. 1990. Postfire diversity patterns in two subassociations of California coastal sage scrub. Journal of Vegetation Science 1:173-180.

O'Leary, J., D. Murphy, and P. Brussard. 1992. The coastal sage scrub community conservation planning region. Natural Community Conservation Planning/Coastal Sage Scrub Special Report No. 2. California Environmental Trust, San Francisco.

Pavlik, B.M., D.L. Nickrent, and A.M. Howald. 1993. The recovery of an endangered plant. I. Creating anew population of Amsinckia grandiflora. Conservation Biology 7:510-526.

Robinson, J.W. and B.D. Risher. 1993. The San Jacintos. Big Santa Anita Historical Society, Arcadia, California.

Schultz, G.P. 1996. Seedling establishment and competition in coastal sage scrub and annual grassland. M.S. thesis. University of California, Riverside CA. 
Skinner, M.W. and Pavlik, B.M. 1994. CNPS inventory of rare and endangered vascular plants of California. California Native Plant Society, Sacramento, CA.

Soulé, M.D., D.T. Bolger, A.C. Alberts, R. Sauvajot, J. Wright, M. Sorice, and S. Hill. 1988. Reconstructed dynamics of rapid extinctions of chaparral-requiring birds in urban habitat islands. Conservation Biology 2: 75-92.

Vitousek P.M. and L.R. Walker. 1989. Biological invasion by Myrica faya in Hawaii - plant demography, nitrogen fixation, ecosystem effects. Ecological Monographs 59:247-265.

Wedin, D.A. and D. Tilman 1990. Species effects on nitrogen cycling: a test with perennial grasses. Oecologia 84:433-441.

Wedin, D.A. and D. Tilman. 1996. Influence of nitrogen loading and species composition on the carbon balance of grasslands. Science 274:1720-1723.

Wellburn, A.R. 1990. Why are oxides of nitrogen usually phytotoxic and not alternative fertilizers? New Phytologist 115:395-429.

Wells, P.V. 1962. Vegetation in relation to geological substratum and fire in the San Luis Obispo Quadrangle, California. Ecological Monographs 32:79-103.
Westman, W.E. 1981. Factors influencing the distribution of species of coastal sage scrub. Ecology 62:439-455.

Westman, W.E. 1990. Detecting early signs of regional air pollution injury to coastal sage scrub. Pp. 323-345 in G.M. Woodwell, ed. The earth in transition: patterns and processes of biotic impoverishment. Cambridge University Press, New York, NY.

Westman, W.E. and J.F. O'Leary. 1986. Measures of resilience: the response of coastal sage scrub to fire. Vegetatio 65:179189.

White, P.S. and J.L. Walker. 1997. Approximating nature's variation: selecting and using reference information in restoration ecology. Restoration Ecology, 5:338-349.

Williams, K. and R.J. Hobbs. 1989. Control of shrub establishment by springtime soil water availability in an annual grassland. Oecologia 81:62-66.

Zedler, P.H.,C.R. Gautier, and G.S. McMaster. 1983. Vegetation change in response to extreme events: the effect of a short interval between fires in California chaparral and coastal sage scrub. Ecology 64:809-818.

Zink, T.A. and M.F. Allen. 1998. The effects of organic amendment on the restoration of a disturbed coast sage scrub habitat. Restoration Ecology, 6:52-58.

Zink, T.A., M.F. Allen, B.I. Heindl-Tenhunen, and E.B. Allen. 1995. The effect of a disturbance corridor on an ecological reserve. Restoration Ecology 3:304-311. 


\title{
Recovery of Coastal Sage Shrub Species After Mechanical Disturbance
}

\author{
Marcia G. Narog, Jan L. Beyers, Timothy E. Paysen and Bonni M. Corcoran \\ USDA Forest Service, Pacific Southwest Research Station, Forest Fire Laboratory, Riverside, CA 92507 \\ Tel. (909) 680 1527; Fax(909) 680 1501; e-mail: mnarog/psw_rfl@fs.fed.us
}

\begin{abstract}
Coastal sage scrub has been replaced by urban and agricultural development in much of southern California. California gnatcatchers (Polioptila californica californica), federally listed as "Threatened," occur almost exclusively in this vegetation type; their survival may depend on restoration of degraded habitat. A 1985 outplanting of five shrub species typical of coastal sage scrub (Artemisia californica, Encelia farinosa, Eriogonum fasciculatum, Salvia apiana, and S. mellifera) was inadvertently cleared of all above ground plant material in 1991. The site was protected from further disturbance, and all species re-established from root crown sprouts or seeds. In fall 1995, we measured and harvested all plants. Grasses, forbs and an introduced ice plant were also present. More than 99 percent of shrubs measured were alive. Artemisia californica was the most abundant shrub and had the greatest cover. Mean shrub height was less than $1 \mathrm{~m}$, although some shrubs reached almost $2 \mathrm{~m}$. Eriogonum fasciculatum had the greatest shrub biomass. Combined grass and litter made up 39 percent of above ground biomass. Increases in plant density and changes in species relative abundance were observed. After this second mechanical disturbance, resprouts of the five shrub species were observed within 1 month after harvest. All outplanted species were resilient to mechanical disturbance.
\end{abstract}

Keywords: Gnatcatcher; restoration; revegetation.

\section{Introduction}

Coastal sage scrub occupies a narrow elevational band generally below $1,200 \mathrm{~m}$ between valley grasslands and higher elevation chaparral in southern California. This plant community, dominated by drought tolerant shrubs, is a subgroup of the soft chaparral vegetation type described by Paysen et al. (1980). Coastal sage scrub has been divided into sub-associations based on floristic composition and geographical factors (Kirkpatrick and Hutchinson 1977; Axlerod 1978; Westman 1981b; Saw- yer and Keeler-Wolf 1995). The southern California subassociations are Riversidian (inland), Diegan (Baja-influenced), and Venturan (northern) sage scrub; they usually include species of Artemisia, Encelia, Eriogonum, and Salvia as dominant shrubs (Westman 1983).

Coastal sage scrub has been replaced by agricultural and urban development throughout much of its range (Westman 1981a; Bowler 1990). Frequent fires at the urban interface, where this vegetation is commonly found, may further reduce its range through type-conversion to grassland (Zedler et al. 1983; Malanson 1985a; Westman 1987). Animal species dependent on this vegetation type are also affected. For example, the California gnatcatcher (Polioptila californica californica), a small songbird federally listed as "threatened," occurs almost exclusively within this vegetation type (Atwood 1993). The orangethroated whiptail (Cnemidophorus hyperythrus), San Diego horned lizard (Phrynosoma coronatum blainvillei), rufous-crowned sparrow (Aimophila ruficeps canescens), and coastal cactus wren (Campylorhynchus brunnecapillus couesi) are other animal species found in the coastal sage scrub that have been proposed for listing or are of special concern to biologists. Efforts to restore degraded coastal sage scrub may be necessary to provide sufficient habitat for the continued survival of this bird and other species.

Coastal sage scrub restoration is required as a mitigation for development in many areas of southern California. However, Bowler (1990) pointed out that few successful restorations are available to serve as models for others. Consequently, observations of coastal sage scrub recovery and regeneration can add to this limited information base. Coastal sage scrub can be quite resilient to disturbance. Westman (1987) noted, coastal sage scrub that has "....been bulldozed, irrigated, fertilized, sprayed with herbicides, and planted with exotic species can return to a semblance of native sage scrub within 1 to 2 decades if such disturbances cease..." (p. 138-139). He based these observations on coastal sage scrub located near Los Angeles (Westman 1976). Whether other areas respond similarly has not been documented. 
Most information concerning coastal sage scrub recovery from disturbance comes from fire effects studies. Coastal sage scrub response to mechanical disturbance compared to fire response has not been studied. Coastal sage shrubs are generally resilient to disturbance by fire if it is not too frequent (Malanson 1985b; Westman and O'Leary 1986). Malanson and O'Leary $(1982,1985)$ found that site-specific fire conditions (e.g., fire intensity) did not alter post-fire shrub regeneration success. They observed that most immediate postfire regeneration occurred by sprouting rather than by seed bank germination. They hypothesized that most coastal sage scrub seeds do not survive heating by fire. Myers and Ellstrand (1986) studied coastal sage scrub at an inland site and found no resprouting after fire; site recovery was slow compared to rates observed at coastal locations. Inherent differences in sprouting ability may also affect coastal sage scrub recovery. For example, Eriogonum fasciculatum may sprout less readily than other species (Westman et al. 1981; Malanson and O'Leary 1982). As O'Leary (1990) pointed out, much still needs to be learned about fire in coastal sage scrub.

We had the opportunity to assess the response of five coastal sage scrub species to mechanical disturbance after an experimental out-planting was accidentally cleared by a weed control effort. The removal was so thorough that no visible seeds or intact root bases were observed. The stand regenerated over the next 4 years. When the site was slated for facility construction, we harvested the plants and compared the regenerated stand to the initial plantings. This paper documents changes in species relative abundance and cover, plant density, and in community structure between the original planting and the final destructive harvest. Along with assessing recovery from mechanical disturbance, we gained insight into possible stand dynamics among some coastal sage shrub species that could occur in restoration plantings.

\section{Site Description and History}

In 1985, five species typical of Riversidian sage scrub (Artemisia californica, Encelia farinosa, Eriogonum fasciculatum, Salvia apiana, and S. mellifera) were outplanted in a native California plant garden at the Forest Fire Laboratory in Riverside, California ( $33^{\circ} 58^{\circ} \mathrm{N}, 117^{\circ}$ 20'W, Riverside East quadrangle, T.2.S., R.4.W., S.30) at $345 \mathrm{~m}$ elevation $(1,050 \mathrm{ft}$.). The soil is unamended Arlington loam (Knecht 1971), which historically and presently supports agricultural and urban development. The nearest natural coastal sage scrub stand was about 1 $\mathrm{km}$ away, separated from the study area by dense urban development. An established chamise (Adenostoma fasciculatum) out-planting was located several meters from the coastal sage shrubs. Twelve individuals of each of the five shrub species were planted from 1 -gallon nursery-grown stock (source population unknown) in an irregular pattern with $1 \mathrm{~m}$ triangle design spacings (Fig. 1). Drip irrigation was initially supplied to ensure plant establishment; it was later discontinued. No records were kept on the duration or frequency of the supplemental watering. The 60 plants and their progeny ultimately expanded into a stand that occupied an area approximately $10 \mathrm{~m} \times 14 \mathrm{~m}$.

The initial out-planting was occasionally weeded of exotic grasses, forbs and most volunteer seedlings. When

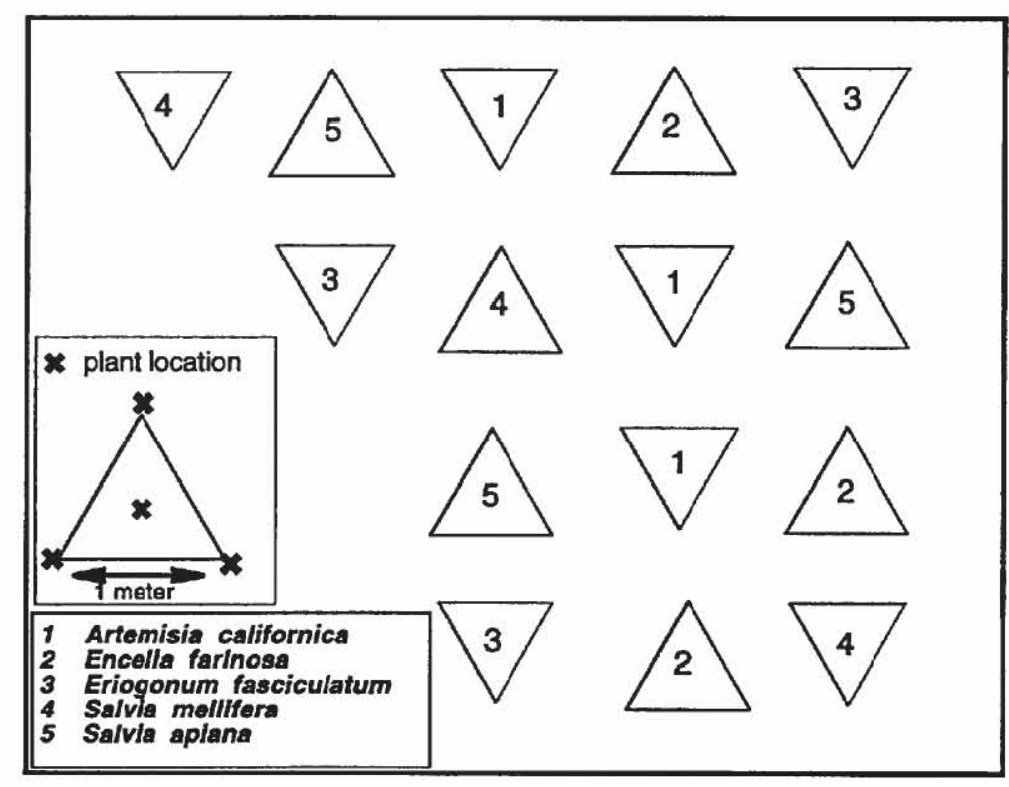

Fig. 1. Twelve each of five species of California coastal sage shrubs (Artemisia californica, Eriogonum fasciculatum, Encelia farinosa, Salvia mellifera, S. apiana) were outplanted in a $1 \mathrm{~m}$ triangle design at the USDA Forest Service, Forest Fire Laboratory in Riverside, CA in 1985. 
shrubs died, they were replaced with new stock to maintain a total of 60 individuals in the stand. In the fall of 1991, when all above-ground portions of the shrubs were inadvertently removed in a "weed control" effort. Some below-ground plant parts were also removed. Shortly thereafter, some shrubs began to resprout. The site was intermittantly watered with overhead sprinklers for a few months and was subsequently protected from further disturbance. After several supplemental waterings, the site received only rainfall. Non-native grasses and forbs initially dominated the site, but there was continued evidence of shrub establishment from seeds and remnant shrub rootcrowns.

During the four years between the weeding disturbance and when our sampling began, all five out-planted shrub species re-established from sprouts or seeds. Because no documentation was made on individual shrubs, it was not possible to determine which shrubs regenerated vegetatively from the original plants after the disturbance and which originated as seedlings. Resprouting from both root bases and major branches further confounded the original planting design. Therefore, we were unable to assign plants to specific age classes.

In October 1995, before facility construction clearing, we inventoried and harvested all plants to evaluate stand recovery and resilience of the five coastal sage shrub species.

\section{Methods}

To facilitate sampling, the $14 \mathrm{~m} \times 10 \mathrm{~m}$ plot was partitioned into $1401-\mathrm{m}^{2}$ cells. The five species of coastal sage shrubs originally planted, plus grasses, forbs, and an exotic ice plant, Galenia pubescens (Aizoaceae), grew in this plot. Species identity, location, and size (height and cover - two perpendicular canopy diameters) of each shrub were recorded. All above-ground plant material was then harvested by systematically clipping each plant at the soil surface and consolidating biomass for each species from each cell.

At the time of harvest, many shrubs were in a summer drought-dormant state and close scrutiny was needed to determine if individuals were dead. Stem hydration, determined by examining the clipped stems of each plant, was used to judge if each plant was alive.

Total above-ground biomass was determined gravimetrically for each species harvested. Individual plants of each species were combined and put into paper bags for each of the $1-\mathrm{m}^{2}$ cells. Biomass was oven dried at $85^{\circ} \mathrm{C}$ until no further weight loss was recorded (three to four days).

Supplemental water and rainfall may affect shrub reproduction, resprout and germination response. Precipitation data from the weather station located at the University of California, Riverside (Multi-agency Fire

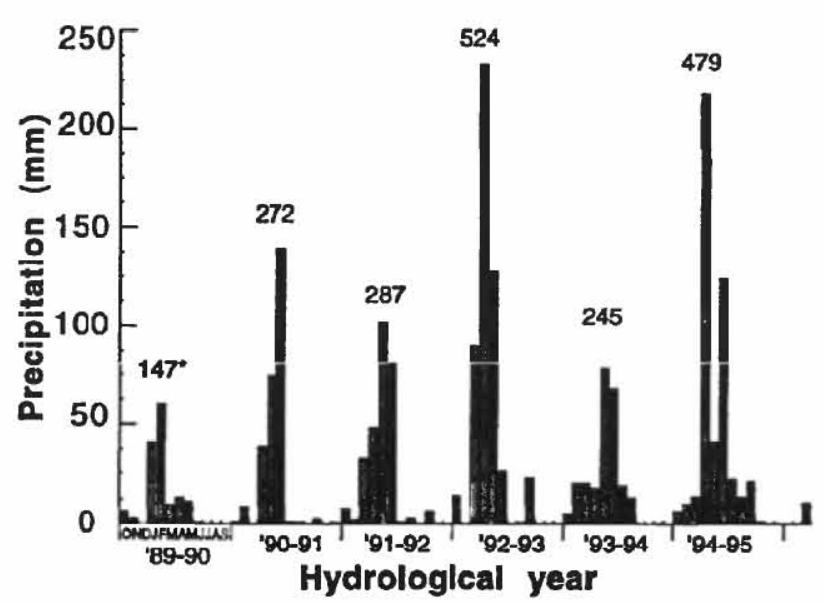

Fig. 2. Monthly and *annual precipitation totals for Riverside, CA for hydrologic years 1989-90 through 1994-95. The long term average for this site is $250 \mathrm{~mm}$ (10 in) per year (University of California, Riverside, Multiagency Fire Weather Unit 1997).

Weather Unit 1997) were used to determine how much rainfall the coastal sage scrub stand received. Average annual precipitation for this location is $250 \mathrm{~mm}$ (10 in) per hydrologic year (October through September). Typical of the Mediterranean climate zone, rain generally fell during winter and spring and was followed by summer drought (Fig. 2). Drought conditions with about half the expected annual rainfall occurred in 1989-90. In contrast, precipitation about twice the annual average occurred in 1992-93 and 1994-95. Only trace amounts of rain fell during the three months prior to plant harvest in 1995.

\section{Results}

All shrub species increased in number and density over time (Table 1). The 140- $\mathrm{m}^{2}$ stand contained 1,982 shrubs for an average density of 14.2 shrubs $\mathrm{m}^{-2}$. Even the least abundant species, Salvia apiana, had over three times the number of individuals as were originally planted. Over

Table 1. Plant abundance, density, relative cover, and total biomass by species at final harvest in a $10 \mathrm{~m} \times 14 \mathrm{~m}$ coastal sage scrub plot located at the USDA Forest Service, Forest Fire Laboratory in Riverside, CA. The initial outplanting consisted of 12 individuals of five shrub species.

\begin{tabular}{llcc}
\hline Species & $\begin{array}{c}\text { Density } \\
\left(\# \mathrm{~m}^{-2}\right)\end{array}$ & $\begin{array}{c}\text { Relative } \\
\text { cover }(\%)\end{array}$ & $\begin{array}{c}\text { Biomass } \\
\mathrm{g} \mathrm{m}^{-2}\end{array}$ \\
\hline Artemisia californica & 8.04 & 68.5 & 238 \\
Encelia farinosa & 0.91 & 2.0 & 285 \\
Eriogonum fasciculatum & 4.2 & 7.7 & 397 \\
Salvia apiana & 0.27 & 1.5 & 29 \\
Salvia mellifera & 0.75 & 6.8 & 34 \\
Galenia pubescens & 0.46 & 0.5 & 14 \\
Forbs & 0.23 & 1.7 & 3 \\
Grass/litter & - & 10.6 & 598 \\
\hline
\end{tabular}




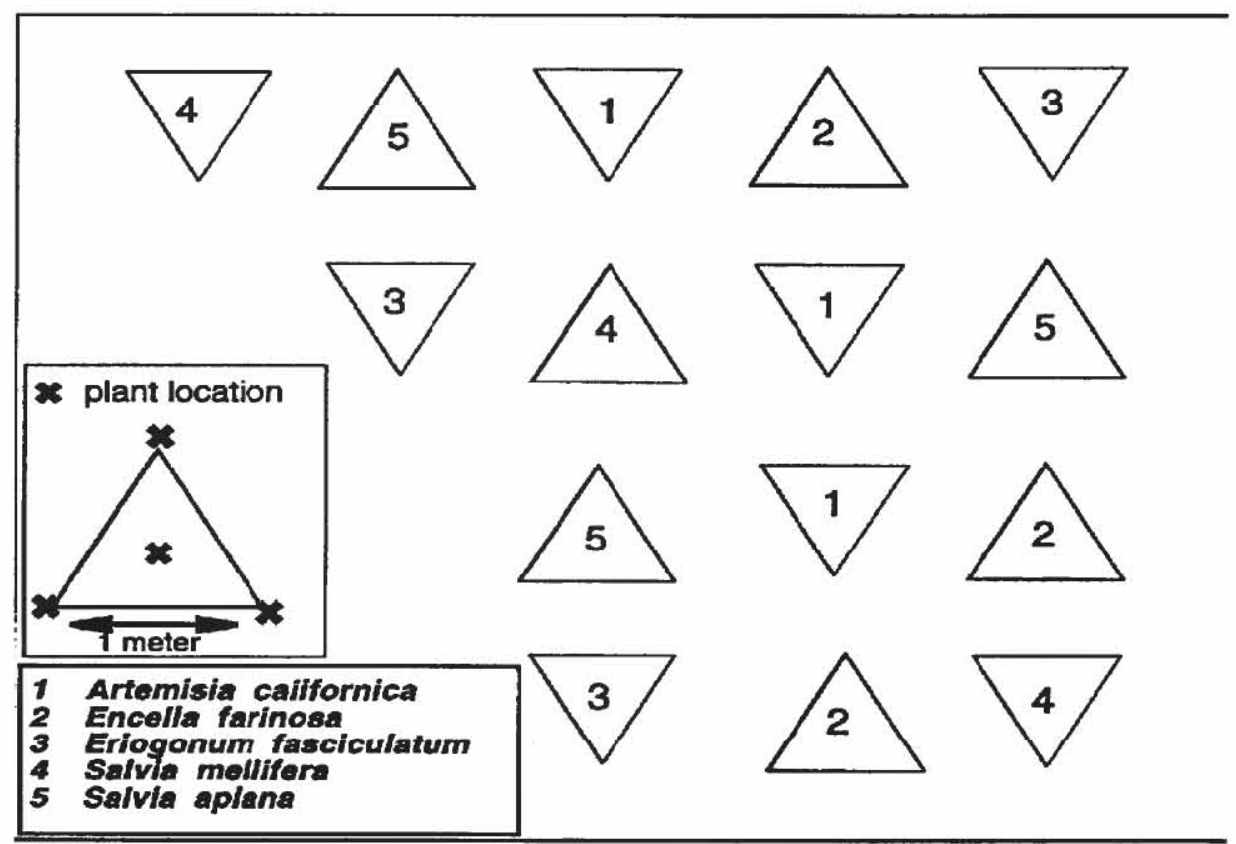

Fig. 3. Relative species abundance of outplanted (initial) and harvested (final) individuals of five species of coastal sage shrubs (Artemisia californica, Eriogonum fasciculatum, Encelia farinosa, Salvia mellifera, S. apiana). Ten years elapsed betwen initial planting and final harvest.

99 percent of the coastal sage shrubs harvested and measured were alive. Of the standing shrubs measured, only two Artemisia californica, six Salvia apiana, and one $S$. mellifera were dead. Relative abundance of shrubs shifted from the original planting of equal numbers of shrubs (Fig. 3); A. californica was the most abundant, representing 56.8 percent of shrubs. Eriogonum fasciculatum, the second most abundant shrub, comprised 29.5 percent, and the other three species combined amounted to 13.6 percent.

At the time of harvest, large shrub canopies overlapped throughout the plot. Many small shrubs, with few or no branches, grew among grass under larger shrub canopies. Mean shrub height was $0.61 \mathrm{~m} \pm 0.33$ (standard deviation), and ranged from $1 \mathrm{~cm}$ branchless seedlings to 1.9 $\mathrm{m}$ shrubs with spreading canopies (Fig. 4). Small statured shrubs were the most abundant as shown by their high numbers in the smallest cover size classes (Fig. 5). Artemesia californica had the greatest number of individuals and composed 79 percent of the shrub cover (Table 1). The most woody of the shrubs, E. fasciculatum, only had about 8 percent of the shrub cover, yet it accounted for 41 percent of the shrub biomass. Total combined standing shrub dry weight was $136.4 \mathrm{~kg}\left(973.9 \mathrm{~g} \mathrm{~m}^{-2}\right)$, or 61 percent of total biomass $\left(158.8 \mathrm{~kg} \mathrm{~m}^{2}\right)$ collected in the plot.

Grasses (mostly Bromus and Avena spp.), forbs (mostly Brassica and Erodium spp.), and a locally introduced ice plant, Galenia pubescens, established in the plot, as did one seedling chamise (Adenostema fasciculatum). They, along with some leaf litter, accounted for $86.0 \mathrm{~kg}$ $\left(614.6 \mathrm{~g} \mathrm{~m}^{-2}\right)$ of dry biomass, or 39 percent of the total collected from the plot. Except for Galenia pubescens and Adenostema fasciculatum, these non-focal species were common throughout the plot. About 12 percent of the $140 \mathrm{~m}^{2}$ area was bare ground.

Some individuals of the five coastal sage shrub species resprouted 1 month following the final October 1995 harvest, but no follow-up measurements were made due to site development.

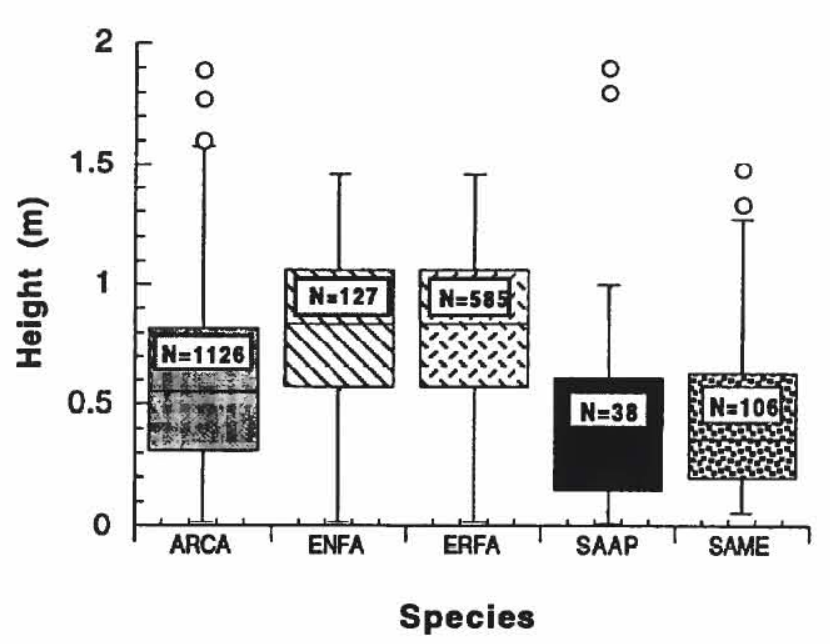

Fig. 4. Box and whisker plots showing the distribution and range of shrub heights for each of five coastal sage shrub species (Artemisia californica, Eriogonumfasciculatum, Enceliafarinosa, Salvia mellifera, S. apiana) at final harvest at the USDA Forest Service, Forest Fire Laboratory in Riverside, CA. Median height for the shrubs in the stand was $0.6 \mathrm{~m}$. 


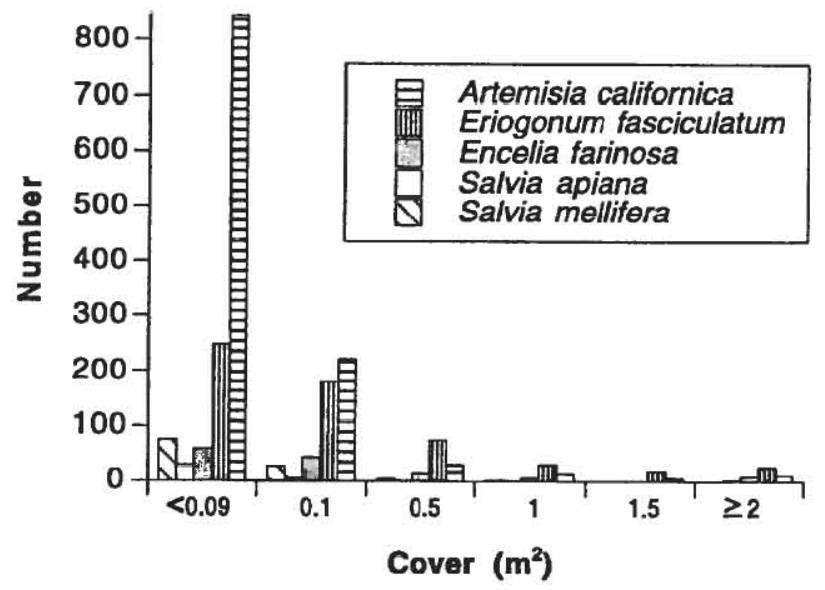

Fig. 5. Number of individual shrubs in each of six cover size classes for five coastal sage shrub species (Artemisia californica, Eriogonum fasciculatum, Encelia farinosa, Salvia mellifera, S. apiana) harvested from a $10 \mathrm{~m} \mathrm{x} 14 \mathrm{~m}$ plot located at the USDA Forest Service, Forest Fire Laboratory in Riverside, CA. Cover was calculated from two perpendicular diameter measures.

\section{Discussion}

Following severe mechanical disturbance, the five coastal sage shrub species in this case study readily regenerated with resprouts and seedlings. It is highly unlikely that off-site seed sources contributed to re-establishment of this stand because no coastal sage shrub parcels were in close proximity to our plot. Shrubs re-established solely from on-site seeds and roots.

Supplemental watering immediately following mechanical disturbance undoubtedly enhanced initial regeneration and survival of our coastal sage shrubs and could have affected species dominance in the stand. Water availability or periods of drought affect plant reserves and resource allocations, which influence production of vegetative growth, reproduction, or quality and quantity of seeding (Larcher 1995). The influence of drought year 198990 on sced production and reserves in the soil prior to site disturbance is important, but no tests were made. The above normal rainfall year (1990-91) undoubtedly affected shrub hydration prior to the mechanical disturbance, but again tests were not made. Multiple wet years most likely enhanced seed germination and resprout success. The high number of small shrubs, particularly Artemisia californica and Eriogonum fasciculatum, may reflect the abundant natural precipitation (Figs. $2 \& 5$ ). Adequate annual precipitation, shelter beneath the shade of large shrub canopies, and abundant grasses and forbs, created an environment where many small statured shrubs survived in a summer drought-dormant state.

Malanson and Westman (1985) developed a model showing that strong post-fire resprouters should dominate after repeated short intervals between fires in Venturan and Riversidian coastal sage scrub. Westman and O'Leary
(1986) evaluated resilence models using four of the five species that we studied. Artemisia californica, Eriogonum fasciculatum, and Salvia mellifera were considered weak resprouters, and Ericelia farinosa was considered a strong resprouter. They suggested that the model should be valuable for both fire and mechanical disturbance. In contrast, we found Artemisia californica and Eriogonum fasciculatum dominated on our mechanically disturbed site. The success of these two species appears to be due to abundant seedling establishment. Similar trends were seen in a coastal sage scrub study in which Artemisia californica became dominant on a disturbed and irrigated site (Westman 1976). Factors that favored dominance of purportedly weak resprouters on our site include: lack of fire, time interval after disturbance, disturbed root bases, seed bank, or available water. Density and dominance may have continued to change if our young stand had remained undisturbed.

Westman and O'Leary (1986) modeled coastal sage scrub sites following disturbance by fire and found inland sites less resilient than coastal sites. The species studied here, although not treated with fire, proved highly resilient to mechanical disturbance. It is not clear whether this is a result of environmental conditions (e.g., supplemental water or favorable rainfall) or possible coastal genotype origins of the purchased shrubs. Common garden studies are needed to separate the effects of climate and genetic origin (i.e., inland vs. coastal) of the different sage scrub species and their ability to respond to disturbance.

Stand biomass was similar to that reported elsewhere for coastal sage scrub, but stand structure differed. Gray and Schlesinger (1981) reported biomass of $1,417 \mathrm{~g} \mathrm{~m}^{-2}$ for 22 year old coastal sage scrub compared to our stand biomass of $1,587 \mathrm{~g} \mathrm{~m}^{-2}$. They also measured a combined shrub density of about 2.5 shrubs $\mathrm{m}^{-2}$ for their site. Our site changed from the original planting average of 0.4 shrubs $\mathrm{m}^{-2}$ to about 14 shrubs $\mathrm{m}^{-2}$ at harvest. Within four years, this mixed aged coastal sage scrub closed canopy stand of uneven shrub structure had developed and become established from the two regeneration strategies, resprouting and seeding. Our young stand contained a high number of small individuals. With time, it may have changed in composition as fewer, larger individuals eventually became dominant.

The change in species composition in our artificial coastal sage scrub stand suggests that restoration projects involving planted stock could also experience changes in dominance. Abundant rainfall and irrigation appeared to have favored Artemisia californica and Eriogonum fasciculatum. Restorationists wishing to create a stand dominated by other species may need to reduce the planting ratio of these two shrubs, particularly if irrigation is used. A different community composition might result if drought conditions prevail. 
The species composition and ratio of the herbaceous component may differ in native stands and could affect shrub species dominance. Non-native annual grasses and forbs made up a sizeable portion of stand biomass (39 percent including leaf litter) in our plot. Wildland stands of coastal sage scrub contain a substantial herbaceous component (Keeley and Keeley 1984; O'Leary and Westman 1988; Read 1994). Eliason and Allen (1994) observed that non-native grass competition depressed growth and survival of Artemisia californica seedlings. Despite the abundance of grass and forbs in our plot, shrub sprouting and seedling recruitment continued, particularly for Artemisia californica. As speculated above, the additional water and increased precipitation may have improved shrub survival. Obviously, further investigations are needed to evaluate the impact of the herbaceous component on the success of coastal sage scrub species.

A close association exists between coastal sage scrub and chaparral, not only in proximity but shared herbaceous species (Westman 1979). Adenostema fasciculatum sometimes grows nearby or in naturally occurring coastal sage scrub communities. Zedler et. al. (1983) suggested that coastal sage scrub would invade the gaps made by fire in a chaparral site in San Diego County. The occurrence of one seedling of Adenostema fasciculatum in the coastal sage scrub plot was unexpected given that Adenostema fasciculatum seedlings were never observed at our native garden site during the 12 years that we maintained it. Conditions in the sage scrub stand were apparently more favorable for Adenostema fasciculatum seedling establishment. Whether the seedling would have persisted or eventually been displaced by the coastal sage shrubs we can not say. However, this suggests that chaparral species with non-refractory seeds (Keeley 1991) could invade isolated or disturbed coastal sage scrub stands quite early in stand regeneration.

\section{Conclusions}

Five outplanted coastal sage shrub species showed resilience to severe mechanical disturbance. Supplemental water and favorable rainfall may have facilitated successful regeneration and reduced mortality at this site. Species composition in the artificial stand changed through time, and Artemisia californica became the dominant shrub for both abundance and cover. We found that a substantial herbaceous understory did not stop these coastal sage shrub species from germinating, resprouting or from gaining dominance. Response of coastal sage scrub to mechanical disturbance at other sites could be different depending on existing weather conditions, species associations, or genomes. Restoration projects may benefit from combining rooted stock, seeds and supplemental watering. Obviously, more research is needed to further address recovery of this variable and dynamic coastal sage scrub.
Acknowledgments. We thank Eugene Hanson, Santiago Herrera, Dave Madden, Ginger Pena, and Bridget Thurman for their help with field sampling and data entry. We appreciate the technical reviews by Dr. Ruth Wilson, Dr. Arlee Montalvo and Melody Lardner; their suggestions greately improved the manuscript.

\section{Literature Cited}

Atwood, J.W. 1993. California gnatcatchers and coastal sage scrub: the biological basis for endangered species listing. Pp 149-169 in J.E. Keeley, ed. Interface between ecology and land development in California. Southern California Academy of Sciences, Los Angeles, CA.

Axelrod, D.I. 1978. The origin of coastal sage vegetation, Alta and Baja California. American Journal of Botany 65:1117-1131.

Bowler, P. A. 1990. Coastal sage scrub restoration-II: the challenge of mitigation. Restoration and Management Notes 8:7882.

Eliason, S.A. and E.B. Allen. 1994. Competition for soil water between Mediterranean annual grasses and Artemisia californica in southern California coastal sage scrub. Supplement to the Bulletin of the Ecological Socicty of America 75:61.

Gray, T.J. and W.H. Schlesinger. 1981. Biomass, production, and litterfall in the coastal sage scrub of southern California. American Journal of Botany 68:24-33.

Keeley, J.E. 1991. Seed germination and life history syndromes in the California chaparral. Botanical Review 57:81-117.

Keeley, J.E. and S.C. Keeley. 1984. Postfire recovery of Californiacoastal sage scrub. American Midland Naturalist 111:105117.

Kirkpatrick, J.B. and C.F. Hutchinson. 1977. The community composition of California coastal sage scrub. Vegetatio 34:2133.

Knecht, A.A. 1971. Soil survey of western Riverside area, California. Cartographic Division, Soil Conservation Service, U.S. Department of Agriculture, Washington, D. C. 157 p.

Larcher, W. 1995. Physiological plant ecology, ecophysiology and stress physiology of functional groups. 3rd ed. SpringerVerlag. New York, NY.

Malanson, G.P. 1985a. Fire management in coastal sage-scrub, southern California, USA. Environmental Conservation 12:141-146.

Malanson, G.P. 1985b. Simulation of competition between alternative shrublife history strategies through recurrent fires. Ecological Modelling 23:271-283.

Malanson, G.P. and J.F. O'Leary. 1982. Post-fire regeneration strategies of Californian coastal sage shrubs. Oecologia 53:355358.

Malanson, G.P. and J.F. O'Leary. 1985. Effects of fire and habitat on post-fire regeneration in Mediterranean-type ecosystems: Ceanothus spinosus chaparral and Californian coastal sage scrub. Oecologia Plantarum 6:169-181.

Malanson, G.P. and W.E. Westman. 1985. Postfire succession in California coastal sage scrub: the role of continual basal sprouting. American Midland Naturalist 113:309-318.

Multi-agency Fire Weather Unit. 1997. University of California, Riverside, Riverside, CA. 
Myers, M.A. and N.C. Ellstrand. 1986. Post-fire succession at an inland (Riversidean) site of coastal sage scrub: variation in community response. Pp. 129-132 in J.J. DeVries, ed. Proceedings of the chaparral ecosystems research conference May 16-17, 1985, California. California Water Resources Center, Davis, CA.

O'Leary, J.F. 1990. Californian coastal sage scrub: general characteristics and considerations for biological conservation. Pp 24-39 in A. A. Schoenherr, ed. Endangered plant communities of southern California. Southern California Botanists Special Publication No. 3. Claremont, CA.

O'Leary, J.F. and W.E. Westman. 1988. Regional disturbance effects on herb succession patterns in coastal sage scrub. Journal of Biogeography 15:775-786.

Paysen, T.E., J.A. Derby, H. Black, Jr., V.C. Bleich, and J.W. Mincks. 1980. A vegetation classification system applied to southern California. USDA Forest Service, General Technical Report PSW-45.

Read, E.A. 1994. The importance of community classification to mitigation and restoration of coastal sage scrub. Restoration Ecology 2:80-86.

Sawyer, J.O. and T. Keeler-Wolf. 1995. A manual of California vegetation. California Native Plant Society, Sacramento, C^.

Westman, W.E. 1976. Vegetation conversion for fire control in Los Angeles. Urban Ecology 2:19-137.

Westman, W.E. 1979. A potential role of coastal sage scrub understories in the recovery of chaparral after fire. Madrono 26:64-68.
Westman, W.E. 1981a. Diversity relations and succession in Californian coastal sage scrub. Ecology 62:170-184.

Westman, W.E. 1981b. Factors influencing the distribution of species of Californian coastal sage scrub. Ecology 62:439455.

Westman, W.E. 1983. Xeric mediterranean-type shrubland associations of Alta and Baja California and the community/ contiuum debate. Vegetatio 52:3-19.

Westman, W.E. 1987. Implications of ecological theory for rare plant conservation in coastal sage scrub. Pp. 133-139 in T.S. Elias, ed. Conservation and management of rare and endangered plants. California Native Plant Society, Sacramento, CA.

Westman, W.E. and J.F. O'Leary. 1986. Measures of resilience: the response of coastal sage scrub to fire. Vegetatio 65:179189.

Westman, W.E., J.F. O'Leary, and G.P. Malanson. 1981. The effects of fire intensity, aspect and substrate on post-fire growth of California coastal sage scrub. Pp. 151-179 in N.S. Margaris and H.A. Mooney, eds. Components of productivity of mediterranean-climate regions: basic and applied aspects. W. Junk Publishers, The Hague.

Zedler, P.H., R.C. Gautier, and G.S. McMaster. 1983. Vegetation change in response to extreme events: the effect of a short interval between fires in California chaparral and coastal scrub. Ecology 64:809-818. 


\title{
Translocation and Grafting of Adult Coastal Cholla (Opuntia prolifera) and Coastal Prickly Pear (Opuntia littoralis) as Mitigation for Cactus Wren Habitat Loss in Burned Areas
}

\author{
Peter A. Bowler, Kenneth B. Pierce, Jr., Vanessa Beauchamp and Tarek Tabshouri \\ Department of Ecology and Evolutionary Biology, University of California, Irvine, CA 92697 \\ Tel. (714) 824-5183; Fax (714) 824-2181; e-mail: pabowler@uci.edu
}

\begin{abstract}
Large individuals of coastal cholla and prickly pear cacti were successfully re-established by cutting, callusing, then planting. Inter- and intraspecies grafting to construct suitable nest canopy habitats were attempted with varying success. Large coastal cholla and prickly pearcacti can be salvaged and translocated easily, which hastens cactus habitat recovery for cactus wrens and other cactus using species.
\end{abstract}

Keywords: Burned areas; Campylorhynchus brunneicapillus; coastal cholla; coastal cactus wren; coastal sage scrub; grafting; Opuntia littoralis; Opuntia prolifera; prickly pear cactus; restoration

\section{Introduction}

In many areas of coastal sage scrub in Orange County cacti are significant community components, both structurally and in terms of site specific cover and abundance. Although seven native cacti and the exotic Opuntia ficusindica have been reported (Roberts 1989), the primary species in coastal sage scrub are coastal prickly pear (Opuntia littoralis var. littoralis), oracle cactus (Opuntia oricola), and coastal cholla (Opuntia prolifera) In historically grazed habitats, prickly pear often becomes the dominant cover and structural element on south-facing, well drained slopes. In Venturan-Diegan sage scrub and other sage scrub subassociations in Orange County, the cactus wren (Campylorhynchus brunneicapillus) nests on Opuntia prolifera as well as on the flat padded prickly pear group, $O$. littoralis and $O$. oricola (Rea and Weaver 1990). The October, 1993 fires in the Laguna Coast Wilderness burned 2,755 hectares of coastal sage scrub (Bontrager et al. 1995), including a significant portion of the extant cactus habitat used by the cactus wren. Orange County is the center of distribution of the coastal cactus wren, and perhaps more than a quarter of the cactus wrens were lost when the habitat burned in 1993. Opuntia prolifera appears to be in decline in most of the preserved habitats in
Orange County and occurs in many small isolated stands.

Coastal sage scrub restoration efforts have usually used planted pads or segments when introducing cacti in habitat re-creations, and planted pads are a common element in roadside mitigations. Cactus has been used extensively in the Mediterranean Basin for browse and to prevent land degradation (Le Houérou 1996). Many cacti are relatively easy to transplant and marauding of desert habitats of cacti for commercial sale was the rationale for laws in many states denying collection of cacti from desert habitats in the public domain.

Transplantation has been attempted by local consulting firms using bulldozers, and, though successful in donor sites with deep soils, most sites are rocky and not conducive to the mechanical movement of cacti. Large, older plants of both prickly pear and cholla are fragile and collapse or lose pads/segments unless handled very gently, which is not possible using mechanized excavation. "Old growth" cacti of both prickly pear and cholla with stature sufficient to allow cactus wren nest building takes many years to develop when beginning from a single or even a branch with a few pads/segments. Thus, experimentation was undertaken to translocate very large, structural arms of prickly pear and intact, complete above-ground chollas. Surviving re-located plants could produce nestable and other cactus habitat decades in advance of the single pad/ segment approach.

\section{Methods}

In this study a series of experiments were attempted using established stands within the University of California, Irvine's Ecological Preserve and nearby Irvine Company lands. The initial phase of the project involved three experiments: the transplantation of mature $O$. littoralis, the transplantation of mature $O$. prolifera, and a small set of grafting trials to ascertain the feasibility of a large scale constructed cactus patch. A substantive stand of very large, old $O$. prolifera within an area destined for devel- 
opment this year, was used as stock for the transplantation.

\section{Translocation of large specimens of Opuntia littoralis}

Coastal prickly pear is abundant in the Ecological Preserve as well as in other areas on Irvine Company lands adjacent to the University campus. Specimens from several different stands on the University of California, Irvine Ecological Preserve were severed at the base and allowed to form calluses. Plants having heterogeneous architecture and relatively easy accessibility were chosen for the project. After three weeks, eight specimens were transported on a solid wooden gurney to the Berkeley Experimental Restoration Site on the University of California, Irvine Ecological Preserve. The callused ends were planted so that at least one quarter of the cactus was in the ground for support. The cacti were planted in a tight patch to emulate natural cactus stands. The patch was lightly watered every other week to maintain optimum growing conditions.

Ten cholla stems were added to the prickly pear patch using prescribed grafting techniques (Baker 1977; Brandt 1978). A small hole was cut with a drill bit into the prickly pear pad. The basal end of an $O$. prolifera stem was then cut and attached to the prickly pear with either a toothpick or bamboo skewer.

A second patch was planted approximately five months later with an additional 17 specimens that were callused for two weeks. No grafting was attempted. Cactus wrens were seen using the patch during courtship within two weeks of planting. This patch is located closer to natural cactus patches and larger than the earlier group.

After six months, all specimens from the first patch display vigorous flowering or cladode production. After one month, $70 \%$ of the second patch had initiated new growth or flowering. Three control cladodes were placed on the ground near the patch of eight specimens in accordance with normal vegetative reproduction. After six months all control cladodes were shriveled, yellowed, and exhibited only two stunted flower buds, which aborted.

\section{Translocation of large specimens of Opuntia prolifera}

Fourteen large (up to 2 meters in height) $O$. prolifera specimens were severed near the ground and transported to the Bison Experimental Restoration Site on the University of California, Irvine Ecological Preserve using an open wood frame gurney, which allowed the arms of the cactus to ride easily in the bed of a pickup. The specimens were gently placed on the ground and were left for six weeks to allow callus formation on the exposed tissue prior to planting. The ten largest specimens, between 0.5 and $2 \mathrm{~m}$ were "planted" in late January. One plant was shallowly planted and supported by reebar sunk into the ground. The other nine were planted in narrow holes of at least $20 \mathrm{~cm}$. in depth. Due to their size, awkward symmetry, and relative fragility, the largest specimens were difficult to handle. These plants were manipulated by using $15 \mathrm{~cm}$ c-clamps fully extended. The c-clamps provided rotating handles that allowed the plants to be supported according to each specimen's individual architecture. They were lifted into the holes and subsequently stood on their own. After two months, several of the specimens appeared to lose color and turgidity. After five months, without artificial watering, all specimens exhibited renewed vigor and new segment growth. This coincided with new growth on the natural stands of $\boldsymbol{O}$. prolifera on the University of California, Irvine Ecological Preserve.

\section{Grafting experiments on Opuntia prolifera} and Opuntia littoralis

Forty cactus grafts were constructed, ten in each of four disparate treatments. Opuntia prolifera segments were severed and grafted onto the same plant, onto another $O$. prolifera plant, and onto $O$. littoralis. Similarly, $O$. littoralis was severed and grafted onto itself (the same plant). Rubber bands and toothpicks were used in all of the grafting efforts involving $O$. prolifera. In the experiment in which $O$. littoralis was self-grafted only rubber bands were used because the severed portions had an excellent fit into the mother plant. Self-grafting was used as a control for physical fit into cuts in the plant and also as a control for genetic compatibility.

Table 1. Percentage success of different grafting regimes.

\begin{tabular}{lcc}
\hline Graft & $\%$ & $\mathrm{~N}$ \\
\hline O. littoralis on self & 87 & 8 \\
O. prolifera on self & 70 & 10 \\
O. prolifera on $O$. prolifera & 20 & 10 \\
O. prolifera on $O$. littoralis & 0 & 10 \\
\hline
\end{tabular}

The grafting trials in which a specimen was severed and then reattached at the cut were generally successful (Table 1). Grafts involving attachment to a different individual were less so, probably due to fitting problems, and interspecies grafts were particularly unsuccessful. It should be noted that, although largely unsuccessful, the $O$. prolifera grafts between individuals trials, 6 of the 10 grafts showed considerable new growth around the stalk. This was not evident in any of the trials involving a specimen grafted to itself. 


\section{Discussion}

Species of cacti such as $O$. prolifera and $O$. littoralis provide important habitat for many animals (Russell and Felker 1987). A minimum level of growth is required in order to provide the structural foundation for use by the local avifauna and other vertebrates. Cactus wrens in Orange and San Diego counties nested in cactus averaging $138 \mathrm{~cm}$ in height with nests around $96 \mathrm{~cm}$ (Rea and Weaver 1990). Opuntia littoralis provides browse for hares, wood rats, and many bird species. These species also use it for shelter and protection along with ground squirrels, quail and lizards (Mohamed-Yasseen et al. 1996). Normal restoration and mitigation methods for cactus species involves placing callused material on the ground and allowing subsequent growth to continue. It may take several years for even modest height to be attained. The age of a similar species, $O$. engelmanii, has been estimated using the number of cladodes (Bowers 1996). We have demonstrated that it is feasible to immediately plant mature $O$. prolifera and $O$. littoralis in such a way as to meet the height and architectural requirements necessary for wildlife use (Ehrlich et al. 1988). The 25 $O$. littoralis specimens planted in the two patches averaged 10 cladodes above ground. According to Bowers (1996), and correcting for the normal slow growth period from seed, these specimens are equal in stature to plants at least seven years old. This is likely a very conservative estimate since the control cladodes on the ground had exhibited no growth after six months. Grafting was only partially successful. The relatively high success rate with self grafting illustrates the importance of precise fit and it might indicate sensitivity to genetic incompatibility. None of the grafted cacti were watered. Although water in a graft can cause rot (Baker 1977), watering the ground may help support grafting success. Most commercial greenhouse cactus grafting involves placing one cactus vertically above another symmetrical sturdy base. Grafting wild plants involves all possible angles and orientations. Classic grafting methods (Baker 1977; Brandt 1978) also have the utility of pots to use as handles for physical manipulation and a substrate for firmly securing specimens during the initial grafting procedures. Great care must be taken in the field when attempting these sorts of constructions. A farm manager at a cactus farm in central California once said, "it was not unusual for over $50 \%$ of the average 60 laborers used during harvest to quit in any given day" (Curtis 1977). Although grafting appears feasible, the strength and practicality of this method is probably limited. The abundant natural growth occurring on all three patches appears to exceed that which may be obtained through artificial means such as grafting.
These methods, predominately translocation, could provide a valuable tool for cactus scrub mitigation in burned areas. By planting several patches spaced throughout a burn site, islands of habitat and shelter can be created. Although "edge effect" will probably remain an important factor, the presence of semi-mature, cactus patches may help encourage animal use in recently burned areas. This method not only benefits the coastal cactus wren for which it provides nesting areas but can also provide shade and shelter for the myriad of animals that use mature cactus habitat.

Acknowledgments. The University of California Natural Reserve System provided computer support for the project, which was sponsored in part by a grant from the Transportation Corridor Agencies. We would also like to thank John DiSilva and Scott Nguyen for their assistance on this project.

\section{Literature Cited}

Baker, M. 1977. The world of cactus \& succulents. Ortho Books, San Ramon, CA.

Brandt, L. 1978. Cactus \& succulents. Sunset Publishing Corp., Menlo Park, CA.

Bontrager, D.R., A.L. Gorospe, and D.K. Kamada. 1995. Breeding biology of the California gnatcatcher in the San Joaquin Hills, Orange County, California. Unpublished report. Prepared for the USDI Fish and Wildlife Service.

Bowers, J.E. 1996. Growth rate and life span of a prickly pear cactus, Opuntia engelmannii, in the northern Sonoran Desert. Southwestern Naturalist 41:315-334.

Curtis, J.R. 1977. Prickly pear farming in the Santa Clara Valley, California. Economic Botany 31:175-179.

Ehrlich, P.R., D.S. Dobkin, and D.Wheye. 1988. The birder's handbook. Simon \& Schuster Inc., New York, N.Y.

Harmsworth Associates. 1996. California gnatcatcher and coastal cactus wren monitoring report for the San Joaquin Hills burn area. Unpublished Report. Prepared for Transportation Corridor Agencies, Santa Ana, CA.

Le Houérou, H.N. 1996. The role of cacti (Opuntia spp.) in erosion control, land reclamation, rehabilitation and agricultural development in the Mediterranean Basin. Journal of Arid Environments 33:135-159.

Mohamed-Yasseen, Y., S.A. Barringer, and W.E. Splittstoesser. 1996. A note on the uses of Opuntia spp. in Central/North America. Journal of Arid Environments 32:347-353.

Rea, A.R. and K.L. Weaver. 1990. The taxonomy, distribution, and status of coastal California cactus wrens. Western Birds 21:81-126.

Roberts, F.M., Jr. 1989. A checklist of the vascular plants of Orange County, California. Museum of Systematic Biology, University of California, Irvine Special Publication No.6.

Russell, C.E. and P. Felker. 1987. The prickly-pears (Opuntia spp., Cactaceae): A source of human and animal food in scmiarid regions. Economic Botany 41:433-445. 


\title{
Survival of Transplanted Coast Live Oaks (Quercus agrifolia) In Southern California.
}

\author{
Rosi Dagit \\ Resource Conservation District of the Santa Monica Mountains, Topanga, CA 90290 \\ Tel. (310) 455-1030; Fax (310) 455-1172); e-mail:oaksrus@aolcom
}

\begin{abstract}
Twenty five coast live oaks (Quercus agrifolia) ranging in size from 15 to 100 centimeters (dbh), transplanted to accommodate housing developments at three different sites in Calabasas, California, were studied for 4 to 5 years after boxing. Transplanted trees, plus 15 native control trees, were monitored quarterly. Water potential, shoot and root growth, and visual condition were measured. Although all 15 controls remained healthy, 20 percent of the transplanted trees died, 12 percent were nearly dead, 44 percent were in decline, 24 percent were stable, and none were improving. If declining transplants fail to stabilize, then projected long-term survival rate would be approximately 10 to 40 percent.
\end{abstract}

Keywords: Mitigation; oaks; transplantation.

\section{Introduction}

Transplantation of mature coast live oak trees (Quercus agrifolia) as mitigation for loss due to development has become increasingly controversial as the extent of oak woodlands in Southern California decreases. In addition to concern over the protection of one species while ignoring the complex associated community, there are also questions of cost effectiveness and long- term tree survival. The cost of moving an oak tree varies with box size and site accessibility, ranging from around $\$ 1,000$ to more than $\$ 100,000$.

To date, few studies have examined transplantation or the physiological consequences of root injury. Our study used both quantitative and qualitative evaluation to assess establishment of transplanted oaks in landscaped settings.

\section{Calabasas Transplant Study}

The City of Calabasas (Los Angeles County), California, Oak Tree Protection Ordinance discourages transplanting and requires mitigation for tree removal. In addition, monitoring of trees that are moved was required for 5 years. In January 1992, monitoring of transplanted trees began at Site 1, followed by the addition of two more sites in April 1993, either as the trees were being boxed, or immediately afterword. All portions of the sites to which trees were moved experienced extensive grading and drainage changes before replanting. Sites 1 and 2 were originally north-facing hillside drainages with intermittent streams, clay soil, and mixed chaparral vegetation. Site 3 was a level riparian area. The perimeter of all three sites had been affected by previous development. Trees were selected for transplanting by the tree-moving company. Concurrent with root pruning and side boxing, the canopies of the selected trees were pruned, removing $50-70 \%$ of living tissues. Deadwood, inner foliage, and terminal buds were trimmed, leaving a thin shell of foliage on the perimeter of the canopy.

A backhoe was used to trench all four sides around each tree at once. Box sizes ranged from $1.5 \times 1.5 \times 1$ meters to $8.5 \times 8 \times 2.5$ meters. Bottom boxing was completed 3 to 6 months later. Trees were watered by truck weekly or more often, as determined by the tree-moving company. All trees were planted in holes dug by backhoes, usually 1 to 2 meters wider than the box and approximately the same depth as the root ball. The box bottoms were left in place, the sides removed, and backfilling done by backhoe and hand labor. Irrigation was installed at Site 2 and modified seasonally. The other two sites continued to be watered by truck once or more weekly.

\section{Monitoring Methodology}

Quantitative and qualitative observations of both transplanted and control trees occured on a quarterly, then semiannual basis. Each tree was given a vigor rating using the International Society of Arboriculture standard condition evaluation for landscape trees which is based on canopy, foliage, trunk, and root condition (Table 1) at every visit. Trees were categorized as very healthy (6), improving/fairly healthy (5), stable/no change (4), declining (3), nearly dead (2), dead (1). 
Table 1. Vigor rating scale.

\begin{tabular}{cll}
\hline Vigor rating & Description & Critcria for cvaluation \\
\hline 1 & Dead & No living canopy, severe root and trunk defects, severe infestation or disease \\
2 & Decline & $\begin{array}{l}\text { Less than } 25 \% \text { growing canopy, major root and trunk defects, severe infestation or } \\
\text { disease }\end{array}$ \\
3 & Stable & $\begin{array}{l}25-50 \text { percent growing canopy, some root and trunk defects, moderate infestation } \\
\text { or disease } \\
\text { Greater than } 50 \text { percent growing canopy, few active root or trunk defects, minor } \\
\text { infestation or disease } \\
\text { Greater than } 75 \text { percent growing canopy, fairly healthy, few root or trunk defects, } \\
\text { minimal infestation or disease } \\
\text { Well balanced, symmetrical canopy, no root or trunk defects, minimal infestation }\end{array}$ \\
\hline
\end{tabular}

Stem water potential was measured to monitor water stress. Mid-day readings of five sample twigs (5 to 13 $\mathrm{cm}$ long) taken from four compass points in full sun on each tree were followed by five pre-dawn samples, using either a PMS Scholander Pressure Chamber (PMS Instrument Company, Corvallis, Oregon), or Model 3005 Plant Water Status Consule (SoilMoisture Equipment Co., Santa Barbara, California).

Root density and data concerning shoot length, number of shoots and leaves were also recorded.

\section{Results}

Control trees maintained a stable, healthy condition during the 5 year study while transplanted trees declined steadily (Fig. 1). By April 1997, five transplanted trees had died, three were nearly dead, eleven were in decline, six were stable, and none were improving.

Canopy condition and vigor appeared closely related. Control trees maintained a dense canopy and normal branching structure, with few epicormic sprouts. Transplanted trees had little apical growth. Instead, epicormic sprouts emerged from the trunk, scaffold branches, and all branches close to the tree interior. Transplanted tree canopies remained characteristically thin, open, and often chlorotic. Trees showing improvement had expanded epicormic growth from the center of the tree out toward the edge, and slowly increased their interior density.

The majority of control trees had visible growth cracks in the trunk bark, indicating active radial growth. Such cracks on the transplants were smaller and fewer in number. The diameter of eight control trees increased over 2 3 years, 5 remained the same and only 1 tree became smaller. Conversely, only 3 transplanted trees expanded, 13 remained the same and 9 decreased.

On the basis of the soil probe observations, only the 2 transplanted trees showing signs of improvement had roots extending outside the planting hole. Most transplanted

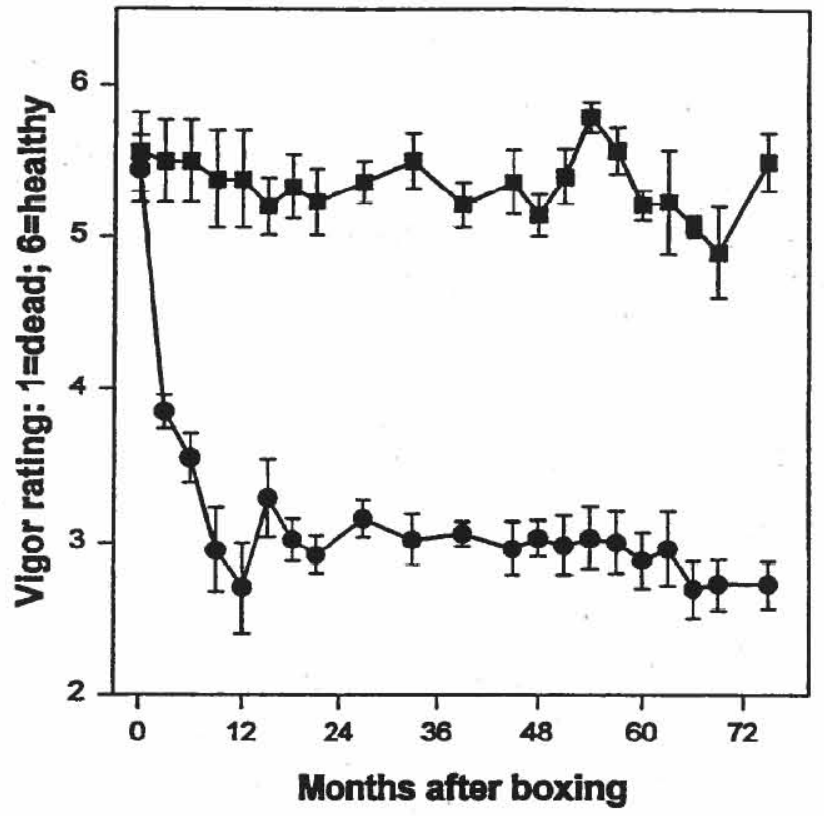

Figure 1. Effect of transplanting on vigor of Quercus agrifolia. Squares $=$ controls, circles $=$ transpants, bar is standarderror of the meanl.

tree roots were sparse and limited by the box size. By contrast, the control trees had dense mats of roots at all areas probed.

Water potentials of control trees did not correlate with final vigor ratings $\left(r^{2}=0.001\right)$. However, a few trends were apparent. The data indicated a higher degree of variability among the transplants, with control trees remaining more consistent at any given time (Fig. 2). Control trees did show more negative summer/fall water potential (July and October), but they rarely dropped below a predawn potential of $-2.5 \mathrm{MPa}$. By contrast, declining transplanted trees routinely exceeded that limit and had much more negative water potential at mid-day. In nearly dead trees, pre-dawn water potentials exceeded those at midday. 


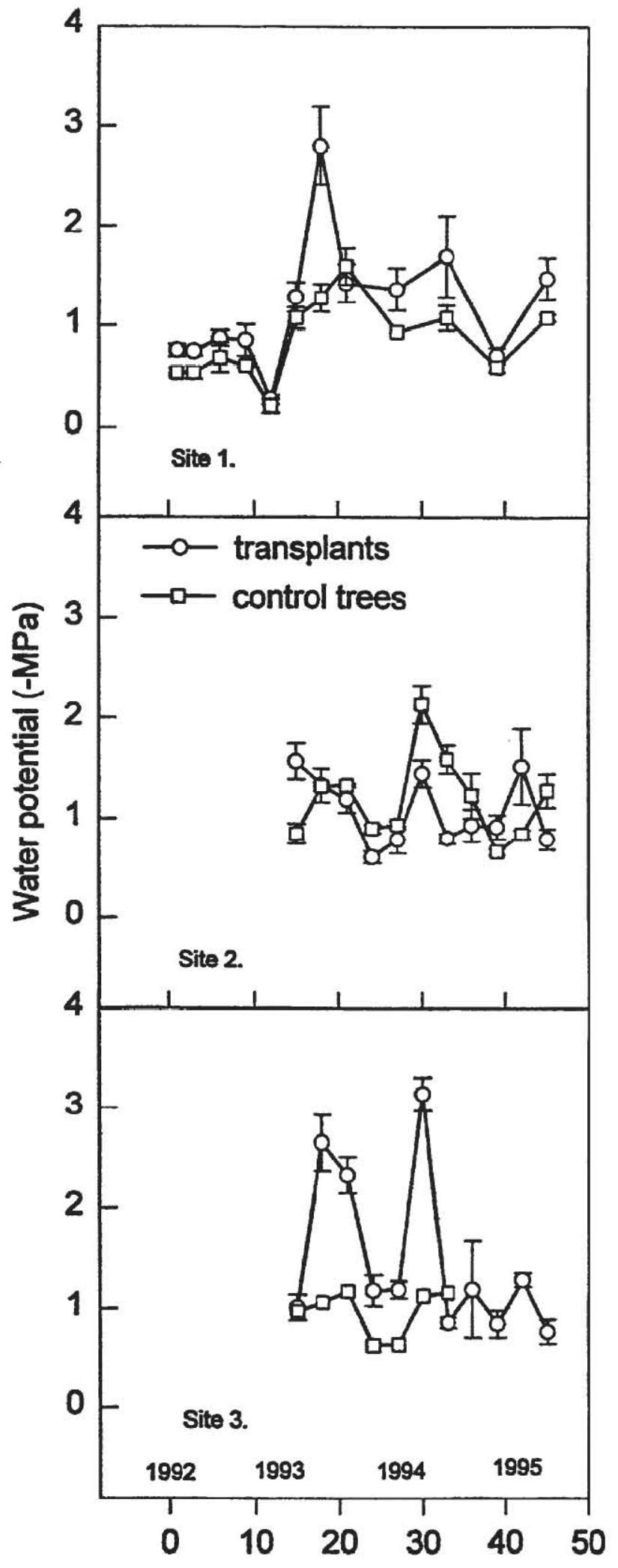

Months after boxing

Figure 2. Pre-dawn stem xylem potentials. Bar is standard error of the mean.

\section{Discussion}

Distributed throughout the coastal regions of the state, coast live oaks can be found in a wide variety of locations, from sea level to 5,000 feet. Despite tremendous adaptability, there appear to be physiological limiting factors difficult to exceed. In order to understand the response of this species to the impacts of transplantation, it was important to review relevant aspects of oak tree biology.

Adapted to the mediterranean climate, coast live oaks are nonetheless greatly affected by the availability of water. Despite the worst statewide drought of this century, which had severe impacts on native trees from 1986 to 1992 (Tietje 1993), the control trees were able to utilize available water resources and thrive. Local rainfall patterns during the study period have been above average.

Vigor ratings were strikingly different between the control and transplanted trees. Transplanted trees steadily declined, due to the large canopy and root loss. Neither root nor canopy recovery has occurred for the majority of trees. However, control trees remained vigorous.

Watson (1985) found that root recovery was related to stem diameter. For each inch of trunk diameter, root replacement following removal took approximately one year in the Midwest. Given a longer growing season in southern California, optimal conditions may allow slightly faster recovery. However, our study found that only two trees $(\mathrm{dbh}=44 \mathrm{~cm}, 64 \mathrm{~cm})$ had evidence of roots extending outside the planting hole. The inability to extend rooting area could be due to the differences in boxed storage time, soil compaction, as well as delayed ability to regenerate lost roots and shoots following traumatic loss.

Hagen (1989) documented that root-related impacts are extremely damaging to most trees, including oaks. A study of coast live oak root pruning at North Ranch, Thousand Oaks (Ventura County), Calif., indicated that while initial water stress was not devastating, accumulation of stress could precipitate decline. "Drastic" root pruning immediately disrupted stem xylem tension, indicating that there were limitations to the amount of root damage that could be sustained before the tree died (Roberts and Smith 1980). In undamaged trees, absorbing roots can extend more than a 100 feet from the trunk (Perry 1982). Rootrelated impacts in southern California can cause stress in trees up to 300 feet away (Alden Kelley, personal communication). Boxing was done in late summer and fall to take advantage of root growth at this time, stimulated by the auxins produced in the less active terminal buds.

In spring, the roots produce hormones stimulating shoot growth in the terminal buds (Coder 1994). Between three and five shoots erupt from each bud, reaching lengths of 30 to $60 \mathrm{~cm}$ if rain is plentiful. Griffin (1973) found that a typical response of oaks to water stress was failure of buds to mature. Transplanted trees in our study had 
limited apical growth (data not shown), supporting this observation.

Impacts on photosynthate production and resultant canopy condition have been shown to be important in maintaining overall vigor. It has been found that as new leaves photosynthesize, carbohydrate reserves were stored in the roots and trunk during wet years to help sustain the oaks through dry periods (Rundel 1980). Oaks moderated transpirational loss by stomatal regulation according to environmental stress (Roberts and Smith 1980). As summer progressed and soil moisture was limited, photosynthesis on the perimeter of the canopy was reduced while it continued in the humid interior. The photosynthetic activity of the larger, inner canopy leaves produced the extra carbohydrates needed to exceed the baseline metabolic requirements of the tree and provided reserves for storage (Hollinger 1992).

In this study, similar water potentials in both control and transplanted trees were noted. Until the transplants were nearly dead, it was not possible to accurately predict their survival using only water potential as an indicator.

While the seasonal trends of water potential between controls and transplants appeared close, the effect on tree vigor was dramatically different. Control trees periodically hit limits of $-2.5 \mathrm{MPa}$ and still maintained overall health and vigor. It has been previously documented that water potentials more negative than $-2.5 \mathrm{MPa}$ resulted in catastrophic emboli (air bubbles in the xylem water columns reducing conductance) causing more than 50 percent loss of conductance (Tyree et al. 1994). When these limits were repeatedly exceeded, tree mortality resulted (Griffin 1973).

The control trees apparently had sufficient energy reserves to replace damaged tissue, and xylem function continued (Davis 1996). By contrast, transplanted trces in decline routinely had a water potential more negative than $-2.5 \mathrm{MPa}$ and showed no signs of recovery, despite irrigation. If embolized tissues cannot be replaced, then continued dieback occurs. Our vigor ratings suggested that the transplants were not able to replace lost conducting vessels as easily, resulting in cumulative decline.

The transplanting techniques commonly used for oaks in southern California (simultaneous trenching on all 4 sides with extensive canopy reduction, followed by relocation within 3-6 months) do not appear conducive to long term survival. Transplanting techniques used in other areas (Himelick 1981) may offer some alternatives to improve establishment. Root preparation by trenching one side at a time more than 6-9 months may allow greater root recovery before relocation. Allowing the canopy to die back naturally to that which can be supported by the root mass may not disrupt photosynthesis and hormonal balance as much and may permit terminal buds to expand. Removal of deadwood and any severely injured branches should be sufficient canopy reduction. Careful storage of boxed trees until planting and placement in a suitable new location sharing soil, drainage, and exposure characteristics of the original site may also improve survival.

\section{Conclusion}

Only $24 \%$ of transplanted trees were stable, while the rest were declining. All continue to require extensive maintenance. Thus it appcars that long-term survival for these transplants would be at best no more than 40 percent, and probably considerably less.

Our data were consistent with trends documented by Scott and Pratini (unpublished data). They observed that between 40 and 60 percent of transplanted trees died soon after boxing, approaching 100 percent when root preparation was poorly done. This initial mortality was frequently ignored when statistics about tree survival were quoted.

Observations of vigor and canopy condition were valuable indicators of overall tree condition. Water potential measurements allowed irrigation modification and indicated tree recovery over time, but alone were not sufficient to predict survivability. Combined with vigor ratings and evaluation of canopy condition, a more complete assessment of tree status was obtained.

Even with improvements to the transplanting procedure, it may be that the highest attainable level of care would not be sufficient to overcome the trauma of transplantation for mature coast live oak trees. While the transplanted trees remained alive, they were no longer selfsustaining natives, but rather high-care exotics that required intensive, long term maintenance.

Given the high cost of moving (over $\$ 450,000$ for 25 trees), maintenance and monitoring (approximately $\$ 40,000$ per year), it appears that a low long- term survival rate fails to justify the expense. If the goal of mitigation is to replace lost resources, then the cost-effectiveness of transplanting oaks needs to be carefully examined.

Acknowledgments: Drs. Steven Davis, Philip Rundel, and Alden Kelley assisted in developing the monitoring protocol, evaluating results and editing the manuscript. Equipment was provided courtesy of University of California at Los Angeles and Pepperdine University. Rick Ryan, Noel Rhodes, Angela Lui and Ken Klementis helped with data collection.

\section{Literature Cited}

Coder, K. 1994. Regulation of tree growth: keeping the green side up. Arborist News 3:33-36.

Davis, S. D. 1996, personal communication. 
Gilman, E.F. 1988. Tree root spread in relation to branch dripline and harvestable root ball. HortScience 23:351-353.

Griffin, J.R. 1973. Xylem sap tension in three woodland oaks of central California. Ecology 54:152-159.

Hagen, B.W. 1989. Tree roots-major considerations for the developer. Tree Notes, No. 2, January 1989.

Harris, R.W. 1992. Arboriculture: care of trees, shrubs and vines in the Landscape. 2d ed. Prentice Hall, Englewood Cliffs, NJ.

Himelick, E.B. 1981. Tree and shrub transplanting manual. International Society of Arboriculture, Savoy, IL.

Hollinger, D.Y. 1992. Leaf and simulated whole-canopy photosynthesis in two co-occurring tree species. Ecology 73:1-14.

Perry, T.O. 1982. The ecology of tree roots and the practical significance thereof. Journal of Arboriculture 8:197-211.

Roberts, S.W. and R.I. Smith. 1980. Aspects of water relations in coast live oaks and valley oaks subjected to root damage from land development operations. Pp.171-175 in T.R. Plumb, ed. Proceedings of the symposium on the ecology, management, and utilization of California oaks. USDA Forest Service, General Technical Report PSW-GTR-44.
Rundel, P.W. 1980. Adaptations of mediterranean-climate oaks to environmental stress. Pp. 43-54 in T.R. Plumb, ed. Proceedings of the symposium on the ecology, management, and utilization of California oaks. USDA Forest Service, General Technical Report PSW-GTR-44.

Scott, T. and N. Pratini. 1992. Efficiency of transplanting oak trees for woodland habitat restoration. Unpublished draft.

Tietje, W., W. Weitkamp, W. Jensen and S. Garcia. 1993. Drought takes toll on Central Coast's native oaks. California Agriculture 47:4-6.

Tyree, M.T., S.D. Davis and H. Cochard. 1994. Biophysical perspectives of xylem evolution: is there a trade-off of hydraulic efficiency for vulnerability to dysfunction? International Association of Wood Anatomists Journal 15:335-360.

Watson, G.W. 1985. Tree size affects root regeneration and top growth after transplanting. Journal of Arboriculture 11:3740.

Watson, G.W. 1994. Root development after transplanting. Pp. 54-68 in G.W. Watson and D. Neely, eds. The landscape below ground. International Society of Arboriculture,Savoy, IL. 


\title{
On the Perils of Ecological Restoration: Lessons from the El Segundo Blue Butterfly
}

\author{
Travis Longcore ${ }^{1}$, Rudi Mattoni ${ }^{1}$, Gordon Pratt $^{2}$ and Catherine Rich ${ }^{\mathbf{1}}$ \\ 'Urban Wildlands Group, Department of Geography, University of California, Los Angeles, CA 90095 \\ Tel. (310) 825-1071; Fax (310) 206-5926; e-mail: longcore@ucla.edu \\ ${ }^{2}$ Department of Entomology, University of California, Riverside, CA 92521
}

\begin{abstract}
Land use planning and permitting in southern California increasingly relies on ecological restoration as mitigation for damage done to natural habitats by development projects. Many restoration attempts fail miserably for a number of reasons. Three areas of concern for restoration projects are: (1) historical accuracy and completeness, (2) ecotype accuracy, and (3) type conversions. Using evidence from a restoration project for the El Segundo blue butterfly we will show the importance of historical accuracy in ecological restoration. Other examples from the $\mathrm{El}$ Segundo dunes will illustrate the vital importance of using local ecotypes in restoration projects. Finally, we will discuss the issues raised by type conversions and other questionable restoration practices, why they are allowed as mitigation, and their effect on regional conservation goals.
\end{abstract}

Keywords: Ecotype accuracy; El Segundo blue butterfly; historical accuracy; mitigation; restoration; type conversion.

\section{Introduction}

Ecological restoration is used as a mitigation for damage done to natural habitats and species by development projects. Although such restoration projects take place under the auspices of public agencies such as the U.S. Army Corps of Engineers, the U.S. Fish and Wildlife Service, the California Coastal Commission, and the California Department of Fish and Game, they often are plagued by weaknesses that go largely unnoticed or unquestioned by environmental activists, the academic community, politicians, and the agencies themselves. Drawing from experience with a revegetation project for the El Segundo blue butterfly, we explore some of the common pitfalls of restoration projects.

Any discussion of restoration requires an understanding of what is meant by the word. The definition arrived upon by a National Research Council committee was "the return of an ecosystem to a close approximation of its condition prior to disturbance" (NRC 1992). Unfortunately, mitigation almost never has re-creation of the historic conditions as its goal, rather, success is defined as establishment of the dominant vegetation in an area (CERPI 1997). If historic conditions are not the goal, as they rarely are, the question arises whether restoration is undertaken to re-assemble the species and ecotypes historically present or to use different species that the restorationist believes will serve the same function in the ecosystem. The distinction here is made between a concentration on diversity or function.

Jordan et al. (1987) suggest that restorationists can illustrate their understanding of ecosystems by imitating rather than copying natural systems. They claim that insight from restoration research will be gained from being able to "create communities that resemble other communities in various ways, but that actually differ from them in species composition" (Jordan et al. 1987). We differ from Jordan et al. about the goals of restoration and restoration research. For reasons that will be illustrated below, we believe that restoration should have as its goal the preservation of biodiversity in a system that requires minimal human management and that is historically accurate and historically complete. To qualify as a "restoration" a project should strive to be historically complete and accurate and consider the reintroduction or management of all biodiversity, including insects, mammals, birds, plants, and cryptobiotic crusts. A project that reintroduces the historically present plants is a "revegetation," a project that only establishes the dominant cover is a "partial revegetation," and any project that establishes species not native to the site is an exercise in "landscaping."

A second aspect of the definition of restoration is what has been called "the ecotype question" (Cairns 1987; Kline and Howell 1987). Debate centers around the relative 
importance of matching local ecotypes when reestablishing plants on a restoration site. Although academic consensus seems to support using local ecotypes (see Millar and Libby 1989; Read et al. 1996; Allen et al. 1999), we illustrate the importance of local ecotypes on higher trophic levels and the maintenance of biodiversity. A project that does not use local ecotypes is not a "restoration."

The final facet of restoration that we discuss is whether type conversion - the creation of one natural community in an area that was previously occupied by another natural community - constitutes restoration. Examples of this specific kind of historical inaccuracy abound, especially for wetland/riparian (Allen and Feddema 1996) and grassland (Keeley 1993) restoration projects. We argue that ecological restoration does not include type conversions.

\section{Historical Accuracy and Completeness}

A story illustrates the dangers of historical inaccuracy. The El Segundo blue butterfly (Euphilotes bernardino allyni Shields) was distributed historically along the El Segundo dunes from Ballona Creek to the Palos Verdes Peninsula (Mattoni 1992). Its sole foodplant for all life stages is the coastal buckwheat, Eriogonum parvifolium Smith. Larvae feed on the flowerheads, pupate directly beneath the plant, and adults perch, mate, use nectar, lay eggs, and probably die on flowerheads (Mattoni 1992).
This butterfly persists in greatest numbers on the dunes at the Los Angeles International Airport (LAX). In 1975 the backdune at LAX was recontoured to realign Pershing Drive. The recontoured backdunes were stabilized with a "natural" seed mix (Mattoni 1989a). Although perhaps well intentioned, the seed mix was representative of coastal sage scrub, not the native dune scrub community. Whether this effort was meant as a restoration is irrelevant, the event of interest is that common buckwheat (Eriogonum fasciculatum (Benth.) Torrey \& A. Gray) was introduced and established on the dunes.

Numerous insects exploit Eriogonum flower-heads, which results in intense competition for the resource. This guild of competitors includes at least 10 species of Lepidoptera, in addition to an unknown number of other orders. While the El Segundo Blue is univoltine (one generation per year) and is specialized for the short, late blooming season of E. parvifolium, other competitors are more opportunistic and will utilize multiple hosts. The introduction of the earlier blooming E. fasciculatum to the dunes therefore had the result of differentially increasing populations of competitors by providing another food source that the El Segundo Blue could not exploit. Pratt (1987) showed that there was a doubling of competitive larvae on $\boldsymbol{E}$. parvifolium flowerheads in mid-August, which, considering an average generation time of one month, corresponded with senescence of $E$. fasciculatum in mid-July (Fig. 1). Increased concentrations of other larvae correlated with depressed El Segundo Blue populations, and experiments confirmed that other microlepi-

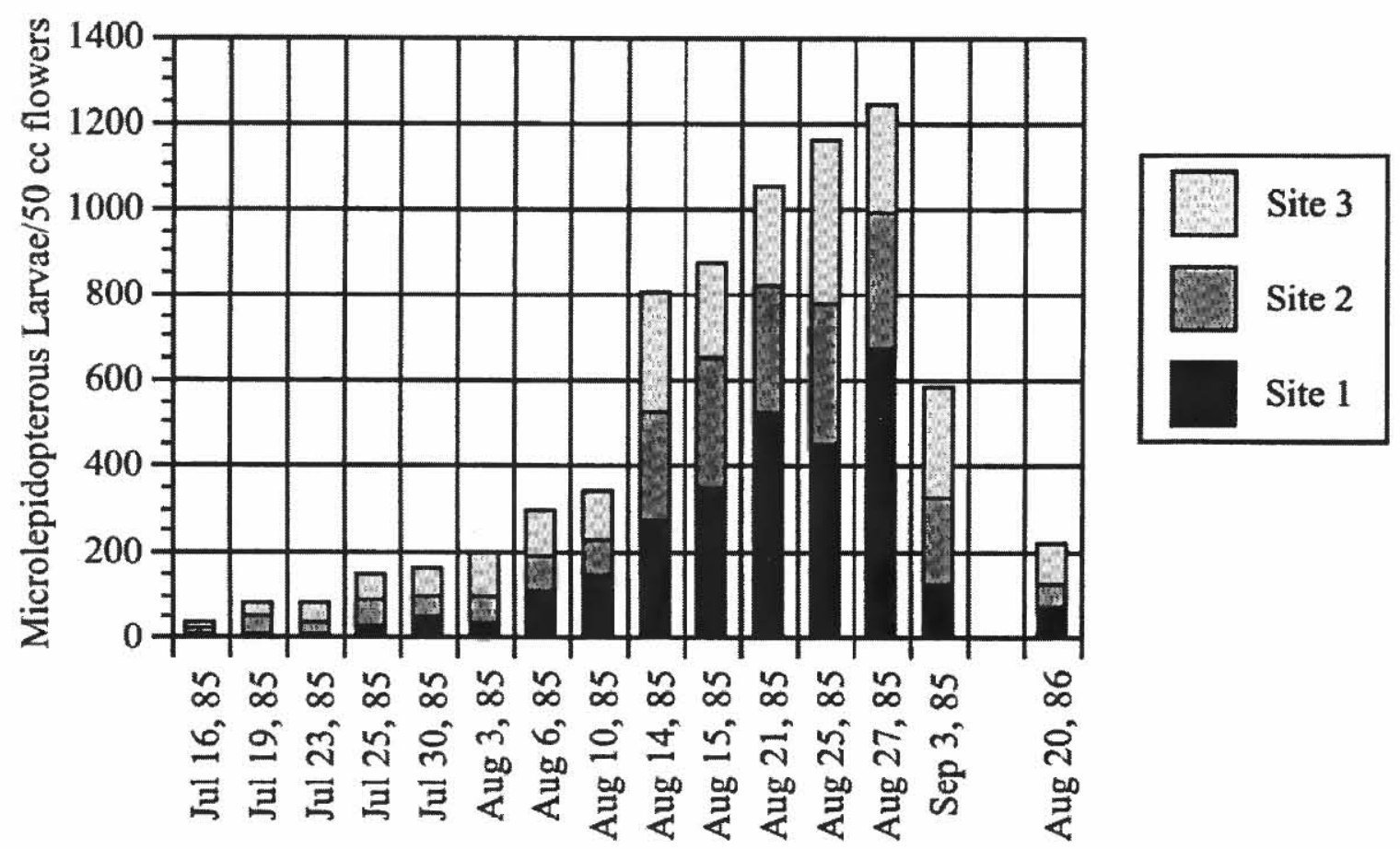

Figure 1. Abundance of larval microlepidopterous competitors (Gelechiidae and Cochylidae) of the El Segunda blue on Eriogonum parvifolium at three sites at LAX (Pratt 1987). 


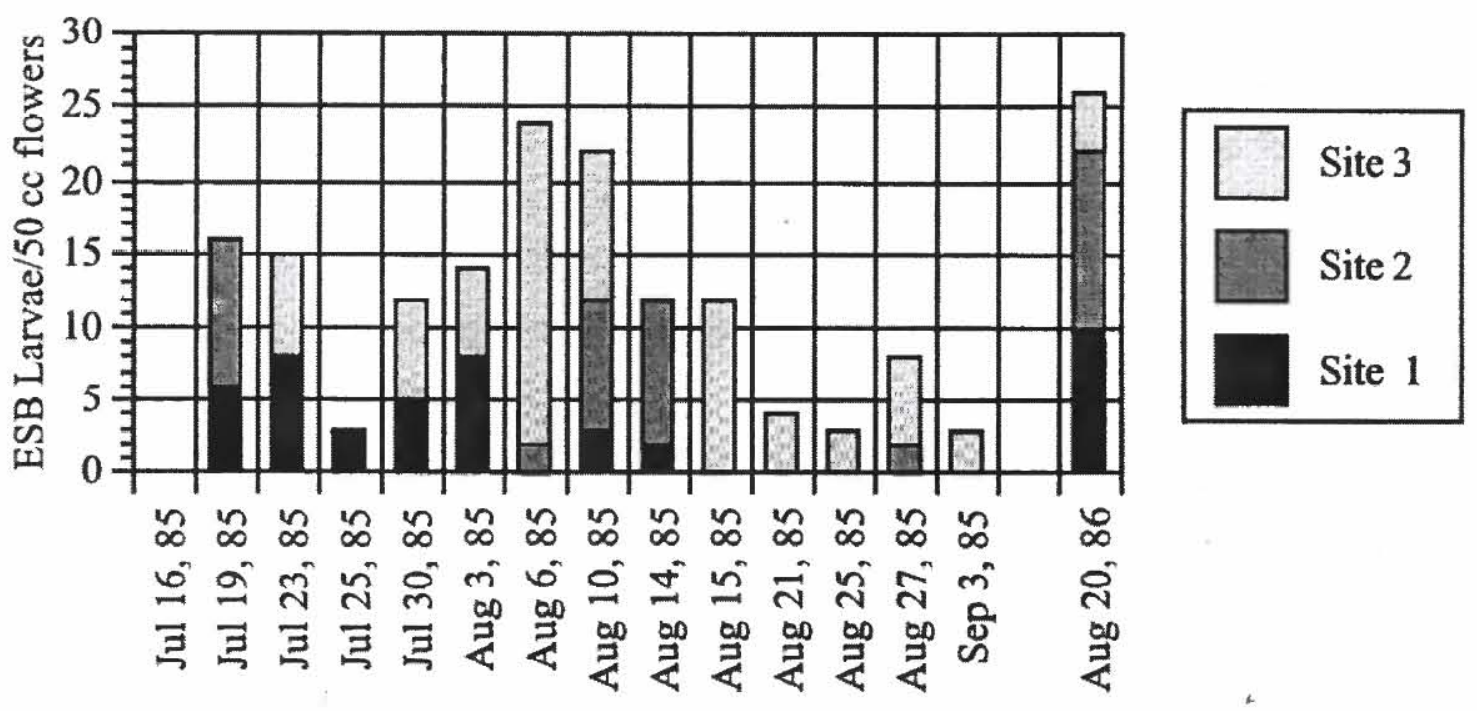

igure 2. Abundance of El Segundo blue (ESB) larvae on Eriogonum parvifolium at three sites at LAX (Pratt 1987).

dopterous larvae outcompete and even cannibalize its larvae. In addition, the other moths probably provide a reserve of parasitoids that they share with the blue (Pratt 1987; Mattoni 1988). The increase in El Segundo Blue and decrease in other larvae shown in the 1986 follow-up sample is likely the result of intense pruning of $E$. fasciculatum to delay flowering (Figs. 1 and 2).

A revegetation program was initiated on the LAX dunes in 1986 and one of the first actions was the removal of E. fasciculatum (Mattoni 1989b). Recovery of the El Segundo Blue over the course of the revegetation program is estimated by using a model based on transect counts (Mattoni et al., in preperation). Increases in the first two years of the program can largely be attributed to removal of $E$. fasciculatum, because newly established $E$. parvifolium had not yet matured (Fig. 3). The resonating effect of $E$. fasciculatum on insect community composi- tion shows the result of introducing just one species that is not native to an area. This observation implies that attention paid to historical distribution of species is a crucial first step to ensure the ecological integrity of restoration projects.

Another implication of this example, gained from recognizing the far-reaching effects of just one species on natural community composition, is that restoration should also strive to be historically complete. Although moths and butterflics are rarcly target specics for restoration projects, and almost never considered in mitigation design, many depend on a single host plant species. Furthermore, butterflies often depend on the rare species in a community, which are often overlooked in restoration efforts. The notion of the importance of a single species on the ecosystem is not new; Paine's (1969) metaphor of the "keystone species" was intended, in his words, "to con-

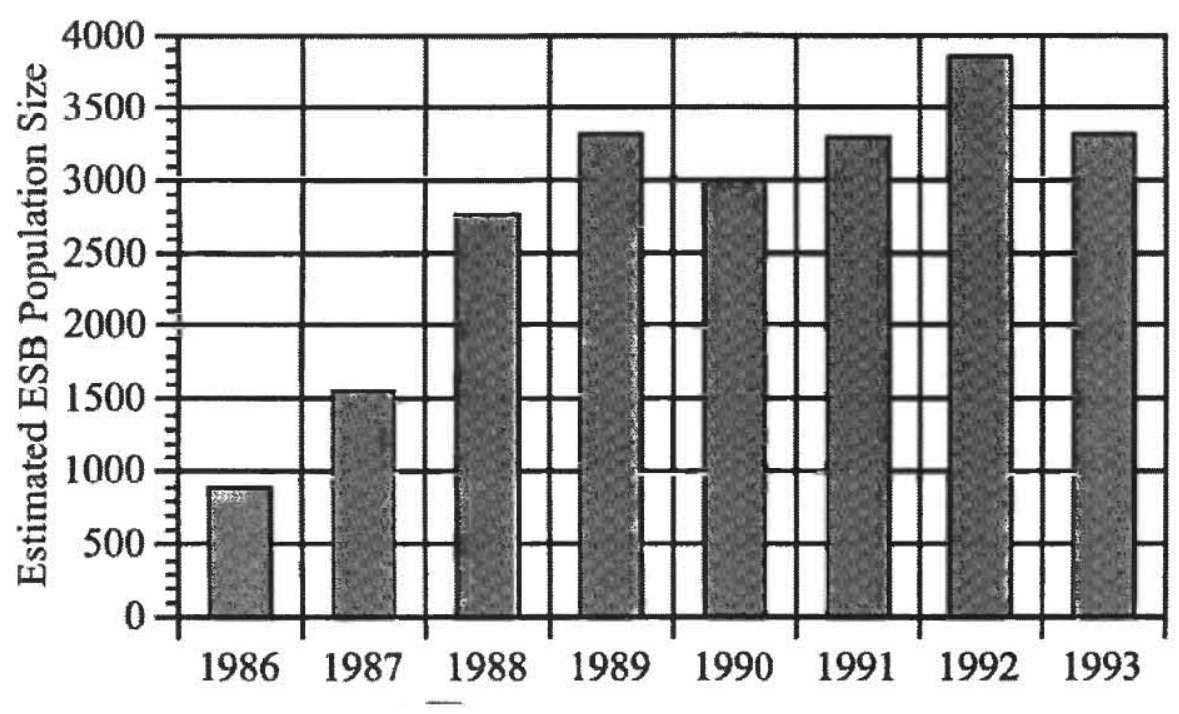

Figure 3. Recovery of the El Segundo blue (ESB) population removal of Eriogonum fasciculatum and provision of more foodplant (Mattoni, Novothy and Longcore, unpublished data). 
vey a sense of nature's dynamic fragility and the unsuspected consequences of removing (or adding) species" (Paine 1995). Omission of one plant species can result in a significantly impoverished restoration.

A second motivation for historical completeness in restoration projects is that speciose systems may be more stable with respect to environmental factors (Putnam 1994). Walker has termed the existence of many species that serve similar ecological roles "ecological redundance" (Walker 1992; Lawton and Brown 1996). "Redundance" is not meant in a pejorative sense, but instead illustrates the importance of similar species being able to compensate functionally (e.g., fixing nitrogen) when another species population has declined (Walker 1995). Ecosystems (and restoration projects) lacking the ecological redundance that characterized the historic condition will be more susceptible to collapse.

\section{Ecotype Accuracy}

The biological species concept (Mayr 1942) is inadequate for restoration purposes; rather attention must be given to local genetic variation in organisms known as "ecotypes" (Turesson 1922; Clausen et al. 1948). In a discussion of conservation biology, Rojas (1992) writes that, "Considering species as typological entities may ... lead workers to disregard geographic variation and to neglect the problem of deciding which level of variability to protect." Rojas concludes that conservation biologists have neglected to understand species concepts relative to their work. We find that applied restorationists also pay too little attention to local, ecotypic variation. However, some writers have addressed the importance of local variation to the success or failure of restoration projects, calling it "the ecotype question" (Cairns 1987).

Scholarly discussion of the ecotype question generally has supported a position of striving for ecotype accuracy. McNeilly (1987) discussed the importance of local ecotypes in heavily degraded areas where plants may have adapted to the extreme toxic conditions of a site, stressing the continuing evolution of plant populations subject to contaminated conditions. Millar and Libby (1989) explored how to maintain a commitment to genetic purity while settling for something less. They note that genetic variation does not necessarily correspond to geographic variation and that one must also consider the microclimatic and edaphic conditions of individuals used for propagules. Proximity does not necessarily denote the appropriate ecotype for a restoration site. Read et al. (1996) note that the internal variation of some species (e.g. $E$. fasciculatum) is much greater than others (e.g. Nasella spp.) allowing the restorationist to make judgments about the necessity for site fidelity on a case-by-case basis.

Although the consensus seems to be that the restorationist should only collect propagules based on particular knowledge of the plants and locations involved, this precept is motivated by concern that plants themselves will survive and are genetically appropriate. However, a restoration is not successful if the plants kill the organisms that depend on them. While a plant of a non-local ecotype may survive when planted as part of a revegetation project, consideration rarely is given to the effects of the plant on other trophic levels. Insects, especially larval forms, give a rough indication of the divergence of different ecotypes.

Consider Eriogonum fasciculatum, which is a foodplant for a large number of insects and is widely used in restoration efforts. We have observed that $E$. fasciculatum shows large geographic variation, which often is overlooked in restoration efforts. We know of two restoration sites where a non-local ecotype was established as part of a restoration project (the Defense Fuel Support Point in San Pedro, and upper Newport Bay). At the Defense Fuel Support Point we do not know the source of the non-native ecotype, but it is visibly different from nearby local individuals and is characterized by a depauperate insect fauna, lacking many common species found nearby on the local ecotype. A few examples of the variation within $E$. fasciculatum involve rearing lepidoptera larvae for research purposes. We found a larva of Hemileuca electra (a saturniid moth) on Eriogonum fasciculatum near Jacumba, CA. It died after being moved to the San Pedro ecotype (Longcore and J. George, unpublished data). Several larvae of Schinia sp. collected in Riverside County on Chaenactis glabriuscula DC. died at once after consuming the ecotype from the El Segundo sand dunes (Mattoni, unpublished data). To borrow a pun from tropical butterfly ecologist Phil DeVries, using the wrong ecotype "add[s] insult to herbivory" (DeVries and Baker 1989).

Research in the late 1960 s and early 1970 s by Paul Ehrlich and colleagues (Breedlove and Ehrlich 1968, 1972; Dolinger et al. 1973) explains the sensitivity of herbivorous larvae to this intraspecific variation. They found that lupine species (Lupinus spp.) subject to herbivory by a lycaenid butterfly (Glaucopsyche lygdamus) showed higher levels and compositional variability of alkaloids, compounds that serve as chemical defenses against the larvae. Further, they discovered that variation in alkaloid content and compusition between lupine populations of the same species was often higher than the variation between populations of different species. Their work clearly shows the localized nature of the interrelationships between species (in this instance a plant-herbivore complex). For the restorationinst, Ehrlich's work illustrates the enormous importance of ecotype fidelity on the potential ecological function of a restoration site. With the exception of species whose genotypic and phenotypic variation are thoroughly explicated with respect to their associated herbivores, local ecotypes should be used in restoration. 


\section{Type Conversions}

Finally, we consider habitat type conversions, wherein the restorationist purposefully establishes one habitat type or vegetation association where it was not found historically. Such intentional or inadvertent type conversions constitute a particularly insidious form of historical inaccuracy. Historical accuracy is a difficult goal for restorationists because often little information is available in an accessible format. Jordan and Packard (1987) describe trial-and-error efforts to identify native plant species that would persist under oaks near Chicago. Early efforts had attempted to establish prairie species under the oaks, but further experimentation revealed that another distinct set of plants was adapted to such conditions. After discovering this fact, Packard happened across an 1846 journal called The Prairie Farmer, which had identified 108 species characteristic of "barrens," the settler term for natural oak savanna. While Packard was pleased to note that those species corresponded with his list of savanna species, complete historical research could have avoided the frustration of attempting to establish a prairie as the understory of oak savanna in the first placc. Bccause of incomplete historical research, many restorations performed as mitigations may indeed be characterized by a such unintentional type conversions.

Similar examples can be found in southern California in a number of areas. Unfortunately, would-be restorationists obliterate the natural community in their attempts to establish the wrong vegetation type. For example, because of an error misinterpreting the extent of the El Segundo dunes (Arnold 1983, 1990; Mattoni 1992), some restoration attempts have tried to establish dune scrub vegetation in areas that were historically occupied by the distinct Los Angeles coastal prairie. It was only through close observation and historical research completed as part of the El Segundo dunes restoration that the prairie was recognized and described. We hope that the recognition and description of the prairie will inform future restoration efforts on the remaining fragments.

The most well documented instances of type conversions have been done as mitigation under Section 404 permits for the Clean Water Act administered by the U.S. Army Corps of Engineers (Allen and Feddema 1996). In a survey of 75 project sites, Allen and Feddema found that only $67 \%$ of the projects had been "successfully completed." Further, they found an overall decrease in wetlands with some types gaining (riparian woodland) while other types declined (freshwater wetland). Distribution of wetland types and overall regional wetland location was changed through the mitigation process. Zedler (1996) also documents and discusses the need for a regional plan to avoid continued replacement of the historic extent of one type of habitat (salt marsh and intertidal flats) with another (deepwater habitat), fueled by mitigation needs.

\section{Conservation and Policy Implications}

Our work with the El Segundo blue butterfly created the opportunity to learn what can go wrong in an ecological restoration project. The mistakes identified here occur on a regular basis in projects identified as "restorations." These projects, even when developed under the supervision of the U.S. Fish and Wildlife Service, the California Department of Fish and Game, the California Coastal Commission, or the U.S. Army Corps of Engineers, frequently are historically inaccurate and incomplete, and pay littlc or no attention to ccotype accuracy or type conversions. Examples abound: the plan written for the Deane Dana Nature Center in FriendshipPark in Palos Verdes proposes to restore coastal sage scrub with a plant list of about a dozen shrubs (out of approximately 150 plant species that can be identified for the site, many of which are no longer found in adjacent areas and will never recolonize naturally); the Ballona Lagoon "restoration" project commenced by bulldozing all vegetation (including natives) leaving no chance for ecotype accuracy; the Ballona Wetlands plan developed for the Playa Vista project converts historic salt marsh into a sediment detention basin surrounded by landscaping with native plants bearing little resemblance to the historic community found on the site (in addition to other marine community conversions, historical inaccuracies, and incompleteness).

Such ecologically deficient "restoration" projects could simply be avoided through better communication from the academic community to the resource agencies. Rather than relying entirely on their own overworked staffs, agencies should solicit peer review for restoration plans from qualified experts in the habitats in question who are free from conflicts of interest. Consultants proposing to design and implement restoration projects should be required to pass examinations indicating field identification skills and historical knowledge of the habitats they profess to understand.

One underlying reason for the continued acceptance of deficient restoration planning and implementation is the simple fact that few biologists choose to pursue careers in politics, in which realm many decisions are ultimately made. Rather, the political world tends to select for more people-oriented participants, who, through no fault of their own, lack a robust biological background. When entire elected bodies have not a single biologist in their midsts, they perforce rely on the opinions of others who may or may not have the proper expertise to advise on the issue at hand. Therefore, if ecologists in the academic community would like to see the fruits of their labors translated into more enlightened policy, more outreach to local and regional policymakers will be required. This conference and its predecessor have in some part served that role. 


\section{Literature Cited}

Allen, A. O. and J.J. Feddema. 1996. Wetland loss and substitution by the Section 404 permit program in southern California, USA. Environmental Management 20:263-274.

Allen, E.B., S.A. Eliason, V.J. Marquez, G.P. Schultz, N.K. Storms, C.D. Stylinski, T.A.Zink, and M.F. Allen. 1999. What are the limits to restoration of coastal sage scrub in southern California. Pp. 253-262 in Keeley, J.E., M. BaerKeeley, and C.J. Fotheringham, eds. 2nd Interface Between Ecology and Land Development in California. International Association of Wildland Fire, Fairfield, WA.

Arnold, R.A. 1983. Ecological studies of six endangered butterflies (Lepidoptera, Lycaenidae): island biogeography, patch dynamics, and the design of habitat preserves. University of California Press, Berkeley, CA.

Arnold, R.A. 1990. Ecology and conservation of two endangered southern California butterflies. Pp. 36-47 in P.J. Bryant and J. Remington, eds. Endangered wildlife and habitats in southern California. Memoirs of the Natural History Foundation of Orange County, Volume 3, Newport Beach, CA.

Breedlove, D.E. and P.R. Ehrlich. 1968. Plant-herbivore coevolution: Lupines and Lycaenids. Science 162:671-672.

Breedlove, D.E. and P.R. Ehrlich. 1972. Coevolution: patterns of legume predation by a lycaenid butterfly. Oecologia 10:99104.

Cairns, J., Jr. 1987. Disturbed ecosystems as opportunities for research in restoration ecology. Pp. 307-320 in W.R. Jordan, III, M.E. Gilpin, and J.D. Abler, eds. Restoration ecology: a synthetic approach to ecological research. Cambridge University Press, Cambridge U.K.

CERPI. 1997. California ecological restoration projects inventory. California State Department of Conservation, (http:// trinity.des.ucdavis.edu/CERPI/CERPI/).

Clausen, J., D.D. Keck, and W.M. Hiesey. 1948. Experimental studies on the nature of species, III: environmental responses of climatic races of Achillea. Carnegie Institution of Washington Publication 581:1-129.

DeVries, P.J. and I. Baker. 1989. Butterfly exploitation of an antplant mutualism: adding insult to herbivory. Journal of the New York Entomological Society 97: 332-340.

Dolinger, P.M., P.R. Ehrlich, W.L. Fitch, and D.E. Breedlove. 1973. Alkaloid and predation patterns in Colorado lupine populations. Oecologia 13:191-204.

Jordan, W.R., III, M.E. Gilpin, and J.D. Abler. 1987. Restoration ecology: ecological restoration as a technique for basic research. Pp. 3-21 in W.R. Jordan, III, M.E. Gilpin, and J.D. Abler, eds. Restoration ecology: a synthetic approach to ecological rescarch. Cambridge University Press, Cambridge, U.K.

Jordan, W.R., III. and S. Packard. 1987. Just a few oddball species: restoration practice and ecological theory. Pp. 18-26 in G.P. Buckley, ed. Biological habitat reconstruction. Belhaven Press, New York, NY.

Keeley, J.E. 1993. Native grassland restoration: the initial stage — assessing suitable sites. Pp. 277-281 in J.E. Keeley, ed. Interface between ecology and land development in California. Southern California Academy of Sciences, Los Angeles, CA.

Kline, V.M. and E.A. Howell. 1987. Prairies. Pp. 75-87 in W.R. Jordan, IIl, M.E. Gilpin, and J.D. Abler, eds. Restoration ecology: a synthetic approach to ecological research. Cambridge University Press, Cambridge, U.K.
Lawton, J.H. and V.K. Brown. 1996. Redundancy in ecosystems. Pp. 256-270 in E.-D. Schulze, and H.A. Mooney, eds. Biodiversity and ecosystem function. Springer-Verlag, Berlin.

McNeilly, Tom. 1987. Evolutionary lessons from degraded ecosystems. Pp. 271-286 in W.R. Jordan, III, M.E. Gilpin, and J.D. Abler, eds. Restoration ecology: a synthetic approach to ecological research. Cambridge University Press, Cambridge, U.K.

Mattoni, R. 1988. Habitat restoration of the El Segundo sand dunes (California). Restoration \& Management Notes 6(1):45.

Mattoni, R. 1989a. Unnatural acts: succession on the El Segundo sand dunes in California. Pp. 581-593 in H.G. Hughes and T.M. Bonnickson, eds. Proceedings of the first SER conference. Society for Ecological Restoration, Madison, WI.

Mattoni, R. 1989b. Species diversity and habitat evaluation across the El Segundo sand dunes at LAX. Report to the Department of Airports, Los Angeles, CA.

Mattoni, R. 1992. The endangered El Segundo blue butterfly. Journal of Research on the Lepidoptera 29:277-304.

Mayr, E. 1942. Sytematics and the origin of species. Columbia University Press, New York.

Millar, C.I. and W.J. Libby. 1989. Disneyland or native ecosystem: genetics and the restorationist. Restoration \& Management Notes 7(1): 18-24.

NRC. 1992. Restoration of aquatic ecosystems: science, technology, and public policy. National Research Council, Washington, D.C.

Paine, R.T. 1969. A note on trophic complexity and community stability. American Naturalist 103:91-93.

Paine, R.T. 1995. A conversation on refining the concept of keystone species. Conservation Biology 9:962-964.

Pratt, G.F. 1987. Competition as a controlling factor of Euphilotes battoides allyni larval abundance (Lepidoptera: Lycaenidae). Atala 15:1-9.

Putnam, R.J. 1994. Community ecology. Chapman \& Hall, London.

Read, E.A., M. Blane, and P. Bowler. 1996. Restoration of coastal sage scrub. Ecesis 6(2):1, 4-5.

Rojas, M. 1992. The species problem and conservation: what are we protecting? Conservation Biology 6:170-178.

Turesson, G. 1922. The genotypic response of the plant species to the habitat. Hereditas 3:211-350.

Walker, B.H. 1992. Biological diversity and ecological redundancy. Conservation Biology 6:18-23.

Walker, B.H. 1995. Conserving biological diversity through ecosystem resilience. Conservation Biology 9:747-752.

Zedler, J.B. 1996. Coastal mitigation in southern California: the need for a regional restoration strategy. Ecological Applications 6:84-93. 


\title{
Preserving the Higher Aims of Restoration: Toward Transpersonal Restorations
}

\author{
Peter A. Bowler \\ Department of Ecology and Evolutionary Biology, University of California, Irvine, CA 92697 \\ Tel. (714) 824-5183; Fax (714) 824-2181; e-mail: pabowler@uci.edu
}

\begin{abstract}
As a restorationist, $\mathrm{I}$ have been reflecting a great deal the past few years about personal commitment to the land and to the fetal ecosystems we attempt to restore. I teach environmental ethics as well as restoration ecology, and have becn increasingly struck by the need to form a recognized link between deep ecology and ecological restoration. It is clearly there for those who read both literatures and dually appreciate their experience in working to restore natural systems, yet no one seems willing to come out and say it. Ecological restoration is an active form of deep ecology because of its foundation in biocentricity.
\end{abstract}

To me what is needed is an ethical standard and lifetime commitment to a site. Each site should have a lifetime steward, and involvement with true restoration should be a pledge - a kind of ethically binding Hippocratic oath - like a marriage, that a restoration will see oversight permanently as it evolves. Restorationists cannot incorporate and become industrial scale corporate habitatists; we should limit our lifetime commitment to what we can touch, know, and nurture within our means and personal scale. Larger, commercial landscape manipulations best defined as reclamation, rehabilitation, and other remedial low order changes have a significant place in being an initial step (though they are not restoration), and perhaps islands of true restoration efforts within them might be a functional way of dealing with large areas. Usually large scale efforts emulate no model habitat, they merely follow a species list with no or little data taken.

"Small is beautiful", and what we touch with our hands and our lives is what is important. We should not depend on restoration for our livelihood, rather restoration should be done for other reasons. Or, if we do, it should be understood that restorationists are not like inverse land development companies - ready and willing to expand indefinitely. Such consulting lifestyles don't merely enable development, they are development. Any true naturalist knows that in his lifetime the site he chooses as his lodestone will probably not be restored in the sense of an authentic model. As restorationists we need to live within the limitations of our ability to deliver sound, lasting stewardship.

While it is essential that restoration be conducted in a manner to benefit the scientific community, i.e., replicable experiments are implemented, data is taken, and information is shared; there is nothing wrong with establishing a relationship with a site - an enjoyment of, identification with, or pride in an evolving restoration project. There are rewards and Zen in watching nature's garden grow, and it is intuitively wrong to buy into the industry of mitigating habitat destruction. Those conducting restoration benefit from re-reading Aldo Leopold and should not be seduced by consultant corporations who are merely another wing of land development. Rather, our commitment as individuals should be to small places for our lifetimes, and we should see them through their successional waves of black mustard and artichokes (two invasive exotics in southern California). Just as individual catalytic converters have the cumulative effect of reducing smog, the aggregate result of life-long responsibility for what we take on as individuals will be a true upgrade of a declining habitat and environment.

It is hard for me to understand how any deep ecologist could take on more than a few acres in her/his lifetime - but certainly no more than a few hundred (a very large space to know and love). When we speak of intimacy with the land, it should be like knowing yourself. I believe we can recover personal geography and land identification lost to most in the urban environment by investing ourselves deeply in small areas. This will not be an industrially attractive proposal, but could be extremely and ultimately fulfilling for restorationists. Rather than a license to restore-scape indefinitely, commitment to a specific personal place for one's lifetime is what restoration should strive toward. Just as great historic conservationists have loved and worked to preserve specific sites, so should restorationists. We cannot re-create an evolutionary context, nor are any of our restorations a substitute for preservation. Aldo Leopold was once asked if his prairie restoration would be successful, and after thought 
Leopold suggested that, yes, perhaps in a thousand years or so it might. We need to keep that humility. An outcome of this proposal might be that the development industry would have to pension restorationists on mitigated sites indefinitely - yet in that scenario all would win; less land would be destroyed and restoration would see a longer stewarded recovery. We need to get off the imprinter and back to the hoe. The blood, sweat and tears of decades of stewardship are lost in the corporate fantasies of a vast landscape of mitigated reality.

Small is beautiful, and we should till the soils of our own mix of ecosystem and humanity. In an ironic way, just as the environments of long-disturbed regions such as Mediterranean Europe are the product of direct and indirect disturbance over time, our restored environments are equally initiated by humans working with nature.

As I review mitigation proposal after mitigation proposal while watching extinction happen, I often wish that those creating the alternative should be required to dedicate themselves to growing into and with their site. If we were forced to take a vow of maintenance and stewardship for our sites, I believe we would be better stewards and would feel more fulfilled as we watch the rise and fall of exotics and natives within the site we are naturesitting. I doubt if I will live to see more than one natural fire cycle on my sites, but I hope I will have thousands of hours of enjoyment watching the grass grow, weeding out exotics and listening to the gnatcatchers mew. We should stretch out our hearts in commitment to avoid the pitfalls of mitigation's quick, dirty, crstatz and timc-linked approach. Spending time simply sitting and listening to the insects, birds, and wind at a site can focus our sense of restorative place, and is a deep ecological recognition that all restorationists - by definition biocentrists - can appreciate. 


\title{
Container Plants for Revegetation. What About the Container?
}

\author{
Mike Evans \\ Tree of Life Nursery, PO Box 635, San Juan Capistrano, CA 92693 \\ Tel. (714) 728- 0685
}

\section{Introduction}

The field of ecological restoration can benefit from a strong, local nursery industry and the ready availability of materials to grow plants. By combining materials and techniques used in agriculture, forestry, and ornamental horticulture, restorationists in California can find all the materials they need to produce healthy container plants. Planners must carefully match the container to the plant species, soil type, planting season and environmental condition of the job site. Professional growers can offer assistance and advice on various container sizes available.

The following conclusions are given regarding containers for restoration projects in California.

\section{Container Design}

No coiling roots (ribbed sides)

No kinks in the stem (deep enough to accomodate early rooting)

Readily available in the horticultural industry.

Cost effective.

Ease of handling (storage, filling transporting, etc.).

Light weight (for transport).

Materials for "reduce/reuse/recycle".

\section{Container Selection for Revegetation Jobs}

To match plant species (size and shape).

Suited for planting season (deep for dry season, shallower ok for rainy season planting).

Suited to planting site (no sense specifying deep containers for steep slopes or rocky ground).

For desired results ("Instant" large plants need large containers. If you can wait for the plant to grow, start with a smaller container size.).

\section{General Rules for Revegetation Jobs}

Use deep or deeper containers than most landscape plantings use. Typical 1, 5, 15 gallon will suffice, but there are deeper variations available.

Ribbed or textured sides.

Root system "air-pruned" with drain holes on bottom and containers grown above ground.

Root inhibiting, copper-based "paints" (such as Spinout (B on inside container walls) will inhibit root coiling.

Tapered profile to allow easy removal of plant.

Easy to handle and transport.

Available in the horticultural trade. 


\title{
Developing Temporary On-site Nurseries for the Purpose of Land Restoration
}

\author{
Melanie Baer-Keeley \\ Horticulture Consultant, 43669 Skyline Drive, Three Rivers, CA 93271 \\ Tel. (559) 561-1907; e-mail: mbkeeley@mindinfo.com
}

\begin{abstract}
Constructing temporary on-site nurseries to propagate site-endemic species is an alternative that is in many ways practical as well as economical. It is especially so in the case of long-term restoration projects located in California's temperate regions, as well as in other mediterranean-type climates throughout the rest of the world. However, to date, this is an under-utilized practice. The feasibility of installing a simple, temporary on-site restoration nursery is considered here.
\end{abstract}

Keywords: Habitat restoration; horticulture; mycorrhizae; native plants; propagation; on-site nursery; restoration; revegetation.

\section{Introduction}

Developing temporary on-site revegetation nurseries can offer practical, economic as well as philosophical advantages in milder climates throughout California and other mediterranean-type regions. In practical terms, an on-site nursery can ensure the success of a revegetation project (1) by propagating from local plant populations which are genetically- and species-appropriate to the replanting site; (2) by increasing the likelihood of pairing seasonal cycles and fluctuations to propagation and planting; (3) by encouraging closer monitoring of cultivated plants-thereby preventing unrecoverable outbreaks of pathogens. No less important are the cost benefits gained from on-site plant production-many of which translate convenience into substantial savings. Philosophicallysetting up an on-site propagation program utilizing only locally collected flora to multiply from, then to reintroduce to that site-truly fulfills the mission as well as definition of land restoration and recovery. Further, the temporary nature of the propagation structures recommended can be easily removed and even the nursery site itself can then be revegetated, minimizing impacts to the land.

\section{Site-suited Flora}

One of the most compelling reasons in support of collecting and propagating native plants on-location is the virtual certainty that the correct species and genetic stock will be used to meet the requirements of the restoration project. Plants generated from locally collected native vegetation are programmed to succeed as they are genetically adapted to many of the environmental peculiarities of that site. Local plant ecotypes are more tolerant of the physical, chemical \& climatic rigors imposed upon them and have a survival edge over those introduced from other origins (Elam 1999; Rice 1999). Conversely, inherent problems accompany the introduction of "exotic" native plants to a revegetation site. 'Contaminating' indigenous plant populations with the genes of imported natives, can breed weaknesses into local populations resulting in the populations' propensity to disease and insect infestations. This potentially destructive situation can be completely eliminated by using strictly on-site collected $\&$ reproduced native plants.

\section{Introducing Microflora}

Clearly, the theory behind re-planting with site-suited native plants can also be applied to the need to establish a balanced soil microflora. Of special importance to the health and vigor of native plants is the formation of a symbiotic relationship between mycorrhizal fungi and their (commonly) species-specific host plants. Without mycorrhizae, a native plant may languish, disadvantaged by its inability to tap into nutrient reserves of well-developed soils. With the mycorrhizal interaction, plants can flourish and systems can more dependably remain in balance. One method of introducing or 'inoculating' native plants with the correct type of soil fungi is called "duffing." This simple technique involves collecting decayed, fallen leaves or "duff" along with top soil from under the canopy of a wild-grown host plant, then incorporating it into upper 
levels of the planting medium of the same species plant (Keeley 1998a; Keeley 1998b). Collecting and introducing mycorrhizae from localized native plants helps ensure that the correct species is matched to its host. This process is greatly expedited with a propagation nursery located near the collection sitc.

\section{Propagation scheduling}

Developing an on-site nursery provides the unique opportunity to match environmentally induced growth cycles with propagation and field-planting tasks. This pairing is critical to project success because it more likely enables the project to proceed at its own natural and realistic pace. Growing and propagating plants is a process that is inextricably linked to weather cycles and cannot always be depended upon to adhere to a theoretical mitigation schedule. Revegetation projects too often become derailed by external events with site preparation/seeding/ planting then occurring unseasonably. Predictably, the results end in disaster. Working with an on-site nursery facility can minimize this unfortunate and often costly predicament. Also, realistically, from the time propagation begins, for some slower-growing species, a full two years of growth may be required until plants are ready to be placed into the ground. So, planting for restoration must occur in planned phases, and must, to an extent, remain flexible.

\section{Access}

The relative location of the growing grounds to the revegetation site has a notable influence on the efficacy and success of the project also. Proximity can be directly related to significant cost savings of "bill-able" transittime. Considering the intensive nature of propagation tasks - many of which must he performed during the limited confines of each specie's ripeness or readiness, it clearly makes sense to position the nursery close to the restoration site (Please see Table 1 for a seasonal schedule of horticultural tasks). To time the collection of the variety and quantity of propagules called for in typical restoration projects can be difficult in itself. When this task is further complicated by each plant's internal growth cycles as well as those influenced by edaphic or environmental factors requires abundant return visits. If commute time inhibits frequency of collecting trips, the moment of propagule ripeness may be missed, delaying propagation of that species for a full year. Or, if the collection-time is missed, the probability increases that exotic natives will be introduced to the revegetation project, risking genetic contamination of site-adapted populations.

\section{Monitoring}

In addition, nearness to the revegetation site can multiply the chances of project success, simply due to a more vigilant on-site presence. The importance of frequently monitoring plant health and vigor throughout the entire restoration process-but particularly during establishment phases-cannot be over-emphasized. Consistent monitoring can head off a throng of problems that can easily jeopardize plants in any stage of growth. Few plants can recover from outbreaks of disease, insect pathogens, weed infestations, problems with irrigation systems if not detected in time. So simply being on-site increases the probability that problems will be recognized and remedied in a timely manner.

Figure 2. A seasonal schedule of native plant propagation tasks for mild climates.

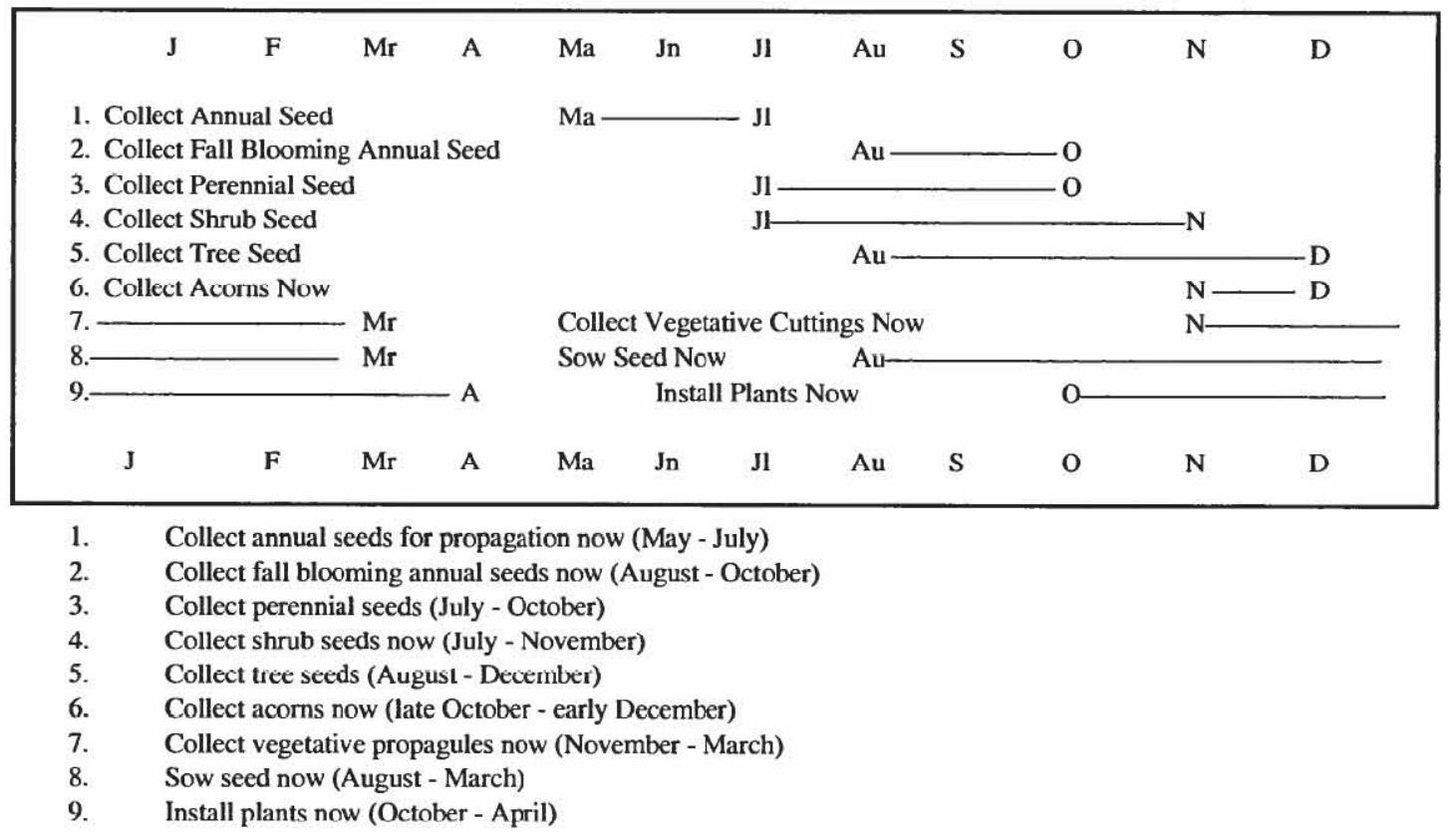




\section{Budgetary Feasibility}

The decision of whether to build an on-site revegetation nursery is often necessarily dictated by budgetary constraints. Anticipation of costs, including start-up versus continuous expenses will show whether the project is to be a good investment or not. Planning processes should consider the availability of a suitable nursery site, scope and duration of project, and the availability of qualified horticultural personnel. The most cost-effective on-site nurseries tend to be associated with large, long-term (approximately $5+$ years) restoration projects. Keeping the nursery design simple, but complete, should, in time, pay for itself in the savings from plants produced. While initial startup costs may seem high, most expenses are onetime structural set-up costs rather than on-going propagation or maintenance costs.

To illustrate, in 1997, an informal feasibility study was performed to evaluate the potential of erecting on on-site nursery to restore land in Puente Hills, California. In this case, we wanted to determine what the minimum costs would be both to accomplish simple planting goals set for the revegetation project as well as what the expenditures would be to build a bare-bones, but completely functioning nursery facility. This approach was taken while keeping in mind that if a more sophisticated design was desired, funds would be available.

In round figures, to revegetate 10 acres of land over 5 years, with approximately 4,000 1 gallon sized plants per acre (spaced 10 feet apart), 40,000 plants would be required. Nursery-purchased 1 gallon plants cost a minimum of $\$ 3.00$ each, so, the expense over a few years could reach roughly $\$ 120,000$. Grading \& erecting a temporary $10,000 \mathrm{ft} 2$ shade structure which could house approximately 150,000 liners or, fewer liners along with larger "growing-on" stock, equipped with hasic propagation equipment-would cost approximately $\$ 20,000$. (Note: Only nursery materials and construction costs are included in this figure.) (See Table 2 for a more detailed accounting). Obviously missing in this estimate is the cost of land and electrical or plumbing improvements. Be that as it may, the potential savings of constructing an on-site revegetation nursery could prove to be substantial.

\section{Growing Structures}

The most basic components of a native plant nursery facility are surprisingly few-in mild climates. The minimum requirements would include a rodent- and bird-proof shade-structure, housing enclosed vegetative cutting beds with a mist or humidifying system and heating cables to produce "bottom heat" where the roots grow, a potting shelter, table and a "hardening-off/growing-on" area for larger plants. Of course, good quality water as well as power must be available. These items are, once again, the absolute minimum horticultural prerequisites throughout moderate climates. However, as the temperature and environment grow more adverse, more climate controls become necessary and a greenhouse, which involves a notable increase in expenditures, becomes mandatory.

Table 2. Estimated costs are based on site-preparation \& construction of $10,000 \mathrm{ft}^{2}$ shade structure. This was done to assess the practicality of developing an on-site nursery to revegetate 10 acres of land over 5+ years. Note: Not included here are costs related to land, power and water. Horticulture product prices supplied by American Horticultural Supply, Inc. Camarillo, California (1997)

Nursery Construction (1997)

Shade Structure:

Site preparation:

Tree Removal (approx $\$ 500$ each $40^{\prime}$ tree) $\$ 1,000$

Grading (approx $\$ 3,000 /$ acre)

Shade Structure Framework (Metal Pipes, fittings set in concrete) Roughly $\$ 1,000 / 1000 \mathrm{ft} 2$. (Based on $10,000 \mathrm{ft}^{2}$ dimensions)

Woven Saran Shade cloth $10,000 \mathrm{ft}^{2}$

Weed-suppression cloth, $\$ .07 \mathrm{ft}^{2}$

Labor (Structure Installation) ( 3 people x $80 \mathrm{hrs}$ x $\$ 8$ )

Subtotal

$\$ 3,000$

$\$ 10,000$

$\$ 1,600$

$\$ 700$

$\$ 2,000$

$\$ 18,300$

Mist System (2 rows, 24' long, x 6' wide bed, on ground) Timer (not including underground plumbing)

PVC (1" \$.21 linear ft.) (above ground only)

Mist heads ( $\$ 1.50$ each, $3 \mathrm{ft}$ apart)(16 nozzles)

Bottom Heat, Heating cables

Thermostat

Thermometer

Installation ( 2 laborers $x 24$ hours $x \$ 10$ )

Subtotal

$\$ 150$

$\$ 25$

$\$ 30$

$\$ 85$

$\$ 60$

$\$ 35$

$\$ 480$

$\$ 865$

Greenhouse (in some cases-optional):

30 ' x 100' kit (not including construction)

Fiberglass Covering

Air conditioning unit ( $3000 \mathrm{ft} 2$ greenhouse)

Weed cloth $(3000 \mathrm{ft} 2 \times .07)$

Gravel (4" x 3,000ft2, \$18/ton x 46 tons)

Construction labor estimate ( 3 people $\times 80 \times \$ 15$ )

Subtotal

$\$ 1,600$

$\$ 2,500$

$\$ 600$

$\$ 210$

$\$ 850$

$\$ 3,600$

$\$ 9,360$

Miscellaneous Expenses:

Gravel ( $\$ 18.00 /$ ton $\times 140$ tons to cover $10,000 \mathrm{ft} 2$ )

Pots

$10,0001 \mathrm{~g}, \$ 15.70 / 100$

$\$ 2,600$

$5,0005 \mathrm{~g}, \$ 17.75 / 25$

$\$ 1,570$

$\$ 3,550$

Potting Soil (approx $\$ 25.00 / \mathrm{cu}$ yr) 1 truckload

( $20 \mathrm{cu}$ yr $\times 20$ deliveries/yr)

$\$ 12,000$

Potting Shed (approx 20' x 15')

$\$ 3,000$

Potting Benches (galvanized tops with backs 4'x 8') (approx \$750) each

Backpack Sprayer

$\$ 500$

Fertilizer, rooting hormones, insecticides

$\$ 150$

$\$ 750$

Tools

$\$ 250$

Labor, Horticulturist ( 260 working days $\mathrm{x} 4 \mathrm{hr} \times \$ 10) \quad \$ 10,400$

Grading other growing-on areas in full sun (est $\$ 3,000 / a c) \quad \$ 3,000$

Subtotal

$\$ 38,770$

Total

$\$ 68,715$ 


\section{Selecting a Productive Nursery Site}

Scouting and selecting the site for a revegetation nursery is essential to determining the feasibility and scope of such an endeavor. Ideally, the property to be restored can include a suitable location for a nursery. Characteristics of a desirable nursery site include: ease of access (roads), suitable size, close proximity to revegetation site, flatness or its potential for limited grading, a full-sun and windfree exposure, good water quality and availability (soluble salts not to exceed $1400 \mathrm{ppm}$ ), low-cost of land, accessibility to electricity, and climate. In addition, it must be zoned for agricultural usage. (Nelson 1978).

Many coastal and lower elevation (under $2000 \mathrm{ft}$.) inland areas throughout California and the South are suitable for constructing temporary on-site revegetation nurseries. In California, the frost-sensitive native laurel sumac (Malosma laurina), is one of the classic indicator plants of a mild climate suitable for situating a nursery. In moderate climates with infrequent freezing of less than five days per year, at no less that approximately $25^{\circ} \mathrm{F}$, most native crops can be grown well. However, this too is variable to species as some plants more tolerant of freezing thrive under colder conditions. Generally, though, as climate and temperatures become more extreme and growing season shortens, climate-controls become increasingly necessary and this, as mentioned involves notable jumps in expenditure. However, having a self-contained greenhouse does significantly increase the length of the growing season and makes propagation generally much easier-certainly a critical benefit in all climates. Once again, the cost, the duration of the project, advantages and disadvantages must be evaluated before beginning such an effort.

\section{Dilemmas}

Despite the numerous advantages, some impediments - quite surmountable - can accompany this sort of endeavor. The primary dilemma lies with finding a qualified horticulturist with the instincts and experience required to make a success of a native plant nursery. The combination of the temporary nature of a project of this type and a general deficit of traincd native plant growers can lead to somewhat of a frustrating situation for administrators.

In preliminary planning phases, several questions must be answered to ascertain the practicality of getting involved in this sort of endeavor: (1) Does the duration and breadth of the proposed project justify its cost? (2) Is there a suitable location available? Is it zoned for nursery activity? (3) Is there an experienced native plant propagator lined up to oversee operations as well as to train nursery workers? (4) Does the time-line of the project match the time required for plant maturation? (5) Are the mandatory high initial nursery setup costs workable within the financial framework of this project? (6) Are the growing structures to be of a temporary or more permanent nature? Are there tax advantages to constructing one or the other?

\section{Conclusion}

In conclusion, while there may be some hurdles to overcome throughout the process of constructing an onsite revegetation nursery, there is more to recommend it: the propagation and replanting of genetically suited native flora; the ability to match propagation to natural cycles; enabling a continued on-site presence to avert pathological or mechanical damage; as well as the time and cost savings due to proximity to the restoration site.

Typically, because this type of project engenders a deeper level of personal involvement and investment, there tends also to be an increased dedication to its success. This commitment to propagating native plants and to restoring damaged landscapes can readily expand beyond project personnel into the public sector. A restoration project including on-premises nursery facilities, can indicate positive intent toward neighboring communities and can go a long way to improve good will and develop project support. Land restoration and recovery done well - from planning, building, growing, field-planting, to maintenance and monitoring, is truly a worthwhile and valuable contribution.

Acknowledgments. My appreciation goes to Jon Keeley for convening both the 1st and 2nd Interface Between Ecology and Land Development in California Conference. The many dedicated environmental professionals sparked ideas, enthusiasm as well as determination among all those in attendance. The participants of both conferences engaged in an essential dialogue that has led to unity of thought, direction, and ultimately a strengthening of environmental vision within this state.

\section{Literature Cited}

Allen, M.F. 1991. The ecology of mycorrhizae. 2nd edition. Cambridge University Press, Cambridge, U.K.

Elam, D. 1999. Population genetic theory and sata in restoration of rare plants: examples from serpentine and vernal pool taxa. Pp. 211-219 in J.E. Keeley, M. Baer-Keeley, and C.J. Fotheringham, eds. 2nd Interface between land development in California. International Association of Wildland Fire, Fairfield, WA

Hartman, H.T. and D.E. Kester. 1975. Plant propagation principles and practices. 3rd edition. Prentice Hall, Inc., Englewood Clifts, NJ

Keeley, M.B. 1998a. The fungus we want among us. Part 1. Southern California Gardener 7(6):5-6. 
Keeley, M.B. 1998b. The fungus we want among us. Part 2. Southern California Gardener 8(2):5,7.

Nelson, PV. 1978. Greenhouse operation and management. Reston Publishing Company Incorporated, Prentice-Hall Company, Reston, VA.

Rice, K.J. 1999. Evolutionary factors affecting the probability of local adaptation or should we expect to see ecotypes behind every rock? Pp. 221-226 in J.E. Keeley, M. Baer-Keeley, and C.J. Fotheringham, eds. 2nd Interface between land development in California. International Association of Wildland Fire, Fairfield, WA

Appendix A. The first, best source of horticultural personnel to staff a nursery are through the native plant-emphasizing botanical gardens or societies within the state. Native plant nurseries and consultants also may also offer supervisory services to oversee the construction and implementation of such a nursery endeavor.

California Native Plant Society

1722 J Street. STE \# 17

Sacramento, CA 95814

(916) 447-CNPS

Rancho Santa Ana Botanic Garden

1500 North College

Claremont, CA 91711

(909) 626-7670

Santa Barbara Botanic Garden

1212 Mission Canyon

Santa Barbara, CA 93105

(805) 563-0352

Theodore Payne Foundation

10459 Tuxford Street

Sun Valley, CA 91352

(818) 768-1802

UC Berkeley Botanical Garden

200 Centennial Drive, \#5045

Berkeley, C^ 94720

(510) 643-2755

UC Davis Arboretum

One Shields Avenue

Davis, CA 95616

(530) $752-2498$
Appendix B. Additional sources of information.

Connelly, K. 1991. Gardener's guide to California wildflowers. Theodore Payne Foundation, Sun Valley, CA.

DeHart, J. 1994. Propagation secrets for California native plants. Jeanine DeHart, Encinitas, CA.

Emery, D.E. 1988. Seed propagation of native California plants. Santa Barbara Botanic Garden, Santa Barbara, CA.

Francis, M. and A. Reimann. 1999. California landscape garden. Ecology, culture, and design. University of California Press, Berkeley, CA.

Hickman, J.C. (ed). 1993. Jepson manual-higher plants of California. University of California Press, Berkeley, CA.

Keator, G. 1990. Complete garden guide to the native perennials of California. Chronicle Books, San Francisco, CA.

Keator, G. 1994. Complete garden guide to the native shrubs of California. Chronicle Books, San Francisco, CA.

Lenz, L. and J. Dourley. 1981. California native trees and shrubs. Rancho Santa Ana Botanic Garden, Claremont, CA.

Perry, B. 1993. Landscape plants for western regions. I and Design Publishing, San Dimas, CA.

Perry, B. 1981. Trees and shrubs for dry California landscapes. Land Design Publishing, San Dimas, CA.

Schmidt, M. 198Growing California Native Plants, University of California Press, Berkeley, CA. 


\section{Index}

Adenostoma fasciculatum 16,22,45,46,47,57ff, 127,268

Artemisia californica 47,253ff,263

Arctostaphylos spp. 47,57ff,93,94

air quality $27,71,97,255$

amphibiansl $37 \mathrm{ff}$

Angeles National Forest 28

badgers 114,116

Baja California 87ff,97ff, 142

bears

-black 6

-grizzly $5,153,155,156$

biogeography 145,196

birds $5,125 \mathrm{ff}, 173 \mathrm{ff}, 245$

biodiversity $2,106,138,237 \mathrm{ff}, 258,281$

bobcat $105 \mathrm{ff}, 113 \mathrm{ff}$

branch dieback 31

breeding system $213,214,225,227 \mathrm{ff}$

Bruce Babbitt 1,4

buffer zones 5

cactus wren habitat 271

California buckwheat [see Eriogonum fasciculatum]

California gnatcatcher $173 \mathrm{ff}, 263$

California Vegetation Type Map 87

camera surveys $113 \mathrm{ff}$

carnivores 105ff,113ff,155

Carrizo Plain 153ff

Ceanothus spp. 22,31,32,45,46,57ff,127

Channel Islands National Park 35

chamise [see Adenostoma fasciculatum]

chaparral $9 \mathrm{ff}, 19 \mathrm{ff}, 57 \mathrm{ff}, 105,114,125,145,147$

Clarkia spp 212-217

Clean Air Act 28

Clean Water Act 285

climate $195 \mathrm{ff}$

coastal dunes 281

coastal sage scrub 28,71,105,114,147,163,167,175,227ff,253ff, 263ff,271ff,282

community structure and function $137,242,245$

conservation banking 186

coyotes $105 \mathrm{ff}, 113 \mathrm{ff}$

Cupressus spp. 89

DNA analysis 106

Dendrochronology $36,42,88 \mathrm{ff}$

Development 18,163

domestic animals $105 \mathrm{ff}$

ecotypes $221,227 \mathrm{ff}, 284$

electrophoresis 230

El Segundo blue $281 \mathrm{ff}$

Emmenanthe penduliflora 47

Endangered Species Act 1,4,163ff, 173,178,186

Eriogonum fasciculatum 130,228,256,265,282 
estuaries $245 \mathrm{ff}$

evapotranspiration $195 \mathrm{ff}$

feral pigs $59,66,67$

fire

-flammability 22

-high intensity $19 \mathrm{ff}, 45$

-ignitions 13,14,27,45

-lightning-ignited 10,45,89,92-94

-postfire regeneration $46,50,71 \mathrm{ff}, 79 \mathrm{ff}, 147,169,227,271$

-postfire seeding $48 \mathrm{ff}$

-prescribed burning 19,27,31,45,46,71ff,76-78

-regime 19ff,37,59,97ff

-return interval 20,40,87ff,255

-season $45 \mathrm{ff}$

-spread rate $9 \mathrm{ff}, 20,22,45$

Fires

-suppression 19,20,40,87ff,97ff

-Bee 24

-Wheeler 25

fish $245 f f$

flooding

-debris flows 20,25,32

-water 19,22

foxes

-grey $105 \mathrm{ff}, 113 \mathrm{ff}$

-red 114,116

fuels

-age mosaic 9ff, 20,91

-fuel breaks 25

-loading $9,17,20,24,45$

gene flow $211 \mathrm{ff}, 226$

genetic

-distance 232-234

-drift 212,213,221ff

-variation 214-218,221ff,227ff

GIS 116,127

Grasslands 75ff, $114,145,153 \mathrm{ff}, 253 \mathrm{ff}$

Grazing 42,57-59,66,257

habitat

-corridors 5,113ff,176,181

-edge effects 133

-fragmentation 1,105ff,113ff,125ff, $181 \mathrm{ff}$

-loss 1,245

Heteromeles arbutifolia $47,57 \mathrm{ff}$

HCPs 1,4,163ff, 173

indicator species 105,237

IGNITS 14ff,

Insects 237,281

I-Zone 31

Joshua Tree National Park 79ff

Lake Perris Recreation Area 107

landscape planning 9,163ff,181ff 
lichens 71

Limnanthes floccosa 212-217

Litigation 28,166,189

Lolium multiflorum 48,99

Los Angeles County 32

Los Padres National Forest 21

Lotus spp. 46,157,227ff,258

Lupinus spp. 46,240

Malosma laurina 47,127

meterological conditions $9,51,153,195 \mathrm{ff}$

migrant species $125 \mathrm{ff}$

MINAGE 10ff,

Miramar Naval Air Station 107,138

Mitigation 163,181ff,245,275,281

Mojave Desert 79

MONITOR 178

Monitoring 169,173,237ff,292

Motte Rimrock Reserve 230

mountain lions $105 \mathrm{ff}, 114$

mycorrhizae 291,292

Nassella spp. 75,153

NCCP $1,161,163 \mathrm{ff}, 167 \mathrm{ff}, 173 \mathrm{ff}$

nitrogen deposition $255,259,260$

non-native species $75,106,139,145 \mathrm{ff}, 153,169,253 \mathrm{ff}, 266$

nurseries $291 \mathrm{ff}$

oaks \{see Quercus\}

obligate seeders 46

opossums $105 \mathrm{ff}, 115,116$

Opuntia spp. 82,153,271ff

Palomar Mountains 22,138

Phacelia spp. 52,240

piÁon-juniper woodlands $79 \mathrm{ff}$

Pinus spp. 35ff, $81,89,90,97 \mathrm{ff}, 150$

plant

-biomass $19,23,267$

-resprouts $20,23,45,46,47,229$

-seedlings 23,45,46,47,49,229

Point Loma Ecological Reserve 107

population growth 1,2

pre-European conditions 10,58,59,153

predators $105 \mathrm{ff}, 155$

propagation $291 \mathrm{ff}$

Prunus spp. $47,57 \mathrm{ff}$

Quercus spp. 47,57ff, $81,135,148,275 \mathrm{ff}$

raccoons $5,105 \mathrm{ff}, 115,116$

raptors 156

rare species $4,211 \mathrm{ff}$

refugia 5

riparian habitats $149,237 \mathrm{ff}$

reptiles $137 \mathrm{ff}, 156$

reserve design $5,165,169,181 \mathrm{ff}$

restoration 153,169,193,195ff,211,217,227,237,245ff,253ff,263, 271,281ff,287ff,289,291 
Rhamnus spp. 47,57ff,

Rhus spp. 46,57ff

road kills 107,117

roadless areas 5

rodents $153 \mathrm{ff}$

Rothermel fire model 16

salt marshes 150

Salvia spp. 46,71ff,228,258,265

San Bernardino National Forest 21,97ff

San Fernando Valley 153

San Jacinto Ranger District 24

San Joaquin Valley $153 \mathrm{ff}$

Santa Ana Mountains 138

Santa Ana winds 10,15,20,45,46

Santa Catalina Island 57ff,

Santa Lucia Mountains 48

Santa Monica Mountains 20,21,31,32,113ff,125ff,145ff

Santa Monica National Recreation Area 113ff, 128,181ff

Santa Rosa Plateau Reserve $75 \mathrm{ff}$

Santa Ynez Mountains 20,48

scrubjay 133

Seeds

-germination $16,46,157$

-seed bank 20,46,229

sensitive species $142,238-240$

serpentine 211

Sierra San Pedro Martir 89ff,97ff

Skunks 5,105ff,115,116

social class 3

species richness $52,71-73$

Starr Ranch Audubon Sanctuary 107

Sweetwater Marsh National Refuge 246

torrey pine [see Pinus torreyana]

Torrey Pines State Reserve 35ff,107,138

transferable credits $181 \mathrm{ff}$

transplantation $227 \mathrm{ff}, 271 \mathrm{ff}, 275 \mathrm{ff}, 289$

tropics 3

urban sprawl 1

urban/wildland interface 7,9,19,45,105ff,113ff,125

U.S. Bureau of Census 5

U.S. Fish \& Wildlife Service 4,167,174,175,281

U.S. Geological Survey 167

water balance $195 \mathrm{ff}$

wetlands $211 \mathrm{ff}, 245 \mathrm{ff}, 281$

wildfires 7,9,19ff,

Wildlands Project 1,5

Wise Use Movement 6

woodlands 148,238

World Wildlife Fund 3,5

Xylococcus bicolor 49

Yucca spp. 79ff, 